\title{
Strategische Gruppen in der deutschen Brauwirtschaft
}

\author{
Dissertation \\ zur Erlangung des Doktorgrades \\ der Fakultät für Agrarwissenschaften \\ der Georg-August-Universität Göttingen
}

vorgelegt von

Christoph Niederhut-Bollmann

geboren in

Springe

Göttingen, im Mai 2006 
D 7

1. Referent: Prof. Dr. Ludwig Theuvsen

2. Korreferent: Prof. Dr. Achim Spiller

Tag der mündlichen Prüfung: 13. Juli 2006 
ABbILDUNGSVERZEICHNIS .IV

TABELLENVERZEICHNIS ............................................................................ VII

ABKÜRZUNGSVERZEICHNIS .........................................................................VIII

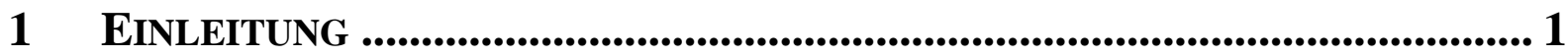

1.1 Problemstellung und Zielsetzung........................................................................ 1

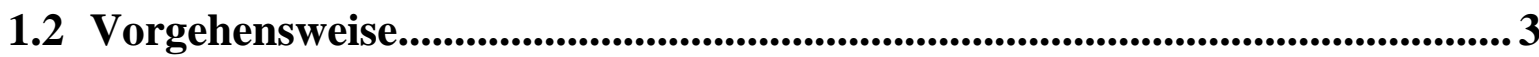

2 DAS KONZEPT DER STRATEGISCHEN GRUPPEN _..................................... 5

2.1 Die Entwicklung des Konzeptes der strategischen Gruppen ............................. 5

2.1.1 Der industrieökonomische Ansatz..........................................................................5

2.1.2 Der betriebswirtschaftliche Ansatz .........................................................................9

2.1.3 Strategische Gruppen als Schnittstelle zwischen industrieökonomischem und betriebswirtschaftlichem Ansatz.......................11

2.2 Grundlagen des Konzeptes der strategischen Gruppen................................... 13

2.3 Empirische Forschung im Bereich strategischer Gruppen...........................15

2.4 Forschungsstand in der Brauwirtschaft .............................................................. 16

2.5 Kritische Würdigung der bisherigen empirischen Forschung und daraus resultierender Forschungsbedarf ............................................................... 17

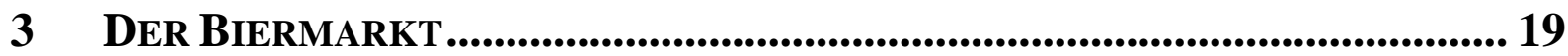

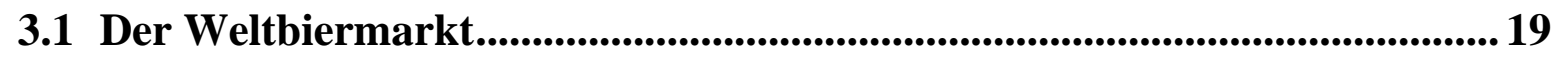

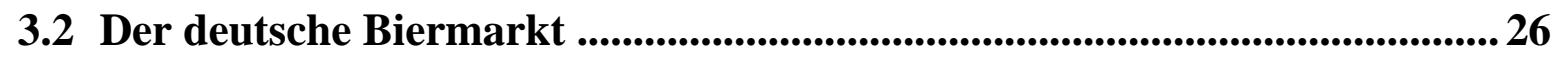

3.2.1 Wirtschaftliche Bedeutung......................................................................................26

3.2.2 Segmentierung des deutschen Biermarkts ...........................................................28

3.2.3 Erweiterte Strukturanalyse des deutschen Biermarktes ...................................33

3.2.3.1 INTENSITÄT DER RIVALITÄT UNTER DEN BESTEHENDEN UNTERNEHMEN......36

3.2.3.1.1 Anzahl und Struktur der Wettbewerber ................................................37

3.2.3.1.2 Branchenentwicklung............................................................................. 41

3.2.3.1.3 Möglichkeiten der Differenzierung ..........................................................4 45 
3.2.3.1.4 Marktaustrittsbarrieren / Überkapazitäten ...........................................51

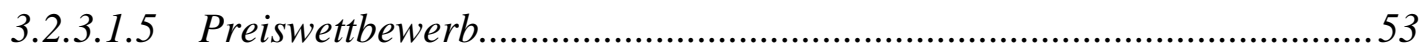

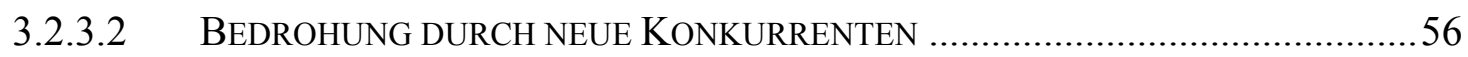

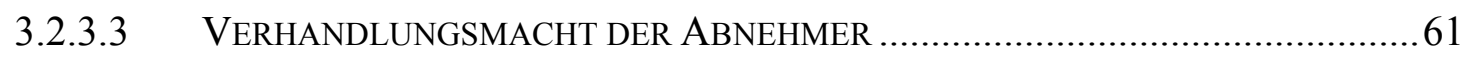

3.2.3.3.1 Absatzwege in der Brauwirtschaft .......................................................61

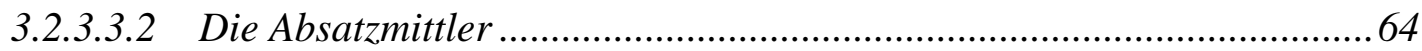

3.2.3.3.2.1 Getränkefachgroßhandel und Getränkeabholmärkte .......................66

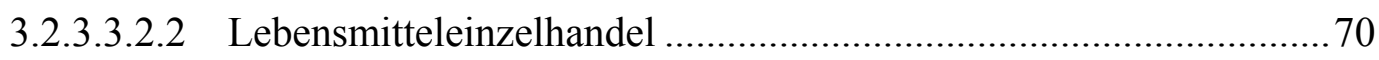

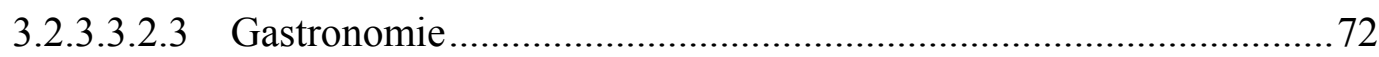

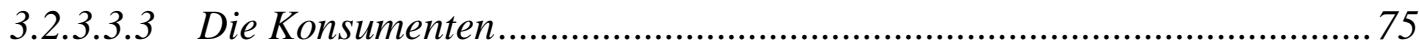

3.2.3.4 BEDROHUNG DURCH ERSATZPRODUKTE ................................................. 77

3.2.3.5 VERHANDLUNGSMACHT DER LIEFERANTEN................................................. 79

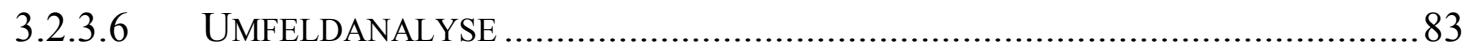

3.2.3.6.1 Soziodemographische Umfeldfaktoren ................................................83

3.2.3.6.2 Politische und rechtliche Umfeldbedingungen .......................................85

3.2.3.6.3 Ökonomische Umfeldbedingungen .......................................................89

3.3 Zwischenfazit: Die deutsche Brauwirtschaft in der Krise ............................. 90

4 EMPIRISCHE ANALYSE DER DEUTSCHEN BRAUWIRTSCHAFT .................... 93

4.1 Forschungsmethodik und Vorgehensweise der Untersuchung...................93

4.1.1 Hypothesenbildung und Ziele der Untersuchung ........................................93

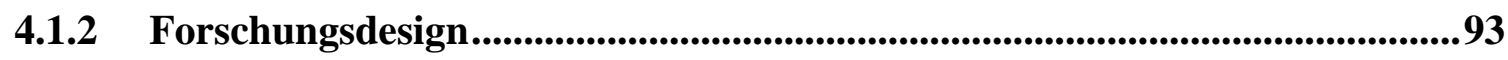

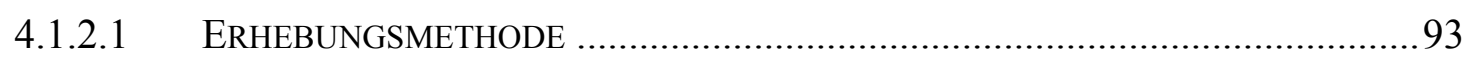

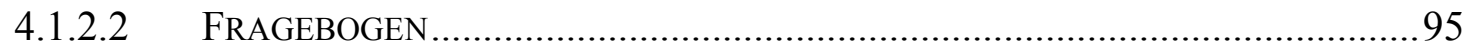

4.1.3 Erhebungsumfang, Rücklaufquote und Auswertung.......................................97

4.1.4 Allgemeine Merkmale der befragten Brauereien ...........................................98

4.2 Branchensituation der deutschen Brauwirtschaft ....................................... 102

4.2.1 Wahrnehmung der Branchensituation durch die deutsche

Brauwirtschaft ..........................................................................................102

4.2.2 Strategische Entwicklungslinien deutscher Brauereien ...................................108

4.2.2.1 THEORETISCHER BEZUGSRAHMEN ............................................................ 108

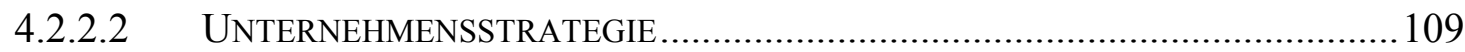

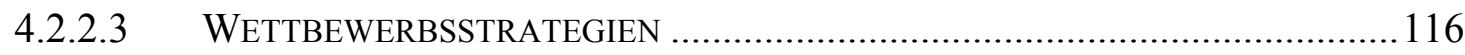




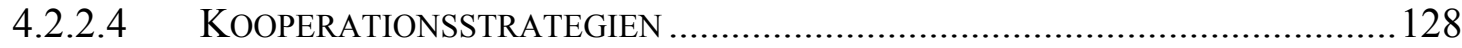

4.2.3 Erfolgslage deutscher Brauereien ..................................................................135

4.2.4 Strategische Planungsprozesse deutscher Brauereien......................................142

4.3 Strategische Gruppen in der deutschen Brauwirtschaft ............................... 149

4.3.1 Operationalisierung der strategischen Dimensionen.........................................149

4.3.2 Faktoranalyse zur Dimensionsreduktion..........................................................151

4.3.3 Clusteranalyse zur Identifizierung strategischer Gruppen ............................154

4.3.4 Weitere Beschreibung der strategischen Gruppen............................................160

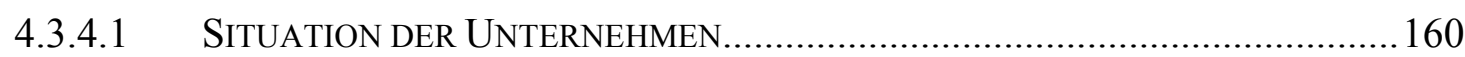

4.3.4.1.1 Unternehmensmerkmale ..................................................................160

4.3.4.1.2 Wahrnehmung der Branchensituation und Wettbewerbsposition .........163

4.3.4.2 ORGANISATORISCHE UMSETZUNG DER STRATEGIE ...................................... 168

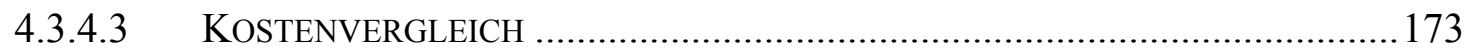

4.3.4.4 STRATEGIEFORMULIERUNG UND -IMPLEMENTIERUNG ...............................175

4.3.5 Strategische Gruppen und Erfolg .....................................................................177

4.3.5.1 OPERATIONALISIERUNG DER ERFOLGSVARIABLEN ……….......................... 177

4.3.5.2 ERFOLGSANALYSE DER STRATEGISCHEN GRUPPEN..................................... 178

5 SCHLUSSFOLGERUNGEN UND IMPLIKATIONEN FÜR DIE

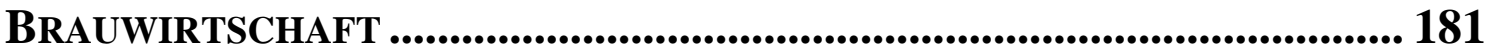

5.1 Zusammenfassung der Untersuchungsergebnisse .......................................... 181

5.2 Implikationen für die deutschen Brauer............................................................... 187

5.3 Ansätze für die weitere Forschung ....................................................................... 188

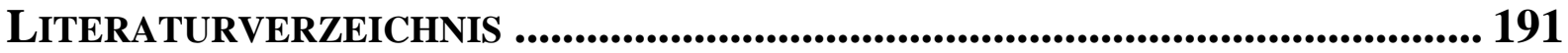

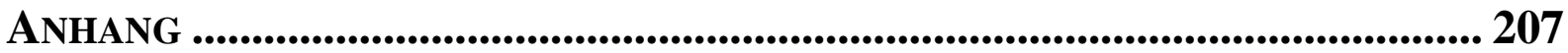




\section{Abbildungsverzeichnis}

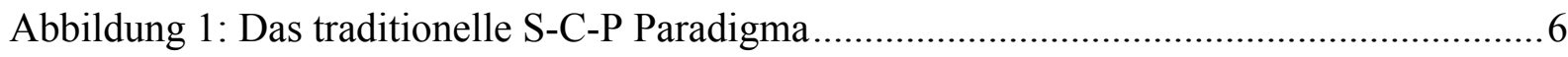

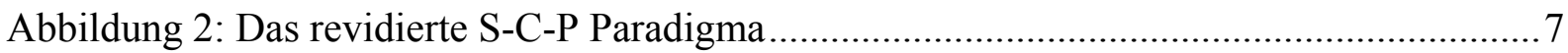

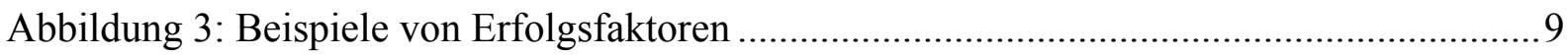

Abbildung 4: Einordnung der strategischen Gruppenforschung ......................................... 12

Abbildung 5: Wachstum des Weltbiermarktes von 1998 bis 2004 .......................................19

Abbildung 6: Weltbiererzeugung nach Regionen 1998 versus 2004 ...................................20

Abbildung 7: Top 10 Länder der Weltbierproduktion 2004 .................................................20

Abbildung 8: Durchschnittliche jährliche Wachstumsrate der Bierproduktion von 1998

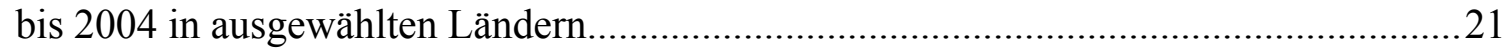

Abbildung 9: Top 10 Länder des jährlichen Bier Pro-Kopf-Verbrauch ..................................22

Abbildung 10: Top 10 der Bierexportländer der Welt im Jahr 2003 _......................................23

Abbildung 11: Entwicklung der weltweit führenden Braukonzerne 1998 bis 2004................24

Abbildung 12: Entwicklung der Marktanteile der wichtigsten Biersorten im

Lebensmitteleinzelhandel und in Getränkeabholmärkten zwischen 1998 und 2004.......29

Abbildung 13: Entwicklung des Absatzes von Biermischgetränken von 1998 bis 2005 .........31

Abbildung 14: Entwicklung des Pro-Kopf-Verbrauchs und des Gesamtbierausstoßes ...........42

Abbildung 15: Vergleich der Konzentrationsraten der Jahre 1991, 2002 und 2004 ...............43

Abbildung 16: Relative Konzentration in der deutschen Brauwirtschaft im Jahr 2004 ..........45

Abbildung 17: Gesamtwerbeausgaben für Bier sowie Werbeausgaben pro hl .......................50

Abbildung 18: Nettoumsätze pro Hektoliter ausgewählter Brauereien in verschiedenen

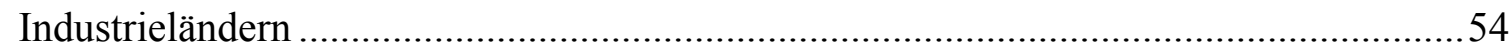

Abbildung 19: Preisklassen Bier 20er 0,51-MW-Kasten von 1999 bis 2005...........................55

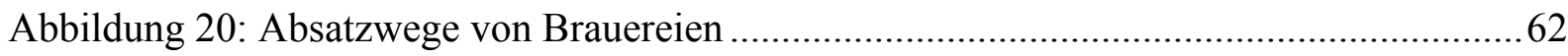

Abbildung 21: „Off-premise“ -Bierabsatz nach Vertriebsschienen .......................................65

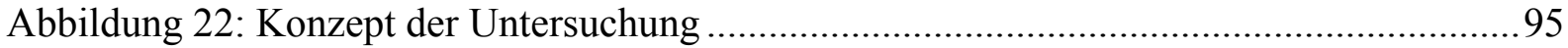

Abbildung 23: Handelt es sich bei Ihrem Unternehmen um ein Familienunternehmen?.........99

Abbildung 24: Ist Ihr Unternehmen in einen Konzern eingebunden? ................................... 99

Abbildung 25: Rechtsformen der an der Untersuchung beteiligten Brauereien nach

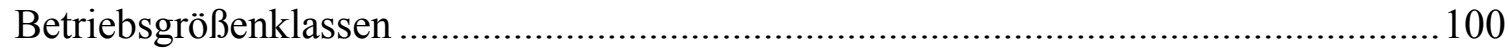

Abbildung 26: Durch wen wird Ihr Unternehmen geleitet? ................................................ 101

Abbildung 27: Einschätzung der Marktmacht verschiedener Absatzmittler .......................... 104

Abbildung 28: Einschätzung der Bedrohung durch neue Wettbewerber im

Kernabsatzgebiet. 
Abbildung 29: Einschätzung der Verhandlungsmacht der wichtigsten Lieferanten 105

Abbildung 30: Einschätzung der Bedrohung durch Ersatzprodukte 106

Abbildung 31: Einschätzung des Einflusses verschiedener Umfeldfaktoren auf die Brauereien 106

Abbildung 32: Treiber des Wettbewerbs im deutschen Biermarkt. 107

Abbildung 33: Anteile der verschiedenen Produkte am Gesamtgetränkeausstoß der Brauereien.

Abbildung 34: Anteil der Getränke aus eigener Herstellung am Gesamtabsatz der Brauereien

Abbildung 35: „Wir werden auch in Zukunft einen eigenen Fuhrpark betreiben.“ 112

Abbildung 36: Bedeutung verschiedener Vertriebswege

Abbildung 37: Internationalisierung der deutschen Brauwirtschaft 113

Abbildung 38: Diversifikation in der Brauwirtschaft 115

Abbildung 39: Anteil der Markenartikel am Gesamtgetränkeausstoß.

Abbildung 40: Einzelhandelspreis der Hauptbiermarke (Kastenform 20 x 0,5 1) 118

Abbildung 41: Anteil der Hauptbiermarke am Gesamtgetränkeausstoß 118

Abbildung 42: Einzelhandelspreis für das preiswerteste Bier (Kastenform 20 x 0,5 1)

Abbildung 43: Marketingausgaben pro Hektoliter im Durchschnitt der Jahre 2001 bis 2003

Abbildung 44: Wahrgenommene relative Stärke des Markenimage

Abbildung 45: „Mit Innovationen bemühen wir uns immer, die ersten am Markt zu sein."

Abbildung 46: Innovationen in der deutschen Brauwirtschaft (geplant oder durchgeführt)

Abbildung 47: Eigene Innovationskraft im Vergleich zum Wettbewerber

Abbildung 48: Einschätzung der eigenen Gesamtkosten in Relation zum

Branchendurchschnitt

Abbildung 49: Durchschnittliche Gesamtkosten pro Hektoliter 127

Abbildung 50: Einschätzung des Kooperationspotentials in verschiedenen Bereichen

Abbildung 51: Anteil der Unternehmen, die mit anderen Brauereien kooperieren oder dieses planen

Abbildung 52: Horizontale Kooperationen in der Brauwirtschaft

Abbildung 53: Einschätzung des Potentials vertikaler Kooperationen

Abbildung 54: Vertikale Kooperationen (realisiert oder in Planung).

Abbildung 55: Vertikale Kooperationen

Abbildung 56: Veränderung des Gesamtgetränkeausstoßes im Zeitraum 2002 bis 2004 
Abbildung 57: Veränderung des Gewinns im Zeitraum 2002 bis 2004 137

Abbildung 58: Produktivität in Relation zum Branchendurchschnitt. 139

Abbildung 59: Rentabilität in Relation zum Branchendurchschnitt. 139

Abbildung 60: Finanzkraft in Relation zum Branchendurchschnitt . 140

Abbildung 61: Prozess des strategischen Managements 142

Abbildung 62: „Auch im Tagesgeschäft haben wir immer die langfristige Strategie im Auge.“

Abbildung 63: „Es werden klare Ziele festgelegt, die bis zu einem bestimmten Zeitpunkt zu erreichen sind.“

Abbildung 64: „Die Geschäftsentwicklung wird im Rahmen vorher festgelegter Planungstermine regelmäßig überprüft.“

Abbildung 65: „Die Strategie und die Ziele unseres Unternehmens werden regelmäßig an alle Führungskräfte und Mitarbeiter kommuniziert.“

Abbildung 66: „Eine konsequente Weiterbildung unserer Mitarbeiter durch externe und interne Stellen ist bei uns Standard.“.

Abbildung 67: „Bei der strategischen Unternehmensplanung unterstützen uns regelmäßig externe Berater.“.

Abbildung 68: Rechtsformen der Unternehmen in den strategischen Gruppen 161

Abbildung 69: Konzernzugehörigkeit nach Clustern 162

Abbildung 70: Unternehmensleitung in den strategischen Gruppen 162

Abbildung 71: Horizontale Kooperationen (realisiert oder in Planung) 170

Abbildung 72: Vertikale Kooperationen (realisiert oder in Planung). 170

Abbildung 73: Übernahme von Getränkefachgroßhändlern (realisiert oder geplant) 171

Abbildung 74: Vergleich der durchschnittlichen Gesamtkosten pro Hektoliter. 174 


\section{Tabellenverzeichnis}

Tabelle 1: Beispiele für Mobilitätsbarrieren in der Brauwirtschaft ........................................ 14

Tabelle 2: Umsatzstärkste Wirtschaftszweige im Ernährungsgewerbe ..................................26

Tabelle 3: Anteil der Gebinde am Bierausstoß der Jahre 1998, 2002 und 2004 in \% .............. 33

Tabelle 4: Struktur der deutschen Brauwirtschaft in den Jahren 1995 und 2004 .....................38

Tabelle 5: Anzahl der Braustätten und Unterschiede in der Größenstruktur nach

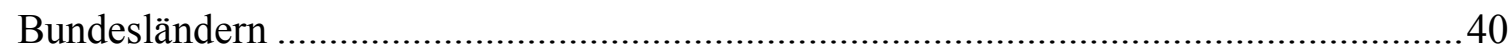

Tabelle 6: Top 10 Biermarken mit ihrem Inlandsabsatz 2004 und 2005................................49

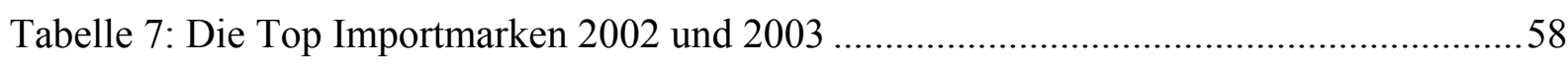

Tabelle 8: Mergers \& Aquisitions internationaler Braukonzerne auf dem deutschen Biermarkt 61

Tabelle 9: Biervertrieb nach Distributionskanal „Off-premise“ versus „On-premise“,

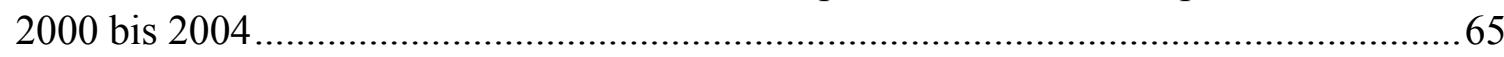

Tabelle 10: Verbrauch von Getränken in Deutschland (Liter pro Kopf und Jahr) ..................78

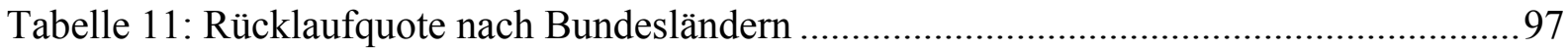

Tabelle 12: Rücklaufquote nach Ausstoßgrößenklassen der Brauereien.................................98

Tabelle 13: Wie viele Mitarbeiter waren in den letzten drei Jahren im Durchschnitt in

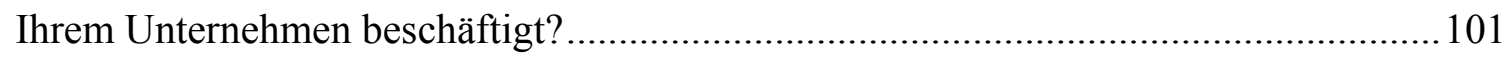

Tabelle 14: Durchschnittliche jährliche Marketingausgaben pro Hektoliter.......................... 120

Tabelle 15: Indikatoren zur Erfassung der Unternehmensstrategien ...................................150

Tabelle 16: Indikatoren zur Erfassung der Geschäftsfeldstrategien ...................................... 150

Tabelle 17: Rotierte Faktorenmatrix der Strategievariablen............................................. 152

Tabelle 18: Analyse der Cluster anhand der clusterbeschreibenden Variablen...................... 156

Tabelle 19: Vergleich zur Wahrnehmung der Branchensituation ......................................... 164

Tabelle 20: Einschätzung der Wettbewerbsposition im Vergleich zum stärksten

Wettbewerber. 166

Tabelle 21: Vergleich der Einschätzung des horizontalen und vertikalen

Kooperationspotentials

Tabelle 22 : Vergleich des Out- bzw. Insourcing im Bereich Fuhrpark sowie der geplanten Wachstumsstrategien.

Tabelle 23: Vergleich der Einschätzung der Gesamtkosten in Relation zum

Branchendurchschnitt

Tabelle 24: Vergleich der Strategieformulierung und -implementierung ............................. 176

Tabelle 25: Veränderung des Unternehmenserfolgs in den Jahren 2002 bis 2004................ 178

Tabelle 26: Erfolg in Relation zum Branchendurchschnitt ..............................................179 


\section{Abkürzungsverzeichnis}

\begin{tabular}{|c|c|}
\hline AfG & alkoholfreie Getränke \\
\hline $\mathrm{AG}$ & Aktiengesellschaft \\
\hline $\mathrm{Bd}$. & Band \\
\hline BLV & Bierlieferungsvertrag \\
\hline BMVEL & $\begin{array}{l}\text { Bundesministerium für Ernährung, Landwirtschaft und } \\
\text { Verbraucherschutz }\end{array}$ \\
\hline bzw. & beziehungsweise \\
\hline bspw. & beispielsweise \\
\hline bzgl. & bezüglich \\
\hline ca. & circa \\
\hline CMA & Centrale Marketinggesellschaft für Agrarwirtschaft \\
\hline CR & Konzentrationsrate \\
\hline d.h. & das heißt \\
\hline et al. & et alii \\
\hline etc. & et cetera \\
\hline EU & Europäische Union \\
\hline e.V. & eingetragener Verein \\
\hline evtl. & eventuell \\
\hline f. & folgende \\
\hline ff. & fortfolgende \\
\hline $\mathrm{F} \& \mathrm{E}$ & Forschung und Entwicklung \\
\hline GAM & Getränkeabholmärkte \\
\hline GFGH & Getränkefachgroßhandel \\
\hline GfK & Gesellschaft für Konsum und Absatzforschung \\
\hline
\end{tabular}




\begin{tabular}{|c|c|}
\hline $\mathrm{GmbH}$ & Gesellschaft mit beschränkter Haftung \\
\hline hl & Hektoliter \\
\hline Hrsg. & Herausgeber \\
\hline H.v. & Herstellung von \\
\hline i.d.R. & in der Regel \\
\hline ink1. & inklusive \\
\hline Jg. & Jahrgang \\
\hline KG & Kommanditgesellschaft \\
\hline $\mathrm{kg}$ & Kilogramm \\
\hline KMU & kleine und mittlere Unternehmen \\
\hline LEH & Lebensmitteleinzelhandel \\
\hline LKW & Lastkraftwagen \\
\hline M\&A & Mergers and Acquisitions \\
\hline Mio. & Million(en) \\
\hline Mrd. & Milliarde(n) \\
\hline MW & Mehrweg \\
\hline $\mathrm{Nr}$. & Nummer \\
\hline $\mathrm{NWS}_{\mathrm{FK}}$ & Nettowertschöpfung zu Faktorkosten \\
\hline o.J. & ohne Jahrgang \\
\hline $0 . \mathrm{V}$. & ohne Verfasser \\
\hline p.a. & per anno \\
\hline PET & Polyethylentherepthalat \\
\hline S. & Seite \\
\hline S-C-P & Structure-Contuct-Performance \\
\hline s. o. & siehe oben \\
\hline sog. & so genannt (-e,-er,-en) \\
\hline
\end{tabular}


SPSS

Thl

u.a

US

USA

usw.

vgl.

z.B.

z.T.
Statistical Product and Service Solution

Tausend Hektoliter

unter anderem

United States

United States of America

und so weiter

vergleiche

zum Beispiel

zum Teil 


\section{Einleitung}

\subsection{Problemstellung und Zielsetzung}

In zahlreichen Branchen der deutschen Wirtschaft ist seit einigen Jahren ein zunehmend schärferer Wettbewerb unter den Marktteilnehmern zu beobachten. Daher steht auf dem Gebiet des strategischen Managements neben der strategischen Führung insbesondere die Wettbewerbsorientierung strategischer Überlegungen im Mittelpunkt der Diskussion. Dies gilt im besonderen Maße für die deutsche Brauwirtschaft, die in eine tiefe, ihre Identität nachhaltig verändernde Krise geraten ist.

Viele Unternehmen haben Probleme bei der Anpassung an neue Marktgegebenheiten. Zur Wahl einer richtigen Strategie, die diesen Anforderungen genügt, ist es daher gerade bei stagnierenden Märkten wichtig, neben der klassischen kundenorientierten Marketingperspektive auch das Verhalten der Wettbewerber in die Überlegungen mit einzubeziehen (BAUER, 1991: S. 392). Aufgrund der Anpassungsprobleme vieler Unternehmen an die sich verändernden Marktgegebenheiten ist festzustellen, dass es in so gut wie jeder Branche - so auch in der Brauwirtschaft - Unternehmen gibt, die trotz zunehmenden Wettbewerbs langfristig eine höhere Profitabilität aufweisen als ihre Konkurrenten. Weder der industrieökonomische Ansatz noch der betriebswirtschaftliche Ansatz können diese Rentabilitätsunterschiede befriedigend erklären. Daher stellt sich die Frage, wie die Wettbewerbsorientierung in die strategischen Entscheidungen einfließen kann und welche Faktoren langfristig profitable von weniger profitablen Unternehmen unterscheiden (PIMPER, 1998: S. 5).

Diese Überlegungen führten schließlich zum Konzept der strategischen Gruppen. Mit diesem Konzept lässt sich die Wettbewerbssituation in einer Branche aufzeigen, es erleichtert Unternehmensvergleiche und zeigt, wie sich Unternehmen vor Mitbewerbern schützen können. Die Mitgliedschaft in einer strategischen Gruppe ist als einer von mehreren Einflussfaktoren auf die Rentabilität von Unternehmen in einer Branche zu sehen (BARTÖLKE, 2000: S. 141). Ferner ist das Konzept dazu verwendbar, eine eigene Strategie für eine Marktteilnahme zu identifizieren.

Das Konzept wird in der vorliegenden Arbeit auf die deutsche Brauwirtschaft angewendet. Auf der Grundlage einer empirischen Untersuchung in der Braubranche 
werden strategische Gruppen ermittelt und deren Besonderheiten aufgezeigt. Des Weiteren wird untersucht, ob sich Rentabilitätsunterschiede zwischen den Gruppen erkennen lassen. Die Bewertung verschiedener Strategien und die Untersuchung der Wettbewerbsintensität in der Braubranche sind ebenfalls Gegenstand der strategischen Gruppenanalyse. Aus theoretischer Sicht besteht der Reiz der Arbeit darin, eine Brücke zwischen dem industrieökonomischen sowie dem betriebswirtschaftlichen Ansatz zu schlagen. Darüber hinaus soll eine weit reichende Untersuchung der Gruppenunterschiede einen erweiterten Einblick in die Bildung und Funktionsweise strategischer Gruppen liefern.

Die Braubranche wurde ausgewählt, da sie in den letzten Jahren durch verschiedene Faktoren unter erheblichen Druck geraten ist. Ursachen sind u.a. ein sinkender ProKopf-Verbrauch, erhebliche Überkapazitäten, eine Beschleunigung des Innovationstempos, der Markteintritt finanzstarker ausländischer Wettbewerber sowie Niedrigpreisstrategien des Handels und wichtiger Wettbewerber. Als Folge dieser Entwicklung scheiden jedes Jahr zahlreiche Brauereien aus dem Markt aus oder gehen in andere, oft ausländische Hände über. Mehr als je zuvor geht es für Brauereien daher darum, zukunftsfähige strategische Positionen zu identifizieren und einzunehmen, um dauerhaft wirtschaftlich erfolgreich zu sein. Noch ist es dafür nicht zu spät. Diese Einschätzung teilt auch DR. RICHARD WEBER, Präsident des Deutschen Brauer-Bundes. Bei der Jahrespressekonferenz 2004/2005 kam er zu dem Schluss, dass der deutsche Biermarkt trotz aller Schwierigkeiten für alle Brauereien Raum für Erfolge biete vorausgesetzt, die Brauereien machten ihre „Hausaufgaben“ (DEUTSCHER BRAUERBund, 2005a). Für die Wahl der Brauwirtschaft als Studienobjekt spricht außerdem die beachtliche Zahl von über 1200 strategisch sehr unterschiedlich positionierten Brauereien in Deutschland. Eine vergleichbare Untersuchung in vielen anderen Branchen würde schon aufgrund der i.d.R. deutlich kleineren Grundgesamtheit auf Schwierigkeiten stoßen.

Der steigende Wettbewerbsdruck stellt jedoch eine große Herausforderung für die strategischen Entscheidungen in der Brauwirtschaft dar. Kenntnisse über die Struktur der Branche sowie über Strategien erfolgreicher Mitbewerber versetzen Brauereien in die Lage, ihre eigenen Strategien zu bewerten und zu überdenken. 
Mit der Anwendung des Konzeptes der strategischen Gruppen auf die Brauwirtschaft soll den Brauereien eine Hilfestellung bei der Bewältigung bestehender und zukünftiger Herausforderungen gegeben werden. Außerdem sollen die Ergebnisse auch bei der Betrachtung wenig konzentrierter, jedoch unter zunehmenden Druck geratener Branchen (z.B. Spirituosen, Mineralwasser) hilfreich sein.

\subsection{Vorgehensweise}

Der Aufbau der Arbeit ist durch die in Kapitel 1.1 beschriebene Problemstellung sowie die Forschungsziele bereits weitestgehend vorgezeichnet. Im Anschluss an das einführende Kapitel werden die theoretischen Grundlagen für eine Ermittlung strategischer Gruppen in der deutschen Brauwirtschaft erarbeitet (Kapitel 2). Ausgehend von einer ausführlichen Darstellung der relevanten Ansätze wird das Konzept der strategischen Gruppen detailliert beschrieben. Im zweiten Teil des Kapitels wird der Forschungsstand im Bereich der strategischen Gruppen - insbesondere in der Brauwirtschaft - auf Basis einer breiten Literaturanalyse dargestellt und der sich daraus ergebende Forschungsbedarf abgeleitet.

Im dritten Kapitel steht eine eingehende Analyse des Biermarktes im Mittelpunkt der Betrachtung. Dabei werden zunächst die Strukturen und Entwicklungen auf dem Weltbiermarkt näher untersucht, um den deutschen Biermarkt im internationalen Vergleich einordnen zu können. Im Anschluss daran erfolgen eine Segmentierung sowie eine erweiterte Branchenanalyse des deutschen Biermarktes. Anhand der Branchenstrukturanalyse nach PORTER (1995: S. 25f.), die durch eine Untersuchung der Umfeldfaktoren erweitert wird, soll der Unterbau für ein umfassendes Verständnis der spezifischen Probleme sowie der zu erörternden strategischen Verhaltensweisen in der deutschen Brauwirtschaft gelegt werden. Die dabei herausgearbeiteten wesentlichen Krisenindikatoren sowie deren Ursachen in der Braubranche werden zum Abschluss des Kapitels in einem Zwischenfazit zusammengefasst.

Das vierte Kapitel beinhaltet die empirische Analyse in Bezug auf Aspekte des strategischen Managements in der deutschen Brauwirtschaft. Auf der Basis der im zweiten und dritten Kapitel erarbeiteten Grundlagen werden zunächst entsprechende Hypothesen formuliert. Im Anschluss erfolgt eine Erläuterung des Forschungsdesigns, wobei insbesondere auf die Erhebungsmethode und die Fragebogenkonstruktion 
eingegangen wird. Nach den methodischen Vorüberlegungen werden Angaben zum Erhebungsumfang, der Rücklaufquote sowie zu allgemeinen Merkmalen der Brauereien getätigt. Daran schließt sich die Darstellung der Ergebnisse an. Dabei wird besonderes Augenmerk auf die Wahrnehmung der Intensität des Branchenwettbewerbs durch die befragten Unternehmen sowie auf die in der Branche verfolgten Unternehmens-, Wettbewerbs- und Kooperationsstrategien gelegt. Außerdem werden die Erfolgslage sowie die strategischen Planungsprozesse deutscher Brauereien näher beleuchtet. Dem Forschungsaufbau folgend werden im nächsten Schritt die strategischen Dimensionen operationalisiert. Unter der Verwendung von Faktor- und Clusteranalysen werden auf der Grundlage der ermittelten Strategievariablen sodann strategische Gruppen in der deutschen Brauwirtschaft identifiziert. Im Anschluss daran werden die Unterschiede zwischen den ermittelten Gruppen u. a. in Bezug auf die Unternehmensmerkmale, die Wahrnehmung der Branchen- und Wettbewerbssituation, die Kosten sowie die organisatorische Umsetzung der Strategie umfassend beschrieben. Ferner wird untersucht, inwieweit ein Zusammenhang zwischen der Strategiewahl und dem Unternehmenserfolg der Brauereien besteht.

Im abschließenden Kapitel der vorliegenden Arbeit werden die wichtigsten Ergebnisse der Untersuchung zusammengefasst. Darauf aufbauend werden zentrale Implikationen für die strategische Unternehmensführung in der deutschen Brauwirtschaft abgeleitet und Ansatzpunkte für weitere Forschungsfelder aufgezeigt. 


\section{Das Konzept der strategischen Gruppen}

\subsection{Die Entwicklung des Konzeptes der strategischen Gruppen}

Die Ausgangsbasis der Forschung zu strategischen Gruppen und deren Implikationen für die betriebswirtschaftliche Strategieforschung sind im Schnittfeld von Betriebs- und Volkswirtschaftlehre angesiedelt. Seit der Einführung des Konzepts der strategischen Gruppen ist dieses insbesondere im angelsächsischen Raum Gegenstand zahlreicher Untersuchungen geworden (COOL/SCHENDEL, 1987: S. 1102). Im deutschsprachigen Raum wurde der Ansatz erst Ende der 1980er Jahre eingeführt (BAUER, 1991: S. 395). In der betriebswirtschaftlichen Forschung war es lange Zeit nicht möglich, einen eindeutigen Zusammenhang zwischen Branchenmerkmalen und dem unterschiedlichen Erfolg von Unternehmen einer Branche zu erklären. Weder die branchenbezogene Sichtweise des industrieökonomischen Ansatzes noch die einzelwirtschaftliche Betrachtungsebene im Rahmen der Strategieforschung sind dazu als Bezugsbasis geeignet. Diese Erkenntnis führte schließlich zu dem Konzept der strategischen Gruppen und dem der Mobilitätsbarrieren (BAUER, 1991: S. 393f.).

Im Folgenden werden der industrieökonomische sowie der betriebswirtschaftliche Ansatz einschließlich ihrer Mängel dargestellt, da das Konzept der strategischen Gruppen auf beiden Forschungsperspektiven aufbaut. Im Anschluss daran wird gezeigt, dass mit diesem Konzept ein Brückenschlag zwischen beiden Ansätzen gelingt.

\subsubsection{DER INDUSTRIEÖKONOMISCHE ANSATZ}

Als Industrieökonomie wird die von der Theorie geleitete empirische Forschung zur Organisation und Struktur von Branchen im weitesten Sinne bezeichnet (BÜHLER/JAEGER, 2002: S. 1). Das Hauptanliegen des industrieökonomischen Ansatzes besteht darin, das Wettbewerbsgeschehen in Branchen zu erklären (BAUER, 1991: S. 390) und zu generellen Aussagen über die Funktionsfähigkeit des Wettbewerbs zu gelangen (BRUNKEN, 1990: S. 21). Die Industrieökonomie als Gegenstand der Forschung wurde von MASON (1949) und BAIN (1959) begründet. Der Ausgangspunkt dieser Arbeiten waren Schwierigkeiten, Beobachtungen des Wirtschaftsgeschehens durch die klassische Wettbewerbstheorie zu erklären (BARTÖLKE, 2000: S. 27). Die Überlegungen von BAIN und MASON führten schließlich zur Entwicklung des StructureConduct-Performance Paradigmas (S-C-P Paradigma), welches die Grundlage für die moderne wirtschaftswissenschaftliche Wettbewerbstheorie bzw. die daraus entwickelten 
Ansätze der Strategieforschung bildet (GaITANides/WestPhAL, 1991: S. 249f.). Das traditionelle S-C-P Paradigma (Abbildung 1) geht von der Annahme aus, dass die Struktur von Märkten (Structure) das Verhalten der Unternehmen (Conduct) bestimmt und sich aufgrund dessen das Marktergebnis (Performance) ableiten lässt.

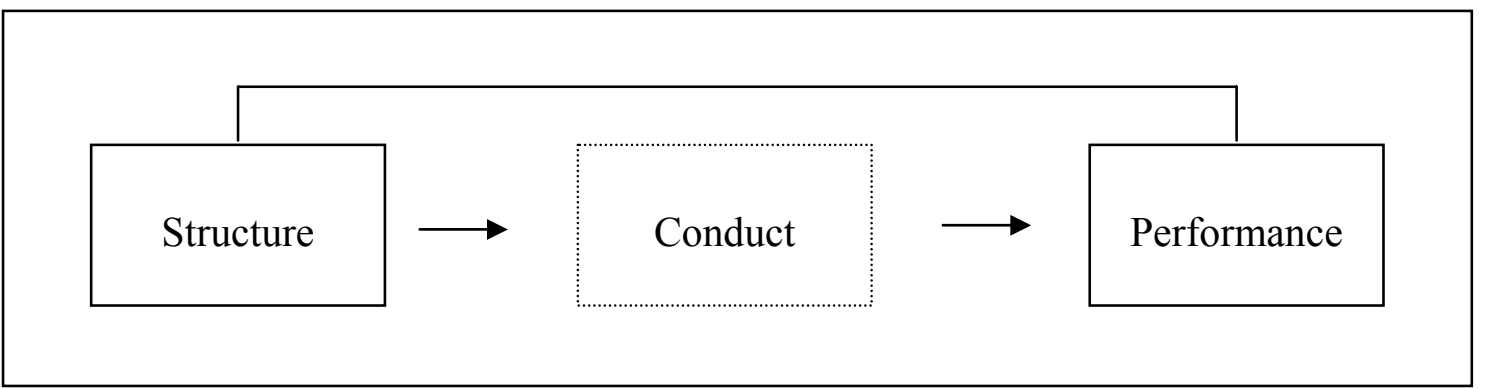

Abbildung 1: Das traditionelle S-C-P Paradigma

Quelle: MINDERLEIN 1989: S. 37

Dabei lassen sich eine strukturalistische und eine behavioristische Position unterscheiden. Die von MASON vertretene behavioristische Position versucht anhand unternehmensspezifischer Marktstrukturen unternehmensspezifische Verhaltensweisen zu klassifizieren. Im Mittelpunkt des Interesses steht dabei das Unternehmen, dessen Entscheidungen von der Marktsituation und der eigenen Situation abhängig sind.

Aus der von BAIN vertretenen Sicht der strukturalistischen Position ist der Zusammenhang zwischen Struktur und Verhalten im Zeitverlauf nicht mehr determiniert. Nach BAIN ist der zentrale Untersuchungsgegenstand nicht das Unternehmen, sondern die Branche. Das Marktergebnis lässt sich daher direkt aus der Marktstruktur herleiten (BÜHLER/JAEGER, 2002: S. 4ff.). Es wird somit unterstellt, dass das Verhalten nicht die unabhängigen Managemententscheidungen repräsentiert, sondern von der Struktur geleitet wird. In empirischen Arbeiten äußert sich dieses oft darin, dass die Verhaltenanalyse übersprungen wird (BESTER, 2003: S. 3). In Abbildung 1 wird dies durch die gestrichelte Linie veranschaulicht. Danach sind Unterschiede zwischen den Unternehmen bis auf die Unternehmensgröße nicht untersuchungsrelevant (Homogenitätsannahme). Bei einer Änderung der Marktstruktur ändern sich auch die Entscheidungen der Unternehmer, was bedeutet, dass der unternehmerische Freiraum vernachlässigbar klein ist (PORTER, 1979: S. 214).

In jüngeren Arbeiten werden gegen das traditionelle S-C-P Paradigma zunehmend empirische Belege angeführt, da Rückkopplungen keine Berücksichtigung finden (BARTÖLKE, 2000: S. 28). Diese Kritik am dargestellten Forschungsparadigma führte im Laufe der Zeit zur Weiterentwickelung. In der folgenden Abbildung 2 wird das 
revidierte S-C-P Paradigma von SCHERER und RosS aufgezeigt (SCHERER/ROSS, 1990: S. 5).

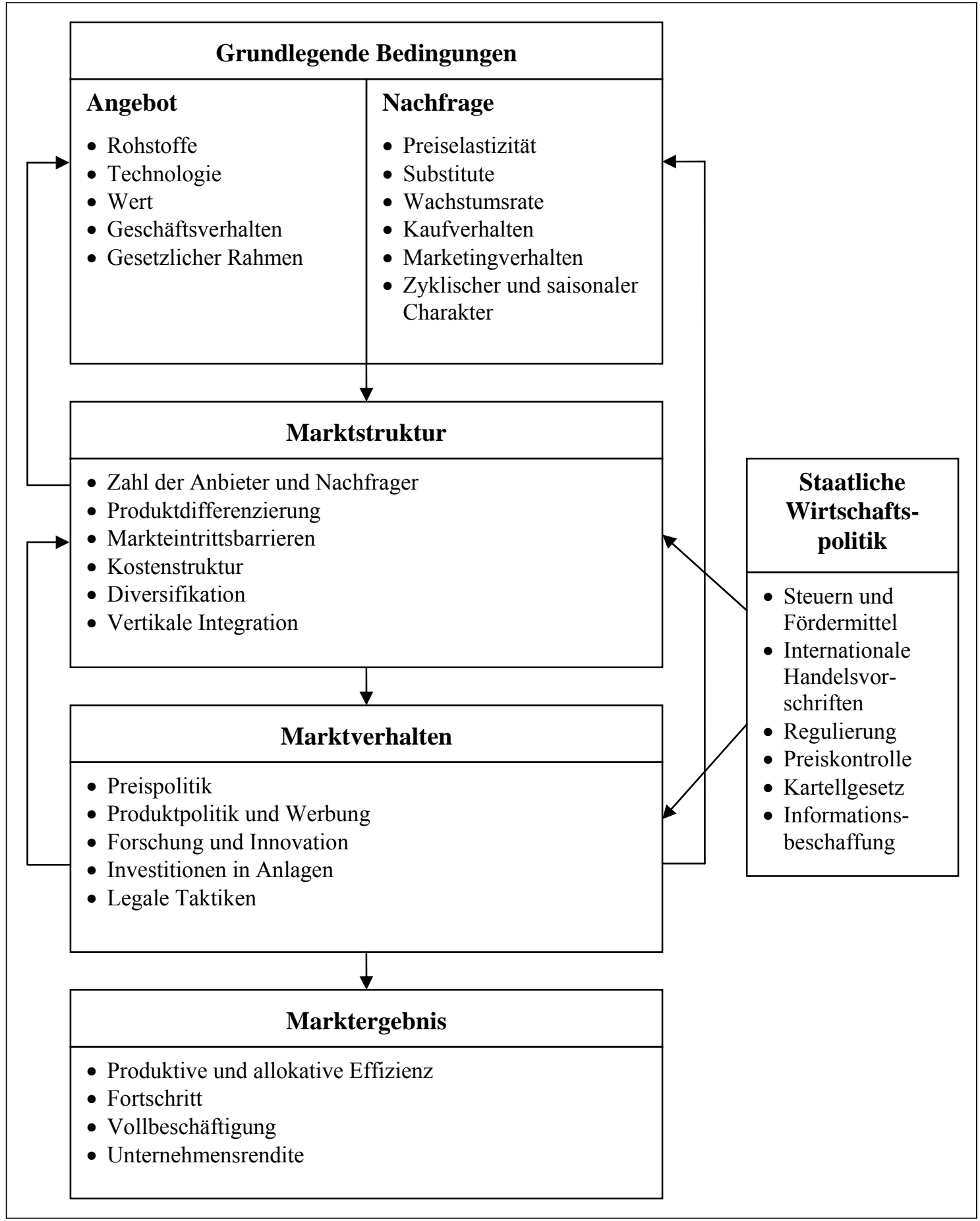

Abbildung 2: Das revidierte S-C-P Paradigma Quelle: SCHERER/Ross, 1990: S. 5; siehe auch BALDAUF, 1996: S. 68

Abbildung 2 liefert einen Überblick über die Zusammenhänge zwischen ausgesuchten Variablen der Marktstruktur, des Marktverhaltens sowie des Marktergebnisses. Bei diesem Ansatz wird unterstellt, dass diese Größen ihrerseits durch bestehende wirtschaftliche, rechtliche und politische Rahmenbedingungen determiniert werden. 
Zugleich wird die Hypothese der einseitigen Kausalbeziehung zwischen Struktur-, Verhaltens- und Ergebnisvariablen fallen gelassen und durch ein dynamisches Modell einer wechselseitigen Interdependenz ersetzt (BÜHLER/JAEGER, 2002: S. 8).

Unter den Begriff Struktur fallen dabei die relativ stabilen Eigenschaften eines Marktes, welche die Wettbewerbsfähigkeit entscheidend beeinflussen (KNIEPS, 2001: S. 48). Zu den bedeutendsten Determinanten der Marktstruktur zählen u.a. die Anzahl und Konzentration von Anbietern und Nachfragern, das Ausmaß und die Art der Produktdifferenzierung sowie die Markteintrittsbarrieren (MARX, 1998: S. 80).

Unter Marktverhalten werden alle alternativen Verhaltensannahmen von aktiven und potenziellen Marktteilnehmern beim Treffen von Entscheidungen über den Einsatz der von ihnen kontrollierten Parameter zusammengefasst, welche dazu dienen, sich den herrschenden Marktbedingungen anzupassen (KNIEPS, 2001: S. 52). Als zentrale Dimensionen des Verhaltens finden die Preis-, Produkt- und Werbepolitik sowie die Forschungs- und Entwicklungsaktivitäten Berücksichtigung. Diese Unternehmenspolitiken beziehen sich nicht nur auf die Kundenseite, sondern auch auf die Konkurrenz (CAVES, 1977: S. 50). In späteren Arbeiten wird das Marktverhalten nicht mehr als bloße Anpassung an vorgegebene Strukturen gesehen, sondern als Möglichkeit der aktiven Gestaltung und Einflussnahme auf die Marktstrukturen selbst. Deshalb können die Begriffe Marktverhalten und Unternehmensstrategie nach PORTER synonym verwendet werden (PORTER, 1981: S. 611; MINDERLEIN, 1989: S. 38).

Das Marktergebnis schließlich ist das Resultat aus den endogenen Verhaltensvariablen der Unternehmer in einzelnen Branchen. $\mathrm{Zu}$ den Marktergebnissen gehören u.a. die Höhe der Unternehmensrenditen, die Produktions- und Allokationseffizienz sowie das Ausmaß des technischen Fortschritts (BÜHLER/JAEGER, 2002: S. 5). Die Unternehmensleistung wird auf unterschiedliche Weise festgestellt. Zum einen können verschiedene Rentabilitätskennzahlen herangezogen werden, zum anderen dient auch die Preis-Kosten-Spanne als Indikator für die Leistung von Unternehmen. Während die am häufigsten verwendeten Rentabilitätskennzahlen die Gesamtkapital- und die Eigenkapitalrendite sind, ergibt sich die Preis-Kosten-Spanne aus der Relation der Verkaufspreise und der Grenzkosten (BALDAuF, 1996: S. 79). Die Höhe des Marktergebnisses drückt letztlich die Fähigkeit der Unternehmen aus, sich den Änderungen marktstruktureller Bedingungen anzupassen (MARX, 1998: S. 81). 
Die Bedeutung der Industrieökonomie sowie des S-C-P Paradigma im Besonderen für das strategische Management wurde von PORTER (PORTER, 1981: S. 609ff.) herausgearbeitet. In seinem Ansatz löst er sich allerdings von der in den traditionellen Modellen getroffenen Annahme einer homogenen Branchenstruktur und richtet sein Hauptaugenmerk auf die innerhalb von Industriezweigen vorzufindenden Unterschiede hinsichtlich unternehmensspezifischer Handlungsweisen und Entscheidungen (BöBEL, 1984: S. 113). Dieses erfolgt mit Hilfe des Konzeptes der strategischen Gruppen, welches im weiteren Verlauf der Arbeit noch näher dargelegt wird.

\subsubsection{DER BETRIEBSWIRTSCHAFTLICHE ANSATZ}

Bei der betriebswirtschaftlichen Forschungsperspektive steht die einzelwirtschaftliche Erfolgsbetrachtung unter Berücksichtigung unternehmensindividueller Stärken und Schwächen im Vordergrund. Die Zielsetzung ist es, den Einfluss etwa von Wettbewerbsstrategien auf den Unternehmenserfolg aufzudecken. Es lassen sich grundsätzlich zwei Forschungsstränge unterscheiden, um über den betriebswirtschaftlichen Ansatz zum Konzept der strategischen Gruppen zu gelangen.

Eine Möglichkeit hat eine Forschungsgruppe um Hatten gewählt, die der Schule der Purdue Universität zugezählt wird. Die grundlegenden Arbeiten stammen von HATten/SCHENDEL (1977), HANDEL/SCHENDEL/COOPER (1978), PATtON (1976) sowie SCHENDEL/PATTON (1978). Im Mittelpunkt steht dabei die Identifizierung der so genannten Erfolgsfaktoren. Dieses sind diejenigen Faktoren, die wesentlichen Einfluss auf den Unternehmenserfolg haben. Einige relevante Erfolgsfaktoren werden in der folgenden Abbildung 3 aufgezeigt.

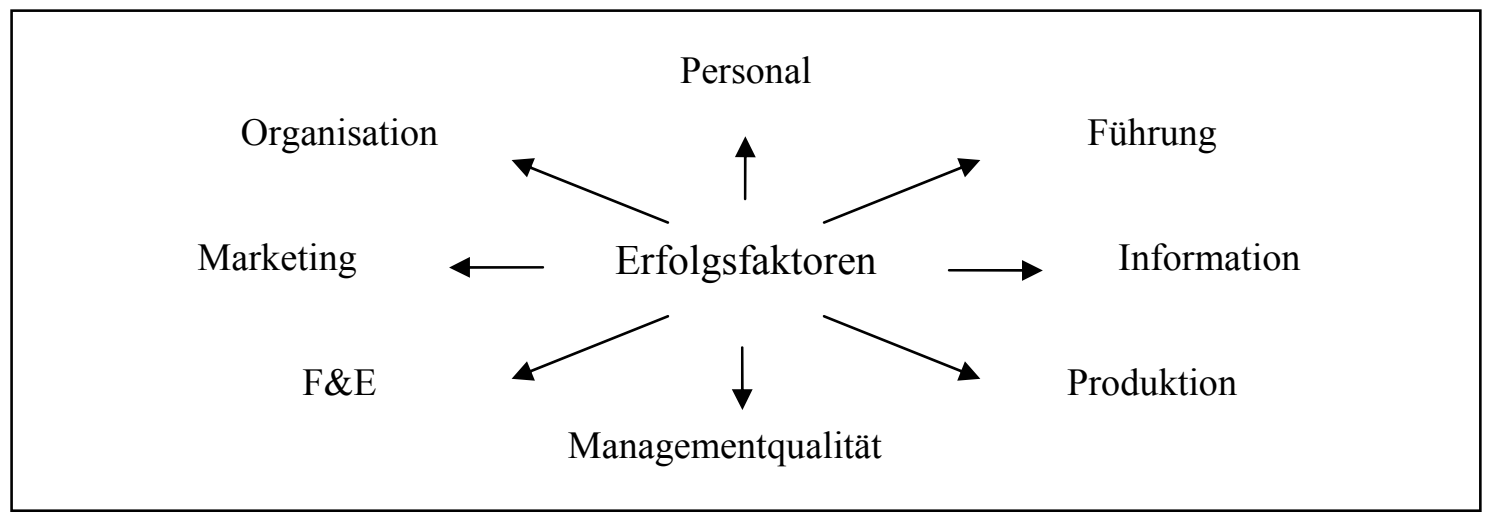

Abbildung 3: Beispiele von Erfolgsfaktoren

Quelle: KLEMM-BAX, 2000: S. 8

Die Erfolgsfaktorenforschung geht davon aus, dass trotz der Mehrdimensionalität und 
Multikausalität des Unternehmenserfolgs eine begrenzte Anzahl wesentlicher Schlüsselgrößen existiert, die den Erfolg eines Unternehmens maßgeblich beeinflussen (WAGNER, 1997: S. 3). Innerhalb der strategischen Planung nehmen diese Faktoren eine Schlüsselfunktion ein. Somit können sie als Grundlage für strategische Entscheidungen und Strategieentwicklungen angesehen werden (GöTtgens, 1996: S. 32). Mit Hilfe identifizierter Erfolgsfaktoren lässt sich der Unternehmenserfolg nicht a priori bestimmen, wohl aber können durch die Kenntnis dieser Faktoren Wettbewerbsvorteile besser aufgebaut und genutzt werden (KLEMM-BAX, 2000: S. 8).

Dieser Forschungsansatz basiert auf der Annahme, dass der Unternehmenserfolg einerseits von Größen bestimmt wird, welche von Unternehmern kontrollierbar sind, und zum anderen von nicht kontrollierbaren Umfeldbedingungen abhängt. Die Bedeutung für die Strategieableitung liegt dabei in der Analyse der wesentlichen Einflussfaktoren auf den Unternehmenserfolg, auf deren Grundlage strategische Gruppen in einer Branche gebildet werden.

Einen anderen Weg hat PORTER, der der Schule der Harvard Universität angehört, eingeschlagen. Er entwickelte ein Rahmenkonzept zur Identifizierung struktureller Merkmale von Branchen. Danach werden die Wettbewerbsintensität und somit auch die Unternehmensrentabilität in einer Branche von den fünf Wettbewerbskräften (FiveForces)

- Bedrohung durch neue Konkurrenten,

- Verhandlungsmacht der Abnehmer,

- Verhandlungsstärke der Lieferanten,

- Bedrohung durch Ersatzprodukte und

- der Rivalität unter den bestehenden Unternehmen

bestimmt. Die Unternehmen müssen ihre Wettbewerbsstrategie auf diese Triebkräfte des Branchenwettbewerbs ausrichten (PORTER, 1995: S. 25f.). In der Auseinandersetzung mit den fünf Wettbewerbskräften gibt es nach PORTER drei Erfolg versprechende Typen strategischer Ansätze. Diese sind die umfassende Kostenführerschaft, die Differenzierung sowie die Konzentration auf Schwerpunkte zur Sicherung bzw. Verbesserung der Wettbewerbssituation. Einige Unternehmen haben 
aber auch dabei Erfolg, mehr als einen Ansatz zu verfolgen (PORTER, 2001: S. 70).

Für PORTER steht das Einzelunternehmen im Vordergrund seiner Betrachtung. Ausgehend davon sieht er dieses im Branchenkontext, beschreibt die Strategien aller wichtigen Wettbewerber und fasst auf Grundlage dieser Beobachtungen Unternehmen zu strategischen Gruppen in einer Branche zusammen.

Im Folgenden werden der industrieökonomische und der betriebswirtschaftliche Forschungsansatz einander gegenübergestellt und gezeigt, wie eine Brücke zwischen beiden Ansätzen geschlagen werden kann.

\subsubsection{STRATEGISCHE GRUPPEN ALS SCHNITTSTELLE ZWISCHEN INDUSTRIEÖKONOMISCHEM UND BETRIEBSWIRTSCHAFTLICHEM ANSATZ}

Bei einem Vergleich des betriebswirtschaftlichen und des industrieökonomischen Ansatzes wird deutlich, dass sich beide Ansätze in ihren Zielsetzungen unterscheiden. Die Vertreter der Industrieökonomik analysieren die Zusammenhänge zwischen der Marktstruktur und dem Markterfolg, um aus dem Ergebnis eine optimale StrukturErfolgsbeziehung unter Berücksichtigung von wettbewerbspolitischen bzw. wohlfahrtsökonomischen Vorstellungen abzuleiten. Demgegenüber ist für die Betriebswirte die Analyse der Wettbewerbsvorteile und des individuellen Unternehmenserfolgs das relevante Untersuchungsziel (PORTER, 1981: S. 612).

Zudem ergibt sich aus der allgemeinen Zweiteilung von Branche einerseits und Unternehmen andererseits, dass es sich bei den beiden Untersuchungseinheiten um verschiedene Aggregationsebenen handelt. Die Industrieökonomen beschränken sich auf die Branchenebene und nehmen an, dass alle Unternehmen bis auf ihre Größe gleich sind. Die Betriebswirte hingegen untersuchen unternehmensindividuelle Eigenschaften, wobei die Berücksichtigung der Stärken und Schwächen der einzelnen Unternehmen im Vordergrund steht.

Auch die Entscheidungsfindungsprozesse werden von beiden Ansätzen unterschiedlich betrachtet. Die Industrieökonomik sieht das Unternehmen als eine Einheit an, welche Entscheidungen als „free standing entity“ mit nur einem Geschäftsfeld trifft und umsetzt. Daraus ergibt sich auch, dass Diversifikationen keine Beachtung finden. Demgegenüber können von Seiten der Betriebswirtschaft die Person des Unternehmers, 
politische Prozesse innerhalb des Unternehmens sowie Diversifikationsentscheidungen berücksichtigt werden (PORTER, 1981: S. 612; BALDAUF, 1996: S. 131).

Die beiden Forschungsrichtungen unterscheiden sich auch im methodischen Vorgehen deutlich voneinander. Die industrieökonomische Forschungsarbeiten gehen typischerweise nur auf eine oder wenige Variablen ein. Auf der anderen Seite fließen in die betriebswirtschaftlichen Untersuchungen in der Regel eine größere Zahl branchenspezifischer Variablen ein (PIEPELOW, 1997: S. 14).

Trotz dieser unterschiedlich ausgerichteten Ansätze vollzog PORTER eine Annäherung beider Forschungsrichtungen, indem er auf das Konzept der strategischen Gruppen zurückgriff. Bei diesem Konzept fließen zum einen Informationen über das einzelne Unternehmen ein, welche bei einer Branchenbetrachtung durch die Zusammenfassung von Informationen nicht erkennbar sind. Es findet eine vergleichende Untersuchung verschiedener Unternehmen statt, um die parallele Existenz unterschiedlicher strategischer Maßnahmen innerhalb einer Branche festzustellen (BARTÖLKE, 2000: S. 18). Zum anderen fließen Informationen über die Branche sowie Interdependenzen zwischen den Erfolgsfaktoren ein, welche bei einer isolierten Betrachtung der Einzelunternehmen evtl. verloren gehen würden. Das Konzept der strategischen Gruppen kann somit eine Brücke zwischen dem Ansatz der Industrieökonomie und der Unternehmensstrategie aus einzelwirtschaftlicher Sicht schlagen. Dies wird in Abbildung 4 grafisch dargestellt.

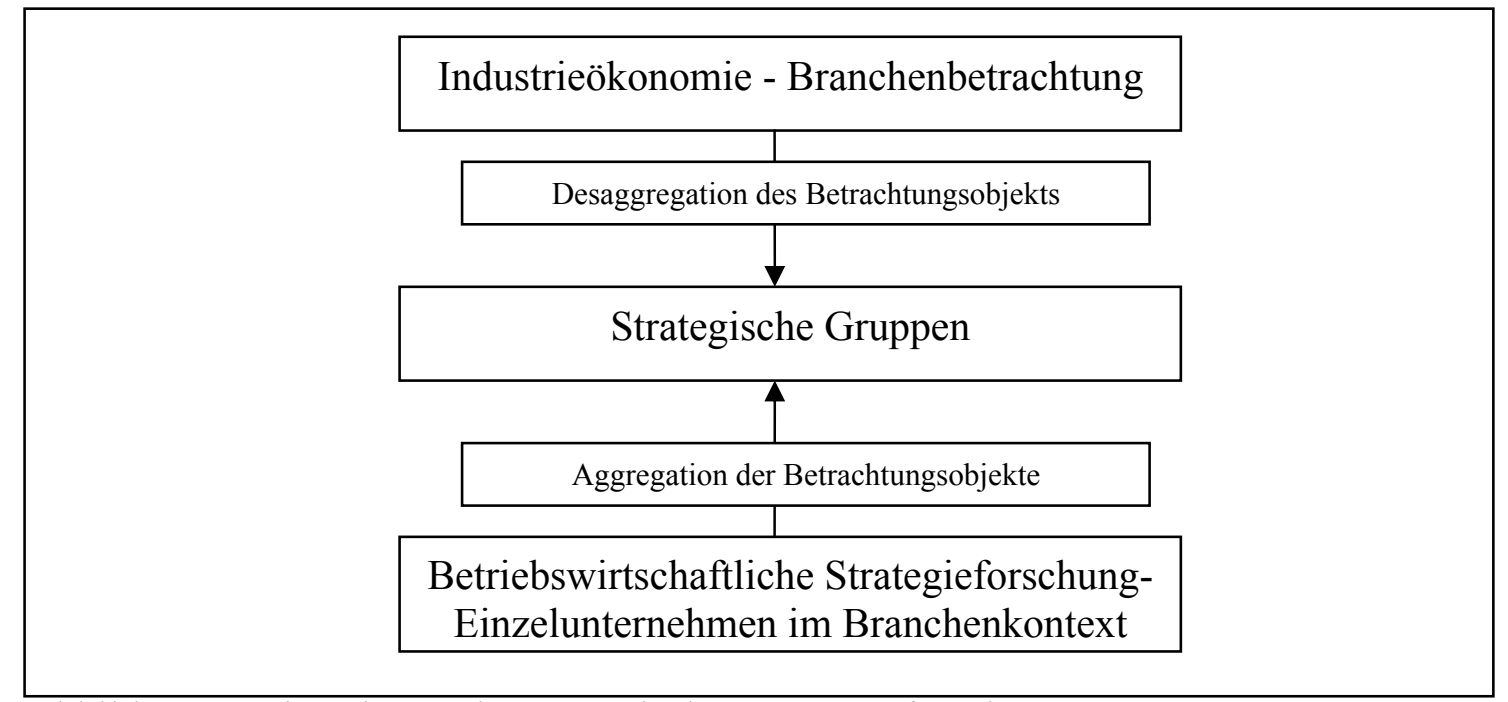

Abbildung 4: Einordnung der strategischen Gruppenforschung Quelle: BALDAUF, 1996: S. 136 


\subsection{Grundlagen des Konzeptes der strategischen Gruppen}

Der Begriff „strategische Gruppe“ wurde erstmals 1972 durch HUNT geprägt, der im Rahmen seiner Dissertation eine Analyse der amerikanischen Haushaltsgeräteindustrie durchführte. Dabei nahm er eine Einteilung in strategische Gruppen anhand der drei Schlüsselvariablen Ausmaß der Produktdifferenzierung, Produktdiversifikation und Ausmaß der vertikalen Integration vor (MCGeE/Thomas, 1986: S. 142).

Eine breitere Aufmerksamkeit verschaffte jedoch erst PORTER dem Konzept mit seinem Werk „Competitive Strategy“ (1980). Danach umfasst eine strategische Gruppe die Unternehmen einer Branche, die dieselbe oder ähnliche Strategien verfolgen. Es sind grundsätzlich drei Ausprägungen strategischer Gruppen in einer Branche denkbar. Wenn alle Unternehmen der Branche dieselbe Strategie verfolgen, gibt es nur eine strategische Gruppe. Umgekehrt kann jedes Unternehmen eine eigene Gruppe darstellen, wenn alle Unternehmen unterschiedliche Strategien verfolgen. Gewöhnlich besteht eine Branche jedoch aus einer kleinen Zahl strategischer Gruppen, die durch signifikante Strategieunterschiede gekennzeichnet sind (PORTER, 1995: S. 177). Die Unternehmen stehen innerhalb der Gruppen im intensiven Wettbewerb und konkurrieren als Ganzes mit anderen strategischen Gruppen (BAUER, 1991: S. 400).

Die Ähnlichkeit der verfolgten Wettbewerbsstrategien äußert sich in ähnlichen Ausprägungen der strategischen Variablen. In diesem Zusammenhang sind z.B. Variablen wie die Unternehmensspezialisierung, die Wahl des Vertriebswegs, der Umfang der FuE-Aktivitäten, der Grad der vertikalen Integration sowie die Preispolitik zu nennen. Die zur Gruppenbildung heranzuziehenden Variablen sind jedoch prinzipiell den branchenspezifischen Besonderheiten anzupassen (PORTER, 1995: S. 174ff.). Für die strategische Situation eines Unternehmens in einer Branche ist es wichtig, dass die Variablen von so großer Bedeutung sind, dass sie im Hinblick auf die Gruppenzugehörigkeit Mobilitätsbarrieren darstellen (HOMBURG/SÜTTERLIN, 1992: S. 639). Da Mobilitätsbarrieren für das Konzept der strategischen Gruppen unabdinglich sind, werden diese im Folgenden näher beschrieben.

Unter Mobilitätsbarrieren versteht man all jene Faktoren, die einerseits den Eintritt von branchenfremden Unternehmen entgegenstehen und andererseits für bereits in der Branche befindliche Unternehmen den Wechsel von einer strategischen Gruppe zu einer 
anderen erschweren bzw. verhindern (MCGEE, 1985: S. 299). Der Begriff geht auf CAVEs/Porter zurück, die das Konzept der Mobilitätsbarrieren als eine Verallgemeinerung des Markteintrittsbarrierenkonzepts von BAIN (1959) verstehen (CAVEs/Porter, 1977: S. 241ff.).

Unternehmen innerhalb einer Gruppe nehmen strategische Entscheidungen vor, die nicht von Unternehmen außerhalb der Gruppe imitiert werden können, ohne dass diese erhebliche Kosten auf sich nehmen müssten, deutlich mehr Zeit benötigten oder große Investitionsrisiken eingehen müssten.

Das Vorhandensein von Mobilitätsbarrieren kann die Dauerhaftigkeit von Rentabilitätsunterschieden zwischen Unternehmen und strategischen Gruppen erklären (CAVes/Ghemawat, 1992: S. 1). PORTER weist in diesem Zusammenhang jedoch darauf hin, dass die Mobilitätsbarrieren lediglich die potenzielle Rentabilität auf Gruppenebene determinieren (PORTER, 1995: S. 182). Der tatsächlich realisierte Unternehmenserfolg ist von der spezifischen Kombination der rentabilitätsbestimmenden Faktoren abhängig (BARTÖLKE, 2000: S. 83; PORTER, 1979: S. 219).

\begin{tabular}{|c|c|c|}
\hline Marktbezogene Aspekte & $\begin{array}{c}\text { Rahmenbedingungen der } \\
\text { Wertschöpfung in der Branche }\end{array}$ & $\begin{array}{l}\text { Strukturmerkmale des } \\
\text { einzelnen Unternehmens }\end{array}$ \\
\hline 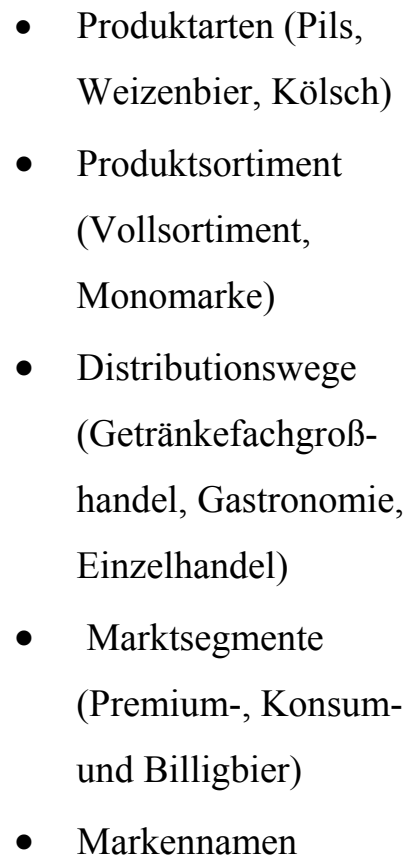 & $\begin{array}{l}\text { - Kostendegressionsmöglich- } \\
\text { keiten (Produktion, } \\
\text { Marketing, Verwaltung) } \\
\text { - Distributionslogistik (eigener } \\
\text { Fuhrpark, Spedition, } \\
\text { Fachgroßhandel) } \\
\text { - F\&E - Know how } \\
\text { (Biermischgetränke, } \\
\text { alkoholfrei Biere) }\end{array}$ & $\begin{array}{ll}\text { - } & \text { Unternehmensgröße } \\
\text { - } & \text { Grad der vertikalen } \\
\text { - } & \text { Grtegration } \\
\text { - } & \text { Diversifikation } \\
\text { - } & \text { Eigentumsverhältnisse } \\
& \text { (Privatunternehmen, } \\
\text { - } & \text { Sonzernbrauerei) } \\
\text { - } & \text { ländlich) } \\
\text { Managementkapazität (städtisch, } \\
\text { und -qualität }\end{array}$ \\
\hline
\end{tabular}

Tabelle 1: Beispiele für Mobilitätsbarrieren in der Brauwirtschaft Quelle: HomburG/SÜTTERLIN, 1992: S. 639; GOEHLER, 1993: S. 139 
Bei der Betrachtung der Ursachen von Mobilitätsbarrieren lässt sich zwischen

- marktbezogenen Aspekten,

- Rahmenbedingungen der Wertschöpfung in der Branche sowie

- Strukturmerkmalen des einzelnen Unternehmens

unterscheiden (HombURG/SÜTTERLIN, 1992: S. 639). Tabelle 1 zeigt Beispiele für mögliche Ursprünge von Mobilitätsbarrieren in der Brauwirtschaft

\subsection{Empirische Forschung im Bereich strategischer Gruppen}

Nachdem der Begriff der strategischen Gruppen erstmals verwendet wurde, folgte eine große Anzahl weiterer empirischer Analysen zu diesem Konzept in verschiedenen Branchen. Das Spektrum der untersuchten Branchen reicht von der Konsumgüterindustrie (Brauwirtschaft, Pharmazeutische Industrie) über den Investitionsgüterbereich (IT-Branche, Chemiebranche, Maschinenbau) bis hin zur Dienstleistungsbranche (Banken, Luftfahrtunternehmen, Versicherungen). Auch die Landwirtschaft wurde in Bezug auf die vorliegende Fragestellung bereits untersucht (MCLEAY/MARTIN/ZWART, 1996: S. 339-351). Ein Forschungsschwerpunkt ist im Konsumgüterbereich festzustellen (McGeE/THOMAS, 1986: S. 151).

Bei einer Klassifikation der Forschungsansätze nach dem jeweils untersuchten Wirtschaftssektor wird deutlich, dass die Art der Produkte tendenziell bestimmte gruppenbildende Variablen und damit Mobilitätsbarrieren impliziert. In der Konsumgüterindustrie resultieren die Abgrenzungsfaktoren im Wesentlichen aus marktbezogenen Aspekten (Marketingstrategie, Vertriebspräsenz, Art und Umfang des Leistungsangebotes) und gelegentlich auch aus den Rahmenbedingungen der Wertschöpfung (F\&E-Intensität) sowie den Strukturmerkmalen des Unternehmens (Grad der vertikalen Integration, Unternehmensgröße). Für die Investitionsgüterbranche lassen die empirischen Ergebnisse die Folgerung zu, dass die Mobilitätsbarrieren in erster Linie aus den Rahmenbedingungen der Wertschöpfung und den unternehmensspezifischen Strukturmerkmalen resultieren. Hierzu zählen die Produktionstechnologien, die F\&E-Intensität, der Grad der vertikalen Integration sowie die Unternehmensgröße (HomBURG, 1992: S. 84). Im Dienstleistungsbereich resultieren die strategischen Gruppen erwartungsgemäß überwiegend aus marktbezogenen Variablen, da der Servicecharakter dieses Wirtschaftszweigs vielfach das entscheidende Differenzierungspotenzial für die Unternehmen bildet (HOMBURG/SÜTTERLIN, 1992: 
S. 643).

Die empirischen Studien lassen sich auch in Hinblick auf die Datenanalyseverfahren, die zur Gruppenbildung herangezogen werden, unterscheiden. In den frühen Studien zu dieser Thematik wurden überwiegend bivariate Ansätze zur Gruppenabgrenzung verwendet. Die Ermittlung der Variablen zur Identifikation der Gruppen erfolgt dabei apriori in der Regel auf der Basis von Plausibilitätsüberlegungen bzw. subjektiven Einschätzungen. Da aus der Vielzahl der möglichen Strategiedimensionen lediglich zwei ausgewählt werden, hat dieses zwar den Vorteil, dass die Interpretation der identifizierten Gruppen erleichtert wird, gleichzeitig kommt es aber zu einem erheblichen Informationsverlust (BAUER, 1991: S. 406, HOMBURG/SÜTTERLIN, 1992: S. 640, MARX, 1998: S. 89).

In den neueren empirischen Untersuchungen dominiert das Streben, über multivariate Datenanalyseverfahren die wesentlichen Kriterien für die Abgrenzung strategischer Gruppen $\mathrm{zu}$ ermitteln. In diesen Arbeiten wird in der Regel eine große Zahl von Variablen berücksichtigt (BARTÖLKE, 2000: S. 94) und mit Hilfe der Analyseverfahren (Faktoranalyse, mehrdimensionale Skalierung) auf zentrale strategiebeschreibende Faktoren verdichtet. Diese Faktoren bilden die Grundlage der Gruppenabgrenzung (MARX, 1998: S. 89).

Für die eigentliche Identifikation der strategischen Gruppen eignet sich insbesondere die Clusteranalyse (HoMBURG/SÜTTERLIN, 1992: S. 640). Dieses Datenanalyseverfahren dominiert die empirischen Arbeiten zu strategischen Gruppen (BARTÖLKE, 2000: S. 102).

\subsection{Forschungsstand in der Brauwirtschaft}

Nachdem einige allgemeine Beobachtungen zur empirischen Forschung im Bereich der strategischen Gruppen dargestellt wurden, wird im Folgenden ein detaillierter Überblick zum Forschungsstand in der Brauwirtschaft zu diesem Themenkomplex gegeben. Die Anlage 1 enthält eine chronologische Aufstellung aller dem Autor bekannten nationalen und internationalen Studien im Bereich der Brauwirtschaft, die eine Abgrenzung strategischer Gruppen vornehmen bzw. in ihre Betrachtungen die Ermittlung von Gruppierungen einbeziehen. Soweit entsprechende Informationen zur Verfügung standen, finden sich für jede Studie Angaben zum Titel, zum Autor, zum Jahr der Veröffentlichung, zu den Datengrundlagen, zum Ziel der Arbeit, zur Methodik und zu 
den Kriterien der Gruppenabgrenzung sowie zu den Ergebnissen und durchgeführten Erfolgsanalysen. Es werden nur die wesentlichen Abgrenzungskriterien sowie Ergebnisse wiedergegeben, um den Umfang der Darstellung einschränken zu können.

\subsection{Kritische Würdigung der bisherigen empirischen Forschung und daraus resultierender Forschungsbedarf}

Im Folgenden werden zunächst allgemeine Defizite der bisherigen empirischen Forschungsarbeiten skizziert. Im Anschluss daran wird auf spezifische Schwächen vorliegender Studien zur deutschen Brauwirtschaft eingegangen und der sich daraus ergebende Forschungsbedarf dargelegt. Bei einer Vielzahl der bisherigen empirischen Arbeiten wurden die Mobilitätsbarrieren im Wesentlichen a-priori aus Plausibilitätsüberlegungen abgeleitet. MCGEe/THOMAS (1986) machen in diesem Zusammenhang einzelnen Studien den Vorwurf, die Auswahl der Strategiedimensionen ohne genügende Sachkenntnis der Branche getroffen $\mathrm{zu}$ haben. Außerdem wird deutlich, dass viele Untersuchungen sehr datengeleitet sind und nur auf Informationen zurückgreifen, die Sekundärstatistiken zu entnehmen sind. Ein Beispiel dafür ist die Arbeit von HatTEN/HATTEN (1985).

Ein weiterer Kritikpunkt ergibt sich aus der Anwendung der Clusteranalyse. Da das Verfahren prinzipiell eine Gruppenabgrenzung zum Ergebnis hat, erscheinen diese Studien nicht ausreichend, um die Existenz strategischer Gruppen zu belegen. Diese Kritik kann jedoch durch eine theoretische Fundierung der Variablen oder die Einbeziehung von Experteneinschätzungen aus der Unternehmenspraxis entkräftet werden (BARTÖLKE, 2000: S. 105).

Weiterhin ist anzumerken, dass die Interpretation der Untersuchungsergebnisse häufig $\mathrm{zu}$ kurzfristig orientiert und oberflächlich gehalten ist. So sind auch HoMBURG und SÜTTERLIN der Auffassung, dass gerade dem Aspekt der Beziehung zwischen der Zugehörigkeit zu einer strategischen Gruppe und der Rentabilität sowie der Ableitung strategischer Implikationen mehr Aufmerksamkeit eingeräumt werden sollte (HOMBURG/SÜTTERLIN, 1992: S. 652). 
Bei den Untersuchungen zur deutschen Brauwirtschaft wird deutlich, dass diese Studien sehr spezifische Fragestellungen bearbeiten. Die Arbeit von BRUNKEN (1990) beschränkt sich auf Wettbewerbsstrategien in der mittelständischen Brauwirtschaft, GOEHLER (1993) analysiert den Erfolg großer Familienunternehmen, MARX (1998) betrachtet international operierende deutsche Brauereien und LUDIN (2001) erarbeitet Unternehmensstrategien für oberbayerische Brauereien mit dem Ziel des Erhaltes der mittelständischen Unternehmensstruktur. Ferner bleibt kritisch anzumerken, dass die Untersuchungen von GOEHLER sowie LUDIN lediglich von einer kleinen Stichprobengröße ausgehen und aus diesem Grund kaum repräsentative Aussagen über erfolgversprechende Strategien in der Brauwirtschaft zulassen.

Abschließend ist festzustellen, dass eine Untersuchung von strategischen Gruppen in der gesamten deutschen Brauwirtschaft bisher nicht durchgeführt wurde. Anhand einer solchen Studie können Einblicke in das Wettbewerbsverhalten der gesamten Brauindustrie sowie Erklärungsbeiträge für verschiedene Strategien und vor allem für evtl. brancheninterne Umpositionierungen gewonnen werden. Dies ist eine Vorraussetzung, um zukünftige Entwicklungen innerhalb der Branche abzuschätzen. Die Notwendigkeit einer Analyse strategischer Gruppen ergibt sich auch aus dem deutlichen Strukturwandel in der Brauwirtschaft in den letzen Jahren, der in den bisherigen Untersuchungen keine Berücksichtigung gefunden hat. 


\section{Der Biermarkt}

\subsection{Der Weltbiermarkt}

Die weltweite Bierproduktion stieg 2004 im Vergleich zum Vorjahr um 4,8 \% auf ein Gesamtvolumen von 1,55 Mrd. Hektoliter an (BALZ, 2005: S. 34). Abbildung 5 veranschaulicht, dass die Weltbierproduktion seit 1998 insgesamt um 19,25\% angestiegen ist. Dies entspricht einer durchschnittlichen jährlichen Wachstumsrate von 3,2 \%. Das deutlichste Wachstum war in diesem Zeitraum in Asien (+ 38,5\%) zu verzeichnen, wohingegen das Wachstum in Europa mit $+18,7 \%$ erheblich geringer ausfiel.

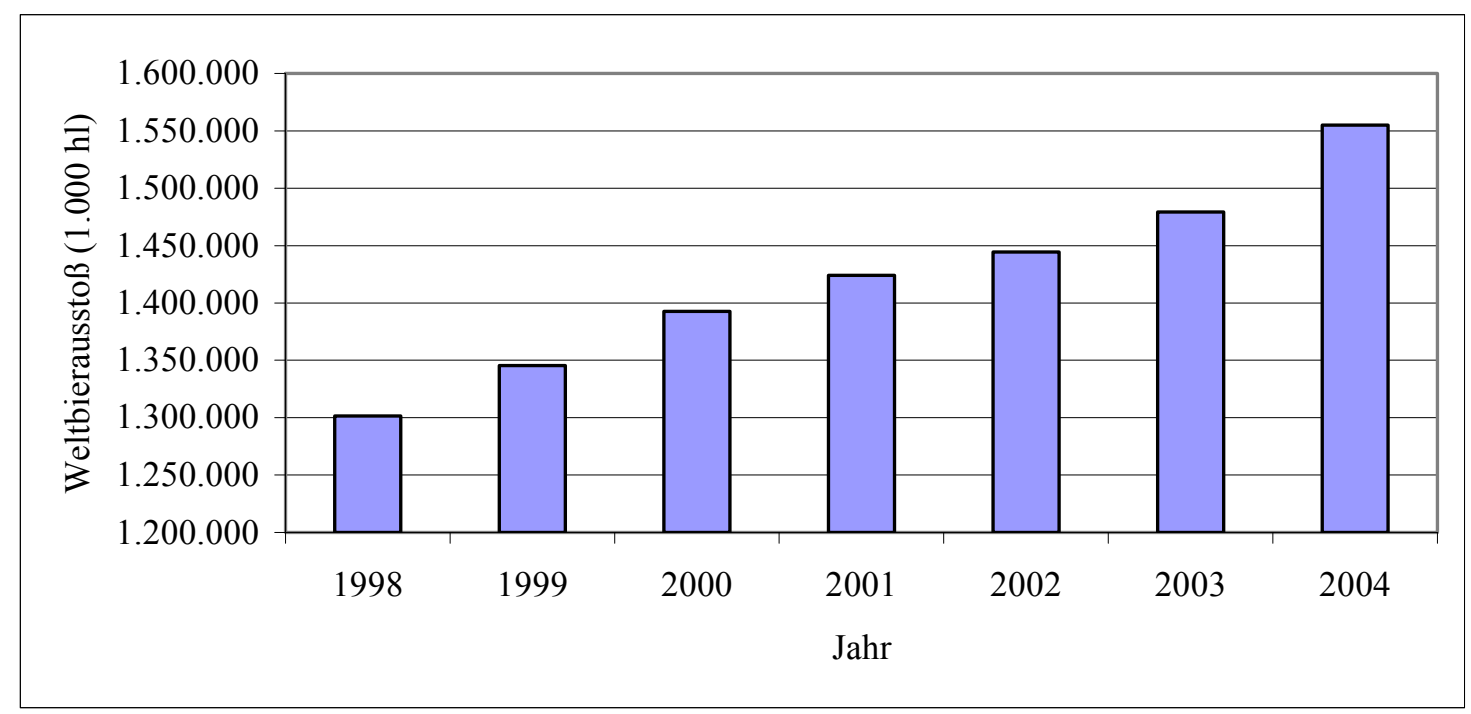

Abbildung 5: Wachstum des Weltbiermarktes von 1998 bis 2004

Quelle: BARTH \& SOHN, 1999/2000, 2001/2002, 2002/2003 und 2004/2005

Trotz der aufgezeigten Entwicklung ist Europa immer noch der größte Bierproduzent der Welt und hat einen Anteil von etwa $34 \%$ an der globalen Bierproduktion (vgl. Abbildung 6) (BARTH \& SOHN, 1999/2000: S. 5; 2004/2005: S. 6). Diese Position ist seit 1998 relativ stabil, obgleich der Bierkonsum in einigen westeuropäischen Ländern seither z. T. deutlich abgenommen hat. Aufgefangen wurde diese Entwicklung jedoch durch steigende Exporte sowie ein starkes Wachstum in Zentral- und Osteuropa. (CANADEAN, 2004: S. 7ff.). 


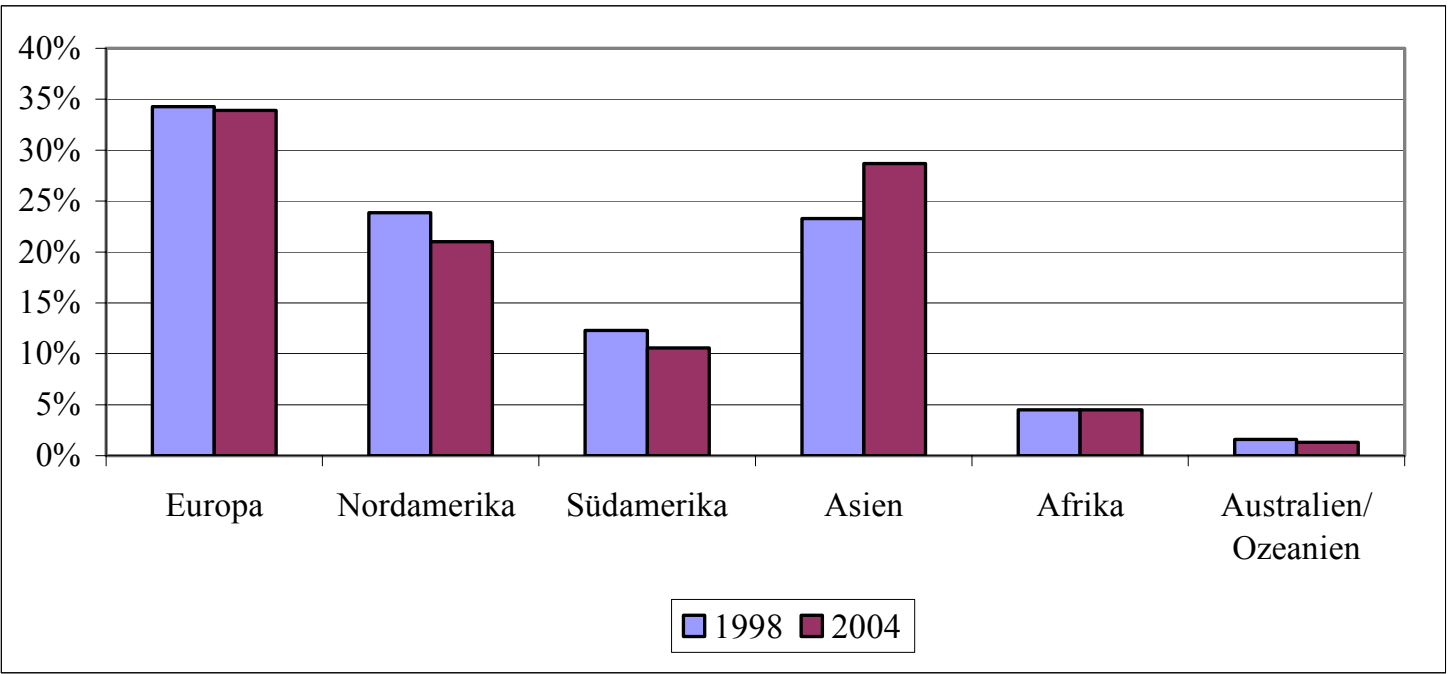

Abbildung 6: Weltbiererzeugung nach Regionen 1998 versus 2004 Quelle: BARTH \& SOHN, 1999/2000: S. 5; 2004/2005: S. 6

Nordamerika und Asien waren 1998 jeweils für etwa ein Viertel der Weltbiererzeugung verantwortlich. In den letzten Jahren haben die nordamerikanischen Brauer jedoch erhebliche Anteile an ihre asiatischen Mitkonkurrenten verloren. Trugen die Nordamerikaner 1998 noch für ca. $24 \%$ und die Asiaten für ca. $23 \%$ der globalen Weltbierproduktion Rechnung, so waren es 2004 bei den Nordamerikanern nur noch ca. $21 \%$, bei den Asiaten hingegen etwa 29 \%. Diese Veränderung dürfte hauptsächlich auf das erhebliche Wachstum des chinesischen Marktes bei gleichzeitig gesättigtem USamerikanischem Markt zurückzuführen sein.

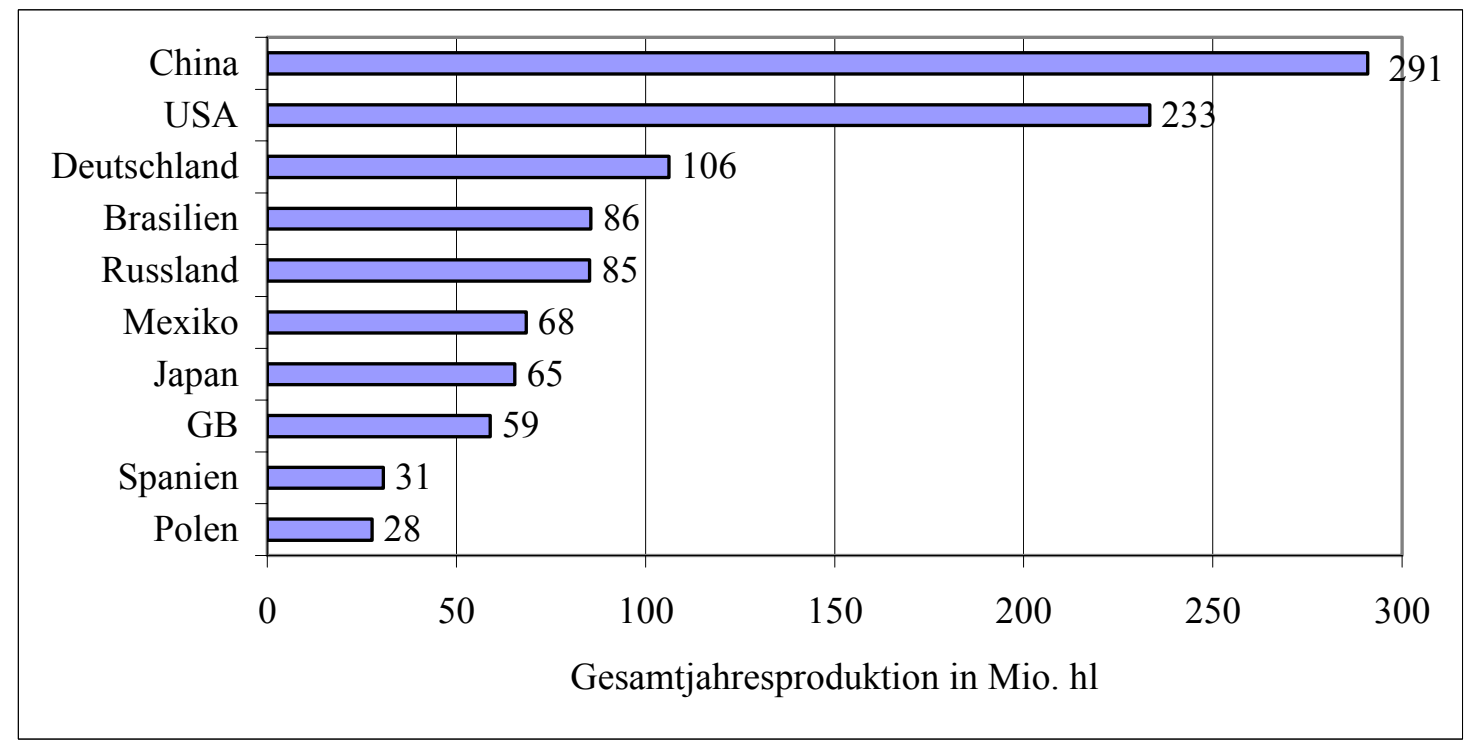

Abbildung 7: Top 10 Länder der Weltbierproduktion 2004

Quelle: BARTH \& SOHN, 2004/2005: S. 6 
Im Jahr 2002 übertraf die chinesische Bierproduktion erstmals die US-amerikanische. Mit einem Produktionsvolumen von 291 Mio. Hektoliter im Jahr 2004 ist der chinesische Markt mit Abstand der größte Biermarkt der Welt gefolgt von den USA und Deutschland. Die weiteren fünf Länder befinden sich alle in etwa in der gleichen Größenklasse zwischen 60 und 85 Millionen Hektoliter. Danach folgen mit einigem Abstand Spanien und Polen. Zusammen kommen diese Top 10 Länder auf einen Anteil von 67,8 \% der weltweiten Bierproduktion (vgl. Abbildung 7).

Von 1998 bis 2004 ist der chinesische Markt jährlich um durchschnittlich 11,3 \% gewachsen. Diese Entwicklung steht in starkem Gegensatz zur Situation auf dem USamerikanischen Markt (233 Mio. Hektoliter), welcher in diesem Zeitraum nahezu konstant geblieben ist, und dem deutschen Markt, welcher seit 1998 jährlich im Durchschnitt um etwa 0,8\% geschrumpft ist (vgl. Abbildung 8). Der chinesische Markt ist jedoch bei weitem nicht der am schnellsten wachsende Biermarkt der Welt. Diese Position nimmt Russland mit einem durchschnittlichen jährlichen Wachstum von 26,9 \% pro Jahr zwischen 1998 und 2004 ein. Die Ukraine ist der am zweit schnellsten wachsende Markt gefolgt von China.

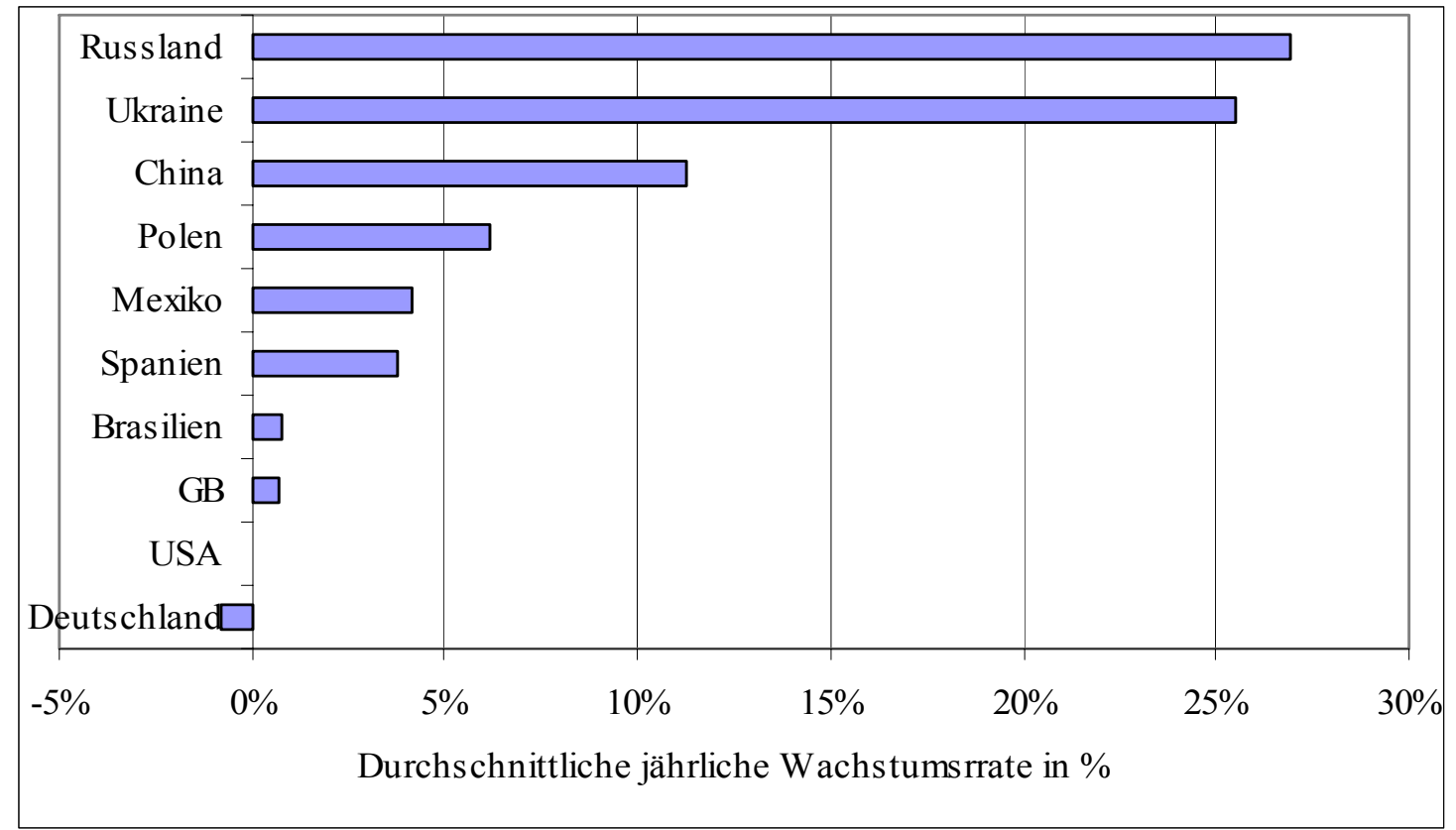

Abbildung 8: Durchschnittliche jährliche Wachstumsrate der Bierproduktion von 1998 bis 2004 in ausgewählten Ländern

Quelle: BARTH \& SOHN, 1999/2000: S. 5; 2004/2005: S. 6

Obgleich in einigen europäischen Ländern seit Jahren ein abnehmender Bierkonsum zu beobachten ist, gehören viele dieser Länder zu denen mit dem höchsten Pro-Kopf- 
Verbrauch der Welt. Den ersten Platz auf dieser Rangliste mit einem pro Kopf Verbrauch von 162 Litern im Jahr 2003 nimmt die Tschechische Republik ein (vgl. Abbildung 9). Dieser hohe Bierkonsum kann zum einen darauf zurückgeführt werden, dass Bier in der Tschechischen Republik auch bei Frauen sehr beliebt ist, und zum anderen auf die steigende Anzahl von Touristen (CANADEAn, 2004: S. 97). Die Iren nehmen mit einem Verbrauch pro Einwohner von 118 Litern den zweiten Platz ein gefolgt von Deutschland (117 Liter). Insgesamt wurden im Jahr 2003 in Westeuropa nicht berücksichtigt sind Zentral- und Osteuropa - etwa 77 Liter Bier pro Einwohner konsumiert. Wenig überraschend ist der geringe Verbrauch in Italien (30 Liter), Frankreich (35,5 Liter) und Griechenland (39 Liter), da in diesen Ländern Wein sehr beliebt ist (THE BREWERS OF EUROPE, 2003).

Vor dem Hintergrund des steigenden Exports und des stark wachsenden Marktes in Zentral- und Osteuropa kann auch für die Zukunft von einer stabilen bis leicht steigenden Bierproduktion in Europa ausgegangen werden.

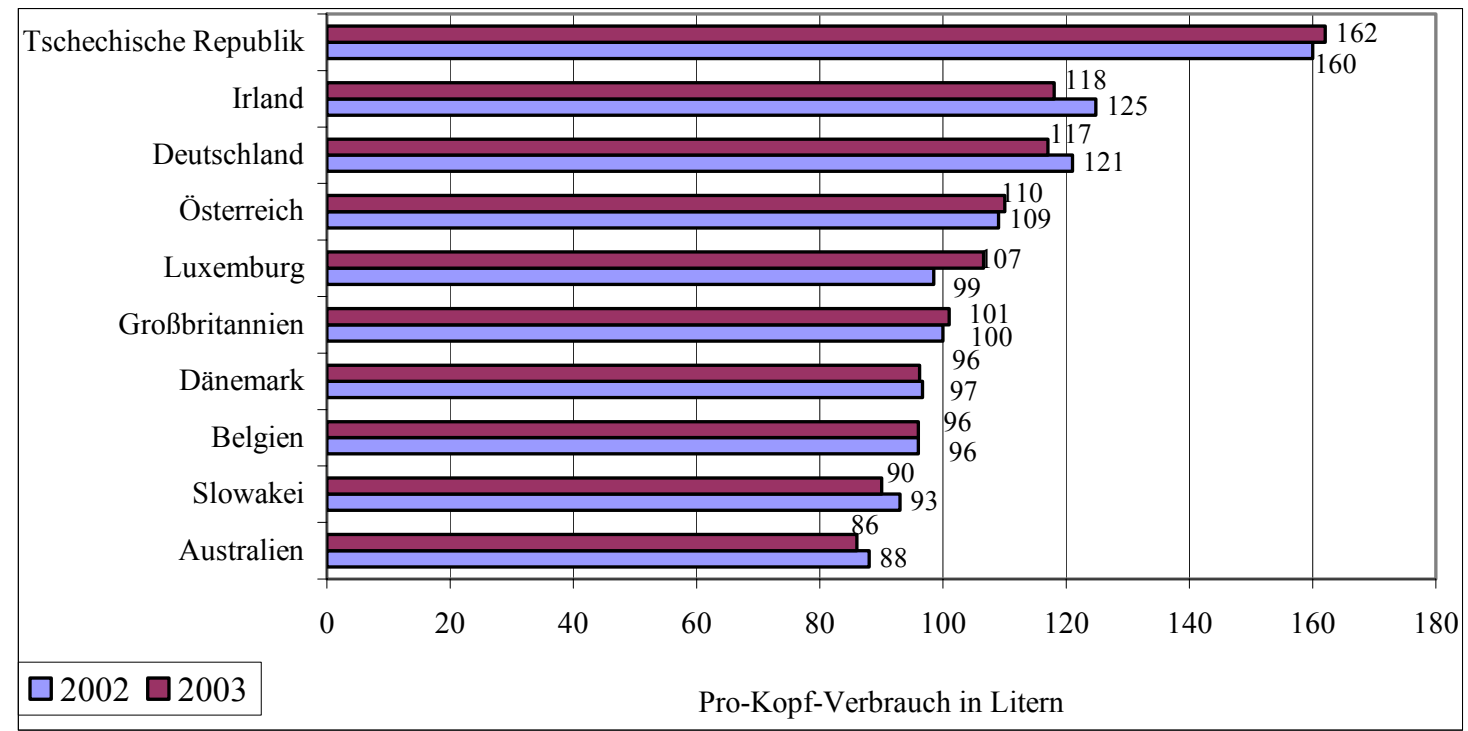

Abbildung 9: Top 10 Länder des jährlichen Bier Pro-Kopf-Verbrauch Quelle: THE BREWERS OF EUROPE, 2003, CANADEAN, 2004: S. 12

Die größten Bierexportländer der Welt sind Mexiko und die Niederlande. So führte Mexiko im Jahr 2003 etwa 13,8 Mio. Hektoliter aus. Die Niederlande exportierten im selben Zeitraum ca. 13,5 Mio. Hektoliter Bier, was hauptsächlich auf den weltweiten Erfolg zwei der größten Biermarken der Welt - Heineken und Amstel - zurückzuführen ist. Mehr als die Hälfte der niederländischen Bierproduktion ist somit für den Export bestimmt (Plato, 2005). Deutschland exportierte 2003 etwa 12 Mio. Hektoliter und 
konnte seinen Export in 2004 sogar noch deutlich ausdehnen (13,7 Mio. Hektoliter) (Deutscher Brauer-Bund, 2005b). Aufgrund der Tatsache, dass auch die Niederlande ihre Ausfuhren steigern konnten, liegt Deutschland somit immer noch auf dem dritten Rang der größten Bier exportierenden Länder der Welt (vgl. Abbildung 10).

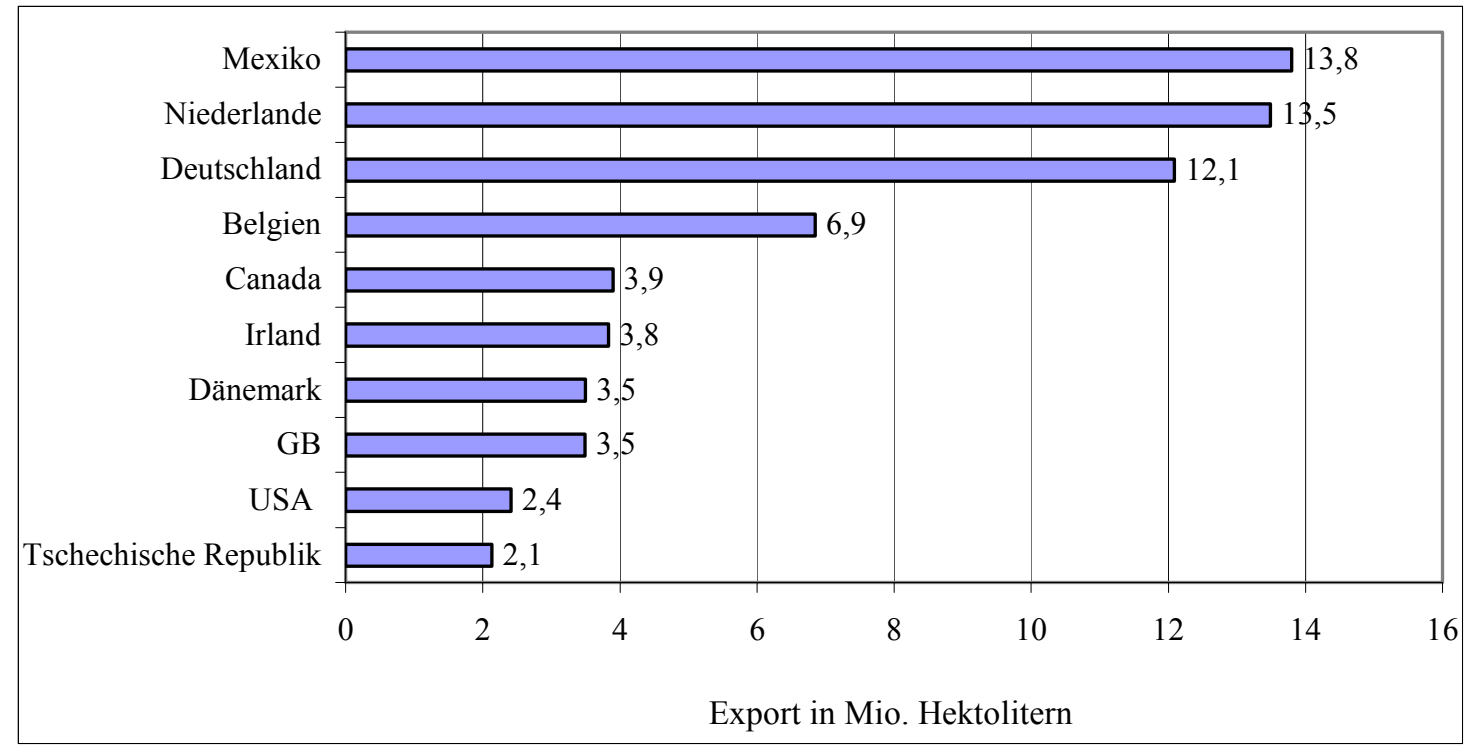

Abbildung 10: Top 10 der Bierexportländer der Welt im Jahr 2003

Quelle: Plato, 2004

Auch wenn Deutschland in Bezug auf die Menge der zweitgrößte Bierexporteur in Europa ist, sind die deutschen Brauer noch immer sehr auf den Heimatmarkt fixiert. Nur etwa $13 \%$ der Gesamtbierproduktion sind für den Export bestimmt. Nach den Niederlanden sind Belgien und Irland am meisten auf den Export konzentriert. In diesen Ländern gehen etwa $47 \%$ (Belgien) bzw. $43 \%$ (Irland) der Gesamtbierproduktion in den Export.

Mit Blick auf den Bierimport ergibt sich ein klares Bild. Danach ist der USamerikanische Markt mit einem Bierimport von etwa 27,8 Mio. Hektolitern im Jahr 2003 bei weiten der größte Importmarkt der Welt. Der Importanteil macht somit etwa $12 \%$ des Gesamtabsatzes im US-amerikanischen Biermarkt aus. Mit einer Menge von ca. 7,7 Mio. Hektoliter ist Großbritannien das zweitgrößte Bierimportland, gefolgt von Frankreich (ca. 5 Mio. Hektoliter), Italien (ca. 4,6 Mio. Hektoliter) und Spanien (ca. 3,6 Mio. Hektoliter). Gerade in Frankreich und Italien dürfte der hohe Importanteil auf dort starke internationale Braukonzerne (wie z.B. Heineken und InBev) zurückzuführen sein, welche ihre Distributionswege auch für den Import ihrer Hauptmarken nutzen. In beiden Ländern liegt der Anteil von importierem Bier am Gesamtabsatz bei etwa $25 \%$ (Plato, 2004). 
Innerhalb der Weltbrauindustrie begann der Konzentrations- und Konsolidierungsprozess später als in anderen Konsumgüterindustrien. Noch bis Ende der 90er Jahre verlief das Wachstum der zehn größten Braukonzerne fast parallel zu dem des gesamten Weltbiermarktes mit jährlichen Wachstumsraten von gut zwei Prozent. So erhöhte sich der Konzentrationsgrad (CR10) von 1989 bis 1998 lediglich von 32,2 \% auf 37,3\% (EBNETH, 2005: S. 1). Abbildung 11 verdeutlicht, dass sich dieses Konzentrationstempo seitdem erheblich erhöht hat. Der Marktanteil der Top 10 Braukonzerne an der weltweiten Bierproduktion stieg durch vermehrte Mergers \& Acquisitions-Tätigkeiten bis 2004 auf etwa 60 Prozent an. Der US-amerikanische Braukonzern Anheuser Busch (144 Mio. hl) war über Jahrzehnte der größte Brauer der Welt. Im März 2004 hat Anheuser Busch diese Position jedoch an die durch eine Fusion der belgischen Interbrew und der brasilianischen Ambev entstandenen InBev abgeben müssen. Durch diese Fusion ist ein globaler Braukonzern mit einem jährlichen Ausstoß von etwa 184 Mio. Hektoliter und einem Weltmarktanteil von ca. $12 \%$ entstanden. Der südafrikanische/US-amerikanische Brauer SABMiller (152 Mio. hl) ist seit 2004 der zweitgrößte Marktteilnehmer, gefolgt von Anheuser Bush, der niederländischen Heineken (126 Mio. hl) und der dänischen Carlsberg (92 Mio. hl).

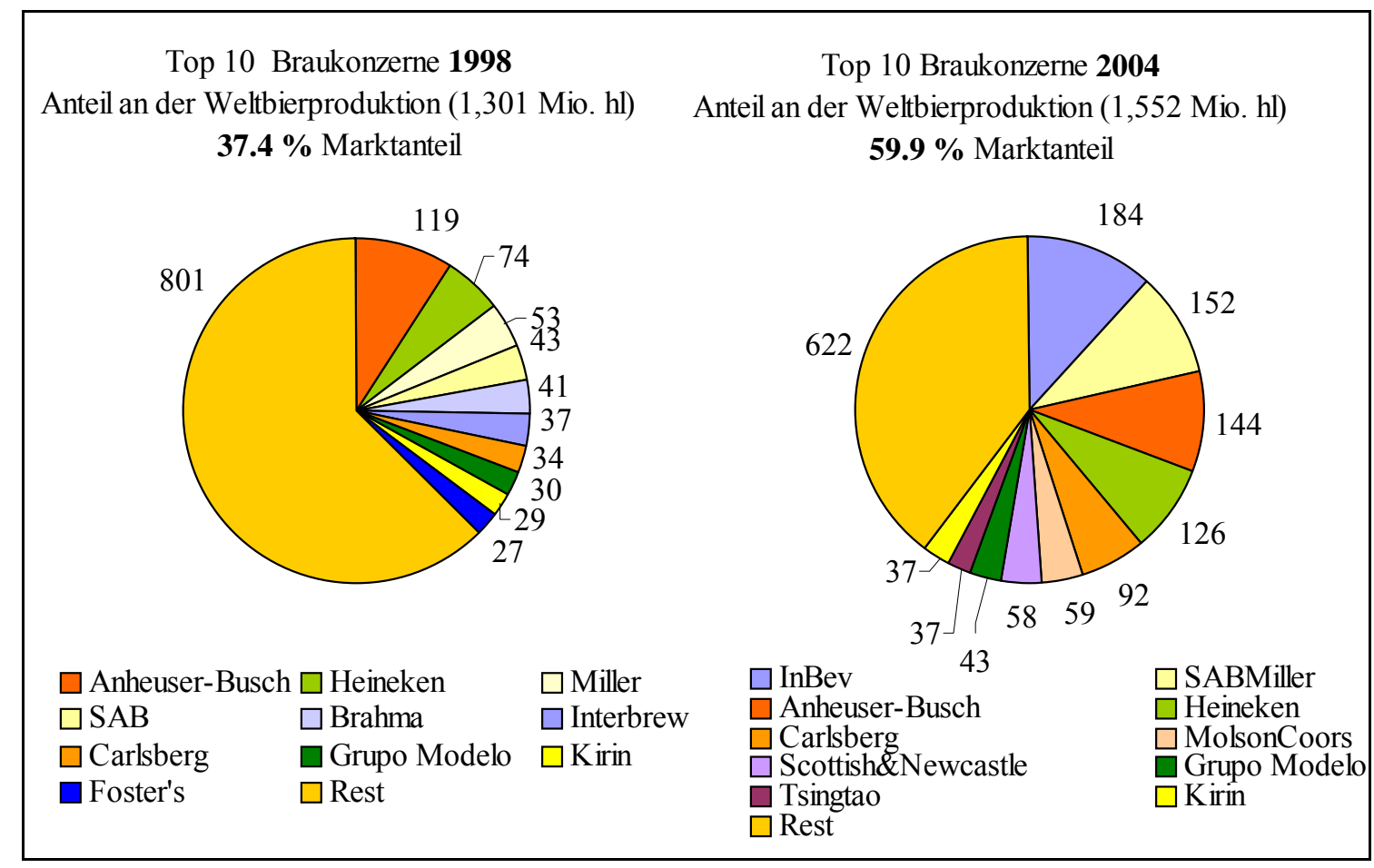

Abbildung 11: Entwicklung der weltweit führenden Braukonzerne 1998 bis 2004 Quelle: EBNETH / THEUVSEN, 2005: S. 44 
Heineken war jahrelang die Nummer 2 in der Welt und die unangefochtene Nummer 1 auf dem europäischen Markt. In den letzten Jahren mussten sich die Niederländer im Vergleich zu ihren Hauptmitbewerbern jedoch mit einem deutlich geringeren Wachstum zufrieden geben. Carlsberg und Scottish \& Newcastle konnten vor allem durch eine Expansion ihres Joint Ventures, der Baltic Beverage Holding, in Osteuropa und Russland deutliches Wachstum erzielen. Wenig Veränderungen ergaben sich bei der mexikanischen Grupo Modelo und der japanischen Kirin (EBNETH/THEUvsen, 2005: S. 44). Durch eine weitere Fusion der US-amerikanischen Brauerei Coors (38,6 Mio. hl) und der kanadischen Brauerei Molson (21 Mio. hl.) konnte auch der so neu geschaffene Braukonzern MolsonCoors in die Riege der führenden Konzerne vorstoßen. Erstmals gelang dieser Schritt 2004 auch einer Brauerei aus China. Vor dem Hintergrund des oben aufgezeigten Wachstums auf dem chinesischen Markt kann davon ausgegangen werden, dass sich die Position von Tsingtao (37 Mio. Hektoliter) schnell verbessern wird (BARTH \& SOHN, 2004/2005: S. 24).

Trotz des aufgezeigten hohen Konzentrationstempos und der zunehmenden Internationalisierung der weltweiten Brauindustrie muss LEVITTS These aus dem Jahr 1983, im Zuge der Globalisierung komme es zu einer weltweiten Vereinheitlichung der Präferenzen der Konsumenten und Unternehmen müssten infolge dessen globale Standarisierungsstrategien verfolgen, als zu pauschal abgelehnt werden (GLAUM ET. AL 2003: S. 269ff.). Wie die meisten Konsumgütermärkte zeichnet sich auch die Braubranche im internationalen Vergleich durch eine Vielzahl regionaler Spezialitäten aus (EBNETH, 2005: S. 3). So geht es den internationalen Braukonzernen zumeist um das Vorantreiben regionaler Marken. Die Etablierung internationaler Marken wie etwa Heineken, Beck`s, Carlsberg oder Stella Artois wird von den großen Marktteilnehmern eher als Ausnahme gesehen (Vossen, 2005: S. 12). Besonders deutlich wird die geschilderte Situation bei der Betrachtung des deutschen Biermarktes, welcher im folgenden Abschnitt näher analysiert wird. 


\subsection{Der deutsche Biermarkt}

\subsubsection{WIRTSCHAFTLICHE BEDEUTUNG}

Die deutsche Brauwirtschaft erreichte im Jahr 2004 einen Umsatz ${ }^{1}$ von 8,39 Mrd. €. Mit einem Anteil von etwa 6,3\% am Gesamtumsatz liegt sie damit, nach den Wirtschaftzweigen Schlachten/Fleischverarbeitung, Milchverarbeitung und der Herstellung von Backwaren sowie von Süßwaren, auf dem fünften Platz der umsatzstärksten Sektoren im gesamten produzierenden Ernährungsgewerbe der Bundesrepublik Deutschland (vgl. Tabelle 2).

Gemessen an der Nettowertschöpfung zu Faktorkosten (NWS $\mathrm{FK}_{\mathrm{FK}}$ steigt die Brauwirtschaft mit einem Anteil von 9,66 \%, nach der Herstellung von Backwaren und den Sektoren Schlachten und Fleischverarbeitung sowie der Milchverarbeitung, auf den vierten Rang.

\begin{tabular}{|c|c|c|c|c|c|c|c|}
\hline $\begin{array}{l}\text { Wirtschaftszweig } \\
-2004- \\
\text { (H.v.= Herstellung } \\
\text { von) }\end{array}$ & $\begin{array}{l}\text { Umsatz } \\
\text { in Mill. } \\
€^{* *}\end{array}$ & $\begin{array}{l}\text { Umsatz- } \\
\text { anteil } \\
\text { in } \%{ }^{* *}\end{array}$ & $\begin{array}{c}\mathrm{NWS}_{\mathrm{FK}} \\
\text { in Mill. } \\
€^{* *} \\
\mathrm{a}\end{array}$ & $\begin{array}{c}\text { Anteil } \\
\text { NWS }_{\mathrm{FK}}{ }^{*} \\
\text { in } \%{ }^{* *}\end{array}$ & $\begin{array}{l}\text { Beschäf- } \\
\text { tigte }^{* *}\end{array}$ & $\begin{array}{l}\text { Umsatz pro } \\
\text { Beschäft. } \\
\text { in } \mathrm{T}^{* *}\end{array}$ & $\begin{array}{l}\mathrm{NWS}_{\mathrm{FK}}{ }^{*} \\
\text { pro } \\
\text { Beschäft. } \\
\text { in } \mathrm{T}^{* *}\end{array}$ \\
\hline $\begin{array}{l}\text { Schlachten und } \\
\text { Fleischverarbeitung }\end{array}$ & $26.335,1$ & 19,98 & 3.647 & 14,72 & 106.742 & 246,7 & 34,1 \\
\hline Milchverarbeitung & $22.160,2$ & 16,81 & 2.482 & 10,02 & 38.792 & 571,2 & 63,9 \\
\hline H.v. Backwaren & $10.710,5$ & 8,12 & 4.624 & 18,66 & 144.918 & 73,9 & 31,9 \\
\hline H.v. Süßwaren & $9.012,3$ & 6,83 & 1.570 & 6,33 & 32.347 & 278,6 & 48,5 \\
\hline H.v. Bier & $8.396,2$ & 6,37 & 2.393 & 9,66 & 33.400 & 251,3 & 71,6 \\
\hline Top 5 & $76.614,3$ & 58,14 & 14.716 & 59,41 & 351.054 & 218,2 & 41,9 \\
\hline $\begin{array}{l}\text { produzierendes } \\
\text { Ernährungsgewerbe } \\
\text { zusammen }\end{array}$ & $131.771,9$ & 100 & 24.769 & 100 & 522.715 & 252 & 47,3 \\
\hline
\end{tabular}

a: Basis 2003

* Nettowertschöpfung zu Faktorkosten

** Betriebe mit 10 Beschäftigten und mehr

Tabelle 2: Umsatzstärkste Wirtschaftszweige im Ernährungsgewerbe Quelle: BMVEL, 2005: S. 255ff.

Insgesamt wurden in Deutschland im Jahr 2004 106,19 Mio. Hektoliter (hl) Bier in 1.274 Braustätten gebraut. Die Anzahl der Beschäftigten ist in den letzten Jahren als Folge von Personalabbau, Rationalisierungsmaßnahmen und Betriebsstilllegungen kontinuierlich zurückgegangen. Arbeiteten im Jahr 1996 noch 47.100 Menschen in der Brauwirtschaft, so ist diese Zahl bis zum Jahr 2004 auf 33.400 gesunken. Der Anteil der in der Brauwirtschaft Beschäftigten an der Gesamtzahl der im produzierenden Ernährungsgewerbe Beschäftigten beträgt somit nur 6,38 \%. Im gleichen Zeitraum stieg

\footnotetext{
${ }^{1}$ Nur in den Betrieben mit 10 und mehr Beschäftigten
} 
die Personalproduktivität gemessen am Jahresbierausstoß pro Beschäftigten um ca. 27 \% an (DEUTSCHER BRAUER-Bund, 2005b). Diese Entwicklung erklärt u. a. auch den im Branchenvergleich hohen Umsatz pro Beschäftigtem von $251.383 €$ und die sehr hohe NWS $_{\mathrm{FK}}$ je Beschäftigten.

Neben den unmittelbar in der Brauwirtschaft tätigen Arbeitnehmern sind nach einer vom Deutschen BRAUER-Bund in Auftrag gegeben Studie über 100.000 Beschäftigte direkt oder indirekt in vorgelagerten Bereichen mit der Brauwirtschaft verbunden. Weitere 50.000 Arbeitnehmer sind in nachgelagerten Bereichen beschäftigt; so können der Brauwirtschaft insgesamt etwa 183.000 Beschäftigte zugerechnet werden (DEUTSCHER BRAUER-Bund, 2001: S. 7).

Das Investitionsvolumen und die bezogenen Vorleistungen ${ }^{2}$ der Brauindustrie lassen sich als Indikatoren für den Grad der wirtschaftlichen Verflechtung mit anderen Branchen heranziehen. Der Investitionsaufwand ${ }^{3}$ der Brauereiunternehmen in Deutschland betrug im Jahr 2001 etwa 610 Mio. Euro. Dieses entspricht einem Betrag von 5,6 Euro je produziertem hl Bier. Die Investitionen flossen zum größten Teil in die Neuanschaffung bzw. Erneuerung von Maschinen, maschinellen Anlagen sowie Betriebs- und Geschäftsausstattungen (526 Mio. Euro). Die restliche Summe wurde in Grundstücke und Bauten investiert (DEUTSCHER BRAUER-BunD, 2003a: S. 85). Der Wert der gesamten Vorleistungen betrug bei den Brauereiunternehmen mit mehr als 20 Beschäftigten im Jahr 2003 etwa 5,3 Milliarden (Mrd.) Euro. Den größten Anteil der Vorleistungen nehmen die Roh-, Hilfs- und Betriebsstoffe (Gerste bzw. Malz, Hopfen und Energiekosten) ein. Insgesamt machen die Vorleistungen etwa $60 \%$ des Bruttoproduktionswertes $^{4}$ aus (BMVEL, 2005:S. 278).

Der Außenhandel hat für viele deutsche Brauereien (z.B. Brauerei Beck \& Co., HolstenBrauerei AG) schon immer eine bedeutende Rolle gespielt (EBBERTZ, 1992: S. 93ff.). In den letzten Jahren haben sich die Exporte deutlich erhöht und gewinnen für die deutsche Brauwirtschaft somit zunehmend an Bedeutung. Betrug die Exportquote im Jahr 1991

\footnotetext{
${ }^{2}$ In die Vorleistungen fließen ein: Materialverbrauch, Einsatz an Handelsware, Kosten für Lohnarbeiten, Kosten für sonstige industrielle/handwerkliche Dienstleistungen, Mieten, Pachten und sonstige Kosten (vgl. Deutscher Brauer-Bund 2003a: S. 118).

${ }^{3}$ Nur in den Betrieben mit 20 und mehr Beschäftigten.

4 Bruttoproduktionswert ohne Umsatzsteuer: Gesamtumsatz ohne Umsatzsteuer plus / minus Bestandsveränderungen an unfertigen und fertigen Erzeugnissen zuzüglich selbsterstellter Anlagen.
} 
noch 5,7 \% (6,1 Mio. hl) am gesamten Bierausstoß, so waren es 2004 bereits 12,91\% (13,71 Mio. hl). Der Import von Bier ist von einem niedrigeren Niveau im Jahr 1991 mit 2,5\% (2,8 Mio. hl) des Inlandsverbrauchs auf 3,3\% (3,12 Mio. hl) im Jahr 2004 gestiegen.

Eine weitere Kennzahl für die wirtschaftliche Bedeutung der deutschen Brauwirtschaft sind die Biersteuereinnahmen. Im Jahr 2004 wurden insgesamt 787,4 Mio. $€$ an Biersteuer gezahlt. Diese Summe entspricht etwa 0,4 \% der Steuereinnahmen der Länder und einer durchschnittlichen Belastung von 7,39 € je hl (DEUTSCHER BRAUERBUND, 2005b).

\subsubsection{SEGMENTIERUNG DES DEUTSCHEN BIERMARKTS}

Da viele Branchen, so auch die deutsche Brauwirtschaft, nicht homogen sind, ist es zur Entwicklung einer Wettbewerbsstrategie erforderlich, die bestehenden Untereinheiten einer Branche $\mathrm{zu}$ identifizieren. Verschiedene Branchensegmente ergeben sich, da Produkte und Abnehmer innerhalb einer Branche Unterschiede aufweisen können. Diese Unterschiede haben direkten Einfluss auf die Vorraussetzungen für Wettbewerbsvorteile und somit für die Attraktivität einer Branchenuntereinheit. Anhand der Segmentierung lassen sich die wichtigsten Fragen des Wettbewerbs innerhalb einer Branche beantworten, nämlich in welchem Bereich ein Unternehmen aktiv werden soll und wie es diesen bedienen kann (PORTER, 1986: S. 301f.). Wie im Folgenden aufgezeigt wird, haben sich in den letzten Jahren gerade im Biermarkt erhebliche Veränderungen hinsichtlich der einzelnen Segmente vollzogen.

Obwohl die Bierherstellung in Deutschland auf die Verwendung von Malz, Hopfen, Wasser und Hefe begrenzt ist, kommen etwa 5.000 der weltweit 10.000 Biere aus Deutschland (Deutscher Brauer-Bund, 2003a: S. 12). Möglichkeiten der Produktvariation beim Brauen entstehen durch Ausnutzung unterschiedlicher Rohstoffeigenschaften und Veränderung der Mengenbeigaben.

Eine Branchensegmentierung des deutschen Biermarktes lässt sich aufgrund unterschiedlicher Produkt- und Gebindeformen durchführen. Zur Darstellung der Produktstruktur wird eine Unterscheidung der Biere in Gattungen, Arten, Sorten und Klassen vorgenommen. Die biersteuerrechtliche Einteilung nach der Biergattung erfolgt 
in Einfachbier, Schankbier, Vollbier und Starkbier. Unterscheidungskriterium ist hierbei der Stammwürzegehalt; dieser bezeichnet den Anteil der aus dem Malz gelösten Stoffe in der noch unvergorenen Würze. Je höher der Stammwürzegehalt, desto stärker ist der Alkoholgehalt des Bieres (DEUTSCHER BRAUER-BUnD, 2005b).

Die Einteilung nach Bierarten erfolgt nach der Brauart. Biere können ober- oder untergärig gebraut werden, dabei kommt es auf die im Brauprozess verwendete Hefe und die Gärungstemperatur an. Bei der obergärigen Brauweise steigt die Hefe nach dem Gärprozess auf und wird dann abgehoben. Untergärige Hefe setzt sich nach der Gärung am Boden des Gärgefäßes ab. Auf der Basis der Bierarten lassen sich die verschiedenen Biersorten zuordnen. Man unterscheidet Pils, Export, Alt, Weizen, Hell, Kölsch, Bock, Leicht, Schwarzbier, Alkoholfrei und kleinere Randsorten. Die Gliederung nach Sorten gilt als gebräuchlichste Unterscheidung für Biere.

Der Absatz der einzelnen Biersorten hat sich in den letzen Jahren sehr unterschiedlich entwickelt (vgl. Abbildung 12). Die Nachfrage wird dabei stark von regionalen Sortenpräferenzen beeinflusst, daher ergeben sich hinsichtlich der Sortenstruktur erhebliche Abweichungen von Region zu Region.

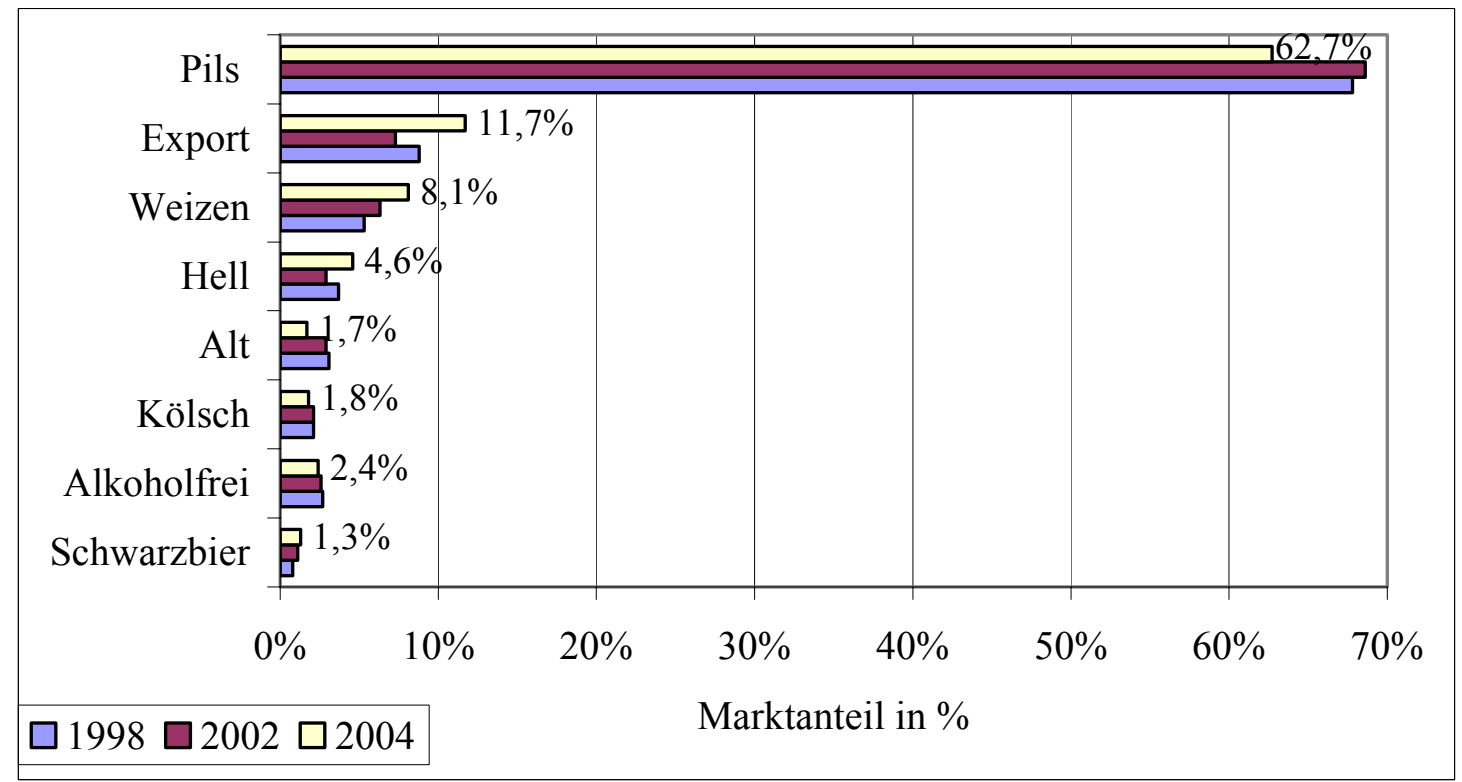

* Die aufgeführten Zahlen in der Abbildung geben die Marktanteile für 2004 wieder. Abbildung 12: Entwicklung der Marktanteile der wichtigsten Biersorten im Lebensmitteleinzelhandel und in Getränkeabholmärkten zwischen 1998 und 2004

Quelle: DeUTSCHER BRAUER-BUnd , 2003a: S. 48f; 2005b

Abbildung 12 veranschaulicht die Entwicklung der Marktanteile der wichtigsten Biersorten im Lebensmitteleinzelhandel (LEH) und in Getränkeabholmärkten (GAM) 
zwischen 1998 und 2004. Es wird deutlich, dass das hopfenbetonte, meist herbe Pils den deutschen Biermarkt mit einem Marktanteil von 62,7 \% dominiert, auch wenn diese Sorte seit $2002(68,6 \%)$ etwa $6 \%$ an Marktanteil verloren hat. Ein Grund für diesen Absatzverlust dürfte der Trend $\mathrm{zu}$ milderem Bier sein. Außerdem hat sich die Einführung des Zwangspfands im Jahr 2003 besonders negativ auf den Marktanteil von Pils ausgewirkt, da ein überdurchschnittlich hoher Anteil dieser Biersorte in Einweggebinden abgesetzt wurde (LATZ-WEBER, 2003a: S. 50).

Die Sorten Export, Hell, Weizen und das relativ kleine Segment Schwarzbier konnten ihre Position hingegen z. T. sehr deutlich ausbauen. Die Sorte Export war in den 1960er Jahren noch die führende Sorte im deutschen Biermarkt, im Jahr 2004 ist sie die zweitwichtigste Biersorte und kommt im LEH und GAM auf einen Markteil von 11,7 \%. Damit konnte Export seit 2002 über 4,5 Prozentpunkte zulegen. Bei der Nachfrage nach Exportbieren zeigt sich ein klares Nord-Süd Gefälle. So wird die Sorte im Norden nur wenig konsumiert, im Süden hingegen ist ihr Absatzanteil vor allem in BadenWürttemberg überdurchschnittlich hoch. Noch deutlicher ist das Verhältnis bei der Sorte Hell. Diese ist fast ausschließlich in Bayern beheimatet, wo sie nach Pils die zweitwichtigste Sorte ist (DEUTSCHER BRAUER-BUND, 2005c). Im gesamten Bundesgebiet hat die Sorte im Jahr 2004 einen Marktanteil von etwa 4,6 \% und konnte diesen seit 2002 somit um ca. 2 Prozentpunkte verbessern.

Bei Weizenbier handelt es sich eigentlich um eine typisch bayerische Spezialität. Die Sorte hat jedoch seit Jahren die Grenzen des Freistaats überschritten und ist mittlerweile im ganzen Bundesgebiet fest etabliert (DEUTSCHER BRAUER-Bund, 2003: S. 49ff.). Mit einem Marktanteil von 8,1 \% ist Weizenbier 2004 die drittwichtigste Biersorte und konnte sich seit 1998 somit kontinuierlich verbessern. Zulegen konnte auch das Schwarzbier. Diese Bierspezialität hat 2004 insgesamt zwar nur einen kleinen Absatzanteil von 1,3\%, ist jedoch gerade in den letzten Jahren erheblich in der Gunst der Verbraucher gestiegen (DEUTSCHER BRAUER-Bund, 2005b; LATZ-WEBER, 2003b: S. 37). Die Sorten Alt und Kölsch sind regionale Spezialitäten, deren Hauptabsatzgebiete in und um Düsseldorf bzw. Köln liegen. Bei Kölsch handelt es sich um eine geschützte Herkunftsbezeichnung, die demnach nur im Kölner Raum gebraut werden darf (O. V., 1999). Beide Sorten haben seit 1998 erhebliche Marktanteile verloren, wobei die Verluste bei Alt deutlich höher ausgefallen sind, so dass Kölsch 2004 auf einen 
Absatzanteil von 1,8 \% gefolgt von Alt mit 1,7\% kommt. Auch die Sorte Alkoholfrei hat seit 1998 Marktanteile eingebüßt und liegt 2004 bei einem Marktanteil von 2,4 \%.

Ein weiteres Segment (,Sorte“) im deutschen Biermarkt, welches seit einigen Jahren vermehrt in der Diskussion steht, sind die Biermischgetränke. Diese konnten ihren Absatzanteil seit 1998 erheblich ausbauen (vgl. Abbildung 13).

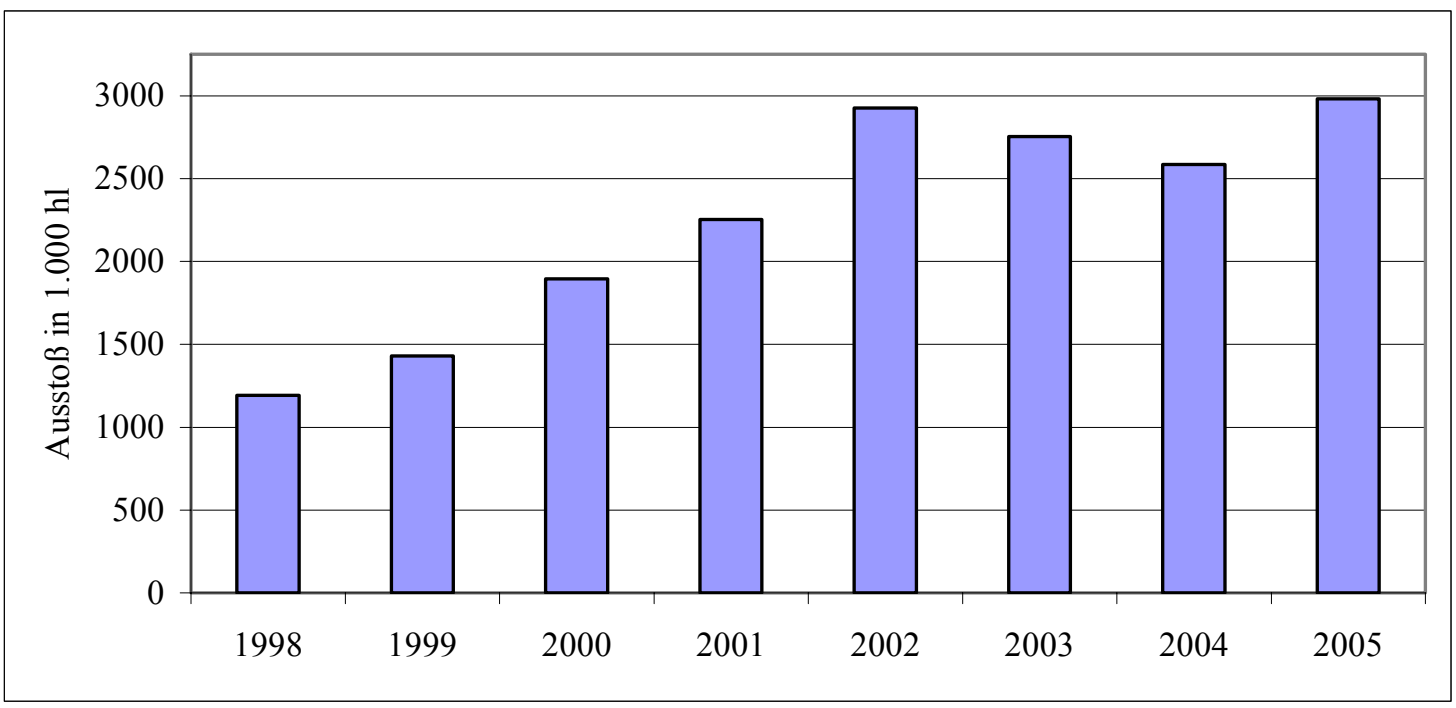

Abbildung 13: Entwicklung des Absatzes von Biermischgetränken von 1998 bis 2005 Quelle: DEUTSCHER-BRAUER-BUND 2003a: S. 42; O. V., 2006a: S. 7

So zeigen die neusten Erhebungen für das Jahr 2005 ${ }^{5}$, dass die Biermixgetränke den Absatzrückgang nach der Einführung des Einwegpfandes und der damit verbundenen Umstellung auf Mehrweggebinde wieder wettgemacht haben (DIETZ, 2005: S. 42). Danach waren die Biermischungen im Jahr 2005 mit etwa 3 Mio. hl oder 2,8\% am gesamten Bierabsatz beteiligt (DEUTSCHER BRAUER-BUND, 2006) und haben sich somit zu einem wichtigen Segment der Braubranche entwickelt. Bemerkenswert ist in diesem Zusammenhang auch das enorme Absatzplus gegenüber dem Jahr 2004 von mehr als 15 \% (O. V., 2006b: S. 18).

Eine weitere gebräuchliche Form der Branchensegmentierung im deutschen Biermarkt ist die Einteilung in die Klassen der Superpremium-, Premium-, Konsum- und Billigbiere (GoEHLER, 1993: S. 142). Diese Segmente haben sich im Zuge der zunehmenden Sättigung des Biermarktes gebildet. Die Brauereien versuchen ihre Produkte durch unterschiedliche Marketingstrategien sowie Qualitäts-, Preis- und Leistungsvariationen auf bestimmte Zielgruppen auszurichten, um damit den

\footnotetext{
${ }^{5}$ Diese Daten lagen für die übrigen Sorten bis zum 01.04.2006 nicht vor.
} 
verschiedenen Präferenzen der Konsumenten besser gerecht zu werden und sich so von den Wettbewerbern abzusetzen (MARX, 1998: S. 25). Als primäres Unterscheidungskriterium kann dabei die Preisrealisierung herangezogen werden.

Bei den Superpremiumbieren handelt es sich um ausländische oder nationale Bierspezialitäten im Höchstpreissegment. Die Premium-Biere hingegen können als die klassischen Markenartikel angesehen werden. Sie sind im Hochpreissegment angesiedelt und erreichen durch verschiedene Marketingmaßnahmen (z. B. Fernsehwerbung) einen hohen Bekanntheitsgrad in ihrem Absatzgebiet. Häufig werden diese Biere national bis international distribuiert. Die Klasse der Konsumbiere wird vorwiegend regional bis überregional abgesetzt und ist im Handel im mittleren Preissegment positioniert. Da es sich in diesem Segment in den meisten Fällen um nicht bzw. nur wenig differenzierte und somit für den Konsumenten leicht substituierbare Biere handelt, verliert diese Klasse seit Jahren zunehmend an Absatzanteilen. Entgegen der Strategie der Markenartikler versuchen die Billigbierhersteller, ausschließlich über extrem niedrige Preise Marktanteile zu gewinnen bzw. zu verteidigen. Sie verzichten dabei i. d. R. nahezu vollständig auf jegliche Differenzierungsmaßnahmen und verfolgen somit eine klassische Preis-Mengen-Strategie. In Niedrigpreissegment sind neben den Produkten reiner Billigbierbrauer auch Zweitmarken etablierter Markenbierproduzenten sowie Handelsmarken des LEH und Eigenmarken des Getränkefachgroßhandels angesiedelt (GOEHLER, 1993: S. 142; MARX, 1998: S. 25, Hofnagel/Kortmann, 1999: S. 123). Dieses Segment gewinnt seit einigen Jahren zunehmend an Bedeutung. So konnten die Billigbiere (Preisklasse $<5,99 €$ pro 0,5 1MW Kasten) ihren Marktanteil im LEH und in Getränkeabholmärkten seit 1999 um etwa 11 Prozentpunkte auf nunmehr $27 \%$ ausbauen (BIRNBAUM, 2005a: S. 8).

Eine weitere Einteilung kann in die verschiedenen Gebindearten erfolgen. Dabei lassen sich auf dem deutschen Biermarkt im Wesentlichen Fassbier, Mehrwegflaschen, Einwegglasflaschen, Dosen sowie Einweg-PET-Flaschen unterscheiden. Fassbier wird zum überwiegenden Anteil in der Gastronomie abgesetzt (CANADEAN, 2005: S. 124), während der Absatz von Flaschen und Dosenbier vorwiegend über den Einzelhandel erfolgt. Die PET-Flaschen werden hingegen fast ausschließlich über den Discount vertrieben und hauptsächlich für die Distribution von Billigbier verwendet (BIRNBAUM, 2005b: S. 8). 
Die Anteile der verschiedenen Gebinde am Bierausstoß haben sich in den letzen Jahren stark verändert (vgl. Tabelle 3). Erheblichen Einfluss auf diese Entwicklung hatte dabei die Einführung des Zwangspfandes auf Einwegverpackungen im Jahr 2003.

\begin{tabular}{|l|c|c|c|c|c|c|}
\hline \multicolumn{1}{|c|}{ Jahr } & Fassbier & $\begin{array}{c}\text { Mehrweg- } \\
\text { flaschen }\end{array}$ & $\begin{array}{c}\text { Einweg } \\
\text { zusammen }\end{array}$ & $\begin{array}{c}\text { Einweg } \\
\text { Dose }\end{array}$ & $\begin{array}{c}\text { Einweg } \\
\text { Flasche }\end{array}$ & $\begin{array}{c}\text { Einweg } \\
\text { PET }\end{array}$ \\
\hline 1998 & 19,51 & 58,75 & 21,74 & 17,10 & 14,64 & - \\
\hline 2002 & 19,17 & 51,10 & 29,73 & 22,69 & 18,74 & 0,01 \\
\hline 2004 & 19,90 & 62,13 & 17,97 & 10,22 & 5,98 & 2,41 \\
\hline $\begin{array}{l}\text { Veränderung } \\
2002 \text { zu 2004 }\end{array}$ & $+3,8$ & $+21,5$ & $-39,6$ & -55 & -68 & +24.000 \\
\hline
\end{tabular}

Tabelle 3: Anteil der Gebinde am Bierausstoß der Jahre 1998, 2002 und 2004 in \% Quelle: DeUTSCHER BRAUER-BUND, 2005c

So hat eine deutliche Verschiebung der Marktanteile von Einweg- zu Gunsten der Mehrwegverpackungen stattgefunden. Im Vergleich der Jahre 2002 zu 2004 hat sich der Einweganteil insgesamt um etwa $40 \%$ verringert, wohingegen der Mehrweganteil um ca. $21 \%$ zugenommen hat.

Nachdem der Fassbieranteil vor 1998 stark zurückgegangen ist, konnte er sich seither stabilisieren und ist auf etwa $20 \%$ leicht angestiegen. Je nach Absatzstrategie der Brauereien variieren die Fassbieranteile sehr stark (KELCH, 2005a: S. 1150). Das Fassbiergeschäft ist für die Brauereien sehr interessant, da in der Gastronomie erheblich höhere Preise als im Handel realisiert werden können und die Verpackungskosten deutlich geringer ausfallen (GoEHLER, 1993: S. 147; CANADEAN, 2005: S. 114). Der größte Anteil am Bierausstoß entfällt 2004 auf die Mehrwegflasche (ca. 62 \%). Dabei hat die 0,5 1 Flasche im LEH und in Getränkeanholmärkten einen Anteil von ca. 78 \%, die 0,33 1 Flasche kommt mit steigender Tendenz hingegen nur auf 13,5 \% (BIRNBAUM, 2005b: S. 8).

\subsubsection{ERWEITERTE STRUKTURANALYSE DES DEUTSCHEN BIERMARKTES}

In seinem grundlegenden Werk zum strategischen Management schuf MiCHAEL E. PORTER (1980, 1985) ein Rahmenkonzept für eine umfassende Analyse der Unternehmensumwelt sowie zur gleichzeitigen Darstellung der Wettbewerbssituation innerhalb einer Branche. PORTER'S Five-Forces Model, welches bereits im Kapitel 2.1.2 kurz angeschnitten wurde, bietet somit einen flexiblen Rahmen zur Beschreibung und 
Bewertung der Wettbewerbsintensität und Attraktivität einer Branche. Auf Grundlage dieser Analyse kann eine Wettbewerbsstrategie zur Schaffung bzw. Aufrechterhaltung von Wettbewerbsvorteilen gegenüber der Konkurrenz und damit verbundenen Erzielung einer überdurchschnittlichen Unternehmensrentabilität entwickelt werden.

Nach PORTER (1995: S. 25f.) wird die Wettbewerbsintensität und Rentabilität einer Branche von fünf Wettbewerbskräften bestimmt. Dieses sind im Einzelnen:

- Intensität der Rivalität unter den bestehenden Wettbewerbern: Die Rivalität unter den bestehenden Unternehmen variiert zwischen verschiedenen Branchen erheblich. Sie wird z. B. von der Anzahl der Wettbewerber, dem Marktwachstum, den Festkosten, evtl. Wechselkosten, Austrittsbarrieren und der Homogenität der Wettbewerber bestimmt. Je höher der Grad der Rivalität, desto niedriger ist die durchschnittliche Rentabilität in einer Branche. Die Messung der Konzentrationsraten ist ein gebräuchliches Instrument, um einen ersten Einblick in die Intensität der Rivalität in einer Branche zu erlangen.

- Bedrohung durch Ersatzprodukte: Eine Bedrohung durch Ersatzprodukte besteht, wenn Preisänderungen in anderen Branchen die Nachfrage in der untersuchten Branche beeinflussen. Enge Substitutionsprodukte begrenzen generell die Möglichkeit der Unternehmen, die Preise zu erhöhen, und limitieren somit die Rentabilität.

- Bedrohung durch neue Anbieter: Die Bedrohung, dass neue Wettbewerber in eine Branche eintreten, hängt in entscheidenden Maße von den Markteintrittsbarrieren ab. Wenn diese gering sind, werden hohe Gewinne schnell neue Wettbewerber anziehen, wodurch der Preiswettbewerb verschärft wird. Ursprünge von Markteintrittsbarrieren können z.B. staatliche Politik, Betriebsgrößenersparnisse, Produktdifferenzierung, Patente, Zugang zu den Vertriebskanälen und spezifische Produktionsanlagen sein

- Verhandlungsmacht der Abnehmer: Wenn die Verhandlungsmacht der Abnehmer hoch ist, haben diese erheblichen Einfluss auf die Preise und begrenzen somit die Rentabilität der Anbieter in der Branche. Käufer haben eine hohe 
Verhandlungsmacht, wenn sie eine hohe Nachfragekonzentration aufweisen, über eine glaubhafte Option der Rückwärtsintegration verfügen, einen großen Anteil der Produktion des Anbieters abnehmen oder einfach und preiswert $\mathrm{zu}$ anderen Lieferanten oder Ersatzprodukten wechseln können.

- Verhandlungsmacht der Lieferanten: Verhandlungsstarke Lieferanten können ihre Produkte $\mathrm{zu}$ einem hohen Preis absetzen und so einen Teil des Gewinns ihrer Kunden für sich vereinnahmen. Lieferanten haben dann eine hohe Verhandlungsmacht, wenn sie ihren Kunden glaubhaft mit einer Vorwärtsintegration drohen können, eine höhere Konzentration als ihre Abnehmer aufweisen, differenzierte Produkte verkaufen, wichtige und schwer $\mathrm{zu}$ substituierende Inputs anbieten oder wenn ihre Kunden hohe Wechselkosten haben.

Darüber hinaus sollte jede Analyse der Branchenstruktur eine Beurteilung zu den wichtigsten Kenndaten der Umfeldfaktoren beinhalten. Das ökologische, technologische, ökonomische und soziodemographische Umfeld sowie die Politik und das Recht haben ebenfalls Einfluss auf das Marktgeschehen und müssen bei der Auswahl einer Wettbewerbsstrategie berücksichtigt werden.

PORTER (1995: S. 62ff.) empfiehlt Unternehmen, eine Position innerhalb einer Branche zu finden, welche ihnen erlaubt, einen überdurchschnittlichen Return on Investment zu generieren. Auch in Branchen mit einer geringen durchschnittlichen Rentabilität ist es für optimal positionierte Unternehmen möglich, überdurchschnittliche Gewinne zu erzielen. PORTER unterscheidet zwischen drei allgemeinen Strategien, welche die Position eines Unternehmens innerhalb einer Branche bestimmen:

- Kostenführerstrategie: Ein Kostenführer produziert $\mathrm{zu}$ einem vorgegebenen Qualitätsniveau preiswerter als alle anderen Wettbewerber und verkauft seine Produkte $\mathrm{zu}$ einem durchschnittlichen und z.T. auch unterdurchschnittlichen Branchenpreis. Eine Kostenführerstrategie ermöglicht es einem Unternehmen, auch dann noch rentabel zu arbeiten, wenn die Preise aufgrund des wachsenden Wettbewerbsdrucks stark fallen. Kostenführer sind in der Regel große Unternehmen, welche Größeneffekte realisieren und die Fähigkeit zum Aufbau kosteneffizienter Beschaffung, Produktion und Vertriebsaktivitäten besitzen. 
- Differenzierungsstrategie: Differenzierte Produkte bieten einzigartige Merkmale wie bekannte Markennamen, überlegene Produktqualität, Innovation, höhere Zuverlässigkeit, besseren Service usw. Unternehmen, die eine Differenzierungsstrategie verfolgen, haben i. d. R. einen Kostennachteil, sie sind aber aufgrund einer höheren Käuferloyalität und der Bereitschaft der Kunden, einen höheren Preis zu bezahlen, gleichwohl profitabel.

- Konzentration auf Schwerpunkte bzw. Nischenstrategie: Unternehmen, die eine Nischenstrategie verfolgen, konzentrieren sich bei der Marktbearbeitung auf ein begrenztes Marktsegment. Innerhalb dieses Marktsegments versuchen die Unternehmen Kostenvorteile zu erlangen oder sich zu differenzieren. Die Güte einer Nischenstrategie hängt in entscheidendem Maße von einer erfolgreichen Marktsegmentierung und Identifikation von Kundengruppen mit einer speziellen Nachfrage ab.

In seinen frühen Beiträgen zum strategischen Management riet PORTER $(1980,1985)$ den Unternehmen, sich klar für eine der allgemeinen Strategien zu entscheiden, da er erwartete, dass Firmen, die sich in einer „stuck in the middle“ -Position befinden, weniger erfolgreich als klar positionierte Unternehmen sein würden. Nichtsdestotrotz gestand PORTER (2001: S. 70) in seinen jüngeren Veröffentlichungen ein, dass Unternehmen einen Wettbewerbsvorteil „... by operating at a lower cost, by commanding a premium price, or by doing both“ erlangen und aufrechterhalten können. Hybride Strategien, welche durch eine Vermischung der verschiedenen allgemeinen Strategien entstehen, haben sich somit zu einem vierten Strategietyp entwickelt, den Unternehmen wählen können (CORSTEN, 1998: S. 1434f.).

Im Folgenden werden die Branchenstruktur und die Entwicklungen in der deutschen Brauwirtschaft anhand PORTER's Five-Forces Models unter Einbeziehung der Umfeldfaktoren aufgezeigt. Die Ausführungen zu den allgemeinen Strategien dienen dem besseren Verständnis des 4. Kapitels.

\subsubsection{Intensität der Rivalität unter den bestehenden Unternehmen}

Die Intensität der Rivalität unter den bestehenden Unternehmen in einer Branche wird nach PORTER vor allem durch eine Vielzahl struktureller Faktoren bestimmt. 
Dieses sind insbesondere:

- die Anzahl und Struktur der Wettbewerber,

- die Branchenentwicklung,

- die Möglichkeiten der Produktdifferenzierung,

- die Kapazitätsauslastung und

- die Marktaustrittsbarrieren.

Ein weiterer Indikator für die Rivalität in einer Branche sind Positionskämpfe in Form von Preiswettbewerb sowie Werbeschlachten (PORTER, 1995: S. 42ff.). In der nachfolgenden Analyse werden die aufgezeigten Faktoren für die deutsche Brauwirtschaft eingehend untersucht.

\subsection{Anzahl und Struktur der Wettbewerber}

Im Jahr 2004 existieren in der Bundesrepublik 1.274 Braustätten; diese Angebotsstruktur ist in der Welt einzigartig (DEUTSCHER BRAUER-BUND: 2003a: S. 20f., 2005b). Deutschland ist damit das Land mit der höchsten Anzahl von Braustätten. Ein Vergleich mit der Struktur der Länder der EU zeigt, dass Deutschland die Rangliste diesbezüglich mit deutlichem Abstand anführt. Belgien nimmt mit 115 Braustätten den zweiten Platz ein, gefolgt von Polen mit nur 65 Produktionsstätten. Von den insgesamt 1.694 Braustätten in der EU befinden sich etwa $75 \%$ in Deutschland (DEUTSCHER BRAUER-BUND, 2005c).

Während die Anzahl der Braustätten relativ einfach zu ermitteln ist, gestaltet sich die Untersuchung der Beschaffenheit der Brauereien etwas schwieriger, da dazu mehrere Indikatoren berücksichtigt werden müssen. Als Unterscheidungskriterien werden im Folgenden die Unternehmensgröße, die Betriebsgrößenstruktur und die Größe des Absatzgebietes herangezogen.

Eine gebräuchliche Maßzahl für die Erfassung der Größe einer Brauerei ist die Gesamtjahresausstoßmenge. Der Umsatz, als weitere potentielle Maßeinheit, lässt sich nur schwer ermitteln, da die erzielten Umsätze nicht den Braustätten, sondern den Unternehmen zuzuordnen sind. Außerdem ist der größte Teil der deutschen Brauereien aufgrund ihrer Rechtsform und Größe nicht publikationspflichtig, so dass keine gesicherten Daten vorliegen. Mit etwa $83.350 \mathrm{hl}$ durchschnittlichem Bierausstoß je Braustätte im Jahr 2004 weist die Bundesrepublik Deutschland die niedrigste 
durchschnittliche Braustättengröße in der EU auf (Großbritannien 957.650 hl und in den Niederlanden 1.702.000 hl je Braustätte). Die Ursache für den geringen Durchschnittswert in Deutschland ist in der großen Anzahl der Braustätten zu sehen.

Tabelle 4 zeigt die Struktur der deutschen Brauwirtschaft nach Betriebsgrößenklassen in den Jahren 1995 und 2004. Es wird deutlich, dass im Jahr 2004 etwa 84,5 \% der deutschen Brauereien nicht mehr als 50.000 hl pro Jahr abgesetzt haben und somit als Kleinbrauereien eingestuft werden können. Etwa 13,2 \% gehören der Klasse der mittleren und mittelgroßen Brauereien $(50.000 \mathrm{hl}$ bis $1.000 .000 \mathrm{hl})$ an und nur ca. 2,2 \% der Unternehmen produzieren als Großbrauereien mehr als 1.000.000 hl Bier pro Jahr. Zwar hat sich die Gesamtzahl der Brauereien in der deutschen Brauwirtschaft seit dem Jahr 1995 nur um etwa 0,6 \% verringert, bei einem genaueren Blick auf die verschiedenen Größenklassen fallen aber deutliche Unterschiede auf. Ein großer Teil der Kleinstbrauereien hat im Bereich der Gasthausbrauereien eine stabile Position gefunden. Dieses Segment hat seit 1995 sogar um 24 \% zugenommen. Ein ganz anderes Bild ergibt sich bei der Betrachtung der kleinen und mittleren Brauereien; bei dieser Gruppe hat die Anzahl bis zu etwa 29 \% abgenommen. Bei den Großbrauereien sind mit Blick auf die Anzahl im Vergleich zum Jahr 1995 keine Veränderungen festzustellen. Allerdings haben diese durch Fusionen und Übernahmen an Größe und Bedeutung deutlich zugenommen (vgl. Kapitel 3.2.3.1.2).

\begin{tabular}{|l|c|c|c|}
\hline $\begin{array}{l}\text { Betriebsgrößenklassen nach } \\
\text { Gesamtjahreserzeugung (THL) }\end{array}$ & 1995 & 2004 & $\begin{array}{c}\text { Veränderung } \\
\text { in \% }\end{array}$ \\
\hline Kleinstbrauereien (unter 5 THL p.a.) & 643 & 796 & $+23,8$ \\
\hline Kleine Brauereien (5 bis 50 THL p.a.) & 393 & 280 & $-28,8$ \\
\hline Mittlere Brauereien (50 bis 200 THL p.a.) & 136 & 116 & $-14,7$ \\
\hline Mittelgroße Brauereien (200 bis 1.000 THL p.a.) & 71 & 53 & $-25,4$ \\
\hline Großbrauereien (über 1.000 THL p.a.) & 29 & 29 & $+/-0$ \\
\hline Gesamt & 1282 & 1274 & $-0,6$ \\
\hline
\end{tabular}

Tabelle 4: Struktur der deutschen Brauwirtschaft in den Jahren 1995 und 2004 Quelle: DEUTSCHER BRAUER-Bund, 2003a: S. 21; 2005b

Ingesamt veranschaulicht die Tabelle 4, dass der deutsche Biermarkt sehr heterogen ist. Die Spannweite reicht von der kleinen Hausbrauerei bis hin zur international tätigen Großbrauerei. Folgt man der am 6. Mai 2003 durch die EU veröffentlichen Definition, so haben kleine und mittelständische Unternehmen (KMU) 10 bis 249 Beschäftigte, erzielen 2 bis 50 Mio. $€$ Umsatz bzw. haben eine Bilanzsumme zwischen 2 und 43 Mio. 
$€$ (COMMISSION, 2003). Orientiert man sich an der Beschäftigtenzahl der EU-Definition, so handelt es sich bei über $90 \%$ der deutschen Brauereien um KMU ${ }^{6}$. Daneben umfasst die Brauwirtschaft eine nicht genau zu bestimmende Anzahl ${ }^{6}$ von Betrieben, die die EU den Kleinstunternehmen (weniger als 10 Beschäftigte und weniger als 2 Mio. $€$ Umsatz bzw. Bilanzsumme) zurechnet. Ferner liegen bezogen auf die Beschäftigtenzahl etwa 10 $\%$ der Unternehmen im deutschen Biermarkt ${ }^{6}$ oberhalb der EU-Grenzen oder sind in internationale Braukonzerne eingebunden (BMVEL, 2005: S. 260ff.). Bedenkt man aber, dass das Institut für Mittelstandsforschung in Bonn die Grenzen des Mittelstands lange Zeit bei 500 Mitarbeitern gezogen hat und als „großer Mittelstand“ häufig auch Unternehmen mit 2.000 und mehr Mitarbeitern bezeichnet werden, so können auch die Groß- und Konzernbrauereien unter einer erweiterten Mittelstandsdefinition subsumiert werden. Dies wird auch dem Selbstverständnis der meisten dieser Unternehmen gerecht; so ,fühlt man sich bei Radeberger (der zweitgrößten deutschen Brauereigruppe) immer noch als Mittelständler“" (O. V., 2005a: S. 678).

In Abhängigkeit von der Größe der Unternehmen umfasst das Kernabsatzgebiet ${ }^{7}$ einer Brauerei einen lokalen, regionalen, überregionalen oder nationalen Bereich. Auch die Markentypisierung der Brauereien kann über das Kernabsatzgebiet abgeleitet werden. So verfügen lokale Brauereien i. d. R. nur über lokale Marken, bei regionalen Brauereien werden zusätzlich Regionalmarken vertrieben usw. (WIESE, 1993: S. 22; BöSKEN-DiEBELS, 1989: S. 24f.). Neben der Anzahl und der Größe der Brauereien ist auch die Marktdichte, d. h. die regionale Verteilung der einzelnen Brauereien, von Bedeutung. Eine räumliche Häufung der Brauereistandorte bzw. eine Überschneidung der Kernabsatzgebiete steigert die Wettbewerbsintensität. Der Standort ist somit ein weiteres Unterscheidungskriterium der Beschaffenheit von Brauereien, da die Unternehmen eines Absatzgebietes in unmittelbarem Wettbewerb zueinander stehen (GOEHLER, 1993: S. 178).

Je nach Bundsland sind die Anzahl sowie die Betriebsgrößenstruktur der Brauereien sehr unterschiedlich (vgl. Tabelle 5). Besonders auffällig sind das starke Nord-Süd Gefälle in Bezug auf den Gesamtbierausstoß je Unternehmen sowie der entsprechende

\footnotetext{
${ }^{6}$ Aus Gründen der Datenverfügbarkeit werden nur Brauereien mit mehr als 10 Beschäftigten berücksichtigt, da in der amtlichen Statistik nur diese Betriebe erfasst sind.

${ }^{7}$ Das Kernabsatzgebiet bezieht sich auf den Absatzradius um die Brauerei, in welchem etwa $70 \%$ des gesamten Absatzes erzielt werden.
} 
Unterschied in der Braustättendichte. Die Gründe für diese Verteilung sind auf die historische Entwicklung des deutschen Brauwesens zurückzuführen. Mit 629 Unternehmen haben nahezu die Hälfte aller deutschen Brauereien ihren Sitz in Bayern. Auf Platz zwei folgen Baden-Württemberg mit 178 Braustätten und NordrheinWestfalen mit 118 Brauereien. Im Vergleich dazu eher wenig Brauereien gibt es in Schleswig-Holstein/Hamburg (13), Mecklenburg-Vorpommern (18) und in SachsenAnhalt (18). Mit Blick auf die Größe der Brauereien zeigt sich, dass die großen Brauereien vor allem in Norddeutschland und Nordrhein-Westfalen angesiedelt sind, wohingegen Bayern überwiegend von kleinen Brauereien geprägt ist.

\begin{tabular}{|l|c|c|c|}
\hline \multicolumn{1}{|c|}{ Bundesland } & $\begin{array}{c}\text { Betriebene } \\
\text { Braustätten } \\
2004\end{array}$ & $\begin{array}{c}\text { Ø Betriebsgröße } \\
\text { (in 1.000 hl) }\end{array}$ & $\begin{array}{c}\text { Bierausstoß } \\
\text { (Anteil in \%) }\end{array}$ \\
\hline Baden-Württemberg & 178 & 43,4 & 7,3 \\
\hline Bayern & 629 & 35,8 & 21,2 \\
\hline Berlin/Brandenburg & 38 & 100 & 3,5 \\
\hline Hessen & 63 & 54,5 & 3,2 \\
\hline Mecklenburg-Vorpommern & 18 & 172 & 2,9 \\
\hline Niedersachsen/Bremen & 49 & 227,3 & 10,5 \\
\hline Nordrhein-Westfalen & 118 & 226,5 & 25,2 \\
\hline Rheinland-Pfalz/Saarland & 52 & 151,6 & 7,4 \\
\hline Sachsen & 55 & 158,9 & 8,2 \\
\hline Sachsen-Anhalt & 18 & 159,1 & 2,7 \\
\hline Schleswig-Holstein/Hamburg & 13 & 328,4 & 4 \\
\hline Thüringen & 43 & 83 & 3,3 \\
\hline Gesamt & 1274 & 83,0 & 100 \\
\hline
\end{tabular}

Tabelle 5: Anzahl der Braustätten und Unterschiede in der Größenstruktur nach Bundesländern

Quelle: DeUTSCHER BRAUER-Bund, 2005b

Die Ausführungen zur Anzahl und Struktur der Wettbewerber in der deutschen Bierbranche verdeutlichen, dass es sich um einen hoch fragmentierten Markt handelt. Der nationale Biermarkt besteht aus einer Vielzahl lokaler, regionaler und überregionaler Märkte, die nebeneinander existieren, sich überschneiden und somit ein vernetztes System von Wettbewerbsbeziehungen kleiner, mittlerer und großer Brauereien bilden (HofNAGEL / KORTMANN, 1999: S. 133). Von Seiten der Verbraucher geben etwa $50 \%$ an, Bier zu konsumieren, somit steht der Anbieterzahl eine große Anzahl von Nachfragern gegenüber (O. V., 2002a: S. 1231f.; SCHULTE, 1998: S. 11). Auf der Anbieterseite handelt sich folglich um ein Oligopol mit hoher Wettbewerbsintensität. Im Ergebnis bleibt festzustellen, dass die Struktur der deutschen 
Brauwirtschaft entscheidenden Einfluss auf den intensiven Wettbewerb innerhalb der Branche ausübt.

\subsection{Branchenentwicklung}

Die Entwicklung des Wachstums bzw. der Schrumpfung einer Branche kann mit Hilfe des Modells des Produktlebenszyklus beschrieben werden. Dieser Zyklus veranschaulicht den Werdegang eines Produktes von dessen Einführung bis zur evtl. Einstellung der Produktion. Während die Wachstumsphase von Marktwachstum gekennzeichnet ist, nimmt das Umsatzwachstum in der Reifephase ab. Die Sättigungsphase beginnt formal dann, wenn die Umsatzkurve ihr Maximum erreicht hat, die Grenzumsätze also negativ werden (BODENSTEIN / SPILLER, 1998: S. 117ff.). In der Sättigungsphase kommt es folglich zur Reduktion des Marktes. Als Maßzahlen für die Branchenentwicklung in der deutschen Brauwirtschaft werden, aus den bereits oben aufgezeigten Gründen, im Folgenden der Gesamtjahresbierausstoß sowie der Pro-KopfVerbrauch herangezogen.

Der deutsche Biermarkt befand sich ab Mitte der 1960er Jahre in der Reifephase, da die bis dahin zweistelligen Zuwachsraten des Bierumsatzes deutlich zurückgingen. Der ProKopf-Verbrauch stieg langsam weiter an, bis er 1976 mit etwa 150 Litern seinen Höchststand erreichte. Im selben Jahr konnte die deutsche Brauwirtschaft mit einem Gesamtausstoß von 96,7 Mio. hl ein vorläufiges Rekordergebnis verbuchen. Danach ging der Bierverbrauch leicht zurück und der Gesamtausstoß schwankte zwischen 92 und 95 Mio. hl. Der Biermarkt trat somit in die Sättigungsphase ein (NAgel / BrÜGgelambert, 1991: S. 23). Im Zuge der Wiedervereinigung kam es zu einem vorübergehenden Marktwachstum, so dass der Gesamtausstoß der Brauereien in den alten Bundesländern im Jahr 1990 auf etwa 104 Mio. hl anstieg. Mit der Eingliederung der Brauereien in den neuen Bundesländern erreichte der gesamtdeutsche Markt 1992 sein Höchstniveau von 120 Mio. hl. Seiher hat die Gesamtjahreserzeugung jedoch deutlich abgenommen (DEUTSCHER BRAUER-BUND, 2003a: S. 4f.).

Die derzeitige Marktphase kann als Reduktionsphase bezeichnet werden. So verdeutlicht Abbildung 14, dass sich der Pro-Kopf-Verbrauch seit 1995 von 137,7 1 Bier um mehr als 201 verringert hat. 


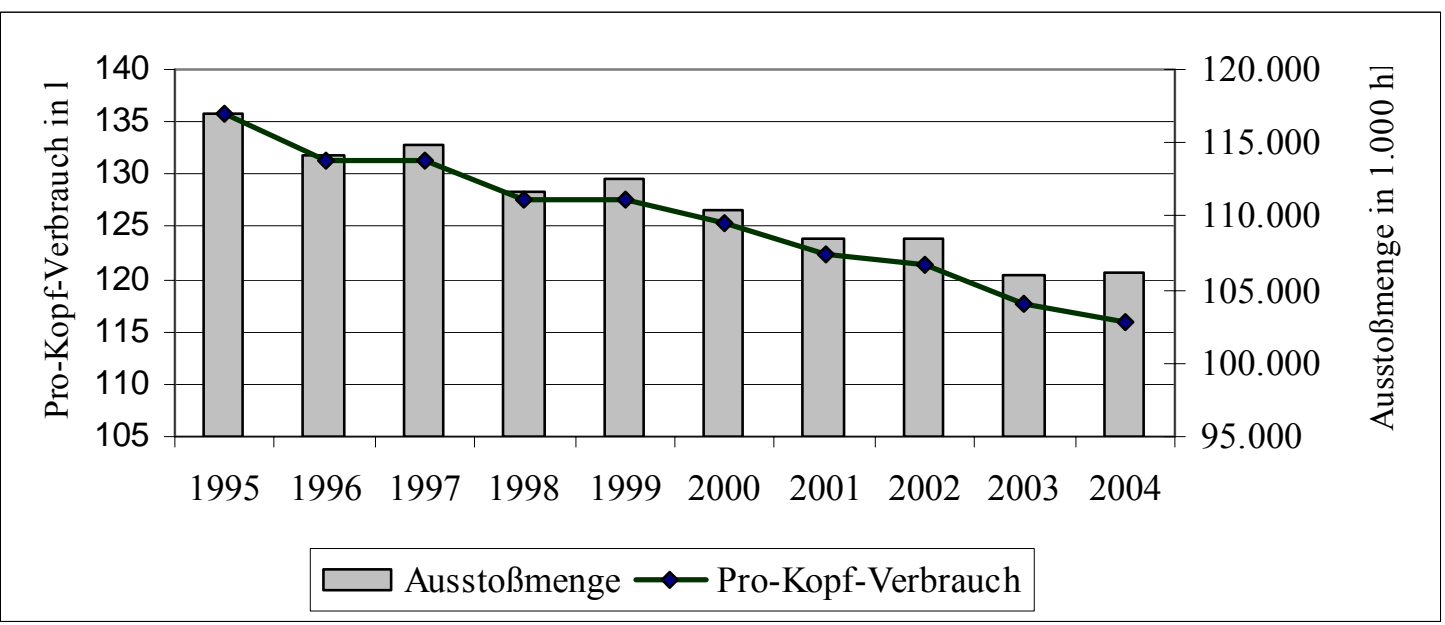

Abbildung 14: Entwicklung des Pro-Kopf-Verbrauchs und des Gesamtbierausstoßes Quelle: Deutscher Brauer-Bund, 2005c

Auch der Gesamtbierausstoß hat von 1995 bis 2003 um über 10 Mio. hl abgenommen. Im Jahr 2004 konnte dieser Trend durch einen stetig steigenden Export vorerst gebremst werden. Die deutschen Brauer, die ihren Marktanteil halten wollen oder gar die Absicht haben, diesen auszudehnen, können dies nur über eine Ausweitung des Exports oder zu Lasten der Mitbewerber realisieren. Absatzwachstum auf dem deutschen Markt kann, als Folge der aufgezeigten Entwicklung nur durch Verdrängung oder durch die Akquisition von Mitbewerbern realisiert werden (FISCHER, 1989: S. 29).

Die Folge des scharfen Wettbewerbs um Marktanteile auf dem deutschen Biermarkt ist die seit Jahren zunehmende Konzentrationsentwicklung in der deutschen Brauwirtschaft. Diese wird im Folgenden anhand der absoluten sowie der relativen Konzentration veranschaulicht.

Von absoluter Konzentration spricht man, wenn ein großer Anteil des gesamten Merkmalsbetrages auf eine kleine Zahl an Merkmalsträgern entfällt (BLEYMÜlLER/GEHLERT, 1989: S. 378f.). Für den deutschen Biermarkt heißt das, dass bei der Messung der absoluten Branchenkonzentration beschrieben wird, auf wie viele Anbieter der Branche sich der Gesamtbierausstoß verteilt.

Mit Blick auf die Entwicklung seit Mitte der 1960er Jahre wird deutlich, dass sich die Anzahl der Brauereien nahezu halbiert hat, wohingegen sich der durchschnittliche Bierausstoß je Braustätte fast verfünffacht hat und der Gesamtbierausstoß von 39 Mio. hl auf 106 Mio. hl gestiegen ist (DEUTSCHER BRAUER-BUND, 2005c; Hofnagel/Kortmann, 1999: S. 134). Somit hat seither eine absolute Konzentration 
stattgefunden. Viele Brauereiunternehmen verfügen über mehrere Braustätten, so dass über die Betriebsstättenanzahl keine Rückschlüsse auf rechtliche und wirtschaftliche Verflechtungen getätigt werden können. Diese Anzahl zeigt somit nur das Mindestmaß der Konzentration auf; je nach Grad der Verflechtung muss die Konzentrationsrate daher höher angenommen werden (WIESE, 1993: S. 44). Der Grad der absoluten Konzentration kann anhand der Berechnung der Konzentrationsrate (CRm) bestimmt werden. CRm ist als derjenige Anteil am gesamten Merkmalsbetrag definiert, der auf die m größten Merkmalsträger entfällt (BLEYMÜLlER/GEHLERT, 1989: S. 378f.). Für die deutsche Brauwirtschaft heißt das, dass bei maximaler Konzentration nur eine Brauerei existieren würde, die den Gesamtjahresausstoß auf sich vereinte.

Abbildung 15 zeigt einen Vergleich der kumulierten Marktanteile der fünf größten Brauereigruppen und Privatbrauereien in Deutschland in den Jahren 1991, 2002 und 2004. Es wird ersichtlich, dass diese vor allem durch Fusionen und Übernahmen in den letzten Jahren deutlich an Bedeutung zugenommen haben.

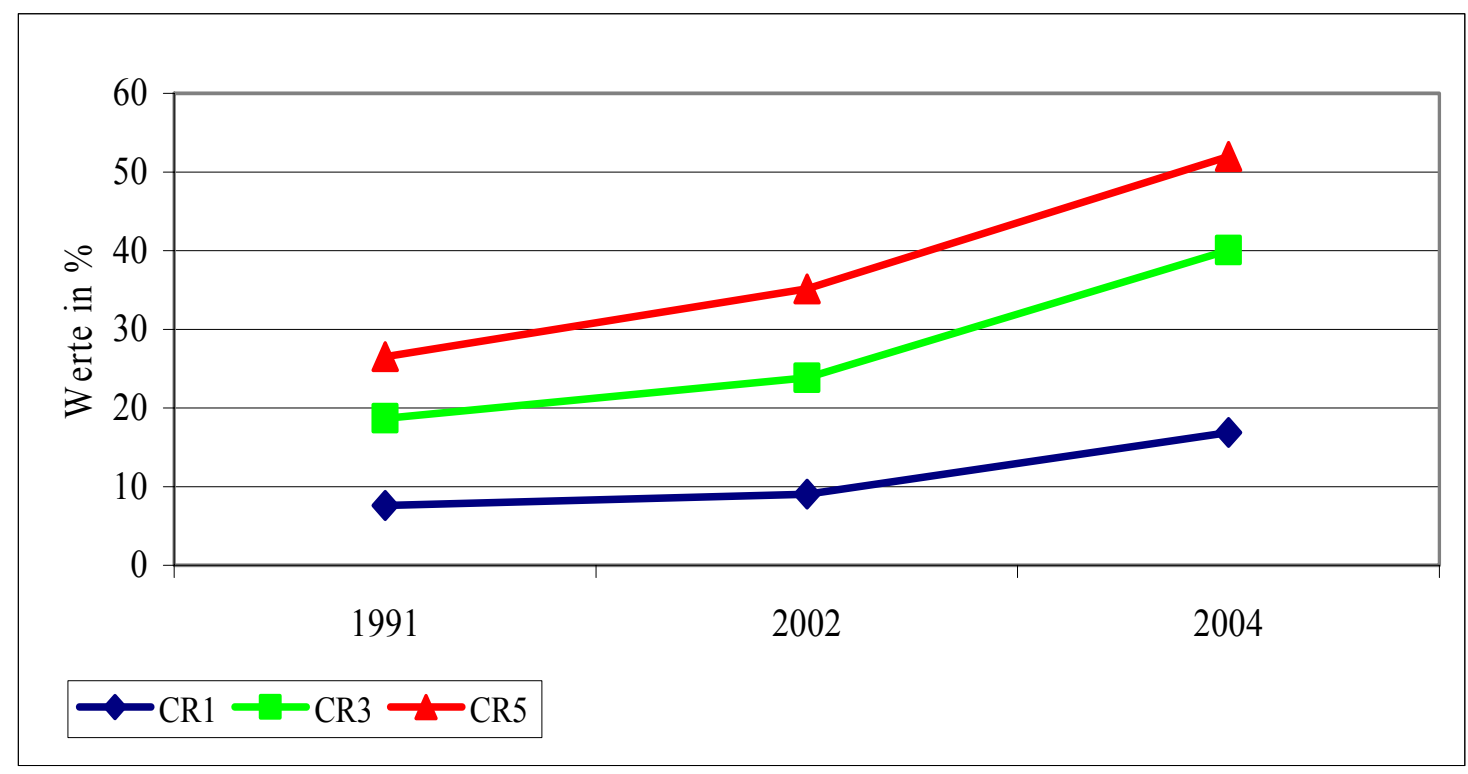

Abbildung 15: Vergleich der Konzentrationsraten der Jahre 1991, 2002 und 2004 Quelle: KELCH, 2004a: S. 45; 2005b: S. 261, eigene Berechnung

Im Jahr 2004 hatte die größte deutsche Brauerei einen Marktanteil von etwa $15 \%$ im Vergleich zu weniger als 7,2 \% im Jahr 1991. CR3 erhöhte sich von 17,7 \% im Jahr 1991 auf etwa $38 \%$ in 2004 und CR5 stieg bis heute auf ca. $51 \%$ an. Die Brauwirtschaft holt somit eine Entwicklung nach, die in vielen anderen Teilen der Getränke- und Lebensmittelwirtschaft als „Ausdünnung der Mitte“ bekannt geworden ist: Entweder Unternehmen sind groß genug, um mit den nationalen und ggf. sogar 
internationalen Kostenführern bzw. Markenartiklern mithalten zu können, oder sie sind klein genug, um sich regional eine überlebensfähige Nische zu suchen. Dazwischen bleibt kaum Platz; die Abnahme der Zahl der klassischen mittelgroßen Konsumbierbrauereien belegt dies eindrucksvoll (vgl. dazu auch Tabelle 4).

Generell kann auf den Weltbiermärkten ein positiver Zusammenhang zwischen der Konzentrationsrate und der Rentabilität festgestellt werden (EBNETH, 2005: S. 5). Ein Vergleich mit den internationalen Märkten zeigt, dass der Konzentrationsgrad in der deutschen Brauwirtschaft noch immer relativ niedrig ist (CREDIT SUISSE / FIRST Boston, 2003: S. 22). So hat man bei Radeberger (der zweitgrößten deutschen Brauereigruppe) eine Agenda aufgelegt, die einen Marktanteil von „20 Prozent plus“ vorsieht, da alle großen Auslandsmärkte zeigen, dass ein Marktanteil von 20-30 Prozent für eine sichere Position im Wettbewerb erstrebenswert ist (PEITSMEIER, 2004: S. 33). Auch vor dem Hintergrund des deutschen Wettbewerbsrechts ist noch Raum für Fusionen und Übernahmen in der deutschen Brauwirtschaft. Nach § 19 (3) GWB sprechen folgende Werte für eine Marktbeherrschung: Ist bei Einzelunternehmen ein Marktanteil von mindestens einem Drittel erreicht oder vereinen drei oder weniger Unternehmen einen Marktanteil von 50 \% bzw. fünf oder weniger Unternehmen einen Marktanteil von zwei Drittel und mehr, wird eine Marktbeherrschung vermutet (BundeSKartellamt, 2001: S. 4). Wie die Abbildung 15 zeigt, sind die deutschen Brauereien von einer kartellrechtlichen Marktmacht insgesamt gesehen noch sehr weit entfernt. Auf regionalen Teilmärkten kann sich z. T. jedoch ein etwas anderes Bild ergeben.

Relative Konzentration liegt vor, wenn ein großer Anteil des gesamten Merkmalsbetrages auf einen kleinen Anteil der Merkmalsträger entfällt (BLEYMÜLLER, ET AL., 2000: S. 191). Wenn sich der Gesamtmerkmalsbetrag sehr ungleichmäßig auf die Merkmalsträger verteilt, spricht man von hoher, bei gleichmäßiger Verteilung hingegen von geringer relativer Konzentration (EBBERTZ, 1992: S. 113). Die relative Konzentration kann anhand der Lorenzkurve graphisch dargestellt werden (vgl. Abbildung 16). 


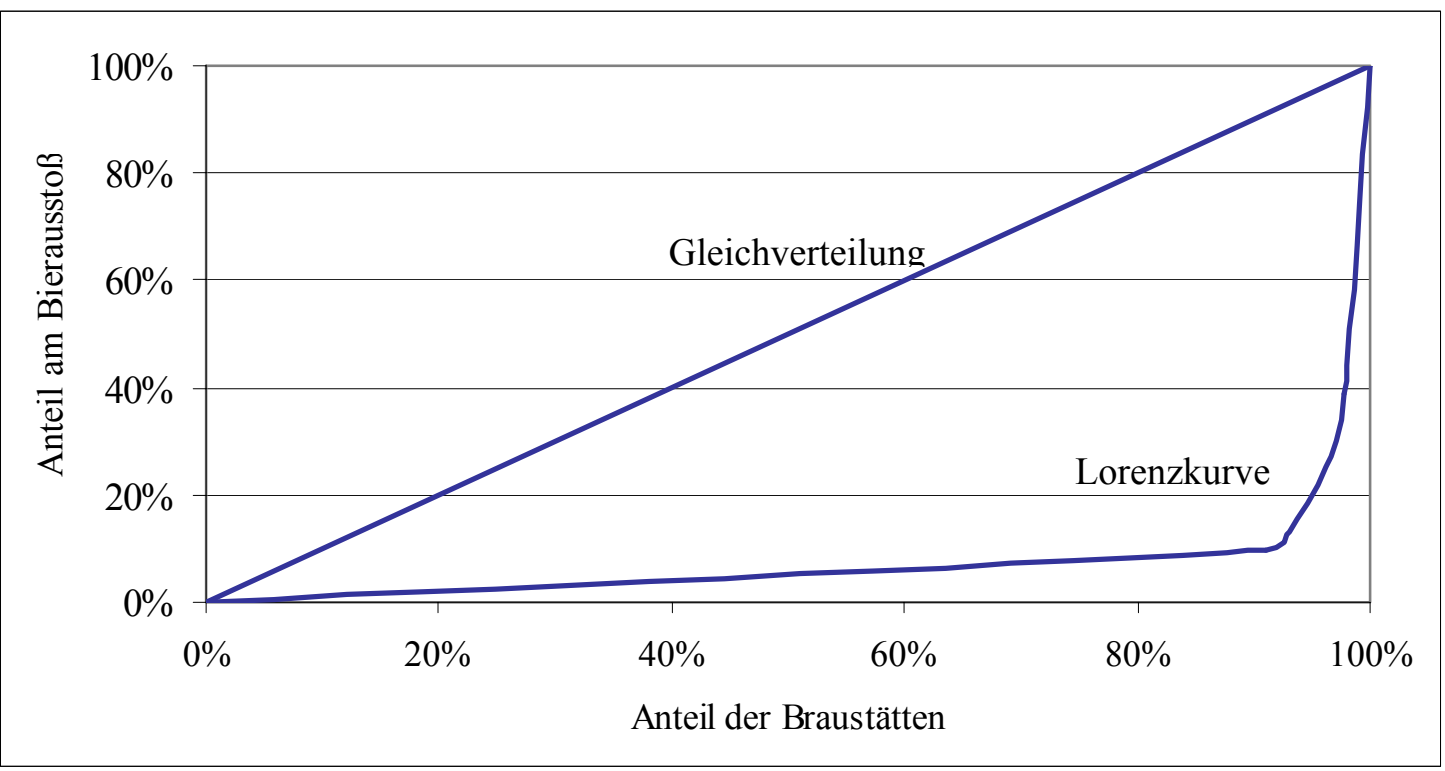

Abbildung 16: Relative Konzentration in der deutschen Brauwirtschaft im Jahr 2004 Quelle: LECHNER, 2003: S. 60, Daten interpoliert; DEUTSCHER BRAUER-BUnd, 2005b

Dabei werden die kumulierten prozentualen Anteile der Brauereien nach Größenklassen und die kumulierten prozentualen Ausstoßmengen in Beziehung gesetzt (Henze, 1994: S. 332). Der Anteil der Fläche zwischen Lorenzkurve und Gleichverteilungsgerade gibt das Ausmaß der relativen Konzentration an. Je größer diese Fläche ist, desto größer ist die relative Konzentration (Lehn, 1996: S. 1ff.). Abbildung 16 verdeutlicht, dass die relative Konzentration auf dem deutschen Biermarkt sehr hoch ist. Obwohl der zahlenmäßige Anteil der größeren Brauereien (Gesamtjahressaustoß > 200.000 hl) im Jahr 2004 nur 6,5 \% betrug, konnten sie einen Anteil von etwa $87 \%$ am Gesamtbierausstoß auf sich vereinen (LECHNER, 2003: S. 60; Deutscher Brauer-Bund, 2005b).

Vor dem Hintergrund der sinkenden Nachfrage auf dem deutschen Biermarkt kann auch für die Zukunft von einer steigenden Konzentration ausgegangen werden. Branchenexperten erwarten, dass sich dieser Prozess weiterhin größtenteils zu Lasten der mittelgroßen Regionalbrauereien mit undifferenzierten Produkten vollziehen wird (ERNST \& YOUNG, 2003: S. 75).

\subsection{Möglichkeiten der Differenzierung}

Bei Bier handelt es sich innerhalb der einzelnen Sorten um ein sehr homogenes und somit austauschbares Produkt. Blindtests beweisen, dass Bier für den Verbraucher kaum unterscheidbar ist (Отто, 2001: S. 18) Die Möglichkeiten der Produktdifferenzierung sind daher - auch aufgrund des Reinheitsgebotes - eingeschränkt. 
Dennoch besteht die generelle Möglichkeit die Produkte in der Brauwirtschaft gegenüber den Konkurrenzprodukten unterscheidbar $\mathrm{zu}$ machen. Diese Differenzierung kann über Innovationen (Biermischgetränke; „Goldbiere“), die Besetzung von Nischen (Spezialitäten), Verpackungs- und Gebindeformen sowie das Marketing erfolgen. Diese Instrumente werden im Folgenden vorgestellt.

\section{Innovationen}

Die Schaffung von neuen Marktsegmenten durch Innovationen ist in den letzten Jahren vermehrt in den Blickpunkt der deutschen Brauwirtschaft geraten. Die Brauer versuchen beispielsweise über Geschmacksdifferenzierungen neue Kundengruppen zu erreichen. So lehnen Frauen und jüngere Konsumenten häufig den herben Geschmack von klassischem Bier ab, daher entwickelten die Brauer für diese Zielgruppe mildere Biersorten, wie z.B. die in den letzen Jahren sehr erfolgreichen „Goldbiere“ (O.V., 2003a: S. 38; KOLBRÜCK, 2005: S. 17). Aber auch die Biermischgetränke zielen mit ihrem häufig süßlichen Geschmack außer auf die Hauptzielgruppe der Jugendlichen auch auf Frauen ab. So sind Biermixgetränke bei Frauen im Durchschnitt wesentlich beliebter als bei Männern (Leuthel, 2001: S. 19). Die Biermixgetränke konnten ihren Marktanteil seit ihrer Einführung deutlich erhöhen (vgl. Kapitel 3.2.2).

Die geltende Gesetzeslage hat die deutschen Brauer lange Zeit davon abgehalten, Bier in Mischungen mit anderen Getränken auf den Markt zu bringen. Biermixgetränke durften nur vor den Augen des Gastes in der Gastronomie entstehen. Erst seit der Änderung des Biersteuergesetzes im Jahr 1993 ist es den Brauereien erlaubt, Biermischgetränke direkt herzustellen und abzufüllen (HIEDEMANN, 2002: S. 40). Seither haben sich die Biermixgetränke bis zum Jahr 2005 zum viertgrößten Segment der Braubranche entwickelt (DIETZ, 2005: S. 42). Durch vielfältige Geschmacksvariationen versuchen die deutschen Brauereien auch weiterhin ihre Produkte von den Wettbewerbererzeugnissen zu differenzieren. So existiert inzwischen ein breites Sortiment an Biermischgetränken. Dieses reicht von klassischen Mischungen mit Zitronenlimonade, Cola oder Berliner Weisse über ausgefallenere Getränke mit Zusätzen wie Cassis, Limette, Apfel oder Kirsch bis hin zu sehr ausgefallenen Getränken mit exotischen Früchten und / oder mit hochprozentigen Alkoholika (HiEDEMANN, 2002: S. 40). Neuere Biermixgetränke versuchen sich z.B. 
über einen Schuss Guarana oder weniger süßen Geschmack von der Konkurrenz abzuheben (MEWES, 2005: S. 58).

Die Abgrenzung vom Wettbewerb durch Innovationen gestaltet sich insgesamt jedoch recht schwierig, da häufig ein hoher Investitionsbedarf in den Bereichen Marketing sowie Forschung \& Entwicklung notwendig ist. Bei einem Misserfolg der Innovation können somit hohe Verluste entstehen, während bei einem Erfolg schnell Nachahmer auftreten. Die Biermischgetränke sowie die „Goldbiere“ wurden schnell nach ihrer erfolgreichen Einführung von anderen Brauereien kopiert. So gibt es mittlerweile etwa 150 „Goldbiere“ am Markt (RosBACH, 2005: S. 44). Dieses Nachahmerverhalten ist auch beim Handel immer häufiger $\mathrm{zu}$ beobachten. Dieser wartet bei einer Neueinführung eines Produktes zunächst dessen Akzeptanz ab, um dann mit günstigen „mee-too-Produkten“ am Markt aktiv zu werden (JACOBY, 2005: S. 52). Die Fähigkeit des Wettbewerbs, Produkteigenschaften in kurzer Zeit zu kopieren, erschwert somit die langfristige Realisierung und Behauptung von innovationsbasierten Wettbewerbsvorteilen in der Brauwirtschaft.

\section{Besetzung von Nischen}

Neben der Entwicklung neuer Geschmacksrichtungen kann eine weitere Form der Differenzierung durch die Verwendung ausgewählter Rohstoffe oder eines besonderen Brau- und Lagerprozesses erfolgen (PSCHORR, 2003: S. 84). Diese Differenzierungsstrategie findet sich besonders bei Nischenanbietern. So bieten Spezialitäten gerade in Zeiten stagnierender Märkte die Chance, gegen den Branchentrend $\mathrm{zu}$ wachsen. Ein Indiz dafür sind z.B. die deutlich zunehmenden Marktanteile von Schwarzbier in den letzen Jahren. Ein weiteres Beispiel ist der Erfolg von „Öko-Bier“, bei dessen Produktion nur Rohstoffe aus ökologischem Anbau verwendet werden (O.V., 2003b: S. 48).

\section{Verpackungs- und Gebindeformen}

In den letzten Jahren ist in der deutschen Brauwirtschaft verstärkt der Trend zu beobachten, sich über das Instrument der Verpackung zu differenzieren. Bestanden die Primärverpackungen für Bier bis vor einigen Jahren nahezu ausschließlich aus braunen oder grünen Glasflaschen bzw. Dosen, kommen seit einiger Zeit mit neuen Produkten zugleich neue Glasfarben (z.B. Klarglas) ins Angebot (O.V., 2005b: S. 1636). Aber 
auch die Formenvielfalt nimmt $\mathrm{zu}$, neben der eleganten Longneck-Flasche und der klassischen Variante gibt es vermehrt Reliefflaschen oder neue Bügelvarianten. Darüber hinaus wird der klassische Kronkorken teilweise durch unterschiedliche Verschlussmöglichkeiten wie bspw. den Dreh-Kronkorken ersetzt (KAROPKA ET AL., 2004: S. 42; LATZ-WEBER, 2003b: S. 37). Zudem sind viele neue Kastenformen auf den Markt gekommen wie z.B. der 11er-Kasten, der teilbare 20er -Bierkasten, Mehrwegkästen mit weicheren Griffen oder Kästen mit einem besonderen Design (ScHÖNROCK, 2003: S. 47). Schließlich wird vermehrt versucht, den Trend zu Kleingebinden zu bedienen (O.V., 2005c: S. 706). Ein Beispiel dafür ist die 0,25 1 Flasche im 15er-Kasten (JACOBY, 2005: S. 52). Die Biere werden somit nicht mehr nur über das Etikett differenziert, sondern Material, Form und Funktionalität spielen zusätzlich eine große Rolle (LEUTHEL, 2001: S. 19).

\section{Marketing}

Die Markenbildung ist die wichtigste Form der Differenzierung in der deutschen Brauwirtschaft. Ziel ist es dabei, dem Bier neben den Grundeigenschaften weitere abgrenzende Attribute wie Prestige, das Erlebnis von besonderem Genuss und Bekanntheit zu verleihen (PSCHORR, 2003: S. 84). Die Differenzierung gelingt in der Brauwirtschaft vor allem über die Vermittlung einer unterschiedlichen Markenwelt, ob „goldene Momente des Lebens“, „Freiheit“ oder „Erfolg und Belohnung“, der Konsument soll sich für die jeweilige Erlebnispositionierung begeistern. Damit sollen die Verbraucher an die Marke gebunden und den Brauereien auf diese Weise langfristig Marktanteile gesichert werden. Darüber hinaus ist es das Hauptziel des Marketings, eine höhere Zahlungsbereitschaft des Konsumenten zu erreichen. So ist der Preis in der Brauwirtschaft ein wesentlicher Faktor, mit dem eine Marke ihren Spitzenanspruch und ihre Wertigkeit demonstriert (ROSBACH, 2005: S. 44).

In den letzten Jahren konnte vermehrt eine sog. Polarisierung des Konsumentenverhaltens beobachtet werden. Zum einen werden zur Deckung der täglichen Grundbedürfnisse preisgünstige Produkte gesucht, während andererseits nicht zuletzt wegen des hohen Sozialprestiges vermehrt Markenprodukte gekauft werden (PSCHORR, 2003: S. 77). Die Markenbildung ist somit ein wichtiges strategisches Mittel für die Vermarktung von Bier (HofnAGEL/KoRTMAnN, 1999: S. 141). 
Tabelle 6 zeigt, dass es sich bei acht der Top 10 Biermarken nach ihrem Inlandsabsatz im Jahr 2005 um Premium-Marken handelt. Diese Biere sind im oberen Preissegment angesiedelt und werden intensiv beworben. Bei nur zwei Marken (Oettinger und Sternburger) handelt es sich um Biere, die im Preiseinstiegsbereich angesiedelt sind. Mit Blick auf die Entwicklung der einzelnen Marken wird - vor dem Hintergrund eines im Jahr 2005 vermutlich leicht gesunkenen Gesamtbierabsatzes in Deutschland - deutlich, dass sowohl die Biere im Preiseinstiegsbereich als auch der überwiegende Teil der aufgezeigten Premium-Biere Marktanteile hinzugewinnen konnten. Damit ist der deutsche Biermarkt ein gutes Beispiel für die eingangs beschriebene Polarisierung des Konsumentenverhaltens. Es wird aber auch deutlich, dass „Premium“ per se keine Erfolgsgarantie ist. So haben die einzelnen Top-Labels bundesweit sehr unterschiedlich abgeschnitten. Während die Unternehmen Warsteiner, Bitburger und Radeberger hohe Absatzverluste hinnehmen mussten, konnten Beck`s, Hasseröder und Krombacher im Jahr 2005 deutlich zulegen. Neben einer guten Marketingstrategie spielen für Erfolg jedoch auch einige weitere Faktoren eine entscheidende Rolle (RosBACH, 2005: S. 44).

\begin{tabular}{|l|c|c|c|c|}
\hline \multicolumn{1}{|c|}{ Marke } & $\begin{array}{c}\text { Brauerei / } \\
\text { Konzern }\end{array}$ & $\begin{array}{c}2005 \text { in } \\
\text { Mio. hl }\end{array}$ & $\begin{array}{c}\text { 2004 in } \\
\text { Mio. hl }\end{array}$ & $\begin{array}{c}\text { Veränderung } \\
\text { in hl }\end{array}$ \\
\hline 1. Oettinger & Oettinger & 5,430 & 5,350 & +80.000 \\
\hline 2. Krombacher & Krombacher & 5,314 & 5,293 & +21.000 \\
\hline 3. Bitburger & Bitburger & 3,729 & 3,878 & -148.516 \\
\hline 4. Warsteiner & Warsteiner & 2,731 & 3,016 & -285.000 \\
\hline 5. Beck`s & InBev & 2,721 & 2,266 & +455.000 \\
\hline 6. Hasseröder & InBev & 2,423 & 2,264 & +159.000 \\
\hline 7. Veltins & Veltins & 2,304 & 2,288 & +16.000 \\
\hline 8. Sternburg & Radeberger & 2,000 & 1,830 & +170.000 \\
\hline 9. Karlsberg & Karlsberg & 1.950 & 1.950 & $+/-0$ \\
\hline 10. Radeberger & Radeberger & 1,800 & 1,851 & -51.000 \\
\hline
\end{tabular}

Tabelle 6: Top 10 Biermarken mit ihrem Inlandsabsatz 2004 und 2005 Quelle: Kelch, 2006: S. 196

Die gesamten Werbeausgaben wuchsen über Jahre beständig an, bis sie 1998 einen Höchstwert von 431 Mio. $€$ (ohne Sponsoring) erreichten (vgl. Abbildung 17). Danach sind die Werbeetats bis 2003 insgesamt auf etwa 334 Mio. $€$ gesunken. Ein Grund 
dafür ist, dass viele Brauereien aufgrund der niedrigeren Ertragslage bedingt durch Absatzrückgänge in allen Bereichen Kosten eingespart haben (Отто, 2001: S. 19). Aber auch die allgemeine wirtschaftliche Lage führte $\mathrm{zu}$ Einsparungen beim Marketing.

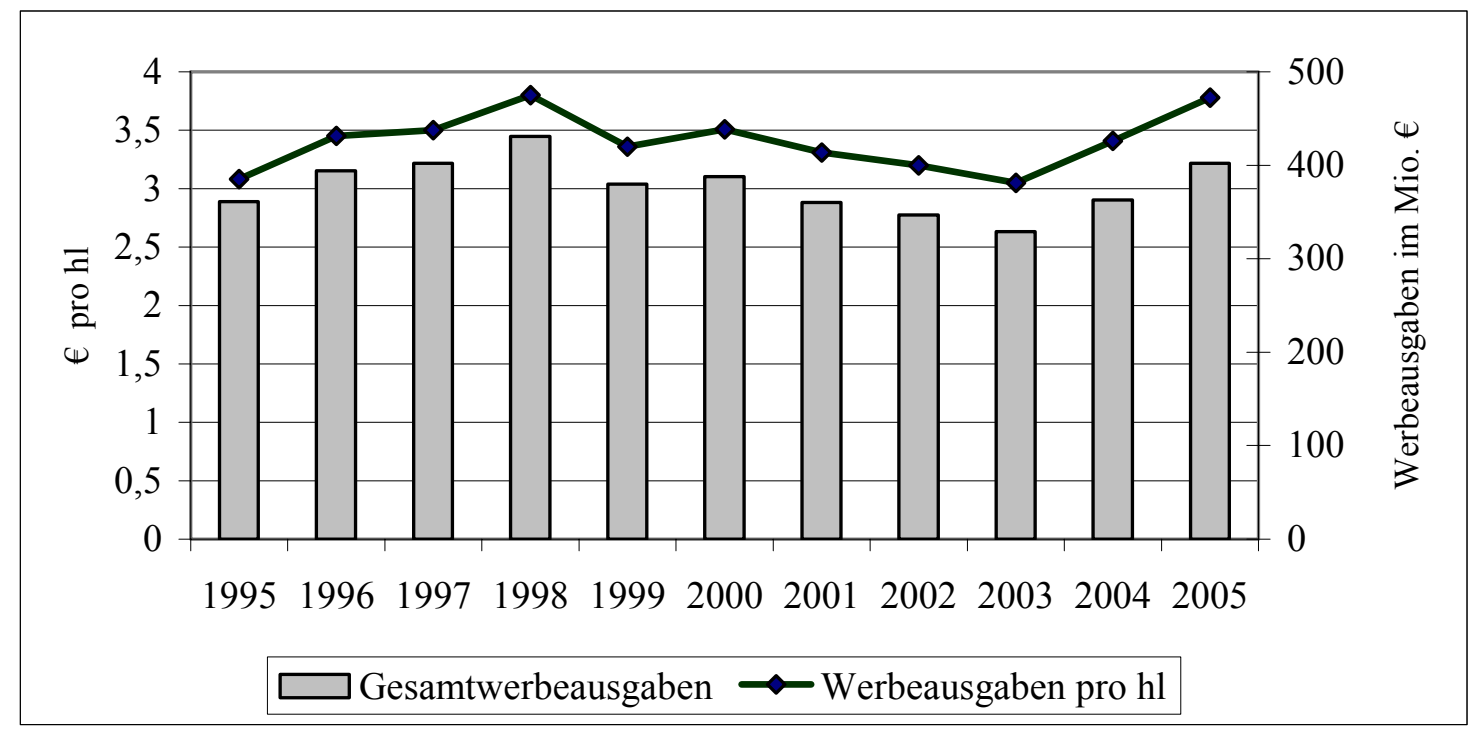

Abbildung 17: Gesamtwerbeausgaben für Bier sowie Werbeausgaben pro hl Quelle: Deutscher Brauer-Bund, 2003a: S. 70; AXEL Springer AG, 2006

So ist nach einer Studie der Nielsen Media Research der gesamte Werbeetat in der allgemeinen Wirtschaft im Jahr 2001 zurückgegangen (O. V., 2002b: S. 845). Seit 2003 haben die Werbeausgaben in der Brauwirtschaft wieder deutlich zugenommen. Im Jahr 2004 stand die Brauwirtschaft in einem Vergleich der 25 werbestärksten Branchen in Deutschland gemessen an den Werbeausgaben auf dem 15. Platz (ZENTRALVERBAND DER DEUTSCHEN WERBEWIRTSCHAFT, 2005). Im letzten Jahr sind die Werbeinvestitionen weiter auf nunmehr 402 Mio. $€$ angestiegen (AXEL SPRINGER AG, 2006). Auf den Hektoliter gesehen sind das Ausgaben für das Marketing (ohne Sponsoring) von 3,78€, damit ist fast wieder das Höchstniveau von 1998 (3,8€ pro hl) erreicht.

Nach Schätzungen liegen die Werbe- und Promotionsausgaben in der deutschen Brauwirtschaft im Durchschnitt bei etwa $8 \%$ der Umsatzerlöse, damit sind diese Ausgaben erheblich niedriger als im restlichen Westeuropa (ca. $13 \%$ ) und den USA (ca. $18 \%$ ). Zwischen den Brauereien gibt es in Bezug auf die Höhe der Werbeausgaben in Abhängigkeit von der gewählten Strategie jedoch erhebliche Unterschiede. Bedenkt man, dass die Biere im Preiseinstiegsbereich so gut wie gar nicht beworben werden, wird klar, dass die Werbeinvestitionen der „Premium“- 
Brauereien deutlich über dem Durchschnitt liegen (vgl. dazu Kapitel 4.2.2.3). So hat die Krombacher Brauerei, eine Brauerei mit einem der höchsten Werbeetats in Deutschland, im Jahr 2003 beispielsweise angegeben, allein etwa 50 Mio. $€$ in ihre Marke zu investieren; dies entspricht ca. $11 \%$ des Umsatzerlöses (CREDIT Suisse/First Boston, 2003: S. 32) und nahezu $10 €$ pro hl Bierausstoß.

Im Ergebnis bleibt festzustellen, dass der Wettbewerb in Bezug auf das Marketing in der Braubranche besonders unter den Markenbieren als sehr intensiv eingestuft werden kann. Auch für die Zukunft ist diesbezüglich keine Abschwächung zu erwarten, da mit einer starken Marke - neben den aufgezeigten Vorteilen - noch weitere positive Effekte verbunden sind. So gilt eine gut positionierte Marke als Ausgangspunkt für eine bessere Verhandlungsposition gegenüber dem Handel. Darüber hinaus stellt eine starke Marke einen bedeutenden immateriellen Vermögensgegenstand dar, welcher vor evtl. Übernahmen schützen bzw. den Wert einer Brauerei erheblich erhöhen kann (HESSE, 2002: S. 1914).

\subsection{Marktaustrittsbarrieren / Überkapazitäten}

$\mathrm{Da}$ die Marktaustrittsbarrieren in einem engen Zusammenhang mit den Überkapazitäten in der Branche stehen, werden diese im Folgenden gemeinsam behandelt.

Bei Marktaustrittsbarrieren handelt es sich nach PORTER um „ökonomische, strategische und emotionale Faktoren, die Unternehmen zum Verbleib in einer Branche veranlassen, selbst wenn sie niedrige oder sogar negative Ertragsraten erwirtschaften“ (PORTER, 1995: S. 48ff.). Eine der größten Marktaustrittsbarrieren in der deutschen Brauwirtschaft - insbesondere für diejenigen Brauer, die sich schon in einem fortgeschrittenen Alter befinden - dürfte die unsichere berufliche Zukunft der Brauer nach einer evtl. Aufgabe ihrer Brauerei sein. Verstärkt wird diese Barriere durch die biermarktspezifischen Betriebsanlagen. Diese führen einerseits zu einer mangelnden Flexibilität, auf die Herstellung von anderen Produkten auszuweichen, andererseits lassen sie häufig nur einen geringen Verkaufserlös erwarten. Kosten für z.B. Sozialpläne, Abfindungen für Mitarbeiter usw. tragen ihr übriges für einen Verbleib im Markt bei (WIESE, 1993: S. 62). Aber auch emotionale Gründe spielen in der deutschen Brauwirtschaft eine große Rolle. So sind gerade viele der kleinen und mittleren Brauer stolz auf ihre Brautradition und führen die häufig seit Generationen 
in Familienbesitz befindlichen Brauereien aus idealistischen Werten fort (BöSKENDiEBELS, 1989: S. 11). In der Hoffnung auf „bessere Zeiten“ weigern sich viele Brauer, ihr Unternehmen aufzugeben bzw. zu verkaufen, auch wenn es aus betriebswirtschaftlicher Sicht sinnvoll wäre. Häufig warten die Brauer mit der Entscheidung, aus dem Markt auszuscheiden, so lange, bis sie wirtschaftlich handlungsunfähig sind und dann aufgeben müssen (HoFNAGEL/KORTMANN, 1999: S. 140). Dadurch verschlechtert sich die Verhandlungsposition gegenüber einem evtl. Käufer erheblich.

Im Ergebnis führen die Marktaustrittsbarrieren in der deutschen Brauwirtschaft zu einer großen Anzahl von Grenzanbietern. Diese verfolgen häufig eine Abschöpfungsstrategie. D. h. es werden keine bzw. nur die allernötigsten Investitionen durchgeführt, um einen möglichst hohen Cash flow zu erzielen, bis z.B. die Altersgrenze erreicht ist. Langfristig führt diese Strategie i. d. R. zur Stilllegung bzw. zum Verkauf des Unternehmens. Durch den Verbleib der Grenzanbieter im Markt unterbleibt kurzfristig der Abbau von Überkapazitäten, wodurch nach PORTER die Rentabilität der gesamten Branche dauerhaft niedrig bleiben kann (PORTER, 1995: S. 46).

Die deutsche Brauwirtschaft ist durch erhebliche Überkapazitäten gekennzeichnet. Diese werden von Branchenkennern auf bis zu 50 \% geschätzt (O. V., 2004a: S. 1722). Ursachen dafür sind der Rückgang des Pro-Kopf Verbrauchs, die Verbesserung der Produktivität, die aufgezeigten Marktaustrittsbarrieren sowie partielle Kapazitätsausweitungen der Brauereien (EBBERTZ, 1992: S. 480). Letztere sind auf positive Branchenprognosen von führenden Unternehmensberatungen und Branchenkennern zurückzuführen, welche sich nicht bewahrheitet haben. So wurde der Braubranche in den 1980er und 1990er Jahren von vielen Experten ein mittel- bis langfristig starkes Marktvolumenwachstum vorausgesagt. Viele Brauereien investieren daraufhin in den Ausbau ihrer Betriebsstätten (HOFNAGEL/KORTMANN, 1999: S. 139). Wie man heute weiß, kam es zu keinem Marktwachstum, sondern das genaue Gegenteil war der Fall. Zum Zeitpunkt der Wiedervereinigung gab es in der deutschen Brauwirtschaft daher schon erhebliche Überkapazitäten. Vor dem Hintergrund, dass der Gesamtabsatz der Brauereien in den alten Bundesländern bedingt durch die Wiedervereinigung von 1989 bis 1990 um $12 \%$ angestiegen ist, investierten die westdeutschen Brauereien wiederum in die Ausweitung ihrer 
Kapazitäten, um am Absatzboom in den neuen Bundesländern zu partizipieren (GOEHLER, 1993: S. 171). Im Jahr 1993 verringerte sich das Absatzwachstum im gemeinsamen deutschen Markt bereits wieder sehr deutlich. Außerdem mussten die westdeutschen Brauer zunehmend Absatzverluste zugunsten der ostdeutschen Biermarken hinnehmen (OMLOR, 2003: S. 36). Im Ergebnis stand die Brauwirtschaft einem noch größeren Kapazitätsüberhang gegenüber (GOEHLER, 1993: S. 171).

Insgesamt haben die Überkapazitäten die Intensität der Rivalität unter den Wettbewerbern auf dem deutschen Biermarkt erheblich erhöht. Erkennen lässt sich dieser Sachverhalt an der Entwicklung des Preisniveaus (vgl. Kapitel 3.2.3.1.5). Wenn die Überkapazitäten nicht deutlich abgebaut werden, ist auch für die Zukunft davon auszugehen, dass der Preisdruck weiterhin hoch bleiben bzw. sich noch weiter verschärfen wird. Einen ersten Schritt, dieser Situation entgegenzuwirken, hat eine große deutsche Brauereigruppe im Jahr 2005 unternommen, indem sie durch die Schließung von zwei Brauereistandorten Kapazitäten in Höhe von 5 Mio. hl vom Markt genommen haben, ohne diese an Billigbierproduzenten zu veräußern (O. V., 2005a: S. 679).

\subsection{Preiswettbewerb}

Die starke Fragmentierung der Branche sowie die beschriebenen Überkapazitäten haben es begünstigt, dass viele Brauer beim Kampf um Marktanteile Preiszugeständnisse gemacht oder die Produktion von Handelsmarken bzw. Zweitmarken im Preiseinstiegsbereich aufgenommen, nicht jedoch Überkapazitäten durch die Schließung von Produktionsstätten abgebaut haben. Abbildung 18 zeigt, dass die deutschen Brauer ihr Bier im Vergleich zu ihren internationalen Mitbewerbern in der Regel zu einem deutlich geringeren Preis abgeben. $\mathrm{Zu}$ erwähnen ist, dass der durchschnittliche Abgabepreis in Deutschland über alle Brauereien vermutlich sogar noch niedriger ist, da in Abbildung 18 aus Gründen der Datenverfügbarkeit nur die großen Markenbieranbieter aufgeführt sind.

Das relativ niedrige Bierpreisniveau in Deutschland ist neben dem Einfluss des Handels (vgl. Kapitel 3.2.3.3.2) eine Folge des harten Verdrängungswettbewerbs in der Braubranche und somit ein Zeichen für einen hohen Rivalitätsgrad. Im Allgemeinen konkurrieren die einzelnen Biere insbesondere innerhalb ihres Preissegments miteinander. Dabei wird vornehmlich im Niedrigpreissegment der 
Konkurrenzkampf über Preisnachlässe ausgetragen (LENZHOFER, 2003: S. 4). Allerdings beeinflussen die einzelnen Biermarktsegmente z. T. auch die Preisrealisierung in den übrigen Segmenten.

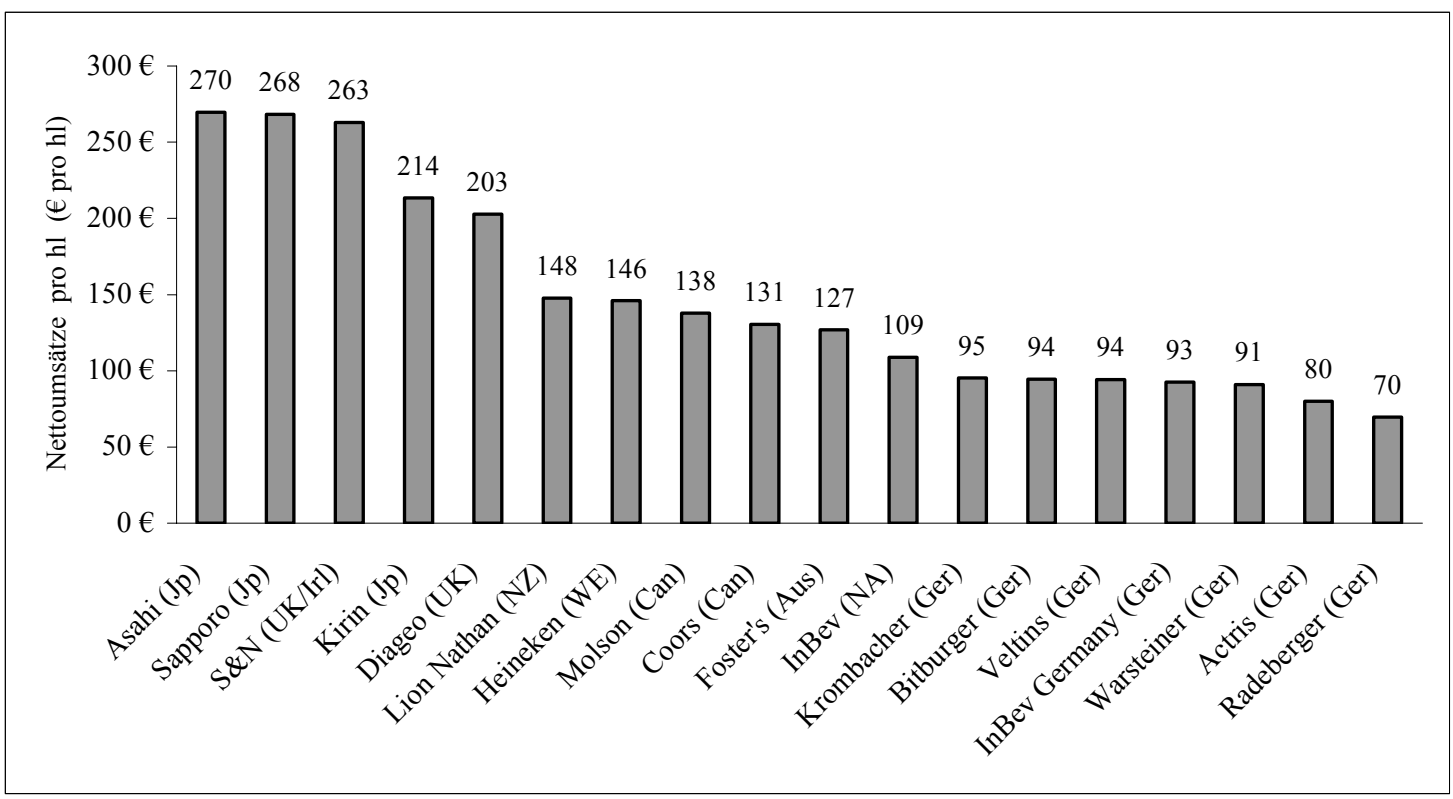

Abbildung 18: Nettoumsätze pro Hektoliter ausgewählter Brauereien in verschiedenen Industrieländern

Quelle: Unternehmensdaten, eigene Berechnung

Abbildung 19 veranschaulicht, dass seit Jahren eine Umschichtung in den einzelnen Preissegmenten zu beobachten ist. So ist der Anteil des Preiseinstiegsbereichs im Handel seit 1999 um $11 \%$ auf nunmehr $27 \%$ angestiegen. Der Anteil der oberen Preisklasse ist 2005 zwar zurückgegangen, hat sich seit 1999 aber dennoch deutlich erhöht und lag 2005 bei 48 \%. Durch diese Entwicklung wurde insbesondere auf die Biere im preislichen Mittelfeld Druck ausgeübt, deren Anteil erheblich abgenommen hat.

Mit Blick auf den Preis im Handel zeigt sich, dass dieser seit 1999 etwas abgenommen hat und im Durchschnitt nunmehr 9,12 € für einen 20er- 0,51-MWKasten beträgt (vgl. Abbildung 19). Auch diese Entwicklung ist auf die Absatzsteigerungen im Preiseinstiegsbereich zurückzuführen. Insgesamt sind die Unterschiede zwischen den Segmenten sehr groß. In Preisen ausgedrückt bedeutet dies, dass der Konsument im Preiseinstiegsbereich durchschnittlich 5,31 € für eine 20er-Kiste à 0,5 1 bezahlt gegenüber 11,13€ für eine hochpreisige Marke. Dieser Unterschied ist jedoch nicht ungewöhnlich und sowohl im Non-Food als auch im Food-Markt anzutreffen. Im Getränkemarkt finden sich Beispiele weit größere 
Preisunterschiede, so z.B. im Wassermarkt, wo höherpreisige Marken z. T. vier bis fünfmal teurer sind als „Billigwasser“, oder auch bei Süßgetränken, bei denen der Faktor Drei bis Vier beträgt. Der Preisvergleich zwischen „Billigbier“ und PremiumMarken ist im Biermarkt jedoch eher rechnerischer Natur, da sich diese Option für den Premiumkäufer i .d. R. nicht stellt. Die Zahl derer, die Premiumbier durch Produkte aus dem Preiseinstiegsbereich substituieren, ist als eher gering einzustufen; die Reaktion des höherpreisigen Markenkäufers besteht eher darin, seinen Konsum zu reduzieren (BIRNBAUM, 2006: S. 8).

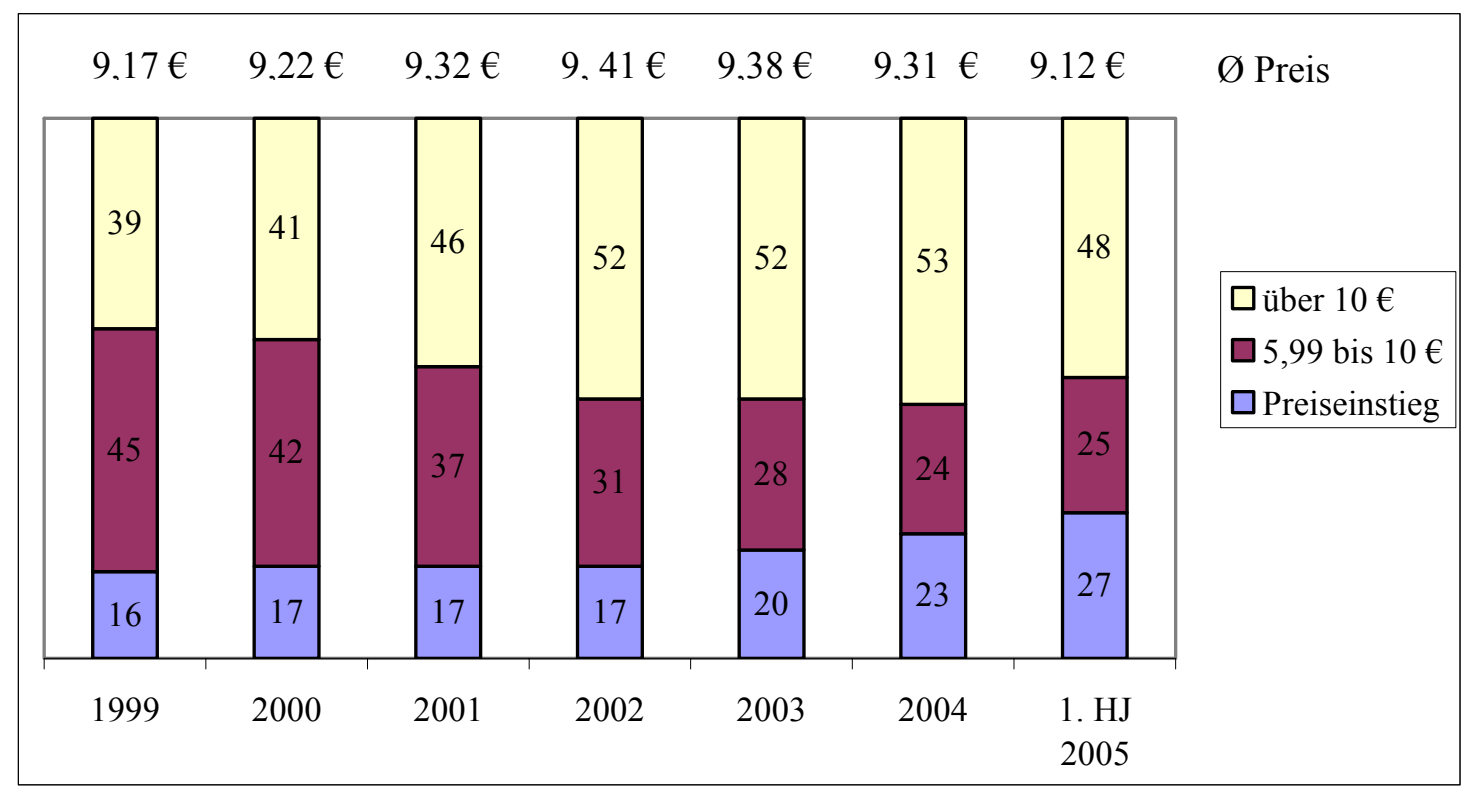

Abbildung 19: Preisklassen Bier 20er 0,51-MW-Kasten von 1999 bis 2005

(Basis: Einkaufsmengen in Prozent)

Quelle: BIRNBAUM, 2005a: S. 8

Aber auch innerhalb der verschiedenen Preissegmente gibt es erhebliche Preisunterschiede. So konnten einige große Markenbierbrauereien ihre Preise seit ersten Anpassungen im Jahr 2000 sukzessive auf z. T. deutlich über $12 €$ für den 20er0,5 1-MW-Kasten erhöhen (LATZ-WeBER, 2004a: S. 42). Allerdings mussten sie dafür Absatzrückgange hinnehmen (SCHMIDT-AUERBACH, 2003: S. 44; Vossen, 2002: S. 14). Zwar zeigen Erfahrungen aus der Braubranche, dass eine Anhebung des Preisniveaus den Absatz nur für eine begrenzte Dauer hemmt, jedoch darf der Preisabstand zu den übrigen Marken im Premiumsegment nicht zu groß werden, da sonst die Gefahr besteht, dass die Verbraucher zu einer anderen Marke im selben Segment wechseln (MAU, 2000: S. 46).

Nach einer Einschätzung von ACNIELSEN wird die Polarisierung des Biermarktes in Hoch- und Niedrigpreismarken anhalten, wobei das Preiseinstiegssegment derzeit im 
Vorteil liegt. Aber auch auf der „Premiumebene“ wird sich der Wettbewerb weiter verstärken. Hier haben die Brauereien, die aus Sicht des Verbrauchers ein höheres Image widerspiegeln, bessere Marktchancen. Die im Premiumsegment angesiedelten Biere bewegen sich jedoch alle auf einem schmalen Grad zwischen Hochpreispolitik und Absatzminus (JACOBY, 2005: S. 52).

Insgesamt wird der Preisdruck auf die Brauereien durch steigende Kosten im Arbeitsund Energiebereich immer stärker. Andererseits werden die Erlöse z. T. durch Listungsgebühren, Werbekostenzuschüsse und Regalmieten des Handels noch weiter geschmälert (MAU, 2000: S. 46). Daher sind Preiserhöhungen für viele Unternehmen in der deutschen Brauwirtschaft von existentieller Bedeutung. Diese nachhaltig durchzusetzen, bleibt jedoch schwierig. Eine Verbesserung der kollektiven Preisdisziplin wäre daher aus Sicht nahezu der gesamten Branche wünschenswert.

Zusammenfassend ergibt die Analyse der Rivalität unter den bestehenden Unternehmen, dass die deutsche Brauwirtschaft durch eine hohe Wettbewerbsintensität gekennzeichnet ist.

\subsubsection{Bedrohung durch neue Konkurrenten}

Im Allgemeinen bringen neue Wettbewerber zusätzliche Kapazitäten in den Markt und verfügen oft über erhebliche Mittel, um Marktanteile zu erobern. Der Markteintritt neuer Konkurrenten kann somit den Wettbewerbsdruck für alle Branchenteilnehmer erhöhen und die erzielbaren Gewinne langfristig senken (PORTER, 1995: S. 29). Die deutsche Brauwirtschaft weicht allerdings insoweit von der allgemeinen Definition ab, als der Markteintritt neuer Wettbewerber i. d. R. nicht über neugeschaffene zusätzliche Kapazitäten erfolgt, sondern - wie im Folgenden aufgezeigt wird - über den Einkauf in bereits bestehende Unternehmen.

Die Wahrscheinlichkeit des Markteintritts potentieller neuer Marktteilnehmer wird zum einen entscheidend durch den Anreiz des Zutritts in einen Markt und zum anderen durch die bestehenden Eintrittsbarrieren bestimmt. Die Markteintrittsanreize drücken die Attraktivität des Marktes für neue Wettbewerber aus; als Hauptkriterium des Markteintritts gilt eine hohe Rendite. Marktzutrittsbarrieren erschweren den Eintritt in eine Branche für neue Wettbewerber. Je höher die Markteintrittsbarrieren sind, desto schwieriger wird es für Unternehmen in den Markt einzudringen und desto höher ist der 
Vorteil der bereits am Markt etablierten Unternehmen gegenüber neuen Wettbewerbern (HoFNAGEL/KorTMANN, 1999: S. 139).

Der deutsche Biermarkt war in den letzten Jahren durch hohe Markteintrittsanreize geprägt. Diese resultieren zum einen daraus, dass es sich um den größten Markt in Westeuropa handelt, der trotz sinkendem Konsum noch immer durch einen der höchsten Pro-Kopf-Verbräuche der Welt gekennzeichnet ist. Darüber hinaus war und ist der deutsche Biermarkt im Vergleich zu anderen Märkten nach wie vor wenig konsolidiert. Vor diesem Hintergrund sehen die ausländischen Brauereien im Rahmen zunehmender Konzentration Raum für Preiserhöhungen und damit zur Verbesserung der Rentabilität. Ein weiterer Grund, auf dem deutschen Markt aktiv zu werden, liegt darin begründet, dass die ausländischen Brauer sich aufgrund der im internationalen Vergleich geringen Gewinne der deutschen Brauereien relativ preiswert einkaufen können, da der Verkaufserlös einer Brauerei entscheidend vom EBITDA abhängt. Diese wirtschaftlichen Fakten machen den deutschen Biermarkt trotz aktuell geringer Renditen für ausländische Anbieter attraktiv. Die Tatsache, dass Deutschland als „Heimat“ des Bieres gilt, verstärkt bei den internationalen Brauereien aus Prestige- und Imagegründen den Anreiz zum Markteintritt. Allerdings muss konstatiert werden, dass die Markteintrittsanreize für neue Wettbewerber durch die bereits auf den deutschen Markt eingetretenen internationalen Braukonzerne inzwischen abgenommen haben.

Den Markteintrittsanreizen stehen allerdings auch einige Markteintrittsbarrieren gegenüber, die vor allem den Import von ausländischen Bieren verhindern. So war das deutsche Reinheitsgebot für ausländische Wettbewerber lange Zeit eine unmittelbare Eintrittsbarriere (WIESE, 1993: S. 61). Bis 1987 durfte nur Bier auf dem deutschen Markt angeboten werden, welches nach dem Reinheitsgebot gebraut wurde. Nach einem Urteil des Europäischen Gerichtshofs im Jahr 1987 wurde das Reinheitsgebot für Importbiere aufgehoben, so dass seither auch andersartig gebrautes Bier eingeführt werden darf. Die deutschen Brauer befürchteten daraufhin erhebliche Absatzeinbussen durch einen erwartenden Anstieg des Importbieres. Doch dazu ist es nicht gekommen, da das Reinheitsgebot gerade für viele der älteren deutschen Verbraucher anscheinend ein wichtiges Qualitätskriterium bei der Kaufentscheidung darstellt. Somit hat sich eine durch staatliche Politik geschaffene Markteintrittsbarriere in ein natürliches Handelshemmnis gewandelt (EBBERTZ, 1992: S. 229ff.). Eine weitere Eintrittsbarriere stellt die starke Fragmentierung sowie das reichhaltige Sorten- und Mengenangebot der 
deutschen Braubranche dar. Der Biermarkt setzt sich aus vielen lokalen, regionalen und überregionalen Teilmärkten zusammen, in denen deutlich abweichende Wettbewerbsbedingungen und regional traditionell geprägte, z. T. stark unterschiedliche Konsumentenpräferenzen vorherrschen.

Die Folge ist, dass es sich für neue Wettbewerber als schwierig erweist, sich im Markt zu positionieren. So hat sich die Importmenge auf dem deutschen Biermarkt von 1987 bis zum Jahr 2004 zwar auf 3,12 Mio. hl erhöht, trotzdem liegt der Anteil mit 3,3 \% am Inlandsverbrauch noch immer auf einem sehr niedrigen Niveau. Der größte Teil der Importmenge stammt aus Dänemark (ca. 30 \%), weitere wichtige Importländer sind die Tschechische Republik, Belgien/Luxemburg und die Niederlande (KELCH, 2004b: S. 1609). Der größte Teil der Importbiere kommt somit aus den an Deutschland angrenzenden europäischen Ländern. Diese Biere werden ausnahmslos nach dem deutschen Reinheitsgebot gebraut, so dass die oben beschriebene mittelbare Eintrittsbarriere damit überwunden wird. Bei den Importen aus Dänemark muss berücksichtigt werden, dass ein großer Teil von dänischen Konsumenten in Deutschland zurückgekauft wird. Die Ursache dafür ist der erhebliche Preisvorteil des Bieres in Deutschland gegenüber den mit einer sehr hohen Alkoholsteuer belasteten Produkten in Dänemark (Kelch, 2003: S. 40f.). Tabelle 7 zeigt den Absatz der wichtigsten ausländischen Biermarken in Deutschland in den Jahren 2002 und 2003.

\begin{tabular}{|l|c|c|}
\hline \multicolumn{1}{|c|}{ Biermarke } & $2003(1.000 \mathrm{hl})$ & $2002(1.000 \mathrm{hl})$ \\
\hline $\begin{array}{l}\text { 1. The Danish Brewery Group, Marken: } \\
\text { Faxe, Ceres, Thor, Chains }\end{array}$ & 762 & 902 \\
\hline 2. Tuborg (in der BRD hergestellt) & 300 & 450 \\
\hline 3. Desperados Karlsberg & 230 & 280 \\
\hline 4. Budweiser Budvar & 214 & 197 \\
\hline 5. Carlsberg (in der BRD hergestellt) & 160 & 100 \\
\hline 6. Pilsener Urquell & 155 & 132 \\
\hline 7. Staropramen & 135 & 95 \\
\hline 8. Guinness & 97 & 73 \\
\hline 9. Heineken & 75 & 50 \\
\hline 10. Miller & 50 & 43 \\
\hline 11. Foster's & 30 & 43 \\
\hline 12. Corona & 27 & 153 \\
\hline
\end{tabular}

Tabelle 7: Die Top Importmarken 2002 und 2003

Quelle: KELCH, 2004b: S. 1609 
Es wird ersichtlich, dass der Absatz einiger Importmarken von 2002 auf 2003 erheblich abgenommen hat; diese Entwicklung ist auf die Einführung des Einwegpfandes zurückzuführen. Einige Brauereien konnten ihren Absatz trotz der schwierigen Rahmenbedingungen jedoch z. T. deutlich steigern. In diesem Zusammenhang fallen besonders die Superpremiumbiere Budweiser, Pilsener Urquell und Staropramen auf. Aber auch die internationalen Marken der Big Player Heineken und Carlsberg konnten ihren Absatz steigern; hier ist anzunehmen, dass diese Brauereien die Distributionswege ihrer lokalen Tochterunternehmen bzw. Beteiligungen nutzen, um auch ihre Hauptmarken abzusetzen. Für die Zukunft ist davon auszugehen, dass die Bedeutung der internationalen Marken sich deutlich erhöhen wird. Die zunehmende Internationalisierung des Konsums verstärkt diese Entwicklung nachhaltig (DEUTSCHER BRAUER-Bund, 2003b: S. 10). Vor allem Jugendliche sind weniger traditionsbewusst und messen dem Reinheitsgebot z. T. keine allzu große Bedeutung mehr bei. Sie sind experimentierfreudiger und durch Bildung und Reisen oft aufgeschlossener gegenüber neuen, auch internationalen Produkten. So erfreuen sich internationale Biere bei Jugendlichen einer zunehmenden Beliebtheit. Besonders deutlich wird dies bei der Betrachtung der Marken Desperados und Corona, die in Szene-Gastronomie sehr erfolgreich abgesetzt werden und nicht nach dem Reinheitsgebot gebraut sind (O.V., 2002c: S. 1455). Damit verliert das Reinheitsgebot als mittelbare Eintrittsbarriere an Gewicht. Aber auch die Marktzutrittsbarriere der starken regionalen Konsumentenpräferenzen sinkt durch den Wertewandel der Verbraucher (GOEHLER, 1993: S. 188).

Eine weitere Eintrittsbarriere stellen die Schwierigkeiten dar, die mit einem Aufbau einer neuen Marke verbunden sind. Um die bestehende Käuferloyalität zu den etablierten Wettbewerbern $\mathrm{zu}$ überwinden, müssen neue Wettbewerber in großem Umfang in den Aufbau eines Markennamens investieren. Die erforderlichen Aufwendungen für die Etablierung eines Markenbieres sind in der Braubranche sehr hoch und führen selbst bei den Marktführern im internationalen Vergleich nur zu einem geringen Marktanteil (vgl. Tabelle 7). Außerdem dauert der Aufbau einer Marke häufig sehr lange und birgt das Risiko, dass bei Misslingen kein Restwert bleibt (PORTER, 1995: S. 29ff.). In engem Zusammenhang mit dem Aufbau einer Marke steht die Markteintrittsbarriere des Zugangs zu den Distributionswegen. Um vom Handel gelistet zu werden, bedarf es einer starken Marke. Der Zugang zum Absatzweg Gastronomie 
wird darüber hinaus durch die Vielzahl brauereieigener Gastronomiebetriebe sowie langfristige Bierlieferungsverträge der etablierten Unternehmen behindert. Diese wirken für in den Markt eintretende Unternehmen wettbewerbsbeschränkend, da sie eine schnelle und kostengünstige Erschließung der Gastronomie als Distributionsweg verhindern (WIESE, 1993: S. 169).

Das in Deutschland geltende Einwegpfand erschwert die Einfuhr von Importbier zusätzlich und ist somit als eine weitere Markteintrittsbarriere anzusehen. So zeigt die Tabelle 7, dass der Absatz gerade vieler internationaler Markten besonders unter der Einführung des Einwegpfands gelitten hat (KELCH, 2004b: S. 1609). Für ausländische Brauereien ist es aus Kostengründen nahe liegend, ihr Bier in Einweggebinden zu exportieren (KUHL, 1990: S. 70). Um aber im Handel großflächig gelistet zu werden, ist es in Deutschland zurzeit in der Regel notwendig, Bier in Mehrweggebinden anzubieten (vgl. Kapitel 3.2.2). Damit kommen auf die Brauereien neben dem kostenintensiveren Transport von Bier in Mehrwegflaschen noch die Aufwendungen für den Rücktransport des Leergutes zu. Die enormen Kosten führen dazu, dass der Transport von Bier je nach realisierbarem Preis nur über eine bestimmte Distanz rentabel ist (GOEHLER, 1993: S. 169f.). Eine Möglichkeit, dieser Eintrittsbarriere entgegenzuwirken, ist eine Vertragsabfüllung vor Ort, aber auch damit sind zusätzliche Kosten verbunden.

Insgesamt war die Bedrohung durch den Markteintritt neuer Wettbewerber durch die aufgezeigten Barrieren für lange Zeit sehr gering. In den letzten Jahren haben jedoch viele bedeutende internationale Brauereikonzerne wie Heineken, Inbev und Carlsberg Einzug in den deutschen Biermarkt gehalten. Während die Export- und Lizenzgeschäfte mit internationalen Marken, wie oben beschrieben, in der Vergangenheit weitgehend erfolglos blieben, erwiesen sich die Übernahmen führender inländischer Brauereien durch die internationalen Braukonzerne als eine weitaus erfolgreichere Markteintrittsstrategie. Dank ihrer im Vergleich zu den Übernahmekandidaten enormen Größe und Finanzkraft fiel den internationalen Großbrauereien der Marktzutritt über Akquisitionen leicht. Den Grundstein für diese Entwicklung legte der niederländische Braukonzern Heineken, der im Februar 2001 einen Anteil von 49,9 \% an der Münchner Schörghuber-Gruppe erwarb. Nachdem Heineken diese Beteiligung durchgeführt hatte, strebten einige andere internationale Braukonzerne ebenfalls auf den deutschen Markt. 
Tabelle 8 gibt einen Überblick über die wichtigsten Akquisitionen durch internationale Braukonzerne auf dem deutschen Biermarkt.

\begin{tabular}{|l|l|l|c|}
\hline Datum & $\begin{array}{l}\text { Erwerbendes } \\
\text { Unternehmen }\end{array}$ & Erworbenes Unternehmen & $\begin{array}{l}\text { Ausstoß } \\
\text { (in Mio. hl) }\end{array}$ \\
\hline Februar 2001 & Heineken & $\begin{array}{l}\text { Gründung der Brau Holding } \\
\text { International, 49,9\% } \\
\text { Heineken, 50,1 \% Brau } \\
\text { Holding der Münchner } \\
\text { Schörghuber-Gruppe }\end{array}$ & 4,7 \\
\hline Juli 2001 & Interbrew (Inbev) & Diebels & 1,4 \\
\hline August 2001 & Interbrew (Inbev) & Beck \& Co & 5,5 \\
\hline Juni 2002 & $\begin{array}{l}\text { Heineken (Brau } \\
\text { Holding International) }\end{array}$ & Karlsberg (45\%) & 3,9 \\
\hline Dez. 2002 & Interbrew (Inbev) & Gilde & 2,3 \\
\hline Sep. 2003 & Interbrew (Inbev) & Spaten & 3,6 \\
\hline Jan. 2004 & Carlsberg & $\begin{array}{l}\text { Holsten (die Marken Licher } \\
\text { und König gehen an die } \\
\text { Bitburger Gruppe) }\end{array}$ & 6,9 \\
\hline Okt. 2004 & $\begin{array}{l}\text { Heineken (Brau } \\
\text { Holding International) }\end{array}$ & $\begin{array}{l}\text { Fürstenberg, Herrenbräu, } \\
\text { Würzburger Hofbräu }\end{array}$ & 1,2 \\
\hline
\end{tabular}

Tabelle 8: Mergers \& Aquisitions internationaler Braukonzerne auf dem deutschen Biermarkt

Nimmt man alle in ausländischem Besitz befindlichen Brauereien und deren Beteiligungen zusammen, so dürften diese seit dem Jahr 2005 auf etwa $30 \%$ des Bierausstoßes in Deutschland Einfluss haben (O.V., 2006c: S. 260). Branchenexperten erwarten eine weiter voranschreitende Internationalisierung und damit einen steigenden Wettbewerbsdruck aufgrund der großen Finanzkraft der internationalen Braukonzerne (Vossen, 2005: S. 12).

\subsubsection{Verhandlungsmacht der Abnehmer}

Die Verhandlungsmacht der Abnehmer ist eine weitere Wettbewerbskraft, welche auf die Brauereien einwirkt. Die Abnehmer können durch ihre unterschiedlich stark ausgeprägte Verhandlungsstärke Einfluss auf die Preise ausüben oder Qualitäts- und Leistungsansprüche an die Lieferanten stellen. Die Verhandlungsposition der Abnehmer wird, wie oben beschrieben, durch verschiedene Faktoren beeinflusst und kann die Rentabilität der gesamten Branche beeinflussen (PORTER, 1995: S. 50ff.).

\subsection{Absatzwege in der Brauwirtschaft}

Im Gegensatz zu vielen anderen Branchen gibt es in der Brauwirtschaft eine große Anzahl von Distributionsmöglichkeiten. Die Wahl der Absatzwege wird weitgehend 
durch die Brauereigröße, die entstehenden Kosten sowie das $\mathrm{zu}$ bedienende Marktsegment bestimmt (BRUnKEN, 1990: S. 71; EBBERTZ, 1992: S. 517). Abbildung 20 zeigt die wichtigsten Absatzwege der Brauereien in Deutschland. Generell kann bei der Gestaltung der Distribution einer Brauerei zwischen direkter Belieferung und indirekter Belieferung über Absatzmittler unterschieden werden. Beim direkten Vertrieb partizipiert nur die Brauerei an der Wertschöpfung im Vertrieb. Die direkte Belieferung an den Endverbraucher kann über einen eigenen Heimdienst, Depots sowie über brauereieigene Gastronomieobjekte und Abholmärkte erfolgen. Bei der indirekten Belieferung übernehmen die Absatzmittler einen großen Teil bzw. die gesamte Distributionsleistung für die Brauereien und nehmen somit eine Mittlerfunktion zu den Endverbrauchern ein. Die wichtigsten Absatzmittler beim indirekten Vertrieb sind der Getränkefachgroßhandel, die Gastronomie, der Lebensmittelgroßhandel, der Lebensmitteleinzelhandel sowie die Getränkeabholmärkte. Darüber hinaus werden auch noch andere Unternehmen wie Tankstellen, Kioske und Automatenaufsteller beliefert, deren Bedeutung aufgrund ihres geringen Absatzanteils jedoch als eher niedrig einzustufen ist (FonTAINE, 2003: S. 99f.) und welche daher in der folgenden Untersuchung nicht gesondert behandelt werden.

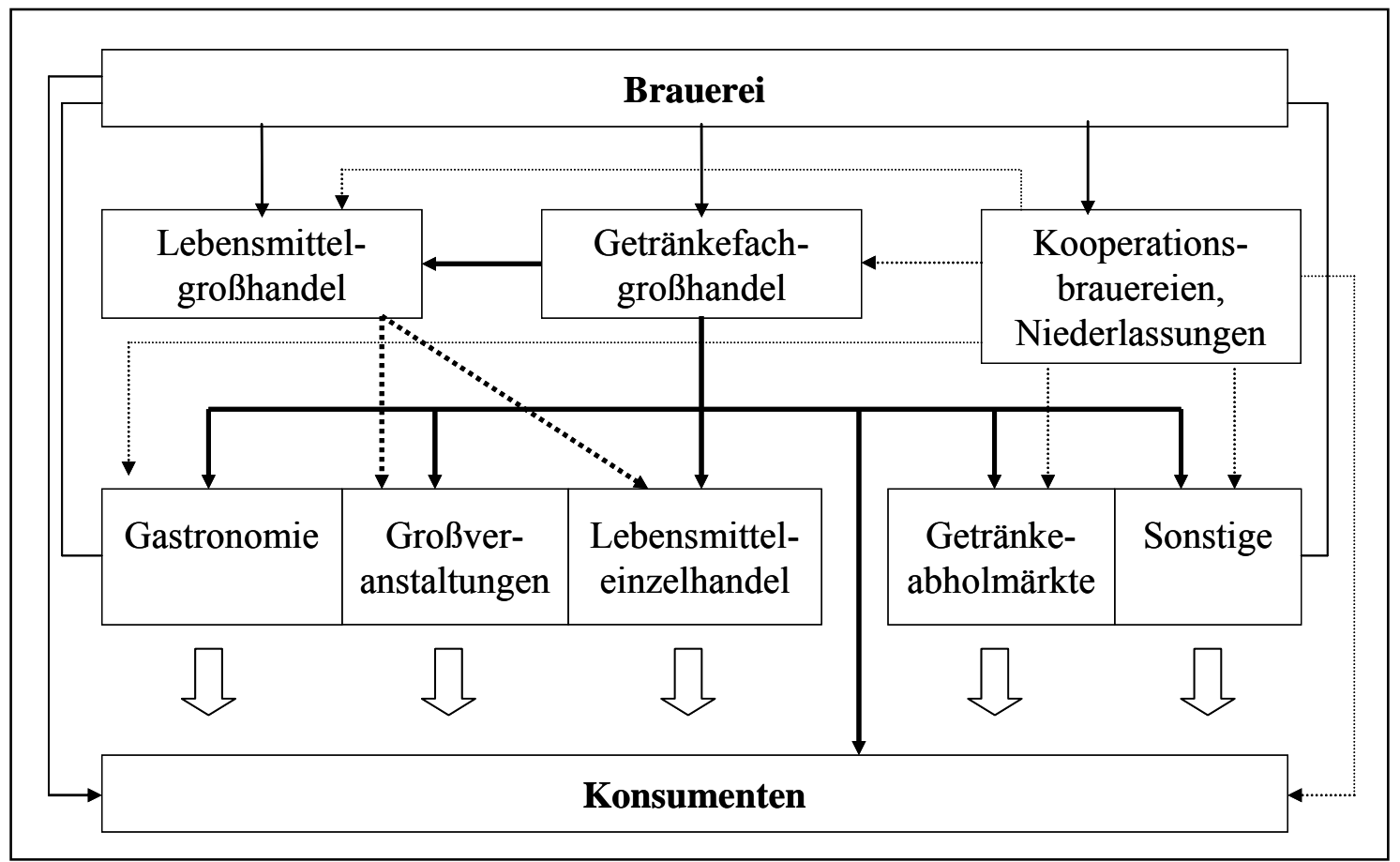

Abbildung 20: Absatzwege von Brauereien

Quelle: FonTAInE, 2003: S. 91ff.; HofNAGEL/KorTMAnN, 1999: S. 139

Bei der Distribution über Absatzmittler kann weiterhin zwischen einer einstufigen und einer zweistufigen indirekten Belieferung unterschieden werden. Beim einstufigen 
Indirektgeschäft erfolgt der Absatz ohne Einschaltung des Großhandels an die Gastronomie, den Lebensmitteleinzelhandel etc. Das zweistufige Indirektgeschäft verläuft über die Distributionsstufe auf der Ebene des Großhandels oder eine Kooperationsbrauerei übernimmt die Vertriebsleistung (BöSKEN-DIEBELS, 1989: S. 32f.; BRUNKEN, 1990: S. 69).

Eine weitere Möglichkeit des direkten Vertriebs besteht in Form des E-Commerce. Wie Ergebnisse einer Studie zeigen, wird das Internet in der Brauwirtschaft jedoch bisher kaum als Vertriebsinstrument genutzt (NiEDERHUT-BollmanN/THEUVSEN, 2006: S. 198). Obwohl einzelne Beispiele eines erfolgreichen und profitablen überregionalen Internet-Vertriebs dokumentiert sind (THEUVSEN, 2003a: S. 206ff.) und andere Brauereien Online-Bestellformulare im Bereich des von ihnen organisierten Heimdienstes einsetzen, hat sich an dieser Situation in den vergangenen Jahren kaum etwas geändert. So geben lediglich etwa $1 \%$ der Unternehmen in der deutschen Brauwirtschaft an, einen Teil des Getränkeabsatzes über E-Commerce zu tätigen (Niederhut-BollmanN / Theuvsen, 2006: S. 198). Insofern werden die z. T. vernehmbaren skeptischen Stimmen zum Online-Vertrieb von Lebensmitteln an Endverbraucher bestätigt (WILKE, 2002: S. 34f.). Allerdings gehen $25 \%$ der befragten Brauereien davon aus, dass das Internet in Zukunft als Absatzweg an Bedeutung gewinnen wird. Dabei werden deutliche Unterschiede zwischen den Größenklassen erkennbar. So sind unter den großen Brauereien nur $18 \%$ der Auffassung, dass der ECommerce für ihr Unternehmen in Zukunft ein erhöhtes Absatzpotential bieten wird, wohingegen es bei den kleinen Unternehmen bis $5.000 \mathrm{hl} / \mathrm{Jahr}$ ca. $36 \%$ sind. Dieses Ergebnis ist nicht überraschend, da eine eingeschränkte Verfügbarkeit als wesentliche Vorraussetzung für einen erfolgreichen Online-Vertrieb von Lebensmitteln betrachtet wird (Theuvsen, 2002: S. 41f.; 2005: S. 406ff.). Online-Shops konkurrieren mit traditionellen Bezugsquellen (Lebensmitteleinzelhandel, Getränkeabholmärkte usw.), aus denen Endverbraucher üblicherweise ihr Bier beziehen. Die Chancen eines Biervertriebs über das Internet steigen daher erheblich an, wenn eine vom Verbraucher gewünschte Biermarke nicht ohne weiteres in traditionellen Vertriebskanälen erhältlich ist. Die Verfügbarkeit eines Lebensmittels außerhalb des Internet wird u. a. durch die Größe des Vertriebsgebietes bestimmt. Ein regional begrenztes Absatzgebiet schafft außerhalb des angestammten Vertriebsgebietes die für den Online Vertrieb notwendige Knappheit. Kleine und mittlere Brauereien weisen daher erheblich bessere 
Vorraussetzungen für einen bundesweiten Online-Vertrieb ihrer Produkte auf als die flächendeckend distribuierten Marken der Großbrauereien.

In der weiteren Analyse der Verhandlungsmacht der Abnehmer in der deutschen Brauwirtschaft werden die Absatzmittler und die Konsumenten, die als Endverbraucher die Gesamtnachfrage nach Bier bestimmen, in zwei gesonderten Gruppen betrachtet.

\subsection{Die Absatzmittler}

Im Folgenden wird zunächst die Verteilung des Bier-Inlandsabsatzes in Deutschland auf die einzelnen Vertriebswege ${ }^{8}$ aufgezeigt, um einen ersten Eindruck von deren Bedeutung für die Brauereien zu erlangen.

Grundsätzlich kann bei der Verteilung des Bier-Inlandverbrauchs auf der letzten Absatzmittlerstufe vor dem Verbraucher eine Unterscheidung nach dem Ort des Konsums des verkauften Bieres vorgenommen werden. Bei der so genannten „Onpremise" -Distribution wird die verkaufte Menge unmittelbar am Ort des Erwerbs konsumiert. Beispiele dafür sind die Gastronomie, Kantinen, Feste und Veranstaltungen, Trinkhallen, Kinos usw. Beim „Off-premise“ -Vertrieb wird die verkaufte Menge zu einem späteren Zeitpunkt und nicht am Ort des Erwerbs konsumiert. Beispiele dafür sind der traditionelle Lebensmitteleinzelhandel (LEH), Verbrauchermärkte, Discounter, Getränkeabholmärkte (GAM), Heimdienste sowie Tankstellen etc. (CANADEAN, 2005: S. 146).

Der Anteil des „On-premise“ -Vertriebs nimmt seit einigen Jahren zu Gunsten der „Offpremise“ -Distribution ab. Tabelle 9 zeigt diese Entwicklung von 2000 bis 2004. Es wird deutlich, dass über „On-premise“ -Absatzwege im Jahr 2004 etwa 44,5\% des Bier-Inlandsverbrauchs abgesetzt wurden. Im Vergleich $\mathrm{zu}$ anderen europäischen Ländern ist dieser Anteil sehr gering. So werden z. B. in Spanien und Großbritannien etwa $60-70 \%$ des Gesamtbierabsatzes über diese Distributionswege abgesetzt (CREDIT SUISSE / FIRST BOSTON, 2003: S. 9)

\footnotetext{
${ }^{8}$ An dieser Stelle wird aus Gründen der Datenverfügbarkeit zunächst nur die letzte Absatzmittlerstufe vor den Konsumenten betrachtet.
} 


\begin{tabular}{|l|c|c|c|c|c|}
\hline \multicolumn{1}{|c|}{ Jahr } & 2000 & 2001 & 2002 & 2003 & 2004 \\
\hline $\begin{array}{l}\text { Bier- } \\
\text { Inlandsverbrauch } \\
\text { in Mio. hl }\end{array}$ & 103,056 & 101,140 & 100,385 & 96,947 & 95,493 \\
\hline $\begin{array}{l}\text { Off-premise } \\
\text { Anteil in \% }\end{array}$ & 54,1 & 54,2 & 54,5 & 54,6 & 55,5 \\
\hline $\begin{array}{l}\text { On-premise } \\
\text { Anteil in \% }\end{array}$ & 45,9 & 45,8 & 45,5 & 45,4 & 44,5 \\
\hline
\end{tabular}

Tabelle 9: Biervertrieb nach Distributionskanal „Off-premise“ versus „On-premise“, 2000 bis 2004

Quelle: CANADEAN, 2005: S. 116

Nach Ergebnissen der Information Resources GmbH (IRI) in Nürnberg wurden im Jahr 2004 etwa 50 Mio. hl Bier im LEH, Discountern und GAM verkauft. Diese Menge entspricht etwa $52 \%$ des Bier-Inlandsabsatzes. Bedenkt man, dass bei den vorliegenden IRI-Zahlen Heimdienste, Tankstellen, Kioske usw. nicht berücksichtigt sind und diese etwa einen Absatz von 2,5 Mio. hl auf sich vereinen (vgl. Abbildung 21), können die Daten der Tabelle 9 somit bestätigt werden (INFORMATION RESOURCES GMBH, 2005).

Abbildung 21 veranschaulicht die Entwicklung der Verteilung des „Off-premise“ Bierabsatzes nach den unterschiedlichen Vertriebsschienen von 2002 bis zum 1 . Halbjahr 2005.

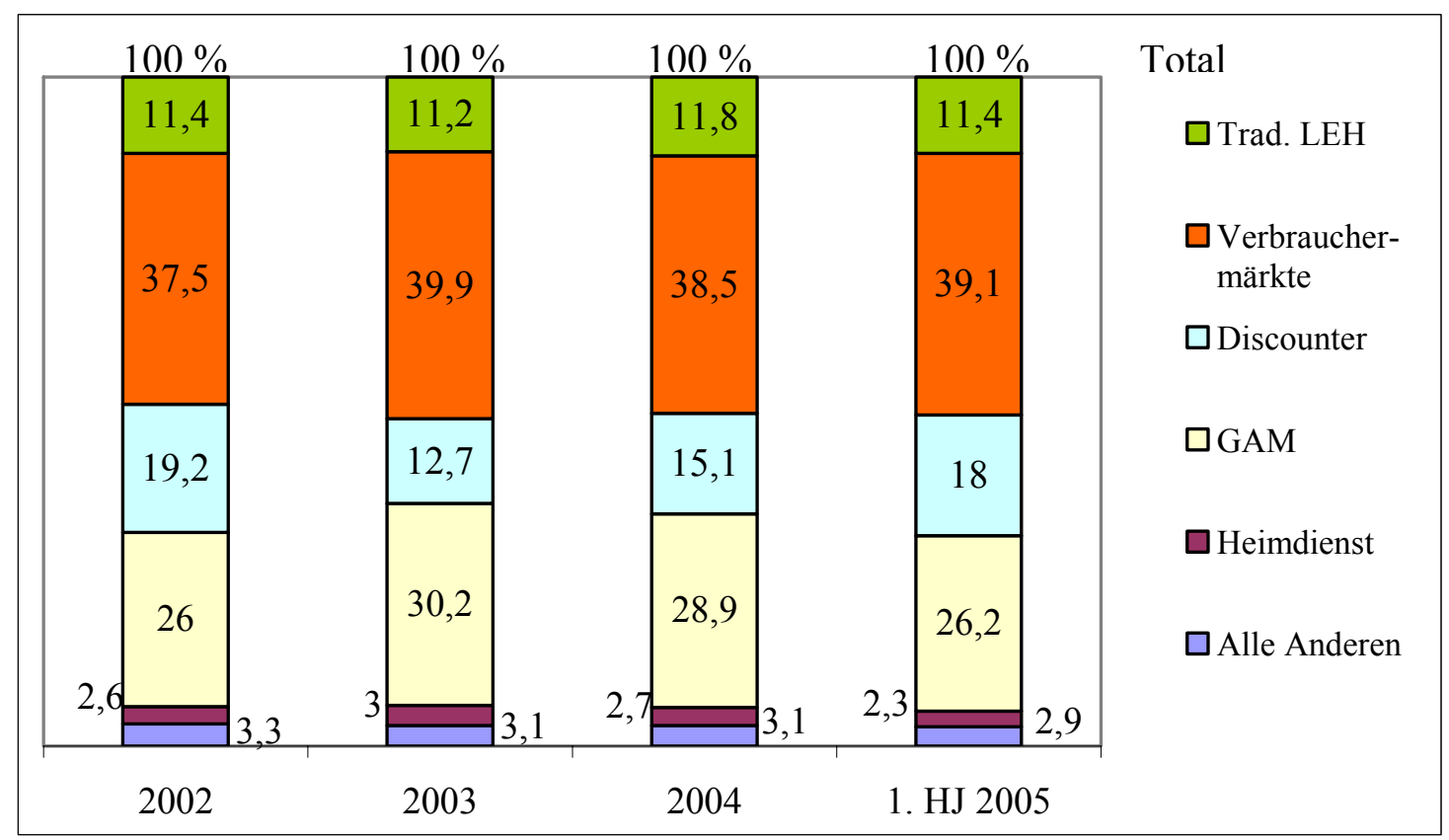

Abbildung 21: „Off-premise“ -Bierabsatz nach Vertriebsschienen Quelle: BIRNBAUM, 2005a: S. 8; 2005c 
Es wird ersichtlich, dass der traditionelle LEH und die Verbrauchermärkte seit 2003 einen stabilen Absatzanteil von etwa $50 \%$ innehaben. Die Discounter konnten ihren Absatzanteil nach erheblichen Verlusten durch die Einführung des Einwegpfands wieder verbessern und liegen in 2005 bei etwa $18 \%$. Die GAM hingegen haben ihre Absatzgewinne, die sie durch das Einwegpfand $\mathrm{zu}$ verzeichnen hatten, nahezu vollständig wieder an die Discounter verloren, und trugen 2005 für etwa 26 \% des „Offpremise“ -Absatzes Rechnung.

Über die Verteilung des „On-Premise“ -Vertriebs auf die unterschiedlichen oben aufgezeigten Absatzwege liegen dem Autor keine Daten vor. In den nachfolgenden Unterkapiteln wird nun die Einflussstärke der wichtigsten Absatzmittler gegenüber den Brauereien näher untersucht; dabei findet auch die Ebene des Großhandels Berücksichtigung.

\subsection{Getränkefachgroßhandel und Getränkeabholmärkte}

Der Getränkefachgroßhandel (GFGH) nimmt eine zentrale Absatzmittlerfunktion zwischen den Brauereien und den nachgelagerten Absatzwegen ein. So werden mittlerweile insgesamt etwa $79 \%$ des Gesamtbierabsatzes in Deutschland über diesen Weg vertrieben (CREDIT SUISSE / FIRST BOSTON, 2003: S. 20). Generell kann der GFGH in Betriebe unterschieden werden, deren Schwerpunkt beim Fassbier und der Gastronomie liegt, und solche, die sich vornehmlich auf Flaschenbier und die Belieferung des LEH konzentrieren (FONTAINE, 2003: S. 102). Im Jahr 2003 waren nach der Umsatzsteuerstatistik 5259 Unternehmen im Getränkefachgroßhandel tätig (INSTITUT FÜR WIRTSCHAFTSFORSCHUNG, 2005a). Diese haben 2004 einen Umsatz von 14,51 Mrd. $€$ erzielt und waren Arbeitgeber für etwa 46.000 Beschäftigte (Bundesverband Des Deutschen GetränKefachgroßhandels E.V., 2006). Mit Blick auf die Umsatzgrößenklassen zeigt sich, dass die Branche von mittelständischen Unternehmen dominiert wird. So erwirtschaften 2003 rund $54 \%$ aller Unternehmen einen Jahresumsatz von weniger als 0,5 Mio. €; am gesamten Umsatz der Branche waren diese Unternehmen jedoch nur zu 2,7\% beteiligt. Auf der anderen Seite der Umsatzskala gibt es fünf Unternehmen, die einen Umsatz von mehr als 250 Mio. $€$ erzielen und damit zusammen über $10 \%$ zum Branchenumsatz beitragen (INSTITUT FÜR WIRTSCHAFTSFORSCHUNG, 2005a). 
Bei der Nutzung der Vertriebsebene des GFGH entsteht eine zusätzliche Handelsspanne und somit ein weiterer Kostenfaktor in der Wertekette. Um die zusätzlichen Kosten zu rechtfertigen, muss der Absatz über den GFGH den Brauereien und bzw. oder der Gastronomie und dem LEH Vorteile gegenüber einer direkten Belieferung bieten. Für die Brauereien liegen diese Vorteile zum einen im Bereich der Logistikleistungen, welche aufgrund von Spezialisierungsvorteilen vom GFGH i. d. R. kostengünstiger ausgeführt werden können, und zum anderen in der Präsenz des GFGH in den regionalen Märkten. So übernimmt der GFGH dort auch die Bereitstellung von Dienstleistungen im Auftrag der Brauereien, wozu die Akquisition neuer Kunden, Serviceleistungen sowie die allgemeine Kundenbetreuung von Gastronomie und Handel zählen (MARX, 1996: S. 29). Diese Aufgaben sind für die Brauereien gerade bei weit entfernten Absatzgebieten nur mit erheblichem Aufwand möglich. Aus diesem Grund wird der GFGH vor allem von überregional und national distribuierenden Brauereien genutzt (Hofnagel / KorTMAnN, 1999: S. 154). Aber auch die Forderung des LEH, die Getränkelogistik (v. a. Leergutrückführung) an wenige oder nur ein Unternehmen zu binden, verstärkt die Bedeutung des GFGH als Absatzkanal für die Brauereien (KAHLEN, 2002: S. 33).

Beim GFGH handelt es sich i. d. R. um ein neutrales Bindeglied (mit Ausnahme von Kooperationen und Beteiligungen von Brauereien am GFGH, die im weiteren Verlauf noch erläutert werden) zwischen Brauerei, Handel und Gastronomie. So wird der Großhändler vor allem die Biere vertreiben, die ihm die höchsten Margen versprechen. Daher werden auch vermehrt Handelsmarken über den GFGH vertrieben, welche häufig höhere Spannen aufweisen als Premiumbiere (o.V., 2002d: S. 1003). Durch das Angebot fremder Biere tritt der GFGH gegenüber den Brauereien nicht nur als möglicher Kunde, sondern auch als Konkurrent auf (FonTAINE, 2003: S. 102). Besonders Brauereien, die Exklusivverträge mit Großhändlern abgeschlossen haben, begeben sich dadurch in eine gewisse Abhängigkeit. Sie müssen darauf vertrauen, dass der GFGH das zugesicherte Gebiet umfangreich erschließt und nicht bevorzugt andere Marken vertreibt, bei denen die Handelsspanne möglicherweise höher ist (WIESE, 1993: S. 311). Insgesamt entscheidet der GFGH mit seinem Sortiment zum großen Teil, welches Bier der Verbraucher im LEH und GAM vorfindet und welches Bier in der Gastronomie ausgeschenkt wird (HoLler/KAHLEN, 2003: S. 26). Somit bestimmt er 
mit der Gestaltung seines Sortiments indirekt über die Marktanteile der verschiedenen Biermarken.

Der Getränkefachgroßhandel ist zurzeit durch einen massiven Konzentrationsprozess gekennzeichnet. So ist die Zahl der Unternehmen seit Jahren rückläufig. Allein im Jahr 2003 gaben 162 Unternehmen bzw. 3 \% ihre Geschäftstätigkeit auf. Insbesondere in den kleineren Umsatzgrößenklassen ging die Zahl der Betriebe stark zurück. Demgegenüber stieg die Zahl der großen Unternehmen (mit Umsätzen über 25 Mio. $€ / J a h r)$ deutlich an (INSTITUT FÜR WIRTSCHAFTSFORSCHUNG, 2005a). Aufgrund der aufgezeigten Entwicklung sowie des großen Absatzanteils hat sich die Verhandlungsmacht des GFHG gegenüber den Brauereien in den letzten Jahren deutlich erhöht. Auch für die Zukunft ist davon auszugehen, dass sich dieser Prozess fortsetzen und die Markteinflussnahme des GFGH weiterhin steigen wird. Vor allem die lokalen und regionalen Brauereien werden dadurch unter Druck gesetzt (DEUTSCHER BRAUERBund, 2003b: S. 21).

In den letzten Jahren konnten einige Beteiligungen und Übernahmen von GFGH durch Brauereien beobachtet werden. So gründeten beispielsweise die drei Brauereien Bitburger, Warsteiner und Krombacher im Jahr 2001 das Gemeinschaftsunternehmen Premium-Getränke $\mathrm{GmbH}$ mit der Intention, gemeinsam regional starke GFGH zu erwerben (VOSSEN, 2001: S. 18). Im Jahr 2003 übernahmen die Brauereien Radeberger, Krombacher und Warsteiner den größten deutschen Getränkefachgroßhändler Trinks mehrheitlich. Als Hauptmotiv für das gesteigerte Interesse an GFGH-Beteiligungen wird der Eintritt der internationalen Braukonzerne Heineken und Interbrew (heute InBev) in den deutschen Markt genannt (Vossen, 2004: S. 44). Die großen Brauereien fürchten den Aufkauf der heimischen Getränkefachgroßhändler durch internationale Braukonzerne und damit die Einflussnahme dieser Unternehmen auf die Distribution, wie es sich z. B. in Frankreich ${ }^{9}$ vollzogen hat (KAHLEN, 2002: S. 33; HolLER/KAHLEN, 2003: S. 26). Der Hauptzweck der Beteiligungen liegt somit in der Sicherung der Absatzwege. Einige deutsche Brauer haben jedoch schon vor dem Eintritt der internationalen Braukonzerne das Potential eines eigenen Fachhandels erkannt. So ist

\footnotetext{
${ }^{9}$ In Frankreich übernahm die niederländische Brauerei Heineken die Brauerei Pécheur/Fischer und kaufte dann in kurzer Zeit die 250 an die Brauerei gebundenen Fachgroßhändler. So wurde die Verhandlungsmacht des GFGH systematisch ausgeschaltet und Heineken sicherte sich seine Distribution. Seither dominieren die Niederländer mit Kronenbourg den französischen Biermarkt (KAHLEN, 2002: S. 33; HOLLER/KAHLEN, 2003: S. 26).
} 
Karlsberg schon jetzt mit etwa 30 Engagements am GFGH beteiligt und hat weitere in Aussicht gestellt. Durch diese Beteiligungen soll die Distribution gesichert und vor allem in der regionalen Gastronomie ausgebaut werden (VosSEN, 2004: S. 44).

Die Beteiligungen und Übernahmen von Getränkefachgroßhändlern durch Brauereien können für die gebundenen Brauereien in Bezug auf die Verhandlungsmacht zu einem ausgeglichenen Verhältnis bis hin zur Kontrolle der Distributionswege führen. Insgesamt wird dadurch die Konzentrationsentwicklung dieses Absatzkanals beschleunigt (KOHLBRÜCK, 2002: S. 17) und die Gefahr einer Benachteiligung der ungebundenen Brauereien erhöht. Insbesondere von kleineren Brauereien wird befürchtet, dass brauereiabhängige Großhändler konkurrierenden Brauereien den Marktzugang erschweren könnten (DEUTSCHER BRAUER-BUND, 2003b: S. 21).

Eine große Zahl der Getränkeabholmärkte (GAM) steht in einem engen Zusammenhang mit dem GFGH, da dieser etwa 7.000 eigene GAM besitzt (Bundesverband Des Deutschen GetränKeFachGroßhandels E.V., 2006). Aus diesem Grund werden die GAM, obgleich sie eine andere Handelsstufe einnehmen, unter einem gemeinsamen Gliederungspunkt mit dem GFGH abgehandelt. Der gesamte Facheinzelhandel mit Getränken verzeichnete 2003 nach der Umsatzsteuerstatistik 11.558 Unternehmen, die einen Umsatz von 5,1 Mrd. € erzielten. Dabei handelt es sich in den meisten Fällen um GAM. Über die genaue Zahl liegen jedoch nur Schätzungen vor. Die GFK weist für das Jahr 200411.890 GAM und damit eine um 2 \% höhere Anzahl als 2003 aus. ACNielsen beziffert die Anzahl auf 9.650, was einen Rückgang gegenüber dem Vorjahr bedeuten würde (INSTITUT FÜR WIRTSCHAFTSFORSCHUNG, 2005a). Beide Ergebnisse verdeutlichen aber den hohen Anteil (ca. 60-72 \%) der GAM, die dem GFGH angehören. Die GAM waren im Jahr 2005 mit knapp einem Drittel am gesamten „Off-premise“ -Bierabsatz beteiligt (vgl. Abbildung 21). Durch die Belieferung bzw. den Verkauf an die Endverbraucher stehen die GAM in direkter Konkurrenz zum LEH. Der direkte Preisvergleich mit diesem überträgt den Preisdruck somit auch auf die GAM, so dass die Brauereien auch auf diesem Absatzweg ähnlichen Konditionen gegenüberstehen. Um diesem direkten Preisvergleich zu entgehen, bietet der GFGH für seine eigenen GAM z. T. auch eigene Handelsmarken an (KuTTENKEULER, 2001: S. 50). 


\subsection{Lebensmitteleinzelhandel}

Der Lebensmitteleinzelhandel als Absatzweg für die Brauereien setzt sich aus dem traditionellen LEH, den Verbrauchermärkten sowie den Discountern zusammen ${ }^{10}$. Abbildung 21 veranschaulicht, dass im Jahr 2005 etwa 68,5 \% des „Off-premise“ Bierabsatzes über den LEH erfolgte (BIRNBAUM, 2005a: S. 8). Insbesondere für Großbrauereien ist der LEH eine wichtige Vertriebsschiene (DEUTSCHER BRAUERBUND, 2003b: S. 14).

Der LEH in Deutschland unterliegt seit einigen Jahren einem beständigen Wandel. So hat sich die Anzahl der Einkaufstätten von 166.250 im Jahr 1970 auf 57.305 im Jahr 2002 reduziert. Insbesondere die Anzahl der kleinen Betriebe des klassischen Einzelhandels ist stark zurückgegangen. Zugenommen haben hingegen die großflächigen Verbrauchermärkte und Discounter (O. V., 2003c: S. 1676). Die aufgezeigte Entwicklung der Betriebsformen wirkt sich negativ auf den realisierbaren Preis für die Brauwirtschaft aus, da besonders die preisaggressiven Anbieter an Bedeutung gewonnen haben. Parallel dazu ist auf Unternehmensebene ein fortlaufender Konzentrationsprozess zu beobachten.

Lag der Anteil der 10 größten LEH am Gesamtumsatz der Branche 1978 noch bei $45 \%$, stieg dieser bis 1990 auf $68 \%$ an (DRESCHER/WEISS, 2001: S. 163ff.). Im Jahr 2004 konnten die Top 5 des LEH (Metro, Rewe, Edeka, Aldi und Schwarz) bereits $64 \%$ des Branchenumsatzes auf sich vereinen. Diesen Top 5 folgten die fünf Unternehmen KarstadtQuelle, Tengelmann, Spar, Leckerland-Tobaccoland und Schlecker, die einen gemeinsamen Marktanteil von 23,5 \% verzeichnen konnten. Das Gewicht der Top 10 lag somit bei etwa 87,8 \% Marktanteil. Insgesamt wurden 2004 von den führenden 30 Unternehmen im LEH 98,2 \% des Branchenumsatzes erwirtschaftet, so dass die übrigen 70 Unternehmen sich mit dem Restanteil von $1,8 \%$ zufrieden geben mussten (BundeSVERBAND DES DeUTSCHEN LEBENSMITTELHANDELS E.V., 2006).

\footnotetext{
${ }^{10}$ Der traditionelle LEH besitzt eine Verkaufsfläche von bis zu $400 \mathrm{~m}^{2}$ mit einem relativ breiten Sortiment von Nahrungs- und Genussmitteln sowie ausgewählten Non-Food-Artikeln. Verbrauchermärkte sind durch eine große Verkaufsfläche zwischen 1000-4000 $\mathrm{m}^{2}$ und durch ein Angebot eines breiten Sortiments auch von weiteren Non-Food-Artikeln gekennzeichnet. Discounter führen dagegen ein begrenztes Sortiment von Waren mit hoher Umschlaggeschwindigkeit unter aggressiver Niedrigpreispolitik (GABLER, 1997: S. 541).
} 
Im Rahmen der Unternehmenskonzentration im LEH kommt es i. d. R. zu einer Zusammenlegung und zentralen Organisation des Einkaufs. Durch eine derartige Bündelung des Einkaufsvolumens erreicht der LEH eine stärkere Verhandlungsposition gegenüber seinen Lieferanten. Mit Blick auf die Brauwirtschaft steht dem stark konzentrierten LEH somit eine Vielzahl von Bieranbietern gegenüber. Der hohe Absatzanteil sowie die große Umsatzbedeutung verstärken die Verhandlungsposition des LEH gegenüber den Brauereien noch weiter. Ferner begünstigen die bestehenden Überkapazitäten in der Braubranche die Macht des LEH, da viele Brauereien zu Preiszugeständnissen bereit sind, um ihre Kapazitäten z. B. mit der Produktion von Handelsmarken auszulasten (vgl. Kapitel 3.2.3.1.5). Mit dem Angebot der Handelsmarken tritt der LEH in direkte Konkurrenz zu den Brauereien, da deren Marken - besonderes die im mittelpreisigen Segment - durch die i. d. R. preisgünstigeren Marken des Handels zusätzlich unter Druck geraten.

Aufgrund der starken Verhandlungsmacht ist es dem LEH gegenüber einem großen Teil der Brauereien möglich, erhebliche Zugeständnisse in der Preis- und Konditionspolitik durchzusetzen, damit die Produkte der Brauereien überhaupt gelistet werden. Die Forderungen des LEH erfolgen meist in Form von Werbekostenzuschüssen. Darunter sind alle Gelder zu verstehen, die von den Brauereien an den Handel fließen. Diese werden im Einzelnen unter verschiedenen Begriffen eingefordert wie z.B. Listungsgebühren, Regalmieten, Gelder zur Verhinderung von Sonderaktionen oder der Auslistung usw. Insgesamt kann man unter diesen Zahlungen Preiszugeständnisse von Seiten der Brauereien verstehen, welche die Einstandspreise z. T. wesentlich verringern (BRUNKEN, 1990: S. 72). Besonders Brauereien ohne eine starke Marke oder solche, die lokale und regionale Biermarken außerhalb des Stammabsatzgebietes vertreiben, stehen dieser Macht fast hilflos gegenüber, da sie sehr leicht austauschbar sind. Brauereien, die über eine starke Marke verfügen, haben eine bessere Verhandlungsposition gegenüber dem LEH, da der Handel aufgrund der starken Nachfrage auf deren Listung häufig nicht verzichten kann (EBBERTZ, 1992: S. 530; VERSTL, 2001: S. 58).

Die Marktmacht des LEH bekommen aber auch die nationalen „Premium-Brauer“ insoweit zu spüren, als ihre Marken häufig mit Sonderpreisaktionen als Frequenzbringer im Handel eingesetzt werden. Diese Vorgehensweise birgt für die Brauereien die Gefahr, dass dadurch das über eine konsequente Preispolitik aufgebaute Markenimage 
und damit die Preisakzeptanz der Konsumenten gefährdet werden (vgl. Kapitel 3.2.3.1.4). Werden Markenbiere in unterschiedlichen Einkaufsstätten $\mathrm{zu}$ deutlich differenzierten Preisen angeboten, neigt der Konsument dazu, das Produkt nur noch zu diesem Aktionspreis zu kaufen und dafür gegebenenfalls die Einkaufsstätte zu wechseln (WIESE, 1993: S. 240).

Auch für die Zukunft ist davon auszugehen, dass der Konzentrationsprozess im LEH weiter voranschreiten wird. So liegt der Marktanteil der Top $10 \mathrm{im} \mathrm{LEH} \mathrm{in} \mathrm{vielen}$ anderen europäischen Ländern (z.B. Frankreich, Österreich, Schweden, Norwegen usw.) bereits heute über $90 \%$ (BUNDESVERBAND DES DEUTSCHEN LEBENSMitTELHANDELS E.V., 2006). Für die Brauwirtschaft ist somit - natürlich auch vor dem Hintergrund des sinkenden Pro-Kopf-Verbrauchs - mit einer weiteren Verschärfung des bzw. mit einem weiterhin sehr hohen Wettbewerbsdruck durch den LEH zu rechnen. Insgesamt sehen die Brauereien den LEH bereits heute als den am stärksten umkämpften Absatzkanal an, in welchem keine Brauerei ohne ein optimales Vertriebskonzept dauerhaft bestehen kann (DEUTSCHER BRAUER-BUND, 2003b: S. 16).

\subsection{Gastronomie}

Die Gastronomie ist neben den bereits aufgezeigten Distributionskanälen ein weiterer wichtiger Absatzweg für die deutsche Brauwirtschaft und ist für den größten Anteil des „On-premise“ -Vertriebs verantwortlich. Die Bedeutung dieses Vertriebskanals ist für die Brauereien je nach Größe sehr unterschiedlich und nimmt mit wachsender Unternehmensgröße i. d. R. deutlich ab. So liegt der Gastronomieanteil am Gesamtabsatz bei den kleineren Brauereien im Durchschnitt bei etwa 40 bis $50 \%$, womit diese sehr stark von der Gastronomie abhängen. Die Großbrauereien hingegen weisen lediglich einen durchschnittlichen Gastronomieanteil von etwa 20 bis $25 \%$ auf (Deutscher Brauer-Bund, 2003b: S. 14; Niederhut-Bollmann, 2005: S. 43).

Nach der Umsatzsteuerstatistik waren 2003 im Gastgewerbe 245.442 Unternehmen tätig, die einen Umsatz von 56,2 Mrd. € erwirtschafteten. Die gesamte Anzahl der Unternehmen im Gastgewerbe gliedert sich in Beherbergungsgewerbe (47.106), Gaststättengewerbe (189.362) sowie Kantinen und Caterer (8.974). Das Gaststättengewerbe lässt sich weiter in speisenorientierte (133.136) und getränkeorientierte Gaststätten (56.199) untergliedern. Die Umsatzentwicklung im Gastgewerbe ist seit Jahren rückläufig, so dass sich viele Betriebe in einer schweren 
Krise befinden (Deutscher Hotel- Und GaStStÄTtenVERBAnd, 2006; O. V., 2002e: S. 1954). Als Folge dieser Entwicklung ist das Gastgewerbe durch einen erheblichen Strukturwandel gekennzeichnet. Besonders davon betroffen sind die traditionellen Formen der biertypischen Gastronomie, wie Eckkneipen, gutbürgerliche Gaststätten oder Schankwirtschaften, welche zunehmend an Bedeutung verlieren (STAUDER, 1995: S. 36). So waren im Jahr 1994 noch etwa 89.400 getränkeorientierte Gaststätten tätig, diese Anzahl hat sich bis 2003 um mehr als 33.000 Betriebe bzw. ca. 37 \% verringert. Die Anzahl der speisenorientierten Gaststätten hat seither hingegen um etwa 12.000 Betriebe bzw. $10 \%$ zugenommen (DEUTSCHER HOTEL- UND GASTSTÄTTENVERBAND, 2006). Besonders erfolgreich in diesem Bereich sind die Systemgastronomien mit internationalem Charakter sowie Fast-Food-Ketten. Bei diesen Konzepten spielt Bier häufig keine oder nur eine sehr geringe Rolle (HUBER, 2002: S. 247). Darüber hinaus wird in der so genannten Erlebnisgastronomie und in Szene-Gaststätten häufig das ertragsschwächere Flaschenbier oder ausländisches Bier konsumiert (O. V., 2002f: S. 408; O. V., 2002c: S. 1455). Insgesamt ist durch die aufgezeigte Entwicklung ein rückläufiger Bierabsatz über das Gastgewerbe zu verzeichnen.

Die Gastronomie hat neben der Bedeutung als Absatzweg noch eine zusätzliche Funktion als Instrument zur Imageprofilierung (BRUNKEN, 1990: S. 68; GOEHLER, 1993: S. 165). So hoffen die Brauer, dass sich positive Ausstrahlungseffekte der Gastronomie auf das Image ihrer Marke übertragen und damit auch der Absatz im Handel positiv beeinflusst wird (MARX, 1998: S. 32). Außerdem fördert die Gastronomie die Markenbekanntheit und gilt als Trendbarometer. Damit ist dieser Vertriebsweg auch für die Neueinführungen von Produkten national distribuierender Markenbrauereien ein optimaler Absatzpartner (O. V., 2000a: S. 1717; HEIMIG, 2003: S. 54). Ein prominentes Beispiel dafür ist die erfolgreiche Markteinführung des Originals der so genannten „Goldbiere“. Dieses Produkt wurde im Jahr 2002 zunächst über die Gastronomie eingeführt (KOHLBRÜCK, 2003: S. 6). Etwa ein halbes Jahr später erfolgte der Absatz über den Handel; der Absatz betrug im Jahr 2005 incl. Gastronomie bereits 720.000 hl (VOSSEN, 2003a: S. 17; VERSTL, 2006: S. 86).

Nicht zuletzt aufgrund des hohen Fassbieranteils ist die Gastronomie trotz des Absatzrückgangs nach wie vor ein interessanter und wichtiger Vertriebsweg für die Brauereien, da das Fassbier durch das höhere Preisniveau in den Gaststätten deutlich 
überdurchschnittliche Erträge pro hl erbringt (EBBERTZ, 1992: S. 522; STAUDER, 1995: S. 35). Die aufgezeigten Gründe erklären den starken Wettbewerb um die imagefördernden Gastronomieobjekte zwischen den Brauereien. So bemühen sich viele Brauereien, diese Objekte durch langfristige Bierlieferungsverträge zu binden. Der Wettbewerb in diesem Bereich wird hauptsächlich durch Zugeständnisse gegenüber diesen Abnehmern in Form von Finanzierungshilfen, Sachzuwendungen oder Serviceleistungen geführt (ROLINCK, 2002: S. 207; MARX, 1998: S. 32f.; BRUNKEN, 1990: S. 167). Diese z. T. sehr hohen Vorleistungen führen dazu, dass die kleinen und mittleren Brauereien i. d. R. nicht mit den großen nationalen und internationalen Wettbewerbern im Markt mithalten können.

Vor dem Hintergrund des hohen Absatzanteils gerade der kleinen und mittleren Brauereien in der Gastronomie lässt sich eine hohe Verhandlungsmacht dieser Abnehmergruppe vermuten. Die Nachfragemacht ist jedoch insoweit eingeschränkt, da sich ein großer Teil der Gastronomieobjekte im Eigentum bzw. Pacht der Brauereien befindet (Hofnagel/KorTManN, 1999: S. 170). Darüber hinaus ist die Abnehmerstruktur stark fragmentiert (DEUTSCHER BRAUER-BUND, 2003b: S. 16) und ein weiterer großer Teil der Gaststätten durch Bierlieferungsverträge (BLV) an die Brauereien gebunden. Durch diese Verträge sichern sich die Brauereien das Recht der alleinigen Belieferung des Gastronomiebetriebes und gewähren im Gegenzug bestimmte Zuwendungen (s. o.). Die Gastronomiebetriebe legen sich mit derartigen Verträgen oft über Jahre auf eine Brauerei fest, wodurch ihre Möglichkeit, den Lieferanten zu wechseln, stark eingeschränkt ist (GOEHLER, 1993: S. 165). Somit nehmen die Brauereien eine befristete Monopolstellung ein; einerseits sichern sie ihren Absatz und andererseits erlangen sie eine gewisse Preissicherheit, da die gebundenen Gaststätten dem Preiswettbewerb der Brauereien untereinander befristet entzogen sind (EBBERTZ, 1992: S. 520).

Im Ergebnis bleibt festzustellen, dass sich die Brauereien gegenüber der Gastronomie in einer wesentlich stärkeren Verhandlungsposition befinden als gegenüber dem GFGH und dem LEH. So wird die Wettbewerbssituation im Gastronomiegeschäft von den Brauereien trotz des sinkendem Volumens auch für die kommenden Jahre als stabil und im Vergleich zu den übrigen Vertriebswegen als einfach eingeschätzt (DEUTSCHER BRAUER-BUND, 2003b: S. 16). 


\subsection{Die Konsumenten}

Der zukünftige Bierverbrauch wird durch eine Vielzahl von Einflussfaktoren bestimmt. So liegen die Hauptursachen für die negative Entwicklung des Bierkonsums zum einen in Veränderungen im Verbraucherverhalten und zum anderen in soziodemografischen Faktoren begründet. $\mathrm{Zu}$ den soziodemografischen Faktoren zählen die Bevölkerungsentwicklung und deren strukturelle Zusammensetzung wie Altersstruktur, Haushaltsgröße, Geschlechteraufteilung etc. Diese Determinanten werden in der vorliegenden Arbeit den Umfeldfaktoren zugeordnet und daher im Kapitel 3.2.3.6 untersucht. Im Mittelpunkt der folgenden Betrachtung stehen die Veränderungen im Verbraucherverhalten (BRUNKEN, 1990: S. 61; DEUTSCHER BRAUER-BUND, 2003b: S. $10)$.

Die Konsumenten haben i. d. R. nur eine indirekte Verhandlungsmacht gegenüber den Brauereien, da sie nicht in direktem Kontakt zu diesen stehen. Ausnahmen dazu bilden lediglich der Heimdienst oder der direkte Vertrieb ab Rampe, die aber nur einen geringen Absatzanteil ausmachen (vgl. Kapitel 3.2.3.3.2) und daher im Weiteren nicht näher analysiert werden. Die Konsumenten nehmen mit ihrem Verhalten als Endverbraucher jedoch Einfluss auf die Gesamtnachfrage sowie die Entwicklung der Produktstruktur in Form von Qualitäts- und Leistungsanforderungen. Das Konsumentenverhalten wird dabei u. a. durch die Persönlichkeit sowie die Wertvorstellungen der einzelnen Verbraucher beeinflusst. Seit einigen Jahren ist eine anhaltende Veränderung des Verbraucherverhaltens festzustellen, welche in einer zunehmenden Orientierung an Gesundheit, Erlebnis und Genuss sowie Individualität ersichtlich wird (HofNAgEL/KORTMAnN, 1999: S. 173; DeUTSCHER BrAUER-Bund, 2003b: S. 10). Diese Änderungen betreffen die Brauereien in besonderem Maße. So substituieren die Konsumenten Bier mehr und mehr durch andere Getränke wie Wasser, Soft Drinks und Wein, welche ihre veränderten Lebensgewohnheiten besser wiedergeben (DEUTSCHER BRAUER-BUND, 2003a: S. 66f.; 2003b: S. 10).

In den letzten Jahren kann, wie oben bereits beschrieben, vermehrt eine Polarisierung (vgl. Kapitel 3.2.3.1.3) des Konsumentenverhaltens beobachtet werden. Diese führt einerseits zu einem gesteigerten Markenbewusstsein, da ein Produkt heute häufig als Statussymbol sowie zur Demonstration von Wohlstand und Karriere dient (HEYSE, 2002a: S. 392). Insbesondere durch das gesteigerte Markenbewusstsein haben die 
Konsumenten eine gewisse Nachfragemacht gegenüber den Absatzmittlern, welche diese an die Brauereien weitergeben (HESSE, 2002: S. 1915). Durch ihre Markenpräferenzen bestimmen die Verbraucher beispielsweise bei den national beworbenen Premiumbieren, welche Produkte sie bei den Absatzmittlern vorfinden wollen. Neben dem steigenden Wunsch nach Qualität und Marke haben die Konsumenten andererseits eine starke Preissensibilität entwickelt. So werden zur Deckung der täglichen Grundbedürfnisse häufig preisgünstige Produkte gesucht, wie anhand der erheblichen Absatzgewinne der Biere im Preiseinstiegsbereich in den letzen Jahren deutlich wird (vgl. Kapitel 3.2.3.1.5). Bei den Konsum- und Billigbieren verlagert sich die Auswahl der Biere auf die Absatzmittler, die diese hauptsächlich nach dem Preiskriterium durchführen (EBBERTZ, 1992: S. 281).

Das Konsumentenverhalten wird von Trendforschern allgemein als multi-optional bezeichnet. So schwankt das Verhalten der Konsumenten je nach Kaufanlass. Dabei stehen einmal Einfachheit, Bescheidenheit und Gesundheit im Vordergrund, ein anderes Mal Genuss, Emotionalität und Luxus (MARX, 1998: S. 21). Unter dieser Entwicklung leidet vor allem die Markentreue, außerdem führt sie zu immer schneller wechselnden Trends und damit zu kürzeren Produktlebenszyklen (GEHRCKENS, 1999: S. 1319). Besonders junge Konsumenten probieren zu verschiedenen Trinkanlässen häufig neue Getränke und Marken (O. V., 2000b, S. 456; RoLINCK, 2002: S. 202). Zudem erhöht gerade diese Konsumentengruppe den Anspruch an die Verpackung in Form von Aussehen, Funktionalität, Gebindeform etc.

Ein weiterer Trend in der Gesellschaft ist der erhöhte Stellenwert des „Erlebens“, wodurch das Reisen $\mathrm{zu}$ einer selbstverständlichen Freizeitbeschäftigung vieler Konsumenten geworden ist. Das Ess- und Trinkverhalten wird durch die Reisen insoweit beeinflusst, als die Verbraucher neue Produkte, wie ausländische Biere oder Weine, kennen lernen, welche sie später mit positiven Urlaubserlebnissen verbindend auch $\mathrm{zu}$ Hause nachfragen. Ingesamt führen die Auslandsaufenthalte $\mathrm{zu}$ einer zunehmenden Internationalisierung des Konsums (DEUTSCHER BRAUER-BUND, 2003b: S. 10), womit eine erhöhte Austauschwahrscheinlichkeit für deutsches Bier einhergeht.

Eine weitere allgemein beobachtbare Entwicklung im Verbraucherverhalten ist die zunehmende Konsumverlagerung von „On-premise“- zum „Off-premise“-Konsum (vgl. 
Tabelle 9). Davon profitieren als Absatzmittler besonders der LEH und die GAM. Anderseits ergeben sich für die Brauereien erhebliche Nachteile, da sie so zunehmend die höheren Erträge im „On-premise“-Bereich - besonders beim Fassbier - verlieren (vgl. Kapitel 3.2.3.3.2.3).

Im Ergebnis kann festgehalten werden, dass die Konsumenten über die Absatzmittler i. d. R. nur eine indirekte Marktmacht gegenüber den Brauereien ausüben. Allerdings erhöht das veränderte Verbraucherverhalten den Druck durch Substitutionsprodukte (vgl. Kapitel 3.2.3.4) und die Anforderungen an die Vermarktung in Form von Innovation, Verpackung und Aufmachung. Der Wandel in den Verbrauchergewohnheiten ist ein Grund dafür, dass der Pro-Kopf-Verbrauch nach Ansicht von Branchenexperten weiter erheblich abnehmen wird. So liegt der Pro-KopfVerbrauch nach deren Prognosen für das Jahr 2007 gerade noch bei 111 Litern und für 2012 sogar nur noch bei 102 Litern (DEUTSCHER-BRAUER-Bund, 2003b: S. 9). Eine solche Entwicklung würde den Kampf um Marktanteile weiter deutlich intensivieren. Die Entwicklung der zunehmenden Preissensibilität der Konsumenten forciert den Preiswettbewerb im deutschen Biermarkt zusätzlich.

\subsubsection{Bedrohung durch Ersatzprodukte}

Unter Ersatzprodukten sind Produkte zu verstehen, die für die Abnehmer die gleiche Funktion wie das Produkt der Branche aufweisen. Die wettbewerbsintensivierende Wirkung besteht in einer Begrenzung des Gewinnpotentials verursacht durch evtl. Absatzeinbußen, erhöhte Werbekosten sowie eingeschränkte Möglichkeiten der Unternehmen, die Preise zu erhöhen (PORTER, 1995: S. 49f.).

Zur Untersuchung der Ersatzprodukte für Bier müssen diese zunächst identifiziert werden. Dabei kommen nach der oben aufgezeigten Definition solche Produkte in Frage, welche die gleiche Funktion wie Bier ausüben. In der vorliegenden Arbeit wird diese Funktion im Erfrischen, Durststillen und aufgrund des Alkoholgehaltes in Entspannung, Kommunikation, Geselligkeit und gegebenenfalls im Berauschen gesehen. Damit kommen als Substitutionsgüter alkoholfreie Getränke wie Mineralwasser, Erfrischungsgetränke und Fruchtsäfte sowie Alkoholgetränke wie Wein Sekt und Spirituosen in Frage (vgl. Tabelle 10). Die sonstigen Getränke wie Kaffee, Tee und Milch, die mit einem Pro-Kopf-Verbrauch von etwa 334 Litern einen großen Anteil des gesamten Getränkeverbrauchs von 7651 im Jahr 2004 ausgemacht haben, bleiben 
außer acht, da von diesen nur ein sehr geringer Substitutionsdruck gegenüber Bier ausgeht (BMVEL, 2005: S. 254; DEUTSCHER BRAUER-Bund, 2003b: S. 10).

\begin{tabular}{|l|ccccc|}
\hline Getränkeart & 2000 & 2001 & 2002 & 2003 & $2004^{\text {a }}$ \\
\hline Alkoholgetränke & $\mathbf{1 5 4 , 2}$ & $\mathbf{1 5 2 , 2}$ & $\mathbf{1 5 1 , 8}$ & $\mathbf{1 4 7 , 3}$ & $\mathbf{1 4 5 , 5}$ \\
Bier & 125,3 & 122,4 & 121,7 & 117,8 & 115,8 \\
Wein & 19 & 19,8 & 20,3 & 19,8 & 20,1 \\
Schaumwein & 4,1 & 4,2 & 3,9 & 3,8 & 3,8 \\
Spirituosen & 5,8 & 5,8 & 5,9 & 5,9 & 5,8 \\
\hline Alkoholfreie Getränke & $\mathbf{2 5 3 , 1}$ & $\mathbf{2 6 1 , 5}$ & $\mathbf{2 7 3 , 2}$ & $\mathbf{2 9 1 , 8}$ & $\mathbf{2 8 4 , 8}$ \\
Wasser & 106,8 & 113,6 & 120 & 135 & 131,3 \\
Erfrischungsgetränke & 105,7 & 107,4 & 112,8 & 114,8 & 113,2 \\
Fruchtsäfte/Nektare & 40,6 & 40,5 & 40,4 & 42 & 40,3 \\
\hline
\end{tabular}

${ }^{\text {a) }}$ Vorläufig - ${ }^{\text {b) }}$ Ohne Kaffee, Tee und Milch.

Tabelle 10: Verbrauch von Getränken in Deutschland (Liter pro Kopf und Jahr)

Quelle: BMVEL, 2005: S. 254

Die alkoholfreien Getränke, insbesondere Wasser und Erfrischungsgetränke, haben in den letzten Jahren ein erhebliches Wachstum erzielen können. Die Tabelle 10 zeigt die Entwicklung seit dem Jahr 2000. Wird ein etwas größerer Zeitraum betrachtet, so stellt man fest, dass der Wasserverbrauch im Jahr 1991 beispielsweise noch bei 79 Litern pro Kopf und Jahr lag und bis zum Jahr 2004 auf etwa 131 Liter gestiegen ist (DEUTSCHER BRAUER-Bund, 2003a: S. 66; BMVEL, 2005: S. 254). Der gesteigerte Konsum von Wasser und Erfrischungsgetränken kann hauptsächlich auf die seit einigen Jahren ausgesprochenen Empfehlungen der Mediziner zurückgeführt werden, möglichst zwei bis drei Liter am Tag zu trinken. Weiterer Gründe sind die strengeren Alkoholgrenzen im Straßenverkehr sowie die Innovationskraft der Anbieter (DEUTSCHER BRAUERBund, 2003b: S. 10). So sind in den letzten Jahren z. B. viele neue Produkte auf den Markt gekommen, die den Konsumenten den Wunsch nach Gesundheit, Wellness und Convenience (z.B. wiederverschließbare PET-Wasserflasche) erfüllen. Auch für die Zukunft wird ein weiterer Ausbau von Marktanteilen in diesem Bereich erwartet (O. V., 2002g: S. 1953).

Die Veränderungen im Verbraucherverhalten (vgl. Kapitel 3.2.3.3.3) stehen in einem engen Zusammenhang mit der Substitution von Produkten. So substituieren die Konsumenten Bier mehr und mehr durch Getränke, die ihren veränderten Lebensstilen und Einstellungen besser entsprechen. Daher haben Softdrinks und Mineralwasser steigende Marktanteile zu verzeichnen (37,18 \% in 2004; $30 \%$ in 1991), während 
alkoholhaltige Getränke Marktanteile verlieren $(19,06 \%$ in $2004 ; 26,2 \%$ in 1991) (Deutscher BRAUER-Bund, 2003a: S. 66; BMVEL, 2005: S. 254). Aber auch innerhalb der Gruppe der alkoholhaltigen Getränke kommt es zu Verschiebungen. Mit Blick auf den quantitativen Verbrauch nimmt Bier mit einem Anteil von etwa $80 \%$ mit Abstand den ersten Platz ein. Während der Bierabsatz in den letzten Jahren jedoch erheblich gesunken ist, konnte Wein seit dem Jahr 2000 ein Absatzplus von etwa 5,5\% verzeichnen. Ein Vergleich der Verbrauchsausgaben für alkoholhaltige Getränke im Haushaltsbereich zeigt, dass Bier Anteile an Wein und alkoholische Mischgetränke verloren hat (BIRNBAUM, 2004: S. 8). So steht Wein für einen kultivierten, zeitgemäßen und gesunden Lebensstil und ersetzt aufgrund dieser Attribute für viele Verbraucher $z$. B. bei Restaurantbesuchen das Bier (HeYSE, 2003: S. 30). Von Seiten der Marktforschung wird die erhöhte Nachfrage als Ergebnis des wachsenden Gesundheitsbewusstseins gesehen, da dem maßvollen Konsum von Wein eine positive Wirkung auf die Gesundheit zugesprochen wird (O. V., 2002h: S. 1231).

Der Konsum von Spirituosen liegt seit dem Jahr 2000 recht konstant bei 5,8 1 pro Kopf und Jahr. Allerdings ist auch in dieser Produktgruppe in den letzten Jahren ein zunehmender Austausch von klassischen Spirituosen durch Mischgetränke aus Spirituosen, so genannten Alcopops oder Ready-to-Drinks, zu beobachten (DEUTSCHER BRAUER-BUND, 2003b: S. 10). Diese Mixgetränke zielen besonders auf jüngere Verbraucher und Frauen ab, womit sie in direkter Konkurrenz zu den Produkten der Brauereien wie den „Goldbieren“ und den Biermischgetränken stehen (SCHMIDTAuerbach, 2003: S. 44; LAtz-Weber, 2003c: S. 50; Vossen, 2003b: S. 58). Auch für die Zukunft wird mit einem signifikanten Wachstum dieser Getränkegruppe gerechnet (DEUTSCHER BRAUER-BUND, 2003b: S. 10).

Zusammenfassend kann festgestellt werden, dass die Substitutionsgefahr durch alkoholhaltige Getränke wie Wein und Alcopops auch in Zukunft als hoch eingestuft werden muss. Aber auch der Druck der alkoholfreien Getränke, besonders des Mineralwassers und der Erfrischungsgetränke, wird aufgrund der oben beschriebenen Veränderungen im Konsumentenverhalten weiterhin hoch bleiben.

\subsubsection{Verhandlungsmacht der Lieferanten}

Die Verhandlungsmacht der Lieferanten kommt dadurch zum Ausdruck, inwieweit diese die Preise erhöhen, die Qualität ihrer Produkte senken oder den Abnehmern 
Lieferbedingungen vorschreiben können (PORTER, 1995: S. 54f.). Eine Erhöhung der Einkaufspreise führt bei den Brauereien zu Kostensteigerungen, welche diese aufgrund der angespannten Branchensituation nur schwer an ihre Abnehmer weitergeben können.

Die Herstellung von Bier ist nach dem deutschen Reinheitsgebot ausschließlich auf die Rohstoffe Hopfen, Malz, Hefe und Wasser beschränkt. Für den Produktionsprozess sind darüber hinaus weitere Faktoren wie Energie und Maschinen notwendig. Außerdem werden für die Abfüllung Packmaterial wie Flaschen und Dosen, Bierkästen, Fässer etc. benötigt. Im Folgenden werden die wichtigsten Beschaffungsgüter der Brauwirtschaft wie Malz, Hopfen sowie Verpackungsmittel hinsichtlich ihrer Lieferantenmacht untersucht. Die übrigen Produktionsfaktoren finden keine Berücksichtigung, da sie entweder nur einen geringen Anteil am Beschaffungsvolumen ausmachen, nur selten beschafft werden müssen oder nicht ohne weiteres frei gehandelt werden wie z. B. Wasser aufgrund eigener Brunnenanlagen (HoFNAGEL/KoRTMANN, 1999: S. 178).

Zunächst zum Malz, bei dem es sich um eines der drei Hauptbestandteile des Bieres handelt. So werden zur Produktion von einem Hektoliter Bier etwa $17 \mathrm{~kg}$ Malz benötigt, welches wiederum aus etwa $22 \mathrm{~kg}$ Braugetreide gewonnen wird. Als Braugetreide wird zu 95 \% Braugerste verwendet, Roggen, Weizen und Dinkel spielen somit nur eine untergeordnete Rolle (CMA, 2006). Nach Angaben des Deutschen Mälzerbundes e. V. waren in Deutschland im Jahr 2003 etwa 50 malzproduzierende Unternehmen tätig, die ca. 2,1 Mio. t Malz hergestellt haben. Von dieser Menge wurden etwa $30 \%$ exportiert. Mit Blick auf die Produktionsmenge lag Deutschland damit nach China und den USA an dritter Stelle in der weltweiten Malzproduktion (O. V., 2004b: S. 93). Seither ist die Malzproduktion in Deutschland jedoch erheblich gesunken, so dass diese im Jahr 2005 nur noch etwa 1,85 Mio. $\mathrm{t}$ erreichte. Ursachen für diesen starken Rückgang sind zum einen in dem geringeren heimischen Malzbedarf und zum anderen im stark rückläufigen Export zu sehen (O. V., 2006d: S. 209). Der Drittlandlandexport ist in den letzen Jahren zunehmend schwieriger geworden, da der Druck durch neue Kapazitäten ausländischer Konkurrenten, z. B. aus den Niederlanden, Frankreich und Dänemark, deutlich zugenommen hat (HERMANNSEN, 2005). Die Folge dieser Entwicklung sind erhebliche Überkapazitäten, die wiederum zu einem härteren Verdrängungswettbewerb führen, der in erster Linie über den Preis ausgetragen wird. (HofNAGEL, 2005; O. V., 2004b: S. 93). 
Ingesamt bleibt festzustellen, dass die Verhandlungsmacht der Mälzereien gegenüber den Brauereien als gering eingestuft werden kann (HERMANNSEN, 2005), da Malz in ausreichender Menge zur Verfügung steht und die deutschen Mälzer durch ausländische Wettbewerber zusätzlich unter Druck stehen. Allerdings muss beachten werden, dass es sich bei Malz um ein Naturprodukt handelt und die Preise in Abhängigkeit von der Braugetreideernte stark schwanken können. Die Gefahr großer Preisschwankungen können die Brauereien aber durch Kontrakte absichern.

Der Hopfen hat auf vielfältige Art Einfluss auf den Brauprozess. So verleiht er dem Bier einen feinbitteren Geschmack und sorgt gleichzeitig für eine natürliche Haltbarkeit. Außerdem beeinflussen die ätherischen Öle des Hopfens das Aroma des Bieres (CMA, 2006). Beim Hopfen kann nach den folgenden drei Sortengruppen unterschieden werden: feiner Aromahopfen, Aromahopfen sowie Bitterhopfen bzw. Hochalphahopfen. Je nach Produktvariante des Bieres werden unterschiedliche Sorten verwendet, die sich in ihren Alphasäuregehalten unterscheiden. Im Jahr 2004 konnten in Deutschland etwa 1.698 Hopfenanbaubetriebe mit einer Gesamtanbaufläche von 17.476 ha gezählt werden. Mit einem Anteil von 37,7 \% an der Weltalphaproduktion war Deutschland im Jahr 2004 vor den USA (33,2 \%) und China (15,8 \%) der größte Alphaproduzent der Welt (BARTH \& SOHN, 2004/2005: S. 9ff.). Es ist jedoch zu beobachten, dass sowohl die Anzahl der Betriebe in Deutsachland als auch die Gesamtanbaufläche seit Jahren stark rückläufig ist. So gab es im Jahr 1996 noch 2.947 Betriebe, die eine Fläche von etwa 21.800 ha bewirtschafteten (DEUTSCHER BRAUER-BUnd, 2003a: S. 92). Diese Entwicklung ist auf erhebliche Hopfenüberschüsse sowie niedrige Preise zurückzuführen. Gründe dafür sind immer höhere Erträge pro ha, anhaltend sinkende Hopfengaben ${ }^{11}$ in der Bierproduktion, der geringere Bedarf der deutschen Brauereien aufgrund des Bierkonsumrückgangs, die Verhandlungsmacht der Großbrauereien sowie die schwachen Dollarkurse in den jüngeren Vergangenheit, welche die deutsche Ware im Verhältnis zu den USA verteuerten (DEUTSCHER HOPFENWIRTSCHAFTSVERBAND E.V., 2006). Insgesamt ist das Hopfenpreisniveau in Deutschland sehr niedrig, so dass die Preise z. T. sogar unter den Gehstehungskosten liegen (o. V., 2002i: S. 593; BARTH \& SoHN, 2004/2005: S. 7). Vor dem Hintergrund sich weiter stark entwickelnder

11 In vielen Wachstumsmärkten wie beispielsweise China wird das Bier aufgrund der Geschmackspräferenzen der Konsumenten nicht so stark gehopft (DEUTSCHER HOPFENWIRTSCHAFTSVERBAND E.V., 2006). Aber auch in den Industrieländern hat sich ein Verbrauchertrend zu weniger gehopften Bieren, welche sich durch einen milderen, weniger herben Geschmack auszeichnen, herausgebildet. 
Biermärkte in China und Osteuropa kann für die Zukunft von einer steigenden Nachfrage nach Hopfen auf dem Weltmarkt ausgegangen werden (BARTH \& SOHN, 2004/2005: S. 23). Aufgrund der noch brachliegenden Potentiale in der Hopfenwirtschaft (siehe Flächenreduktion) dürfte sich die Verhandlungsposition der Hopfenlieferanten dadurch mittel- bis langfristig jedoch nicht entscheidend verbessern.

Im Ergebnis bleibt festzustellen, dass die Verhandlungsmacht der Hopfenlieferanten gegenüber den Brauereien aufgrund des hohen Angebotes, der abnehmenden Nachfrage in Deutschland sowie des Konkurrenzdrucks z.B. aus den USA als niedrig eingestuft werden kann. Allerdings muss auch beim Hopfen beachtet werden, dass es sich wie beim Malz um ein Naturprodukt handelt, dessen Preis je nach Erntemenge stark schwanken kann. Aber auch in diesem Fall können Preisschwankungen durch Kontrakte abgesichert werden.

Auch der Markt für Verpackungsmittel wie Flaschen und Dosen hat sich in den letzten Jahren stark verändert. Durch das Pflichtpfand auf Einweg-Getränkeverpackungen hat sich die Nachfrage nach Verpackungen von den meisten Herstellern in der Getränkebranche verschoben. So haben beispielsweise die Weißblechdosen von 2003 bis 2004 rund $25 \%$ Marktanteil verloren. Insgesamt wurden $8 \%$ weniger Weißblechverpackungen hergestellt, da auch Konservendosen unter Substitutionsdruck durch gekühlte Verpackungen in thermogeformten Kunststoffverpackungen stehen. Ähnliche Einbußen hatte die Glasindustrie zu verzeichnen, die etwa um $8 \%$ bei Flaschen und ca. um $6 \%$ bei Konservenglas schrumpfte (o. V., 2006e). Besonders stark hat der Glasanteil bei Wasserflaschen abgenommen. Diese Entwicklung ist jedoch nicht primär auf das Einwegpfand zurückzuführen, sondern vielmehr auf einen generellen Trend zu PET in diesem Bereich. Wurden bis vor einigen Jahren noch etwa 3 Mrd. Wasserflaschen aus Glas pro Jahr produziert, sind es heute weniger als 1 Mrd. (O. V., 2005d). Die Folge dieser Entwicklung sind erhebliche Überkapazitäten, die im Jahr 2005 bereits z. T. durch Stilllegungen abgebaut wurden (O. V., 2006e). Mit Blick auf die Brauindustrie ist die Nachfrage nach Mehrweggebinden seit 2003 deutlich gestiegen, während die Nachfrage nach Dosen und Einwegflaschen spürbar abnahm (vgl. Kapitel 3.2.2; Tabelle 3). Darüber hinaus öffnete sich der Weg für eine für die deutsche Brauwirtschaft neue Gebindeform - die PET-Flasche (KROST, 2004a: S. 3). Diese wurde insbesondere durch die Discounter aufgenommen, die nach der Einführung des 
Dosenpfandes die betroffenen Getränke ausgelistet hatten und nach einer Alternative suchten (KROST, 2004b: S. 2).

Die Glasflasche ist in der Brauindustrie mit einem Absatzanteil von ca. 68 \% (Mehrweg und Einweg) im Jahr 2004 nach wie vor die häufigste Verpackung, gefolgt von der Dose mit etwa $10 \%$. Den Flaschen- als auch den Dosenlieferanten kann vor dem Hintergrund der oben aufgezeigten Entwicklung sowie einer prognostizieren weiteren Verringerung des Bierabsatzes nur eine geringe Verhandlungsmacht gegenüber den Brauereien attestiert werden. Gleiches gilt für die Lieferanten von PET-Flaschen, da diese Flaschen nur einen sehr geringen Absatzanteil ausmachen.

Zusammenfassend kann festgestellt werden, dass die Verhandlungsmacht der Lieferanten der wichtigsten Beschaffungsgüter in der Brauwirtschaft als gering einzustufen ist. Die Hauptgründe dafür sind der rückläufige Biermarkt in Deutschland, die bestehenden Überkapazitäten der Zulieferer sowie die daraus resultierende gesicherte Verfügbarkeit der zu beschaffenden Produkte.

\subsubsection{Umfeldanalyse}

Im Rahmen der Umfeldanalyse werden die soziodemographischen sowie die politischen und rechtlichen sowie die ökonomischen Einflüsse untersucht. Veränderungen dieser Rahmenbedingungen können indirekt Einfluss auf die Wettbewerbsentwicklung nehmen, indem sie auf die einzelnen wettbewerbsbestimmenden Faktoren einwirken.

\subsection{Soziodemographische Umfeldfaktoren}

Die soziodemographischen Faktoren gehören zu den Hauptgründen für die negative Entwicklung des Bierkonsums. Sie beinhalten die Bevölkerungsentwicklung und deren strukturelle Zusammensetzung wie Altersstruktur, Haushaltsgröße sowie die Geschlechteraufteilung.

Im Jahr 2003 hatte Deutschland etwa 82,5 Mio. Einwohner. Nach Prognosen ${ }^{12}$ des Statistischen Bundesamtes wird die Bevölkerungszahl nach einem geringen Anstieg auf

\footnotetext{
${ }^{12}$ Es handelt sich dabei um die „mittlere Variante“ einer Vorausberechnung, der die folgenden Annahmen zu Grunde liegen: Konstante Geburtenhäufigkeit von durchschnittlichen 1,4 Kindern pro Frau, Erhöhung der Lebenserwartung bei Geburt bis zum Jahr 2050 für Jungen auf 81,1 Jahre und bei Mädchen auf 86,6
} 
83 Mio. ab dem Jahr 2013 zurückgehen und bis zum Jahr 2050 auf das Niveau des Jahres 1963 (gut 75 Mio. Einwohner) sinken. $\mathrm{Zu}$ diesem langfristigen Bevölkerungsrückgang kommt es, da in Deutschland - wie schon in den vergangenen 30 Jahren - auch in den nächsten fünf Jahrzehnten stets mehr Menschen sterben werden als Kinder zur Welt kommen (Statistisches Bundesamt, 2003a: S. 5ff.). Ohne die Zuwanderung und die große Zahl der eingebürgerten Ausländer wäre schon vor langer Zeit ein deutlicher Bevölkerungsrückgang $\mathrm{zu}$ verzeichnen gewesen. Durch den Bevölkerungsrückgang wird die Anzahl der potentiellen Biertrinker abnehmen. Außerdem kann der größer werdende Anteil der Ausländer dazu führen, dass Bier vermehrt durch andere Getränke ersetzt wird. Während es sich bei Bier für viele Deutsche um ein traditionelles Getränk handelt, haben viele Einwanderer gänzlich andere Ess- und Trinkgewohnheiten.

Neben der Einwohnerzahl verändert sich auch die Altersstruktur der Bevölkerung. Aufgrund der rückläufigen Geburtenentwicklung und des medizinischen Fortschritts wird es zukünftig weniger junge und immer mehr ältere Einwohner geben. Auch diese Verschiebung wird sich negativ auf die Biernachfrage auswirken, da die jeweiligen Altersgruppen unterschiedliche Bedürfnisse und Intensitäten in Bezug auf den Konsum aufweisen. So nimmt der Getränkekonsum mit fortschreitendem Alter stetig ab (GEHRCKENS, 1999: S. 1319). Die Gruppe der Konsumenten im Alter zwischen 15 und 34 Jahren, die als Hauptverbrauchergruppe für Bier angesehen werden kann, ist in den letzten Jahren um $11 \%$ auf einen Bevölkerungsanteil von nur noch $25 \%$ gesunken. Prognosen gehen davon aus, dass dieser Anteil sich in den nächsten 5 Jahren um weitere $7 \%$ auf $18 \%$ verringern wird (STATISTISCHES BUNDESAMT, 2003b: S. 55; CREDIT SUISSE/FIRST BOSTON, 2003: S. 6). Aufgrund des weiteren Rückgangs dieser sehr konsumfreudigen Bevölkerungsgruppe ist damit $\mathrm{zu}$ rechnen, dass der Pro-KopfVerbrauch sowie der gesamte Inlandsabsatz in Zukunft weiter zurückgehen werden. Diese Entwicklung wird außerdem dadurch verschärft, dass sich der Anteil der Jugendlichen und jungen Erwachsenen, die mindestens einmal die Woche Bier trinken, drastisch reduziert hat. Während 1973 noch $42 \%$ dieser Gruppe mindestens einmal die Woche Bier tranken, waren es im Jahr 2001 nur noch $23 \%$ (DEUTSCHER BRAUERBUND, 2003a: S. 68).

Jahre und ein jährlicher positiver Wanderungssaldo von rund 200.000 Personen (STATISTISCHES BUNDESAMT, 2003a: S. 5ff.). 
Auch mit Blick auf die Verteilung des Bierkonsums zwischen den Geschlechtern zeigen sich deutliche Unterschiede. Allerdings kommen in diesem Zusammenhang verschiedene Studien zu recht uneinheitlichen Ergebnissen. Während nach einer Studie der GfK $55 \%$ der ca. 42,1 Mio. Frauen in Deutschland Bier trinken, sind es nach Ergebnissen des Marktforschungsinstituts Mintel lediglich $30 \%$. Der Anteil der insgesamt etwa 40,3 Mio. Männer, die Bier trinken, liegt nach beiden Studien deutlich höher. So sind dies nach Mintel etwa 69 \% und laut GfK sogar 86 \%. Darüber hinaus ist ein deutlicher Unterschied in der Konsumintensität $\mathrm{zu}$ verzeichnen. So wird das Gesamtverbrauchsvolumen der Frauen auf lediglich etwa sechs bis sieben Mio. hl im Jahr geschätzt, so dass die weitaus größere Menge von ca. 90 Mio. hl auf die Männer entfällt (O. V., 2003a: S. 38; O. V., 2002h: S. 1231). Insgesamt wird deutlich, dass die Frauen als Konsumentengruppe für Bier noch ein erhebliches Potential darstellen, welches es durch Marketing und neue Produkte zu heben gilt.

Ein weiterer Trend, der die Brauwirtschaft betrifft, sind die Veränderungen in der Struktur der Haushalte. So ist deren Anzahl (39,1 Mio. im Jahr 2004) in den letzten Jahren zunehmend gestiegen, während die durchschnittliche Haushaltsgröße sich fortlaufend verkleinert hat. Die Folge daraus ist, dass die Haushaltsstruktur durch immer kleinere Haushalte geprägt wird; im Jahr 2004 lag der Anteil der Zwei-PersonenHaushalte bereits bei $34 \%$ und der der Einpersonenhaushalte sogar bei etwa $37 \%$ (StATISTisches BundeSAMT, 2005). Diese Entwicklung hat zwar keinen bedeutenden Einfluss auf die Höhe des absoluten Bierkonsums, sie hat jedoch Auswirkungen auf die Bedarfsstruktur und das Kaufverhalten und fördert so z. B. die Nachfrage nach kleineren Gebinden.

\subsection{Politische und rechtliche Umfeldbedingungen}

Die politischen und rechtlichen Rahmenbedingungen wirken in vielfältiger Weise auf die Brauwirtschaft ein. Aus der Vielzahl der Rechtsvorschriften, die die Brauwirtschaft direkt oder indirekt betreffen, werden im Folgenden nur die herausgegriffen, welche in der aktuellen Diskussion stehen und Einfluss auf die Wettbewerbsintensität haben. Dazu zählen die Umweltpolitik, die Finanzpolitik, die Verkehrspolitik sowie die Alkoholpolitik. 
Die Umweltpolitik hat von allen Gesetzgebungsbereichen in den letzten Jahren den größten Einfluss auf die Brauwirtschaft ausgeübt. Dabei muss zunächst zwischen solchen Maßnahmen differenziert werden, die für alle Wirtschaftszweige gleichermaßen gelten, wie z. B. die Ökosteuer, und solchen, welche die Brau- und Getränkewirtschaft im Speziellen betreffen. Dazu zählt die seit 1991 geltende Verpackungsverordnung, mit welcher der Gesetzgeber vor dem Hintergrund des steigenden Abfallvolumens versucht, über eine Mehrwegquote die Menge der Einwegverpackungen zu reduzieren. Seit dem 1. Januar 2003 gilt zusätzlich ein Pflichtpfand auf Dosen und einigen anderen Einwegverpackungen für bestimmte Getränke. Dazu zählen jegliche Varianten von Bier einschließlich Biermischgetränken, Mineralwasser mit und ohne Kohlensäure sowie Erfrischungsgetränke mit Kohlensäure. Als Kriterium für die Bepfandung gilt nicht ausschließlich die Verpackung, sondern auch der Inhalt. So bestehen Ausnahmeregelungen für Wein, Sekt, Spirituosen und deren Mischgetränke. (BUNDESMINISTERIUM FÜR UMWELT, NATURSCHUTZ UND REAKTORSICHERHEIT, 2004). Nach einer Novellierung der Verpackungsverordnung können ab dem 1. Mai 2006 leere Einwegflaschen und Dosen überall dort zurückgegeben werden, wo Einweg verkauft wird (O. V., 2005e: S. 1076). Außerdem wird es ein einheitliches Zwangspfand von 25 Cent für ökologisch nachteilige Einweg-Getränkeverpackungen geben, welches auch auf Alkopops, Eistee und sonstige Erfrischungsgetränke erweitert wird (O. V., 2005f).

Die Einführung des Einwegpfandes führte $\mathrm{zu}$ erheblichen Verschiebungen und Umstrukturierungen in der Brauwirtschaft. So brach der Bierabsatz in Einwegverpackungen im Jahr 2003 deutlich ein, da der LEH auf die Pfandverordnung vielfach mit Auslistungen reagierte. Der Dosenbierabsatz bei den deutschen Brauereien ging beispielsweise im ersten Halbjahr 2003 um bis zu 81 \% zurück (VOSSEN, 2003c: S. 14). Insbesondere Brauereien, deren Einweganteil deutlich über dem Durchschnitt lag, konnten ihre Verluste in vielen Fällen nicht mit einem höheren Absatz im Mehrwegbereich ausgleichen und gerieten so in finanzielle Schwierigkeiten. Andererseits konnten gerade viele kleinere und mittlere Brauereien, die aus wirtschaftlichen Gründen häufig nur Mehrweg abfüllen können und daher auf einen stabilen Markt in diesem Bereich angewiesen sind, durch das Pflichtpfand gewinnen (O. V., 2005g: S. 256). Aufgrund der Novellierung der Verpackungsverordnung kann sich diese Entwicklung ab Mai 2006 auch in der Brauwirtschaft wieder ins Gegenteil kehren. So zeigt sich schon heute, dass das bepfandete Einweg auf Kosten von Mehrweg kräftig 
an Marktanteilen gewinnen wird (Vossen, 2006). Bereits im Vorgriff auf das einheitliche Einweg-Rücknahmesystem haben sowohl der LEH, vor allem aber die Discounter, alkoholfreie Getränke in Einweg großflächig wieder eingelistet und bauen ihr Einwegsortiment kontinuierlich weiter aus (O. V., 2006f: S. 87). Inwieweit dieser Trend auch die Brauwirtschaft erreichen wird, bleibt abzuwarten; große Brauereien in Deutschland bereiten sich aber schon auf das „Revival der Bierdose“ vor (VossEN, 2006).

Auch im Rahmen der Finanzpolitik nimmt der Staat über das Biersteuergesetz Einfluss auf die Wettbewerbssituation in der Brauwirtschaft. Die Steuerschuld einer Brauerei errechnet sich aus dem Gesamtjahresausstoß und dem Stammwürzegehalt des Bieres. Kleine und mittlere Brauereien mit einer Gesamtjahreserzeugung von weniger als 200.000 Hektoliter können ermäßigte Steuersätze in Anspruch nehmen. Voraussetzung dafür ist, dass die Brauereien rechtlich und wirtschaftlich unabhängig sind. Der durch diese Steuerermäßigung ausgestaltete Schutz kleinerer Brauereien dient als strukturfördernde Maßnahme (DEUTSCHER BRAUER-BUND, 2003a: S. 147). In Abhängigkeit von der Jahreserzeugung kann sich der Regelsteuersatz anhand einer Mengenstaffel um bis zu $44 \%$ reduzieren. Dabei werden sog. Staffelsteuersätze zugrunde gelegt (ZoLL, 2006). Mit Wirkung zum 1. Januar 2004 wurde das Biersteuergesetz insoweit verändert, dass die ermäßigten Steuersätze der Brauereien bis 200.000 hl Gesamtjahreserzeugung um zwölf Prozent erhöht wurden und somit nur die kleinen und mittleren Unternehmen von dieser Maßnahme betroffen sind. Hintergrund der Biersteuererhöhung war das von der Politik vorgelegte Papier „Subventionsabbau im Konsens“, wonach der Abbau von Subventionen über alle Bereiche von maximal $12 \%$ erreicht werden sollte. Naturgemäß handelt es sich nach Ansicht von Vertretern der brauwirtschaftlichen Verbände bei den abgestuften Steuertarifen nicht um eine Subvention (HAHN, 2004: S. 270f.). Sie sind weiter der Auffassung, dass es durch die Erhöhung der Biersteuer zu erheblichen Belastungen der mittelständischen Betriebe komme, welche angesichts der ohnehin geringen Renditen der Branche zu einer Gefährdung vieler Brauereien führe. Zusätzlich wurde angemerkt, dass die Entwicklung im Bereich der Biersteuer die Benachteiligung des Bieres gegenüber dem mit Steuern unbelasteten Wein zusätzlich verstärkt (O. V., 2004c: S. 51). Aus den aufgezeigten Gründen reichte der DEUTSCHE BRAUER-BUND ein Musterklageverfahren gegen die 
Biersteuererhöhung ein. So bleibt offen, ob dieses Gesetz Bestand haben und langfristig den Strukturwandel in der Brauwirtschaft weiter vorantreiben wird.

Eine weitere Entwicklung, welche die Biersteuer nachhaltig erhöhen kann, ist auf Pläne der Europäischen Kommission zurückzuführen. Diese sehen eine Anhebung des Mindeststeuersatzes für Bier vor. So kommt die Kommission zu dem Schluss, dass es einer stärkeren Annäherung der unterschiedlich hohen Verbrauchssteuersätze, also auch der Biersteuer, in den einzelnen Mitgliedsstaaten bedürfe, um das Ausmaß an Wettbewerbsverzerrungen und Steuerbetrug zu verringern (O. V., 2006g: S. 170). Eine Realisierung dieser Pläne würde in Deutschland auf eine Erhöhung des Regelsteuersatzes für Bier von rund $30 \%$ hinauslaufen. Eine derart hohe Steuererhöhung würde die deutsche Brauwirtschaft weiter unter Druck setzen und als Folge eines daraus resultierenden höheren Bierpreises die Substitutionsgefahr z. B. durch Wein weiter erhöhen.

Auch die für den 1. Januar 2007 beschlossene Umsatzsteuererhöhung von drei Prozentpunkten wird die Brauwirtschaft nach Ansicht von Branchenexperten erheblich belasten. So leidet die Branche, wie oben aufgezeigt, bereits heute unter der in Deutschland vorherrschenden Konsumzurückhaltung in Handel und Gastronomie. Eine Erhöhung der Umsatzsteuer würde die Kaufkraft der Verbraucher verringern und den Absatz des in Deutschland mit dem vollen Mehrwertsteuersatz von $16 \%$ belegten Bieres weiter belasten. Hinzu kommt, dass die Umsatzsteuererhöhung auch auf die Biersteuer erhoben wird, was zu einer weiteren Benachteiligung gegenüber dem Wein führt (o. V., 2005h: S. 919).

Die Verkehrspolitik mit der daraus resultierenden Gesetzgebung hat ebenfalls Einfluss auf die Situation in der Brauwirtschaft. So hat sich die Herabsetzung der Promillegrenze von 0,8 auf 0,5 Promille negativ auf den Bierkonsum ausgewirkt und den Konsum von alkoholfreien Getränken in der Gastronomie beflügelt. Außerdem wird dadurch die Verlagerung des Alkoholkonsums vom „On-premise“- zum „Off-premise“-Bereich (vgl. Kapitel 3.2.3.3.2) gefördert. Die Einführung der aktuell diskutierten Null-PromilleGrenze für Fahranfänger würde diese Entwicklung weiter verschärfen (DEUTSCHER BRAUER-Bund, 2005a). Darüber hinaus hatte auch die Einführung der LKW-Maut negative Folgen für die Brauwirtschaft, da sich dadurch die Transportkosten deutlich 
erhöht haben und diese Kosten nicht ohne weiteres an die Kunden weiter gegeben werden konnten.

Mit Blick auf die Alkoholpolitik ist derzeit eine Verschärfung bereits bestehender Tendenzen festzustellen. So gerät der Alkohol mehr und mehr in den Blickpunkt der Verbraucherschützer, Verkehrs-, Familien-, Gesundheits- und Finanzpolitiker. Neben der bereits oben beschriebenen Entwicklung werden aktuell sowohl auf europäischer als auch auf nationaler Ebene folgende Themen diskutiert: Eine Erhöhung des Abgabealters auf 18 Jahre für alle alkoholhaltigen Getränke, eine Eingrenzung der Verkaufsstellen und -zeiten, Verkaufsmonopole, Werbeverbote für Alkohol sowie eine Erhöhung der Alkoholsteuern (O. V., 2005i: S. 462; DeUTSCHER BRAUER-BUND, 2005a). Sollte es zu einer Umsetzung eines oder mehrerer dieser Vorschläge kommen, hätte dieses stark negative Folgen für die deutsche Brauwirtschaft. So würde beispielsweise ein Werbeverbot für Alkohol die Marketingmöglichkeiten der Braubranche und damit die Möglichkeiten der Differenzierung von den Wettbewerbern erheblich einschränken. Darunter würden hauptsächlich die Markenbierbrauer leiden, da es diesen kaum noch möglich wäre, eine erhöhte Zahlungsbereitschaft aufgrund der Marke beim Verbraucher zu erzeugen.

\subsubsection{3 Ökonomische Umfeldbedingungen}

Von der allgemeinen wirtschaftlichen Lage sind der Handel, die Gastronomie sowie die Brauereien im gleichen Maße betroffen. Der Umfang des privaten Konsums hat in den vergangenen Jahren enttäuscht. Zu Beginn des Jahres 2005 ist zwar die dritte und letzte Entlastungsstufe der Steuerreform 2005 in Kraft getreten, in der Summe ergab sich für die Arbeitnehmer aufgrund zusätzlicher Belastungen durch Sozialabgaben jedoch eine Mehrbelastung von 0,45 Prozentpunkten. Darüber hinaus sind die Verbraucherpreise aufgrund der starken Verteuerung der Energie deutlich gestiegen. Insgesamt sind die real verfügbaren Arbeitseinkommen der privaten Haushalte gesunken. Für das Jahr 2006 werden die Einkommen nach Prognosen des IFO Instituts real gerechnet stagnieren (INSTITUT FÜR WIRTSCHAFTSFORSCHUNG, 2005b: S. 49f.). Die Arbeitslosenquote lag zuletzt bei 12,1\%; im früheren Bundesgebiet betrug sie 10,2\% und in den neuen Ländern 19,2\%. Angesichts der unsicheren Einkommens- und Beschäftigungsperspektiven ist die Sparquote sehr hoch. Die Zurückhaltung der Verbraucher zeigt sich bei den Einzelhandelsumsätzen, die im Jahresschlussquartal 
2005 beispielsweise um 1,4\% zurückgegangen sind. Die Umsatzentwicklung im Gastgewerbe war ebenfalls rückläufig (BUNDESMINISTERIUM FÜR WIRTSCHAFT UND TeChnologie, 2006: S. 7). Aufgrund der geplanten Mehrwertsteueranhebung um 3 Prozentpunkte zum 1. Januar 2007 dürfte die hohe Sparquote in der zweiten Jahreshälfte 2006 etwas sinken, da dadurch die vorzeitige Anschaffung von langlebigen Gebrauchsgütern gefördert wird. Die Brauwirtschaft wird davon allerdings wohl kaum profitieren. Neben den Absatzrückgängen von Bier in der Gastronomie und dem allgemeinen Konsumrückgang hat sich bei vielen Konsumenten die Preissensibilität in den letzten Jahren deutlich erhöht. Diese Entwicklung begünstigt insbesondere den LEH mit niedrigen Preisen, welcher vorwiegend die für die Brauereien umsatzschwachen Biere im Preiseinstiegsbereich vertreibt (LATZ-WEBER, 2003d: S. 68). Ingesamt kann festgestellt werden, dass notwendige Preiserhöhungen seitens der Brauereien durch die aufgezeigte wirtschaftliche Situation der Verbraucher nachhaltig erschwert werden.

\subsection{Zwischenfazit: Die deutsche Brauwirtschaft in der Krise}

Mit einem Produktionsvolumen von 106,19 Millionen hl im Jahr 2004 ist Deutschland nach China und den USA der drittgrößte Bierproduzent der Welt und die Nummer eins in Europa (BALZ, 2005: S. 34). Der Bierverbrauch in Deutschland lag im letzten Jahr bei etwa 95 Mio. hl (115,8 1 pro Kopf), 13,7 Mio. hl wurden exportiert und ca. 3,1 Mio. hl wurden eingeführt. Im Jahr 2004 existierten in der Bundesrepublik 1.274 Braustätten; diese Angebotsstruktur ist in der Welt einzigartig. Deutschland ist damit nach wie vor das Land mit der höchsten Anzahl von Braustätten. Von den insgesamt 1.694 Braustätten der EU befinden sich etwa $75 \%$ in Deutschland. Mit etwa $83.350 \mathrm{hl}$ durchschnittlichen Bierausstoß je Braustätte im Jahr 2004 weist die Bundesrepublik Deutschland die niedrigste durchschnittliche Braustättengröße in der EU auf (DEUTSCHER BRAUER-BUnd, 2005b).

Die deutsche Brauwirtschaft befindet sich seit einigen Jahren in einer tiefen Krise. Die Folge dieser Entwicklung ist ein zunehmender Konzentrationsprozess in Form von Verdrängung, Übernahmen und Beteiligungskäufen. Ein Blick auf die Entwicklung der Branchenstruktur verdeutlicht zwar (vgl. Tabelle 4, S. 39), dass sich die Gesamtzahl der Brauereien in der Brauwirtschaft nur geringfügig verändert hat. Bei einem genauren Blick auf die verschiedenen Größenklassen fallen aber deutliche Unterschiede auf. So hat die Zahl der Kleinstbrauereien (bis 5.000 hl/Jahr) deutlich zugenommen. Ein ganz 
anderes Bild ergibt sich dagegen bei der Betrachtung des Mittelfelds, in dem sich Brauereien mit einem Ausstoß von 5.000 bis 1 Mio. hl pro Jahr bewegen. In dieser Gruppe hat sich die Zahl deutlich vermindert. Die Zahl der Großbrauereien ist dagegen konstant geblieben; zugleich haben diese durch Fusionen und Übernahmen an Größe und Bedeutung deutlich gewonnen. So erhöhte sich der kombinierte Marktanteil der drei größten Brauereien von 18,7 \% im Jahr 1995 auf etwa 38 \% in 2004, und der Marktanteil der größten Fünf stieg bis heute auf zusammen rund 51 \%. Ein weiteres Anzeichen für die Krisensituation der deutschen Braubranche ist die Tatsache, dass in Deutschland nur wenig Geld mit Bier verdient wird. Der Hauptgrund dafür ist der relativ niedrige Preis für Bier im Vergleich zu Märkten anderer Industriestaaten (vgl. Abbildung 18, S. 55). Es gibt eine Reihe von Ursachen für die schlechte Preissituation in der deutschen Braubranche: sinkender Gesamt- und Pro-Kopf-Verbrauch, Überkapazitäten, Konzentration im Handel sowie der Markteintritt ausländischer Wettbewerber. Auf die Ursachen der Krise wird im Folgenden näher eingegangen.

Die Hauptursache für die Krise in der deutschen Brauwirtschaft ist in der deutlichen Abnahme des Pro-Kopf-Verbrauchs in den letzten Jahren zu sehen. So hat sich dieser seit 1995 um mehr als 201 verringert. Dadurch hat auch der Gesamtbierausstoß der deutschen Brauereien von 1995 bis 2003 um über 10 Mio. hl abgenommen (vgl. Abbildung 14, S. 43). Diese Entwicklung konnte erst im Jahr 2004 durch einen stetig ansteigenden Export aufgehalten werden. Die wichtigsten Gründe für die negative Entwicklung des Bierkonsums sind zum einen Veränderungen im Verbraucherverhalten und zum anderen der demografische Faktor. So substituieren die Konsumenten Bier mehr und mehr durch andere Getränke wie Wasser, Soft Drinks und Wein, welche ihre veränderten Lebensgewohnheiten besser widerspiegeln. Mit Blick auf die demografische Entwicklung wird ersichtlich, dass das Durchschnittsalter der Deutschen in den letzten Jahren deutlich zugenommen hat. Darüber hinaus ist der Anteil der Konsumenten im Alter zwischen 15 und 35 Jahren, die als Hauptkonsumenten für Bier angesehen werden können, in den letzten Jahren stark gesunken. Prognosen gehen davon aus, dass sich dieser Anteil in den nächsten 5 Jahren weiter verringern wird. Aufgrund des weiteren Rückgangs dieser sehr konsumfreudigen Konsumentengruppe ist damit zu rechnen, dass der Pro-Kopf-Verbrauch sowie der gesamte Inlandsabsatz in Zukunft weiter zurückgehen werden. Die sinkende Nachfrage nach Bier hat zu erheblichen Überkapazitäten geführt. Die starke Fragmentierung der Branche hat es begünstigt, dass viele Brauer beim Kampf um Marktanteile Preiszugeständnisse 
gemacht, nicht jedoch Überkapazitäten durch die Schließung von Produktionsstätten abgebaut haben. Die weit verbreiteten Niedrigpreisstrategien setzen den Biermarkt zusätzlich unter Druck.

Eine weitere Ursache für die Krise in der Braubranche ist in der wachsenden Verhandlungsmacht verschiedener Absatzmittler zu sehen. So nehmen die Größe und die Macht der Getränkefachgroßhändler (GFGH) sowie des Lebensmitteleinzelhandels (LEH) durch den fortschreitenden Konzentrationsprozess dieser Branchen gegenüber den Brauereien stetig zu. Der dadurch entstehenden enormen Einkaufsmacht sind die Brauereien ausgesetzt, so dass sie in den Jahresgesprächen für Listungen, Platzierungen und Konditionen oft erhebliche Zugeständnisse eingehen müssen. Während die kleinen mittelständischen Brauereien, die keine starke Marke besitzen, dieser Macht fast hilflos gegenüber stehen, verfügen die Brauereien mit starken Marken über eine bessere Verhandlungsposition gegenüber dem LEH sowie dem GFGH.

Die Bedrohung durch den Markteintritt neuer Wettbewerber war lange Zeit sehr gering. Diese Situation hat sich in den letzten Jahren jedoch grundlegend verändert. So haben viele bedeutende internationale Brauereikonzerne führende inländische Brauereien übernommen. Branchenexperten gehen auch für die Zukunft davon aus, dass die Internationalisierung auf dem deutschen Biermarkt weiter voranschreitet und damit der Wettbewerbsdruck weiter zunehmen wird. 


\section{Empirische Analyse der deutschen Brauwirtschaft}

\subsection{Forschungsmethodik und Vorgehensweise der Untersuchung}

\subsubsection{HYPOTHESENBILDUNG UND ZIELE DER UNTERSUCHUNG}

Ausgehend vom theoretischen Bezugsrahmen der Untersuchung sowie theoretischer Erklärungsansätze lassen sich vor dem Hintergrund der Wettbewerbsbedingungen im deutschen Biermarkt drei grundlegende Hypothesen formulieren, die den übergeordneten Orientierungsrahmen der empirischen Untersuchung bilden.

Hypothese 1: Bei der Auseinandersetzung mit den Wettbewerbskräften des Marktes verwenden Brauereien unterschiedliche Strategiealternativen und lassen sich demzufolge in strategische Gruppen einteilen.

Hypothese 2: Die Strategiewahl und damit die Zugehörigkeit zu einer strategischen Gruppe werden im Wesentlichen durch Unterschiede in der Wahrnehmung der Branchensituation bestimmt.

Hypothese 3: Die Zugehörigkeit zu verschiedenen strategischen Gruppen erklärt einen Teil der Erfolgsunterschiede zwischen den Brauereien.

Die Ausrichtung einer Analyse auf eine Prüfung von Hypothesen bestimmter Sachverhalte entspricht einem konfirmatorischen Vorgehen. Dieses zeichnet sich dadurch aus, dass auf der Basis von Theorien und gegebenenfalls den Ergebnissen empirischer Untersuchungen Hypothesen formuliert werden, welche durch eine empirische Datenanalyse anschließend überprüft und entsprechend bestätigt oder verworfen werden (EFFEN, 1995: S. 110).

Im folgenden Kapitel wird zunächst das Forschungsdesign erläutert, im Anschluss daran erfolgen die Darstellung der Ergebnisse sowie die Überprüfung der Basishypothesen.

\subsubsection{FORSCHUNGSDESIGN}

\subsubsection{Erhebungsmethode}

Für die empirische Überprüfung der aufgestellten Hypothesen zu den strategischen Gruppen in der deutschen Brauwirtschaft wurde eine umfassende empirische Studie 
durchgeführt. Die Notwendigkeit einer Primärerhebung ergab sich aus der Tatsache, dass die aufgrund der spezifischen Fragestellung benötigten aktuellen Informationen nicht anhand von Sekundärquellen verfügbar waren. Originäre Daten werden üblicherweise durch Befragungen oder Beobachtungen erhoben (BEREKOVEN/EcKerT/Ellenrieder, 1999: S. 49), wobei die Befragung das wichtigste und am häufigsten genutzte Verfahren der Datenerhebung darstellt. Dabei können nach dem Erhebungsmodus schriftliche, persönliche, telefonische sowie Internetbefragungen unterschieden werden.

Die Datenerhebung der vorliegenden Arbeit erfolgte in Form einer schriftlichen Befragung mittels eines standardisierten Fragebogens. Diese Vorgehensweise bietet im Vergleich zum mündlichen Interview die Vorteile der geringeren Kosten, der räumlichen Ungebundenheit sowie der Möglichkeit, schwer erreichbare Berufskreise zu interviewen (EBENDA: S. 113). Die Nachteile, wie eine evtl. geringe Rücklaufquote sowie die Unkontrollierbarkeit der Erhebungssituation (HERRMANN/HOMBURG, 1999: S. 27), wurden durch verschiedene Maßnahmen beseitigt oder zumindest abgemildert, um die Befragten zu motivieren, den Fragebogen korrekt beantwortet zurückzusenden.

Im ersten Schritt wurden die Unternehmensadressen ${ }^{13}$ um die Namen der Inhaber bzw. Geschäftsführer erweitert, um eine persönliche Ansprache zu gewährleisten und sicherzustellen, dass der Fragebogen von kompetenten Personen beantwortet wird. Außerdem wurde ein personalisiertes Anschreiben (Beispiel siehe Anlage 3) an die Befragten hinzugefügt, welches in die Thematik einführen sollte, die anonyme Behandlung der Daten garantierte und den Auskunftspersonen die Übermittlung der in der Untersuchung gewonnenen Ergebnisse versprach. Dieser Brief wurde durch ein Referenzschreiben (Beispiel siehe Anlage 4) der jeweiligen regionalen Mitgliedsverbände ${ }^{14}$ des DEUTSCHEN BRAUER-Bundes ergänzt. Des Weiteren wurde dem Fragebogen ein adressierter und frankierter Rückumschlag beigefügt. Schließlich wurden die angeschriebenen Brauereien ca. drei Wochen nach der Aussendung des Fragebogens telefonisch kontaktiert, um die Unternehmen auf diesem Wege an die

${ }^{13}$ Die Unternehmensadressen und die Namen der Inhaber bzw. Geschäftsführer sind dem BRAUEREIADRESSBUCH 2004/05 entnommen und wurden teilweise von den regionalen Brauereiverbänden zur Verfügung gestellt.

${ }^{14}$ Die Studie wurde durch ein Referenzschreiben des Bayerischen Brauerbund e.V., des BadenWürttembergischen Brauerbund e.V., des Brauerbund Hessen / Rheinland-Pfalz e.V., des Brauerbund Thüringen e.V., des Verband Rheinisch-Westfälischer Brauereien e.V., des Verband der Brauereien des Saarlandes e.V. sowie der Sozietät Norddeutscher Brauereiverbände e.V. unterstützt. 
Rücksendung zu erinnern und bei evtl. aufgetretenen Fragen Hilfestellung zu geben (FRIEDRICHS, 1990: S. 236ff.).

\subsubsection{Fragebogen}

Bei der Konzeption der Studie wurde das auf MASON (1949) und BAIN (1959) zurückgehende Structure-Conduct-Performance Paradigma (S-C-P Paradigma) als theoretischen Unterbau aufgegriffen. Abbildung 22 fasst das auf den vorgestellten Überlegungen (vgl. Abbildung 1, S. 6) fußende Untersuchungskonzept zusammen. Danach bestimmen die jeweiligen situativen Rahmenbedingungen maßgeblich die Strategien der Unternehmen; umgekehrt beeinflussen die Strategien aber auch die Wettbewerbsbedingungen in der Branche, z. B. den Preisdruck und die Innovationsgeschwindigkeit. Im Einzelnen wird die Situation bestimmt durch unternehmensinterne Rahmenbedingungen (Größe, Finanzkraft, Standort usw.), die fünf Wettbewerbskräfte sowie das weitere Branchenumfeld, z. B. rechtliche und gesamtwirtschaftliche Entwicklungen. Der Unternehmenserfolg wiederum hängt davon $\mathrm{ab}$, welche Strategien Brauereien verfolgen, wie gut diese Strategien auf die Situation abgestimmt sind und wie sich die Branche insgesamt entwickelt. Schließlich wird das Konzept durch die Berücksichtigung der Strategieformulierung und -implementierung als moderierende Variable erweitert, denn keine noch so gute Strategie hilft den Unternehmen, wenn sie schlecht umgesetzt und mangelhaft implementiert wird.

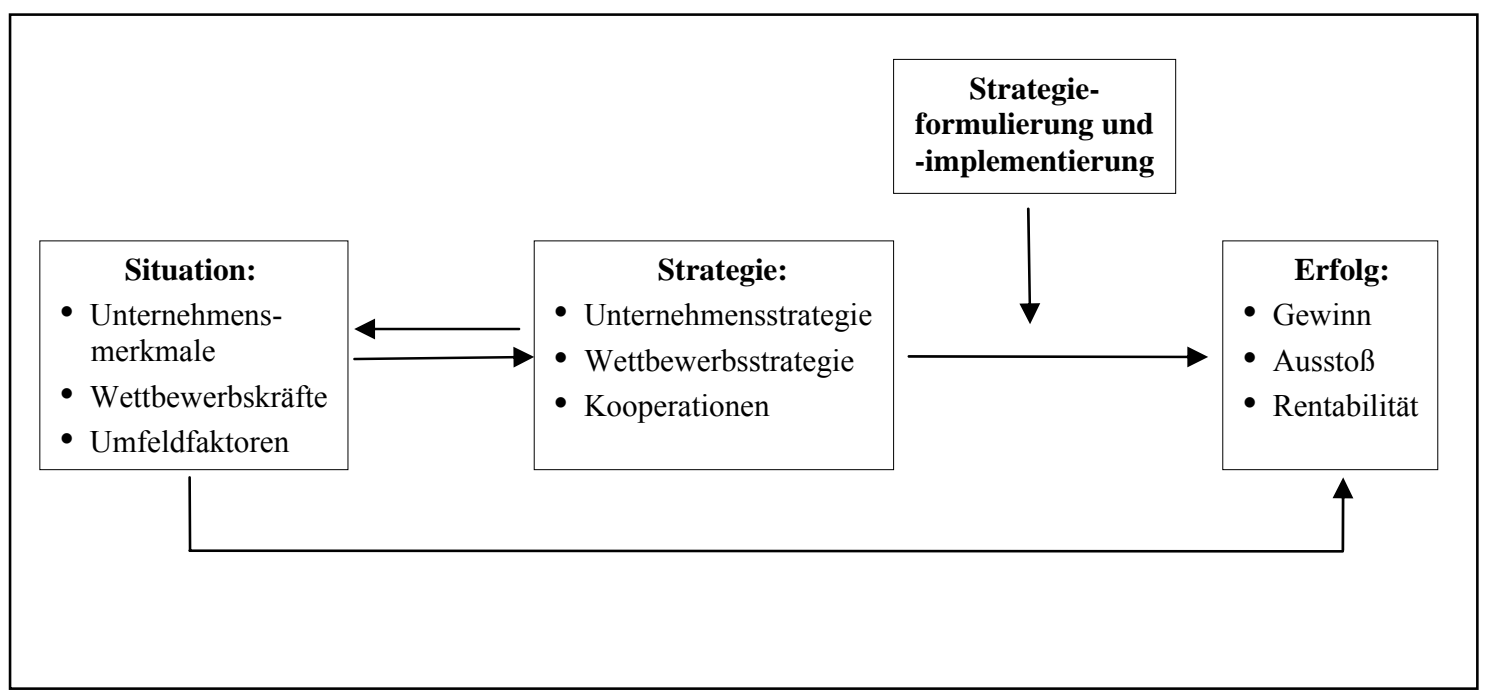

Abbildung 22: Konzept der Untersuchung

Die Auswahl der wesentlichen Dimensionen des untersuchungsleitenden Konzepts erfolgte anhand eines eingehenden Studiums der Branchenliteratur und Fachpresse sowie persönlicher Gespräche mit Experten der Brauwirtschaft. Die Anlage 2 zeigt die 
Einbindung aller abgeleiteten Variablen in das theoretische Referenzmodell. Daraus ergibt sich der folgende Aufbau des Fragebogens, welcher zur Erhöhung der Übersichtlichkeit sowie zur Erleichterung der Fragenbeantwortung wie folgt gegliedert wurde (siehe Anlage 5):

I. Allgemeine Fragen (Unternehmensmerkmale)

II. Situation und Entwicklung des Unternehmens

III. Märkte und Produkte

1. Produktpolitik

2. Märkte und Absatzwege

3. Kosten

4. Marketing und Markenführung

5. Innovation

IV. Kooperation

V. Erfolg

VI. Strategieformulierung und Implementierung

Die Fragen sind überwiegend in geschlossener Form gestellt worden, womit den Befragten die Antwortmöglichkeiten fest vorgegeben wurden (BEREKOVEN/EcKERT/ElLENRIEDER, 1999: S. 101). Damit kann eine einheitliche Datengewinnung und Vergleichbarkeit der Ergebnisse sowie eine schnelle Bearbeitung und Auswertung des Fragebogens gewährleistet werden. Je nach Themenhintergrund wurden unterschiedliche Frageformen verwendet. So wurden neben Alternativ- und Selektivfragen (Mehrfach-Auswahl-Frage) auch Skalafragen (Sonderform der Selektivfrage) und Fragen nach absoluten Größen wie z.B. den Kosten pro Hektoliter oder nach der Verteilung von Prozentwerten auf bestimmte Bezugsgrößen gefragt. Die Bewertungsfragen wurden anhand einer 5-Punkte Skala (Ratingskala) gestellt, welche durch verbal abgestufte Antwortmöglichkeiten gekennzeichnet sind (HüTTNER, 1999: S. 104ff.).

Der Fragebogen wurde in einer Expertenrunde ausführlich diskutiert und im Dezember 2004 einem Pretest mit branchenneutralen Personen, Führungskräften der Brauwirtschaft sowie Verbandsvertretern unterzogen (KIRCHHOFF ET AL., 2003: S. 24f.). Durch den Test konnten teilweise unklare Frageformulierungen identifiziert und die verwendeten Messkonstrukte überprüft werden. Ferner ergab der Pretest 
Anhaltspunkte für die benötigte Befragungszeit als auch Informationen in Bezug auf die Sensibilität bestimmter Fragen. Somit konnten durch den Pretest vor der eigentlichen Unternehmensbefragung einige Missverständnisse und Mängel eliminiert werden.

\subsubsection{ERHEBUNGSUMFANG, RÜCKLAUFQUOTE UND AUSWERTUNG}

Die in der vorliegenden Arbeit zu diskutierenden empirischen Befunde basieren auf einer Vollerhebung, die im Zeitraum Januar bis April 2005 in der deutschen Brauwirtschaft durchgeführt wurde. Die Tabelle 11 zeigt die Anzahl betriebener Braustätten, die Anzahl der angeschriebenen Brauereien sowie den Rücklauf beantworteter Fragebögen nach der regionalen Verteilung auf die Bundesländer. Die Unterschiede zwischen der Anzahl der betriebenen Braustätten und der angeschriebenen Brauereien in Tabelle 11 sind auf Differenzen zwischen den von den regionalen Brauereiverbänden zur Verfügung gestellten sowie den im Brauerei-Adressbuch veröffentlichten Daten einerseits und der offiziellen Statistik des DEUTSCHEN BRAUERBUNDES auf der anderen Seite zurückzuführen.

\begin{tabular}{|l|c|c|c|c|}
\hline & $\begin{array}{c}\text { Betriebene } \\
\text { Braustätten } \\
2004^{*}\end{array}$ & $\begin{array}{c}\text { Ange- } \\
\text { schriebene } \\
\text { Brauereien }\end{array}$ & $\begin{array}{c}\text { Rücklauf } \\
\text { beantworteter } \\
\text { Fragebögen } \\
\text { absolut }\end{array}$ & $\begin{array}{c}\text { Rücklauf } \\
\text { beantworteter } \\
\text { Fragebögen } \\
\text { in \% }\end{array}$ \\
\hline Baden-Württemberg & 178 & 161 & 43 & 26,7 \\
\hline Bayern & 629 & 689 & 160 & 23,2 \\
\hline Berlin/Brandenburg & 38 & 30 & 5 & 16,7 \\
\hline Hessen & 63 & 60 & 10 & 16,7 \\
\hline Mecklenburg-Vorpommern & 18 & 13 & 0 & 0 \\
\hline Niedersachsen/Bremen & 49 & 41 & 9 & 21,9 \\
\hline Nordrhein-Westfalen & 118 & 118 & 20 & 16,9 \\
\hline Rheinland-Pfalz/Saarland & 52 & 42 & 6 & 14,3 \\
\hline Sachsen & 55 & 43 & 9 & 20,9 \\
\hline Sachsen-Anhalt & 18 & 16 & 4 & 25 \\
\hline $\begin{array}{l}\text { Schleswig-Holstein/ } \\
\text { Hamburg }\end{array}$ & 13 & 13 & 2 & 15,3 \\
\hline Thüringen & 43 & 34 & 11 & 32,3 \\
\hline keine Angabe & & & 2 & \\
\hline Gesamt & 1274 & 1260 & 281 & 22,3 \\
\hline
\end{tabular}

Tabelle 11: Rücklaufquote nach Bundesländern

*Quelle: Deutscher Brauer-Bund, 2005b

Aus der Grundgesamtheit der 1260 angeschriebenen Brauereien konnten 281 vollständig ausgefüllte Fragebögen in der Auswertung berücksichtigt werden, was einer Rücklaufquote von 22,3\% aller in Deutschland betriebenen Braustätten entspricht. Rechnet man die Brauereien bis 5.000 Hektoliter Gesamtjahreserzeugung heraus, dann erhöht sich diese Quote sogar auf 39,5 \%. Angesichts der zunehmenden Zurückhaltung 
der Unternehmen gegenüber schriftlichen Befragungen, dem umfangreichen Fragebogen und der Brisanz des zu untersuchenden Sachverhalts kann diese Rücklaufquote als sehr zufrieden stellend betrachtet werden.

Die statistische Auswertung der erhobenen Daten erfolgte mit Hilfe der Software „SPSS 12. 0 für Windows“. Dabei kamen neben deskriptiven Datenanalyseverfahren auch multivariate Verfahren wie die Faktor-, Cluster- und Varianzanalyse zur Anwendung.

\subsubsection{Allgemeine MERKMAle DER Befragten BRAUEREIEN}

Im Folgenden werden zunächst einige allgemeine Daten aufgezeigt, um einen Überblick über die Merkmalsstruktur der befragten Unternehmen zu erlangen. Dabei wird u. a. eine Einteilung der Unternehmen nach der Gesamtjahreserzeugung, der Rechtsform, der Mitarbeiterzahl sowie der Unternehmensleitung nach Betriebsgrößenklassen vorgenommen. Die Ergebnisse der eigentlichen Untersuchung schließen sich in den folgenden Kapiteln der Arbeit an.

Die Analyse der Angaben zum Gesamtgetränkeausstoß der befragten Brauereien veranschaulicht, dass alle Unternehmensgrößen in der Studie Berücksichtigung finden. Die Tabelle 12 zeigt die Verteilung der an der Untersuchung beteiligten Brauereien nach Ausstoßgrößenklassen.

\begin{tabular}{|c|c|c|c|}
\hline $\begin{array}{l}\text { Betriebsgrößenklasse } \\
\text { nach der Gesamt- } \\
\text { jahreserzeugung (hl) }\end{array}$ & $\begin{array}{c}\text { Betriebene } \\
\text { Braustätten im Jahr } \\
\text { 2004* }\end{array}$ & $\begin{array}{c}\text { Rücklauf } \\
\text { ausgefüllter } \\
\text { Fragebögen }\end{array}$ & $\begin{array}{l}\text { Rücklaufquote } \\
\text { in } \%\end{array}$ \\
\hline bis 5.000 & 796 & 92 & 11,55 \\
\hline bis 10.000 & 85 & \multirow{3}{*}{138} & \multirow{3}{*}{39,2} \\
\hline bis 50.000 & 195 & & \\
\hline bis 100.000 & 72 & & \\
\hline bis 200.000 & 44 & \multirow{2}{*}{42} & \multirow{2}{*}{55,26} \\
\hline bis 500.000 & 32 & & \\
\hline bis 1 Mill. & 21 & \multirow{2}{*}{9} & \multirow{2}{*}{18} \\
\hline über 1 Mill. & 29 & & \\
\hline Gesamt & 1274 & 281 & 22,3 \\
\hline
\end{tabular}

Tabelle 12: Rücklaufquote nach Ausstoßgrößenklassen der Brauereien

*Quelle: DEUTSCHER BRAUER-Bund, 2005b 
Bei den 281 Brauereien, die den Fragebogen beantwortet zurückgesendet haben, handelt es sich überwiegend um Familienunternehmen (84\%), von denen die Mehrzahl (91,8 $\%)$ nicht in einen Konzern eingebunden ist.

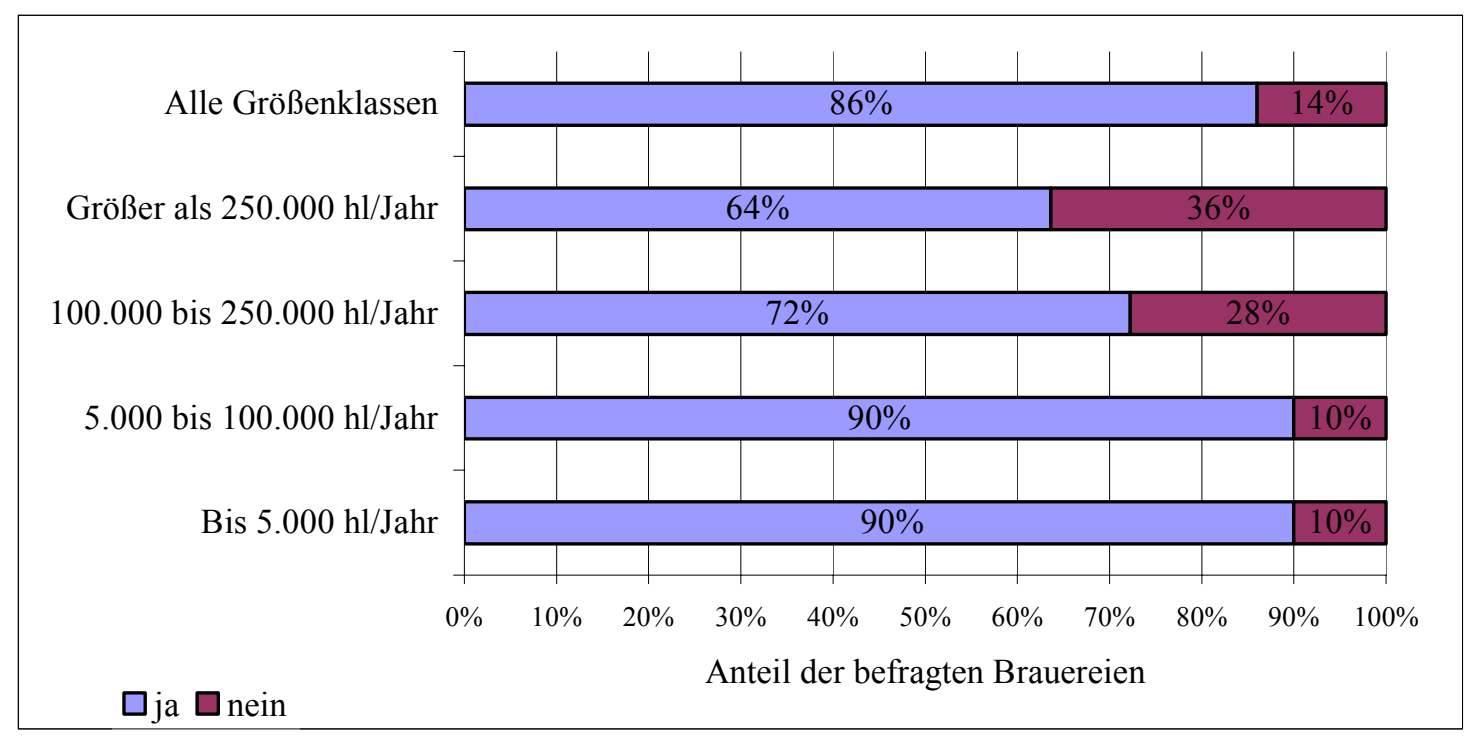

Abbildung 23: Handelt es sich bei Ihrem Unternehmen um ein Familienunternehmen?

Allerdings gibt es bei beiden Angaben deutliche Unterschiede zwischen den verschiedenen Betriebsgrößenklassen; dieses wird durch die Abbildungen 23 und 24 veranschaulicht. Es wird deutlich, dass der prozentuale Anteil der Familienunternehmen mit steigender Betriebsgröße abnimmt. Genau entgegengesetzt verhält es sich mit den Unternehmen, die in einen Konzern eingebunden sind; hier steigt der prozentuale Anteil mit steigender Betriebsgröße.

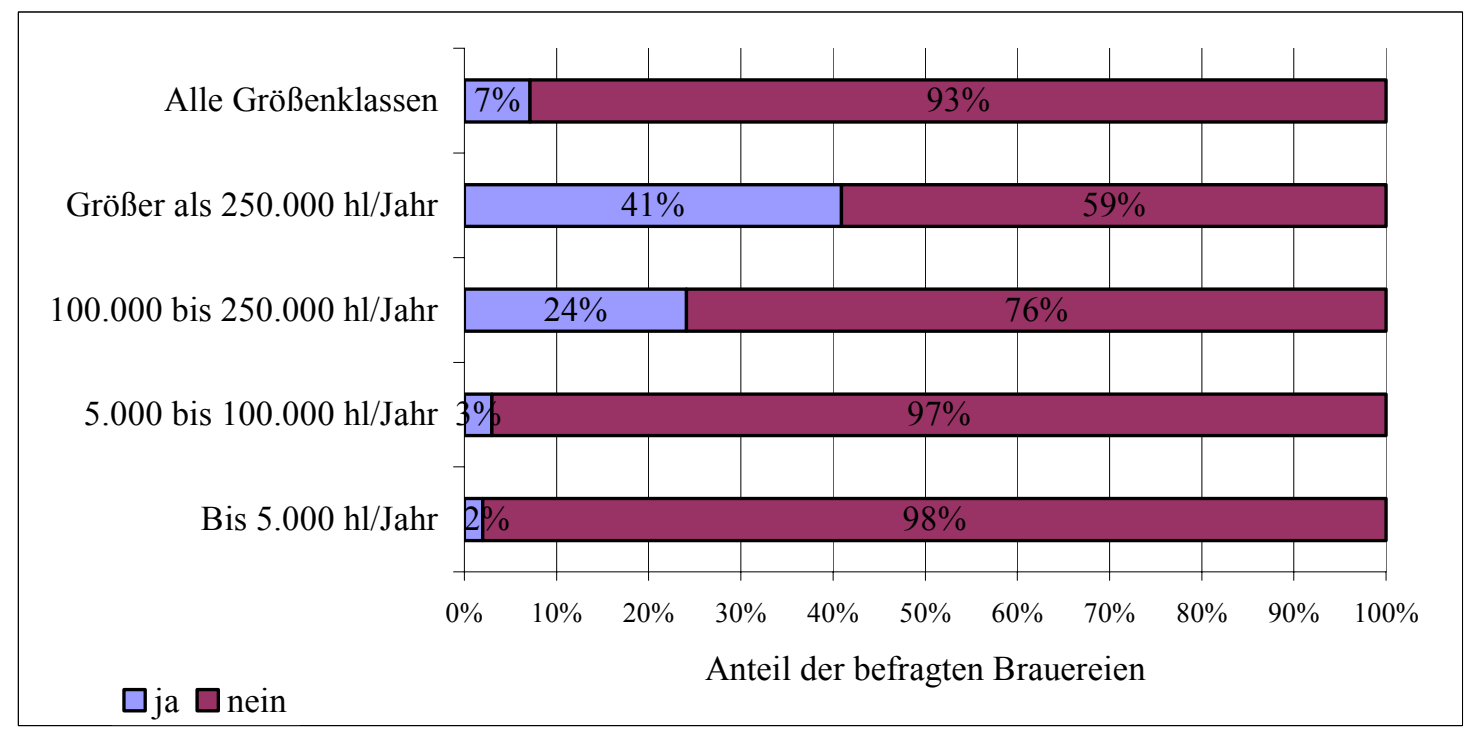

Abbildung 24: Ist Ihr Unternehmen in einen Konzern eingebunden? 
Auch bei der Verteilung der Rechtsformen der in der Befragung untersuchten Unternehmen gibt es deutliche Unterschiede in Abhängigkeit von der Größe der Brauereien, wie die Abbildung 25 verdeutlicht. Bei den kleinen Brauereien bis 5.000 hl Gesamtjahreserzeugung dominiert das Einzelunternehmen (66 \%). Dieser Anteil nimmt mit steigender Betriebsgröße zu Gunsten der übrigen Rechtsformen deutlich ab. Bei den Brauereien mit mehr als $250.000 \mathrm{hl}$ Gesamtjahreserzeugung sind die $\mathrm{GmbH}$ (42 \%) und die $\mathrm{GmbH} \&$ Co. KG (33 \%) die häufigsten Rechtsformen, aber auch die AG (10\%) und die KG (10\%) treten wesentlich häufiger auf als bei den kleinen Unternehmen.

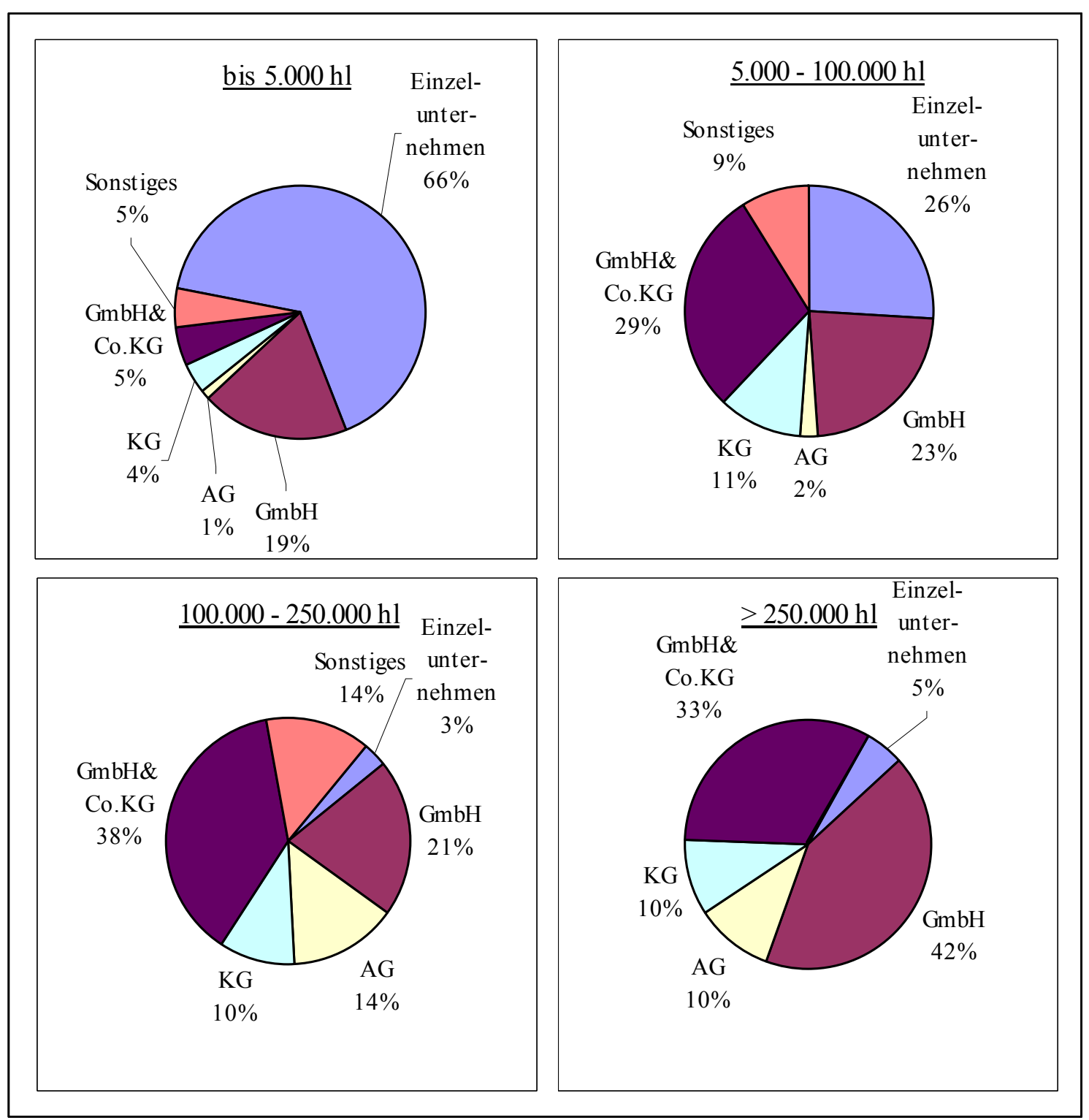

Abbildung 25: Rechtsformen der an der Untersuchung beteiligten Brauereien nach Betriebsgrößenklassen

Die Unternehmensführung liegt beim größten Teil (77\%) der befragten Brauereien in den Händen der Inhaber bzw. eines Gesellschafters. Der Abbildung 26 ist zu entnehmen, dass sich das Management mit zunehmender Ausstoßgröße im Durchschnitt 
anscheinend professionalisiert, da sich der Anteil der angestellten Geschäftsführer bzw. Vorstände an der Unternehmensleitung deutlich erhöht.

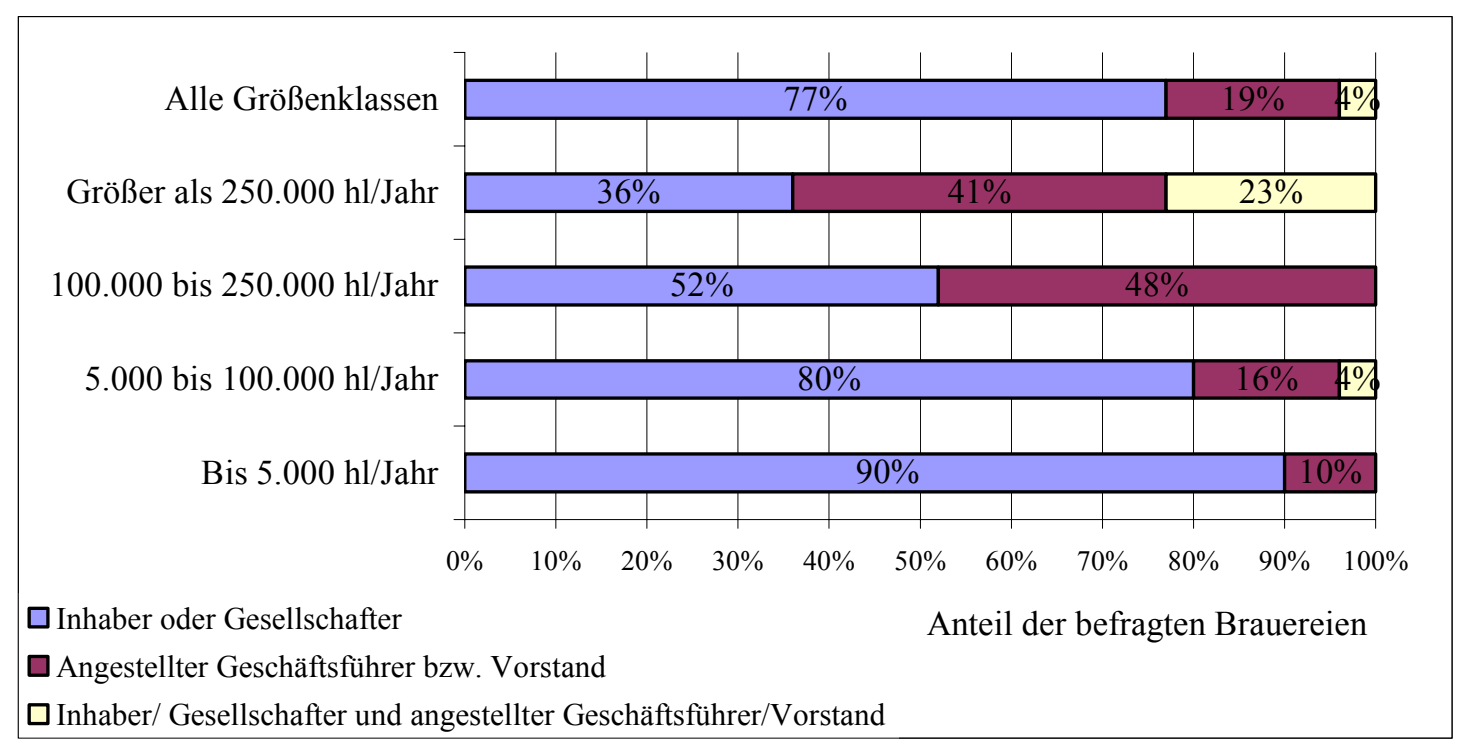

Abbildung 26: Durch wen wird Ihr Unternehmen geleitet?

Was die Größenverteilung nach Beschäftigten betrifft, so kann festgestellt werden, dass $68 \%$ aller befragten Unternehmen weniger als 31 Beschäftigte aufweisen.

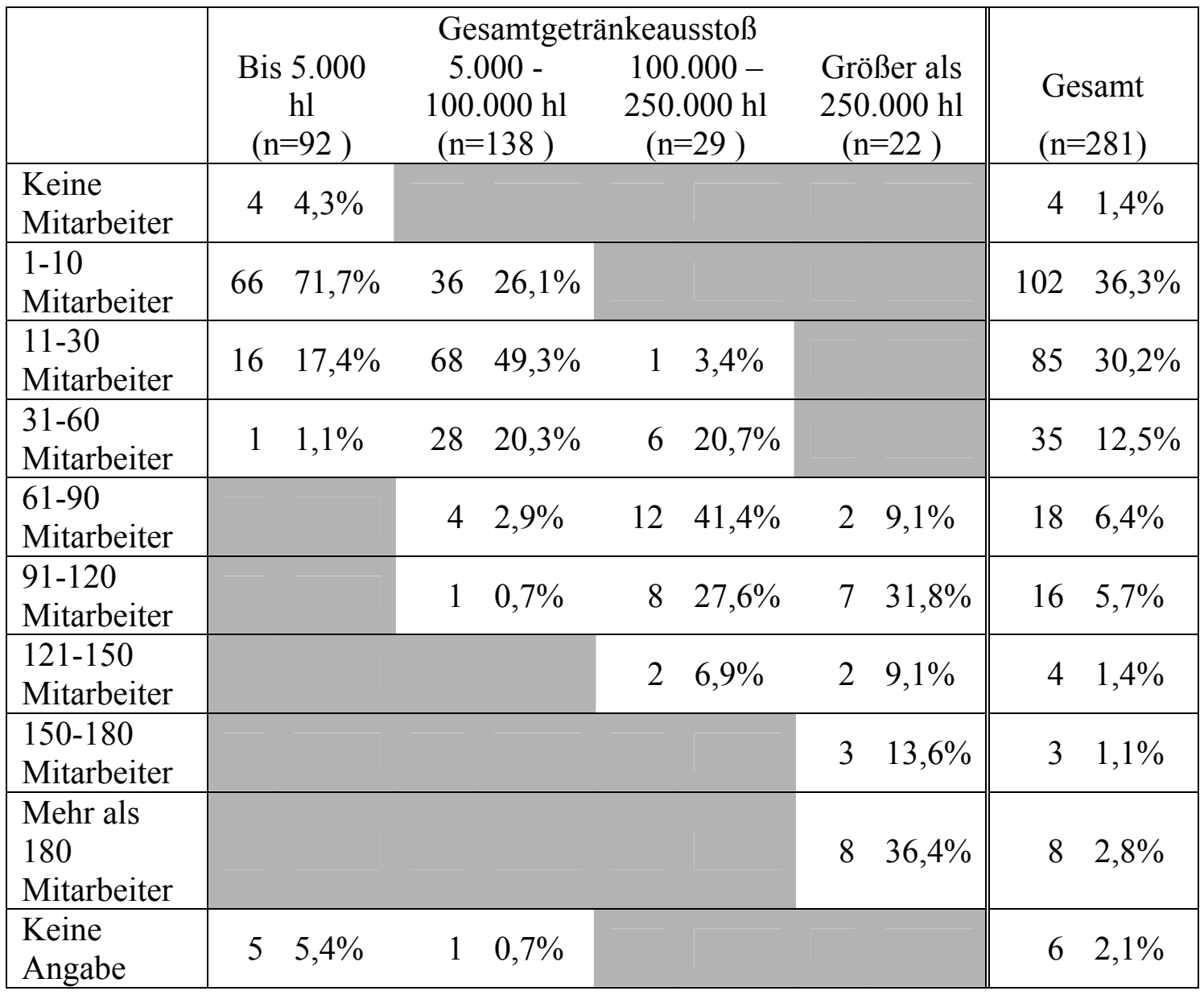

Tabelle 13: Wie viele Mitarbeiter waren in den letzten drei Jahren im Durchschnitt in Ihrem Unternehmen beschäftigt? 
Tabelle 13 zeigt die Anzahl der Mitarbeiter nach Betriebsgrößenklassen in der deutschen Brauwirtschaft. Dabei wird ersichtlich, dass die Mitarbeiteranzahl sowohl bei Unternehmen der verschiedenen Größenklassen - wie anzunehmen war - als auch bei denen vergleichbarer Größe stark variiert.

\subsection{Branchensituation der deutschen Brauwirtschaft}

\subsubsection{WAHRNEHMUNG DER BRANCHENSITUATION DURCH DIE DEUTSCHE BRAUWIRTSCHAFT}

KARL WEICK (1985, S. 192) hat darauf hingewiesen, dass die Grenzen zwischen einem Unternehmen und seiner Umwelt letztlich willkürlich gezogen sind und jederzeit verändert werden können. Unternehmen beziehen sich bewusst auf bestimmte Wirklichkeitsausschnitte (und vernachlässigen andere) und gestalten in diesem Sinne aktiv die jeweils für sie relevante Umwelt. Diesen Vorgang der aktiven Selektion einer bestimmten Umwelt durch ein Unternehmen bezeichnet WEICK (1979) als „enactment“; er geht davon aus, dass es so viele verschiedene „enacted environments“ gibt wie Unternehmen existieren (WEICK, 1985: S. 192). Nur die jeweils wahrgenommene Umwelt bestimmt, wie sich Unternehmen strategisch verhalten (BERGER/BERNHARDMEHLICH, 2001: S. 165). Erst dann bspw., wenn ein Unternehmen einen Markt als wettbewerbsintensiv wahrnimmt und sich entsprechend verhält, hat der Markt diese Eigenschaft tatsächlich auch (WEICK, 2001: S. 133). Entscheidend für das Verständnis unternehmerischen Handelns in einer Branche ist daher weniger, wie die Unternehmensumwelt (vermeintlich) objektiv ist, sondern mit welchen Etiketten Unternehmen sie versehen. Es ist aus diesem Grund für die Untersuchung der Wege, welche die Brauer aus der Krise suchen, entscheidend, wie sie ihre Branche selbst erleben. Ergänzend zu der bereits im Kapitel 3.2.3 durchgeführten Branchenanalyse werden daher hier die Einschätzungen der befragten Brauer zur Branchensituation wiedergegeben.

In der Befragung antworteten über $82 \%$ der Unternehmen, dass sie den Wettbewerbsdruck in ihrem Kernabsatzgebiet inzwischen als hoch oder sogar sehr hoch einschätzen. Diese Wahrnehmung teilen $66 \%$ der Unternehmen in der Gruppe der Kleinbrauereien (bis $5.000 \mathrm{hl} / \mathrm{Jahr}$ ), über $87 \%$ der Brauereien mit bis zu $100.000 \mathrm{hl}$ Ausstoß pro Jahr und ausnahmslos alle Brauereien mit einem Jahresausstoß von über 100.000 hl. Offenbar hat somit immerhin rund ein Drittel der Kleinbrauereien nach 
eigener Einschätzung eine mehr oder minder geschützte Nische im Markt gefunden, während die größeren und großen Brauereien sich ungeschützt dem scharfen Wind des Wettbewerbs ausgesetzt sehen.

Im Folgenden wird dargelegt, in welchem Ausmaß die oben beschriebenen fünf Wettbewerbskräfte nach Ansicht der Unternehmen zur Intensivierung des Wettbewerbs beitragen. Ergänzend werden die Meinungen $\mathrm{zu}$ wichtigen Umfeldfaktoren, die ebenfalls Einfluss auf das Marktgeschehen haben und daher bei der strategischen Positionierung berücksichtigt werden müssen, in die Untersuchung einbezogen.

Die Verhandlungsmacht der verschiedenen Abnehmer wird von den Brauereien je nach Größe und Distributionsreichweite recht unterschiedlich eingeschätzt (vgl. Abbildung 27). Die Macht der Gastronomie betrachten die meisten Brauereien als relativ niedrig. Am höchsten wird sie noch in der Gruppe der Brauereien mit 5.000 bis $10.000 \mathrm{hl}$ Jahresausstoß empfunden; immerhin etwa $27 \%$ dieser Brauereien halten die Verhandlungsmacht der Gastronomie für hoch bis sehr hoch. Dies ist damit zu erklären, dass kleinere Brauereien einen deutlich höheren Absatzanteil über die Gastronomie erzielen, während dieser Vertriebsweg für Großbrauereien relativ an Bedeutung verloren hat. Zugleich sind an die Brauereien mit 5.000 bis $100.000 \mathrm{hl} / \mathrm{Jahr}$ im Mittel nur etwa $33 \%$ der Gastronomiekunden durch Bierlieferverträge gebunden, während dieser Prozentsatz mit zunehmendem Ausstoß ansteigt und bei den Unternehmen mit mehr als 250.000 hl/Jahr im Mittel etwa 64 \% erreicht. Die Gastronomen haben daher gegenüber kleineren Brauereien eine vergleichsweise gute Verhandlungsposition.

Die Brauereien sind, wie oben bereits erwähnt, einer enormen Einkaufsmacht des LEH ausgesetzt; etwa $36 \%$ der befragten Unternehmen halten sie für hoch bis sehr hoch. Bei den Brauereien mit mehr als 250.000 hl Ausstoß pro Jahr sind dies sogar 73 \%, da bei diesen Unternehmen der Absatz über den LEH in der Regel eine wesentlich größere Rolle spielt als bei den kleineren Brauereien.

Die Verhandlungsmacht des Getränkefachgroßhandels schätzen lediglich noch etwa 18 $\%$ der Brauereien als niedrig bis sehr niedrig ein, während $48 \%$ sie als hoch bis sehr hoch wahrnehmen. Da für größere Brauereien dieser Absatzweg wiederum eine überdurchschnittliche Bedeutung besitzt, überrascht es nicht, dass sie in einem stärkeren 
Maße als andere Brauereien dem Getränkefachgroßhandel eine hohe Verhandlungsmacht attestieren.

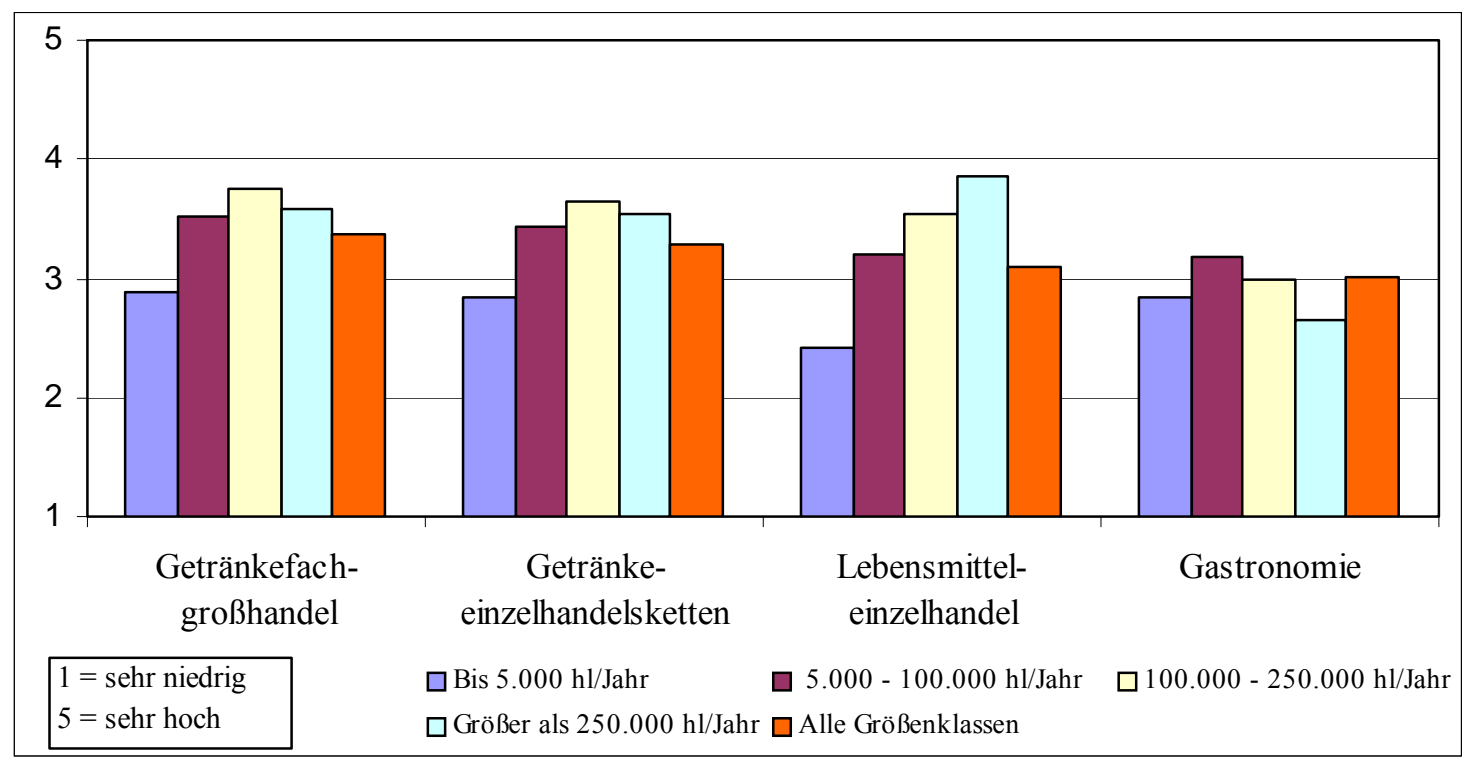

Abbildung 27: Einschätzung der Marktmacht verschiedener Absatzmittler

Die Brauereien empfinden die Bedrohung, welche von einem Markteintritt neuer Wettbewerber in ihr Kernabsatzgebiet ausgeht, insgesamt sehr unterschiedlich. So schätzen ca. 30 \% der befragten Brauereien diese Bedrohung als hoch bis sehr hoch ein; umgekehrt halten etwa $33 \%$ sie für gering bis sehr gering. Auch werden wieder deutliche Unterschiede zwischen den Größenklassen erkennbar; mit zunehmender Größe der Brauerei und damit in aller Regel auch des Kernabsatzgebietes wird die von potentiellen neuen Wettbewerbern ausgehende Bedrohung als intensiver wahrgenommen (vgl. Abbildung 28).

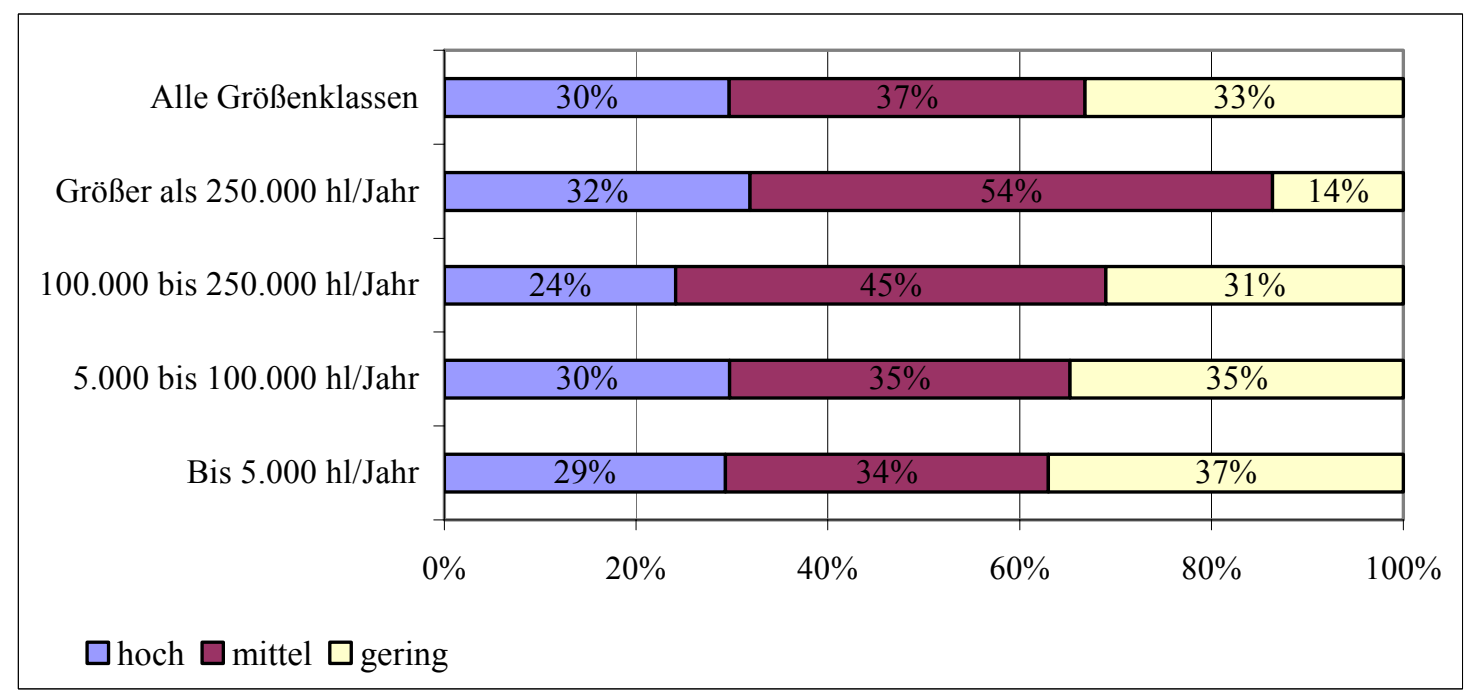

Abbildung 28: Einschätzung der Bedrohung durch neue Wettbewerber im Kernabsatzgebiet 
Die Analyse der Verhandlungsstärke der Lieferanten bezieht sich auf die Lieferanten der wichtigsten Beschaffungsgüter. Durch die sinkende Nachfrage seitens der Brauereien sind auf Lieferantenseite erhebliche Überkapazitäten entstanden. Darüber hinaus stehen die Lieferanten im starken Wettbewerb mit ausländischen Anbietern, so dass a priori davon auszugehen war, dass die Verhandlungsmacht gegenüber den Brauereien in den meisten Fällen als eher niedrig eingestuft werden würde (vgl. Kapitel 3.2.3.5). Entgegen dieser Erwartung halten etwa $23 \%$ aller befragten Brauereien die Verhandlungsstärke der Lieferanten für hoch (vgl. Abbildung 29). Interessant ist, dass in der Größenklasse mit mehr als 250.000 hl Ausstoß pro Jahr sogar ca. 32 \% die Verhandlungsmacht der Lieferanten als hoch einstufen, während in der Gruppe der Brauereien mit 100.000 bis 250.000 hl Jahresausstoß lediglich etwa $14 \%$ der Befragten dieser Auffassung sind. Ein Grund für die deutlich unterschiedliche Einschätzung könnte die starke Beteiligung der Brauereien mit einem Jahresausstoß von 100.000 bis $250.000 \mathrm{hl} / \mathrm{Jahr}$ an Einkaufskooperationen sein.

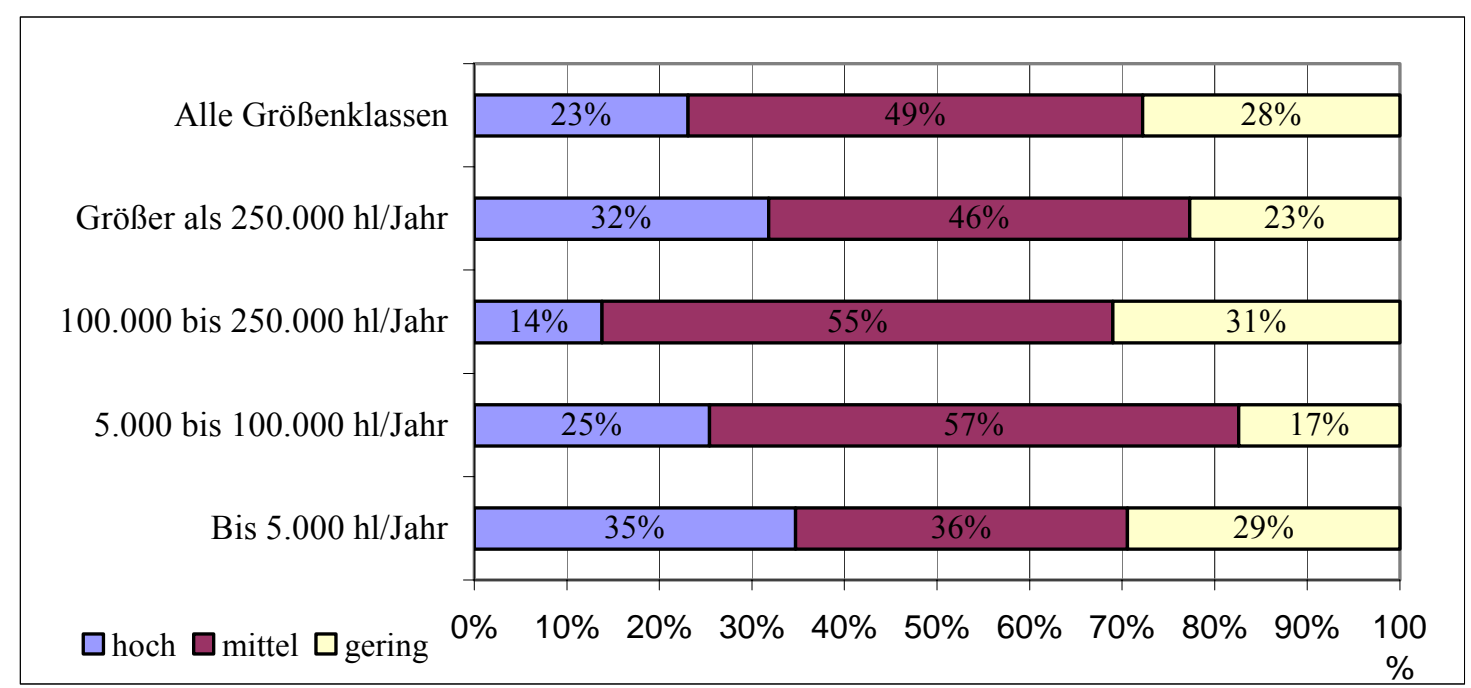

Abbildung 29: Einschätzung der Verhandlungsmacht der wichtigsten Lieferanten

Die Konsumenten üben nicht unmittelbar Marktmacht gegenüber den Brauereien aus, doch erhöht das veränderte Verbraucherverhalten den Wettbewerbsdruck, der von Ersatzprodukten (z.B. Mineralwasser, Wein, Alkopops) ausgeht, und die Anforderungen an die Vermarktung in Form von Produkt- und Gebindeinnovationen. Die Bedrohung der Absatzchancen durch Substitutionsprodukte wird von den Brauereien sehr unterschiedlich eingeschätzt. Die größeren Brauereien sehen darin eine deutlich größere Gefährdung als die kleineren (vgl. Abbildung 30). Ein Grund dafür könnte die geringere Bedeutung des LEH als Absatzweg für die kleineren Brauereien sein, da gerade bei diesem Distributionskanal die Absatzrückgänge besonders hoch sind. 


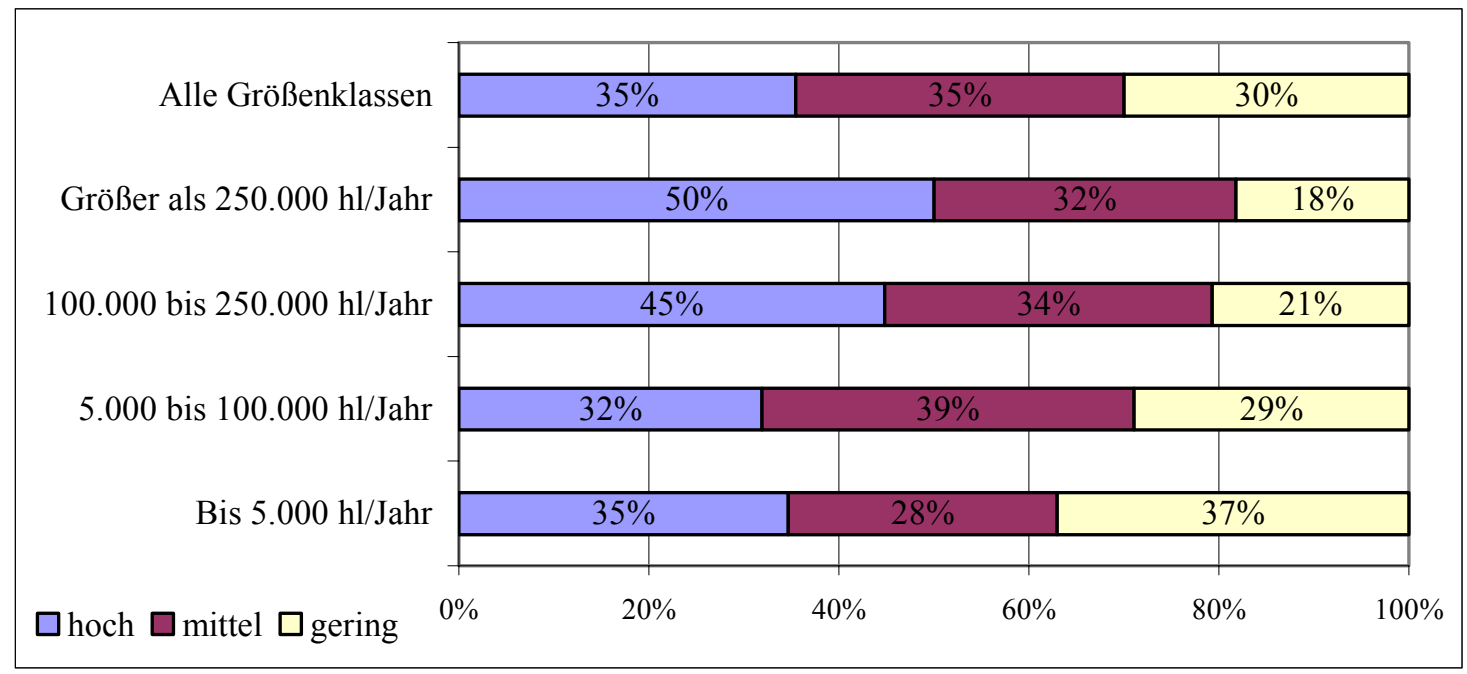

Abbildung 30: Einschätzung der Bedrohung durch Ersatzprodukte

Das politisch-rechtliche Umfeld ist u.a. aufgrund des 2003 eingeführten Einwegpfands von entscheidender Bedeutung für die Branche. Etwa $46 \%$ aller befragten Brauereien konnten nach eigenen Angaben durch die neue Pfandregelung ihre Wettbewerbssituation verbessern. Andererseits sagen auch etwa $32 \%$ der großen bis sehr großen Brauereien, dass sich ihre Position dadurch verschlechtert habe; bei den kleinen Brauereien teilen nur etwa $11 \%$ diese Auffassung. Der höhere Einweganteil national distribuierender Großbrauereien könnte ein Grund für diese Auffassungsunterschiede sein. Ein mögliches Werbeverbot für Bier, eine Kapitalverknappung durch Basel II und insb. die steuerlichen Rahmenbedingungen werden von vielen Brauereien als weitere Bedrohungen in ihrem Umfeld wahrgenommen. Interessant ist, dass sich das Reinheitsgebot weiterhin weitgehend ungeteilter Zustimmung erfreut und offenbar nicht als hinderlich bspw. für Produktinnovationen betrachtet wird (vgl. Abbildung 31).

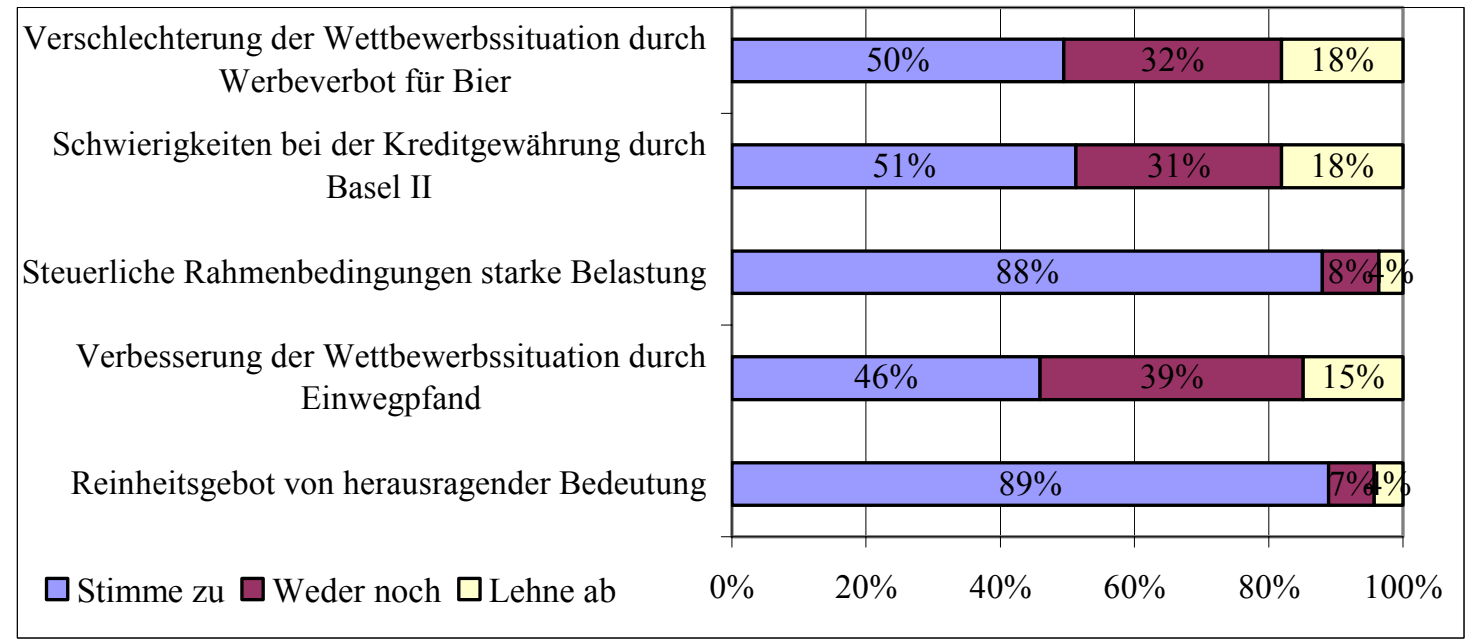

Abbildung 31: Einschätzung des Einflusses verschiedener Umfeldfaktoren auf die Brauereien 
Abbildung 31 fasst die Einschätzungen der befragten Brauereien zu den Treibern des Wettbewerbs im engeren Sinne, also ohne Umfeldfaktoren, zusammen. Dabei wird der Mittelwert über alle befragten Brauereien unter Vernachlässigung größenabhängiger Unterschiede verwendet. Der von den Konkurrenten ausgehende Wettbewerbsdruck und die Macht des Handels werden als dominierende Kräfte wahrgenommen. Auf den nächsten Plätzen folgen die Bedrohung durch Substitutionsprodukte und die Angst vor neuen Wettbewerbern im eigenen Kernabsatzgebiet. Die Verhandlungsstärke der Lieferanten wird dagegen im Mittel vergleichsweise gering eingeschätzt

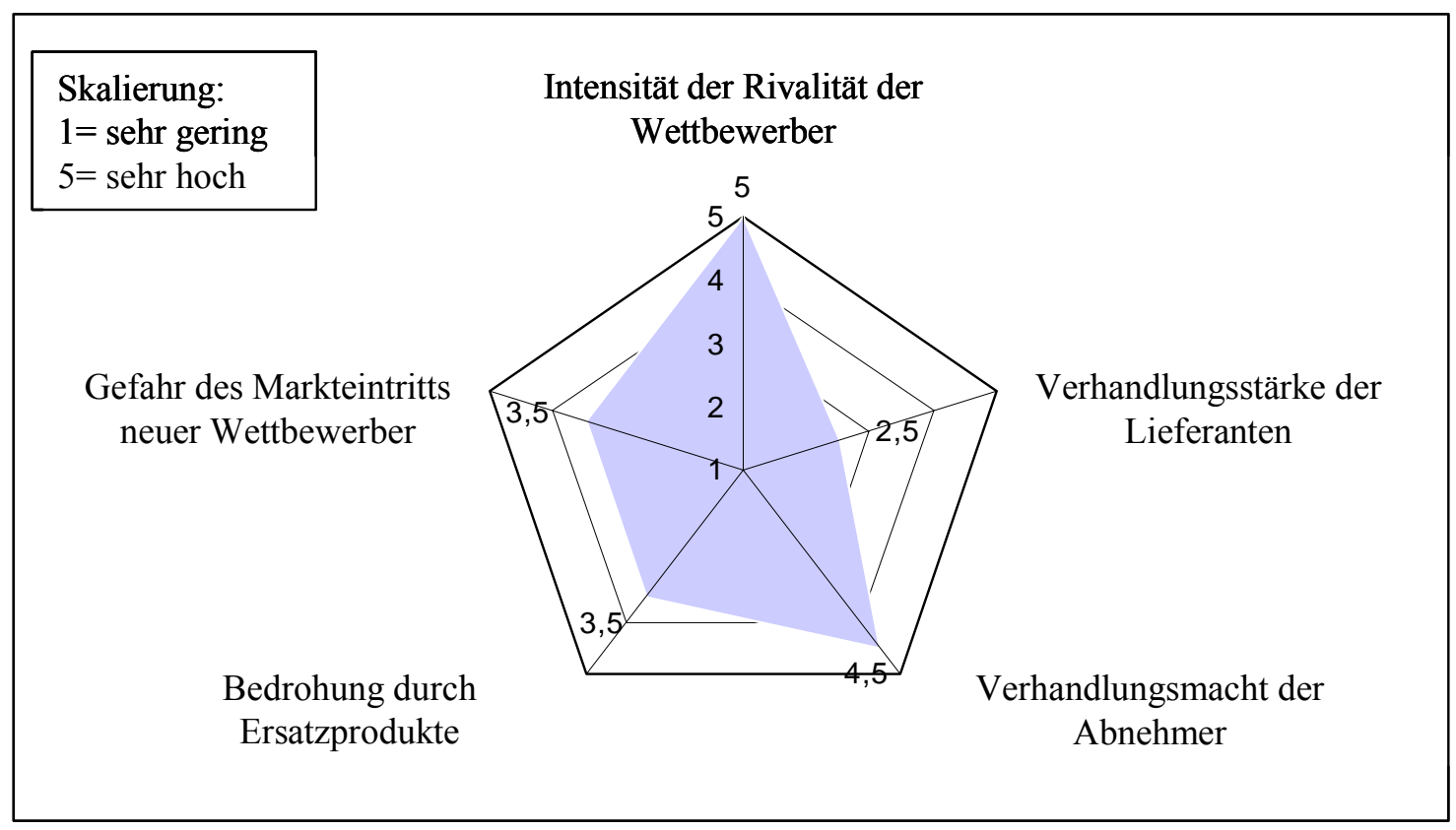

Abbildung 32: Treiber des Wettbewerbs im deutschen Biermarkt Quelle: Eigenerstellung in Anlehnung an HofNAGEL/KORTMANN, 1999: S. 212

Im Ergebnis bleibt festzustellen, dass die Wettbewerbsintensität im deutschen Biermarkt von den meisten Brauereien als sehr hoch wahrgenommen wird. Gleichwohl werden auch weiterhin vor allem größenabhängige Unterschiede deutlich, die darauf hindeuten, dass Unternehmen verschiedener Größenklassen partiell in unterschiedlichen (erlebten) Umwelten agieren. Insoweit wird deutlich, dass die im Kapitel 3.2.3 wiedergegebene Einschätzung der Wettbewerbssituation zwar im Mittel von allen Brauern geteilt wird, dass im Einzelnen allerdings auch erhebliche, vor allem größenabhängige Unterschiede deutlich werden. Insoweit wird die Branche im Sinne WEICKS (1985) tatsächlich nicht von allen Unternehmen gleich erlebt.

Trotz der insgesamt eher krisenhaften Wahrnehmung des Branchenumfelds stellen sich viele Brauereien selbstbewusst den Herausforderungen. So schätzen immerhin rund 31 \% der befragten Unternehmen ihre eigene Wettbewerbsstärke höher ein als die des 
Hauptkonkurrenten im Kernabsatzgebiet. Andererseits - und dies mag ein Grund für das Ausscheiden gerade vieler mittelgroßer Betriebe aus der Produktion sein - erkennen $25 \%$ der Brauereien die Überlegenheit der Wettbewerber an.

\subsubsection{STRATEGISCHE ENTWICKLUNGSLINIEN DEUTSCHER BRAUEREIEN}

\subsubsection{Theoretischer Bezugsrahmen}

Wie die obigen Ausführungen gezeigt haben, sprechen sowohl die sich verändernden Branchenstrukturen als auch die Einschätzung des wettbewerblichen Umfelds durch die Unternehmen dafür, dass viele Unternehmen in der deutschen Brauwirtschaft stärker als je zuvor in ihrer Existenz bedroht sind. Erfolgsgeschichten einzelner Brauereien unterschiedlicher Größe zeigen gleichwohl, dass es möglich ist, sich gegen den negativen Trend im deutschen Biermarkt $\mathrm{zu}$ behaupten und auch in einer schrumpfenden und hart umkämpften Branche erfolgreich zu sein. Ob und inwieweit dies gelingt, hängt maßgeblich von den jeweils verfolgten Strategien ab.

Strategien sind längerfristig gültige Grundsatzentscheidungen, die den Rahmen für nachgelagerte operative Entscheidungen bilden und die der langfristigen Sicherung des Erfolgs dienen (FRESE, 1987: S. 117). Eine Strategie bestimmt die grundsätzliche Ausrichtung eines Unternehmens im Markt, legt das Verhalten gegenüber den Marktteilnehmern fest und determiniert, wie die Ressourcen zur Erreichung der Unternehmensziele einzusetzen sind. Die Betriebswirtschaftslehre unterscheidet nach dem Geltungsbereich zwei Ebenen des strategischen Managements, die Ebene des Gesamtunternehmens und die Ebene einzelner Geschäftsfelder (BARNEY: 2001):

- Unternehmensstrategie: Auf der Ebene des Gesamtunternehmens besteht die zentrale strategische Aufgabe darin festzulegen, mit welchen Produkten und auf welchen Märkten das Unternehmen agieren will. Neben der Produktpalette und der Marktabgrenzung sind u.a. auch Entscheidungen über Leistungstiefe, Vertriebswege, Internationalisierung, Wachstum sowie Diversifikation der unternehmensstrategischen Ebene zuzurechnen. Die Unternehmensstrategien deutscher Brauer bilden einen Schwerpunkt der folgenden Betrachtungen.

- Geschäftsfeldstrategien: Auf der Ebene der einzelnen Geschäftsfelder ist zu entscheiden, mit welcher Wettbewerbsstrategie der einzelne Geschäftsbereich im Markt operieren soll. Unter einer Wettbewerbs- bzw. Geschäftsfeldstrategie wird die Art der Marktbeeinflussung innerhalb eines einzelnen Geschäftsfeldes 
verstanden. Die von PORTER (1995) popularisierte Unterscheidung von Kostenführerschafts-, Differenzierungs- und Nischenstrategien zeigt mögliche Wege zur Erzielung von Wettbewerbsvorteilen in einzelnen Geschäftsfeldern auf. Auch auf der wettbewerbsstrategischen Ebene eröffnen sich den Brauereien Ansatzpunkte, z.B. mittels Produktinnovationen, Schärfung des Markenprofils oder Erschließung von Preiseinstiegssegmenten Wege aus der Krise zu finden.

HoFER und SCHENDEL (1978, S. 27ff.) unterscheiden mit den Funktionalstrategien, die das langfristige Vorgehen in einzelnen betrieblichen Funktionsbereichen festlegen, eine dritte Strategieebene, die jedoch eng mit der jeweils verfolgten Wettbewerbsstrategie verknüpft ist und aus diesem Grund hier nicht näher betrachtet werden soll. Im Anschluss werden stattdessen die Kooperationsstrategien in der deutschen Brauwirtschaft näher beleuchtet, da diese sowohl bei der erfolgreichen Umsetzung der Unternehmensstrategie als auch der Geschäftsfeldstrategien hilfreich sein können.

\subsubsection{Unternehmensstrategie}

Im Zentrum der Unternehmensstrategie steht die Frage, mit welchen Produkten die Unternehmen am Markt agieren. Abbildung 33 veranschaulicht die Anteile der wichtigsten Biersorten, der Biermischgetränke sowie der alkoholfreien Getränke an der Produktpalette der befragten Brauereien.

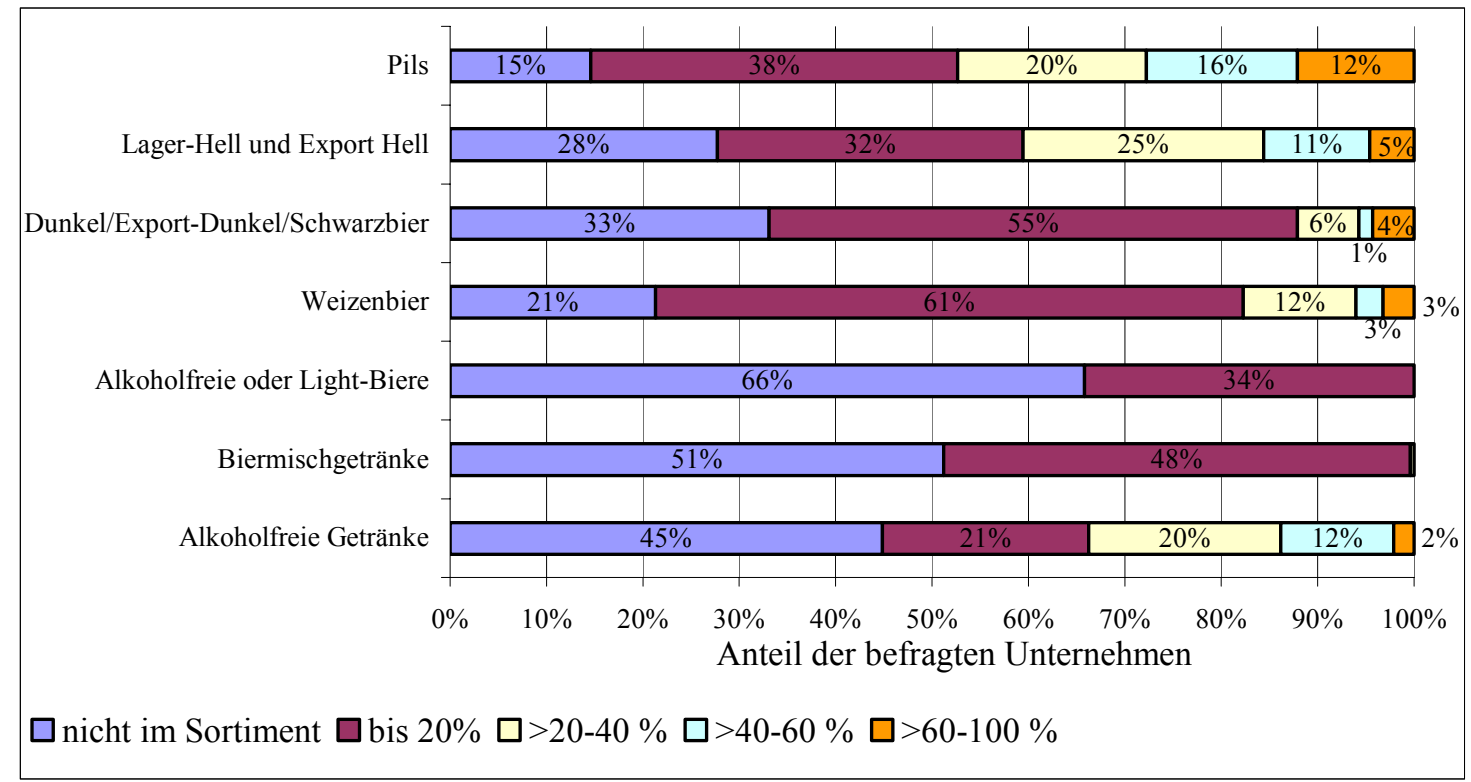

Abbildung 33: Anteile der verschiedenen Produkte am Gesamtgetränkeausstoß der Brauereien

Pils ist - das ist nicht überraschend - die dominierende Biersorte im Produktportfolio deutscher Brauereien. Nur 15 \% der befragten Brauereien haben kein Pils im Sortiment; 
bei immerhin $12 \%$ der untersuchten Brauereien machen Pilsbiere über $60 \%$ des Gesamtgetränkeausstoßes aus. Diese Pilsspezialisten sind zumindest zahlenmäßig eine Ausnahme, denn die große Mehrzahl der Brauereien ist nicht extrem spezialisiert. So liegen die Anteile einzelner Produkte am Gesamtgetränkeausstoß in der Regel unter $60 \%$, vielfach sogar unter $20 \%$. Allerdings ist ein deutlicher Unterschied zwischen den verschiedenen Größenklassen festzustellen; bei vielen größeren Brauereien (über $100.000 \mathrm{hl}$ pro Jahr) liegen die Ausstoßanteile von Pils und Weizen deutlich über dem Branchendurchschnitt.

Rund die Hälfte der Brauereien versucht, am Boom der Biermischgetränke durch Einstieg in dieses neue Marktsegment zu partizipieren. Von ganz wenigen Ausnahmen abgesehen ist daraus bislang kein dominierendes Geschäft geworden. Alkoholfreie Getränke sind in vielen Fällen ein deutlich wichtigeres Standbein.

Bei der Leistungstiefe steht die Frage im Vordergrund, welche Produkte bzw. Dienstleistungen selbst erstellt und welche zugekauft werden sollen. Diese Frage kann sowohl für die Kernfunktionen des Unternehmens, insbesondere die Getränkeherstellung, wie auch für unterstützende Dienstleistungen, etwa den Fuhrpark, gestellt werden. Die Umgestaltung von Wertschöpfungsketten hat sich als ein wesentlicher Baustein der Etablierung neuer Geschäftsmodelle erwiesen (KRÜGER, 2002: S. 63ff.). Je zentraler der Stellenwert einer für das Outsourcing ins Auge gefassten Teilfunktion im Unternehmen ist, desto umfassender ist der daraus resultierende betriebliche Wandel.

Abbildung 34 veranschaulicht die Anteile der Getränke aus eigener Herstellung am Gesamtgetränkeabsatz der befragten Unternehmen. Dabei wird ersichtlich, dass der Anteil der selbsterzeugten Getränke bei einem Viertel der befragten Brauereien unter 80 $\%$ und bei weiteren $18 \%$ sogar unter $60 \%$ liegt. Zwischen den verschiedenen Größenklassen bestehen in dieser Hinsicht jedoch erhebliche Unterschiede. So entfällt in der Tendenz mit steigender Gesamtjahreserzeugung ein höherer Anteil auf Getränke aus eigener Herstellung. Im Detail ist das Bild allerdings widersprüchlich. So finden sich in der Gruppe der Kleinbrauereien sowohl viele Unternehmen, die ausschließlich auf eigene Herstellung setzen, als auch viele Betriebe, für die der Handel mit zugekauften Produkten eine wichtige Rolle spielt. 


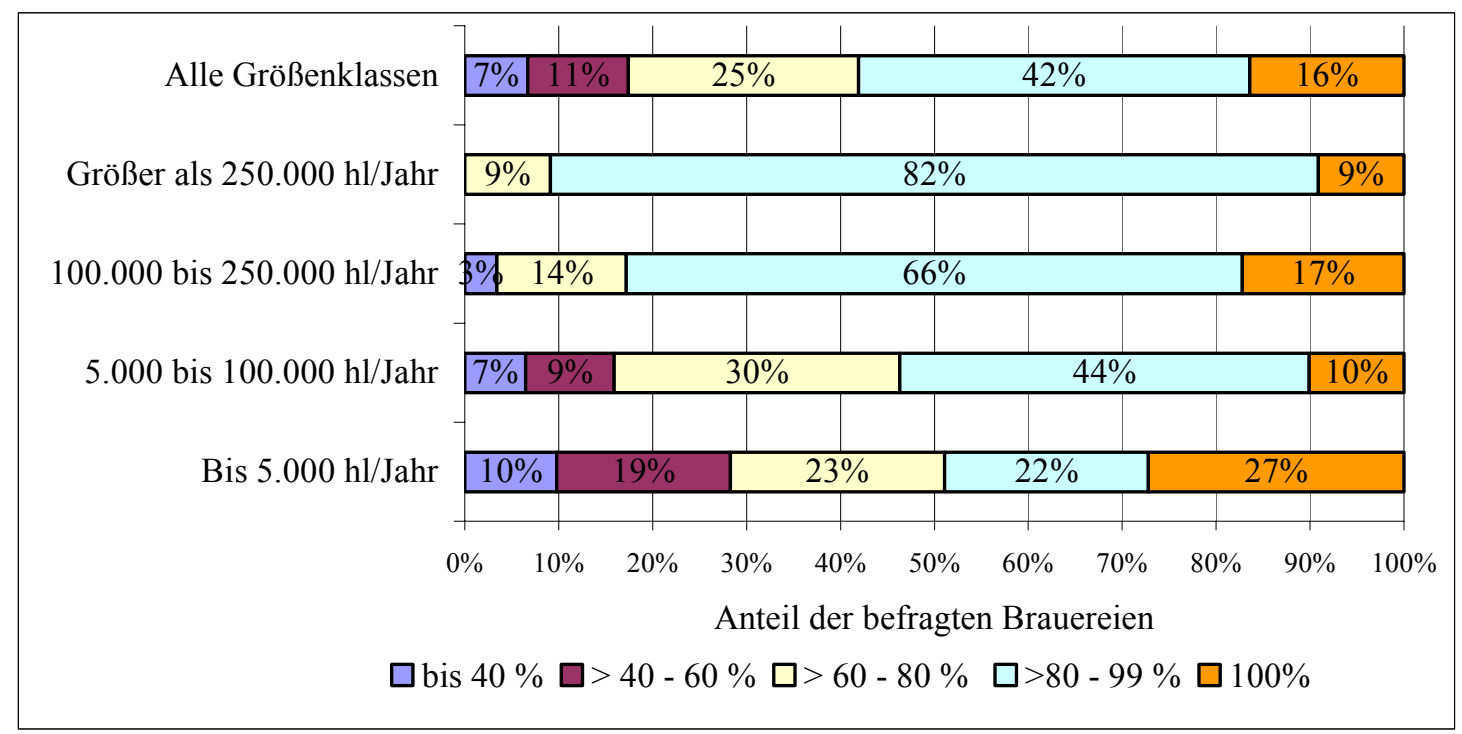

Abbildung 34: Anteil der Getränke aus eigener Herstellung am Gesamtabsatz der Brauereien

Erhebliche Überkapazitäten in der Branche, erfolgreiche Vorbilder im SoftdrinkBereich wie etwa Red Bull sowie der bei vielen Brauern ohnehin bedeutende Handelsanteil legen die Frage nahe, ob Brauereien sich vorstellen können, die Brautätigkeit in Zukunft vollständig auszulagern, um sich ganz auf den Vertrieb zu konzentrieren. Dieser Frage stimmten immerhin 8,5 \% aller Brauereien zu. Sie würden sich durch die Realisierung dieses Geschäftsmodells aus der bisherigen Produktionsorientierung lösen und sich darauf konzentrieren, das Ende der Wertschöpfungskette zu kontrollieren. Folgt man der Begriffsfassung von PRAHALAD und HAMEL (1990: S. 83f.), so eröffnen Kernkompetenzen den Zugang zu einer Vielzahl von Märkten, leisten einen wesentlichen Beitrag zu dem vom Kunden wahrgenommenen Nutzen eines Produkts und sind für Wettbewerber schwer zu imitieren. Angesichts erheblicher Überkapazitäten in der Branche und weitgehend standardisierter Brauverfahren ist $\mathrm{zu}$ fragen, ob die Kernkompetenzen einer Brauerei heute nicht eher im Vertriebs- als im Produktionsbereich liegen (sollten). Das Outsourcing der Produktion stünde vor diesem Hintergrund im Einklang mit der zentralen Forderung des kernkompetenzorientierten Ansatzes im strategischen Management, sich auf Kernkompetenzen zu konzentrieren (THEUVSEN, 2001: S. 1644ff.).

Mit Blick auf den Fuhrpark zeichnet sich ein klares Bild ab. Etwa $74 \%$ aller befragten Brauereien wollen auch in Zukunft einen eigenen Fuhrpark unterhalten. Allerdings sind auch hier wieder deutliche Unterschiede festzustellen. Aus Abbildung 35 wird 
ersichtlich, dass die größeren, oft national distribuierenden Brauereien sich am ehesten ein Outsourcing der Logistik vorstellen können. Die unter besonderem Wettbewerbsdruck stehenden mittelgroßen Brauereien stehen Veränderungen im Bereich des Fuhrparks dagegen wesentlich weniger aufgeschlossen gegenüber. Es ist zu prüfen, ob nicht auch an dieser Stelle eine stärkere Konzentration auf Kernkompetenzen sinnvoll wäre.

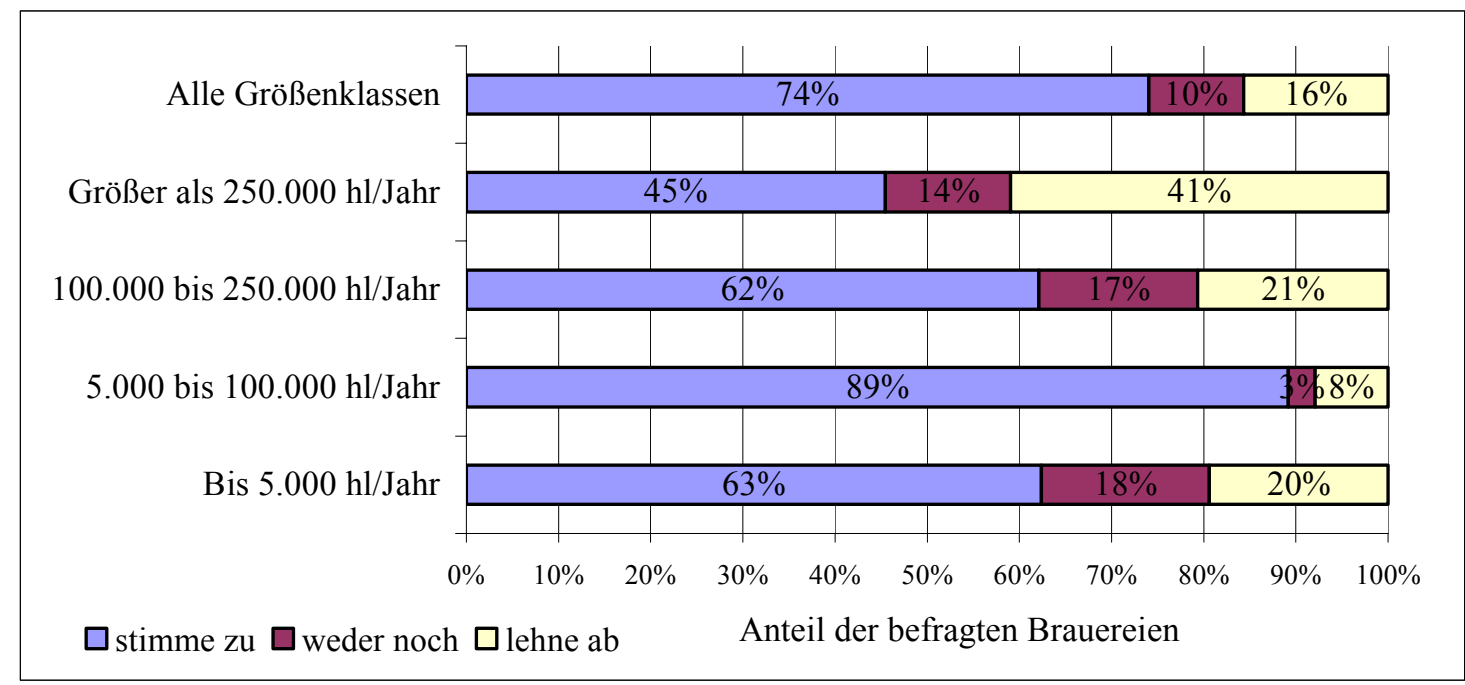

Abbildung 35: „Wir werden auch in Zukunft einen eigenen Fuhrpark betreiben.“

Neben dem Produkt- und Tätigkeitsspektrum bestimmen auch die bedienten Marktsegmente und Vertriebskanäle die Unternehmensstrategie einer Brauerei. Abbildung 36 gibt die Anteile am Gesamtgetränkeausstoß der befragten Unternehmen wieder, die über die verschiedenen Vertriebswege abgesetzt werden.

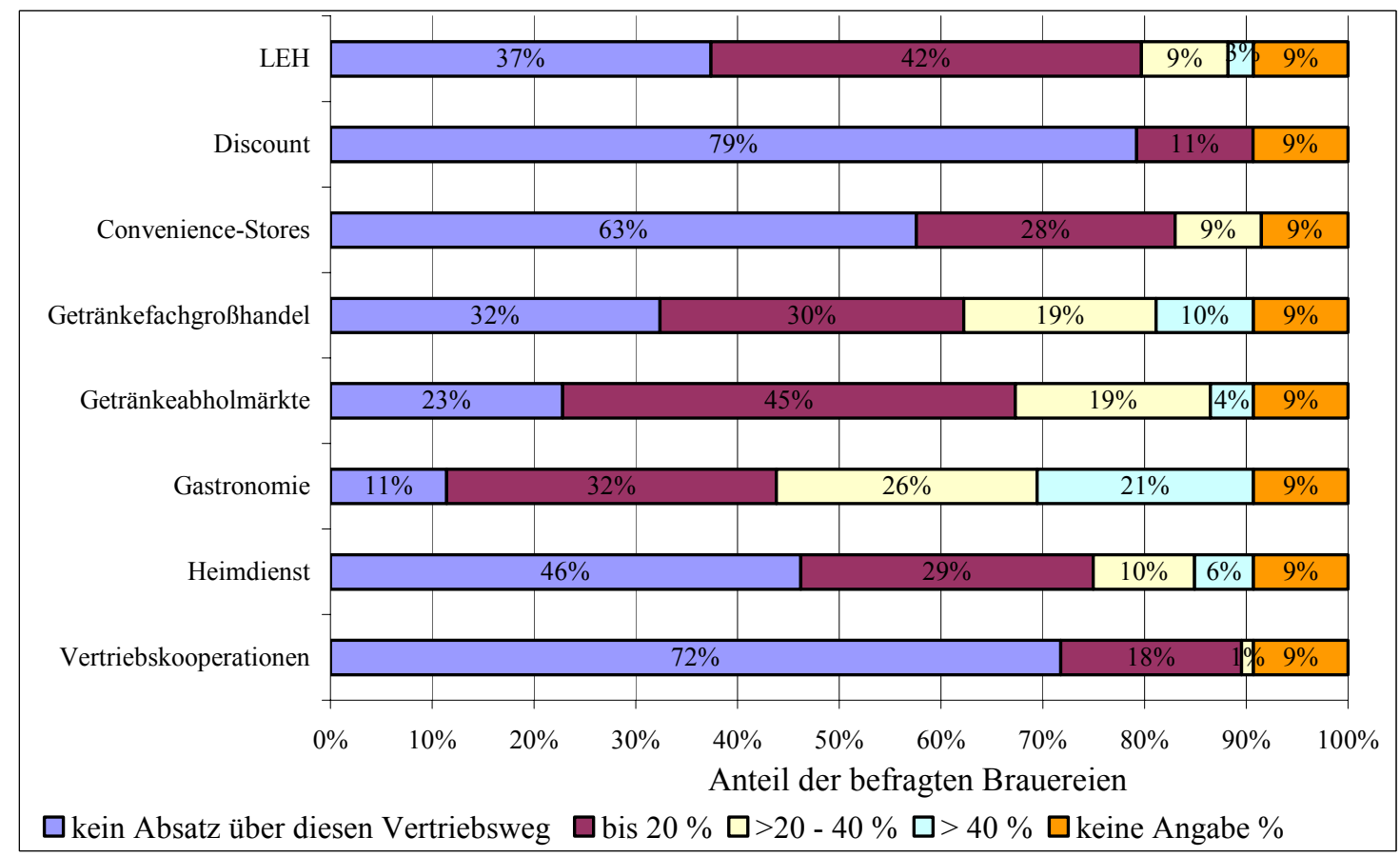

Abbildung 36: Bedeutung verschiedener Vertriebswege 
Gemessen an der Zahl der Brauereien ist die Gastronomie der wichtigste Vertriebsweg; er wird von $89 \%$ der Unternehmen genutzt. Es folgen der Getränkefachgroßhandel (68 $\%$ ) und der Lebensmitteleinzelhandel (63\%). Heimdienste und Vertriebskooperationen sind für das Gros der Brauereien von nachrangiger Bedeutung. Erst recht gilt dies für Discounter, die oft ein national weitgehend einheitliches Produktangebot haben und daher nur wenigen (Groß-)Brauereien Absatzchancen bieten.

Bei genauerem Hinsehen werden wieder deutliche Unterschiede zwischen den verschiedenen Größenklassen erkennbar. So steigt z.B. - bedingt durch die wachsende Ausdehnung des Absatzgebietes - die Bedeutung des Getränkefachgroßhandels mit zunehmender Betriebsgröße deutlich an. Die kleineren Brauereien (5.000 bis 100.000 hl pro Jahr) setzen im Durchschnitt nur etwa $24 \%$ des gesamten Getränkeausstoßes über diesen Vertriebsweg ab, wohingegen es bei den größeren Unternehmen durchschnittlich etwa $43 \%$ sind. Bei Betrachtung der Gastronomie ergibt sich ein genau entgegengesetztes Bild. Während die Kleinstbrauereien (bis 5000 hl/Jahr) ca. 50 \% ihres Bieres über die Gastronomie absetzen, beträgt der vergleichbare Wert bei Brauereien mit mehr als $250.000 \mathrm{hl} / \mathrm{Jahr}$ im Durchschnitt nur etwa $19 \%$.

Verglichen mit großen ausländischen Wettbewerbern besitzt die Internationalisierung für die meisten deutschen Brauereien bislang eine erheblich geringere Bedeutung. Trotzdem sind schon jetzt ca. $22 \%$ aller befragten Brauereien international tätig oder beabsichtigen, in naher Zukunft international tätig $\mathrm{zu}$ werden. Insoweit werden die Anstrengungen, auf neuen Märkten $\mathrm{Fu} ß \mathrm{zu}$ fassen und das Produkt-/Marktspektrum entsprechend zu erweitern, erheblich verstärkt. Mit steigender Betriebsgröße nimmt die Bedeutung des internationalen Geschäfts erwartungsgemäß zu (vgl. Abbildung 37).

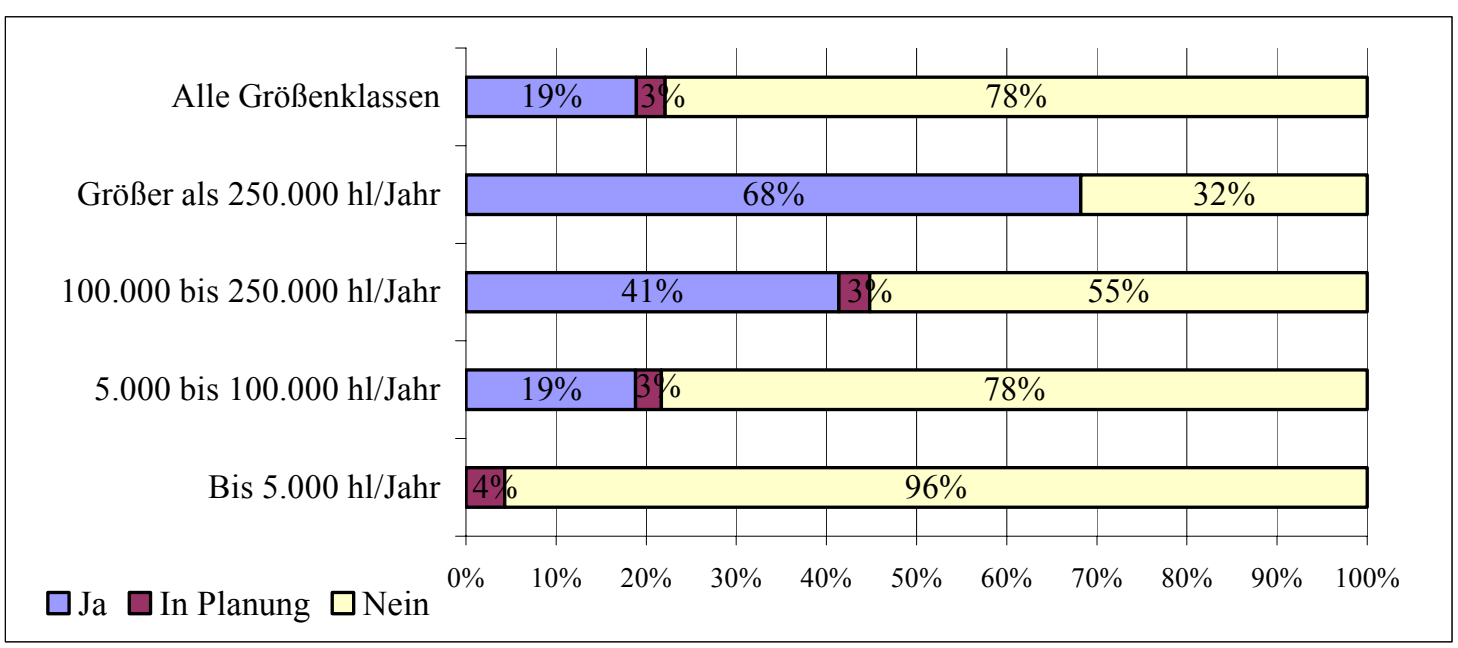

Abbildung 37: Internationalisierung der deutschen Brauwirtschaft 
Je nach Umfang der ins Ausland verlagerten Finanz- und Managementressourcen können unterschiedlich weit reichende Formen der Internationalisierung unterschieden werden (MEISSNER/GERBER, 1980: S. 217ff.). Die Markterschließung im Ausland erfolgt bei 96 \% der befragten Brauereien über Exporte. Lizenzvergaben, Joint Ventures und andere anspruchsvollere Formen der Internationalisierung werden nur von rund 13 $\%$ der international tätigen Brauereien gewählt. Der Auslandsabsatz aller befragten international tätigen Brauereien beläuft sich im Schnitt auf etwa 6,3 \% des Gesamtabsatzes.

Rund 17,5 \% der Befragten sind der Ansicht, dass die Bedeutung der Internationalisierung für ihr Unternehmen in Zukunft steigen wird. Die Entwicklung des Auslandsabsatzes in den letzten drei Jahren bestätigt diese Einschätzung; im Durchschnitt aller befragten Unternehmen haben die Ausfuhren um ca. $23 \%$ zugenommen. Diese Zahl belegt, dass der Export für viele Brauereien ein Weg sein kann, Absatzverluste im Inland zu kompensieren. Zugleich wird erkennbar, dass die Chancen, die das Auslandsgeschäft angesichts des hervorragenden Rufs des deutschen Bieres bietet, bislang nur unzureichend genutzt worden sind. Kleinere Brauereien versuchen teilweise mit Hilfe von Vertriebskooperationen, das Auslandsgeschäft besser als bisher zu erschließen (HofBAUER, 2005: S. 3).

Hinsichtlich der strategischen Entwicklungsrichtung können sich Unternehmen für Wachstums-, Stabilisierungs- oder Schrumpfungsstrategien entscheiden (BECKER/FALlgatTER, 2005: S. 119ff.). Im schrumpfenden und hart umkämpften deutschen Biermarkt verfolgen viele Unternehmen eine Wachstumsstrategie. So haben etwa $9 \%$ aller Befragten in den letzten fünf Jahren eine oder mehrere andere Brauereien übernommen. Der Durchschnittswert ist in diesem Fall allerdings wenig aussagekräftig, da Mergers \& Acquisitions für die große Zahl der Kleinst- und Kleinbrauereien naturgemäß kaum in Frage kommen. In diesen Gruppen haben dementsprechend nur $3 \%$ bzw. 8 \% der Brauer die entsprechende Frage bejaht. Etwa $17 \%$ der Brauereien mit einem Jahresausstoß von 100.000 bis $250.000 \mathrm{hl} / \mathrm{Jahr}$ und sogar $41 \%$ aller befragten Unternehmen in der Größenklasse über $250.000 \mathrm{hl} / \mathrm{Jahr}$ haben dagegen eine Strategie des externen Wachstums eingeschlagen. Für die Zukunft ziehen ca. 35 \% der befragten Unternehmen über $100.000 \mathrm{hl} / \mathrm{Jahr}$ weitere Zukäufe in Betracht. 
Auf der anderen Seite sind etwa $20 \%$ aller befragten Brauereien mit ihrem Marktanteil zufrieden und ergreifen daher keine Maßnahmen zu seiner Erweiterung. Spiegelbildlich zum Wachstum durch Zukäufe sind auch hier wieder deutliche Unterschiede zwischen den Größenklassen zu erkennen. So sind unter den großen Brauereien nur 4,5 \% mit ihrem Marktanteil zufrieden, wohingegen es bei den kleinen Unternehmen (bis 5.000 hl/Jahr) ca. $24 \%$ sind.

Die Diversifikation kann nicht nur Kern einer auf der Erschließung neuer Produkt/Marktkombinationen basierenden Wachstumsstrategie, sondern auch eine Form der Risikostreuung sein (ANSOFF, 1965: S. 108ff.). Eine vorwiegend horizontale oder laterale Diversifikation kann von Brauereien eingesetzt werden, um die Abhängigkeit vom Stammgeschäft und damit vom schwierigen Biermarkt zu verringern. In der Braubranche stellt der Vertrieb von alkoholfreien Getränken eine traditionelle und aufgrund der guten Ergänzung mit dem Kerngeschäft nahe liegende Diversifikationsmöglichkeit dar, die von ca. $55 \%$ der befragten Unternehmen ergriffen worden ist (vgl. Abbildung 33, S. 111). Daneben existiert vielfach ein in der Regel allerdings eher unbedeutender Vertrieb von Nebenprodukten (Gläser, Bierdeckel, sonstige Zubehör- und Werbeartikel). Für weitere, z. T. bereits weiter vom Kerngeschäft entfernt liegende Arten der Diversifikation - Catering, Eventmanagement, Reisen, Komplementärprodukte wie Nahrungsmittel oder Spirituosen usw. - haben sich immerhin ca. $32 \%$ der befragten Brauereien entschieden. Es überrascht nicht, dass diese Form der Ausweitung des Produktspektrums bei den großen Brauereien über $250.000 \mathrm{hl} / \mathrm{Jahr}$ nicht, bei den Kleinstbrauereien dagegen sehr verbreitet ist (vgl. Abbildung 38).

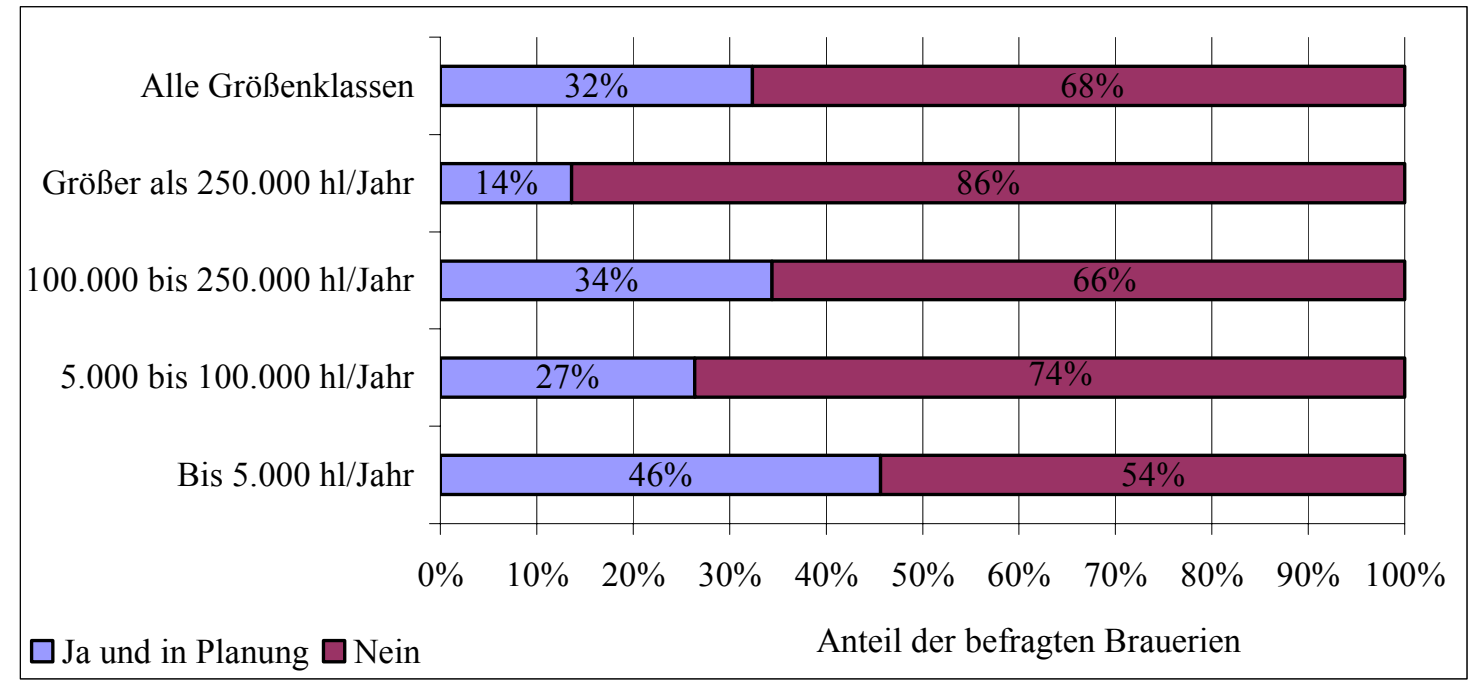

Abbildung 38: Diversifikation in der Brauwirtschaft 
Eine weitere Möglichkeit der Diversifikation in der Brauwirtschaft bietet die vertikale Integration durch Übernahme einzelner Vertriebspartner. Im Mittelpunkt des Interesses steht in letzter Zeit vor allem der Getränkefachgroßhandel. Etwa $9 \%$ aller befragten Brauereien haben in der Vergangenheit bereits einen oder mehrere Getränkefachgroßhändler übernommen oder planen für die Zukunft eine Übernahme. In der Gruppe der großen Brauereien (über 250.000 hl/Jahr) haben sich sogar ca. 27 \% aller Befragten für diesen Diversifikationsschritt entschieden oder planen ihn.

Fasst man die bislang dargestellten Ergebnisse zusammen, so lassen sich mit Blick auf die Erschließung neuer Märkte durch unternehmensstrategische Maßnahmen etwas vereinfachend zwei Unternehmens-Cluster in der deutschen Brauwirtschaft unterscheiden: die expandierenden Spezialisten und die regionalen Diversifizierer.

Die Gruppe der expandierenden Spezialisten besteht überwiegend aus großen Brauereien, die - gestützt auf eigene Braukapazitäten und regional oder sogar national bekannte Marken - eine Ausdehnung des Absatzes anstreben. Externes Wachstum durch Übernahmen und eine zunehmende Internationalisierung der Geschäftsaktivitäten sind typisch für diese Gruppe. Angesichts eines überregionalen und oft noch wachsenden Absatzgebietes sind der Getränkefachgroßhandel und der Lebensmitteleinzelhandel dominierende Vertriebswege.

Die regionalen Diversifizierer bilden die zweite Gruppe. Diese Brauereien sind im Durchschnitt deutlich kleiner und verfolgen eine eher gastronomieorientierte Strategie. Ihr Leistungsangebot ist stärker diversifiziert; der Handel mit zugekauften Produkten, alkoholfreie Getränke sowie weitere Produkte und Dienstleistungen wie z.B. Catering spielen eine wichtige Rolle. Im Idealfall ergibt sich eine Unternehmensstrategie, die dem Endverbraucher eine „Erlebniswelt um das Bier“ präsentiert und zugleich eine Risikostreuung ermöglicht.

\subsubsection{Wettbewerbsstrategien}

Im Folgenden werden die Geschäftsbereichs- bzw. Wettbewerbsstrategien der befragten Unternehmen näher untersucht. Im Mittelpunkt stehen dabei die wichtigen Elemente Markenmanagement, Preispolitik, Kosten sowie Innovationsbereitschaft. Alle genannten Aspekte stehen in engem Zusammenhang mit der Absicherung bereits 
bedienter bzw. der Erschließung möglicher neuer Marktsegmente (z.B. Premiumsegment oder Preiseinstiegsbereich).

Zunächst zu der Frage, inwieweit die Unternehmen mit Markenartikeln (Herstellermarken) oder Handelsmarken am Markt agieren. Abbildung 39 veranschaulicht den Anteil der Markenartikel am Gesamtgetränkeausstoß der befragten Brauereien.

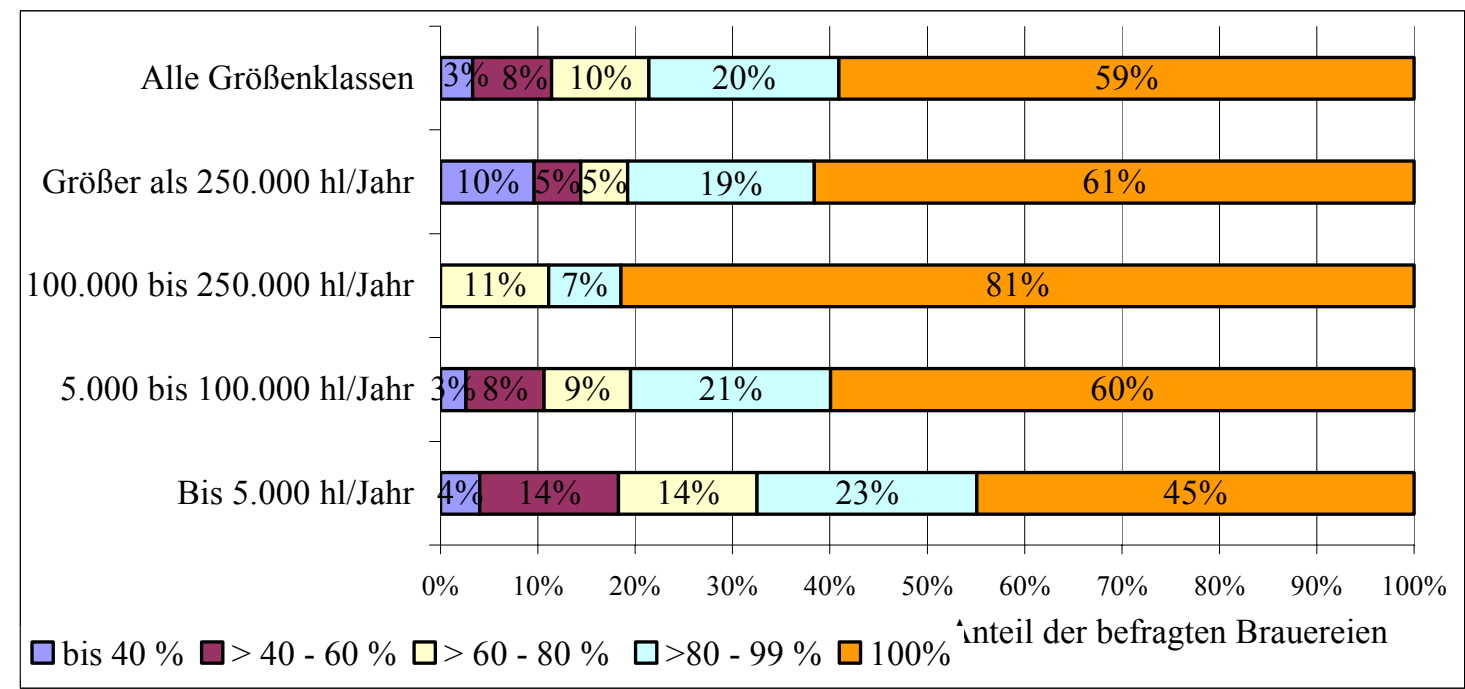

Abbildung 39: Anteil der Markenartikel am Gesamtgetränkeausstoß

Dabei wird ersichtlich, dass immerhin knapp $60 \%$ aller befragten Brauereien ausschließlich eigene Marken produzieren. Weitere $20 \%$ haben einen Markenanteil, der mehr als $80 \%$ des Gesamtausstoßes umfasst; bei etwa $11 \%$ der Unternehmen liegt der Anteil der Marken nur bei bis zu 60 \% des Gesamtabsatzes. Im Einzelnen bestehen in dieser Hinsicht erhebliche Unterschiede. So stechen besonders die Brauereien mit einem Jahresausstoß von 100.000 bis 250.000 hl hervor, von denen $81 \%$ gänzlich auf die Produktion von Handelsmarken verzichten; keine der befragten Brauereien dieser Größenordnung hat angegeben, weniger als $60 \%$ des Gesamtabsatzes mit eigenen Marken zu erzielen. In der Größenklasse über $250.000 \mathrm{hl} / \mathrm{Jahr}$ ergibt sich ein anderes Bild; etwa $15 \%$ dieser Unternehmen produzieren überwiegend Handelmarken. Hier ist anzunehmen, dass Überkapazitäten zur Produktion von Handelsmarken genutzt werden, um Marktanteile zu halten und zur Deckung der Fixkosten beizutragen.

Mit Blick auf die Preispolitik stellt sich die Frage, welche Verkaufspreise im Handel durchsetzbar sind. Abbildung 40 veranschaulicht die Preise, $\mathrm{zu}$ denen die Hauptbiermarken der befragten Brauereien in der Kastenform 20 x 0,5 1 üblicherweise 
im Handel angeboten werden. Auch hier werden wieder interessante Unterschiede sichtbar. So können in der Tendenz mit steigender Gesamtjahreserzeugung höhere Preise im Handel erzielt werden. Im Detail ist das Bild allerdings widersprüchlich. So finden sich in allen Größenklassen sowohl viele Brauereien, die mehr als $12 €$ pro Kasten erzielen, als auch zahlreiche Unternehmen, die nicht mehr als $10 €$ und z. T. sogar nicht einmal $9 €$ als Abgabepreis im Handel durchsetzen können.

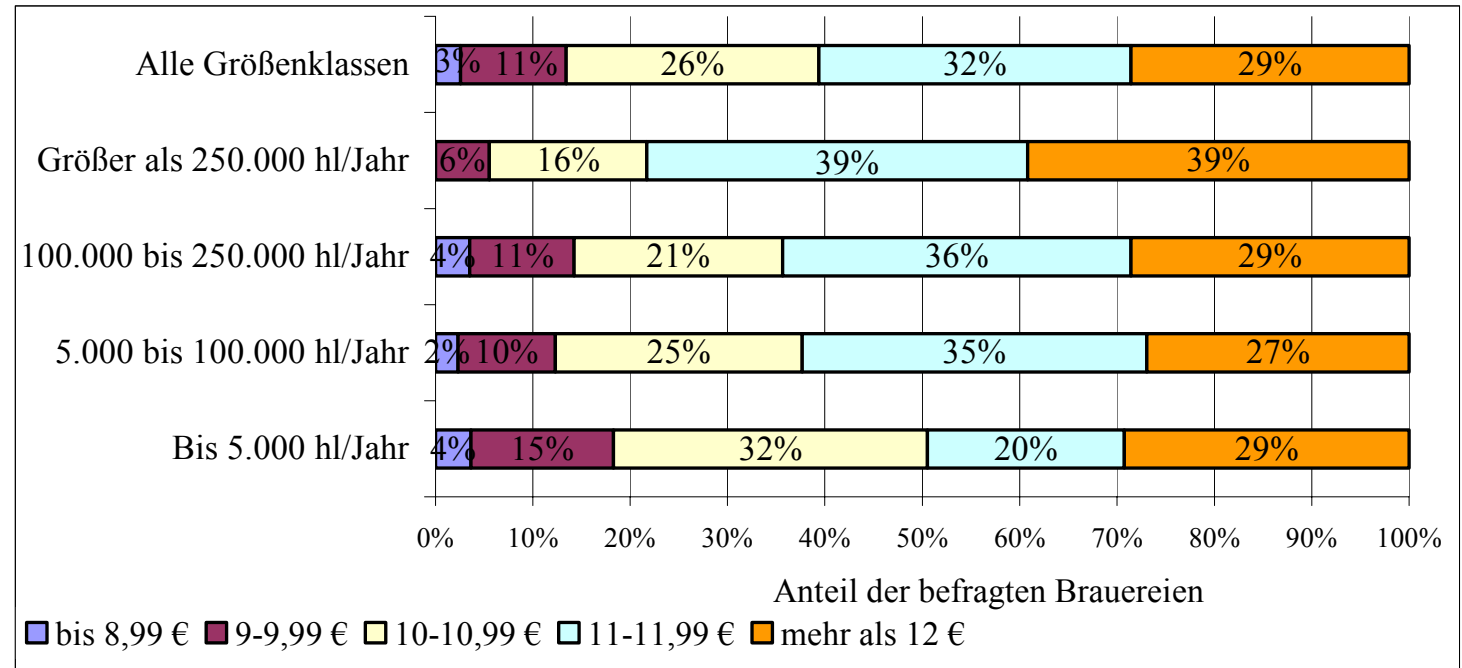

Abbildung 40: Einzelhandelspreis der Hauptbiermarke (Kastenform 20 x 0,5 1)

Neben dem Preis ist der Anteil der Hauptbiermarke am Gesamtgetränkeausstoß von Interesse (Abbildung 41). Auch insoweit sind wieder deutliche Unterschiede zwischen den verschiedenen Größenklassen zu erkennen.

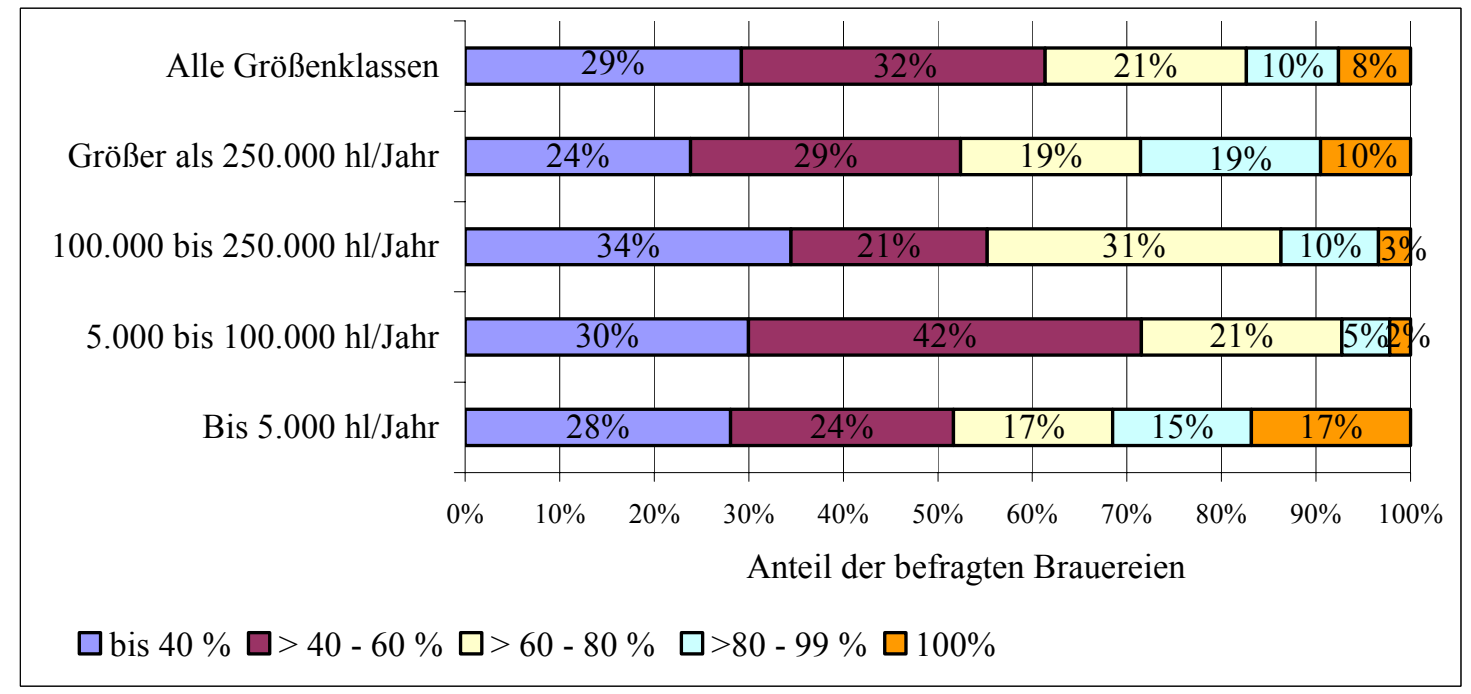

Abbildung 41: Anteil der Hauptbiermarke am Gesamtgetränkeausstoß

Klammert man die Kleinstbrauereien mit bis zu 5.000 hl/Jahr aus der Betrachtung aus, so steigt mit zunehmender Gesamtjahreserzeugung der Anteil derjenigen Unternehmen deutlich an, die mehr als $60 \%$ ihres Absatzes mit einer Marke erzielen oder sogar eine 
Monomarkenstrategie verfolgen. In der Gesamtstichprobe liegt der Anteil der Hauptbiermarke bei rund einem Drittel der befragten Brauereien unter $60 \%$ und bei weiteren $29 \%$ sogar unter $40 \%$.

Da die wenigsten Brauereien ihren Gesamtabsatz mit nur einer Hauptmarke tätigen, stellt sich die Frage, zu welchem Preis Zweit- oder Handelsmarken abgesetzt werden können. Diese Marken werden in der Regel weniger intensiv und z. T. auch gar nicht beworben und ihre Herkunft ist für den Verbraucher oftmals nicht oder zumindest nicht auf den ersten Blick zu erkennen. Abbildung 42 veranschaulicht die Preise, zu denen die preiswertesten Biere der befragten Brauereien in der Kastenform 20 x 0,51 normalerweise im Handel angeboten werden.

Aus Abbildung 42 wird ersichtlich, dass das preiswerteste Bier bei etwa $62 \%$ der befragten Unternehmen nicht unter $10 €$ je Kasten an Endverbraucher abgeben wird und diese Brauereien sich somit für eine Hochpreisstrategie auch im Zweitmarkenbereich entschieden haben. Auf der anderen Seite kostet aber bei etwa $9 \%$ der Brauereien der preiswerteste Kasten unter $8 €$ und bei weiteren $4 \%$ sogar unter $6 €$. Zwischen den Größenklassen werden insoweit wieder deutliche Unterschiede sichtbar.

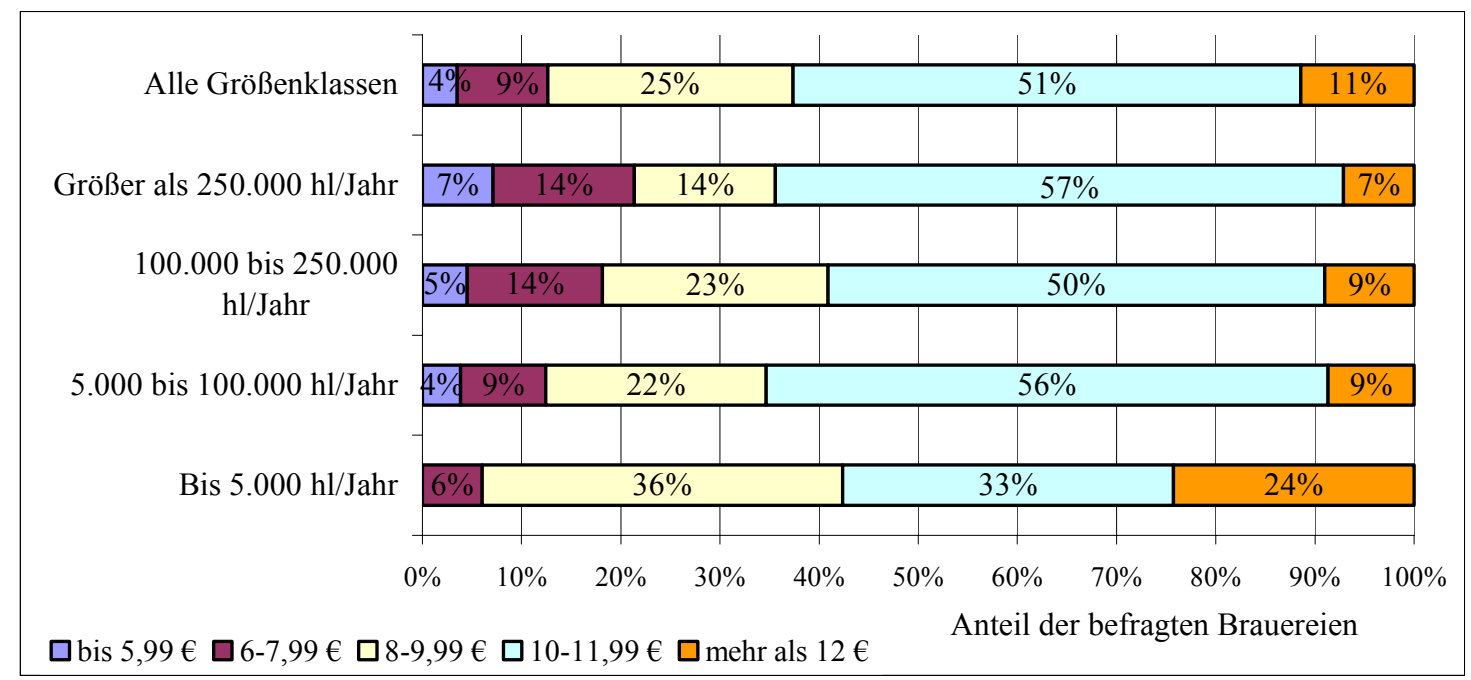

Abbildung 42: Einzelhandelspreis für das preiswerteste Bier (Kastenform 20 x 0,5 1)

So steigt der Anteil derer, die ihr Heil im Preiseinstiegsbereich suchen, mit zunehmender Betriebsgröße erheblich an. Dieses Ergebnis unterstreicht nochmals die bereits an anderer Stelle geäußerte Vermutung, dass vor allem Großbrauereien Überkapazitäten durch die Produktion von „Billigbier“ auslasten. Allerdings stellt Abbildung 42 in dieser Hinsicht auch Brauern mit 100.000 bis 250.000 hl/Jahr kein 
gutes Zeugnis aus; zugleich können diese seltener als der Branchendurchschnitt Kastenpreise über $10 €$ für das preiswerteste Bier erzielen.

Einen Hinweis auf die Differenzierung über Marken und Markenmanagement gibt die Höhe der Marketingausgaben. Tabelle 14 zeigt für die befragten Brauereien die Mittelwerte der Marketingausgaben pro Hektoliter (inkl. Sponsoring und Verkaufsförderung) im Durchschnitt der Jahre 2001 bis 2003. Aus Tabelle 14 ist zu ersehen, dass die Marketingausgaben je Hektoliter bei den Brauereien, die mehr als $100.000 \mathrm{hl} / \mathrm{Jahr}$ absetzen, in der Tendenz wesentlich höher liegen als bei den kleineren Unternehmen. Außerdem kann abgelesen werden, dass seit 2001 die Werbeausgaben pro Hektoliter in allen Größenklassen zugenommen haben - entweder, weil Absatzrückgängen mit vermehrten Marketinganstrengungen begegnet wird, oder, weil sich ein (weitgehend) konstantes Marketingbudget auf eine sinkende Absatzmenge verteilt.

\begin{tabular}{|l|c|c|c|c|c|}
\hline & \multicolumn{4}{|c|}{ Gesamtgetränkeausstoß } & \multirow{2}{*}{ Gesamt } \\
\cline { 2 - 5 } & Bis $5.000 \mathrm{hl}$ & $\begin{array}{c}5.000- \\
100.000 \mathrm{hl}\end{array}$ & $\begin{array}{c}100.000- \\
250.000 \mathrm{hl}\end{array}$ & $\begin{array}{c}\text { Größer als } \\
250.000 \mathrm{hl}\end{array}$ & \\
\hline $\begin{array}{l}\text { Durchschnittliche } \\
\text { Marketingausgaben } \\
2001\end{array}$ & $5,26 € / \mathrm{hl}$ & $5,20 € / \mathrm{hl}$ & $7,44 € / \mathrm{hl}$ & $7,07 € / \mathrm{hl}$ & $5,62 € / \mathrm{hl}$ \\
\hline $\begin{array}{l}\text { Durchschnittliche } \\
\text { Marketingausgaben } \\
2002\end{array}$ & $5,86 € / \mathrm{hl}$ & $5,35 € / \mathrm{hl}$ & $7,34 € / \mathrm{hl}$ & $7,54 € / \mathrm{hl}$ & $5,87 € / \mathrm{hl}$ \\
\hline $\begin{array}{l}\text { Durchschnittliche } \\
\text { Marketingausgaben } \\
2003\end{array}$ & $6,92 € / \mathrm{hl}$ & $5,44 € / \mathrm{hl}$ & $7,66 € / \mathrm{hl}$ & $7,27 € / \mathrm{hl}$ & $6,22 € / \mathrm{hl}$ \\
\hline $\begin{array}{l}\text { Durchschnittliche } \\
\text { Marketingausgaben } \\
\mathbf{2 0 0 1} \text { - 2003 }\end{array}$ & $\mathbf{6 , 0 8} € / \mathbf{h l}$ & $\mathbf{5 , 3 4} € / \mathbf{h l}$ & $\mathbf{7 , 4 8} € / \mathbf{h l}$ & $\mathbf{7 , 2 9} € / \mathbf{h l}$ & $\mathbf{5 , 9 2} € / \mathbf{h l}$ \\
\hline
\end{tabular}

Tabelle 14: Durchschnittliche jährliche Marketingausgaben pro Hektoliter

Abbildung 43 veranschaulicht anhand des Durchschnitts der Jahre 2001 bis 2003 die Abweichungen vom Mittelwert in den einzelnen Betriebsgrößenklassen. Es ist zu erkennen, dass es in allen Größenklassen enorme Unterschiede in der Höhe der Marketingausgaben gibt. Vielen Brauereien ist die Werbung nur bis $\mathrm{zu} 2 € / \mathrm{hl}$ wert, andere geben weit über $10 € / \mathrm{hl}$ aus. Marketingausgaben von bis $\mathrm{zu} 2 € / \mathrm{hl}$ sind bei kleineren Brauereien häufig zu beobachten, während bei Brauereien mit 100.000 bis $250.000 \mathrm{hl} / \mathrm{Jahr}$ derart geringe Marketingaufwendungen nur selten und in der Gruppe der Großbrauereien gar nicht vorkommen. Auf der anderen Seite steigt mit wachsender 
Unternehmensgröße der Anteil der Unternehmen, die mehr als $8 € / \mathrm{hl}$ oder sogar mehr als $10 € / \mathrm{hl}$ für das Marketing ausgeben. Lediglich die Kleinstbrauereien, bei denen sich die jährlichen Marketingaufwendungen auf weniger als $5.000 \mathrm{hl}$ verteilen, stellen insoweit eine Ausnahme dar.

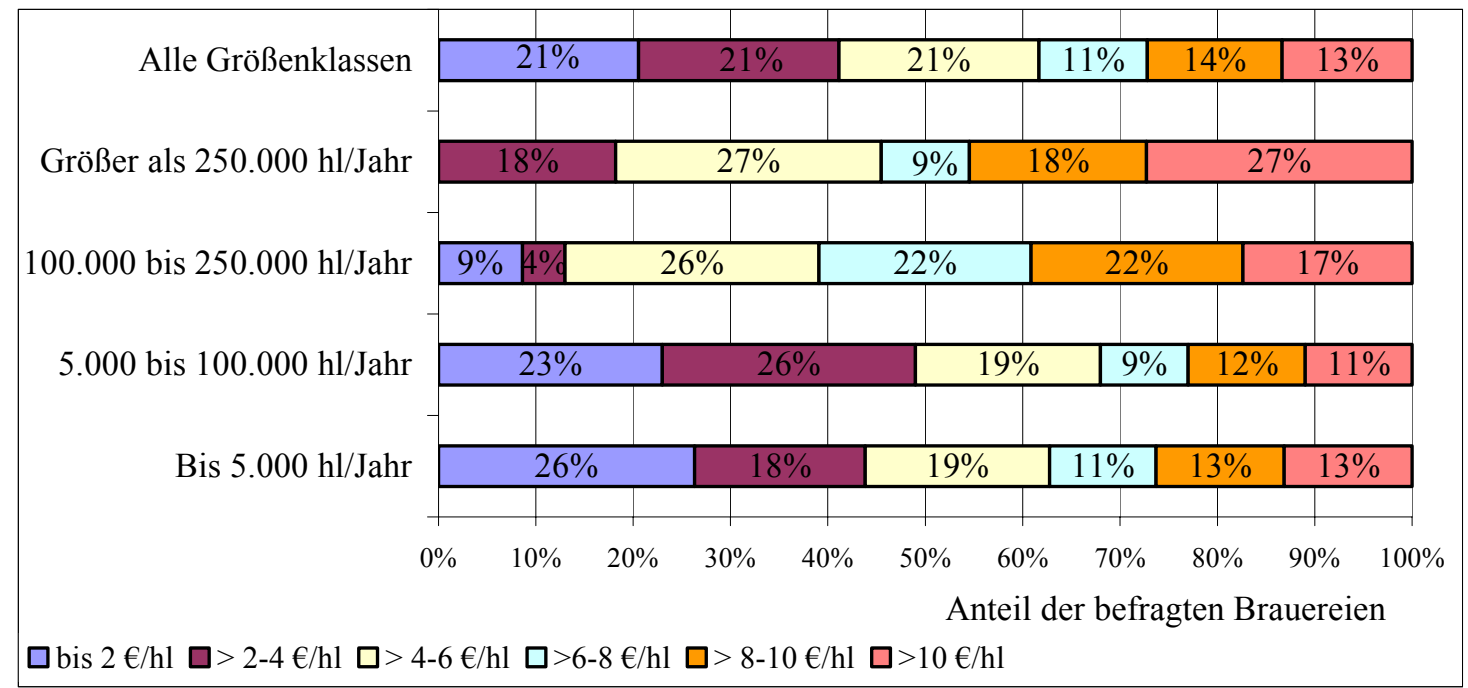

Abbildung 43: Marketingausgaben pro Hektoliter im Durchschnitt der Jahre 2001 bis 2003

Die Marketingaktivitäten der Brauereien sind nicht zuletzt auf die Stärkung des Images der eigenen Marke/n und damit der Absicherung bzw. Ausweitung des Absatzes im Premiumbereich gerichtet. Abbildung 44 stellt dar, wie die befragten Unternehmen ihr Markenimage im Vergleich zum Hauptwettbewerber wahrnehmen.

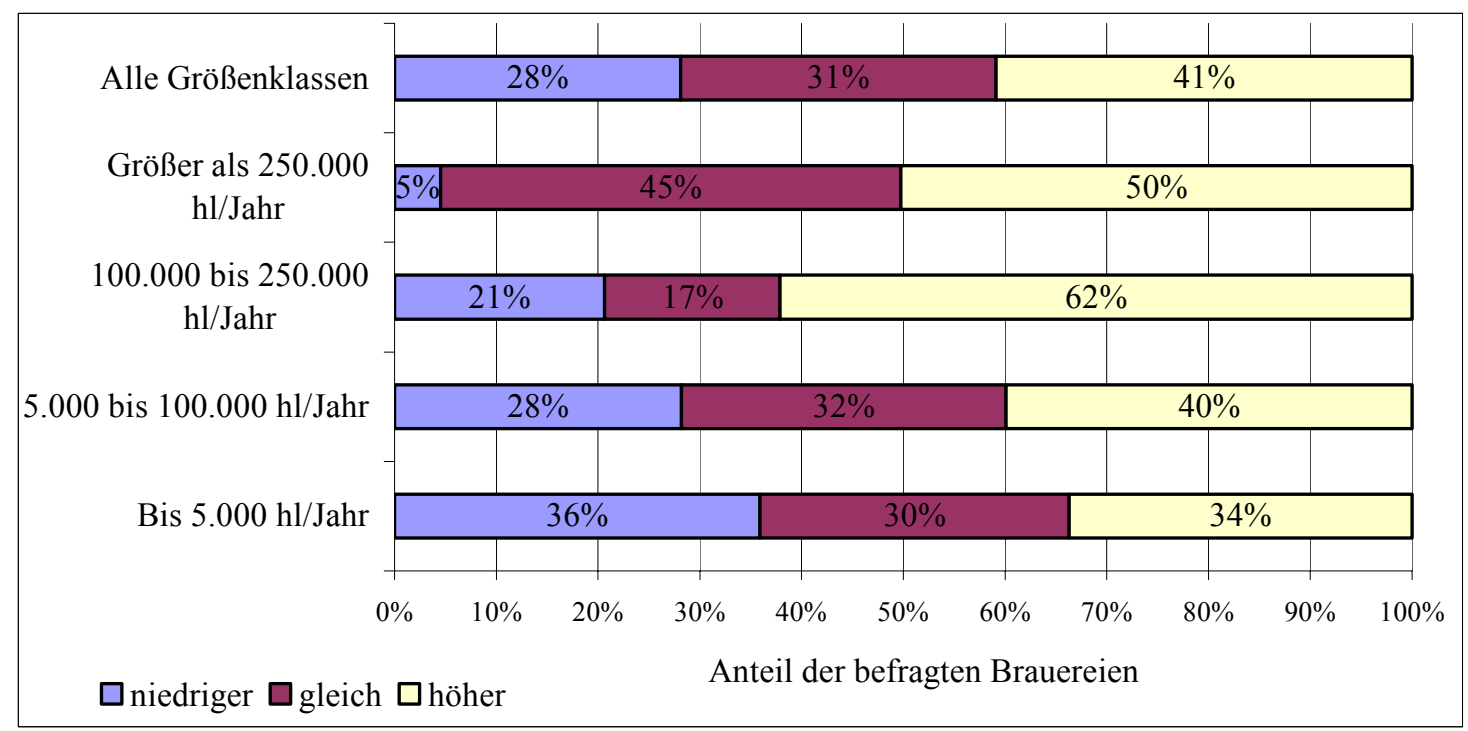

Abbildung 44: Wahrgenommene relative Stärke des Markenimage

Immerhin rund $41 \%$ der Befragten beurteilen ihre Wettbewerbsposition in dieser Hinsicht positiv und sehen einen Imagevorsprung vor der Konkurrenz. Andererseits 
erkennen auch $28 \%$ der Brauereien die Überlegenheit der Wettbewerber an. Während jedoch bei den kleineren Unternehmen bis zu $36 \%$ der Brauereien ihr Markenimage als schwächer einschätzen als das der Hauptwettbewerber, sind dies bei den Großbrauereien nur $5 \%$. Insoweit werden die bereits bei der Höhe der Marketingausgaben erkennbaren größenabhängigen Unterschiede bestätigt.

Innovationen, z.B. die Einführung von Biermischgetränken, sind vor dem Hintergrund des Absatzrückgangs der klassischen Produkte der deutschen Brauwirtschaft in den letzten Jahren mehr und mehr in den Blickpunkt des Interesses gerückt. So können mit neuen Produkten oftmals höhere Preise im Handel durchgesetzt und evtl. Absatzverluste in anderen Bereichen kompensiert werden. Nach der Innovationsneigung der Unternehmen kann in Pioniere bzw. Innovatoren und „second mover“ unterschieden werden (Hoppe/LehMANN-Grube, 2001: S. 419ff.). Einerseits bietet das Pionierverhalten aufgrund der Innovation die Chance, eine kurzfristige Monopolstellung $\mathrm{zu}$ erlangen und so Pioniergewinne zu generieren. Andererseits ist aber wegen der Ungewissheit hinsichtlich der weiteren Marktentwicklung und des Markterfolgs der Neuheit das Risiko einer Fehlinvestition für den Pionier oftmals sehr hoch. Der ,second mover" hat den Vorteil des geringeren Risikos, weil Fehler des Pioniers vermieden werden können und weniger Aufwendungen zur Marktentwicklung betrieben werden müssen. Er hat aber auch den Nachteil, dass der Pionier den von ihm eroberten Platz bereits besetzt hält. Späteinsteiger müssen daher Markteintrittsbarrieren überwinden und ihre Strategie am Verhalten des Innovators ausrichten. Zudem ist das Differenzierungspotential einer „second mover“-Strategie begrenzt, da nachgeahmte Innovationen zwar noch „new to the company“, aber nicht mehr „new to the industry“ sind (ROSENOE, 2005).

Ein aktuelles Beispiel aus der deutschen Brauwirtschaft ist die sehr erfolgreiche Markteinführung milder Biere in Klarglasflaschen („Goldbiere“). Diese Innovation hat schnell Nachahmer gefunden, welche aber ganz überwiegend deutlich weniger erfolgreich sind als das „Original“. Abbildung 45 veranschaulicht, inwieweit sich die befragten Brauereien eher als Pioniere oder als ,second mover“" sehen.

Rund $45 \%$ der Befragten nehmen sich als Pioniere und nur $18 \%$ als „,second mover“ wahr. Mit steigender Gesamtjahreserzeugung schätzen sich erheblich mehr 
Unternehmen als Innovatoren ein. Dieses Ergebnis ist nicht überraschend, da die größeren Unternehmen in der Regel über eine größere Finanzkraft verfügen und somit die Investitionen und das Risiko, welche mit einer Innovation verbunden sind, eher tragen können. Im Detail ist das Bild allerdings widersprüchlich. So finden sich z. B. in der Gruppe der Kleinbrauereien sowohl viele Unternehmen, die sich als Pioniere betrachten, als auch zahlreiche Betriebe, die die Auffassung vertreten, eher „second mover" zu sein.

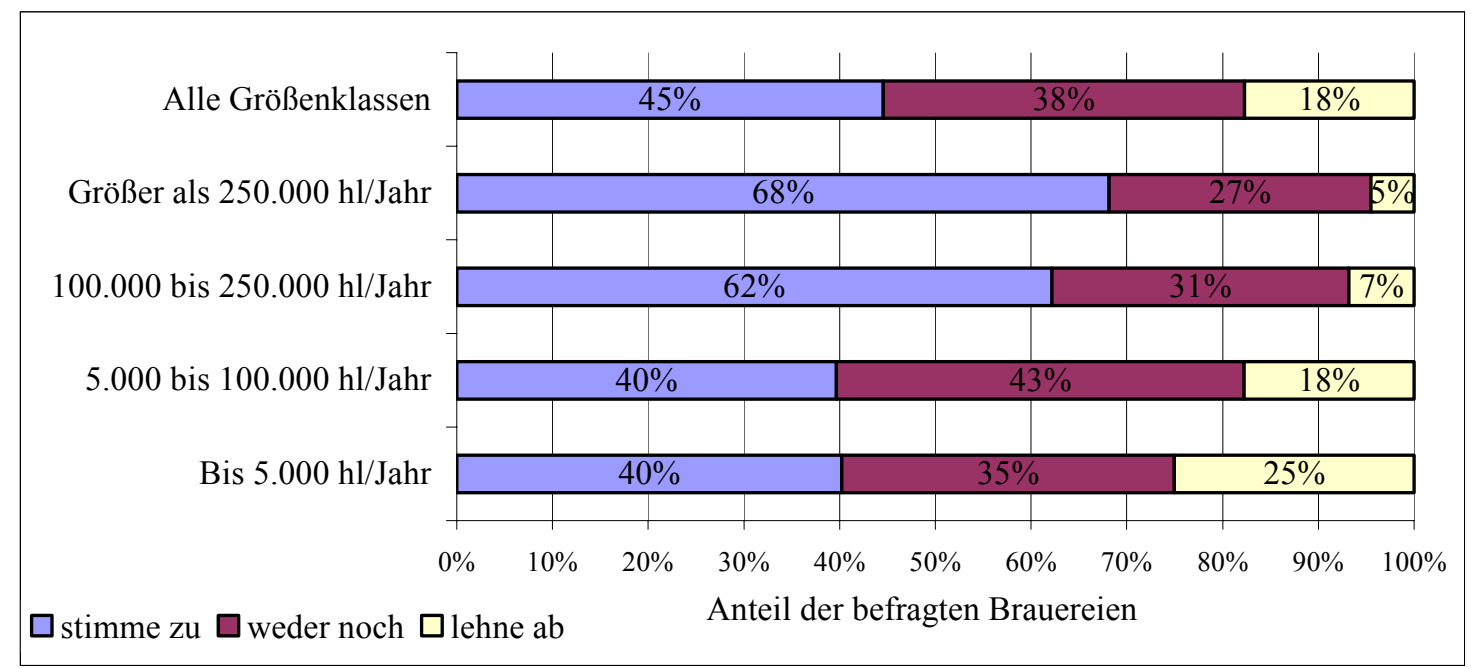

Abbildung 45: „Mit Innovationen bemühen wir uns immer, die ersten am Markt zu sein."

Im Zusammenhang mit der Innovationsneigung ist es auch von Interesse, in welchen Bereichen die befragten Brauereien innovative Ansätze verfolgen. Aktuelle Beispiele sind Biermischgetränke, mildere Biere, innovative Flaschenformen und -farben, Neuerungen bei Kastenform bzw. -größe und -design sowie die Aufnahme neuer Biersorten in das Produktionsprogramm.

Abbildung 46 zeigt, in welchem Maße die befragten Brauereien Innovationen planen oder bereits durchgeführt haben. Bedenkt man, dass sich etwa 15 bis $20 \%$ der Befragten nicht zu Innovationen geäußert haben, dürfte die Zahl der Neuerungen tatsächlich sogar etwas über den ausgewiesenen Werten liegen. Aber auch so ergeben sich sehr beachtliche Resultate. So haben etwa $40 \%$ aller befragten Brauereien Biermischgetränke im Produktportfolio, bei den Unternehmen mit einem Ausstoß von mehr als $250.000 \mathrm{hl} / \mathrm{Jahr}$ sind es rund $68 \%$ und bei den Brauereien in der Größenklasse von 100.000 bis $250.000 \mathrm{hl} / \mathrm{Jahr}$ sogar ca. $72 \%$. Bei der Einführung von milderen Bieren stechen die Großbrauer mit einem Anteil von 54,5 \% hervor. 
Bei allen in Abbildung 46 berücksichtigten Innovationen werden erhebliche Unterschiede zwischen den Größenklassen sichtbar. In der Regel wächst die Innovationsfreude mit steigender Betriebsgröße deutlich an. Lediglich bei der Einführung neuer Biersorten ist der Anteil der kleineren Brauereien überdurchschnittlich hoch. Hier ist anzunehmen, dass sich viele kleinere Unternehmen ähnlich wie amerikanische „micro-breweries“ durch innovative Spezialitäten Marktnischen schaffen und auf diese Weise vom breiten Markt abgrenzen wollen (BASTIAN ET AL., 1999: S. 552ff.). Außerdem sind die notwendigen Investitionen bei dieser Art der Neuerung vergleichsweise niedrig, so dass das Risiko überschaubar bleibt.

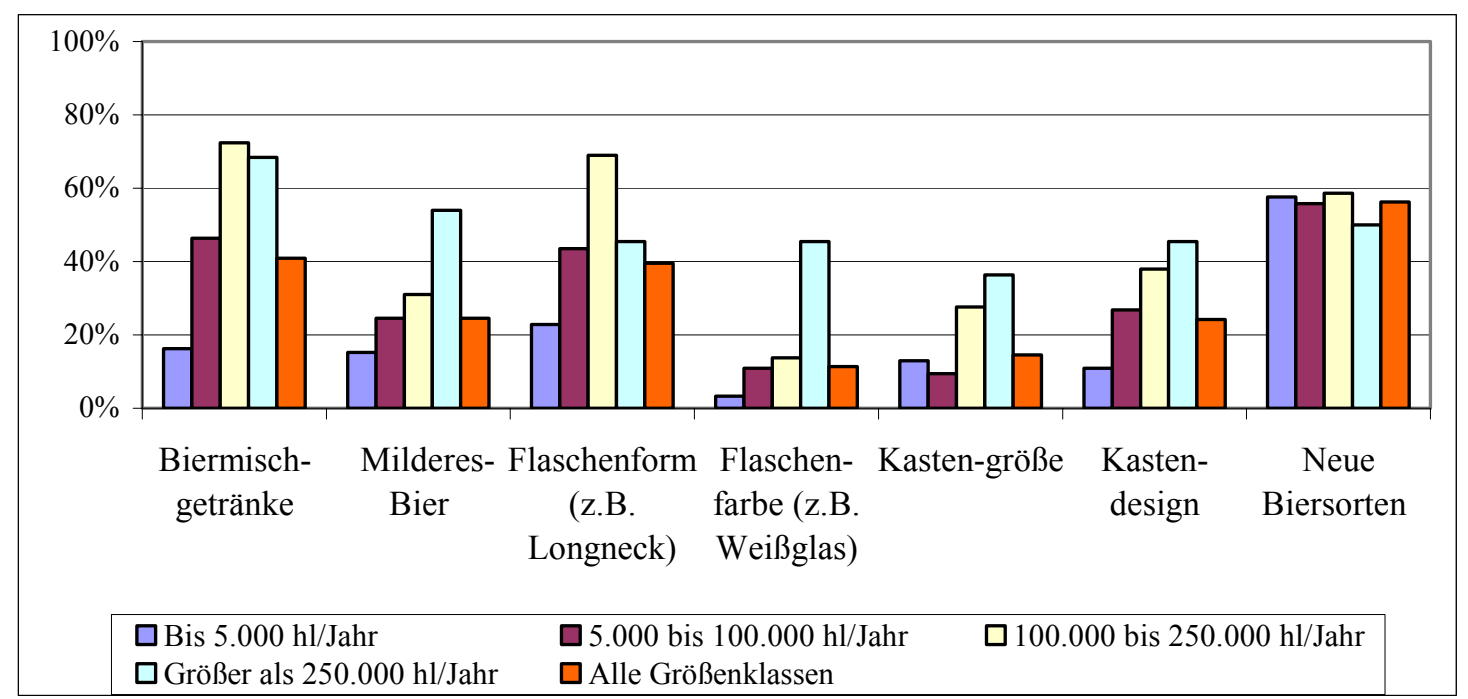

Abbildung 46: Innovationen in der deutschen Brauwirtschaft (geplant oder durchgeführt)

Neben der Unterscheidung in Pioniere und „second mover“ sowie der Betrachtung der jeweiligen Innovationsschwerpunkte interessiert auch die Innovationskraft der Unternehmen. Abbildung 47 stellt dar, wie die befragten Brauereien ihre Innovationskraft im Vergleich zu den Hauptwettbewerbern bewerten.

Immerhin $42 \%$ der Befragten sehen sich im Vorteil gegenüber der Konkurrenz, doch erkennen auch $25 \%$ der Brauereien die Überlegenheit der Wettbewerber an. Dieses Ergebnis lässt vor dem Hintergrund des tatsächlichen Innovationsverhaltens (Abbildung 46) vermuten, dass viele Brauereien ihre Innovationskraft überschätzen. Besonders deutlich wird dies bei der Betrachtung der Unternehmen in der Größenklasse von 100.000 bis $250.000 \mathrm{hl} / \mathrm{Jahr}$. In dieser Gruppe schätzen nur $17 \%$ der befragten Brauer ihre Innovationskraft niedriger ein als die der Hauptwettbewerber. Diese Einschätzung 
entspricht allem Anschein nach nicht ganz der Realität. Um noch einmal das Beispiel der „Goldbiere“ heranzuziehen: Die vielfache Kopie dieser Innovation spricht weder für besondere Innovationskraft noch wird sie höchstwahrscheinlich von übermäßigem Erfolg gekrönt sein. Aber vorrangig durch die Nachahmung dieser Neuerung sind viele der Brauer in letzter Zeit aufgefallen.

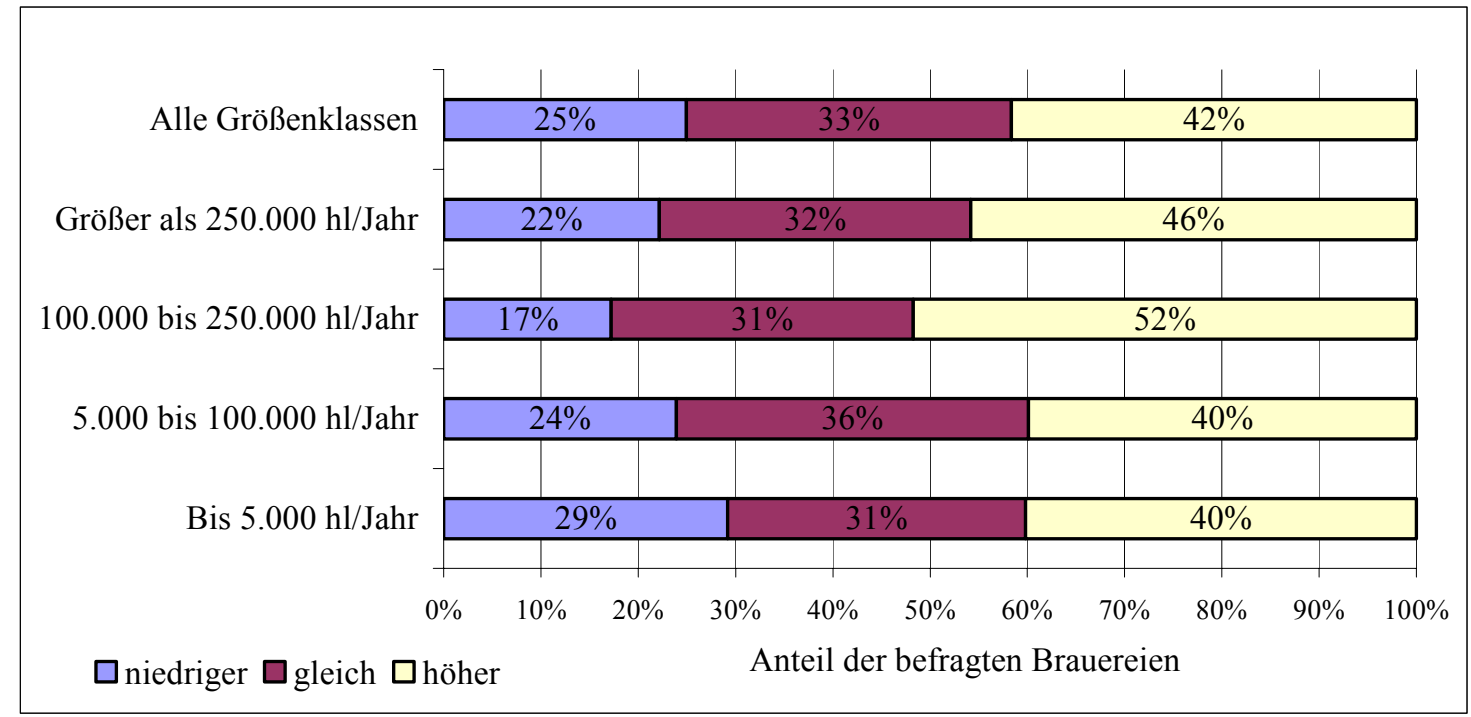

Abbildung 47: Eigene Innovationskraft im Vergleich zum Wettbewerber

Innovationen sind - vor allem, wenn sie ,new to the industry“ sind - wichtig für die Differenzierung des Angebots. Jedoch dürfen auch Brauereien mit Differenzierungsstrategie den Kostenabstand $\mathrm{zu}$ den Kostenführern nicht $\mathrm{zu}$ groß werden lassen. Erst recht sind die Kosten von zentraler Bedeutung, wenn Brauereien sich konsequent für eine Kostenführerschafts- bzw. Niedrigpreisstrategie und die Erschließung von Marktpotentialen im Preiseinstiegsbereich entschieden haben.

Abbildung 48 veranschaulicht, wie die befragten Brauereien ihre durchschnittlichen Gesamtkosten im Vergleich zum Branchendurchschnitt beurteilen. Etwa $58 \%$ aller befragten Brauereien vermuten, dass ihre Kosten oberhalb des Branchendurchschnitts liegen. Nur $17 \%$ der Unternehmen vertreten die Auffassung, dass ihre Kosten unterdurchschnittlich sind.

Wie so oft sind auch hier wieder deutliche Unterschiede zwischen den Größenklassen festzustellen. So geht mit steigender Gesamtjahreserzeugung tendenziell ein deutlich geringerer Anteil der Brauereien davon aus, dass ihre Kosten über dem Branchenmittel liegen. Gleichwohl ist das Antwortverhalten in allen Größenklassen sehr gemischt. 
Entweder sind die Kostenstrukturen innerhalb wie auch zwischen den Größenklassen tatsächlich sehr unterschiedlich, oder die Kostentransparenz ist gering und die Brauereien tun sich schwer mit der richtigen Einschätzung ihrer Kostenposition in Relation zum Wettbewerb. Für letztere Vermutung spricht, dass von einigen befragten Brauereien auf der einen Seite hohe durchschnittliche Gesamtkosten von z.B. $80 € / \mathrm{hl}$ genannt wurden, diese Unternehmen auf der anderen Seite aber zugleich meinen, niedrigere Kosten als der Branchenschnitt zu haben. Umgekehrt gibt es auch viele Unternehmen, die nur Kosten in Höhe von etwa $45 € / \mathrm{hl}$ angegeben haben und diese als überdurchschnittlich einschätzten.

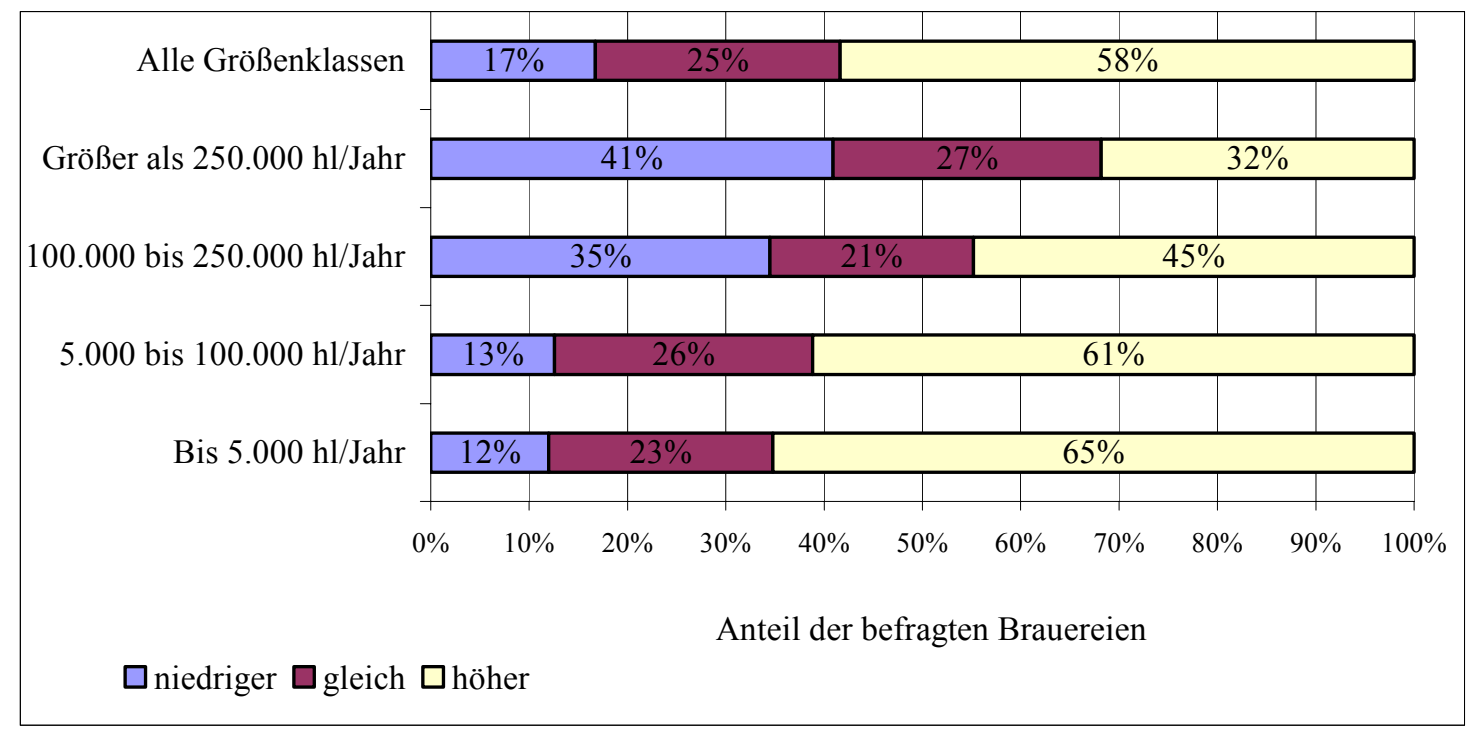

Abbildung 48: Einschätzung der eigenen Gesamtkosten in Relation zum Branchendurchschnitt

Abbildung 49 zeigt die durchschnittlichen Kosten pro Hektoliter differenziert nach dem Gesamtgetränkeausstoß der befragten Brauereien. Die Aussagekraft der Abbildung ist allerdings insoweit eingeschränkt als viele größere Brauereien die Beantwortung der Frage verweigert und sich einige bedeutende Kostenführer nicht an der Umfrage beteiligt haben. Trotzdem sind die Ergebnisse angesichts der zuvor vermuteten Kostenintransparenz interessant.

Über alle befragten Brauereien liegen die Kosten bei etwa $63 € / \mathrm{hl}$. Brauereien mit einem Ausstoß von bis zu $5000 \mathrm{hl} / \mathrm{Jahr}$ liegen mit durchschnittlich etwa $67 € / \mathrm{hl}$ über, die Großbrauereien mit durchschnittlich $55 € / \mathrm{hl}$ deutlich unter dem Branchendurchschnitt. Dieses Resultat ist aufgrund der Größeneffekte nicht überraschend. Bemerkenswert ist jedoch, das die zweithöchsten Kosten mit durchschnittlich etwa $66 € / \mathrm{hl}$ von Brauereien mit einem Ausstoß von 100.000 bis 
$250.000 \mathrm{hl} / \mathrm{Jahr}$ genannt wurden. Eine Ursache könnte sein, dass viele regionale Brauereien ihr Distributionsgebiet weit ausgedehnt haben. Dies führt oftmals nur zu einem unwesentlichen Mehrabsatz, erhöht die Kosten für Vertrieb und Marketing jedoch erheblich.

Bei näherer Betrachtung zeigen sich in den verschiedenen Größenklassen deutliche Unterschiede. So variieren die Kosten innerhalb der Gruppe der kleineren Brauereien zwischen $30 € / \mathrm{hl}$ und über $100 € / \mathrm{hl}$. Selbst, wenn man mögliche Ungenauigkeiten bei der Kostenermittlung in Rechnung stellt, ist diese Spannweite enorm. Bedenklich stimmt, dass einige kleinere Unternehmen ihre Kosten überhaupt nicht quantifizieren konnten.

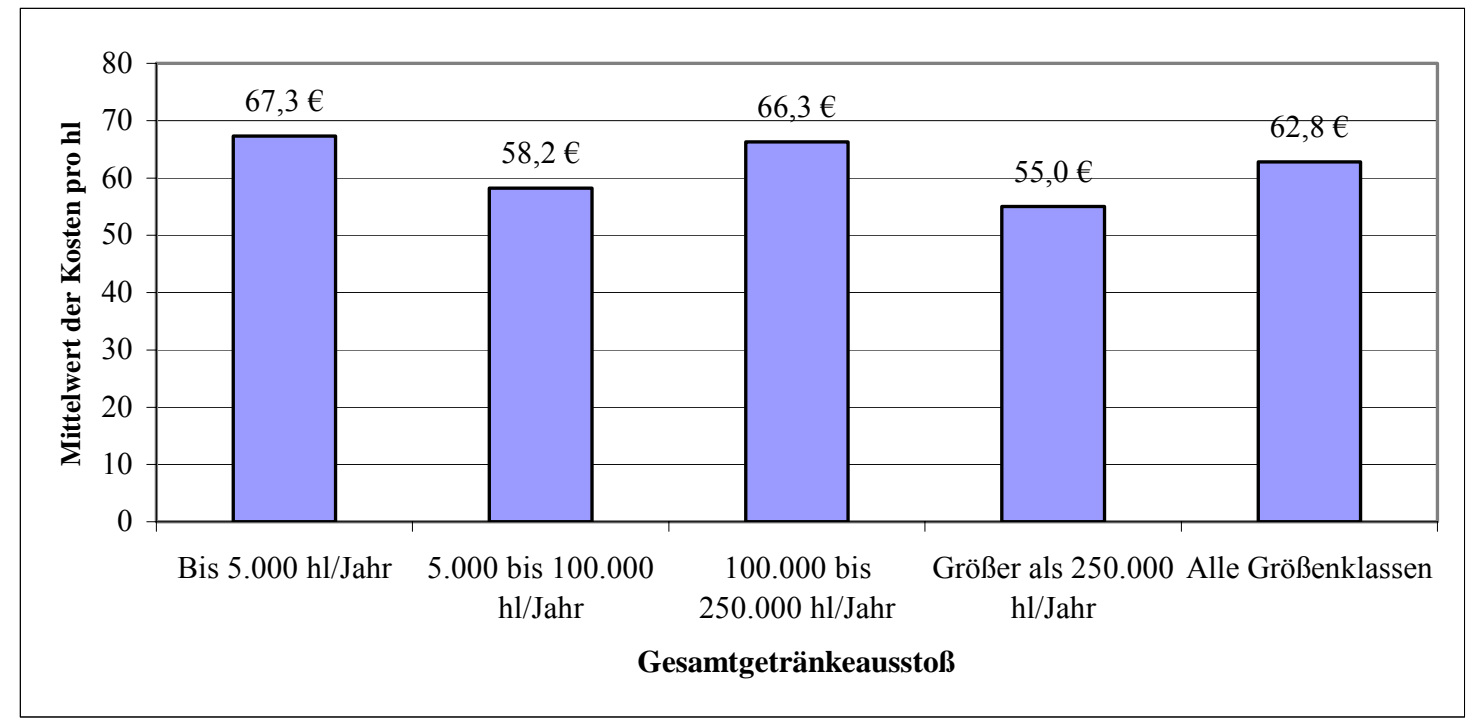

Abbildung 49: Durchschnittliche Gesamtkosten pro Hektoliter

$\mathrm{Zu}$ den Wettbewerbstrategien ist im Ergebnis festzustellen, dass sowohl die Differenzierung als auch die Kostenführerschaft eine bedeutende Rolle spielen, und dies sogar oft im selben Unternehmen. Die empirischen Ergebnisse belegen, dass die deutsche Brauwirtschaft in weiten Teilen durch eine starke Markenorientierung geprägt ist. So liegen die Marketingausgaben aller befragten Brauereien im Mittel bei immerhin etwa $6 € /$ hl. Neben der Markenorientierung spielen auch Innovationen eine bedeutende Rolle. Einschränkend ist allerdings anzumerken, dass es sich abweichend von der Selbsteinschätzung vieler Brauereien vielfach nicht um Innovationen, die „new to the industry“ wären, sondern lediglich um Nachahmungen erfolgreicher Pioniere handelt. Darüber hinaus wurde deutlich, dass ein erheblicher Teil der Brauer zumindest teilweise oder sogar überwiegend auch den Preiseinstiegsbereich bedient. Insoweit wird dem nach eigener Einschätzung schärfer gewordenen Wettbewerb nicht nur mit einer 
Differenzierung des Angebots, sondern auch mit Preis- bzw. Kostenführerschaftsstrategien begegnet. Im Ergebnis führt dies zu einer Situation, die typisch für viele reife Konsumgütermärkte ist: Mangels fehlender Innovationsmöglichkeiten bei den Kernproduktfunktionen wird danach getrachtet, durch eine wachsende Produktvielfalt und die Besetzung aller Marktnischen heterogene Konsumentenbedürfnisse zu bedienen (BAUDISCH, 2005).

\subsubsection{Kooperationsstrategien}

Von Branchenkennern wird schon seit Jahren das Eingehen von strategischen Kooperationen empfohlen, um in der Brauwirtschaft im harten Wettbewerb dauerhaft wirtschaftlich erfolgreich sein zu können (WIECHELL, 2001: S. 1823ff.; HEYSE, 2002b: S. 480; HAhN, 2002a: 298ff.; 2002b: S. 705ff.; LATZ-WeBer, 2004b: S. 59). Andererseits wurde bei Befragungen deutscher Brauer immer wieder eine eher gering ausgeprägte Kooperationsbereitschaft deutlich (HENKE, 2002: S. 108; LÜCK/HENKE, 2003: S. 22). Im folgenden Abschnitt wird vor dem Hintergrund der sich verschärfenden Wettbewerbsbedingungen aufgezeigt, wie die deutschen Brauereien das Potential von Kooperationen aktuell einschätzen und inwieweit sie an Kooperationen in verschiedenen Bereichen beteiligt sind.

Als Kooperation wird eine freiwillige, vertraglich vereinbarte Zusammenarbeit selbständig wirtschaftender Unternehmen bezeichnet. Die Zusammenarbeit erstreckt sich dabei über einen längeren Zeitraum und kann mündlich oder schriftlich vereinbart werden. Mit Kooperationen wird das Ziel verfolgt, Wettbewerbsvorteile zu erzielen bzw. zu erhalten, um auf diese Weise langfristig den Erfolg und die dauerhafte Existenz der kooperierenden Unternehmen $\mathrm{zu}$ sichern. Im Einzelfall können ganz unterschiedliche Ziele wie Kostensenkung, Erlössteigerung, die Sortimentsabrundung, die Eröffnung von Wachstumspotentialen oder auch die Erschließung neuer, z.B. internationaler Märkte relevant sein. Für eine langfristig stabile Zusammenarbeit ist es wichtig, dass sich für alle beteiligten Partner mehr Vor- als Nachteile ergeben, die jeweilige Wettbewerbsposition also gestärkt wird (THEUVSEN, 2003b: S. 4).

Kooperationen treten in der Brauwirtschaft als vertikale und horizontale Kooperationen auf. Vertikale Kooperationen sind auf die Zusammenarbeit von Brauereien mit vor- 
oder nachgelagerten Produktionsstufen, z.B. Absatzmittlern, gerichtet. Horizontale Kooperationen bezeichnen demgegenüber die Zusammenarbeit mit anderen Brauereien, z. B. bei der Beschaffung oder im Vertrieb (BERENTZEN, 1983: S. $130 \mathrm{u}$. $163)$.

Das Potential für Kooperationen mit anderen Brauereien wird von den befragten Unternehmen je nach Größe und Distributionsreichweite recht unterschiedlich eingeschätzt (Abbildung 50). Innerhalb der verschiedenen Größenklassen ist das Antwortverhalten ebenfalls sehr gemischt. So finden sich in allen Gruppen sowohl viele Unternehmen, die weit reichende Möglichkeiten für Kooperationen sehen, als auch zahlreiche Betriebe, die die Auffassung vertreten, dass das Kooperationspotential eher niedrig sei.

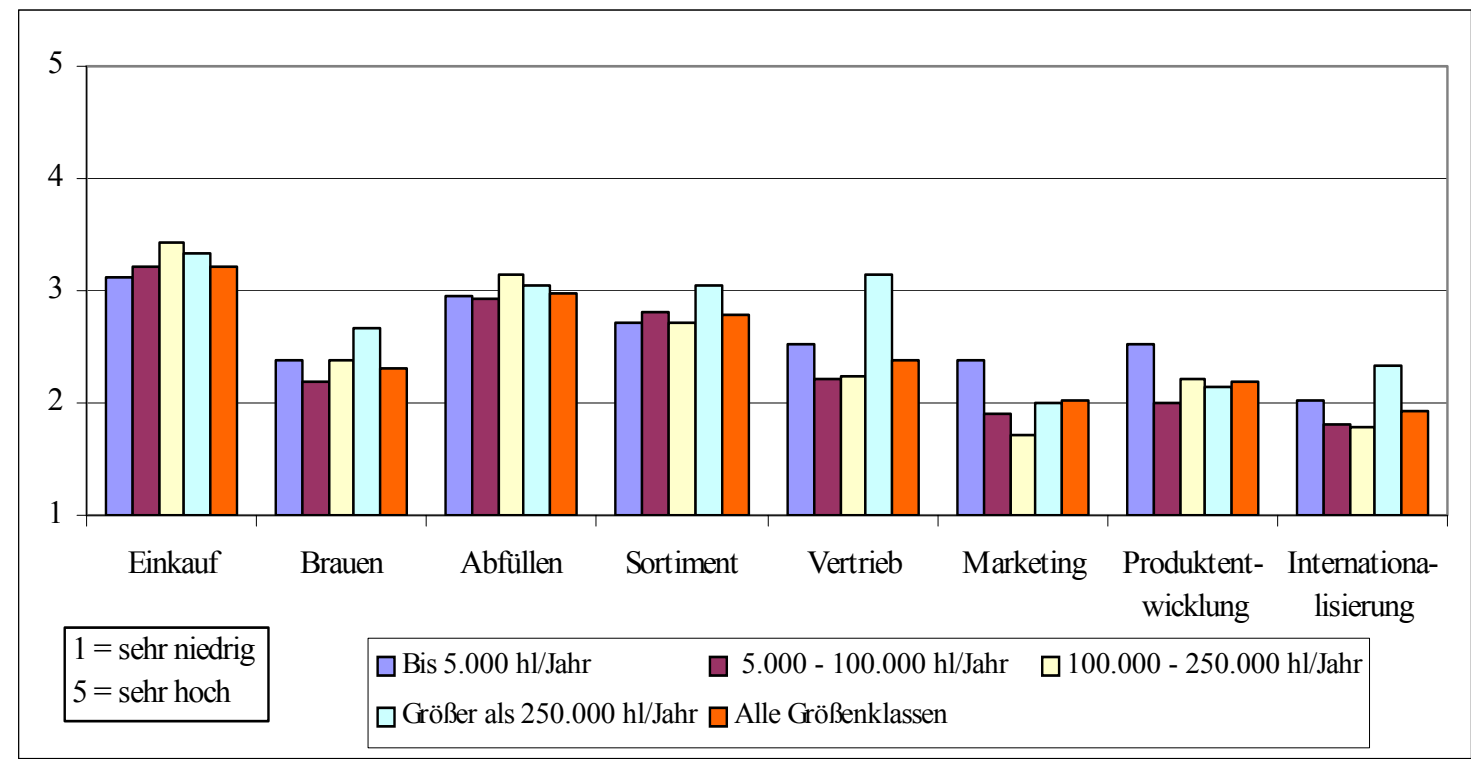

Abbildung 50: Einschätzung des Kooperationspotentials in verschiedenen Bereichen

Insgesamt sehen die Brauereien am ehesten Kooperationsmöglichkeiten im Bereich des Einkaufs; etwa $50 \%$ aller befragten Unternehmen halten das Potential in diesem Bereich für hoch oder sehr hoch. Bei den Brauereien mit einem Jahresausstoß von 100.000 bis $250.000 \mathrm{hl}$ sind es sogar ca. $64 \%$. Dieser Wert liegt höher als bei den kleineren Brauereien (bis 100.000 hl Jahresausstoß), obwohl bei letzteren die positiven Effekte einer Einkaufskooperation noch ausgeprägter sein dürften. Als mögliche Gründe dafür kommen ein professionelleres Management größerer Brauereien sowie positive Erfahrungen, die diese Unternehmen bereits in der Vergangenheit mit Einkaufskooperationen gesammelt haben, in Frage. 
Auf dem zweiten Platz folgen die Abfüllkooperationen; etwa $39 \%$ der Brauereien sehen große bis sehr große Möglichkeiten zur Zusammenarbeit in diesem Bereich. Auch hier ist wieder $\mathrm{zu}$ beobachten, dass die größeren Brauereien das Kooperationspotential tendenziell etwas höher einschätzen als ihre kleineren Wettbewerber. Im Bereich Sortiment (z.B. Produktaustausch) halten immerhin noch etwa $29 \%$ der befragten Brauereien das Kooperationspotential für hoch bis sehr hoch.

In den übrigen Bereichen wie Brauen, Vertrieb, Marketing, Produktentwicklung und Internationalisierung werden deutlich weniger Möglichkeiten zur unternehmensübergreifenden Zusammenarbeit gesehen. Der überwiegende Teil der Befragten stuft das Kooperationspotential als eher niedrig ein; nur noch - je nach betrachtetem Funktionsbereich - etwa 8 bis $19 \%$ der Brauereien antworteten mit „hoch“ oder „sehr hoch“. Hier stellt sich die Frage, ob nicht angesichts hoher Überkapazitäten in der Branche und in vielen Fällen sehr geringer Exportquoten von den Unternehmen Potentiale verschenkt werden. Immerhin sind gerade in jüngster Zeit einige interessante Konzepte für die gemeinsame Bearbeitung ausländischer Märkte durch mittelständische Brauer vorgestellt worden, die Vorbildcharakter erlangen könnten (HOFBAUER, 2005: S. 3).

Auffällig bei der Bewertung der Kooperationspotentiale sind einige deutliche Abweichungen vom Branchendurchschnitt. So schätzen die Brauereien in der Größenklasse über $250.000 \mathrm{hl} / \mathrm{Jahr}$ das Potential von nationalen wie auch internationalen Vertriebskooperationen überdurchschnittlich hoch ein. Gründe dafür können das größere Distributionsgebiet und der höhere Internationalisierungsgrad der Großbrauereien sein. In den Bereichen Marketing und Produktentwicklung wiederum stechen die Kleinbrauereien (bis $5.000 \mathrm{hl} / \mathrm{Jahr}$ ) heraus. Ihr sehr begrenztes Marketingbudget sowie eingeschränkte Möglichkeiten der Produktentwicklung sind nahe liegende Erklärungen.

Fasst man alle betrieblichen Funktionsbereiche zusammen, so wird deutlich, dass fasst die Hälfte aller Unternehmen bereits Kooperationen mit anderen Brauereien eingegangen ist oder sie zumindest vorbereitet (Abbildung 51). Zwischen den verschiedenen Größenklassen bestehen in dieser Hinsicht erneut erhebliche Unterschiede. Klammert man die Kleinstbrauereien mit bis zu $5.000 \mathrm{hl} / \mathrm{Jahr}$ aus der Betrachtung aus, so steigt mit zunehmender Gesamtjahreserzeugung der Anteil 
derjenigen Unternehmen deutlich an, die in eine Kooperation eingebunden sind. Vor dem Hintergrund der Einschätzungen des Kooperationspotentials verwundert es nicht, dass in der Gruppe der großen Brauereien (über $250.000 \mathrm{hl} / \mathrm{Jahr}$ ) sogar $73 \%$ aller Befragten an einer horizontalen Kooperation beteiligt sind.

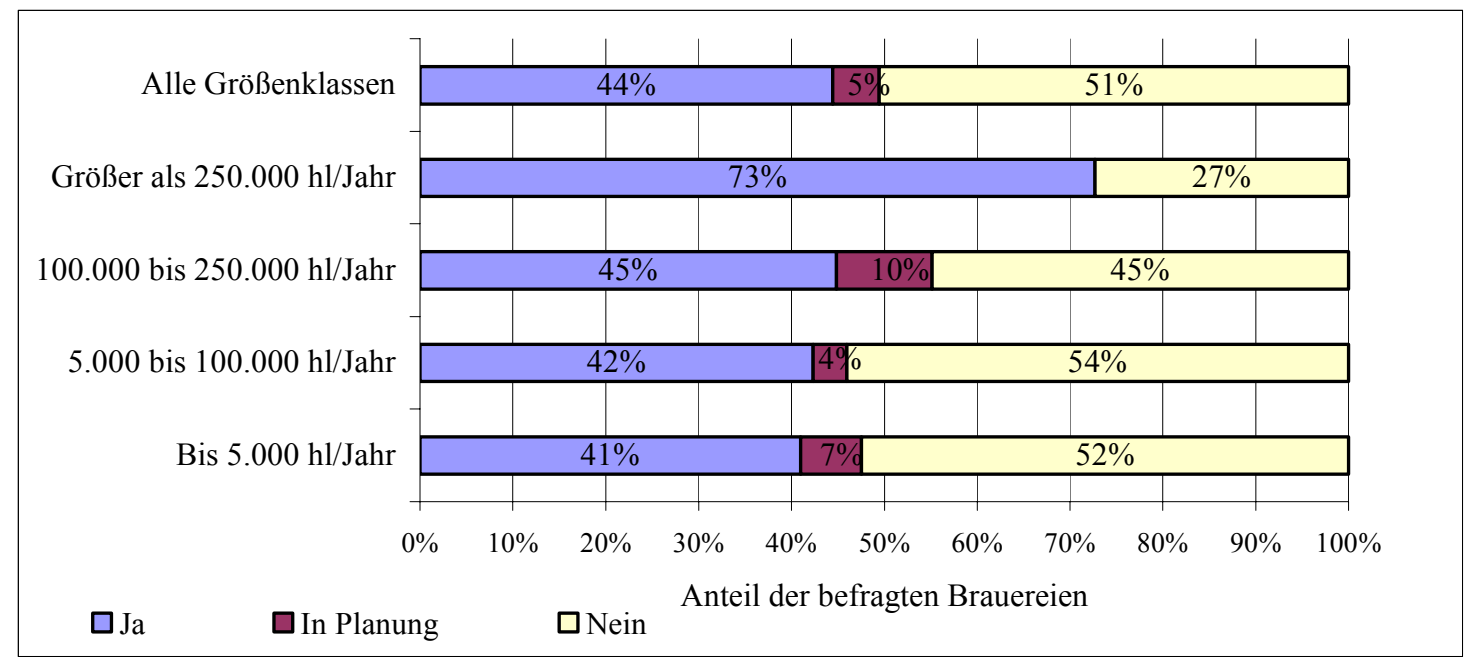

Abbildung 51: Anteil der Unternehmen, die mit anderen Brauereien kooperieren oder dieses planen

Betrachtet man nur die Unternehmen, die bereits horizontale Kooperationen eingegangen sind oder diese planen, so wird aus Abbildung 52 ersichtlich, welche Kooperationen in der Brauwirtschaft dominieren. Das Bild der tatsächlich eingegangenen oder in Vorbereitung befindlichen Kooperationen entspricht im Großen und Ganzen den oben wiedergegebenen Einschätzungen zum Kooperationspotential.

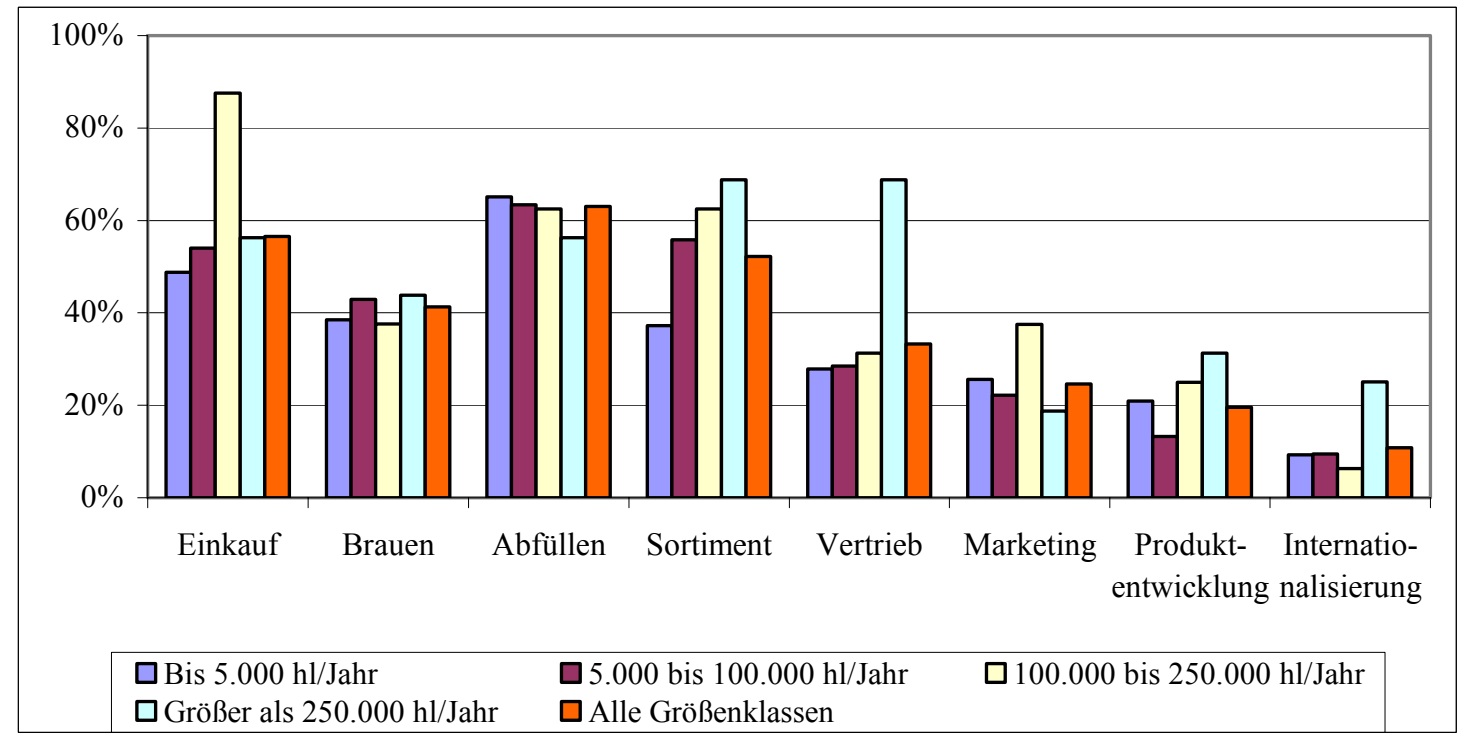

Abbildung 52: Horizontale Kooperationen in der Brauwirtschaft

$(100 \%=$ Zahl der Brauereien, die mit einer anderen Brauerei bzw. anderen Brauereien kooperieren oder dieses planen) 
Bei einer detaillierteren Betrachtung werden einige interessante Unterschiede deutlich. Die meisten Kooperationen sind danach im Bereich der Abfüllung vereinbart worden; hier nimmt mit steigendem Gesamtjahresausstoß die Bedeutung von Kooperationen leicht ab. Auf den nächsten Plätzen folgen Kooperationen in den Bereichen Einkauf, Sortiment und Brauen. Bei den Einkaufskooperationen stechen besonders die Brauereien mit einem Jahresausstoß von 100.000 bis 250.000 hl hervor; nahezu $90 \%$ der Unternehmen dieser Gruppe, die mit anderen Brauereien zusammenarbeiten, kooperieren in der Beschaffung. Die übrigen Bereiche - Vertrieb, Marketing, Produktentwicklung und Internationalisierung - spielen insgesamt eine eher untergeordnete Rolle. Eine Ausnahme bilden Vertriebskooperationen in der Gruppe der großen Brauereien (über $250.000 \mathrm{hl} / \mathrm{Jahr}$ ); etwa $70 \%$ der Unternehmen dieser Größenklasse, die mit anderen Brauereien zusammenarbeiten, kooperieren im Vertrieb.

Neben einer Zusammenarbeit mit anderen Brauereien können auch vertikale Kooperationen mit vor- oder nachgelagerten Produktionsstufen für die deutschen Brauer von Interesse sein. Ein Beispiel, welches auch in der Fachliteratur vermehrt diskutiert wird, sind Kooperationen mit dem Getränkefachgroßhandel (VosSEN, 2004: S. 44; O. V., 2005a: S. 679).

Abbildung 53 zeigt, wie die befragten Brauereien das Kooperationspotential mit Unternehmen auf vor- oder nachgelagerten Produktionsstufen einschätzen.

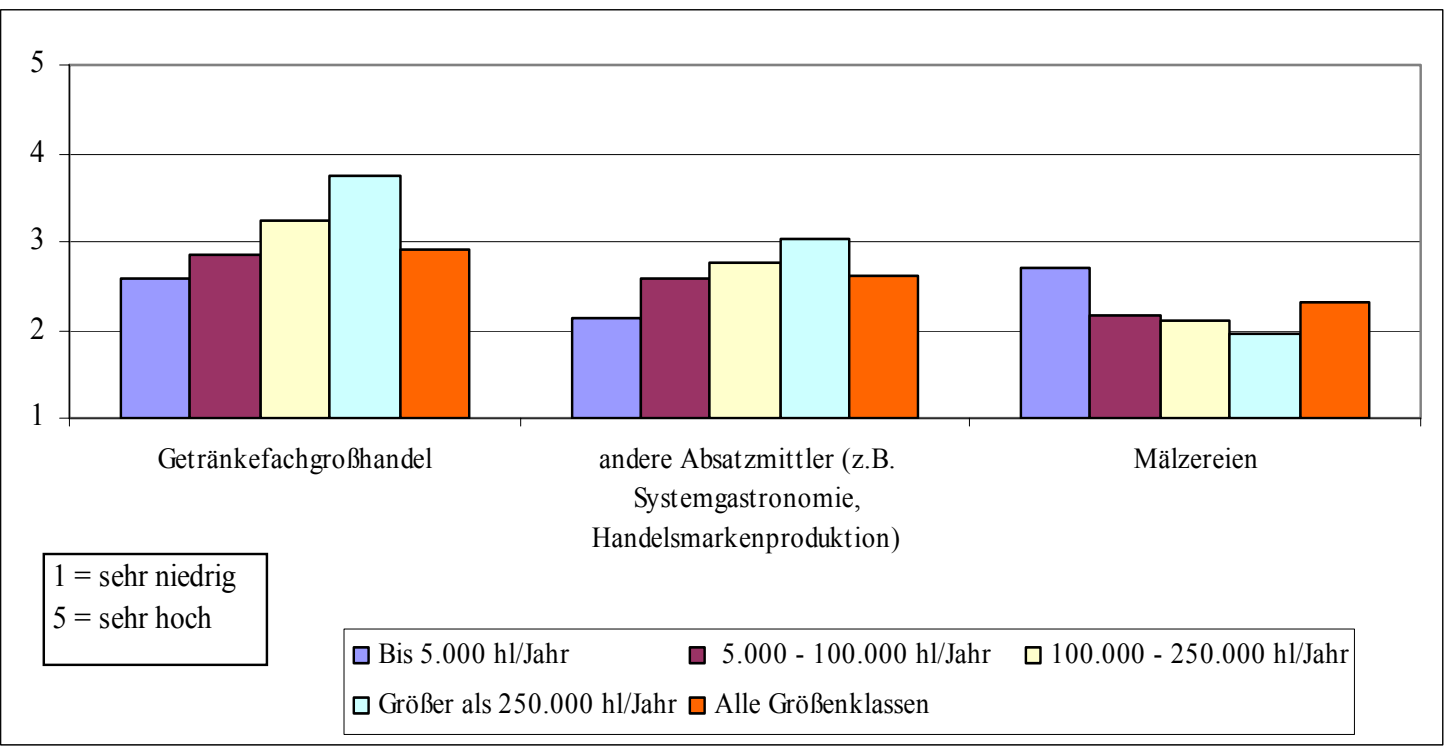

Abbildung 53: Einschätzung des Potentials vertikaler Kooperationen 
Insgesamt ist für die Brauereien der Getränkefachgroßhandel der interessanteste Partner; etwa $35 \%$ aller befragten Unternehmen halten das Potential für eine Zusammenarbeit für hoch bis sehr hoch; bei den großen Brauereien (über 250.000 hl/Jahr) sind dies sogar 76 \%. Ein Grund dafür dürfte die mit wachsender Betriebsgröße und Ausdehnung des Absatzgebietes zunehmende Bedeutung des Getränkefachgroßhandels als Vertriebspartner sein. Das Kooperationspotential von Mälzereien wird spiegelbildlich dazu von den kleinen Brauereien höher eingeschätzt; ca. $30 \%$ betrachten es als hoch bis sehr hoch (gesamte Stichprobe: $18 \%$ ). Das größere Interesse kleiner Brauereien an Kooperationen mit Mälzereien könnte darauf zurückzuführen sein, dass für sie die tiefe Verwurzelung in der jeweiligen Region und damit verbunden auch der regionale Bezug von Rohstoffen Möglichkeiten zur Differenzierung im Wettbewerb bieten. Auffällig ist, dass in allen Größenklassen das Antwortverhalten sehr gemischt ist.

Abbildung 54 veranschaulicht die Anteile der Brauereien, die mit Unternehmen im voroder nachgelagerten Bereich kooperieren oder dieses planen. Es wird ersichtlich, dass nur $17 \%$ der befragten Brauereien an einer vertikalen Kooperation beteiligt sind oder sie ins Auge gefasst haben. Zwischen den verschiedenen Größenklassen bestehen in dieser Hinsicht jedoch wieder einige bemerkenswerte Unterschiede.

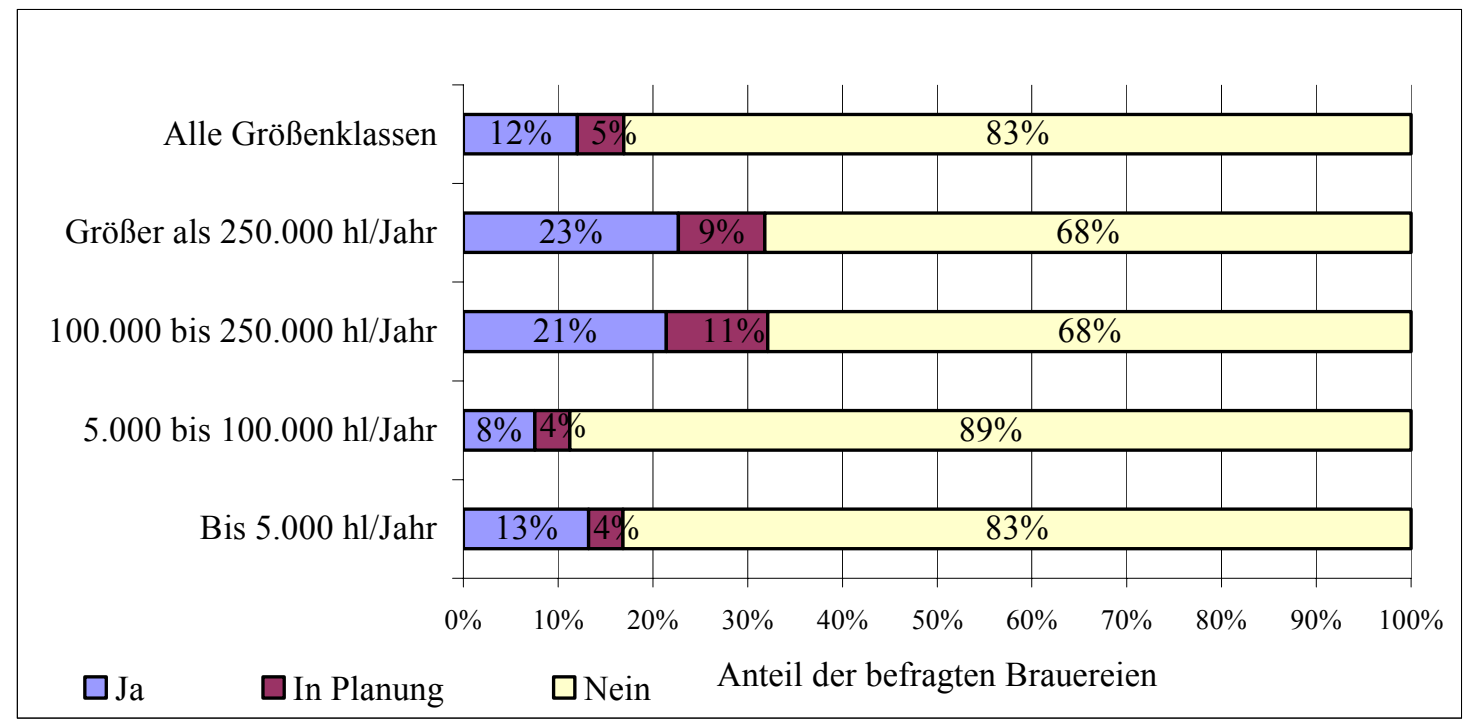

Abbildung 54: Vertikale Kooperationen (realisiert oder in Planung)

So liegt der Anteil der Unternehmen, die mit Betrieben im vor- oder nachgelagerten Bereich zusammenarbeiten oder dieses planen, in der Gruppe der Brauereien mit einem Jahresausstoß von über 100.000 hl mit $32 \%$ erheblich über dem Branchendurchschnitt. Mit Blick auf die Einschätzung der Kooperationspotentiale (Abbildung 53) verwundert 
dieses Ergebnis nicht. Abbildung 55 verdeutlicht, dass vertikale Kooperationen am häufigsten mit dem Getränkefachgroßhandel eingegangen werden.

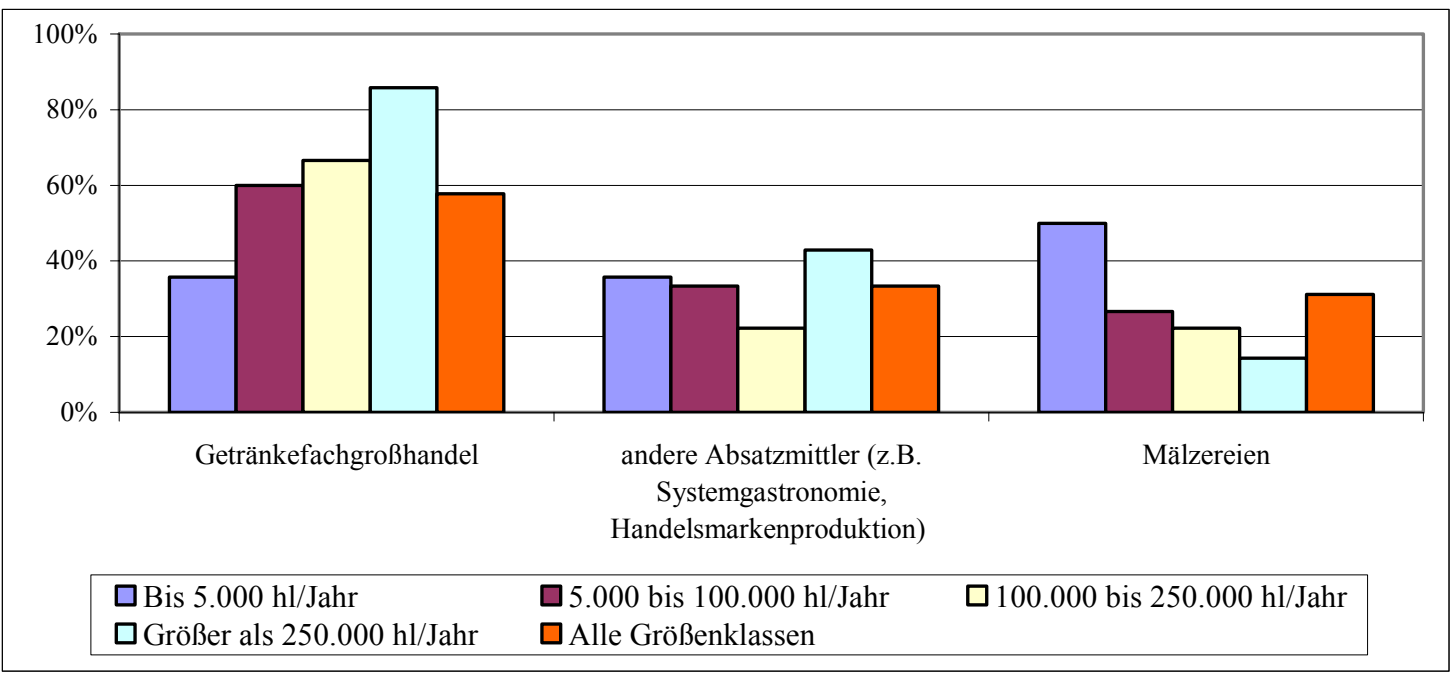

Abbildung 55: Vertikale Kooperationen

$(100 \%=$ Zahl der Brauereien, welche mit mindestens einem vor- oder nachgelagerten Unternehmen kooperieren oder dieses planen)

Dabei fallen besonders die großen Brauereien auf; etwa $85 \%$ der Unternehmen dieser Gruppe, die mit dem vor- oder nachgelagerten Bereich kooperieren, haben Partner im Getränkefachgroßhandel gefunden. Die Kooperationen mit anderen Absatzmittlern und Mälzereien spielen insgesamt eher eine untergeordnete Rolle. Im Bereich der Kooperationen mit Mälzereien fallen die Kleinstbrauereien mit bis zu $5.000 \mathrm{hl} / \mathrm{Jahr}$ allerdings besonders auf; ca. $50 \%$ der vertikal kooperierenden Unternehmen dieser Gruppe arbeiten mit Mälzereien zusammen.

Im Ergebnis bleibt festzustellen, dass von den im Rahmen dieser Arbeit befragten Brauereien immerhin etwa $50 \%$ an einer horizontalen Kooperation beteiligt sind oder eine solche Zusammenarbeit planen. Bei den größeren Brauereien liegt dieser Anteil sogar noch deutlich höher. Insgesamt werden die Möglichkeiten horizontaler Kooperationen von den befragten Unternehmen allerdings sehr unterschiedlich beurteilt.

Die Potentiale für eine Zusammenarbeit mit Unternehmen im vor- oder nachgelagerten Bereich werden insgesamt deutlich geringer eingeschätzt als die Chancen horizontaler Kooperationen. Am ehesten sind nach Auskunft der Befragten Kooperationen mit Absatzmittlern, speziell dem Getränkefachgroßhandel, von Interesse. Ingesamt sind $17 \%$ der befragten Brauereien eine vertikale Kooperation eingegangen oder planen 
diese. Dass dieser Anteil bei den größeren Brauereien $32 \%$ beträgt, weist wiederum auf die großen Unterschiede im Antwortverhalten hin.

Die Ergebnisse dieser Studie zeigen, dass die Kooperationsbereitschaft vieler deutscher Brauer nicht so gering ist, wie häufig angenommen wird (HENKE, 2002: S. 121; LÜCK/HENKE, 2003: S. 22). Andererseits wird aber auch deutlich, dass ein großer Teil der Brauereien beim Thema ,Kooperationen’ weiterhin abseits steht. Im Einzelfall mag es dafür gute Gründe geben. Vor dem Hintergrund des sich verschärfenden Wettbewerbs und der fortgesetzt schwierigen Branchensituation sollte diese Position jedoch regelmäßig überprüft werden, um keine Chancen zur Verbesserung der Wettbewerbsposition und zur Sicherung der Zukunft des Unternehmens zu verschenken.

\subsubsection{ERFOLGSLAGE DEUTSCHER BRAUEREIEN}

Die obigen Ausführungen haben ein facettenreiches Bild des unternehmens- und wettbewerbsstrategischen Managements in der deutschen Brauwirtschaft gezeichnet. Deutlich geworden ist, wie zahlreich die Versuche sind, der von den Branchenmitgliedern wahrgenommenen Krise der Branche zu begegnen und $u$. a. durch Wachstum, Internationalisierung, Diversifikation, Innovation sowie Marken- und Preisdifferenzierung möglichst neue (Teil-)Märkte zu erschließen. Bislang ungeklärt geblieben ist, mit welchem Erfolg dies geschieht.

Die deutliche Abnahme der Zahl der klassischen mittelgroßen Konsumbierbrauereien (Tabelle 4, S. 39) wird oft in dem Sinne interpretiert, dass Unternehmen entweder groß genug sein müssen, um mit den nationalen und ggf. sogar internationalen Kostenführern bzw. Markenartiklern mithalten zu können, oder klein genug sein sollten, um sich eine überlebensfähige Nische suchen zu können. Dazwischen - so die häufig geäußerte Auffassung - bleibt kaum Platz zum Überleben (O. V., 2005a: S. 678ff.). Sollte diese Interpretation zutreffen, dürften nur die sehr kleinen und die sehr großen Marktteilnehmer in der deutschen Brauwirtschaft profitabel sein und langfristig erfolgreich im Markt bestehen können. Die Frage, ob und inwieweit diese Annahme zutrifft oder ob sich auch mittelständische Brauer erfolgreich im Markt behaupten, steht im folgenden Kapitel im Mittelpunkt der Betrachtung. 
Der Unternehmenserfolg wurden im Rahmen der Untersuchung in zwei Stufen abgefragt. Im ersten Schritt wurden die Brauereien nach der prozentualen Gesamtveränderung von Gesamtgetränkeausstoß, Umsatz und Gewinn im Zeitraum von 2002 bis 2004 gefragt. Im Anschluss daran wurden die Brauereien gebeten, ihre Produktivität, Rentabilität und Finanzkraft im Vergleich zum Branchendurchschnitt einzuschätzen. Im Folgenden werden ausgewählte Ergebnisse vorgestellt.

Abbildung 56 zeigt, inwieweit sich der Getränkeausstoß der befragten Brauereien in den Jahren 2002 bis 2004 insgesamt verändert hat. Etwa 47 \% der Befragten konnten ihren Gesamtausstoß in diesem Zeitraum mehr oder minder stark erhöhen; andererseits mussten $34 \%$ teilweise beträchtliche Absatzverluste hinnehmen. Angesichts des fortschreitenden Rückgangs des Pro-Kopf-Verbrauchs im Inland und der nicht im selben Maße wachsenden Exporte ist dies ein Befragungsergebnis, das als überraschend gut bezeichnet werden muss. Zugleich belegen die Zahlen, dass auch in schrumpfenden Branchen ein Teil der Unternehmen wachsen kann, sei es durch Marktanteilsgewinne im Inland oder durch Ausbau des Auslandsgeschäfts.

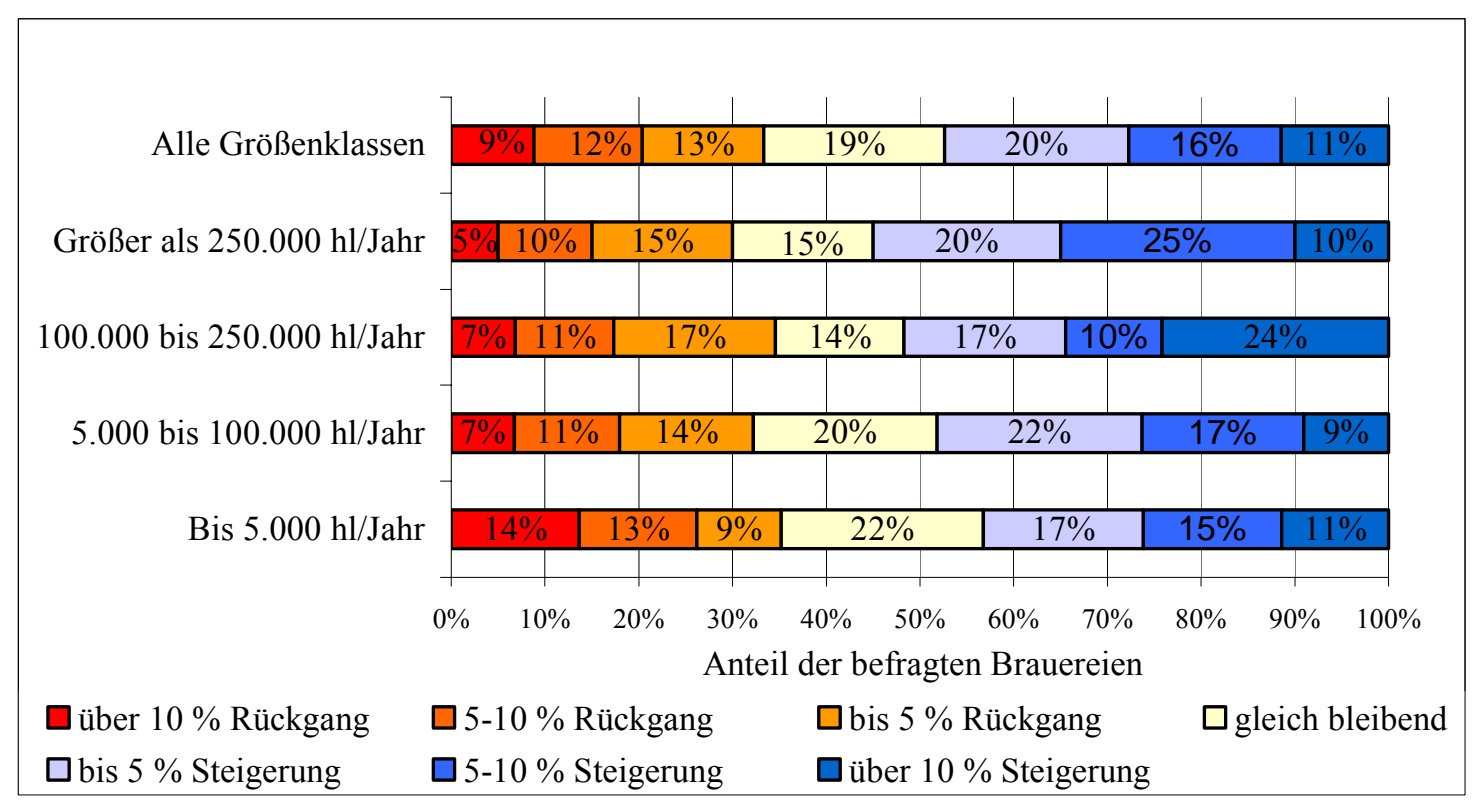

Abbildung 56: Veränderung des Gesamtgetränkeausstoßes im Zeitraum 2002 bis 2004

Zwischen den verschiedenen Größenklassen werden mit Blick auf die Ausstoßentwicklung Unterschiede deutlich. So steigt mit zunehmendem Ausstoß der Anteil der Brauereien, der Absatzzuwächse erzielen konnte. Dies steht im Einklang mit der zunehmenden Branchenkonzentration. Im Detail ist das Bild allerdings extrem widersprüchlich. Letztlich gibt es in allen Größenklassen, auch in den unter besonderem 
Druck stehenden mittleren Segmenten, Gewinner und Verlierer. Besonders deutlich wird dies bei der Betrachtung der Unternehmen in der Größenklasse von 100.000 bis $250.000 \mathrm{hl} / \mathrm{Jahr}$. In dieser Gruppe konnten nach eigenen Angaben etwa $24 \%$ der Brauereien ihren Ausstoß um mehr als $10 \%$ steigern, gleichzeitig hatten aber auch etwa $7 \%$ der Befragungsteilnehmer einen Absatzrückgang von über $10 \%$ zu verzeichnen.

Die Betrachtung der Ausstoßentwicklung alleine reicht nicht aus, um Aussagen über die Erfolgslage der Unternehmen zu tätigen. Sie wäre vielmehr Ausdruck eines reinen „Hektoliterdenkens“, wie es der deutschen Brauwirtschaft gelegentlich vorgeworfen wird (VERSTL, 2005: S. 173). Aus diesem Grund ist die Betrachtung weiterer Erfolgsmaße unerlässlich.

Abbildung 57 zeigt, inwieweit sich der Gewinn der befragten Unternehmen in den Jahren 2002 bis 2004 verändert hat. Dabei wird ersichtlich, dass immerhin etwa $43 \%$ der Befragten ihren Gewinn z. T. sogar deutlich erhöhen konnten, während auf der anderen Seite bei ca. $24 \%$ der Brauereien der Gewinn teilweise erheblich gesunken ist.

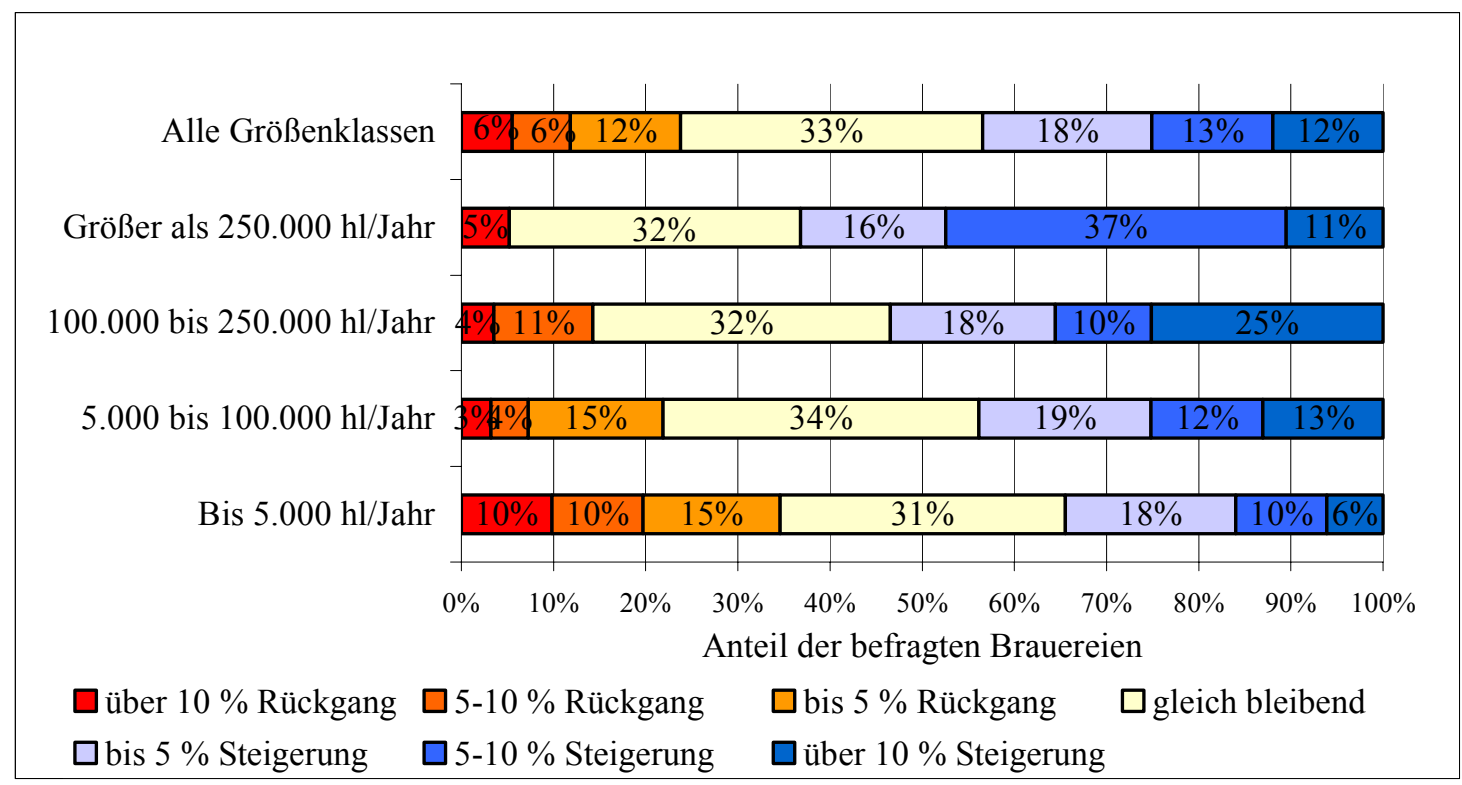

Abbildung 57: Veränderung des Gewinns im Zeitraum 2002 bis 2004

Auch hier sind wieder Unterschiede zwischen den verschiedenen Größenklassen festzustellen. So scheinen die größeren Brauereien insgesamt erfolgreicher zu sein; mit steigender Gesamtjahreserzeugung wächst der Anteil der Brauereien, die ihren Gewinn erhöhen konnten. Spiegelbildlich dazu verringert sich der Anteil der Unternehmen, die einen Gewinnrückgang zu verzeichnen hatten. Die Kleinstbrauereien weisen von allen Größenklassen die ungünstigste Gewinnentwicklung auf. Sie scheinen mehrheitlich in 
besonderer Weise von der in den letzten Jahren allgemein schwierigen Lage der Gastronomie und Veränderungen des Konsumentenverhaltens, etwa der Hinwendung zur Systemgastronomie, betroffen zu sein (vgl. Kapitel 3.2.3.3.2.3)

Bei einem Vergleich der Abbildung 56 und 57 wird deutlich, dass der Anteil der Brauereien, die in den Jahren 2002 bis 2004 einen Gewinnrückgang zu verzeichnen hatten, deutlich unter dem Anteil der Unternehmen liegt, die eine Verringerung des Gesamtgetränkeabsatzes hinnehmen mussten. Dies lässt darauf schließen, dass Preiserhöhungen durchgesetzt bzw. Kostensenkungen realisiert werden konnten. Die größeren Brauereien scheinen dabei tendenziell erfolgreicher gewesen zu sein, da bei ihnen der aufgezeigte Unterschied besonders ausgeprägt ist.

Neben den prozentualen Veränderungen von Absatz und Gewinn ist auch von Interesse, wie die Unternehmen ihren eigenen Erfolg in Relation zum Branchendurchschnitt wahrnehmen. Abbildung 58 stellt dar, wie die befragten Brauereien ihre Produktivität (Umsatz minus Fremdleistungen je Beschäftigtem) im Vergleich zum Durchschnitt der Branche einschätzen. Etwa $30 \%$ der Befragten attestieren sich insoweit einen Vorsprung vor der Konkurrenz, während 31 \% der Brauereien die Überlegenheit der Wettbewerber anerkennen.

Die Arbeitsproduktivität ist eine der gebräuchlichsten und wirtschaftlich aussagekräftigsten Produktivitätskennziffern. Sie gibt an, wie groß der produktive Beitrag eines jeden Beschäftigten ist. Ein Anstieg der Arbeitsproduktivität bedeutet, dass sich die Wertschöpfung in Bezug auf den Arbeitseinsatz erhöht hat bzw. dass das angestrebte Produktionsergebnis mit weniger Arbeitsstunden erreicht wurde. Einfluss auf die Arbeitsproduktivität haben vor allem der technische Fortschritt und die Arbeitsintensität. Vor diesem Hintergrund überrascht es nicht, dass deutliche Unterschiede zwischen den Größenklassen festzustellen sind. Meist sind größere Brauereien wesentlich stärker automatisiert, mit der Folge einer entsprechend höheren Arbeitsproduktivität. Dies spiegelt sich auch in der in Abbildung 58 wiedergegebenen Selbsteinschätzung wieder. Mit steigender Gesamtjahreserzeugung geht tendenziell ein deutlich höherer Anteil der Brauereien davon aus, dass ihre Produktivität über dem Branchenmittel liegt. 


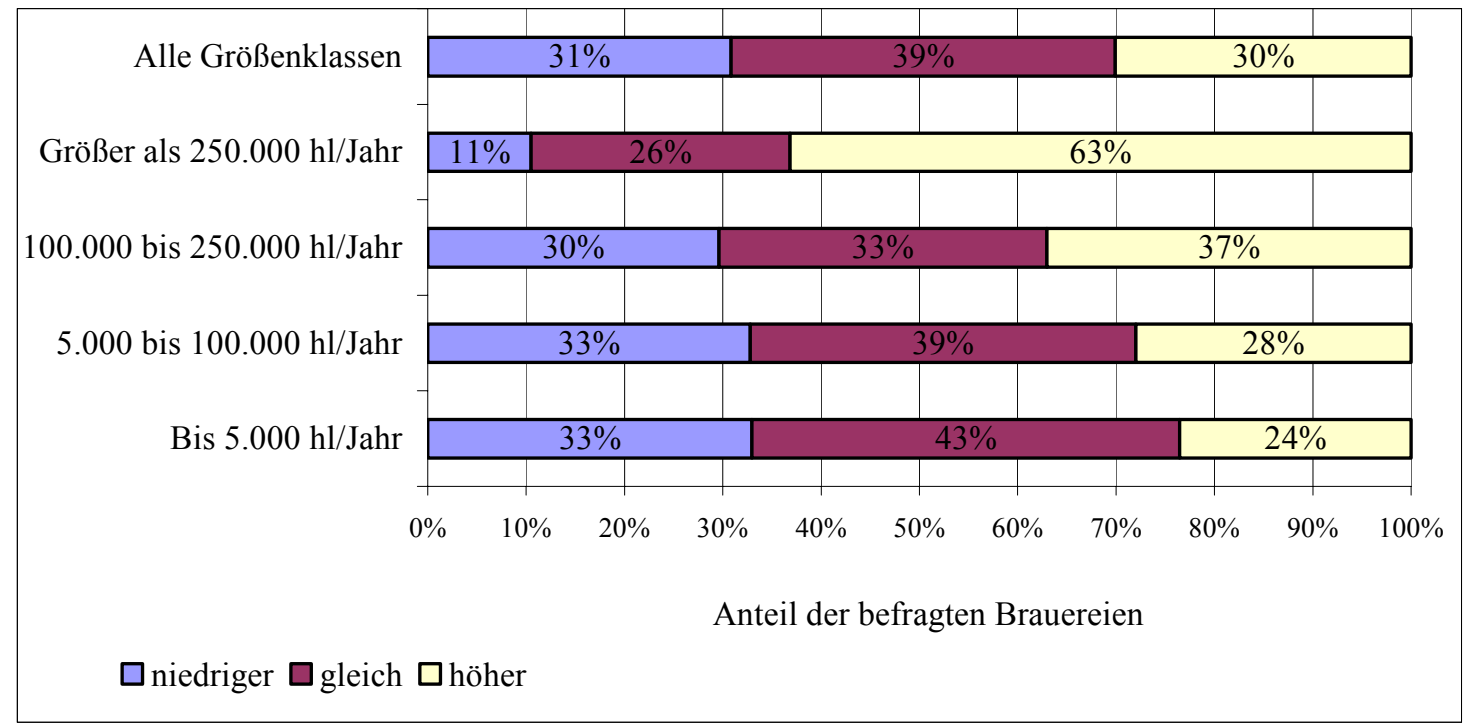

Abbildung 58: Produktivität in Relation zum Branchendurchschnitt

Von Kennern der deutschen Brauwirtschaft wird seit Jahren gefordert, dass anstelle des reinen Mengendenkens der Rentabilitätsgedanke wieder mehr in den Mittelpunkt der Überlegungen rücken sollte (KALLMEYER, 2002: S. 1; VERSTL, 2005: S. 173). Die Rentabilität ist eine der wichtigsten Erfolgskennzahlen von Unternehmen. Sie gibt Auskunft darüber, wie hoch der Gewinn in Relation zum eingesetzten Kapital ist (REHSE, 2004: S. 10).

Abbildung 59 veranschaulicht, wie die befragten Brauereien ihre Rentabilität im Vergleich zum Branchendurchschnitt beurteilen. Das Bild entspricht im Großen und Ganzen den oben wiedergegebenen Einschätzungen zur Produktivität entspricht, da diese Erfolgskennziffern in enger Beziehung zueinander stehen.

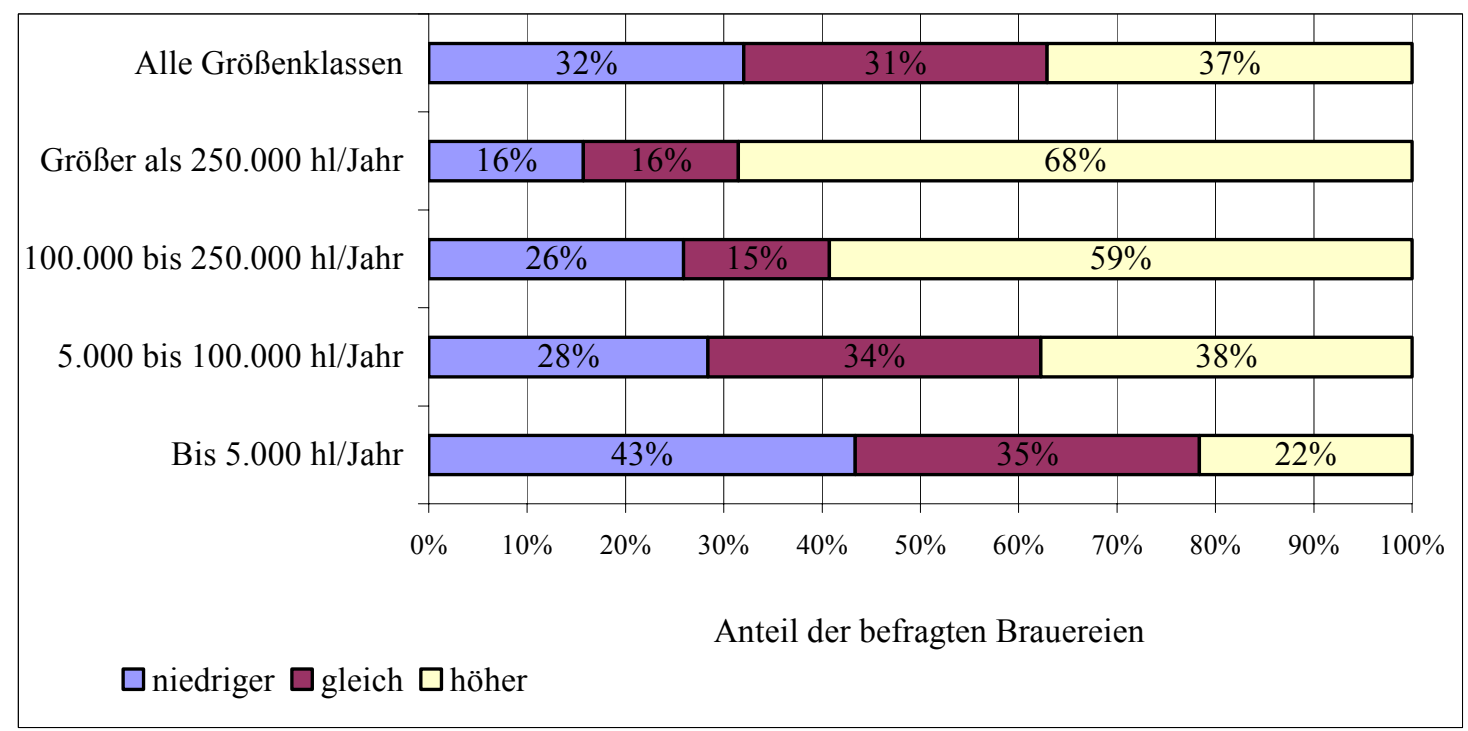

Abbildung 59: Rentabilität in Relation zum Branchendurchschnitt 
Etwa $37 \%$ aller befragten Brauereien vermuten, dass ihre Rentabilität oberhalb des Branchendurchschnitts liegt. Nur etwa $32 \%$ der Unternehmen gehen davon aus, dass ihre Rentabilität im nationalen Vergleich unterdurchschnittlich ist. Im Einzelnen bestehen in dieser Hinsicht wieder erhebliche Unterschiede zwischen den Größenklassen. So meinen von den Unternehmen mit einem Ausstoß von mehr als $250.000 \mathrm{hl} / \mathrm{Jahr}$ rund $68 \%$, dass ihre Rentabilität über dem Branchendurchschnitt liegt, wohingegen es bei den Kleinstbrauereien (bis $5.000 \mathrm{hl}$ ) nur etwa $22 \%$ sind. Im internationalen Vergleich allerdings ist die Rentabilität der deutschen Brauwirtschaft unterdurchschnittlich; dies gilt vor allem im Vergleich zu den führenden internationalen Braukonzernen wie Heineken und InBev (EBNETH, 2005: S. 5).

Die Liquidität/Finanzkraft ist eine weitere wichtige Kennziffer des Erfolgs von Unternehmen. Sie gibt Auskunft über freie Mittel für neue Aktivitäten sowie die Möglichkeit von Kreditfinanzierungen und ist somit gerade für die zukünftige Entwicklung der Unternehmen von herausragender Bedeutung (REHSE, 2004: S. 23).

Abbildung 60 zeigt, wie die befragten Unternehmen ihre Finanzkraft im Vergleich zum Branchenmittel einschätzen. Dabei wird ersichtlich, dass $32 \%$ aller befragten Brauereien ihre Finanzkraft über dem Branchendurchschnitt erachten; etwa $31 \%$ sind der Meinung, ihre Finanzkraft sei unterdurchschnittlich.

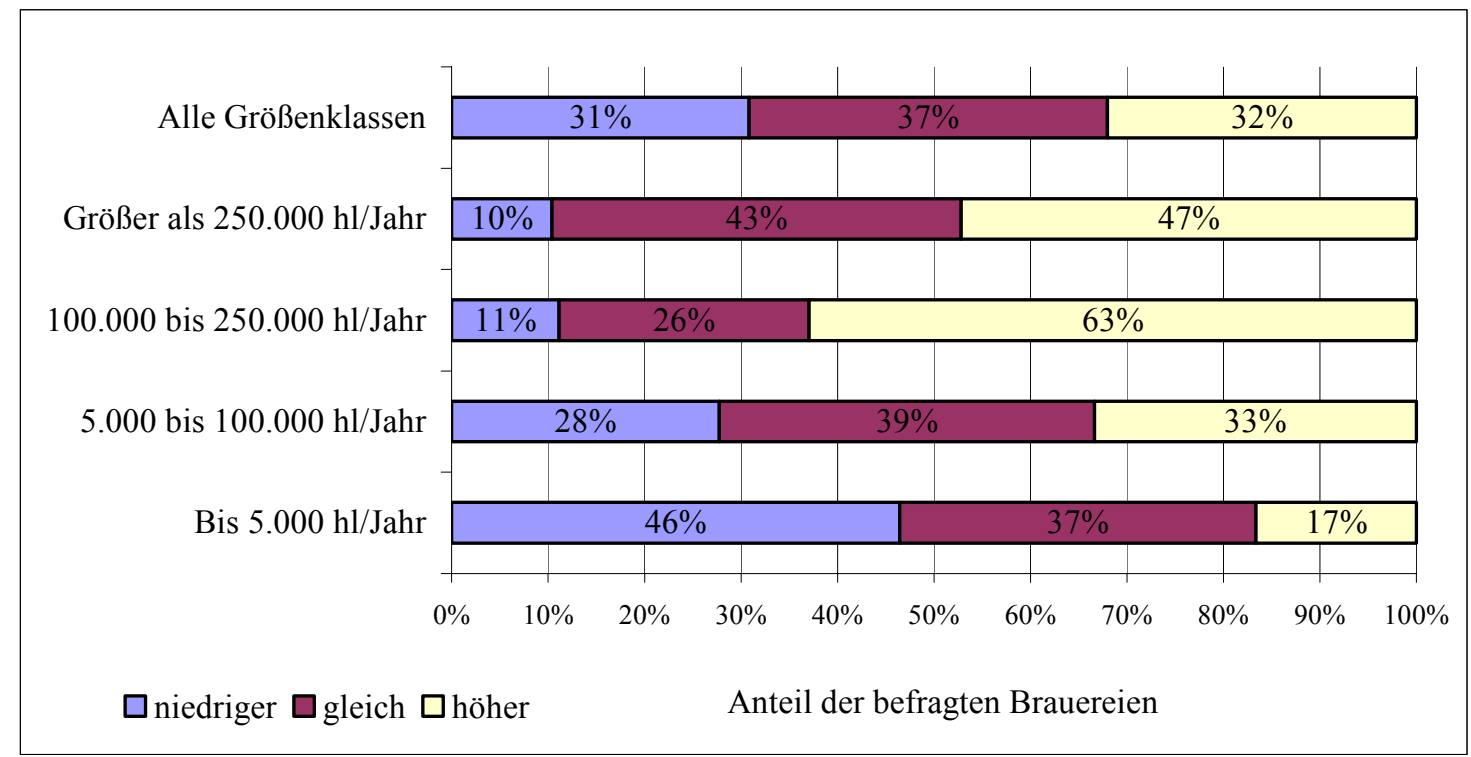

Abbildung 60: Finanzkraft in Relation zum Branchendurchschnitt 
Es bestehen wieder erhebliche Unterschiede zwischen den verschiedenen Größenklassen. So heben sich besonders die Brauereien mit einem Jahresausstoß von 100.000 bis $250.000 \mathrm{hl}$ von der Grundgesamtheit ab, von denen sich $63 \%$ eine über dem Branchendurchschnitt liegende Finanzkraft bescheinigen - ein angesichts der Entwicklung in dieser Größenklasse (vgl. Tabelle 4, S. 39) durchaus überraschende Aussage. Auffällig ist im Vergleich dazu die nach eigener Einschätzung geringere Finanzkraft der Großbrauereien; hier dürften die Akquisitionen der letzten Jahre, Vorleistungen im Exportgeschäft oder auch hohe Marketingaufwendungen die Ursachen sein.

Zusammenfassend ist festzuhalten, dass immerhin etwa $43 \%$ der im Rahmen der Studie befragten Brauereien ihren Gewinn in den Jahren 2002 bis 2004 erhöhen konnten. Bei den größeren Brauereien liegt dieser Anteil sogar noch deutlich darüber. Des Weiteren attestieren sich rund zwei Drittel der Befragten eine Rentabilität und Finanzkraft, die zumindest nicht schlechter als im Branchendurchschnitt ist. Auch wenn andere Brauereien angeben, dass sie Gewinnrückgänge hinnehmen mussten und nur unterdurchschnittlich erfolgreich sind, so ist doch insgesamt die Erfolgsentwicklung und -lage vieler Brauereien besser als zunächst erwartet. Es kann allerdings nicht ausgeschlossen werden, dass sich tendenziell mehr erfolgreiche Brauer an der Umfrage beteiligt haben. Insoweit ist bei einer Übertragung des Befunds auf die übrigen Brauereien, die nicht in der Umfrage vertreten sind, Vorsicht angeraten. Ferner ist es denkbar, dass die Aufwärtsentwicklung von einem sehr niedrigen Niveau aus erfolgte; insofern kann trotz positiver Entwicklung das Gewinnniveau weiterhin unbefriedigend sein.

Sowohl bei der Entwicklung von Absatz und Gewinn als auch bei der Einschätzung des eigenen Erfolgs in Relation zum Branchendurchschnitt zeigt sich, dass sich in allen Größenklassen sowohl erfolgreiche als auch weniger erfolgreiche Brauereien finden. Dies ist mit Blick auf die eingangs zitierte These von der „Ausdünnung der Mitte“ außerordentlich interessant, zeigt sich doch, dass die Auffassung, nach der nur sehr kleine und sehr große Unternehmen auf Dauer erfolgreich im Wettbewerb bestehen können, in dieser Form nicht uneingeschränkt richtig ist. Vielmehr scheint es in hohem Maße auf die individuellen (Management-)Fähigkeiten und die jeweilige strategische Positionierung anzukommen. Die Zugehörigkeit zu einer bestimmten Größenklasse 
entscheidet dagegen keineswegs per se über den Erfolg eines Unternehmens. Dies zeigen auch einige gescheiterte Großbrauereien bzw. Braukonzerne. Das bedeutet, dass ein beachtlicher Teil der deutschen Brauereien unabhängig von ihrer Größe mit Erfolg die Chancen nutzt, die der deutsche Biermarkt trotz aller unbestreitbaren Schwierigkeiten weiterhin bietet. Trotzdem wird sich der Konsolidierungsprozess auch in Zukunft fortsetzen. Es besteht aber vor dem Hintergrund der dargestellten Ergebnisse die Aussicht darauf, dass er weniger ausgeprägt als vielfach befürchtet ausfallen wird (ERnst \& YounG, 2003: S. 8). Insoweit gibt es Anlass zur Hoffnung, dass die im internationalen Vergleich tatsächlich einmalige deutsche Brauwirtschaft und Braukultur auch in Zukunft in vielfältiger Form erhalten bleiben wird.

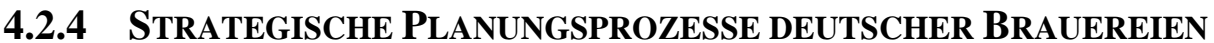

Im hart umkämpften deutschen Biermarkt werden langfristig nur die Brauereien wirtschaftlich erfolgreich sein, die für ihr Unternehmen eine klare Ausrichtung sowie Ziele vorgeben und diese mit einem ganzheitlichen Konzept verfolgen. Grundlage dafür ist ein funktionierendes strategisches Management, welches z.B. auch die Verhandlungen bei Kreditvergaben unter dem Einfluss von Basel II erleichtert.

Beim strategischen Management handelt es sich um eine Führungsaufgabe, die von besonderer Bedeutung für den Erfolg eines Unternehmens ist. Es zielt darauf ab, die Marktposition eines Unternehmens und die Ausgestaltung seiner Ressourcenbasis so zu bestimmen, dass das Unternehmen Vorteile gegenüber seinen Konkurrenten aufbauen und langfristig erfolgreich bestehen kann (BURR ET AL., 2004: S. 75f.).

\begin{tabular}{|c|c|c|}
\hline $\begin{array}{l}\text { Strategische } \\
\text { Analyse }\end{array}$ & $\begin{array}{l}\text { Strategie- } \\
\text { formulierung }\end{array}$ & $\begin{array}{l}\text { Strategie- } \\
\text { implementierung }\end{array}$ \\
\hline $\begin{array}{l}\text { - Externe Analyse } \\
\text { - Interne Analyse }\end{array}$ & $\begin{array}{l}\text { - Entwicklung von } \\
\text { Strategien } \\
\text { - Beurteilung der } \\
\text { Strategiealternativen } \\
\text { - Entscheidung für eine } \\
\text { Strategie }\end{array}$ & $\begin{array}{l}\text { - Gestaltung von } \\
\text { Strukturen und Systemen } \\
\text { - Operationalisierung von } \\
\text { Strategien } \\
\text { - Information, Schulung und } \\
\text { Motivation der Mitarbeiter }\end{array}$ \\
\hline
\end{tabular}

Abbildung 61: Prozess des strategischen Managements Quelle: HungENBERG, 2001: S. 9 
Im Rahmen des strategischen Managements ist u. a. eine Entscheidung über die Unternehmensstrategie zu treffen, die zeigt, wie die Unternehmensziele erreicht werden sollen. Das strategische Management kann nach HungENBERG (2001: S. 8ff.) idealtypisch als Entscheidungsprozess beschrieben werden, der in die Teilschritte Analyse, Formulierung und Auswahl sowie Implementierung von Strategien unterteilt werden kann (Abbildung 61).

Die Frage, ob und inwieweit dieser Prozess in der deutschen Brauwirtschaft Anwendung findet, steht im Mittelpunkt des folgenden Abschnitts. Mit Blick auf die Selbsteinschätzung der befragten Brauereien zeichnet sich ein klares Bild ab. Etwa $82 \%$ der Befragten geben an, auch im Tagesgeschäft immer die langfristige Strategie im Auge zu haben. Nur $5 \%$ der Unternehmen lehnen diese Aussage ab (Abbildung 62).

Zwischen den verschiedenen Größenklassen bestehen in dieser Hinsicht einige kleinere, gleichwohl bemerkenswerte Unterschiede. So stechen besonders die Brauereien mit einem Jahresausstoß von 100.000 bis 250.000 hl hervor, von denen $96 \%$ der Auffassung sind, die Strategie immer im Auge zu haben. Bei den Kleinstbrauereien (bis $5.000 \mathrm{hl}$ ) sind es hingegen nur $77 \%$.

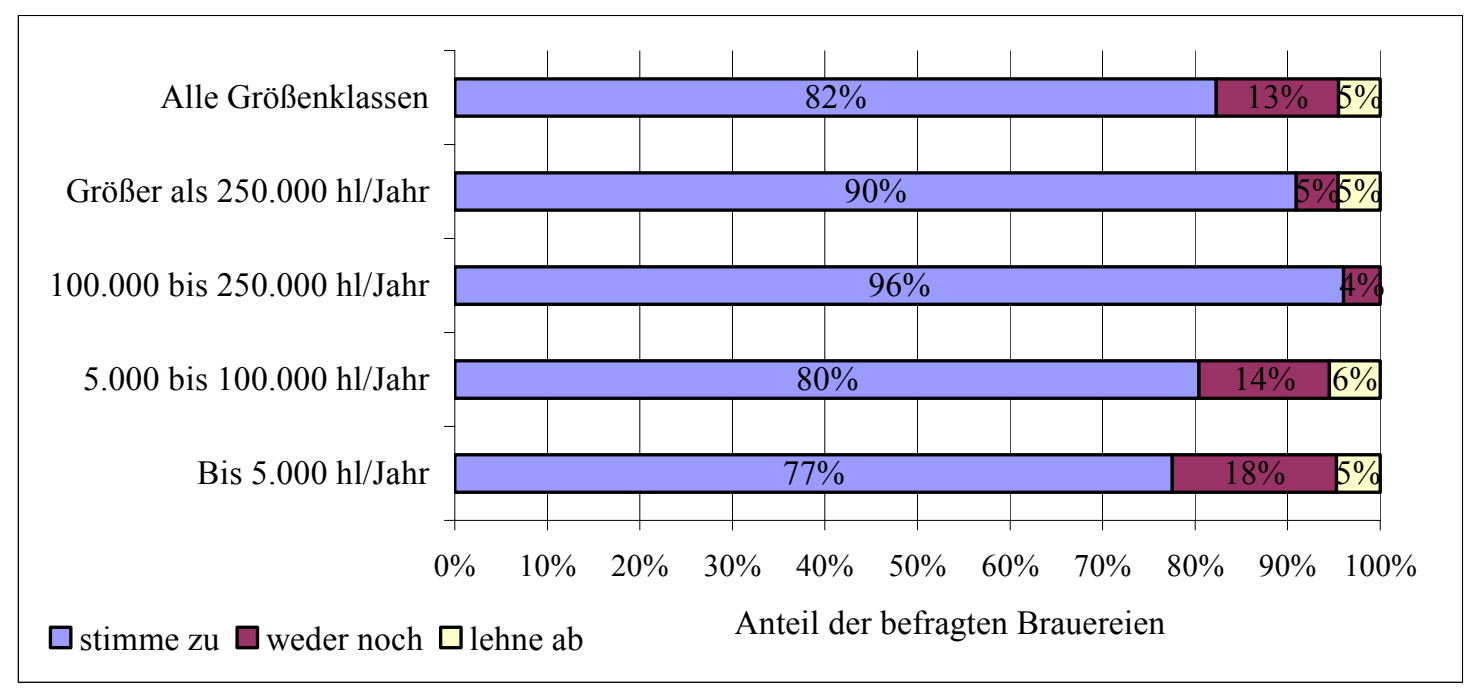

Abbildung 62: „Auch im Tagesgeschäft haben wir immer die langfristige Strategie im Auge.“

Im Folgenden wird nun überprüft, ob es sich bei dieser Selbsteinschätzung der Brauereien lediglich um ein Lippenbekenntnis handelt oder ob es der Realität entspricht. Dazu wird untersucht, ob wichtige Elemente des strategischen Managements (Abbildung 61) in den befragten Brauereien angewendet werden. 
$\mathrm{Zu}$ den grundlegenden betrieblichen Entscheidungen und unverzichtbaren Elementen des strategischen Managements gehört die Festsetzung der Unternehmensziele (MACHARZINA, 2003: S. 187ff.). Die Brauereien sollten dabei möglichst klaren, realistischen und gut messbaren Zielen den Vorrang geben. Diese können z.B. leistungswirtschaftlicher (bspw. Marktanteil) oder auch finanzwirtschaftlicher Art (Rentabilität, Liquidität u. ä.) sein. Etwa $54 \%$ aller Befragten definieren für ihr Unternehmen klare Ziele, die bis $\mathrm{zu}$ einem bestimmten Zeitpunkt zu erreichen sind. Allerdings sind insoweit deutliche Unterschiede zwischen den verschiedenen Größenklassen festzustellen. Aus Abbildung 63 wird ersichtlich, dass mit steigender Gesamtjahreserzeugung erheblich mehr Unternehmen klare Ziele festlegen. Dieses Ergebnis ist nicht überraschend, da die größeren Unternehmen häufig durch ein professionelleres Management geführt werden. Zugleich wird es mit wachsender Größe und zunehmender innerbetrieblicher Arbeitsteilung für die Unternehmen immer wichtiger, die Koordinations- und Motivationsfunktion von Zielen zu nutzen.

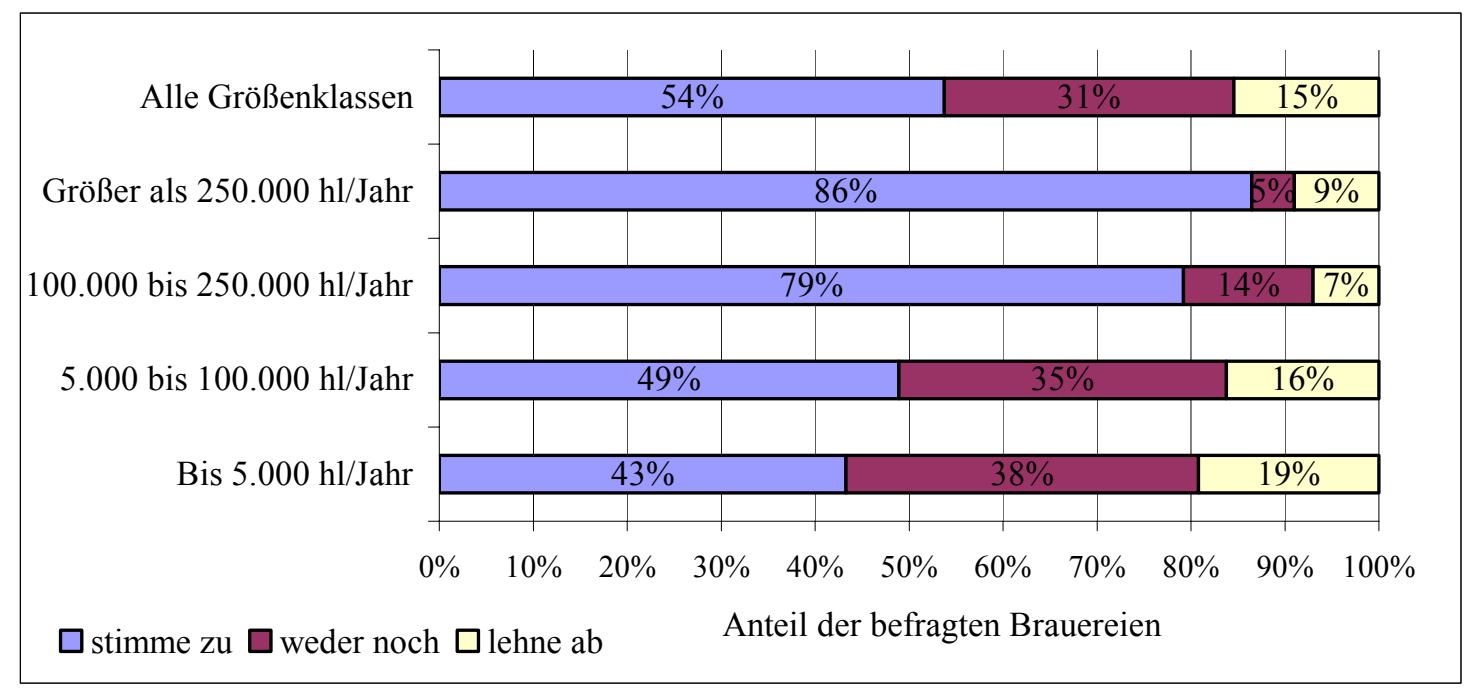

Abbildung 63: „Es werden klare Ziele festgelegt, die bis zu einem bestimmten Zeitpunkt zu erreichen sind.“

Bei einem Vergleich der Abbildung 62 und 63 wird deutlich, dass der Anteil der Brauereien, die klare Ziele festlegen, deutlich unter dem Anteil der Unternehmen liegt, die der Auffassung sind, die langfristige Strategie immer im Auge zu haben. Da eine Zielvorgabe aber die Grundlage einer jeden langfristigen Strategie ist, lassen die aufgezeigten Unterschiede vermuten, dass sich viele Brauereien in Bezug auf eine langfristige Strategieorientierung anscheinend überschätzen.

Um eine Strategie zu verwirklichen, müssen in einem Unternehmen entsprechende Strukturen und Systeme eingerichtet werden. Ein Beispiel ist die Festlegung bestimmter 
Planungstermine, zu denen die Entwicklung des Unternehmens regelmäßig überprüft wird (MACHARZINA, 2003: S. 190). Bei rund $55 \%$ der befragten Brauereien ist ein System fester Planungstermine bereits etabliert. Auch hier ist wieder zu beobachten, dass mit steigender Gesamtjahreserzeugung der Anteil der Brauereien, die ihre Geschäftsentwicklung im Rahmen entsprechender Planungstermine regelmäßig überprüfen, deutlich ansteigt (Abbildung 64). Dieses Ergebnis überrascht nicht, da die größeren Unternehmen häufiger in verschiedene Abteilungen wie z.B. Produktion, Marketing und Vertrieb gegliedert sind, deren Aktivitäten auch in zeitlicher Hinsicht koordiniert werden müssen, um ein einheitliches und aufeinander abgestimmtes Vorgehen zu gewährleisten. Bei den kleineren Brauereien ist dies aufgrund der geringeren Größe und der weniger stark ausdifferenzierten Organisation naturgemäß deutlich seltener erforderlich.

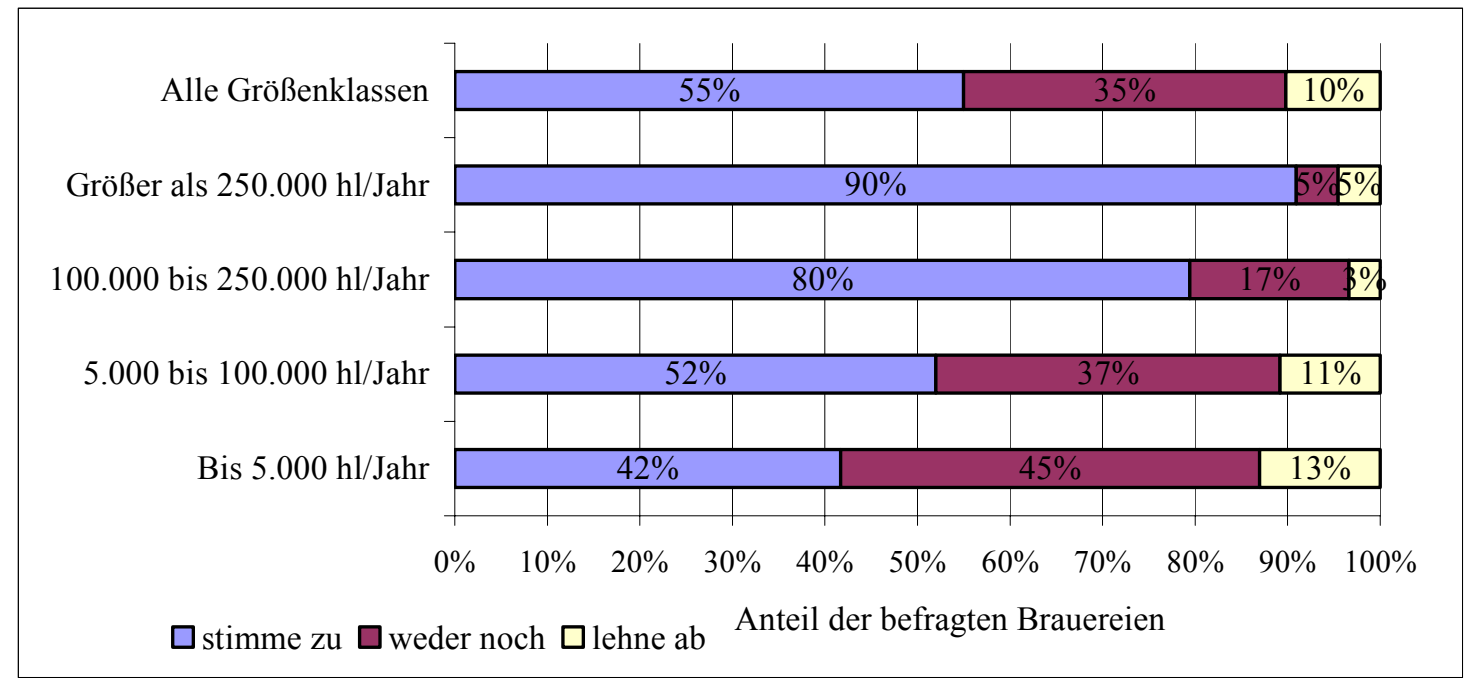

Abbildung 64: „Die Geschäftsentwicklung wird im Rahmen vorher festgelegter Planungstermine regelmäßig überprüft.“

Insgesamt zeigt sich, dass auch der Anteil der Unternehmen, die ihre Geschäftsentwicklung regelmäßig zu festen Terminen überprüfen, erheblich unter dem Anteil der Brauereien liegt, die angeben, die langfristige Strategie immer im Auge zu haben. Für die Umsetzung einer Strategie sowie die Erreichung der gesetzten Ziele ist es jedoch unumgänglich, die Entwicklung des Betriebs regelmäßig zu überprüfen, um z. B. notwendige Anpassungsmaßnahmen rechtzeitig erkennen und durchführen zu können. Bei den Brauereien, die ein solches System noch nicht eingeführt haben, ist folglich anzunehmen, dass sie ihre Strategie entgegen ihrer eigenen Einschätzung nicht immer im Blick haben. Insofern bestätigt sich der bereits bei der Analyse des Zielsetzungsverhaltens geäußerte Verdacht. 
Der Erfolg einer Strategie wird maßgeblich durch ihre Umsetzung beeinflusst. Daher ist eine enge Vernetzung der strategischen Planung mit den für die Realisierung der Pläne zuständigen Mitarbeitern im Unternehmen ebenso unverzichtbar wie ausreichend qualifiziertes Personal. Regelmäßige Information und Schulungen sind daher außerordentlich wichtig. Aus Abbildung 65 wird ersichtlich, dass etwa $63 \%$ aller befragten Brauereien die Strategie und die Ziele ihres Unternehmens regelmäßig an alle Führungskräfte und Mitarbeiter kommunizieren. Eine konsequente Weiterbildung der Mitarbeiter durch externe und interne Stellen ist hingegen nur bei $48 \%$ der befragten Unternehmen Standard (Abbildung 66).

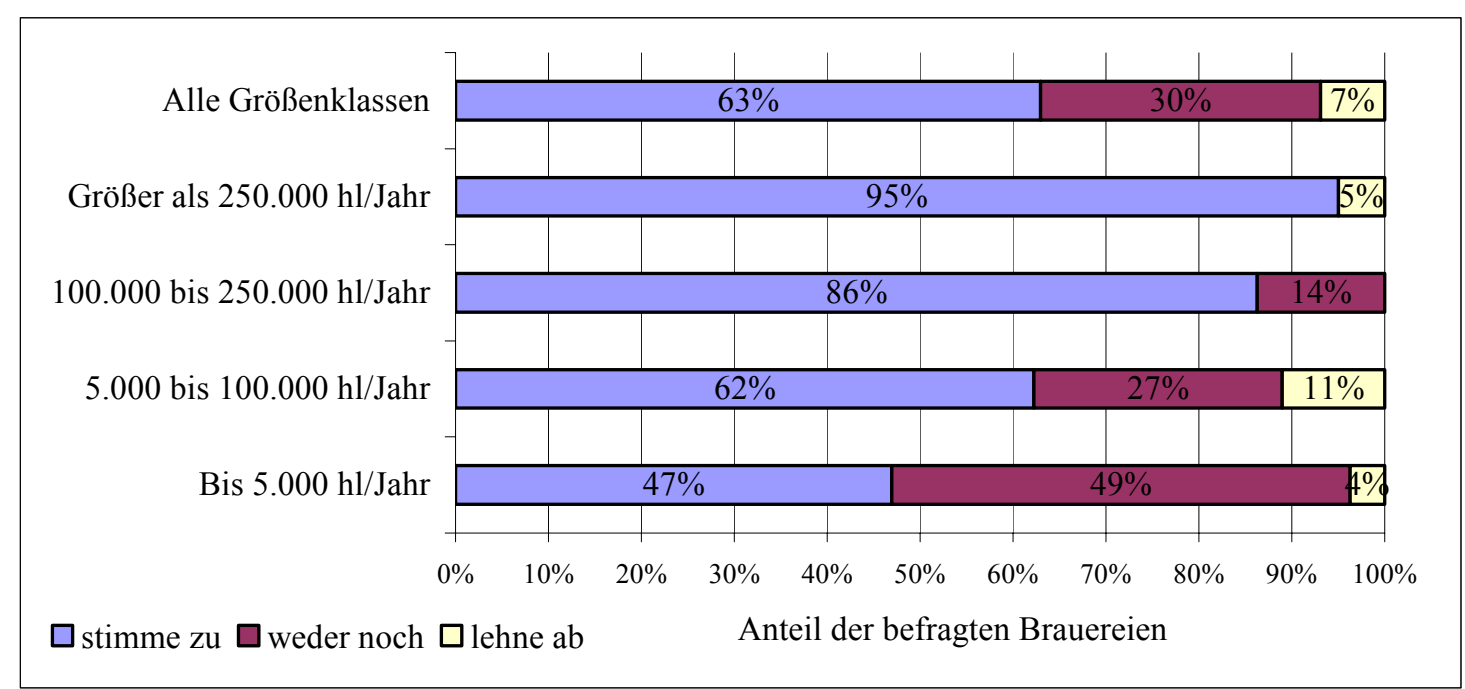

Abbildung 65: „Die Strategie und die Ziele unseres Unternehmens werden regelmäßig an alle Führungskräfte und Mitarbeiter kommuniziert."

Sowohl bei der Informationspolitik als auch bei der Schulung der Mitarbeiter werden die bereits an anderer Stelle festgestellten Unterschiede zwischen den verschiedenen Größenklassen erneut erkennbar. So nimmt der Anteil der Unternehmen, die ihre Mitarbeiter regelmäßig über die Strategie informieren und eine konsequente Weiterbildung durchführen, mit steigender Gesamtjahreserzeugung deutlich zu. Beides ist leicht nachzuvollziehen. So steigt mit abnehmender Überschaubarkeit einer Organisation der Informations- und Know-how-Bedarf der Mitarbeiter naturgemäß an. In kleineren Brauereien werden die anspruchsvolleren Tätigkeiten dagegen häufig direkt von der Geschäftsleitung durchgeführt; Schulungen der Angestellten sind somit häufig nicht im selben Umfang wie in Großunternehmen nötig. Außerdem können die kleineren Brauereien im operativen Geschäft oft nicht auf die Mitarbeiter verzichten, da die verschiedenen Positionen im Unternehmen in der Regel nur einfach besetzt sind. 
Die Freistellung des Personals für Schulungsveranstaltungen scheitert daher häufig an organisatorischen Schwierigkeiten.

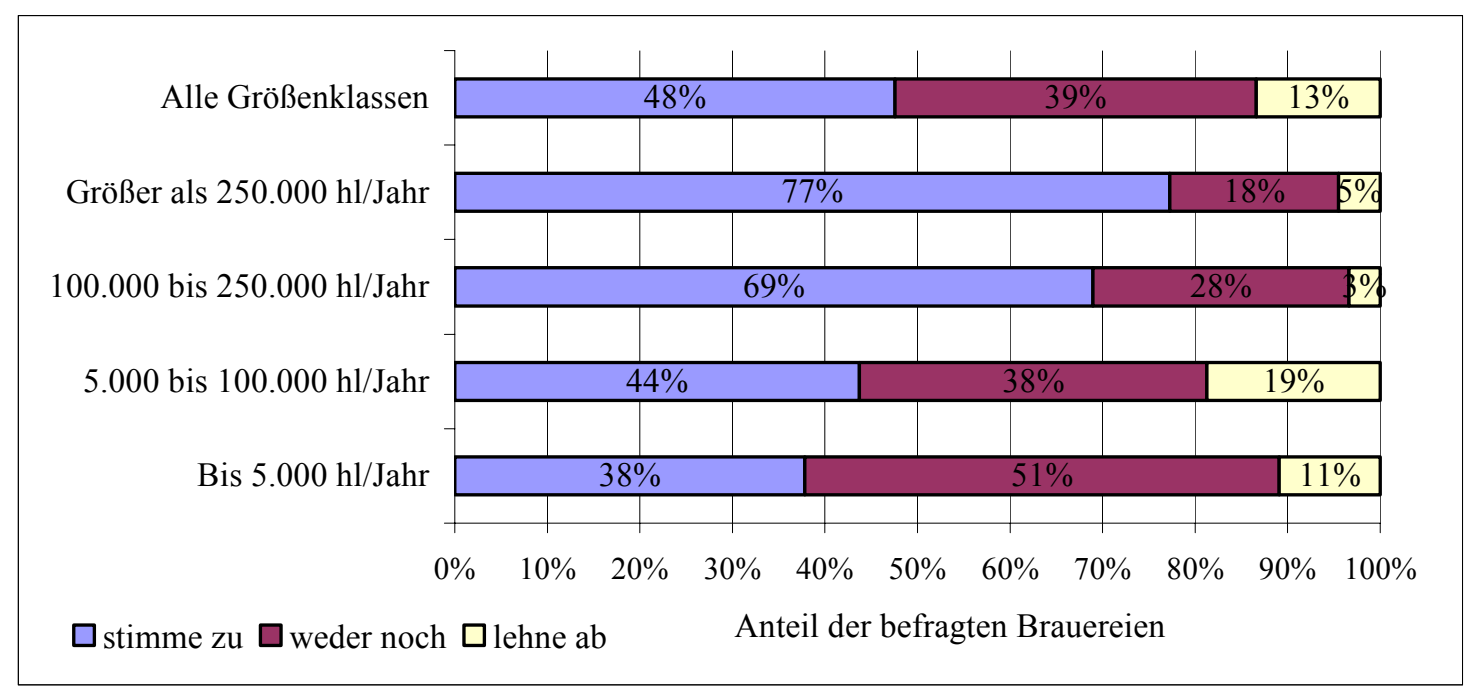

Abbildung 66: „Eine konsequente Weiterbildung unserer Mitarbeiter durch externe und interne Stellen ist bei uns Standard.“

Im Zusammenhang mit strategischen Planungsprozessen in der deutschen Brauwirtschaft ist es auch von Interesse, ob die Brauereien auf Hilfe von außen zurückgreifen. Abbildung 67 veranschaulicht, dass sich nur etwa $27 \%$ der befragten Brauereien regelmäßig bei der strategischen Unternehmensplanung durch externe Berater unterstützen lassen. Im Einzelnen bestehen in dieser Hinsicht erhebliche Unterschiede. Besonders auffällig sind auch hier die Brauereien mit einem Jahresausstoß von 100.000 bis $250.000 \mathrm{hl}$, von denen $41 \%$ der Befragten regelmäßig auf die Hilfe externer Berater zurückgreifen, wohingegen bei den Kleinstbrauereien (bis $5.000 \mathrm{hl}$ ) nur $13 \%$ der Befragten derartige Hilfe in Anspruch nehmen. Bei den Großbrauereien (über $250.000 \mathrm{hl}$ ) ist die Bedeutung der externen Beratung geringer; bei ihnen kann dank stärkerer Spezialisierung vermutlich intern mehr Management-Knowhow und -kapazität aufgebaut werden. Kleinstbrauereien (bis $5.000 \mathrm{hl}$ ) nehmen nur selten externe Hilfe in Anspruch; die Konsultation von Beratern dürfte wegen der geringen Unternehmensgröße oftmals nicht erforderlich, aufgrund begrenzter Finanzkraft aber häufig auch nicht finanzierbar sein. 


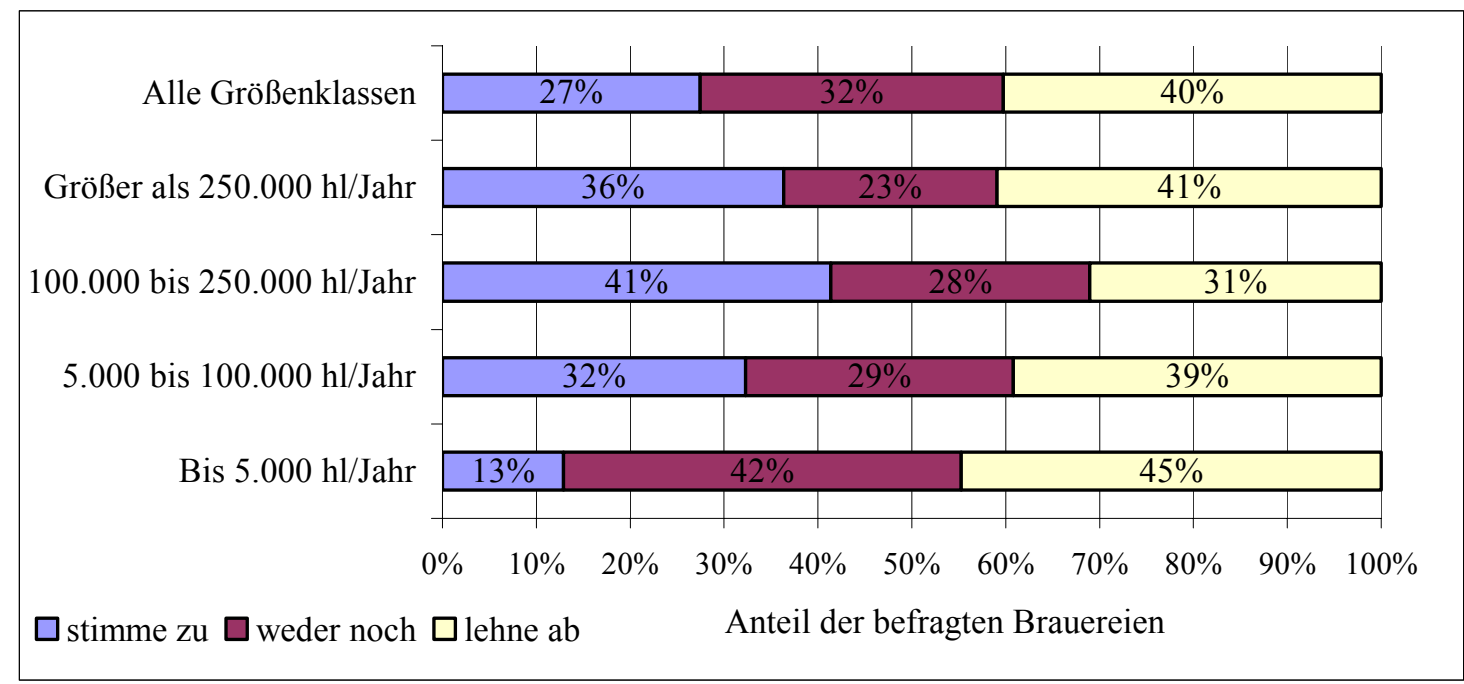

Abbildung 67: „Bei der strategischen Unternehmensplanung unterstützen uns regelmäßig externe Berater.“

Zusammenfassend ist festzustellen, dass etwa $82 \%$ der im Rahmen der Studie befragten Brauereien der Auffassung sind, auch im Tagesgeschäft die langfristige Strategie immer im Auge zu haben. Bei den größeren Brauereien liegt dieser Anteil sogar noch deutlich darüber. Gleichzeitig zeigen die Ergebnisse aber auch, dass diese Selbsteinschätzung der befragten Unternehmen einer kritischern Prüfung nur bedingt standhält; wichtige Elemente des strategischen Managements, z.B. die Formulierung von Zielen sowie die Überprüfung der Geschäftsentwicklung zu festgelegten Planungsterminen, finden in vielen Fällen keine Anwendung.

Die Umfrageergebnisse legen die Vermutung nahe, dass gerade viele kleinere Brauereien ihre langfristige Strategieorientierung überschätzen; die Unternehmen scheinen z.T. mehr ,nach dem Bauchgefühl“ denn auf der Grundlage strategischer Planungsprozesse geführt $\mathrm{zu}$ werden. Diese Methode mag im Einzelnen gut funktionieren, dürfte aber z.B. bei Kreditverhandlungen an ihre Grenzen stoßen, da von den Banken im Ratingverfahren klar formulierte und zukunftsfähige Strategien gefordert werden. Bei der Mehrzahl der größeren Brauereien ist strategische Unternehmensplanung hingegen ein fester und durch wichtige Elemente des strategischen Managements gestützter Prozess. Die Brauereien, bei denen dieser Prozess noch nicht etabliert ist, sollten dessen Einführung prüfen, da ein strategisches Vorgehen und eine systematische Umsetzung der Unternehmensziele elementare Grundlagen für eine langfristige Sicherung des Unternehmenserfolgs sind. 


\subsection{Strategische Gruppen in der deutschen Brauwirtschaft}

\subsubsection{OPERATIONALISIERUNG DER STRATEGISCHEN DIMENSIONEN}

Zur Prüfung der Hypothesen werden zunächst die Merkmalsarten der Brauereien, die im Hinblick auf die Abgrenzung sowie die Beschreibung strategischer Gruppen von besonderer Relevanz sind, herausgearbeitet. Die Auswahl der wesentlichen Variablen erfolgte anhand eines eingehenden Studiums der Branchenliteratur und Fachpresse sowie persönlicher Gespräche mit Experten der Brauwirtschaft. Im Anhang (Anlage 2) wird die Einbindung aller abgeleiteten Variablen in das theoretische Referenzmodell aufgezeigt. Im Folgenden werden die Strategievariablen näher beleuchtet.

\section{Strategievariablen}

Die Strategievariablen sollten als Gruppierungsvariablen für die empirische Ermittlung typisch für das strategische Verhalten der Brauereien sein. Die Variablen, die die Strategie abbilden, beziehen sich im Wesentlichen auf die Unterscheidung der Betriebswirtschaftslehre in zwei Ebenen des strategischen Managements nach dem Geltungsbereich, die Ebene des Gesamtunternehmens und die Ebene einzelner Geschäftsfelder:

Unternehmensstrategien: Auf der Ebene des Gesamtunternehmens besteht die zentrale strategische Aufgabe darin festzulegen, mit welchen Produkten und auf welchen Märkten das Unternehmen agieren will. Neben der Produktpalette und der Marktabgrenzung sind auch Entscheidungen über Vertriebswege, Internationalisierung, Wachstum sowie Diversifikation der Unternehmensstrategie zuzurechnen. In Tabelle 15 sind die Indikatoren aufgelistet, welche dazu geeignet sind, die Unternehmensstrategien einzufangen.

\begin{tabular}{|c|c|}
\hline $\begin{array}{l}\text { Elemente der } \\
\text { Unternehmensstrategie }\end{array}$ & Variable \\
\hline Produkte/Diversifikation & $\begin{array}{l}\text { 1. Anteile der verschiedenen Biersorten } \\
\text { 2. Anteile alkoholfreie und sonstige Getränke } \\
\text { 3. Nebenprodukte } \\
\text { 4. andere Geschäftsfelder } \\
\text { 5. Getränke aus eigener Herstellung }\end{array}$ \\
\hline Märkte & $\begin{array}{l}\text { 6. Größe des Kernabsatzgebietes (regional, } \\
\text { überregional, national, international) } \\
\text { 7. Bedeutung der Internationalisierung } \\
\text { 8. Gesamtgetränkeausstoß }\end{array}$ \\
\hline
\end{tabular}




\begin{tabular}{|l|l|}
\hline Vertriebswege & 9 Anteile verschiedener Distributionswege \\
\hline Wachstum & 10. externes Wachstum durch Zukauf anderer \\
& Brauereien, anderer Getränkehersteller sowie \\
& von Markenrechten \\
& 11. internationale Tätigkeit in Planung \\
& 12. mit Marktanteil zufrieden, daher keine \\
& Maßnahmen zur Erweiterung \\
\hline
\end{tabular}

Tabelle 15: Indikatoren zur Erfassung der Unternehmensstrategien

Die Strategie des Marktausstiegs durch Verkauf oder Schließung wurde nicht explizit abgefragt, da sie von Branchenexperten im Pretest als zu sensibel eingestuft wurde. Da sich die Größe der Brauereien (Gesamtgetränkeausstoß) in Voruntersuchungen als wichtige Einflussvariable auf die gewählte Strategie herausgestellt hat, wird diese in die Analyse einbezogen.

Geschäftsbereichsstrategien: Auf der Ebene der einzelnen Geschäftsfelder ist zu entscheiden, mit welcher Wettbewerbsstrategie (z.B. Differenzierung, Kostenführerschaft oder Nischenstrategie) der einzelne Geschäftsbereich im Markt operieren soll. Die Indikatoren für diese Strategiealternativen sind der Tabelle $16 \mathrm{zu}$ entnehmen.

\begin{tabular}{|c|c|}
\hline $\begin{array}{l}\text { Elemente der } \\
\text { Geschäftsbereichstrategien }\end{array}$ & Variable \\
\hline Kostenführerschaft & $\begin{array}{l}\text { 1. Einstiegspreis } \\
\text { 2. Kosten /hl } \\
\text { 3. wenig Werbung } \\
\text { 4. direkte Distribution } \\
\text { 5. second mover } \\
\text { 6. Handelsmarkenanteil } \\
\text { 7. hohe Kapazitätsauslastung }\end{array}$ \\
\hline Differenzierung & $\begin{array}{l}\text { 8. Höhe der Werbeausgaben, Sponsoring } \\
\text { (Markenimage) } \\
\text { 9. Innovationen } \\
\text { 10. Anteile Gebinde z.B. Fass (inkl. Innovation) } \\
\text { 11. Qualität } \\
\text { 12. eigene Gastronomie } \\
\text { 13. Belieferung von Prestigeobjekten } \\
\text { 14. regionaler Bezug } \\
\text { 15. Mono-Marke/Anteil Hauptbiermarke } \\
\text { 16. Anteil E-Commerce }\end{array}$ \\
\hline Nische & $\begin{array}{l}\text { 17. Anteil Produktnische/Spezialitäten } \\
\text { 18. regionale Nische }\end{array}$ \\
\hline
\end{tabular}

Tabelle 16: Indikatoren zur Erfassung der Geschäftsfeldstrategien 


\subsubsection{FAKTORANALYSE ZUR DIMENSIONSREDUKTION}

Für eine sachgerechte Ermittlung von strategischen Gruppen in der deutschen Brauwirtschaft ist es notwendig, eine Vielzahl von Einflussvariablen zu berücksichtigen. Voruntersuchungen in Form von Korrelationsanalysen deuteten auf das Vorhandensein von bestimmten Dimensionen hin. Um die voneinander unabhängigen Dimensionen zu identifizieren, wurde eine Faktoranalyse (Hauptkomponentenverfahren mit Varimax-Rotation) durchgeführt. Auf diese Weise gelang es, die Vielzahl möglicher Strategievariablen (siehe Tabelle 15 und 16) auf wenige, wichtige Einflussfaktoren zurückzuführen. Diese Methode bietet den Vorteil, dass dadurch viele mögliche Einflussfaktoren getestet werden können und erst im nachhinein entschieden werden muss, welche Variablen oder Variablenbündel tatsächlich erklärungsrelevant sind (BACKhaus ET. AL., 2000: S. 253). Die Güte der Daten für die Faktoranalyse wurde mit dem KMO-Koeffizienten (Kaiser-Meyer-Olkin, Measure of Sampling Adequacy) und dem Barlett-Test geprüft. Der KMO-Koeffizient zeigt an, ob substanzielle Korrelationen vorliegen, die die Durchführung einer Faktoranalyse rechtfertigen. Der Wert liegt bei 0,696 was für eine ,ziemlich gute“ Eignung der Daten spricht (BACKHAUS ET. AL., 2000: S. 269). Der Barlett-Test prüft die Nullhypothese, dass alle Korrelationen gleich null sind. Die Prüfgröße ist Chi-Quadrat-verteilt und beträgt 986,31 bei 351 Freiheitsgraden und ist somit signifikant $($ sig. $=, 000)$; das heißt, die Korrelationen weichen signifikant von null ab.

In die Faktoranalyse sind alle aufgezeigten Strategievariablen eingeflossen. Statistische Kriterien wie Eigenvalue und Screeplot sowie Plausibilitätsüberlegungen legen nahe, eine Sechs-Faktor-Lösung zu verwenden, die 49,71 \% der Varianz erklärt. Tabelle 17 gibt die Ergebnisse der Analyse wieder und zeigt die hinter den jeweiligen Faktoren stehenden Variablen und die zugehörigen Faktorladungen.

Die extrahierten Faktoren können wie folgt charakterisiert werden:

- Faktor 1: Größe und Reichweite

- Faktor 2: Differenzierung durch Innovation

- Faktor 3: Differenzierung durch Marke

- Faktor 4: Eigenbierorientierung

- Faktor 5: Bereitschaft für neue Wege

- Faktor 6: Konsumbierorientierung 


\begin{tabular}{|c|c|c|c|c|c|c|}
\hline Variable & $\begin{array}{c}\text { Faktor 1 } \\
\text { Größe und } \\
\text { Reichweite }\end{array}$ & $\begin{array}{c}\text { Faktor } 2 \\
\text { Differenzie- } \\
\text { rung durch } \\
\text { Innovation } \\
\end{array}$ & $\begin{array}{l}\text { Faktor } 3 \\
\text { Differenzie- } \\
\text { rung durch } \\
\text { Marke } \\
\end{array}$ & $\begin{array}{c}\text { Faktor } 4 \\
\text { Eigenbier- } \\
\text { orientierung }\end{array}$ & $\begin{array}{l}\text { Faktor } 5 \\
\text { Neue } \\
\text { Wege }\end{array}$ & $\begin{array}{c}\text { Faktor } 6 \\
\text { Konsumbier } \\
\text {-orientierung }\end{array}$ \\
\hline Gesamtgetränkeausstoß & 0,844 & & & & & \\
\hline $\begin{array}{l}\text { Größe des Kernabsatzgebiet } \\
\text { Absatz über }\end{array}$ & 0,727 & & & & & \\
\hline Getränkefachgroßhandel & 0,630 & & & & & \\
\hline Brauereieigene Gaststätten & 0,568 & & & & & \\
\hline $\begin{array}{l}\text { Innovationskraft im } \\
\text { Verhältnis zum stärksten } \\
\text { Wettbewerber } \\
\text { Kapazitätsauslastung im } \\
\text { Vergleich zum stärksten }\end{array}$ & & 0,729 & & & & \\
\hline $\begin{array}{l}\text { Wettbewerber } \\
\text { Mit Innovationen bemühen } \\
\text { wir uns immer, die Ersten am } \\
\text { Markt zu sein }\end{array}$ & & 0,596 & & & 0,455 & \\
\hline $\begin{array}{l}\text { Markenimage im Vergleich } \\
\text { zum stärksten Wettbewerber }\end{array}$ & & 0,618 & 0,414 & & & \\
\hline $\begin{array}{l}\text { Produktqualität im Vergleich } \\
\text { zum stärksten Wettbewerber }\end{array}$ & & & 0,692 & & & \\
\hline $\begin{array}{l}\text { Verkaufspreise im Vergleich } \\
\text { zum stärksten Wettbewerber }\end{array}$ & & & 0,658 & & & \\
\hline $\begin{array}{l}\text { Anteil Markenartikel an der } \\
\text { Vermarktung }\end{array}$ & & & 0,560 & & & \\
\hline $\begin{array}{l}\text { Anteil Hauptbiermarke am } \\
\text { Gesamtgetränkeausstoß }\end{array}$ & & & & 0,783 & & \\
\hline $\begin{array}{l}\text { Gesamtgetränkeabsatz } \\
\text { alkoholfreie Getränke } \\
\text { Getränke aus eigener } \\
\text { Herstellung }\end{array}$ & & & & $\begin{array}{r}-0,708 \\
0,479\end{array}$ & & \\
\hline $\begin{array}{l}\text { Bedeutung der } \\
\text { Internationalisierung für } \\
\text { Unternehmen wird steigen }\end{array}$ & & & & & 0,774 & \\
\hline $\begin{array}{l}\text { Internationalisierung } \\
\text { gegenwärtig hohe Bedeutung }\end{array}$ & & & & & 0,726 & \\
\hline $\begin{array}{l}\text { Gesamtgetränkeabsatz } \\
\text { Weizenbiere } \\
\text { Gesamtgetränkeabsatz Pils- } \\
\text { biere } \\
\text { Einstiegspreis } \\
\text { Hauptbiermarke Kastenform } \\
20 \text { x 0,51 }\end{array}$ & & & $-0,353$ & 0,357 & & $\begin{array}{l}-0,747 \\
0,731\end{array}$ \\
\hline Cronbachs Alpha & 0,727 & 0,681 & 0,714 & 0,623 & 0,606 & 0,598 \\
\hline$\%$ der Varianz & 15,33 & 8,761 & 8,441 & 6,465 & 5,469 & 5,245 \\
\hline
\end{tabular}

Tabelle 17: Rotierte Faktorenmatrix der Strategievariablen

(Faktorladungen unter 0,35 werden nicht ausgewiesen)

Der erste Faktor, Größe und Reichweite, sammelt alle Variablen, welche für die Größe der befragten Brauereien stehen. Namentlich sind das die Variablen Gesamtgetränkeausstoß, Absatzanteil über Getränkefachgroßhandel sowie die Anzahl brauereieigener Gaststätten. Die Ladungen der Variablen machen einen positiven Zusammenhang zwischen Größe und Reichweite deutlich. Je größer die Brauerei gemessen am Gesamtgetränkeausstoß ist, desto größer ist auch das Kernabsatzgebiet. 
Außerdem steigt - bedingt durch die wachsende Ausdehnung des Absatzgebietes - die Bedeutung des Getränkefachgroßhandels mit wachsender Betriebsgröße deutlich an. Darüber hinaus ist zu beobachten, dass die größeren Brauereien überdurchschnittlich viele brauereieigene Gaststätten besitzen.

Der zweite Faktor sammelt die Variablen, welche für Innovationskraft, Innovationsgeschwindigkeit, Markenimage und die Höhe der Kapazitätsauslastung im Vergleich zum stärksten Wettbewerber stehen. Je höher die Innovationskraft, desto höher sind die Innovationsgeschwindigkeit, die Kapazitätsauslastung und das Markenimage. Die negative Ladung auf das Statement „Mit Innovationen bemühen wir uns immer, die Ersten am Markt zu sein“ lässt sich durch die entgegengesetzte Skalierung ( 1 = stimme vollständig zu) im Vergleich zur Variable „Innovationskraft im Verhältnis zum stärksten Wettbewerber“ ( 1 = lehne vollständig ab) erklären. Der Faktor 2 wird folglich mit dem Etikett „Differenzierung durch Innovation“ belegt.

Der dritte Faktor bündelt die Variablen, welche für eine „Differenzierung durch Marke“ stehen. Die Höhe der Produktqualität und des Markenimages geht mit einem höheren Verkaufspreis im Vergleich zum stärksten Wettbewerber und höheren Anteilen von Markenartikeln an der Vermarktung einher.

Der vierte Faktor wird im Lichte der hohen Ladung auf den Anteil der Hauptbiermarke am Gesamtgetränkeausstoß und der positiven Ladung der Variable „Getränke aus eigener Herstellung“ als „Eigenbierorientierung“ bezeichnet. Die hohe negative Ladung der Variable „Gesamtgetränkeabsatz alkoholfreier Getränke“ auf diesen Faktor untermauert dieses Label.

Der fünfte Faktor sammelt die Variablen, welche die gegenwärtige und zukünftige Bedeutung der Internationalisierung beschreiben. Diese stehen in Zusammenhang mit dem Statement „Mit Innovationen bemühen wir uns immer, die ersten am Markt zu sein“. Somit kann Faktor 5 mit dem Etikett „Bereitschaft für neue Wege“ versehen werden.

Im sechsten Faktor schließlich sind die Variablen enthalten, die die „Konsumbierorientierung“ beschreiben. Dieses wird durch die hohe positive Ladung 
auf die Variable „Gesamtgetränkeabsatz Pilsbiere“ bei gleichzeitig positiver Ladung auf den Einstiegspreis der Hauptbiermarke und hoher negativer Ladung auf den Gesamtgetränkeabsatz von Weizenbieren deutlich.

\subsubsection{CLUSTERANALYSE ZUR IDENTIFIZIERUNG STRATEGISCHER GRUPPEN}

Um strategische Gruppen zu identifizieren, wurde auf die hierarchische Clusteranalyse zurückgegriffen. Die Zielsetzung der Clusteranalyse besteht in der Zusammenfassung der Brauereien zu Gruppen. Die Mitglieder einer Gruppe sollen sich dabei möglichst ähnlich sein, zwischen den Gruppen sollen demgegenüber so gut wie keine Ähnlichkeiten bestehen. Als clusterbildende Variablen wurden die mit der Faktoranalyse identifizierten sechs Strategiedimensionen verwendet.

In einem ersten Schritt wurde das Single-Linkage-Verfahren (Nächstgelegener Nachbar) angewendet, um so genannte Ausreißer identifizieren zu können. Dabei zeigten sich keine Unternehmen, die sich in ihrer Variablenausprägung wesentlich von den anderen abheben und somit aus der Analyse entfernt werden müssten.

Als endgültiger Fusionierungsalgorithmus wurde das Ward-Verfahren ausgewählt. Dieses Verfahren zeichnet sich dadurch aus, dass die Clusterbildung nach dem Varianzkriterium erfolgt. Dabei werden jeweils nur solche Unternehmen zu einem Cluster zusammengefasst, welche die Varianz in einer Gruppe so wenig wie möglich erhöhen. Dadurch werden insgesamt sehr homogene Gruppen gebildet (BACKHAUS ET. AL 2000: S. 357f.).

Das Dendrogramm zeigt Strukturen, die auf eine Sechs-Clusterlösung schließen lassen. Um diese Annahme näher zu untersuchen, wird als methodisches Instrumentarium das Elbow-Kriterium herangezogen, das sich aus der Beziehung zwischen der Fehlerquadratsumme und der Anzahl der Cluster ergibt. Dabei wird deutlich, dass die Heterogenität beim Übergang von einer Fünf-Clusterlösung zu einer SechsClusterlösung stark zunimmt. Auf Grund dieses Ergebnisses sowie getätigter Plausibilitätsüberlegungen wird die Sechs-Clusterlösung zur näheren Analyse herangezogen. Dem Cluster 1 können 17, dem 2. Cluster 55, dem 3. Cluster 48, dem 4. Cluster 52, dem 5. Cluster 83 und dem 6. Cluster 26 Unternehmen zugeordnet werden. 
Zur Überprüfung der Ergebnisse der Clusteranalyse kann die Diskriminanzanalyse herangezogen werden. Diese geht von bekannten Gruppen aus und versucht, die Unterschiede zwischen diesen durch die Analyse möglicher diskriminierender Variablen aufzudecken. Dabei wird der Zusammenhang einer nominalen Zielgröße und einer oder mehrerer metrischer Einflussgrößen aufgedeckt. Die im Rahmen der Clusteranalyse gefundene Gruppierung wird als nominale Zielgröße betrachtet. Die Diskriminanzanalyse untersucht dann, inwieweit die in die Clusteranalyse eingeflossenen Einflussgrößen in der Lage sind, diese Gruppierung zu erklären. Die letztendliche Übereinstimmung zwischen dem Gruppenergebnis der Diskriminanz- und der Clusteranalyse kann als relatives Validitätskriterium verwendet werden (BACKHAUS ET. AL., 2000: S. 145ff.). Im vorliegenden Fall konnte die Gruppenzuordnung zu 87,2 \% bestätigt werden.

Im Folgenden wird anhand eines Mittelwertvergleichs untersucht, inwieweit sich die Gruppen voneinander in den clusterbeschreibenden Variablen unterscheiden. Die Gruppenmittelwerte werden sodann mittels einer Varianzanalyse $^{15}$ auf ihr Signifikanzniveau getestet. Die Ergebnisse dieser Tests sind der Tabelle $18 \mathrm{zu}$ entnehmen. Die detaillierte Beschreibung der Gruppen erfolgt im Anschluss.

15 Aufgrund der teilweisen Verletzung der Normalverteilungsannahme wurde ergänzend ein KruskalWallis-Test durchgeführt. Dabei wird deutlich, dass die Ergebnisse nicht durch die unterschiedliche Berechnungsmethode beeinflusst werden. Daher werden auch im Folgenden (wenn sich keine Unterschiede ergeben) nur die Ergebnisse der Varianzanalyse aufgezeigt. 


\begin{tabular}{|c|c|c|c|c|c|c|c|}
\hline Clusterbeschreibende Variablen & $\begin{array}{c}\text { Cluster } \\
1 \\
\mathrm{n}=17\end{array}$ & $\begin{array}{c}\text { Cluster } \\
2 \\
\mathrm{n}=55\end{array}$ & $\begin{array}{c}\text { Cluster } \\
3 \\
\mathrm{n}=48 \\
\end{array}$ & $\begin{array}{c}\text { Cluster } \\
4 \\
\mathrm{n}=52 \\
\end{array}$ & $\begin{array}{c}\text { Cluster } \\
5 \\
\mathrm{n}=83\end{array}$ & $\begin{array}{c}\text { Cluster } \\
6 \\
\mathrm{n}=26 \\
\end{array}$ & Skalierung \\
\hline \multicolumn{8}{|l|}{ Faktor 1: Größe und Reichweite } \\
\hline Gesamtgetränkeaussto $\beta_{* * *}$ & $\begin{array}{c}2,59 \\
(1,179)\end{array}$ & $\begin{array}{l}1,73 \\
(0,56)\end{array}$ & $\begin{array}{c}1,62 \\
(0,606)\end{array}$ & $\begin{array}{c}1,88 \\
(0,90)\end{array}$ & $\begin{array}{c}1,71 \\
(0,595)\end{array}$ & $\begin{array}{c}3,31 \\
(0,736)\end{array}$ & $\begin{array}{l}1=\text { bis } 5.000 \mathrm{hl} \\
2=\text { bis } 100.000 \mathrm{hl} \\
3=100.000 \mathrm{bis} \\
250.000 \mathrm{hl} \mathrm{usw} .\end{array}$ \\
\hline Größe des Kernabsatzgebiet*** & $\begin{array}{c}2,06 \\
(1,249)\end{array}$ & $\begin{array}{c}1,15 \\
(0,356)\end{array}$ & $\begin{array}{c}1,23 \\
(0,425)\end{array}$ & $\begin{array}{c}1,31 \\
(0,466)\end{array}$ & $\begin{array}{c}1,16 \\
(0,366)\end{array}$ & $\begin{array}{c}2,15 \\
(0,784)\end{array}$ & $\begin{array}{l}1=\text { lokal, } 2=\text { regional, } \\
3=\text { überregional }\end{array}$ \\
\hline $\begin{array}{l}\text { Absatz über } \\
\text { Getränkefachgroßhandel*** }\end{array}$ & $\begin{array}{l}27,56 \\
(26,72)\end{array}$ & $\begin{array}{c}13,54 \\
(14,05)\end{array}$ & $\begin{array}{c}11,27 \\
(14,97)\end{array}$ & $\begin{array}{c}20,04 \\
(18,82)\end{array}$ & $\begin{array}{c}10,56 \\
(14,92)\end{array}$ & $\begin{array}{c}41,06 \\
(44,52)\end{array}$ & $\begin{array}{l}\% \text { des } \\
\text { Getränkeabsatzes }\end{array}$ \\
\hline Brauereieigene Gaststätten*** & $\begin{array}{c}17,31 \\
(24,03)\end{array}$ & $\begin{array}{c}4,22 \\
(5,58)\end{array}$ & $\begin{array}{c}4,71 \\
(5,61)\end{array}$ & $\begin{array}{c}3,88 \\
(5,84)\end{array}$ & $\begin{array}{c}4,2 \\
(6,16)\end{array}$ & $\begin{array}{c}41,06 \\
(44,52)\end{array}$ & Anzahl \\
\hline \multicolumn{8}{|c|}{ Faktor 2: Differenzierung durch Innovation } \\
\hline $\begin{array}{l}\text { Innovationskraft im Verhältnis } \\
\text { zum stärksten Wettbewerber** }\end{array}$ & $\begin{array}{c}2,88 \\
(0,781)\end{array}$ & $\begin{array}{c}3,83 \\
(0,771)\end{array}$ & $\begin{array}{c}2,93 \\
(1,223)\end{array}$ & $\begin{array}{c}2,78 \\
(1,026)\end{array}$ & $\begin{array}{c}3,15 \\
(0,878)\end{array}$ & $\begin{array}{c}3,65 \\
(0,797)\end{array}$ & \multirow{4}{*}{$\begin{array}{l}\text { deutlich niedriger } \\
=1 \text {, deutlich } \\
\text { höher }=5 \\
\text { deutlich niedriger } \\
=1 \text {, deutlich } \\
\text { höher=5 } \\
\text { stimme vollständig } \\
\text { zu=1, lehne } \\
\text { vollständig ab=5 } \\
\text { deutlich niedriger } \\
=1 \text {, deutlich } \\
\text { höher=5 }\end{array}$} \\
\hline $\begin{array}{l}\text { Kapazitätsauslastung im } \\
\text { Vergleich zum stärksten } \\
\text { Wettbewerber*** }\end{array}$ & $\begin{array}{c}3,06 \\
(0,827)\end{array}$ & $\begin{array}{c}2,87 \\
(0,933)\end{array}$ & $\begin{array}{c}2,59 \\
(1,041)\end{array}$ & $\begin{array}{c}2,47 \\
(0,924)\end{array}$ & $\begin{array}{c}3,10 \\
(1,033)\end{array}$ & $\begin{array}{c}3,31 \\
(0,884)\end{array}$ & \\
\hline $\begin{array}{l}\text { Mit Innovationen bemühen wir } \\
\text { uns immer, die Ersten am Markt } \\
\text { zu sein* }\end{array}$ & $\begin{array}{c}3,12 \\
(0,993)\end{array}$ & $\begin{array}{c}2,04 \\
(0,881)\end{array}$ & $\begin{array}{c}2,89 \\
(0,982)\end{array}$ & $\begin{array}{c}3,00 \\
(0,97)\end{array}$ & $\begin{array}{c}2,94 \\
(0,992)\end{array}$ & $\begin{array}{c}2,12 \\
(0,431)\end{array}$ & \\
\hline $\begin{array}{l}\text { Markenimage im Vergleich zum } \\
\text { stärksten Wettbewerber** }\end{array}$ & $\begin{array}{c}3,94 \\
(0,659)\end{array}$ & $\begin{array}{c}3,69 \\
(0,940)\end{array}$ & $\begin{array}{c}2,41 \\
(1,066)\end{array}$ & $\begin{array}{c}2,83 \\
(1,136)\end{array}$ & $\begin{array}{c}3,25 \\
(0,954)\end{array}$ & $\begin{array}{c}3,31 \\
(0,884)\end{array}$ & \\
\hline \multicolumn{8}{|c|}{ Faktor 3: Differenzierung durch Marke } \\
\hline $\begin{array}{l}\text { Produktqualität im Vergleich } \\
\text { zum stärksten Wettbewerber** }\end{array}$ & $\begin{array}{c}4,00 \\
(0,612)\end{array}$ & $\begin{array}{c}3,89 \\
(0,685)\end{array}$ & $\begin{array}{c}2,87 \\
(0,806)\end{array}$ & $\begin{array}{c}3,86 \\
(0,825)\end{array}$ & $\begin{array}{c}3,61 \\
(0,703)\end{array}$ & $\begin{array}{c}3,62 \\
(0,941)\end{array}$ & \multirow{3}{*}{$\begin{array}{l}\text { deutlich niedriger } \\
=1 \text {, deutlich } \\
\text { höher }=5 \\
\text { deutlich niedriger } \\
=1 \text {, deutlich } \\
\text { höher }=5 \\
\% \text { des } \\
\text { Getränkeabsatz }\end{array}$} \\
\hline $\begin{array}{l}\text { Verkaufspreise im Vergleich } \\
\text { zum stärksten Wettbewerber** }\end{array}$ & $\begin{array}{c}4,00 \\
(0,612)\end{array}$ & $\begin{array}{c}3,78 \\
(0,937)\end{array}$ & $\begin{array}{c}2,73 \\
(0,939)\end{array}$ & $\begin{array}{c}3,57 \\
(0,755)\end{array}$ & $\begin{array}{c}3,09 \\
(0,860)\end{array}$ & $\begin{array}{c}3,50 \\
(0,949)\end{array}$ & \\
\hline $\begin{array}{l}\text { Anteil Markenartikel an der } \\
\text { Vermarktung* }\end{array}$ & $\begin{array}{c}100 \\
(0,000) \\
\end{array}$ & $\begin{array}{c}95,85 \\
(9,546)\end{array}$ & $\begin{array}{l}67,85 \\
(25,31)\end{array}$ & $\begin{array}{c}94,97 \\
(12,83)\end{array}$ & $\begin{array}{c}91,83 \\
(15,23)\end{array}$ & $\begin{array}{l}89,07 \\
(16,9)\end{array}$ & \\
\hline \multicolumn{8}{|l|}{ Faktor 4: Eigenbierorientierung } \\
\hline $\begin{array}{l}\text { Anteil Hauptbiermarke am } \\
\text { Gesamtgetränkeausstoß } \beta^{* * *}\end{array}$ & $\begin{array}{c}62,53 \\
(20,07)\end{array}$ & $\begin{array}{c}41,34 \\
(14,36)\end{array}$ & $\begin{array}{c}51,67 \\
(24,81)\end{array}$ & $\begin{array}{c}69,13 \\
(18,79)\end{array}$ & $\begin{array}{c}62,34 \\
(22,85)\end{array}$ & $\begin{array}{c}57,52 \\
(28,33)\end{array}$ & \multirow{3}{*}{$\begin{array}{l}\% \text { des } \\
\text { Getränkeabsatzes } \\
\% \text { des } \\
\text { Getränkeabsatzes } \\
\% \text { des } \\
\text { Getränkeabsatzes }\end{array}$} \\
\hline $\begin{array}{l}\text { Gesamtgetränkeabsatz } \\
\text { alkoholfreie Getränke*** }\end{array}$ & $\begin{array}{c}4,63 \\
(6,826)\end{array}$ & $\begin{array}{c}19,67 \\
817,57)\end{array}$ & $\begin{array}{c}21,04 \\
(21,25)\end{array}$ & $\begin{array}{c}2,17 \\
(4,75)\end{array}$ & $\begin{array}{c}21,66 \\
(21,29)\end{array}$ & $\begin{array}{c}15,96 \\
(21,62)\end{array}$ & \\
\hline $\begin{array}{l}\text { Getränke aus eigener } \\
\text { Herstellung*** }\end{array}$ & $\begin{array}{c}91,59 \\
(9,631) \\
\end{array}$ & $\begin{array}{c}80,24 \\
(16,20)\end{array}$ & $\begin{array}{c}63,53 \\
(22,72)\end{array}$ & $\begin{array}{c}88,53 \\
(17,68)\end{array}$ & $\begin{array}{c}81,76 \\
(17,91)\end{array}$ & $\begin{array}{c}91,12 \\
(11,48)\end{array}$ & \\
\hline \multicolumn{8}{|c|}{ Faktor 5: Bereitschaft für neue Wege } \\
\hline $\begin{array}{l}\text { Bedeutung der } \\
\text { Internationalisierung für } \\
\text { Unternehmen wird steigen** }\end{array}$ & $\begin{array}{c}3,24 \\
(1,033)\end{array}$ & $\begin{array}{c}3,20 \\
(1,053)\end{array}$ & $\begin{array}{c}3,34 \\
(1,140)\end{array}$ & $\begin{array}{c}3,57 \\
(1,204)\end{array}$ & $\begin{array}{c}4,35 \\
(0,793)\end{array}$ & $\begin{array}{c}3,27 \\
(1,251)\end{array}$ & \multirow{2}{*}{$\begin{array}{l}\text { stimme vollständig } \\
\mathrm{zu}=1 \text {, lehne } \\
\text { vollständig } \mathrm{ab}=5 \\
\text { stimme vollständig } \\
\mathrm{zu}=1 \text {, lehne } \\
\text { vollständig } \mathrm{ab}=5\end{array}$} \\
\hline $\begin{array}{l}\text { Internationalisierung } \\
\text { gegenwärtig hohe Bedeutung* }\end{array}$ & $\begin{array}{c}3,00 \\
(1,061)\end{array}$ & $\begin{array}{c}2,58 \\
(1,066)\end{array}$ & $\begin{array}{c}2,85 \\
(1,032)\end{array}$ & $\begin{array}{c}3,25 \\
(1,163)\end{array}$ & $\begin{array}{c}4,11 \\
(0,880)\end{array}$ & $\begin{array}{c}2,81 \\
(1,059)\end{array}$ & \\
\hline \multicolumn{8}{|l|}{ Faktor 6: Konsumbierorientierung } \\
\hline $\begin{array}{l}\text { Gesamtgetränkeabsatz } \\
\text { Weizenbiere**** }\end{array}$ & $\begin{array}{c}56,39 \\
(29,86)\end{array}$ & $\begin{array}{c}14,22 \\
(9,401)\end{array}$ & $\begin{array}{c}16,98 \\
(17,65)\end{array}$ & $\begin{array}{c}7,40 \\
(9,659)\end{array}$ & $\begin{array}{c}9,11 \\
(8,514)\end{array}$ & $\begin{array}{c}9,68 \\
(8,878)\end{array}$ & $\begin{array}{l}\% \text { des } \\
\text { Getränkeabsatzes }\end{array}$ \\
\hline $\begin{array}{l}\text { Gesamtgetränkeabsatz Pils- } \\
\text { Biere*** }\end{array}$ & $\begin{array}{c}5,31 \\
(12,48)\end{array}$ & $\begin{array}{c}19,69 \\
(16,93)\end{array}$ & $\begin{array}{c}19,82 \\
(21,21)\end{array}$ & $\begin{array}{c}50,93 \\
(28,78)\end{array}$ & $\begin{array}{c}26,61 \\
(24,030\end{array}$ & $\begin{array}{c}39,54 \\
(33,64)\end{array}$ & $\begin{array}{l}\% \text { des } \\
\text { Getränkeabsatzes }\end{array}$ \\
\hline $\begin{array}{l}\text { Einstiegspreis Hauptbiermarke } \\
\text { Kastenform } 20 \times 0,51^{* * *}\end{array}$ & $\begin{array}{c}1,06 \\
(0,243)\end{array}$ & $\begin{array}{c}1,72 \\
(0,854)\end{array}$ & $\begin{array}{c}2,46 \\
(1,022)\end{array}$ & $\begin{array}{c}2,41 \\
(1,183)\end{array}$ & $\begin{array}{c}2,80 \\
(0,994)\end{array}$ & $\begin{array}{c}2,09 \\
(1,019)\end{array}$ & $\begin{array}{l}1=12 € \text { und mehr } \\
2=11-11,99 € \\
3=10-10,99 € \text { usw. }\end{array}$ \\
\hline
\end{tabular}

a: Für die Cluster sind zuerst die Mittelwerte angegeben; die Standardabweichungen folgen in Klammern unter jedem Mittelwert.

b ***, **, *: der Zellenmittelwert unterscheidet sich signifikant vom standardisierten Mittelwert der Gesamtstichprobe auf dem .001-, .01-, .05-Niveau.

Tabelle 18: Analyse der Cluster anhand der clusterbeschreibenden Variablen 


\section{Cluster 1: „Weizenbier-Markendifferenzierer“ (n=17)}

Das Cluster 1 besteht aus Brauereien, die durch eine überdurchschnittliche Betonung der Differenzierung durch Marke gekennzeichnet sind. Die Einstiegspreise der Hauptbiermarke liegen in diesem Cluster wie die Anteile der Getränke aus eigener Herstellung und die der Hauptbiermarke deutlich über dem Durchschnitt aller Befragten. Darüber hinaus spielen Innovationen in diesem Cluster keine herausragende Rolle, gleichzeitig sind die Erwartungen und die gegenwärtige Bedeutung in Bezug auf die Internationalisierung jedoch überdurchschnittlich hoch. Schließlich liegen der Pilsbieranteile und die Anteile der alkoholfreien Getränke zugunsten hoher Anteile von Weizenbier am Gesamtgetränkeabsatz deutlich unter dem Durchschnitt.

\section{Cluster 2: „Lokale Sortiments- Innovatoren (n=55)}

Das Cluster 2 setzt besonders auf die Differenzierung durch Innovation. Zudem zeichnen sich die Brauereien dieses Clusters durch ein Vollsortiment aus. Die Einstiegspreise der Hauptbiermarke liegen erheblich über dem Durchschnitt, die Anteile der Hauptbiermarke am Gesamtgetränkeausstoß jedoch deutlich darunter. Die Internationalisierung hat für diese Unternehmen bereits heute eine hohe Bedeutung. Darüber hinaus gehen sie von einer weiter steigenden Bedeutung der Internationalisierung aus. Die Unternehmen dieses Clusters sind kleiner als der Durchschnitt, haben einen hohen Anteil von Markenartikeln an der Vermarktung und bedienen hauptsächlich den lokalen bis regionalen Bereich.

\section{Cluster 3: „Lokale handelsorientierte Vollsortimenter“ $(n=48)$}

Die Unternehmen des Clusters 3 sind im überdurchschnittlichem Maße durch den Handel mit Getränken gekennzeichnet. Dieses wird durch den im Verhältnis zur Gesamtstichprobe geringen Anteil der Getränke aus eigener Herstellung deutlich. Die Anteile der Markenartikel und der Hauptbiermarke am Gesamtgetränkeausstoß liegen wie die Größe der Brauereien und der Einstiegspreis der Hauptbiermarke deutlich unter dem Durchschnitt der Befragten. Die Gruppe zeichnet sich weiterhin dadurch aus, dass die Differenzierung durch Marke und Innovation im Vergleich zu den übrigen befragten Unternehmen eine erheblich geringere Bedeutung besitzt. Ferner führen die Brauereien diese Clusters ein Vollsortiment mit einem überdurchschnittlichen Ausstoßanteil von alkoholfreien Getränken im lokalen bis regionalen Bereich. 


\section{Cluster 4: „Lokale Pilsspezialisten“ $(n=52)$}

Die Brauereien des Clusters 4 sind durch eine überdurchschnittlich starke Spezialisierung auf Pilsbiere bei gleichzeitig deutlich unterdurchschnittlichen Anteilen von alkoholfreien Getränken am Gesamtgetränkeabsatz gekennzeichnet. Die Differenzierung durch Innovation spielt in dieser Gruppe im Vergleich zur Gesamtstichprobe eine untergeordnete Rolle. Die Differenzierung durch Marke ist jedoch überdurchschnittlich ausgeprägt. Auffällig sind auch die überdurchschnittlichen Anteile von Getränken aus eigener Herstellung sowie der Hauptbiermarke am Gesamtgetränkeausstoß. Die Unternehmen dieser Gruppe können nur einen vergleichsweise geringen Einstiegspreis für ihre Hauptbiermarke erzielen, sind im Mittel kleiner als der Rest der Befragten und bedienen hauptsächlich den lokalen bis regionalen Bereich.

\section{Cluster 5: „Lokale Konsumbiervollsortimenter“ (n=83)}

Das Cluster 5 besteht aus Brauereien, die nur einen unterdurchschnittlichen Einstiegspreis für ihre Hauptbiermarke erzielen können, jedoch gleichzeitig eine überdurchschnittliche Kapazitätsauslastung aufweisen. Die Unternehmen dieser Gruppe führen ein Vollsortiment mit einem sehr hohen Anteil alkoholfreier Getränke. Die Bedeutung der Internationalisierung sowie von Innovationen ist im Vergleich zur Gesamtstichprobe sehr gering. Die Differenzierung durch Marke sowie der Anteil der Hauptbiermarke am Gesamtausstoß liegen jedoch über dem Durchschnitt. Schließlich ist den Brauereien $\mathrm{zu}$ konstatieren, dass sie hauptsächlich den regionalen bis überregionalen Markt beliefern und ihr Gesamtgetränkeausstoß etwas unter dem Durchschnitt aller Befragten liegt.

\section{Cluster 6: „Große eigensortimentorientierte Innovatoren“ $(n=26)$}

Das Cluster 6 besteht aus Brauereien, die durch eine überdurchschnittliche Differenzierung durch Innovation gekennzeichnet sind. Die Unternehmen bedienen hauptsächlich den regionalen bis überregionalen Markt und sind deutlich größer als der Durchschnitt. Die Brauereien dieser Gruppe arbeiten mit einem Vollsortiment und haben einen im Verhältnis zur Gesamtstichprobe höheren Pilsabsatz sowie einen höheren Anteil von Getränken aus eigener Herstellung. Darüber hinaus liegt der 
Einstiegspreis der Hauptbiermarke in diesem Cluster wie die Kapazitätsauslastung, das Markenimage und die Bedeutung der Internationalisierung deutlich über dem Durchschnitt aller Befragten.

Anliegen des vorliegenden Kapitels war es, im Rahmen der empirischen Untersuchung, $\mathrm{zu}$ überprüfen, ob sich strategische Gruppen in der deutschen Brauwirtschaft ermitteln lassen. Die bisherigen Ausführungen erlauben es, bezüglich der Hypothese 1 folgenden Befund zu formulieren:

Aufgrund der ermittelten Ergebnisse kann die Hypothese 1 bestätigt werden. Die Brauereien verwenden bei der Auseinandersetzung mit den Wettbewerbskräften des Marktes unterschiedliche Strategiealternativen und lassen sich demzufolge in strategische Gruppen einteilen. 


\subsubsection{WEITERE BESCHREIBUNG DER STRATEGISCHEN GRUPPEN}

Nachdem die Analyse der ermittelten Cluster bisher nur auf Grundlage der in die Faktoranalyse eingeflossenen Variablen durchgeführt wurde, wird im Folgenden eine weiterreichende Beschreibung der strategischen Gruppen in der deutschen Brauwirtschaft vorgenommen. Dazu werden die Variablen herangezogen, welche die Situation der Unternehmen, die organisatorische Umsetzung der Strategie, die Kosten sowie die Strategieformulierung und -implementierung beschreiben (vgl. Anlage 2). Anhand von Mittelwertvergleichen wird analysiert, inwieweit sich die strategischen Gruppen in den entsprechenden Variablen unterscheiden. Die Gruppenmittelwerte werden daraufhin anhand der Methode der Varianzanalyse auf ihr Signifikanzniveau getestet (BACKHAUS ET AL., 2000: S. 72ff.).

\subsubsection{Situation der Unternehmen}

Im Zusammenhang mit der Situation der Unternehmen wird untersucht, inwieweit die Cluster sich in zentralen strukturellen Unternehmensmerkmalen wie Rechtsform, Konzernzugehörigkeit und Unternehmensführung unterscheiden. Darüber hinaus wird analysiert, ob zwischen den Clustern Unterschiede in der Wahrnehmung der Branchensituation bestehen und wie die Wettbewerbsposition gegenüber den Mitbewerbern in den verschiedenen Clustern eingeschätzt wird.

\subsection{Unternehmensmerkmale}

Im Folgenden stehen zunächst die Unternehmensmerkmale im Mittelpunkt der Betrachtung. Abbildung 68 veranschaulicht die Anteile der verschiedenen Rechtsformen der Brauereien in den ermittelten Clustern. Über alle Cluster sind $35 \%$ der befragten Unternehmen als Einzelunternehmen organisiert, $23 \%$ sind als $\mathrm{GmbH}$ tätig und $22 \%$ haben die Rechtsform einer $\mathrm{GmbH} \&$ Co. KG. Die übrigen Rechtsformen haben insgesamt eine eher niedrige Bedeutung. Zwischen den verschiedenen Clustern bestehen mit Blick auf die Einzelunternehmen im Vergleich zu den Gesellschaftsunternehmen jedoch erhebliche Unterschiede in der Bedeutung der Rechtsformen, die nach dem Chi-Quadrat Tests als höchst signifikant $(p=0,002)$ einzustufen sind. 


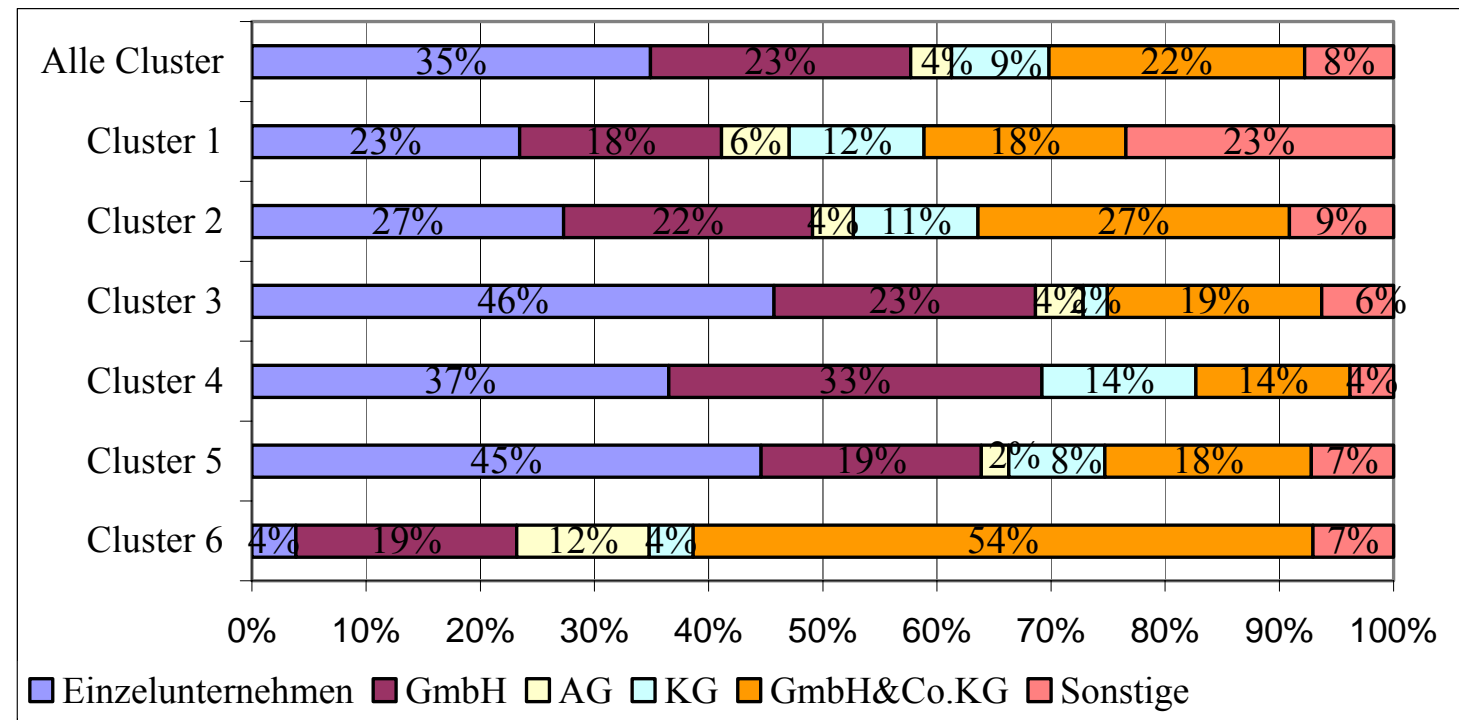

Abbildung 68: Rechtsformen der Unternehmen in den strategischen Gruppen

Das Cluster 1 sticht einerseits dadurch hervor, dass der Anteil der Einzelunternehmen in dieser Gruppe erheblich unter dem Durchschnitt liegt, andererseits weisen die sonstigen Rechtsformen eine deutlich überdurchschnittliche Bedeutung auf. Das Cluster 2 zeichnet sich dadurch aus, dass auch in dieser Gruppe der Anteil der Einzelunternehmen unter dem Durchschnitt liegt. Die Rechtsform der GmbH \& Co. KG hat dort hingegen eine überdurchschnittliche Bedeutung. In den Clustern 3, 4 und 5 liegt der Anteil der Einzelunternehmen deutlich über dem Mittel der gesamten Stichprobe. Das Cluster 6 hebt sich schließlich besonders dadurch hervor, dass der Anteil der Einzelunternehmen in dieser Gruppe bei nur $4 \%$ liegt. Mit einem Anteil von $54 \%$ hat die Rechtsform der $\mathrm{GmbH} \& \mathrm{Co} . \mathrm{KG}$ in dieser Gruppe hingegen eine deutlich überdurchschnittliche Bedeutung. Eine mögliche Erklärung für die voneinander abweichende Bedeutung der verschiedenen Rechtsformen zwischen den einzelnen Clustern könnte auf Unterschiede der durchschnittlichen Unternehmensgröße in den verschiedenen strategischen Gruppen zurückzuführen sein.

Im Zusammenhang mit der Rechtsform ist auch von Interesse, ob die Unternehmen einem Konzern angehören. Abbildung 69 zeigt, dass über alle befragten Brauereien nur $7 \%$ in einen Konzern eingebunden sind. Zwischen den verschiedenen Clustern zeigen sich wieder deutliche Unterschiede. So heben sich besonders das Cluster 1 mit $24 \%$ und das Cluster 6 mit $15 \%$ Anteil der Brauereien, die in einen Konzern eingebunden sind, ab. Im Cluster 4 liegt der Anteil der Unternehmen, die einem Konzern angehören, mit $8 \%$ noch etwas über dem durchschnittlichen Anteil in der gesamten Stichprobe, wohingegen die Anteile in den Clustern 2, 3 und $5 \mathrm{z}$. T. deutlich darunter liegen. 


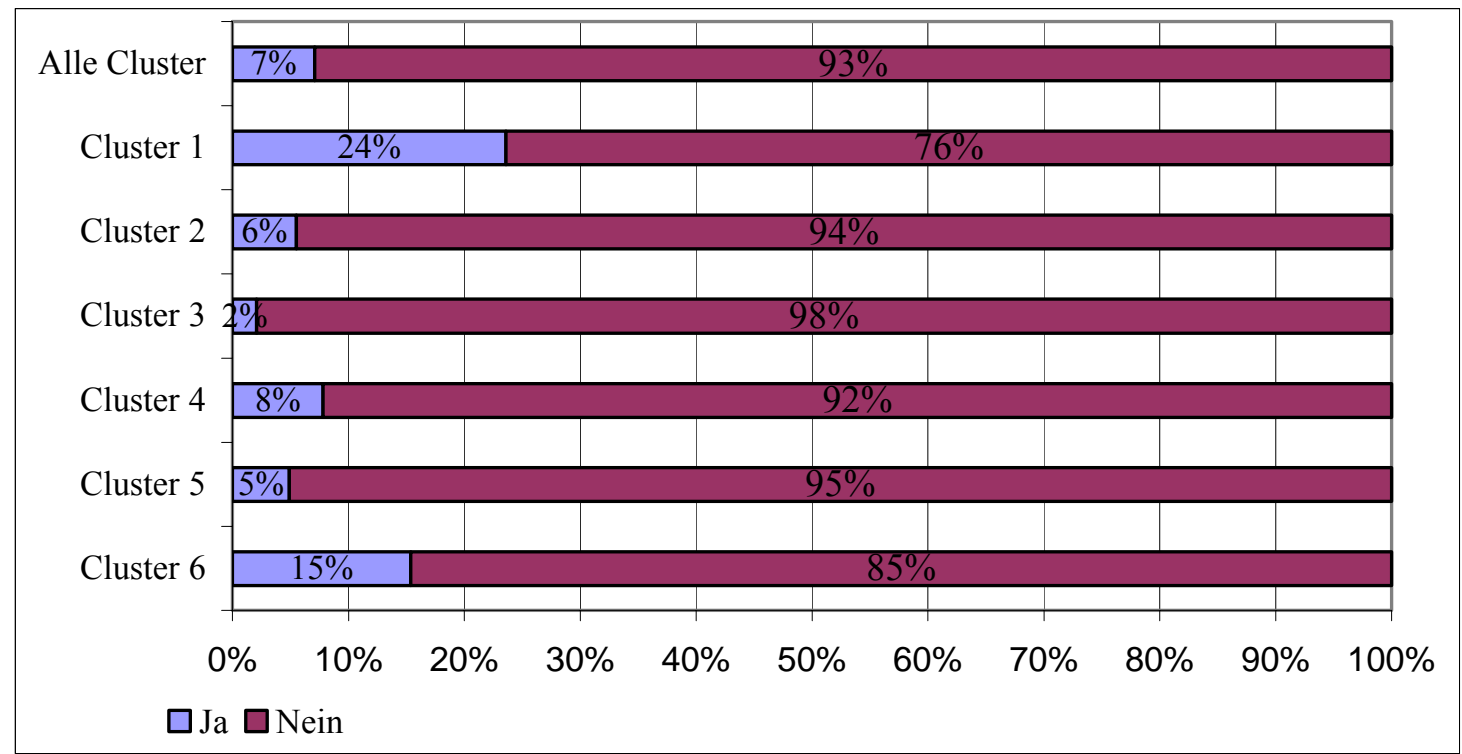

Abbildung 69: Konzernzugehörigkeit nach Clustern

Eine Vorraussetzung des Chi-Quadrat Test ist, dass nur in maximal $20 \%$ der Felder der Kreuztabelle erwartete Häufigkeiten $<5$ auftreten dürfen (BÜHL/ZÖFEL, 2000: S. 240). Diese Vorraussetzung wird aufgrund der geringen Zahl der befragten Unternehmen, die in einen Konzern eingebunden sind, nicht erfüllt. Daher lassen sich in diesem Fall nur tendenzielle Unterschiede zwischen den Gruppen belegen.

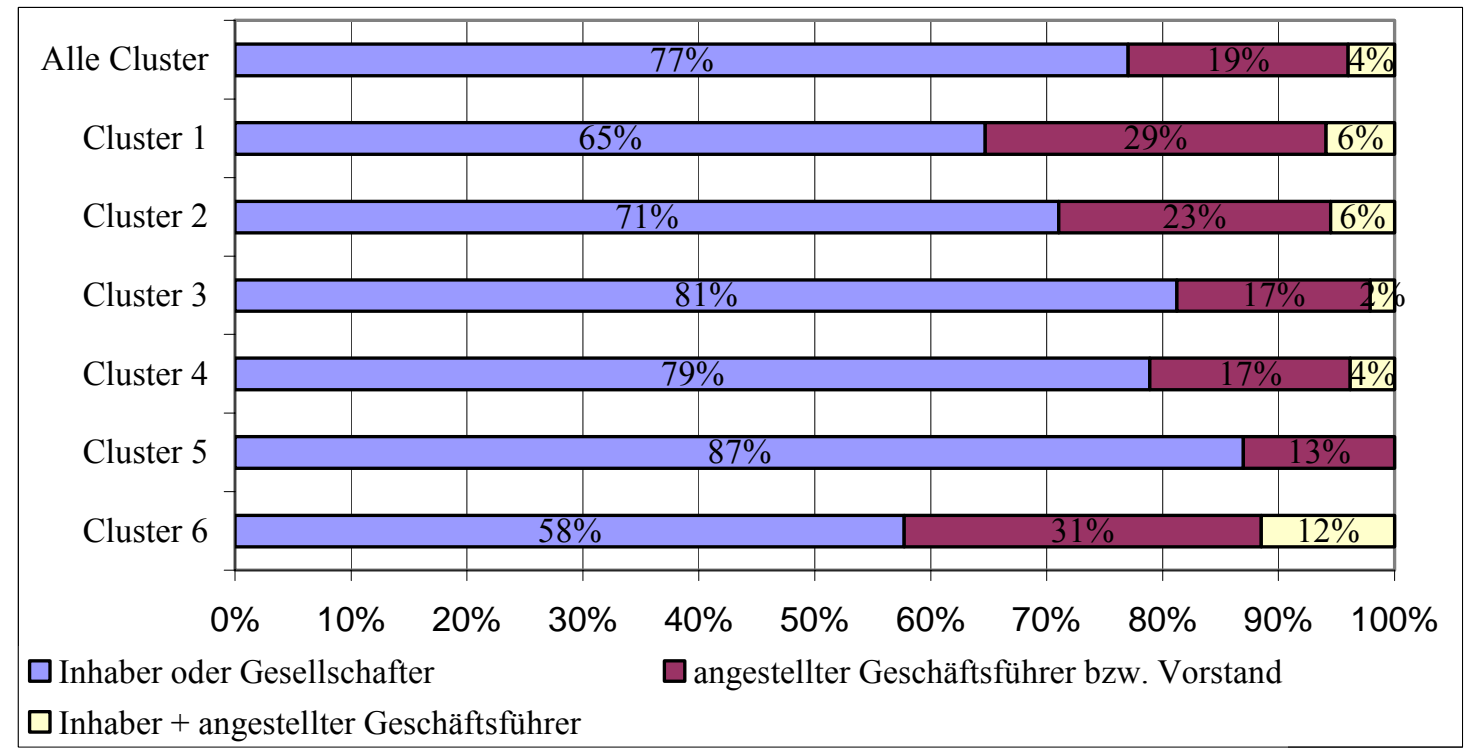

Abbildung 70: Unternehmensleitung in den strategischen Gruppen

Ein weiteres wichtiges Unternehmensmerkmal ist die Form der Unternehmensleitung. Abbildung 70 veranschaulicht inwieweit die Unternehmen durch den Inhaber bzw. Gesellschafter, durch einen angestellten Geschäftsführer bzw. Vorstand oder aber gemeinsam durch einen Inhaber und angestellten Geschäftsführer geleitet werden. 
Dabei wird ersichtlich, dass über alle befragten Unternehmen $77 \%$ durch den Inhaber oder einen Gesellschafter geführt werden. Bei nur $23 \%$ der Befragten erfolgt die Unternehmensleitung durch einen angestellten Geschäftsführer bzw. Vorstand oder gemeinsam durch einen Inhaber und einem angestellten Geschäftsführer. Zwischen den verschiedenen Clustern werden nach dem Ergebnis des Chi-Quadrat Tests wieder signifikante Unterschiede $(p=0,022)$ deutlich. So sticht besonders das Cluster 5 hervor, in dem $87 \%$ der Brauereien durch den Inhaber oder Gesellschafter geführt werden. Andererseits liegt dieser Anteil im Cluster 1 mit $65 \%$ und im Cluster 6 mit $58 \%$ deutlich unter dem Mittel der Grundgesamtheit.

Zusammenfassend kann festgestellt werden, dass sich die ermittelten strategischen Gruppen in wichtigen Unternehmensmerkmalen unterscheiden. Hoch signifikante Unterschiede bestehen dabei in Bezug auf die Rechtsformen sowie die Unternehmensleitung. Mit Blick auf die Konzernzugehörigkeit lassen sich tendenzielle Unterschiede zwischen den Gruppen belegen.

\subsection{Wahrnehmung der Branchensituation und Wettbewerbsposition}

Nachdem im Kapitel 4.2.1 die Wahrnehmung der Branchensituation durch die befragten Brauereien bereits detailliert dargelegt wurde, wird im Folgenden untersucht, ob in dieser Hinsicht Unterschiede zwischen den ermittelten strategischen Gruppen (Hypothese 2) bestehen. Im Anschluss daran werden die Einschätzungen zur Wettbewerbsposition der befragten Unternehmen auf etwaige Gruppenunterschiede geprüft.

Die Ergebnisse des Tests in Bezug auf die Wahrnehmung der Branchensituation zeigt die Tabelle 19. Das jeweilige Signifikanzniveau ist dabei im Anschluss an die Variablenbeschreibungen abzulesen. Dabei wird deutlich, dass insgesamt eher geringe Unterschiede zwischen den strategischen Gruppen bestehen. Signifikante Unterschiede (zu $\alpha<0.05)$ sind hinsichtlich einiger Umfeldfaktoren - namentlich der Einschätzung der Bedeutung des Reinheitsgebots sowie eventueller Schwierigkeiten durch Basel II bei der Kreditgewährung - zu erkennen. Die Bedeutung des Reinheitsgebotes wird von den Brauereien im Cluster 2 und im Cluster 4 am höchsten eingeschätzt, wohingegen die Unternehmen im Cluster 1 und im Cluster 6 die Bedeutung als deutlich niedriger erachten. Ein Grund für diesen Auffassungsunterschied könnte sein, dass sich die 
kleineren Brauereien der Cluster 2 und 4 durch das Reinheitsgebot eher gegenüber internationalen Wettbewerbern geschützt fühlen als die größeren Unternehmen.

\begin{tabular}{|c|c|c|c|c|c|c|c|}
\hline $\begin{array}{l}\text { Variablen zur } \\
\text { Wahrnehmung der } \\
\text { Branchensituation }\end{array}$ & $\begin{array}{c}\text { Cluster } \\
1\end{array}$ & $\begin{array}{c}\text { Cluster } \\
2\end{array}$ & $\begin{array}{c}\text { Cluster } \\
3\end{array}$ & $\begin{array}{c}\text { Cluster } \\
4\end{array}$ & $\begin{array}{l}\text { Cluster } \\
5\end{array}$ & $\begin{array}{c}\text { Cluster } \\
6 \\
\mathrm{n}=26 \\
\end{array}$ & Skalierung \\
\hline $\begin{array}{l}\text { Wettbewerbsdruck im } \\
\text { Kernabsatzgebiet }(p=0,464)\end{array}$ & $\begin{array}{c}4,12 \\
(0,697)\end{array}$ & $\begin{array}{c}4,09 \\
(1,05)\end{array}$ & $\begin{array}{c}4,10 \\
(0,881)\end{array}$ & $\begin{array}{c}4,12 \\
(0,704)\end{array}$ & $\begin{array}{c}3,98 \\
(0,889)\end{array}$ & $\begin{array}{c}4,38 \\
(0,496)\end{array}$ & $\begin{array}{l}1=\text { sehr niedrig } \\
5=\operatorname{sehr} \text { hoch }\end{array}$ \\
\hline $\begin{array}{l}\text { Umfang der Bedrohung } \\
\text { durch Eintritt neuer } \\
\text { Wettbewerber im } \\
\text { Kernabsatzgebiet }(p=0,099)\end{array}$ & $\begin{array}{c}2,94 \\
(0,748)\end{array}$ & $\begin{array}{c}2,75 \\
(1,075)\end{array}$ & $\begin{array}{c}3,04 \\
(0,922)\end{array}$ & $\begin{array}{c}2,92 \\
(1,064)\end{array}$ & $\begin{array}{c}2,79 \\
(0,871)\end{array}$ & $\begin{array}{c}3,35 \\
(0,797)\end{array}$ & $\begin{array}{l}1=\text { sehr niedrig } \\
5=\text { sehr hoch }\end{array}$ \\
\hline $\begin{array}{l}\text { Bedrohung durch } \\
\text { Substitutionsprodukte } \\
(\mathrm{p}=0,466)\end{array}$ & $\begin{array}{c}2,82 \\
(0,728)\end{array}$ & $\begin{array}{c}3,13 \\
(0,924)\end{array}$ & $\begin{array}{c}3,15 \\
(1,072)\end{array}$ & $\begin{array}{c}2,94 \\
(1,092)\end{array}$ & $\begin{array}{c}2,90 \\
(0,897)\end{array}$ & $\begin{array}{c}3,20 \\
(0,913)\end{array}$ & $\begin{array}{l}1=\text { sehr niedrig } \\
5=\text { sehr hoch }\end{array}$ \\
\hline $\begin{array}{l}\text { Verhandlungsmacht der } \\
\text { Lieferanten }(p=0,613)\end{array}$ & $\begin{array}{c}2,71 \\
(0,920)\end{array}$ & $\begin{array}{c}2,89 \\
(0,945) \\
\end{array}$ & $\begin{array}{c}2,85 \\
(0,691) \\
\end{array}$ & $\begin{array}{c}3,02 \\
(0,896)\end{array}$ & $\begin{array}{c}3,00 \\
(0,770)\end{array}$ & $\begin{array}{c}3,08 \\
(0,935)\end{array}$ & $\begin{array}{l}1=\text { sehr niedrig } \\
5=\operatorname{sehr} \text { hoch }\end{array}$ \\
\hline \multicolumn{8}{|l|}{$\begin{array}{l}\text { Verhandlungsmacht } \\
\text { verschiedener Absatzmittler }\end{array}$} \\
\hline $\begin{array}{l}\text { Getränkeeinzelhandelsketten } \\
(p=0,16)\end{array}$ & $\begin{array}{c}3,19 \\
(1,223)\end{array}$ & $\begin{array}{c}3,35 \\
(1,128)\end{array}$ & $\begin{array}{c}3,58 \\
(1,295)\end{array}$ & $\begin{array}{c}3,15 \\
(1,233)\end{array}$ & $\begin{array}{c}3,09 \\
(1243)\end{array}$ & $\begin{array}{c}3,65 \\
(0,754)\end{array}$ & $\begin{array}{l}1=\text { sehr niedrig } \\
5=\operatorname{sehr} \text { hoch }\end{array}$ \\
\hline $\begin{array}{l}\text { Getränkefachgroßhandel } \\
(p=0,303)\end{array}$ & $\begin{array}{c}3,25 \\
(1,342)\end{array}$ & $\begin{array}{c}3,48 \\
(1,196)\end{array}$ & $\begin{array}{c}3,47 \\
(1,22)\end{array}$ & $\begin{array}{c}3,22 \\
(1,123)\end{array}$ & $\begin{array}{c}3,20 \\
(1,09)\end{array}$ & $\begin{array}{c}3,73 \\
(0,827)\end{array}$ & $\begin{array}{l}1=\text { sehr niedrig } \\
5=\text { sehr hoch }\end{array}$ \\
\hline $\begin{array}{l}\text { Lebensmitteleinzelhandel } \\
(p=0,094)\end{array}$ & $\begin{array}{c}3,13 \\
(1,147)\end{array}$ & $\begin{array}{c}3,10 \\
(1,11)\end{array}$ & $\begin{array}{c}2,86 \\
(1,32)\end{array}$ & $\begin{array}{c}3,16 \\
(1,31)\end{array}$ & $\begin{array}{c}2,96 \\
(1,205)\end{array}$ & $\begin{array}{c}3,73 \\
(1,282)\end{array}$ & $\begin{array}{l}1=\text { sehr niedrig } \\
5=\text { sehr hoch }\end{array}$ \\
\hline Gastronomie $(\mathrm{p}=0,348)$ & $\begin{array}{c}3,35 \\
(0,702)\end{array}$ & $\begin{array}{c}3,21 \\
(0,977)\end{array}$ & $\begin{array}{c}2,93 \\
(1,009)\end{array}$ & $\begin{array}{c}3,02 \\
(0,958)\end{array}$ & $\begin{array}{c}2,94 \\
(0,985)\end{array}$ & $\begin{array}{c}2,88 \\
(0,833)\end{array}$ & $\begin{array}{l}1=\text { sehr niedrig } \\
5=\text { sehr hoch }\end{array}$ \\
\hline \multicolumn{8}{|l|}{$\begin{array}{l}\text { Einfluss verschiedener } \\
\text { Umfeldfaktoren }\end{array}$} \\
\hline $\begin{array}{l}\text { Reinheitsgebot hohe } \\
\text { Bedeutung }(\mathbf{p}=\mathbf{0 , 0 4})\end{array}$ & $\begin{array}{c}2,18 \\
(0,809)\end{array}$ & $\begin{array}{c}1,44 \\
(0,811)\end{array}$ & $\begin{array}{c}1,50 \\
(0,722)\end{array}$ & $\begin{array}{c}1,42 \\
(0,696)\end{array}$ & $\begin{array}{c}1,52 \\
(0,805)\end{array}$ & $\begin{array}{c}1,92 \\
(1,129)\end{array}$ & $\begin{array}{l}1=\text { stimme vollständig zu } \\
5=\text { lehne vollständig ab }\end{array}$ \\
\hline $\begin{array}{l}\text { Verbesserung der } \\
\text { Wettbewerbsposition durch } \\
\text { Einwegpfand }(p=0,086)\end{array}$ & $\begin{array}{c}2,82 \\
(0,883)\end{array}$ & $\begin{array}{c}2,53 \\
(1,034)\end{array}$ & $\begin{array}{c}2,67 \\
(1,076)\end{array}$ & $\begin{array}{c}2,21 \\
(1,016)\end{array}$ & $\begin{array}{c}2,58 \\
(1,028)\end{array}$ & $\begin{array}{c}2,88 \\
(1,306)\end{array}$ & $\begin{array}{l}1=\text { stimme vollständig zu } \\
5=\text { lehne vollständig ab }\end{array}$ \\
\hline $\begin{array}{l}\text { Veränderung des } \\
\text { Verbraucherverhaltens hat } \\
\text { starken Einfluss auf } \\
\text { Wettbewerbsintensität } \\
(\mathrm{p}=0,472)\end{array}$ & $\begin{array}{c}1,76 \\
(0,664)\end{array}$ & $\begin{array}{c}1,74 \\
(0,589)\end{array}$ & $\begin{array}{c}1,85 \\
(0,566)\end{array}$ & $\begin{array}{c}1,76 \\
(0,681)\end{array}$ & $\begin{array}{c}1,88 \\
(0,620)\end{array}$ & $\begin{array}{c}1,62 \\
(0,571)\end{array}$ & $\begin{array}{l}1=\text { stimme vollständig zu } \\
5=\text { lehne vollständig ab }\end{array}$ \\
\hline $\begin{array}{l}\text { Schwierigkeiten durch Basel } \\
\text { II bei Kreditvergabe } \\
(\mathbf{p = 0 , 0 2 3 )}\end{array}$ & $\begin{array}{c}2,94 \\
(1,088)\end{array}$ & $\begin{array}{c}2,38 \\
(1,274)\end{array}$ & $\begin{array}{c}2,06 \\
(0,845)\end{array}$ & $\begin{array}{c}2,61 \\
(1,297)\end{array}$ & $\begin{array}{c}2,62 \\
(1,118)\end{array}$ & $\begin{array}{c}2,77 \\
(0,863)\end{array}$ & $\begin{array}{l}1=\text { stimme vollständig zu } \\
5=\text { lehne vollständig ab }\end{array}$ \\
\hline $\begin{array}{l}\text { Verschlechterung der } \\
\text { Wettbewerbssituation durch } \\
\text { Werbeverbot für Bier } \\
(p=0,123)\end{array}$ & $\begin{array}{c}2,82 \\
(1,074)\end{array}$ & $\begin{array}{c}2,16 \\
(1,198)\end{array}$ & $\begin{array}{c}2,49 \\
(1,30)\end{array}$ & $\begin{array}{c}2,44 \\
(1,211)\end{array}$ & $\begin{array}{c}2,68 \\
(1,064)\end{array}$ & $\begin{array}{c}2,31 \\
(1,011)\end{array}$ & $\begin{array}{l}1=\text { stimme vollständig zu } \\
5=\text { lehne vollständig ab }\end{array}$ \\
\hline
\end{tabular}

a: Für die Cluster sind zuerst die Mittelwerte angegeben; die Standardabweichungen folgen in Klammern unter jedem Mittelwert.

Tabelle 19: Vergleich zur Wahrnehmung der Branchensituation

Schwierigkeiten durch die Vorgaben im Rahmen von Basel II bei einer Kreditvergabe erwarten besonders die Unternehmen des Clusters 3 sowie des Clusters 2. Auch hier stechen wieder die Brauereien des Clusters 1 und des Clusters 6 hervor, die tendenziell 
am wenigsten mit Schwierigkeiten in diesem Bereich rechnen. Dieser Unterschied in der Einschätzung könnte darauf zurückzuführen sein, dass die tendenziell größeren Brauereien der Clusters 1 und 6 i. d. R. durch ein professionelleres Management geleitet werden, welches die Vorgaben von Basel II besser umsetzen kann (z.B. Aufstellen und Umsetzen eines Strategieplanes).

Auch in Bezug auf das im Jahr 2003 eingeführte Einwegpfand zeigen sich tendenziell deutliche Unterschiede zwischen den ermittelten Gruppen in der deutschen Brauwirtschaft, wenn diese statistisch auch nicht als signifikant $(p=0,086)$ bezeichnet werden können. Danach konnten besonders die Brauereien im Cluster 2 und im Cluster 4 ihre Wettbewerbsposition durch die Einführung des Einwegpfandes verbessern. Im Cluster 6 hat sich die Position im Wettbewerb durch diesen Umfeldfaktor am deutlichsten verschlechtert. Ein Grund für diesen Unterschied dürfte der deutlich höhere Einweganteil der großen national distribuierenden Brauereien sein, welche sich im Cluster 6 wiederfinden.

Mit Blick auf die fünf Wettbewerbskräfte nach PORTER (1980) zeigt sich, dass die Branchensituation über alle Cluster insgesamt recht ähnlich wahrgenommen wird. Es ergeben sich keine statistisch signifikanten Unterschiede zwischen den ermittelten strategischen Gruppen. Wohl aber werden einige interessante tendenzielle Unterschiede ersichtlich, welche im Folgenden näher beleuchtet werden.

So wird deutlich, dass die Bedrohung durch den Eintritt neuer Wettbewerber in das Kernabsatzgebiet von den Brauereien im Cluster 6 und im Cluster 3 als überdurchschnittlich hoch wahrgenommen wird. In Bezug auf das Cluster 6 dürfte diese Einschätzung darauf zurückzuführen sein, dass mit zunehmender Größe der Brauereien und damit in der Regel auch des Kernabsatzgebietes mehr potentielle Wettbewerber, z.B. internationale Braukonzerne, auf den Plan treten. Bei den Brauereien des Clusters 3 ist dieses Ergebnis wohl eher durch die im Vergleich zu den anderen Clustern geringe Bedeutung der Differenzierung durch Marke und Innovation zu erklären.

Ein weiterer deutlicher tendenzieller Unterschied ergibt sich bei der Betrachtung der Verhandlungsmacht des Lebensmitteleinzelhandels (LEH). Diese wird von den Brauereien im Cluster 3 und Cluster 5 als besonders niedrig wahrgenommen, von den Unternehmen im Cluster 6 hingegen als besonders hoch. Diese unterschiedliche 
Einschätzung dürfte auf die wesentlich höhere Bedeutung dieses Absatzweges für die größeren Brauereien zurückzuführen sein.

Vor dem Hintergrund der Wahrnehmung der Branchensituation ist auch von Interesse, inwieweit zwischen den ermittelten strategischen Gruppen Unterschiede in der Einschätzung der Wettbewerbsposition der befragten Brauereien im Vergleich zu den Mitbewerbern bestehen. Tabelle 20 stellt diese Gruppenunterschiede dar. Das jeweilige Signifikanzniveau ist dabei im Anschluss an die Variablenbeschreibungen abzulesen. Dabei wird deutlich, dass bei nahezu allen in die Analyse eingeflossenen Variablen höchst signifikante Unterschiede zwischen den strategischen Gruppen vorliegen. Lediglich in Bezug auf die Höhe der Werbeausgaben sowie den Umfang der Serviceleistungen zeigen sich keine statistisch signifikanten Unterschiede. Einige interessante Gruppenunterschiede werden im Folgenden näher beleuchtet.

\begin{tabular}{|c|c|c|c|c|c|c|c|}
\hline \multirow{2}{*}{$\begin{array}{l}\text { Beurteilung der } \\
\text { Wettbewerbsposition im } \\
\text { Vergleich zum stärksten } \\
\text { Wettbewerber in Bezug } \\
\text { auf .... }\end{array}$} & $\begin{array}{c}\text { Cluster } \\
1\end{array}$ & $\begin{array}{c}\text { Cluster } \\
2\end{array}$ & $\begin{array}{c}\text { Cluster } \\
3\end{array}$ & $\begin{array}{c}\text { Cluster } \\
4\end{array}$ & $\begin{array}{c}\text { Cluster } \\
5\end{array}$ & $\begin{array}{c}\text { Cluster } \\
6\end{array}$ & Skalierung \\
\hline & $\mathrm{n}=17$ & $\mathrm{n}=55$ & $\mathrm{n}=48$ & $\mathrm{n}=52$ & $\mathrm{n}=83$ & $\mathrm{n}=26$ & \\
\hline $\begin{array}{l}\text { die Produktqualität } \\
(\mathbf{p}<\mathbf{0 , 0 0 1 )}\end{array}$ & $\begin{array}{c}4,00 \\
(0,612)\end{array}$ & $\begin{array}{c}3,89 \\
(0,685)\end{array}$ & $\begin{array}{c}2,87 \\
(0,806)\end{array}$ & $\begin{array}{c}3,86 \\
(0,825)\end{array}$ & $\begin{array}{c}3,61 \\
(0,703)\end{array}$ & $\begin{array}{c}3,62 \\
(0,941)\end{array}$ & $\begin{array}{l}1=\text { deutlich niedriger } \\
5=\text { deutlich höher }\end{array}$ \\
\hline $\begin{array}{l}\text { die Kapazitätsauslastung } \\
(\mathbf{p}=\mathbf{0 , 0 0 1})\end{array}$ & $\begin{array}{c}3,06 \\
(0,827)\end{array}$ & $\begin{array}{c}2,87 \\
(0,933)\end{array}$ & $\begin{array}{c}2,59 \\
(1,04)\end{array}$ & $\begin{array}{c}2,47 \\
(0,924)\end{array}$ & $\begin{array}{c}3,10 \\
(1,033)\end{array}$ & $\begin{array}{c}3,31 \\
(0,884)\end{array}$ & $\begin{array}{l}1=\text { deutlich niedriger } \\
5=\text { deutlich höher }\end{array}$ \\
\hline $\begin{array}{l}\text { den Marktanteil } \\
(\mathbf{p}=\mathbf{0 , 0 0 2})\end{array}$ & $\begin{array}{c}2,71 \\
(0,920)\end{array}$ & $\begin{array}{c}2,59 \\
(0,962)\end{array}$ & $\begin{array}{c}2,20 \\
(1,11)\end{array}$ & $\begin{array}{c}2,06 \\
(1,173)\end{array}$ & $\begin{array}{c}2,54 \\
(1,089)\end{array}$ & $\begin{array}{c}3,04 \\
(0,999)\end{array}$ & $\begin{array}{l}1=\text { deutlich niedriger } \\
5=\text { deutlich höher }\end{array}$ \\
\hline $\begin{array}{l}\text { die Verkaufspreise } \\
(\mathbf{p}<\mathbf{0 , 0 0 1})\end{array}$ & $\begin{array}{c}4,00 \\
(0,791\end{array}$ & $\begin{array}{c}3,78 \\
(0,937)\end{array}$ & $\begin{array}{c}2,73 \\
(0,939)\end{array}$ & $\begin{array}{c}3,57 \\
(0,755) \\
\end{array}$ & $\begin{array}{c}3,09 \\
(0,860)\end{array}$ & $\begin{array}{c}3,50 \\
(0,949)\end{array}$ & $\begin{array}{l}1=\text { deutlich niedriger } \\
5=\text { deutlich höher }\end{array}$ \\
\hline $\begin{array}{l}\text { die Innovationskraft } \\
(\mathbf{p}<\mathbf{0 , 0 0 1})\end{array}$ & $\begin{array}{c}2,88 \\
(0,781)\end{array}$ & $\begin{array}{c}3,83 \\
(0,771)\end{array}$ & $\begin{array}{c}2,93 \\
(1,223)\end{array}$ & $\begin{array}{c}2,78 \\
(1,026)\end{array}$ & $\begin{array}{c}3,15 \\
(0,878)\end{array}$ & $\begin{array}{c}3,65 \\
(0,797)\end{array}$ & $\begin{array}{l}1=\text { deutlich niedriger } \\
5=\text { deutlich höher }\end{array}$ \\
\hline $\begin{array}{l}\text { das Markenimage } \\
(\mathbf{p}<\mathbf{0 , 0 0 1})\end{array}$ & $\begin{array}{c}3,94 \\
(0,659) \\
\end{array}$ & $\begin{array}{c}3,69 \\
(0,940) \\
\end{array}$ & $\begin{array}{c}2,41 \\
(1,06)\end{array}$ & $\begin{array}{c}2,83 \\
(1,136)\end{array}$ & $\begin{array}{c}3,25 \\
(0,954)\end{array}$ & $\begin{array}{c}3,31 \\
(0,884)\end{array}$ & $\begin{array}{l}1=\text { deutlich niedriger } \\
5=\text { deutlich höher }\end{array}$ \\
\hline $\begin{array}{l}\text { die Höhe der } \\
\text { Werbeausgaben } \\
(p=0,275)\end{array}$ & $\begin{array}{c}2,29 \\
(1,105)\end{array}$ & $\begin{array}{c}2,30 \\
(1,03)\end{array}$ & $\begin{array}{c}2,30 \\
(1,28)\end{array}$ & $\begin{array}{c}1,88 \\
(0,931)\end{array}$ & $\begin{array}{c}2,10 \\
(1,093)\end{array}$ & $\begin{array}{c}2,40 \\
(1,225)\end{array}$ & $\begin{array}{l}1=\text { deutlich niedriger } \\
5=\text { deutlich höher }\end{array}$ \\
\hline $\begin{array}{l}\text { die Investitionen } \\
(\mathbf{p}<\mathbf{0 , 0 0 1 )}\end{array}$ & $\begin{array}{c}3,18 \\
(1,131)\end{array}$ & $\begin{array}{c}2,85 \\
(0,911)\end{array}$ & $\begin{array}{c}2,31 \\
(1,104)\end{array}$ & $\begin{array}{c}2,39 \\
(1,133)\end{array}$ & $\begin{array}{c}3,05 \\
(1,049)\end{array}$ & $\begin{array}{c}3,12 \\
(1,13)\end{array}$ & $\begin{array}{l}1=\text { deutlich niedriger } \\
5=\text { deutlich höher }\end{array}$ \\
\hline $\begin{array}{l}\text { die Serviceleistungen } \\
(p=0,143)\end{array}$ & $\begin{array}{c}3,12 \\
(1,11)\end{array}$ & $\begin{array}{c}3,55 \\
(0,997)\end{array}$ & $\begin{array}{c}3,02 \\
(1,055)\end{array}$ & $\begin{array}{c}3,20 \\
(1,161)\end{array}$ & $\begin{array}{c}3,43 \\
(0,925)\end{array}$ & $\begin{array}{c}3,35 \\
(1,198)\end{array}$ & $\begin{array}{l}1=\text { deutlich niedriger } \\
5=\text { deutlich höher }\end{array}$ \\
\hline
\end{tabular}

a: Für die Cluster sind zuerst die Mittelwerte angegeben; die Standardabweichungen folgen in Klammern unter jedem Mittelwert.

Tabelle 20: Einschätzung der Wettbewerbsposition im Vergleich zum stärksten Wettbewerber

So wird die Qualität ihrer Produkte von den Brauereien im Cluster 1 und im Cluster 2 am höchsten eingeschätzt, wohingegen die Brauereien im Cluster 3 diese am niedrigsten bewerten. Hier ist davon auszugehen, dass die Unternehmen in den Clustern 1 und 2 aufgrund ihrer ausgeprägten Differenzierungsstrategie wesentlich mehr Wert 
auf die Qualität legen als die Brauereien des Clusters 3, bei welchen die Differenzierung eine nicht so große Rolle spielt. Diese Annahme wird auch durch die Betrachtung der Einschätzung zu den Verkaufspreisen gestützt, bei welcher sich ein ähnliches Bild ergibt.

Mit Blick auf die Kapazitätsauslastung und den Marktanteil zeigt sich, dass diese von den Unternehmen des Clusters 3 und des Clusters 4 am niedrigsten eingeschätzt werden. Über alle befragten Brauereien schätzen sich die Unternehmen des Clusters 6 in diesen Punkten am besten ein.

In Bezug auf Investitionen wird deutlich, dass diese wiederum von den Unternehmen in den Clustern 3 und 4 am niedrigsten eingestuft werden. Die Brauereien im Cluster 1, im Cluster 6 sowie im Cluster 5 vertreten die Auffassung, deutlich höhere Investitionen getätigt zu haben als der Durchschnitt der Befragten.

Zusammenfassend kann hinsichtlich der Wahrnehmung der Branchensituation festgehalten werden, dass sich bei der Analyse der fünf Wettbewerbskräfte keine statistisch signifikanten, sondern lediglich tendenzielle Gruppenunterschiede gezeigt haben. Bei der Untersuchung der Umfeldfaktoren konnten hingegen signifikante Unterschiede zwischen den ermittelten Clustern bezüglich der

- Bedeutung des Reinheitsgebotes sowie

- der Einschätzung möglicher Schwierigkeiten durch Basel II bei der Kreditvergabe ermittelt werden.

Die Ausführungen hinsichtlich der Wahrnehmung der Branchensituation lassen in Bezug auf die Hypothese 2 somit den folgenden Befund zu:

Aufgrund der ermittelten Ergebnisse muss die Hypothese 2 verworfen werden. Die Strategiewahl und damit die Zugehörigkeit zu einer strategischen Gruppe werden nicht im Wesentlichen durch Unterschiede in der Wahrnehmung der Branchensituation bestimmt; vielmehr wird die Situation der deutschen Brauwirtschaft über alle Cluster insgesamt recht ähnlich wahrgenommen.

Bei der Betrachtung der Einschätzungen zur Wettbewerbsposition der befragten Brauereien im Vergleich zu den Mitbewerbern ergab sich ein deutlich klareres Bild. Demnach gibt es bezüglich der folgenden Merkmale 
- Produktqualität,

- Kapazitätsauslastung,

- Marktanteil,

- Verkaufspreise,

- Innovationskraft,

- Markenimage sowie

- Investitionen

höchst signifikante Unterschiede zwischen den ermittelten strategischen Gruppen.

\subsubsection{Organisatorische Umsetzung der Strategie}

Im Folgendem wird aufgezeigt, ob und inwieweit Unterschiede in der organisatorischen Umsetzung der Strategien zwischen den ermittelten strategischen Gruppen bestehen. Dazu werden die Variablen, welche das Potential und die Umsetzung von horizontalen und vertikalen Kooperationen (vgl. Kapitel 4.2.2.4), die geplante Wachstumsstrategie sowie das Out- und Insourcing (z. B. Getränkefachgroßhandel, Fuhrpark) der Unternehmen beschreiben, herangezogen.

Tabelle 21 zeigt die Gruppenunterschiede in Bezug auf die Einschätzung des Potentials von horizontalen und vertikalen Kooperationen auf. Dabei wird deutlich, dass sich hinsichtlich des Kooperationspotentials auf horizontaler Ebene in den verschiedenen Bereichen keine statistisch signifikanten Unterschiede zwischen den Clustern ergeben. Es werden jedoch wieder einige interessante tendenzielle Unterschiede erkennbar, auf welche nun näher eingegangen wird.

So wird ersichtlich, dass das Kooperationspotential im Bereich Einkauf von den Brauereien im Cluster 1 sowie im Cluster 6 als besonders hoch eingeschätzt wird, wohingegen die Unternehmen des Clusters 3 dieses am niedrigsten bewerten. Weitere deutliche Abweichungen vom Branchendurchschnitt zeigen sich bei der Betrachtung der Einschätzung der Potentiale einer Zusammenarbeit in den Bereichen Brauen, Abfüllen und Sortiment. Die Brauereien im Cluster 6 und im Cluster 3 sehen die Möglichkeiten, die eine Zusammenarbeit in diesen Bereichen bieten kann, als überdurchschnittlich hoch an. Andererseits schätzen die Brauereien des Clusters 1 das Potential in diesen Bereichen deutlich unterdurchschnittlich ein. Ein anderes Bild ergibt sich bei den Aussagen zu den Vertriebskooperationen. Das Potential einer solchen 
Zusammenarbeit wird von den Betrieben in der Gruppe 1 und der Gruppe 3 am höchsten bewertet, wohingegen die Brauereien in den Clustern 2 und 5 das Potential einer solchen Kooperation am niedrigsten bewerten.

\begin{tabular}{|c|c|c|c|c|c|c|c|}
\hline $\begin{array}{l}\text { Einschätzung des } \\
\text { Kooperationspotentials }\end{array}$ & $\begin{array}{c}\text { Cluster } 1 \\
\mathrm{n}=17\end{array}$ & $\begin{array}{c}\text { Cluster } 2 \\
\mathrm{n}=55\end{array}$ & $\begin{array}{c}\text { Cluster } 3 \\
\mathrm{n}=48 \\
\end{array}$ & $\begin{array}{c}\text { Cluster } 4 \\
n=52 \\
\end{array}$ & $\begin{array}{c}\text { Cluster } 5 \\
n=83\end{array}$ & $\begin{array}{c}\text { Cluster } 6 \\
\mathrm{n}=26 \\
\end{array}$ & Skalierung \\
\hline \multicolumn{8}{|l|}{$\begin{array}{l}\text { auf horizontaler Ebene im } \\
\text { Bereich..... }\end{array}$} \\
\hline Einkauf $(p=0,507)$ & $\begin{array}{c}3,50 \\
(1,033)\end{array}$ & $\begin{array}{c}3,25 \\
(1,074)\end{array}$ & $\begin{array}{c}2,93 \\
(1,301)\end{array}$ & $\begin{array}{c}3,24 \\
(1,251)\end{array}$ & $\begin{array}{c}3,23 \\
(1,187)\end{array}$ & $\begin{array}{c}3,44 \\
(1,294)\end{array}$ & $\begin{array}{l}1=\text { sehr niedrig } \\
5=\text { sehr hoch }\end{array}$ \\
\hline Brauen $(\mathrm{p}=0,155)$ & $\begin{array}{c}2,06 \\
(1,124)\end{array}$ & $\begin{array}{c}2,38 \\
(1,193)\end{array}$ & $\begin{array}{c}2,56 \\
(1,181)\end{array}$ & $\begin{array}{c}2,22 \\
(1,191)\end{array}$ & $\begin{array}{c}2,13 \\
(1,087)\end{array}$ & $\begin{array}{c}2,72 \\
(1,208)\end{array}$ & $\begin{array}{l}1=\text { sehr niedrig } \\
5=\text { sehr hoch }\end{array}$ \\
\hline Abfüllen $(\mathrm{p}=0,657)$ & $\begin{array}{c}2,56 \\
(0,964)\end{array}$ & $\begin{array}{c}3,08 \\
(1,468)\end{array}$ & $\begin{array}{c}3,09 \\
(1,291)\end{array}$ & $\begin{array}{c}2,92 \\
(1,455)\end{array}$ & $\begin{array}{c}2,89 \\
(1,292)\end{array}$ & $\begin{array}{c}3,20 \\
(1,080)\end{array}$ & $\begin{array}{l}1=\text { sehr niedrig } \\
5=\text { sehr hoch }\end{array}$ \\
\hline Sortiment $(\mathrm{p}=0,224)$ & $\begin{array}{c}2,56 \\
(0,964)\end{array}$ & $\begin{array}{c}2,92 \\
(1,104)\end{array}$ & $\begin{array}{c}2,95 \\
(1,180)\end{array}$ & $\begin{array}{c}2,65 \\
(1,110)\end{array}$ & $\begin{array}{c}2,64 \\
(1,087)\end{array}$ & $\begin{array}{c}3,12 \\
(0,927)\end{array}$ & $\begin{array}{l}1=\text { sehr niedrig } \\
5=\text { sehr hoch }\end{array}$ \\
\hline Vertrieb $(p=0,095)$ & $\begin{array}{c}2,94 \\
(1,237)\end{array}$ & $\begin{array}{c}2,26 \\
(1,103)\end{array}$ & $\begin{array}{c}2,64 \\
(1,123)\end{array}$ & $\begin{array}{c}2,38 \\
(1,178)\end{array}$ & $\begin{array}{c}2,19 \\
(1,016)\end{array}$ & $\begin{array}{c}2,50 \\
(1,103)\end{array}$ & $\begin{array}{l}1=\text { sehr niedrig } \\
5=\text { sehr hoch }\end{array}$ \\
\hline Marketing $(\mathrm{p}=0,307)$ & $\begin{array}{c}1,69 \\
(1,014)\end{array}$ & $\begin{array}{c}2,28 \\
(1,161)\end{array}$ & $\begin{array}{c}2,09 \\
(1,019)\end{array}$ & $\begin{array}{c}1,94 \\
(1,019)\end{array}$ & $\begin{array}{c}2,03 \\
(0,891)\end{array}$ & $\begin{array}{c}1,88 \\
(0,971)\end{array}$ & $\begin{array}{l}1=\text { sehr niedrig } \\
5=\text { sehr hoch }\end{array}$ \\
\hline $\begin{array}{l}\text { Produktentwicklung } \\
(\mathrm{p}=0,853)\end{array}$ & $\begin{array}{c}1,88 \\
(1,088)\end{array}$ & $\begin{array}{c}2,20 \\
(1,069)\end{array}$ & $\begin{array}{c}2,21 \\
(1,125)\end{array}$ & $\begin{array}{c}2,31 \\
(1,274)\end{array}$ & $\begin{array}{c}2,16 \\
(1,047)\end{array}$ & $\begin{array}{c}2,24 \\
(1,052)\end{array}$ & $\begin{array}{l}1=\text { sehr niedrig } \\
5=\text { sehr hoch }\end{array}$ \\
\hline $\begin{array}{l}\text { Internationalisierung } \\
(p=0,542)\end{array}$ & $\begin{array}{c}2,25 \\
(1,065)\end{array}$ & $\begin{array}{c}2,00 \\
(1,088)\end{array}$ & $\begin{array}{c}1,93 \\
(1,078)\end{array}$ & $\begin{array}{c}1,96 \\
(1,166)\end{array}$ & $\begin{array}{c}1,74 \\
(0,952)\end{array}$ & $\begin{array}{c}2,00 \\
(1,118)\end{array}$ & $\begin{array}{l}1=\text { sehr niedrig } \\
5=\text { sehr hoch }\end{array}$ \\
\hline \multicolumn{8}{|l|}{ auf vertikaler Ebene mit..... } \\
\hline $\begin{array}{l}\text { Getränkefachgroßhandel } \\
(\mathbf{p}<\mathbf{0 , 0 0 1})\end{array}$ & $\begin{array}{c}3,00 \\
(1,109)\end{array}$ & $\begin{array}{c}2,77 \\
(1,057)\end{array}$ & $\begin{array}{c}2,98 \\
(1,093)\end{array}$ & $\begin{array}{c}3,07 \\
(1,129)\end{array}$ & $\begin{array}{c}2,54 \\
(1,239)\end{array}$ & $\begin{array}{c}3,79 \\
(0,932)\end{array}$ & $\begin{array}{l}1=\text { sehr niedrig } \\
5=\text { sehr hoch }\end{array}$ \\
\hline $\begin{array}{l}\text { anderen Absatzmittlern } \\
(\mathbf{p}=\mathbf{0 , 0 1 8})\end{array}$ & $\begin{array}{c}3,00 \\
(0,784)\end{array}$ & $\begin{array}{c}2,71 \\
(1,071)\end{array}$ & $\begin{array}{c}2,57 \\
(1,129)\end{array}$ & $\begin{array}{c}2,78 \\
(1,020)\end{array}$ & $\begin{array}{c}2,29 \\
(1,008)\end{array}$ & $\begin{array}{c}3,04 \\
(1,022)\end{array}$ & $\begin{array}{l}1=\text { sehr niedrig } \\
5=\text { sehr hoch }\end{array}$ \\
\hline Mälzereien $(p=0,884)$ & $\begin{array}{c}2,47 \\
(1,187) \\
\end{array}$ & $\begin{array}{c}2,35 \\
(1,165) \\
\end{array}$ & $\begin{array}{c}2,26 \\
(1,026) \\
\end{array}$ & $\begin{array}{c}2,51 \\
(1,333) \\
\end{array}$ & $\begin{array}{c}2,15 \\
(1,284) \\
\end{array}$ & $\begin{array}{c}2,21 \\
(1,179) \\
\end{array}$ & $\begin{array}{l}1=\text { sehr niedrig } \\
5=\text { sehr hoch }\end{array}$ \\
\hline
\end{tabular}

a: Für die Cluster sind zuerst die Mittelwerte angegeben; die Standardabweichungen folgen in Klammern unter jedem Mittelwert.

Tabelle 21: Vergleich der Einschätzung des horizontalen und vertikalen Kooperationspotentials

Mit Blick auf die Einschätzungen des Kooperationspotentials auf vertikaler Ebene mit dem Getränkefachgroßhandel $(p<0.001)$ sowie anderen Absatzmittlern $(p=0,018)$ ergeben sich hoch signifikante Unterschiede zwischen den strategischen Gruppen. Die Brauereien des Clusters 6, des Clusters 4 und des Clusters 1 sehen die Möglichkeiten einer Zusammenarbeit in diesen Bereichen als besonders hoch an. Die Unternehmen des Clusters 5 hingegen schätzen das Potential von vertikalen Kooperationen im Vergleich zum Gesamtmittel am niedrigsten ein.

Abbildung 71 veranschaulicht, dass $49 \%$ aller befragten Unternehmen auf horizontaler Ebene kooperieren oder dieses planen. Vor dem Hintergrund der Einschätzungen des Kooperationspotentials verwundert es jedoch nicht, dass nach dem Chi-Quadrat Test in 
dieser Hinsicht keine signifikanten Unterschiede $(\mathrm{p}=0,764)$ zwischen den strategischen Gruppen bestehen. Lediglich das Cluster 1 hebt sich vergleichsweise deutlich von der gesamten Stichprobe ab, da in dieser Gruppe immerhin 59 \% der Unternehmen in eine horizontale Zusammenarbeit eingebunden sind oder diese planen.

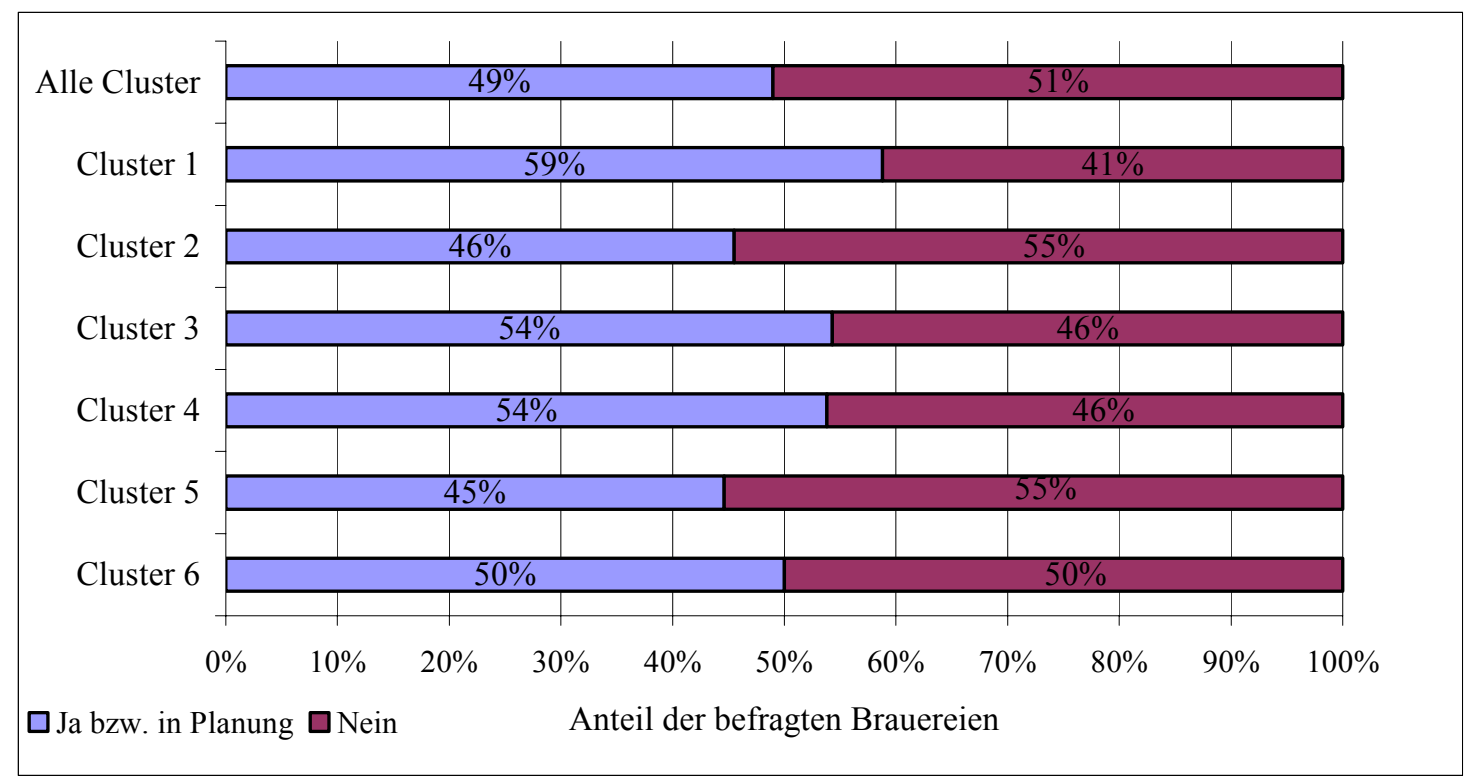

Abbildung 71: Horizontale Kooperationen (realisiert oder in Planung)

Auch mit Blick auf die Anteile der Brauereien, die mit Unternehmen im vor- oder nachgelagerten Bereich kooperieren oder dieses planen (Abbildung 72), ergeben sich keine signifikanten $(\mathrm{p}=0,513)$ Gruppenunterschiede.

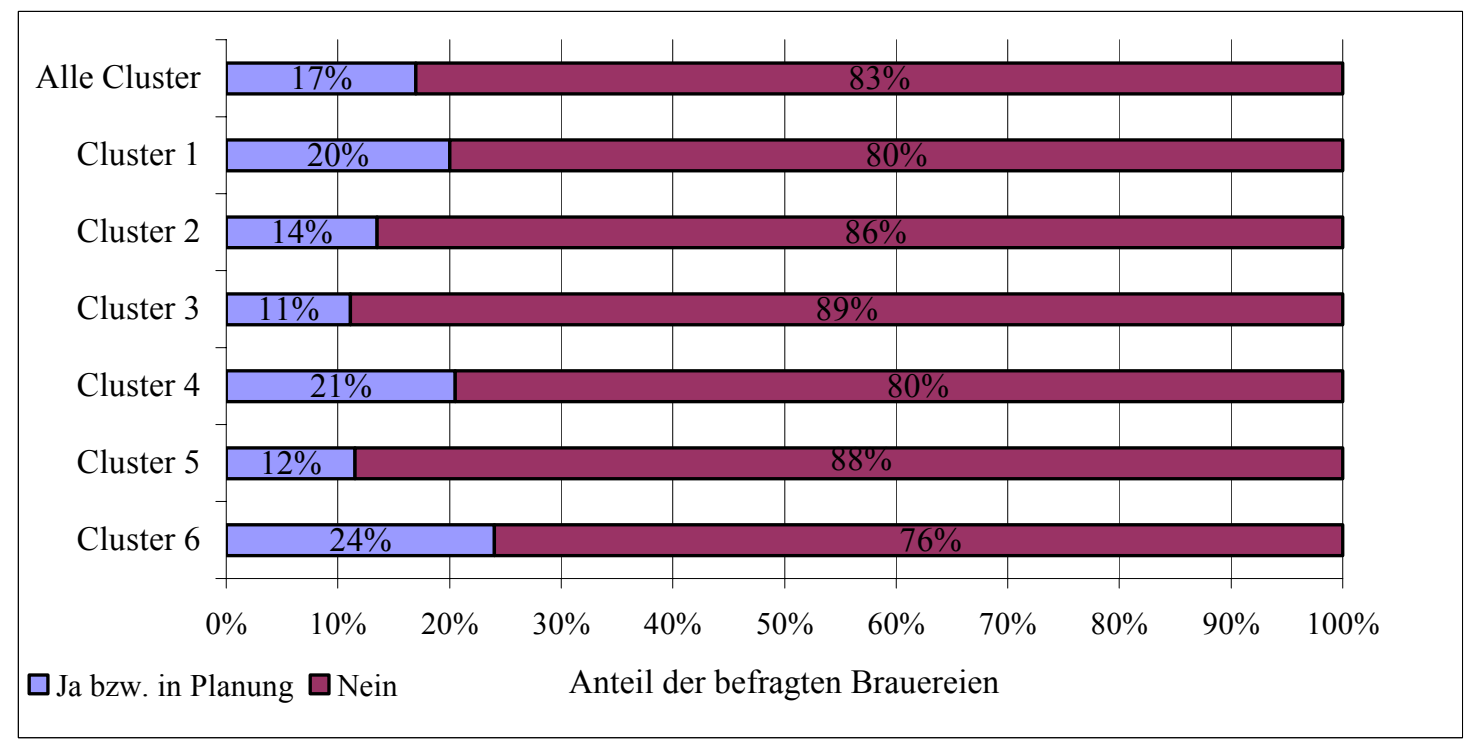

Abbildung 72: Vertikale Kooperationen (realisiert oder in Planung)

In diesem Bereich sind insgesamt nur $17 \%$ der befragten Brauereien an einer Kooperation beteilig. Vom Durchschnitt aller Befragten heben sich nur die Brauereien 
des Clusters 6 deutlich ab, von denen immerhin $24 \%$ mit Unternehmen im vor- oder nachgelagerten Bereich zusammenarbeiten oder dieses planen.

In Bezug auf das Out- und Insourcing in der deutschen Brauwirtschaft stehen aktuell besonders der Getränkefachgroßhandel und der Fuhrpark im Mittelpunkt der Diskussion. Abbildung 73 zeigt, dass etwa $9 \%$ der befragten Brauereien bereits einen Getränkefachgroßhändler übernommen haben oder dieses planen. Zwischen den strategischen Gruppen bestehen in dieser Hinsicht höchst signifikante Unterschiede $(\mathrm{p}=0,009)$.

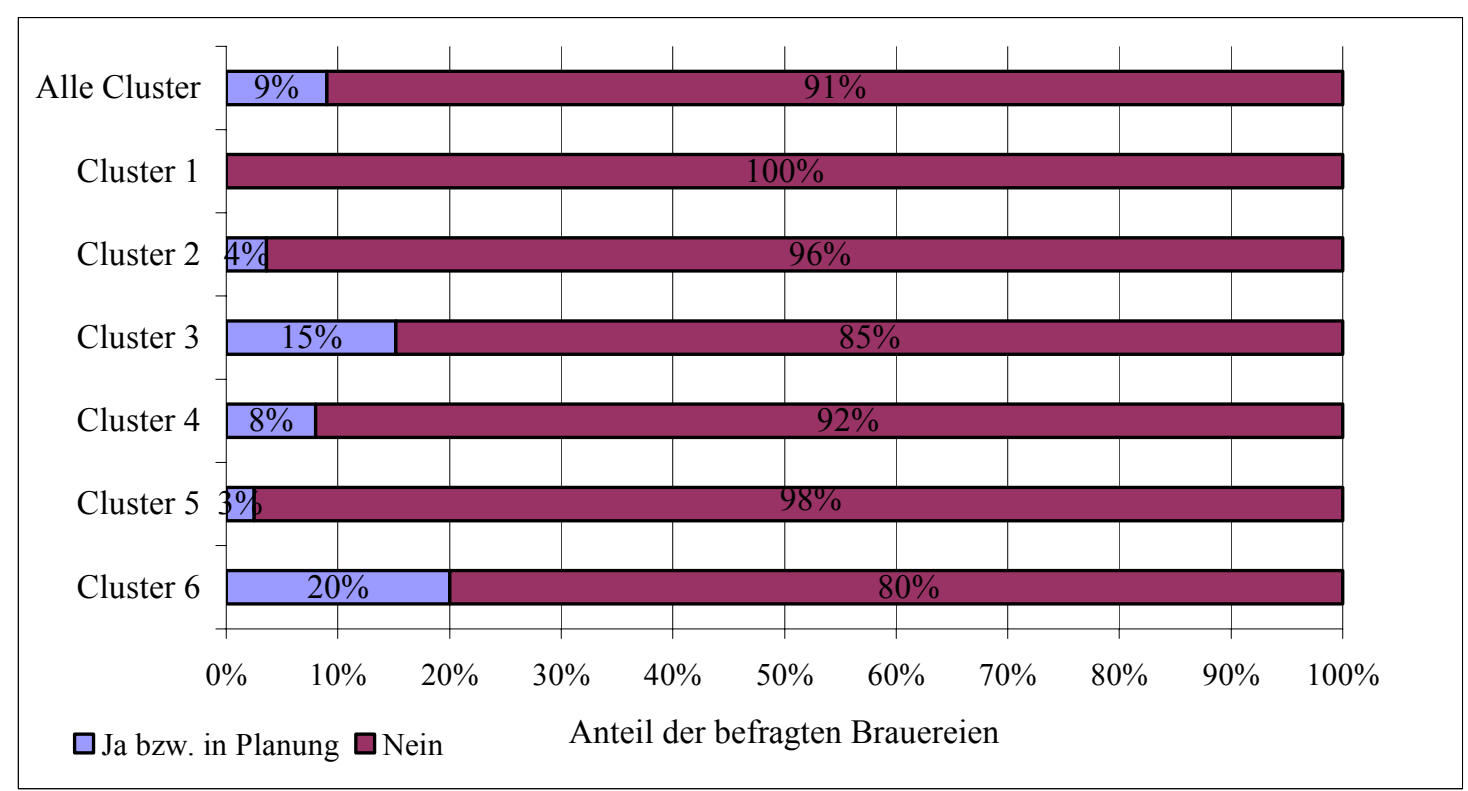

Abbildung 73: Übernahme von Getränkefachgroßhändlern (realisiert oder geplant)

So haben sich im 3. Cluster $15 \%$ und im Cluster 6 sogar $20 \%$ der Befragten für eine vertikale Integration in diesem Bereich entschieden oder planen eine solche. Das Cluster 1 hingegen hebt sich dadurch von der Grundgesamtheit ab, dass gar keine Brauerei dieser Gruppe die Übernahme eines Getränkefachgroßhändlers vorgenommen hat oder dieses plant.

Bei der Untersuchung der Frage, inwieweit sich die Brauereien ein Outsourcing des Fuhrparks vorstellen können, werden wiederum höchst signifikante Unterschiede zwischen den strategischen Gruppen sichtbar (Tabelle 22). Die Brauereien des Clusters 6 und des Cluster 1 - also eher die Brauereien mit einem größeren Distributionsgebiet können sich am ehesten ein Outsourcing der Logistik vorstellen. Die Brauereien in den übrigen Clustern stehen Veränderungen in diesem Bereich wesentlich kritischer 
gegenüber. Besonders deutlich wird diese Einstellung bei der Betrachtung des Clusters

5.

Tabelle 22 zeigt, dass sich auch mit Blick auf die geplanten Wachstumsstrategien wieder signifikante bis höchst signifikante Unterschiede zwischen den ermittelten Clustern erkennen lassen. Einen Zukauf anderer Brauereien ziehen demnach eher die Unternehmen im Cluster 1, im Cluster 2 und im Cluster 6 in Betracht. Die Brauereien in den übrigen Clustern stehen einer solchen Option wesentlich weniger aufgeschlossen gegenüber.

\begin{tabular}{|c|c|c|c|c|c|c|c|}
\hline Variablen zur Beschreibung & $\begin{array}{c}\text { Cluster } 1 \\
\mathrm{n}=17\end{array}$ & $\begin{array}{c}\text { Cluster } 2 \\
n=55\end{array}$ & $\begin{array}{c}\text { Cluster } 3 \\
\mathrm{n}=48\end{array}$ & $\begin{array}{c}\text { Cluster } 4 \\
n=52\end{array}$ & $\begin{array}{c}\text { Cluster } 5 \\
n=83\end{array}$ & $\begin{array}{c}\text { Cluster } 6 \\
\mathrm{n}=26\end{array}$ & Skalierung \\
\hline \multicolumn{8}{|l|}{ des Out- bzw. Insourcing... } \\
\hline $\begin{array}{l}\text { Wir werden auch in Zukunft } \\
\text { einen eigenen Fuhrpark } \\
\text { betreiben }(\mathbf{p}=\mathbf{0 , 0 0 1})\end{array}$ & $\begin{array}{c}2,29 \\
(1,105)\end{array}$ & $\begin{array}{c}2,07 \\
(1,215)\end{array}$ & $\begin{array}{c}2,20 \\
(0,869)\end{array}$ & $\begin{array}{c}2,18 \\
(1,126)\end{array}$ & $\begin{array}{c}1,96 \\
(1,082)\end{array}$ & $\begin{array}{c}3,12 \\
(1,505)\end{array}$ & $\begin{array}{l}\text { stimme vollständig } \\
\mathrm{zu}=1 \text {, lehne } \\
\text { vollständig } \mathrm{ab}=5\end{array}$ \\
\hline \multicolumn{8}{|l|}{$\begin{array}{l}\text { der geplanten } \\
\text { Wachstumsstrategie..... }\end{array}$} \\
\hline $\begin{array}{l}\text { Zukauf anderer Brauereien } \\
\text { wird in Betracht gezogen } \\
(\mathbf{p = 0 , 0 2 9 )}\end{array}$ & $\begin{array}{c}3,47 \\
(1,281)\end{array}$ & $\begin{array}{c}3,98 \\
(1,141)\end{array}$ & $\begin{array}{c}4,09 \\
(0,973)\end{array}$ & $\begin{array}{c}4,10 \\
(1,269)\end{array}$ & $\begin{array}{c}4,31 \\
(0,889)\end{array}$ & $\begin{array}{c}3,69 \\
(1,158)\end{array}$ & $\begin{array}{l}\text { stimme vollständig } \\
\mathrm{zu}=1 \text {, lehne } \\
\text { vollständig } \mathrm{ab}=5\end{array}$ \\
\hline $\begin{array}{l}\text { Zukauf anderer Getränke- } \\
\text { hersteller wird in Betracht } \\
\text { gezogen }(\mathbf{p}=\mathbf{0 , 0 4 7})\end{array}$ & $\begin{array}{c}4,18 \\
(0,883)\end{array}$ & $\begin{array}{c}4,28 \\
(0,834)\end{array}$ & $\begin{array}{c}3,76 \\
(1,048)\end{array}$ & $\begin{array}{c}4,22 \\
(0,945)\end{array}$ & $\begin{array}{c}4,26 \\
(0,932)\end{array}$ & $\begin{array}{c}3,96 \\
(0,958)\end{array}$ & $\begin{array}{l}\text { stimme vollständig } \\
\mathrm{zu}=1 \text {, lehne } \\
\text { vollständig } \mathrm{ab}=5\end{array}$ \\
\hline $\begin{array}{l}\text { Zukauf von Markenrechten } \\
\text { anderer Brauereien wird in } \\
\text { Betracht gezogen }(\mathbf{p}<\mathbf{0 , 0 0 1})\end{array}$ & $\begin{array}{c}3,94 \\
(0,899)\end{array}$ & $\begin{array}{c}4,09 \\
(0,996)\end{array}$ & $\begin{array}{c}3,72 \\
(1,026)\end{array}$ & $\begin{array}{c}4,08 \\
(1,152)\end{array}$ & $\begin{array}{c}4,46 \\
(0,672)\end{array}$ & $\begin{array}{c}3,73 \\
(0,962)\end{array}$ & $\begin{array}{l}\text { stimme vollständig } \\
\mathrm{zu}=1 \text {, lehne } \\
\text { vollständig } \mathrm{ab}=5\end{array}$ \\
\hline $\begin{array}{l}\text { Keine Maßnahmen zur } \\
\text { Erweiterung, da mit jetzigem } \\
\text { Marktanteil zufrieden } \\
(\mathbf{p = 0 , 0 2 4 )}\end{array}$ & $\begin{array}{c}3,41 \\
(1,004)\end{array}$ & $\begin{array}{c}3,81 \\
(1,029)\end{array}$ & $\begin{array}{c}3,61 \\
(0,954)\end{array}$ & $\begin{array}{c}3,55 \\
(1,137)\end{array}$ & $\begin{array}{c}3,19 \\
(1,137)\end{array}$ & $\begin{array}{c}3,69 \\
(0,970)\end{array}$ & $\begin{array}{l}\text { stimme vollständig } \\
\mathrm{zu}=1 \text {, lehne } \\
\text { vollständig } \mathrm{ab}=5\end{array}$ \\
\hline $\begin{array}{l}\text { Können uns vorstellen, die } \\
\text { Brautätigkeit auszulagern, um } \\
\text { uns voll auf den Vertrieb zu } \\
\text { konzentrieren }(\mathbf{p}<\mathbf{0 , 0 0 1})\end{array}$ & $\begin{array}{c}4,53 \\
(0,624)\end{array}$ & $\begin{array}{c}4,28 \\
(0,899)\end{array}$ & $\begin{array}{c}3,57 \\
(1,205)\end{array}$ & $\begin{array}{c}4,33 \\
(0,993)\end{array}$ & $\begin{array}{c}4,35 \\
(0,948)\end{array}$ & $\begin{array}{c}4,15 \\
(1,008)\end{array}$ & $\begin{array}{l}\text { stimme vollständig } \\
\mathrm{zu}=1 \text {, lehne } \\
\text { vollständig } \mathrm{ab}=5\end{array}$ \\
\hline
\end{tabular}

a: Für die Cluster sind zuerst die Mittelwerte angegeben; die Standardabweichungen folgen in Klammern unter jedem Mittelwert.

Tabelle 22 : Vergleich des Out- bzw. Insourcing im Bereich Fuhrpark sowie der geplanten Wachstumsstrategien

Ein Zukauf anderer Getränkehersteller sowie von Markenrechten kommt am ehesten für die Brauereien des Clusters 3 und des Clusters 6 in Frage. Die Unternehmen im Cluster 5 und im Cluster 2 betrachten ein derartiges Wachstum deutlich kritischer.

Mit Blick auf die Frage, ob sich die Brauereien vorstellen können, die Brautätigkeit in Zukunft vollständig auszulagern, um sich ganz auf den Vertrieb zu konzentrieren, zeigt 
sich, dass die Brauerein im Cluster 3 und im Cluster 5 dieser Frage am ehesten zustimmen. In den übrigen Clustern ist die Zustimmung hingegen erheblich geringer.

Zusammenfassend kann hinsichtlich der organisatorischen Umsetzung der Strategien festgestellt werden, dass bei der Untersuchung der Einschätzungen der Potentiale horizontaler Kooperationen sowie der Umsetzung von sowohl horizontalen als auch vertikalen Kooperationen keine signifikanten, sondern nur tendenzielle Unterschiede zwischen den strategischen Gruppen bestehen. Bei der Analyse der Einschätzungen zum Potential von vertikalen Kooperationen konnten hingegen hoch signifikante Unterschiede bezüglich des Kooperationspotentials mit

- dem Getränkefachgroßhandel sowie

- anderen Absatzmittlern aufgezeigt werden.

Stark signifikante Unterschiede zwischen den strategischen Gruppen konnten auch in Bezug auf das Out- bzw. Insourcing sowie die geplanten Wachstumsstrategien der Unternehmen in den folgenden Bereichen festgestellt werden:

- Übernahme von Getränkefachgroßhändlern,

- Outsourcing des Fuhrparks,

- Zukauf anderer Brauereien,

- Zukauf anderer Getränkehersteller,

- Zukauf von Markenrechten anderer Brauereien,

- keinen Maßnahmen zur Erweiterung sowie

- einer möglichen Auslagerung der Brautätigkeit und vollständigen Konzentration auf den Vertrieb.

\subsubsection{Kostenvergleich}

Im Zusammenhang mit der organisatorischen Umsetzung der Strategie ist es für den Unternehmenserfolg von entscheidender Bedeutung, die Kosten stets im Auge zu haben. Die Kosten im Vergleich zum Branchendurchschnitt sind zwar in die Faktoranalyse eingeflossen, aufgrund der geringen Ladung von -0,326 auf den Faktor 1 (Größe und Reichweite) sind sie jedoch nicht in der aufgezeigten rotierten Faktorenmatrix (vgl. Kapitel 4.3.2, Tabelle 17) ausgewiesen und somit bisher noch 
nicht explizit behandelt worden. Daher wird nun im Folgenden analysiert, ob und inwieweit Unterschiede in Bezug auf die Kosten zwischen den ermittelten strategischen Gruppen bestehen.

Mit Blick auf die Einschätzung der Kosten in Relation zum Branchendurchschnitt werden signifikante Unterschiede zwischen den Clustern ersichtlich (vgl. Tabelle 23).

\begin{tabular}{|lcccccc|c|}
\hline Einschätzung .... & Cluster & Cluster & Cluster & Cluster & Cluster & Cluster & Skalierung \\
& $\begin{array}{c}1 \\
\mathrm{n}=17\end{array}$ & $\begin{array}{c}2 \\
\mathrm{n}=55\end{array}$ & $\begin{array}{c}3 \\
\mathrm{n}=48\end{array}$ & $\begin{array}{c}4 \\
\mathrm{n}=52\end{array}$ & $\begin{array}{c}\mathrm{n}=83 \\
\mathrm{n}=26\end{array}$ & $\mathbf{2}$ \\
\hline der Kosten im Vergleich & 3,53 & 3,68 & 3,57 & 3,80 & 3,48 & 3,04 & $1=$ deutlich geringer \\
zum Branchendurchschnitt & $(1,125)$ & $(0,956)$ & $(0,875)$ & $(1,02)$ & $(0,963)$ & $(1,06)$ & $5=$ deutlich höher \\
$(\mathbf{p = 0 , 0 5})$ & & & & & & & \\
\hline
\end{tabular}

Tabelle 23: Vergleich der Einschätzung der Gesamtkosten in Relation zum Branchendurchschnitt

Es wird deutlich, dass die Kosten von den Brauereien im Cluster 6 insgesamt am niedrigsten eingeschätzt werden. Aber auch die Unternehmen im Cluster 5 und im Cluster 1 stufen ihre Kosten als unterdurchschnittlich ein. Das Gegenteil dazu bilden das Cluster 4 und das Cluster 2, welche ihre Kosten für überdurchschnittlich erachten.

In Bezug auf die Höhe der durchschnittlichen Kosten pro Hektoliter sind keine signifikanten Unterschiede $(\mathrm{p}=0,682)$ zwischen den ermittelten Clustern zu erkennen (vgl. Abbildung 74).

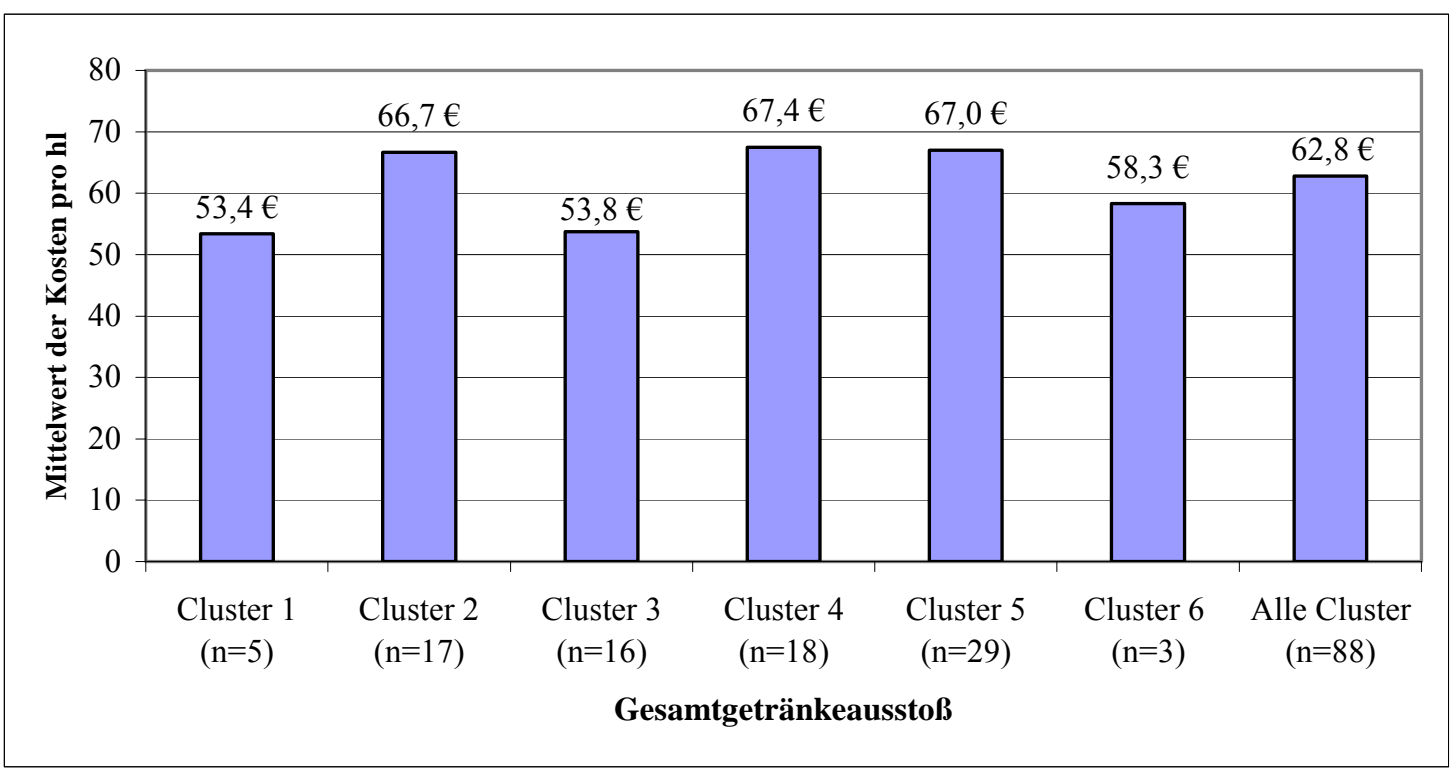

Abbildung 74: Vergleich der durchschnittlichen Gesamtkosten pro Hektoliter

Es werden jedoch einige tendenzielle Unterschiede deutlich. So liegen die durchschnittlichen Kosten der Brauereien im Cluster 1 und Cluster 6 z. T. deutlich unter und bei den Brauereien im Cluster 2 und im Cluster 4 über dem Gesamtmittel. 
Diese Angaben stehen somit im Einklang mit der Selbsteinschätzung der befragten Brauereien bezüglich ihrer Gesamtkosten in Relation zum Branchendurchschnitt. Entgegen dieser Selbsteinschätzung geben die Brauereien im Cluster 3 jedoch deutlich unterdurchschnittliche und die Brauereien im Cluster 5 deutlich überdurchschnittliche Kosten an. Insgesamt ist die Aussagekraft der Abbildung 74 allerdings insoweit eingeschränkt als nur etwa $30 \%$ aller befragten Brauereien diese Frage beantwortet haben. Aus diesem Grund finden die Angaben zu den durchschnittlichen Gesamtkosten pro Hektoliter in der weiteren Interpretation keine Berücksichtigung

\subsubsection{Strategieformulierung und -implementierung}

Im Folgenden wird dargestellt, inwieweit sich die ermittelten strategischen Gruppen in der Strategieformulierung und -implementierung unterscheiden. Dazu werden u. a. die Variablen herangezogen, welche wichtige Elemente des strategischen Managements (vgl. Kapitel 4.2.4) beschreiben.

Die ermittelten Gruppenunterschiede zeigt die Tabelle 24. Mit Blick auf die Frage, ob die befragten Brauereien auch im Tagesgeschäft immer die langfristige Strategie im Auge haben, wird eine breite Zustimmung der Brauereien in allen Clustern deutlich. Somit ergeben sich diesbezüglich keine statistisch signifikanten, sondern nur tendenzielle Unterschiede zwischen den ermittelten Gruppen. Die Brauereien im Cluster 1 und im Cluster 6 heben sich dabei durch eine besonders deutliche Zustimmung von der gesamten Stichprobe ab.

Bei der Analyse, inwieweit wichtige Elemente des strategischen Managements in den befragten Brauereien angewendet werden, zeigen sich jedoch hoch signifikante Unterschiede zwischen den strategischen Gruppen. So wird ersichtlich, dass die Festlegung klarer Ziele, die Kommunikation der Strategie und der Ziele an alle Mitarbeiter sowie eine konsequente Weiterbildung der Mitarbeiter im Cluster 6, im Cluster 1 und im Cluster 2 eine wesentlich höhere Bedeutung als in den übrigen Gruppen besitzen. Die höchste Relevanz messen diesen Elementen, wie auch der Überprüfung der Geschäftsentwicklung in vorher festgelegten Planungsterminen, wiederum die Brauereien in der Gruppe 1 und in der Gruppe $6 \mathrm{zu}$. 
Auch bei der Einschätzung zur Qualität des eigenen Managements zeigt sich ein ähnliches Bild. Dieses wird von den Brauereien im Cluster 3, im Cluster 4 und im Cluster 5 signifikant schlechter als in den übrigen Gruppen eingeschätzt.

\begin{tabular}{|c|c|c|c|c|c|c|c|}
\hline $\begin{array}{l}\text { Variablen zur Beschreibung der } \\
\text { Strategieformulierung und } \\
\text { implementierung }\end{array}$ & $\begin{array}{c}\text { Cluster } \\
1 \\
\mathrm{n}=17\end{array}$ & $\begin{array}{c}\text { Cluster } \\
2 \\
\mathrm{n}=55\end{array}$ & $\begin{array}{c}\begin{array}{c}\text { Cluster } \\
3 \\
\mathrm{n}=48\end{array} \\
\end{array}$ & $\begin{array}{c}\text { Cluster } \\
4 \\
\mathrm{n}=52\end{array}$ & $\begin{array}{c}\text { Cluster } \\
5 \\
\mathrm{n}=83 \\
\end{array}$ & $\begin{array}{c}\text { Cluster } \\
6 \\
\mathrm{n}=26\end{array}$ & Skalierung \\
\hline $\begin{array}{l}\text { Auch im Tagesgeschäft wird die } \\
\text { langfristige Strategie immer im Auge } \\
\text { behalten }(\mathrm{p}=0,106)\end{array}$ & $\begin{array}{c}1,71 \\
(0,588)\end{array}$ & $\begin{array}{c}2,06 \\
(0,712)\end{array}$ & $\begin{array}{c}2,18 \\
(0,786)\end{array}$ & $\begin{array}{c}1,96 \\
(0,755)\end{array}$ & $\begin{array}{c}2,10 \\
(0,690)\end{array}$ & $\begin{array}{c}1,81 \\
(0,634)\end{array}$ & $\begin{array}{l}\text { stimme vollständig zu } \\
=1 \text {, lehne vollständig } \\
\mathrm{ab}=5\end{array}$ \\
\hline $\begin{array}{l}\text { Es werden klare Ziele festgelegt, die } \\
\text { bis zu einem bestimmten Zeitpunkt zu } \\
\text { erreichen sind }(\mathbf{p}=\mathbf{0 , 0 0 7})\end{array}$ & $\begin{array}{c}2,18 \\
(0,951)\end{array}$ & $\begin{array}{c}2,43 \\
(0,747)\end{array}$ & $\begin{array}{c}2,63 \\
(1,024)\end{array}$ & $\begin{array}{c}2,52 \\
(1,091)\end{array}$ & $\begin{array}{c}2,86 \\
(0,962)\end{array}$ & $\begin{array}{c}2,15 \\
(0,834)\end{array}$ & $\begin{array}{l}\text { stimme vollständig zu } \\
=1 \text {, lehne vollständig } \\
a b=5\end{array}$ \\
\hline $\begin{array}{l}\text { Geschäftsentwicklung wird in vorher } \\
\text { festgelegten Planungsterminen } \\
\text { regelmäßig überprüft }(\mathbf{p = 0 , 0 0 2})\end{array}$ & $\begin{array}{c}2,12 \\
(0,993)\end{array}$ & $\begin{array}{c}2,49 \\
(0,750)\end{array}$ & $\begin{array}{c}2,64 \\
(0,879)\end{array}$ & $\begin{array}{c}2,46 \\
(1,054)\end{array}$ & $\begin{array}{c}2,61 \\
(0,732)\end{array}$ & $\begin{array}{c}1,88 \\
(0,766)\end{array}$ & $\begin{array}{l}\text { stimme vollständig zu } \\
=1 \text {, lehne vollständig } \\
\mathrm{ab}=5\end{array}$ \\
\hline $\begin{array}{l}\text { Die Strategie und die Ziele werden } \\
\text { regelmäßig an alle Führungskräfte } \\
\text { und Mitarbeiter kommuniziert } \\
(\mathbf{p = 0 , 0 0 4 )}\end{array}$ & $\begin{array}{c}2,00 \\
(1,033)\end{array}$ & $\begin{array}{c}2,28 \\
(0,863)\end{array}$ & $\begin{array}{c}2,37 \\
(0,817)\end{array}$ & $\begin{array}{c}2,29 \\
(0,707)\end{array}$ & $\begin{array}{c}2,60 \\
(0,781)\end{array}$ & $\begin{array}{c}1,92 \\
(0,688)\end{array}$ & $\begin{array}{l}\text { stimme vollständig zu } \\
=1 \text {, lehne vollständig } \\
\mathrm{ab}=5\end{array}$ \\
\hline $\begin{array}{l}\text { Eine konsequente Weiterbildung } \\
\text { unserer Mitarbeiter durch externe und } \\
\text { interne Stellen ist bei uns Standard } \\
(\mathbf{p = 0 , 0 2 0})\end{array}$ & $\begin{array}{c}2,41 \\
(0,939)\end{array}$ & $\begin{array}{c}2,47 \\
(0,823)\end{array}$ & $\begin{array}{c}2,79 \\
(0,914)\end{array}$ & $\begin{array}{c}2,63 \\
(0,859)\end{array}$ & $\begin{array}{c}2,82 \\
(0,855)\end{array}$ & $\begin{array}{c}2,23 \\
(0,765)\end{array}$ & $\begin{array}{l}\text { stimme vollständig zu } \\
=1 \text {, lehne vollständig } \\
\mathrm{ab}=5\end{array}$ \\
\hline $\begin{array}{l}\text { Unser Unternehmen ist in } \\
\text { verschiedene Abteilungen gegliedert } \\
(\mathbf{p}<\mathbf{0 , 0 0 1})\end{array}$ & $\begin{array}{c}2,59 \\
(1,228)\end{array}$ & $\begin{array}{c}3,30 \\
(1,049)\end{array}$ & $\begin{array}{c}3,37 \\
(1,024)\end{array}$ & $\begin{array}{c}3,18 \\
(1,137)\end{array}$ & $\begin{array}{c}3,72 \\
(1,028)\end{array}$ & $\begin{array}{c}2,19 \\
(0,981)\end{array}$ & $\begin{array}{l}\text { stimme vollständig zu } \\
=1 \text {, lehne vollständig } \\
\mathrm{ab}=5\end{array}$ \\
\hline $\begin{array}{l}\text { Unser Management ist im Vergleich } \\
\text { zum Branchendurchschnitt über- } \\
\text { durchschnittlich innovativ und } \\
\text { erfolgreich }(\mathbf{p}=\mathbf{0 , 0 0 3})\end{array}$ & $\begin{array}{c}2,50 \\
(0,894)\end{array}$ & $\begin{array}{c}2,45 \\
(0,798)\end{array}$ & $\begin{array}{c}2,77 \\
(0,937)\end{array}$ & $\begin{array}{c}2,81 \\
(0,711)\end{array}$ & $\begin{array}{c}2,76 \\
(0,675)\end{array}$ & $\begin{array}{c}2,16 \\
(0,746)\end{array}$ & $\begin{array}{l}\text { stimme vollständig zu } \\
=1 \text {, lehne vollständig } \\
\mathrm{ab}=5\end{array}$ \\
\hline $\begin{array}{l}\text { Bei der strategischen } \\
\text { Unternehmensplanung unterstützen } \\
\text { uns regelmäßig externe Berater } \\
(\mathrm{p}=0,317)\end{array}$ & $\begin{array}{c}3,06 \\
(1,435)\end{array}$ & $\begin{array}{c}3,02 \\
(1,009)\end{array}$ & $\begin{array}{c}3,21 \\
(1,036)\end{array}$ & $\begin{array}{c}3,24 \\
(1,188)\end{array}$ & $\begin{array}{c}3,45 \\
(1,033)\end{array}$ & $\begin{array}{c}3,12 \\
(1,107)\end{array}$ & $\begin{array}{l}\text { stimme vollständig zu } \\
=1 \text {, lehne vollständig } \\
a b=5\end{array}$ \\
\hline
\end{tabular}

a: Für die Cluster sind zuerst die Mittelwerte angegeben; die Standardabweichungen folgen in Klammern unter jedem Mittelwert.

Tabelle 24: Vergleich der Strategieformulierung und -implementierung

Interessant ist in diesem Zusammenhang auch, dass sich bei der strategischen Unternehmensplanung tendenziell eher die Brauereien durch Berater unterstützen lassen, die ihr Management im Branchendurchschnitt als deutlich besser einschätzen und bei denen wichtige Elemente des strategischen Managements bereits eine breite Anwendung finden.

Zusammenfassend kann festgehalten werden, dass sich hinsichtlich der Strategieformulierung und -implementierung in Bezug auf die folgenden Merkmale 
- Festlegung klarer Ziele,

- Überprüfung der Geschäftsentwicklung in vorher festgelegten Planungsterminen,

- Kommunikation der Strategie und der Ziele an alle Mitarbeiter,

- Konsequente Weiterbildung der Mitarbeiter,

- Gliederung des Unternehmens in verschieden Abteillungen sowie

- der Einschätzung der Managementqualität

stark signifikante Unterschiede zwischen den strategischen Gruppen zeigen.

\subsubsection{STRATEGISCHE GRUPPEN UND ERFOLG}

Nachdem die Erfolgslage der deutschen Brauereien bereits im Kapitel 4.2.3 näher beschrieben wurde, gilt es nachfolgend $\mathrm{zu}$ prüfen, ob sich die identifizierten strategischen Gruppen durch unterschiedliche Erfolge auszeichnen. Ausgehend von der Hypothese 3 (vgl. Kapitel 4.1.1) werden dazu zunächst die Variablen aufgezeigt, mit welchen der Unternehmenserfolg in der empirischen Analyse abgefragt wurde. Im Anschluss daran werden diese Merkmale mittels einer Varianzanalyse auf signifikante Gruppenunterschiede untersucht.

\subsubsection{Operationalisierung der Erfolgsvariablen}

Die Erfolgsvariablen wurden in der empirischen Analyse in zwei Schritten abgefragt. Im ersten Schritt wurden die Brauereien nach der ungefähren prozentualen Gesamtveränderung der nachfolgenden Erfolgsgrößen im Zeitraum 2002 bis 2004 für ihr Unternehmen befragt:

- Gesamtgetränkeausstoß,

- Umsatz,

- Gewinn,

- Return on Investment.

Bei diesen üblichen Größen kann davon ausgegangen werden, dass sie den Befragten für ihr Unternehmen vorliegen und die Fragen somit ohne viel Aufwand zu beantworten sind. Im Anschluss daran folgte eine Selbsteinschätzung der befragten Brauereien zum Erfolg ihres Unternehmens im Vergleich zum Branchendurchschnitt in den nachfolgenden Bereichen: 
- Produktivität,

- Durchschnittliche Rentabilität,

- Finanzkraft.

Diese zweistufige Vorgehensweise hat den Vorteil, dass eventuelle Fehleinschätzungen im Vergleich zum Branchendurchschnitt z. T. aufgedeckt werden können.

Darüber hinaus wurde nach dem durchschnittlichen Return on Investment in den letzten Jahren gefragt. Da diese Frage nicht von einem ausreichend großen Anteil der befragten Brauereien beantwortet wurde, wird sie nicht in die weitere Analyse aufgenommen.

\subsubsection{Erfolgsanalyse der strategischen Gruppen}

Die Ergebnisse der Analyse der Gruppenunterschiede in Bezug auf die prozentuale Veränderung der oben aufgezeigten Erfolgsgrößen in den Jahren 2002 bis 2004 zeigt die Tabelle 25. Dabei wird deutlich, dass diesbezüglich bei allen vier Erfolgsvariablen signifikante Unterschiede zwischen den strategischen Gruppen bestehen. Betrachtet man nun die Veränderung des Erfolgs im Einzelnen, dann fällt auf, dass das Cluster 1 bei nahezu allen an dieser Stelle untersuchten Erfolgsvariablen - die Ausnahmen bildet der Gesamtgetränkeausstoß - am besten abschneidet.

\begin{tabular}{|c|c|c|c|c|c|c|c|}
\hline $\begin{array}{l}\text { Veränderung der nachfolgenden } \\
\text { Erfolgsgrößen in den Jahren } 2002 \text { bis } \\
2004\end{array}$ & $\begin{array}{c}\text { Cluster } \\
1 \\
\mathrm{n}=17\end{array}$ & $\begin{array}{c}\text { Cluster } \\
2 \\
\mathrm{n}=55\end{array}$ & $\begin{array}{c}\text { Cluster } \\
3 \\
\mathrm{n}=48\end{array}$ & $\begin{array}{c}\text { Cluster } \\
4 \\
\mathrm{n}=52\end{array}$ & $\begin{array}{c}\text { Cluster } \\
5 \\
\mathrm{n}=83\end{array}$ & $\begin{array}{c}\text { Cluster } \\
6 \\
\mathrm{n}=26\end{array}$ & Skalierung \\
\hline Gesamtgetränkeausstoß $(\mathbf{p}=\mathbf{0 , 0 1 9})$ & $\begin{array}{c}4,47 \\
(1,407)\end{array}$ & $\begin{array}{c}4,06 \\
(1,754)\end{array}$ & $\begin{array}{c}3,47 \\
(1,866)\end{array}$ & $\begin{array}{c}4,31 \\
(1,853)\end{array}$ & $\begin{array}{c}4,60 \\
(1,693)\end{array}$ & $\begin{array}{c}4,56 \\
(1,850)\end{array}$ & $\begin{array}{l}3=\text { bis } 5 \% \text { Rückgang } \\
4=\text { gleich bleibend } \\
5=\text { bis } 5 \% \text { Steigerung }\end{array}$ \\
\hline Umsatz (p=0,008) & $\begin{array}{c}5,00 \\
(1,519)\end{array}$ & $\begin{array}{c}4,20 \\
(1,685)\end{array}$ & $\begin{array}{c}3,57 \\
(1,889)\end{array}$ & $\begin{array}{c}4,24 \\
(1,797)\end{array}$ & $\begin{array}{c}4,77 \\
(1,643)\end{array}$ & $\begin{array}{c}4,54 \\
(1,668)\end{array}$ & $\begin{array}{l}3=\text { bis } 5 \% \text { Rückgang } \\
4=\text { gleich bleibend } \\
5=\text { bis } 5 \% \text { Steigerung }\end{array}$ \\
\hline Gewinn $(\mathbf{p}=\mathbf{0 , 0 0 2})$ & $\begin{array}{c}5,50 \\
(1,401)\end{array}$ & $\begin{array}{c}4,30 \\
(1,502)\end{array}$ & $\begin{array}{c}3,64 \\
(1,665)\end{array}$ & $\begin{array}{c}4,35 \\
(1,604)\end{array}$ & $\begin{array}{c}4,62 \\
(1,468)\end{array}$ & $\begin{array}{c}4,63 \\
(1,583)\end{array}$ & $\begin{array}{l}3=\text { bis } 5 \% \text { Rückgang } \\
4=\text { gleich bleibend } \\
5=\text { bis } 5 \% \text { Steigerung }\end{array}$ \\
\hline Return on Investment $(\mathbf{p}=\mathbf{0 , 0 0 2})$ & $\begin{array}{c}5,54 \\
(1,450)\end{array}$ & $\begin{array}{c}4,13 \\
(1,439)\end{array}$ & $\begin{array}{c}3,41 \\
(1,570)\end{array}$ & $\begin{array}{c}4,21 \\
(1,663)\end{array}$ & $\begin{array}{c}4,35 \\
(1,246)\end{array}$ & $\begin{array}{c}4,39 \\
(1,720)\end{array}$ & $\begin{array}{l}3=\text { bis } 5 \% \text { Rückgang } \\
4=\text { gleich bleibend } \\
5=\text { bis } 5 \% \text { Steigerung }\end{array}$ \\
\hline
\end{tabular}

a: Für die Cluster sind zuerst die Mittelwerte angegeben; die Standardabweichungen folgen in Klammern unter jedem Mittelwert.

Tabelle 25: Veränderung des Unternehmenserfolgs in den Jahren 2002 bis 2004

Das Gegenteil dazu bildet das Cluster 3. Die Brauereien in dieser Gruppe weisen bei allen betrachteten Erfolgsgrößen die schlechtesten Resultate auf. Insgesamt konnten die Unternehmen im Cluster 1, im Cluster 5 sowie im Cluster 6 ihren Erfolg im 
betrachteten Zeitraum überdurchschnittlich stark verbessern, wohingegen die Brauereien in den übrigen Clustern tendenziell eine unterdurchschnittliche Erfolgsentwicklung zu verzeichnen hatten.

Die Tabelle 26 zeigt, inwieweit gruppenspezifische Unterschiede in Bezug auf die Einschätzung des Erfolgs in Relation zum Branchendurchschnitt bestehen. Mit der Rentabilität und der Finanzkraft weisen zwei der drei untersuchten Erfolgsvariablen dabei ein statistisch signifikantes Ergebnis auf.

In Bezug auf die Produktivität im Branchendurchschnitt ergibt sich kein signifikantes Ergebnis; es sind jedoch tendenzielle Unterschiede zu erkennen. So wird diese von den Brauereien im Cluster 6 als deutlich besser als beim Durchschnitt der gesamten Stichprobe eingeschätzt. Die Brauereien im Cluster 3 und im Cluster 4 erachten ihre Produktivität hingegen als unterdurchschnittlich.

\begin{tabular}{|c|c|c|c|c|c|c|c|}
\hline $\begin{array}{l}\text { Erfolg in Relation zum } \\
\text { Branchendurchschnitt im Bereich.... }\end{array}$ & $\begin{array}{c}\text { Cluster } \\
1 \\
\mathrm{n}=17 \\
\end{array}$ & $\begin{array}{c}\text { Cluster } \\
2 \\
\mathrm{n}=55\end{array}$ & $\begin{array}{c}\text { Cluster } \\
3 \\
n=48 \\
\end{array}$ & $\begin{array}{c}\text { Cluster } \\
4 \\
n=52\end{array}$ & $\begin{array}{c}\begin{array}{c}\text { Cluster } \\
5 \\
n=83\end{array} \\
\end{array}$ & $\begin{array}{c}\begin{array}{c}\text { Cluster } \\
6 \\
n=26\end{array} \\
\end{array}$ & Skalierung \\
\hline Produktivität $(\mathrm{p}=0,230)$ & $\begin{array}{c}3,00 \\
(0,961)\end{array}$ & $\begin{array}{c}3,00 \\
(1,020)\end{array}$ & $\begin{array}{c}2,84 \\
(0,796)\end{array}$ & $\begin{array}{c}2,86 \\
(1,080)\end{array}$ & $\begin{array}{c}3,01 \\
(0,905)\end{array}$ & $\begin{array}{c}3,42 \\
(0,881)\end{array}$ & $\begin{array}{l}1=\text { deutlich niedriger } \\
5=\text { deutlich höher }\end{array}$ \\
\hline Rentabilität $(\mathbf{p}=\mathbf{0 , 0 0 6})$ & $\begin{array}{c}3,86 \\
(0,949)\end{array}$ & $\begin{array}{c}3,10 \\
(1,118)\end{array}$ & $\begin{array}{c}2,78 \\
(0,795)\end{array}$ & $\begin{array}{c}3,02 \\
(1,078)\end{array}$ & $\begin{array}{c}3,13 \\
(0,963)\end{array}$ & $\begin{array}{c}3,50 \\
(1,103)\end{array}$ & $\begin{array}{l}1=\text { deutlich niedriger } \\
5=\text { deutlich höher }\end{array}$ \\
\hline Finanzkraft $(\mathbf{p}=\mathbf{0 , 0 0 4})$ & $\begin{array}{c}3,86 \\
(0,949)\end{array}$ & $\begin{array}{c}2,88 \\
(1,081)\end{array}$ & $\begin{array}{c}2,64 \\
(1,143)\end{array}$ & $\begin{array}{c}2,94 \\
(1,038)\end{array}$ & $\begin{array}{c}3,08 \\
(0,990)\end{array}$ & $\begin{array}{c}3,29 \\
(1,083)\end{array}$ & $\begin{array}{l}1=\text { deutlich niedriger } \\
5=\text { deutlich höher }\end{array}$ \\
\hline
\end{tabular}

a: Für die Cluster sind zuerst die Mittelwerte angegeben; die Standardabweichungen folgen in Klammern unter jedem Mittelwert.

Tabelle 26: Erfolg in Relation zum Branchendurchschnitt

Mit Blick auf die Rentabilität verzeichnen nach eigener Einschätzung die Brauereien des Cluster 1 den größten Erfolg, gefolgt vom Cluster 6 und vom Cluster 5. Die Unternehmen des Clusters 3 schätzen sich wiederum am schlechtesten ein. Auch die Brauereien im Cluster 4 halten ihre Rentabilität für unterdurchschnittlich, wohingegen die Einschätzung des Clusters 2 etwa dem des Gesamtmittels entspricht.

Bei der Untersuchung der Finanzkraft ergibt sich ein sehr ähnliches Bild. Diese wird von den gleichen Clustern in der gleichen Reihenfolge als überdurchschnittlich eingestuft wie bei der Frage zur Rentabilität. Ebenso schätzen sich die Brauereien des 
Clusters 3 erneut am schlechtesten ein. Auffällig ist jedoch, dass die Brauereien des Clusters 2 ihre Finanzkraft auf einem unterhalb des Branchendurchschnitts liegenden Niveaus noch niedriger einschätzen als die Unternehmen der Gruppe 4.

Zusammenfassend kann festgestellt werden, dass hinsichtlich der Veränderung der folgenden Erfolgsgrößen

- Gesamtgetränkeausstoß,

- Umsatz,

- Gewinn sowie

- Return on Investment

signifikante Unterschiede zwischen den strategischen Gruppen bestehen. Auch bei der Untersuchung der Einschätzung des Erfolgs im Vergleich zum Branchendurchschnitt zeigen sich signifikante Gruppenunterschiede in den Bereichen

- Rentabilität und

- Finanzkraft.

Die Ausführungen zur Untersuchung des Erfolgs erlauben es in Bezug auf die Hypothese 3 das folgende Ergebnis zu formulieren:

Aufgrund der ermittelten Ergebnisse kann die Hypothese 3 bestätigt werden. Die Zugehörigkeit $\mathrm{zu}$ verschiedenen strategischen Gruppen erklärt einen Teil der Erfolgsunterschiede zwischen den Brauereien. 


\section{Schlussfolgerungen und Implikationen für die Brauwirtschaft}

\subsection{Zusammenfassung der Untersuchungsergebnisse}

Die Zielsetzung der vorliegenden Arbeit bestand darin zu untersuchen, welchen Beitrag das Konzept der strategischen Gruppen zur Analyse der deutschen Brauwirtschaft leisten kann. Auf der Grundlage einer empirischen Untersuchung in der Braubranche wurden strategische Gruppen ermittelt und deren Besonderheiten aufgezeigt. Ergänzend wurde den Fragen nachgegangen, inwieweit sich Unterschiede im Erfolg sowie der Wahrnehmung der Branchensituation zwischen den Gruppen erkennen lassen. Im Folgenden werden zunächst die wesentlichen Ergebnisse der Studie in Bezug auf die allgemeine Branchensituation sowie das strategische Management in komprimierter Form dargelegt. Im Anschluss daran erfolgt eine zusammenfassende Darstellung der Resultate zu den ermittelten strategischen Gruppen.

Im ersten Kapitel wurden entsprechend den Forschungszielen der Arbeit zunächst die theoretischen Grundlagen erläutert, der Forschungsstand im Bereich der strategischen Gruppen aufgezeigt sowie der sich daraus ergebende Forschungsbedarf abgeleitet. Den eigentlichen Ausgangspunkt der Untersuchung bildete eine erweiterte Branchenstrukturanalyse der deutschen Brauwirtschaft. Dabei wurde deutlich, dass sich die Branche seit mehr als einem Jahrzehnt in einer tiefen Krise befindet Ursächlich dafür sind u.a. veränderte Verbrauchergewohnheiten, erhebliche Überkapazitäten, Marktanteilsgewinne von Handelsmarken und Discountern, neue Beschaffungsstrategien des Handels, zunehmende Branchenkonzentration sowie der Markteintritt ausländischer Wettbewerber.

Die Ergebnisse der empirischen Untersuchung zur Branchensituation und zum strategischen Management in der Brauwirtschaft zeigen, dass nach Einschätzung der befragten Brauereien der von den Konkurrenten ausgehende Wettbewerbsdruck und die Macht des Handels die dominierenden Triebkräfte des Wettbewerbs sind. Danach folgen die Bedrohung durch Substitutionsprodukte und die Angst vor neuen Wettbewerbern im eigenen Kernabsatzgebiet. Die Verhandlungsstärke der Lieferanten wird hingegen im Mittel vergleichsweise gering eingeschätzt. Insgesamt wird die Wettbewerbsintensität im deutschen Biermarkt von den meisten Brauereien als sehr 
hoch wahrgenommen. Dennoch schätzen etwa ein Drittel der befragten Unternehmen ihre Wettbewerbsstärke höher ein als die der Hauptkonkurrenten.

Mit Blick auf die Unternehmensstrategien in der deutschen Brauwirtschaft zeigt sich, dass sich zunächst stark vereinfacht zwei Typen von Brauereien unterscheiden lassen. Zum einen die expandierenden Spezialisten, die überwiegend aus großen Brauereien bestehen und welche auf Grundlage ihrer eigenen Braukapazitäten eine Ausdehnung des Absatzes anstreben. Typisch für diese Brauereien sind externes Wachstum durch Übernahmen sowie eine im Mittel stärkere Bedeutung der Internationalisierung. Vor dem Hintergrund eines überdurchschnittlich großen Absatzgebietes sind der Getränkefachgroßhandel und der LEH die Hauptvertriebswege. Zum anderen bilden die regionalen Diversifizierer die zweite Art typischer Brauereien, die im Durchschnitt erheblich kleiner und eher gastronomieorientiert sind. Das Leistungsspektrum dieser Brauereien ist wesentlich stärker diversifiziert, so dass der Handel mit zugekauften Produkten, alkoholfreie Getränke sowie weitere Produkte und Dienstleistungen eine wichtige Rolle spielen. Die Brauwirtschaft holt mit dieser Polarisierung der Unternehmensstrategien eine Entwicklung nach, die in vielen anderen Teilen der Getränke- und Lebensmittelbranche als „Ausdünnung der Mitte“ bekannt geworden ist. Entweder Unternehmen sind groß genug, um mit den national und ggf. sogar internationalen Kostenführern bzw. Markenartiklern mithalten zu können, oder sie sind klein genug, um sich regional eine überlebensfähige Nische zu suchen. Dazwischen bleibt kaum Platz; die Abnahme der Zahl der mittelgroßen Konsumbierbrauereien belegt dies eindrucksvoll.

Bezüglich der Gestaltung der wettbewerbsstrategischen Positionierung belegen die empirischen Ergebnisse, dass sowohl die Differenzierung als auch die Kostenführerschaft eine wichtige Rolle in der deutschen Brauwirtschaft einnehmen, und dieses sogar oft im selben Unternehmen. So ist die Braubranche in weiten Teilen durch eine starke Markenorientierung geprägt. Andererseits variieren die Marketingausgaben zwischen den Brauereien erheblich und ein großer Teil der Brauer bedient zumindest teilweise oder sogar überwiegend den Preiseinstiegsbereich. Dem zunehmenden Wettbewerbsdruck wird somit nicht nur mit einer Differenzierung des Angebots, sondern auch mit Preis- bzw. Kostenführerschaftsstrategien begegnet. Bei einem Vergleich der in der Befragung deutlich gewordenen Einschätzung der Imagestärke der 
eigenen Produkte und der im Handel erzielten Preise drängt sich jedoch der Eindruck auf, dass ein Teil der befragten Brauereien ihre Marken überbewerten. So schätzen immerhin etwa $72 \%$ der Brauereien ihr Markenimage als mindestens so stark wie das des Hauptkonkurrenten ein. Zugleich reicht die Hauptmarke bei vielen Brauereien aber nicht, um die Kapazitäten auszulasten; es müssen auch Zweit- oder Handelsmarken produziert werden. Daher muss durchaus kritisch hinterfragt werden, ob es sich in diesen Fällen wirklich um Marken, die dem Konsumenten eine Botschaft vermitteln, oder um bloße Markierungen der Produkte handelt. Neben der Orientierung auf Marken spielen auch Innovationen eine wichtige Rolle in der deutschen Brauwirtschaft. Abweichend von der Selbsteinschätzung vieler Brauereien handelt es sich jedoch in vielen Fällen nicht um wirkliche Innovationen, sondern lediglich um Nachahmungen erfolgreicher Pioniere. Wenn vor diesem Hintergrund die eigene Innovationskraft nur von $25 \%$ der Befragten niedriger als im Branchendurchschnitt eingeschätzt wird, so scheinen sich auch in dieser Hinsicht viele Unternehmen zu überschätzen. Eine auch vom Konsumenten wahrgenommene Differenzierung des Produktangebots durch Innovationen dürfte tatsächlich nur wenigen Brauereien gelungen sein. Die Frage nach den durchschnittlichen Gesamtkosten wird von den Brauereien sehr unterschiedlich beantwortet; im Durchschnitt liegen die Kosten nach Einschätzung der Unternehmen bei $63 € / \mathrm{hl}$.

Im Hinblick auf die Kooperationsstrategien deutscher Brauereien wurde deutlich, dass sich immerhin etwa $50 \%$ der befragten Brauereien an einer horizontalen Kooperation beteiligt haben oder dieses planen. Bei den größeren Brauereien liegt dieser Anteil sogar noch deutlich höher. Die Potentiale für eine Zusammenarbeit mit Unternehmen im vor oder nachgelagerten Bereich werden deutlich geringer eingeschätzt als die Möglichkeiten horizontaler Kooperationen. So sind auch nur etwa $17 \%$ der befragten Unternehmen an vertikalen Kooperationen beteiligt. Am ehesten sind nach Auskunft der Befragten Kooperationen mit Absatzmittlern, im Besonderen dem Getränkefachgroßhandel, von Interesse. Insgesamt zeigen die Ergebnisse, dass die Kooperationsbereitschaft vieler deutscher Brauereien nicht so gering ist, wie häufig angenommen wird.

Die Analyse der Erfolgslage deutscher Brauereien ergab, dass sich sowohl bei der Entwicklung von Absatz und Gewinn als auch bei der Einschätzung des eigenen Erfolgs 
in Relation zum Branchendurchschnitt in allen Größenklassen sowohl erfolgreiche als auch weniger erfolgreiche Brauereien finden lassen. Somit wird klar, dass die Zugehörigkeit zu einer bestimmten Größenklasse keineswegs per se über den Erfolg einer Brauerei entscheidet. Vielmehr scheint es in hohem Maße auf die individuellen Managementfähigkeiten und die jeweilige strategische Positionierung anzukommen.

Mit Blick auf die strategischen Planungsprozesse zeigt sich abschließend, dass gerade bei vielen kleineren Brauereien wichtige Elemente des strategischen Managements keine Anwendung finden. Bei der Mehrzahl der größeren Brauereien ist strategische Unternehmensplanung hingegen ein fester und durch wichtige Elemente des strategischen Managements gestützter Prozess.

Nach der allgemeinen Beschreibung der Branchensituation sowie des strategischen Managements in der deutschen Brauwirtschaft bildete die Identifizierung strategischer Gruppen den Kern der empirischen Untersuchung. Mit Hilfe einer Faktoranalyse gelang es, die Vielzahl der Strategievariablen auf einige wenige, wichtige Einflussfaktoren zurückzuführen. Auf dieser Grundlage wurden anhand des Verfahrens der hierarchischen Clusteranalyse strategische Gruppen in der untersuchten Branche ermittelt. Insgesamt konnten sechs verschiedene strategische Gruppen identifiziert werden:

- Cluster 1: „Weizenbier-Markendifferenzierer“ $(\mathrm{n}=17)$,

- Cluster 2: „Lokale Sortiments-Innovatoren“ $(n=55)$,

- Cluster 3: „Lokale handelsorientierte Vollsortimenter“ $(n=48)$,

- Cluster 4: „Lokale Pilsspezialisten“ ( $\mathrm{n}=52)$,

- Cluster 5: „Lokale Konsumbiervollsortimenter“ ( $\mathrm{n}=83)$,

- Cluster 6: „Große eigensortimentorientierte Innovatoren“ (n=26).

Die ermittelten strategischen Gruppen unterscheiden sich durch eine Reihe von Mobilitätsbarrieren signifikant voneinander. So konnte festgestellt werden, dass die Größe und Reichweite, die Eigenbierorientierung sowie die Konsumbierorientierung das größte diskriminatorische Potential besitzen. Außerdem haben die Differenzierung durch Innovation und Marke sowie die Bereitschaft für neue Wege einen wesentlichen Einfluss auf die Strategiewahl. Bei den aufgezeigten Faktoren handelt es sich um 
Mobilitätsbarrieren, da sie dem Wechsel von einer strategischen Gruppe in andere entgegenstehen. Mit anderen Worten: Die diesbezüglichen strategischen Entscheidungen, die von den Brauereien einer bestimmten strategischen Gruppe getroffen werden, können nicht ohne Weiteres von anderen Brauereien imitiert werden. So ist es für die Brauereien z.B. nicht so einfach möglich, den häufig lukrativeren Eigenbieranteil gegenüber fremden Marken im Sortiment zu erhöhen, ohne dass diese erhebliche Kosten auf sich nehmen müssten oder viel Zeit benötigten. Mit Blick auf eine hohe Konsumbierorientierung ist es für die Unternehmen schwer, diese zu Gunsten einer stärkeren Markenorientierung zu überwinden, da häufig die Investitionen in den langfristigen Aufbau einer Marke gescheut werden oder aber ein Defizit an MarketingKnow-how zu beobachten ist. Die übrigen gruppenbildenden Faktoren wirken in ähnlicher Weise als Mobilitätsbarrieren.

Hinsichtlich der Wahrnehmung der Branchensituation konnte festgestellt werden, dass sich keine signifikanten Unterschiede zwischen den strategischen Gruppen erkennen lassen; vielmehr wird die Situation der deutschen Brauwirtschaft über alle Cluster insgesamt recht ähnlich wahrgenommen. Wohl aber bestehen deutliche Unterschiede in der Einschätzung wichtiger Merkmale der eigenen Wettbewerbsposition zwischen den ermittelten Gruppen.

Schließlich wurde der Frage nachgegangen, inwieweit die Zugehörigkeit zu einer strategischen Gruppe erfolgsrelevant ist. Die Operationalisierung des Unternehmenserfolgs erfolgte in zwei Stufen anhand einer Kombination verschiedener Bewertungsmaßstäbe. Berücksichtigung fanden u. a. die prozentualen Gesamtveränderungen des Gesamtgetränkeausstoßes, Umsatzes und Gewinns im Zeitraum von 2002 bis 2004 sowie eine Selbsteinschätzung der befragten Brauereien im Hinblick auf ihre Produktivität, Rentabilität und Finanzkraft im Vergleich zum Branchendurchschnitt. Die identifizierten Cluster wurden mittels einer Varianzanalyse auf signifikante Erfolgsunterschiede untersucht. Dabei wurde deutlich, dass hinsichtlich der prozentualen Veränderung der oben aufgezeigten Erfolgsgrößen in den Jahren 2002 bis 2004 signifikante Unterschiede bestehen. Ferner zeigte sich, dass das Cluster 1 („Weizenbier-Markendifferenzierer") bei drei von vier Erfolgsvariablen - die Ausnahme bildet der Gesamtgetränkeausstoß - am besten abschneidet. Das Gegenstück dazu bildet Cluster 3 („Lokale handelsorientierte Vollsortimenter"). Die Brauereien 
dieser Gruppe weisen durchgängig die schlechtesten Resultate auf. Über alle strategischen Gruppen konnten die Unternehmen in den Clustern 1, 5 und 6 ihren Erfolg im betrachteten Zeitraum überdurchschnittlich verbessern, wohingegen die übrigen Gruppen tendenziell eine unterdurchschnittliche Erfolgsentwicklung aufweisen. Die Selbsteinschätzung von Rentabilität und Finanzkraft durch die Befragten bestätigt dieses Ergebnis. Bei beiden Größen bestehen signifikante Unterschiede zwischen den Gruppen, und in beiden Fällen stufen sich die Unternehmen des Clusters 1 am besten und die des Clusters 3 am schlechtesten ein.

Die aufgezeigten Ergebnisse überraschen besonders im Hinblick auf das Cluster 5 „Lokale Konsumbiervollsortimenter“ $(n=83)$. Hier wäre vor dem Hintergrund des unterdurchschnittlichen Einstiegspreises für die Hauptbiermarke sowie der geringen Bedeutung der Strategieformulierung und -implementierung anzunehmen gewesen, dass der Unternehmenserfolg sich ebenfalls unterdurchschnittlich entwickelt hätte. Allerdings scheinen eine starke regionale Verankerung, welche in Form einer überdurchschnittlichen Kapazitätsauslastung und eines hohen Anteils der Hauptbiermarke (deren Preis zwar unter dem Mittel der Befragten liegt, aber immerhin noch über $10 €$ für die 20 x 0 ,5l-Kiste beträgt) sowie im Branchendurchschnitt geringerer Kosten deutlich wird, diese Mängel mehr als auszugleichen. Auch das Ergebnis in Bezug auf das Cluster 2 überrascht. Diesbezüglich hätte man mit Blick auf den hohen Einstiegspreis der Hauptbiermarke davon ausgehen können, dass sich der Unternehmenserfolg überdurchschnittlich entwickelt hätte. Hier scheinen der geringe Anteil der Hauptbiermarke sowie im Branchendurchschnitt deutlich höhere Kosten die Hauptgründe für die gegenteilige Entwicklung zu sein.

Insgesamt zeigen die empirischen Befunde, dass das Konzept der strategischen Gruppen ein geeigneter konzeptioneller Rahmen für die Analyse der deutschen Brauwirtschaft ist. Darüber hinaus fanden die Annahmen dieses Konzeptes - Existenz einer i.d.R. begrenzten Zahl strategischer Gruppen sowie von Erfolgsunterschieden zwischen den Unternehmen verschiedener Gruppen - in der untersuchten Branche Bestätigung. Die Hypothese einer unterschiedlichen Wahrnehmung der Branchensituation zwischen den ermittelten Gruppen wurde hingegen verworfen. 


\subsection{Implikationen für die deutschen Brauer}

Auf Grundlage der aufgezeigten Ergebnisse werden im Folgenden einige allgemeine Handlungsempfehlungen für die Gestaltung des strategischen Managements in der deutschen Brauwirtschaft abgeleitet, da eine konkrete Strategieentwicklung nur unter Berücksichtigung der individuellen Unternehmenssituation erfolgen kann.

Dazu ist zunächst festzuhalten, dass die Ergebnisse der vorliegenden Arbeit den deutschen Brauern eine Orientierungshilfe im Wettbewerb bieten, da sie eine Bestimmung der eigenen Position und ggf. einen Vergleich mit erfolgreicheren Wettbewerbern ermöglichen. Zugleich wird deutlich, an welchen „Stellschrauben gedreht" werden muss, um bei Bedarf strategische Lücken zu schließen und die zwischen den Gruppen bestehenden Mobilitätsbarrieren möglichst zu überwinden. Aus dem ressourcenbasierten Ansatz im strategischen Management ist bekannt, dass aus der internen Ressourcenausstattung resultierende Mobilitätsbarrieren unterschiedlich hoch sein können. Das Hauptaugenmerk sollten die Unternehmen bevorzugt auf jene Barrieren richten, die für sie am ehesten überwindbar erscheinen, wie z. B. die Stärkung der Bereitschaft für neue Wege.

In der Literatur zum strategischen Management ist unbestritten, dass zwei Arten von Unternehmen im Markt erfolgreich sein können: eindeutige Kostenführer, die jeden Preiskampf erfolgreich mitgehen können, und Unternehmen mit einem klar differenzierten Produktangebot. Klare Differenzierung bedeutet dabei, Produkte anzubieten, die sich in wesentlichen kaufrelevanten Merkmalen - Marke, Innovationsgrad, regionale Herkunft, Spezialitäten usw. - für den Verbraucher erkennbar von konkurrierenden Angeboten abheben. $\mathrm{Ob}$ diese Forderung von vielen deutschen Brauereien aktuell erfüllt wird, muss angesichts der aufgezeigten Ergebnisse dieser Arbeit bezweifelt werden. Daher ist den deutschen Brauern anzuraten, ihre strategische Positionierung diesbezüglich zu überprüfen und ggf. anzupassen.

Mit Blick auf die Preispolitik ist die Gefahr groß, dass niedrigpreisige Angebote auf Dauer höher positionierte Marken beschädigen. Insofern muss durchaus kritisch hinterfragt werden, ob und wie es auf Dauer in einem Unternehmen gelingen kann, dem nach eigener Einschätzung schärfer gewordenen Wettbewerb nicht ausschließlich mit einer Differenzierung des Angebots, sondern auch mit Preisführerschaftsstrategien zu 
begegnen. Eine klare Trennung nicht nur im äußeren Erscheinungsbild und ggf. im werblichen Auftritt, sondern insbesondere auch im Vertrieb sind aller Erfahrung nach unabdingbar, um Verwässerungseffekten vorzubeugen. Darüber hinaus muss die Kraft aufgebracht werden, auch einmal „Nein“ zu sagen, wenn der Groß- und Einzelhandel mit Blick auf die gleichzeitige Produktion von Handels- und Preiseinstiegsmarken Preiszugeständnisse bei den Hauptmarken verlangen. Insgesamt sind u. a. auch vor dem Hintergrund der steigenden Kosten (z. B. Energie) Preissteigerungen aus Sicht des Autors unausweichlich, um die Rentabilität in der deutschen Brauwirtschaft zu steigern bzw. zu sichern. Inwieweit diese jedoch erfolgreich durchgeführt werden können, hängt in hohem Maße von der Preisdisziplin der gesamten Branche ab.

In Bezug auf Kooperationen in der deutschen Brauwirtschaft wird einerseits zwar deutlich, dass viele Brauer diesen aufgeschlossen gegenüberstehen. Andererseits wird aber auch ersichtlich, dass ein großer Teil der Brauereien beim Thema Kooperationen weiterhin abseits steht. Diese Brauereien sollten ihre Position überprüfen, um keine Chancen zur Verbesserung der Wettbewerbssituation zu verschenken. Insbesondere vertikale Kooperationen zur Sicherung der Absatzwege, z. B. mit dem Handel oder der Gastronomie, sollten neben den horizontalen Kooperationen vermehrt in den Fokus der Betrachtung rücken.

Schließlich sollten die Brauereien, bei denen die strategische Unternehmensplanung noch kein fester und durch wichtige Elemente des strategischen Managements unterstützter Prozess ist, ihre Planungsverfahren überprüfen. Eine Etablierung strategischer Planungsprozesse sollte vorgenommen werden, da ein strategisches Vorgehen sowie eine systematische Umsetzung der Unternehmensziele elementare Grundlagen für eine langfristige Sicherung des Unternehmenserfolgs darstellen.

\subsection{Ansätze für die weitere Forschung}

Auf der Grundlage der vorliegenden Untersuchungsergebnisse werden im Folgenden einige Ansatzpunkte für die weitere Forschung aufgezeigt. Ein Bereich der zukünftigen Untersuchungen sollte darauf ausgerichtet sein, näher zu analysieren, welche Prozesse die Zugehörigkeit einzelner Unternehmen $\mathrm{zu}$ bestimmten strategischen Gruppen erklären und warum Unternehmen in ihren Gruppen selbst dann verharren, wenn andere Gruppen erfolgreicher sind und die Mobilitätsbarrieren nicht unüberwindbar erscheinen. 
Eine mögliche Erklärung für dieses Verhalten könnte der neo-institutionalistische Ansatz der Managementlehre bieten. Das zentrale Element dieses Ansatzes besteht in der Analyse der strukturellen Einbindung von Organisationen in ihre Umwelt. Dabei wird angenommen, dass Unternehmen in einem institutionellen Kontext gefangen sind, der sich prägend auf ihre Struktur und ihre Verhaltensweisen auswirkt und sie zu Verhaltensweisen veranlasst, die im Gegensatz zum streng betriebswirtschaftlichen Denken stehen können (DiMaggio/Powell, 1991: S. 63ff.). Strategische Konformität, so die Grundannahme, ist in der Praxis häufig weiter verbreitet als es die Betriebswirtschaftslehre traditionell annimmt (WALGENBACH, 2001: S. 319ff.). Auch in der deutschen Brauwirtschaft gibt es deutliche Ansätze für Imitationsprozesse, z. B. mit Blick auf die Kopien der „Goldbiere“. Daher könnte eine Unterscheidung in Kernunternehmen, welche genau die Gruppenstrategie verfolgen, und Nebenunternehmen, die eine eigenständigere Strategie verfolgen, sowie Vorreiterunternehmen innerhalb einer strategischen Gruppe erweiterte Einblicke in Bezug auf das strategische Management in der deutschen Brauwirtschaft schaffen.

Darüber hinaus könnte eine begrenzte Ausstattung mit wettbewerbsrelevanten Ressourcen ausschlaggebend für das eingangs dieses Kapitels beschriebene Verhalten der Unternehmen sein (LEASK/PARNELL, 2005: S. 458ff.). Der ressourcenbasierte Ansatz geht von der grundlegenden Annahme aus, dass unternehmensinterne Ressourcen von zentraler Bedeutung für die Wettbewerbsposition eines Unternehmens sind. Im Mittelpunkt steht die Identifizierung derjenigen Ressourcen, welche einem Unternehmen einen Wettbewerbsvorteil verschaffen. Erst in einem zweiten Schritt wird der Frage nachgegangen, auf welchen Märkten sich diese Ressourcen erfolgreich einsetzen lassen (THEUVSEN, 2001: S. 1644). Der strategische Denkprozess wird folglich umgekehrt. Das Konzept der strategischen Gruppen und der ressourcenbasierte Ansatz repräsentieren somit zwar unterschiedliche, aber sich ergänzende Sichtweisen in Bezug auf die Entstehung von Unternehmens- und Wettbewerbsstrategien (LEASK/PARNELL, 2005: S. 458ff.). Eine über die in der vorliegenden Arbeit hinausgehende Untersuchung der Bedeutung von Ressourcen als Mobilitätsbarrieren könnte daher zu einem besseren Verständnis der Prozesse innerhalb der Unternehmen bei der Bildung von Wettbewerbsvorteilen beitragen. 
Ein weiterer Erklärungsansatz für das Verharren in bestimmten strategischen Gruppen könnte auf Pfadabhängigkeiten der Unternehmen zurückzuführen sein. So hat die jüngere Pfadforschung gezeigt, dass das Festhalten an ehemals erfolgreichen, zwischenzeitlich jedoch obsolet gewordenen Erfolgsrezepten eine Ursache für den Niedergang von Unternehmen sein kann (MILLER, 1993: S. 116ff.). Auch diesbezüglich sollte eine weiterführende Forschung mit Blick auf die Brauwirtschaft in Erwägung gezogen werden.

Außerdem sollte ein weitergehender Ansatz im Rahmen zukünftiger Forschungsarbeiten darin bestehen, die Entwicklung im Zeitablauf zu untersuchen. Dabei scheint es erstrebenswert, die Unterschiede im Unternehmenserfolg sowie evtl. Gruppenwechsel in den Mittelpunkt der dynamischen Betrachtung $\mathrm{zu}$ stellen, um zusätzliche Erkenntnisse in Bezug auf Erfolg versprechende Strategien in der deutschen Brauwirtschaft zu gewinnen.

Die Forschungstätigkeit der vorliegenden Arbeit war ausschließlich auf die deutsche Brauwirtschaft ausgerichtet. Weitere Forschungsüberlegungen könnten darin bestehen $\mathrm{zu}$ analysieren, inwieweit die Ergebnisse auch in der Brauwirtschaft anderer Länder sowie in anderen Branchen Bestätigung finden. Eine Übertragung der Untersuchung auf vergleichbare Branchen (z. B. Spirituosen, Mineralwasser) ist daher ebenfalls anzuregen. 


\section{Literaturverzeichnis}

Ansoff, H.I. (1965): Corporate Strategy: An Analytical Approach to Business Policy for Growth and Expansion, New York.

Axel Springer AG (2006): Trend Topics - Bier, Axel Springer AG - Marketing Anzeigen, Hamburg, Www.mediapilot.de/images/20060206/0055.pdf; Zugriffsdatum: 23.02.2006.

Backhaus et. al. (2000): Multivariate Analyseverfahren, 9. Auflage, Berlin.

Balz, M. (2005): Branchen im Blickpunkt: Anmerkungen und Daten zum Weltbiermarkt, in: ifo Schnelldienst, Heft 17, S. 34-36.

Bain, J.S. (1959): Industrial Organization, New York.

Baldauf, A. (1996): Strategische Gruppen in der Bauindustrie, Wiesbaden.

Barney, J.B. (2001): Gaining and Sustaining Competitive Advantage, 2. Auflage, Upper Saddle River, NJ.

Barth, J. \& Sohn (1999/2000ff.): Der Barth Bericht Hopfen, verschiedene Jahrgänge, Nürnberg.

Bartölke, I.-U. (2000): Strategische Gruppen und Strategieforschung: Ansätze für eine dynamische Wettbewerbsbetrachtung, Wiesbaden.

Bastian, C.T. et al. (1999): The Niche Market Potential: The Case of the U.S. Craft Brewing Industry, in: Review of Agricultural Economics, 21. Jg., S. 552-562.

Baudisch, A.F. (2005): Evolving Heterogeneity of Consumer Behavior: Panel Analysis of Preference Formation in the German Footwear Market 1980-91, Vortrag im Rahmen des 4. European Meeting on Applied Evolutionary Economics, Utrecht, 19.-21.05.2005.

Bauer, H.H. (1991): Unternehmensstrategie und Strategische Gruppen, in: Kliestner, K.-P. / Schmidt, R. (Hrsg.): Unternehmensdynamik - Horst Albach zum 60. Geburtstag, Wiesbaden, S. 389-416.

Becker, F.G./Fallgatter, M.J. (2005): Strategische Unternehmungsführung: Eine Einführung, 2. Auflage, Berlin.

Berger, U./Bernhard-Mehlich, I. (2001): Die Verhaltenswissenschaftliche Entscheidungstheorie, in: Kieser, A. (Hrsg.): Organisationstheorien, 4. Auflage, Stuttgart u.a., S. 133-168.

Berekoven, L./Eckert, W./Ellenrieder, P. (1999): Marktforschung: Methodische Grundlagen und praktische Anwendung, 8. Auflage, Wiesbaden. 
Berentzen, J.-B. (1983): Wettbewerb, Kooperation und Konzentration in der Brauwirtschaft - Eine empirische Analyse im nordwestdeutschen Raum, Münster.

Bester, H. (2003): Theorie der Industrieökonomik, Berlin.

Bleymüller, J./Gehlert, G. (1989): Konzentrationsmessung, in: Wirtschaftswissenschaftliches Studium, 18. Jg., S. 378-384.

Bleymüller, J./Gehlert, G./Gülicher, H. (2000): Statistik für Wirtschaftswissenschaftler, 12. Auflage, München.

Birnbaum, G. (2004): Konsumklima und Getränkebudget, in: Brauindustrie, 89. Jg., Heft 2, S. 8.

Birnbaum, G. (2005a): Preis- und Promotionsaktivitäten im Biermarkt, in: Brauindustrie, 90. Jg., Heft 10, S. 8.

Birnbaum, G. (2005b): Discounter und PET - eine Erfolgsstory?, in: Brauindustrie, 90. Jg., Heft 4, S. 8.

Birnbaum, G. (2005c): Strukturveränderungen im Biermarkt - Entwicklungen und Trends aus Sicht der Konsumforschung, Vortrag im Rahmen des 8. Deutschen IIR Bierkongress vom 16.-17.02.2005 in Köln.

Birnbaum, G. (2006): Ausreichend Potential für höherpreisige Biere!, in: Brauindustrie, 91. Jg., Heft 3, S. 8.

BMVEL (2005): Statistisches Jahrbuch über Ernährung, Landwirtschaft und Forsten der Bundesrepublik Deutschland 2005, Bundesministerium für Verbraucherschutz, Ernährung und Landwirtschaft (Hrsg.), 49. Jg., Münster.

Bodenstein, G./ Spiller, A. (1998): Marketing: Strategien, Instrumente und Organisation, Landsberg a. Lech.

Böbel, I. (1984): Wettbewerb und Infrastruktur, Berlin.

Bösken-Diebels, P. (1989): Die Gastronomie als Absatzweg der deutschen Brauwirtschaft, Frankfurt a. M.

Brauerei-Adressbuch (2004/05): Brauerei Adressbuch: Brauereien, Mälzereien, Fachschulen, Verbände und Unternehmensberater in Deutschland, 23. Auflage, Nürnberg.

Brunken, A. (1990): Wettbewerbsstrategien in der mittelständischen Brauwirtschaft, Nürnberg.

Bühl, A./Zöfel, P. (2000): SPSS Version 10: Einführung in die moderne Datenanalyse unter Windows, 7. Auflage, München.

Bühler, S./Jaeger, F. (2002): Einführung in die Industrieökonomik, Berlin. 
Bundeskartellamt (2001): Das Untersagungskriterium in der Fusionskontrolle Marktbeherrschende Stellung versus Substantial Lessening of Competition? Diskussionspapier für die Sitzung des Arbeitskreises Kartellrecht am 08.-09. Oktober 2001, Bonn.

Bundesministerium für Umwelt, Naturschutz und Reaktorsicherheit (2004): Fragen und Antworten zum „Dosenpfand“, www.bmu.de; Zugriffsdatum: 14.04.2004.

Bundesministerium für Wirtschaft und Technologie (2006): Die wirtschaftliche Lage in der Bundesrepublik Deutschland, Monatsbericht 01/02-2006, Bundesministerium für Wirtschaft und Technologie (Hrsg.), Berlin.

Bundesverband des Deutschen Getränkefachgroßhandels e.V. (2006): Die wirtschaftliche Bedeutung - $\quad$ Strukturdaten, www.bvgetraenkefachgrosshandel.de; Zugriffsdatum: 18.03.2006.

Bundesverband des Deutschen Lebensmitteleinzelhandels e. V. (2006): Zahlen \& Fakten / Situation, www.lebensmitteleinzelhandel-bvl.de; Zugriffsdatum: 22.03.2006.

Burr, W. et al. (2004): Unternehmensführung: Strategien der Gestaltung und des Wachstums von Unternehmen, WiSo-Kurzlehrbücher - Reihe Betriebswirtschaft, München.

Canadean (2004): The Beer Service, Annual Report - 2004 Cycle, Global Beer Report.

Canadean (2005): The Beer Service, Annual Report - 2005 Cycle, Germany.

Caves, R.E. (1977): American Industry: Structure, Conduct, Performance, Englewood Cliffs, NJ.

Caves, R.E./Porter, M.E. (1977): From Entry Barriers to Mobility Barriers: Conjectural Decisions and Contrived Deterrence to New Competition, in: Quarterly Journal of Economics, 91. Jg., S. 241-261.

Caves, R.E./Ghemawat, P. (1992): Identifying Mobility Barriers, in: Strategic Management Journal, 13. Jg., Nr. 1, S. 1-12.

CMA (2006): Deutsches Bier, www.cma.de; Zugriffsdatum: 29.03.2006.

Commission (2003): Commission Recommendation of 6 May 2003 Concerning the Definition of Micro, Small and Medium-Sized Enterprises. 2003/361/EC.

Cool, K./Schendel, D.E. (1987): Strategic Group Formation and Performance: The Case of U.S. Pharmaceutical Industry, 1963-1982, in: Management Science, 33. Jg., Nr. 9, S. 1102-1124.

Corsten, H. (1998): Von generischen zu hybriden Wettbewerbsstrategien, in: Das Wirtschaftsstudium, 27. Jg., S. 1434-1440. 
Credit Suisse/First Boston (2003): The German Beer Industry, London

Day, D.L./Levin, A.Y./Li, H. (1995): Strategic Leaders or Strategic Groups: A Longitudinal Data Envelopment Analysis of the U.S. Brewing Industry, in: European Journal of Operational Research, 80. Jg., Nr. 3, S. 619-638.

Deutscher Brauer-Bund (2001): 23. Statistischer Bericht 2001, Bonn.

Deutscher Brauer-Bund (2003a): 24. Statistischer Bericht 2003, Bonn.

Deutscher Brauer-Bund (2003b): Perspektiven im Biermarkt der Zukunft, Deutscher Brauer-Bund e.V./Rölfs MC Partner (Hrsg.), Bonn.

Deutscher Brauer-Bund (2005a): Jahrespressekonferenz, Rede des Präsidenten des Deutschen Brauer-Bundes, Dr. Richard Weber, 23.06.2005, Freiburg, www.brauer-bund.de; Zugriffsdatum: 14.10.2005.

Deutscher Brauer-Bund (2005b): Statistik-Daten und Fakten aus der Brauwirtschaft, www.brauer-bund.de; Zugriffsdatum: 14.10.2005.

Deutscher Brauer-Bund (2005c): Taschenbroschüre 2004, Berlin.

Deutscher Brauer-Bund (2006): Statistik-Daten und Fakten aus der Brauwirtschaft, www.brauer-bund.de; Zugriffsdatum: 30.03.2006.

Deutscher Hopfenwirtschaftsverband e. V. (2006): 60 Jahre Hopfenwirtschaft in Deutschland, www.hopfen.de; Zugriffsdatum: 12.04.2006.

Deutscher Hotel- und Gaststättenverband (2006): Daten und Fakten, www.dehoga.de; Zugriffsdatum: 23.03.2006.

Dietz, D. (2005): Biermix mischt den Markt auf, in: Lebensmittel Zeitung, Nr. 43 vom 28.10.2005, S. 42.

DiMaggio, P.J./Powell, W.W. (1991): The iron cage revisited: Institutional isomorphism and collective rationality in organizational fields, in: Powell, W.W./DiMaggio, P.J (Hrsg.): The New Institutionalism in Organizational Analysis, Chicago, S. 63-82 (überarbeitete Version des gleichlautenden Beitrags in: American Sociological Review, 48. Jg., 1983, S. 147-160).

Drescher, K./Weiss, C. (2001): Bestimmungsfaktoren der regionalen Marktstruktur im deutschen Lebensmitteleinzelhandel, in: Konjunkturpolitik, Bd. 47, Nr. 2, S. 163-180.

Ernst \& Young (2003): Brauereien 2015: Wege aus der Krise. Ein Szenario über die weitere Entwicklung im deutschen Biermarkt, Frankfurt a. M.

Ebbertz, L. (1992): Die Konzentration im Braugewerbe der Bundesrepublik Deutschland, Frankfurt a. M. 
Ebneth/Theuvsen (2005): Konzentrationstempo, Internationalisierung und Erfolg europäischer Braukonzerne, in: Brauindustrie, 90. Jg., Heft 9, S. 44-49.

Ebneth (2005): Main Player und Profitabilität in der Weltbrauindustrie, unveröffentlichtes Arbeitspapier, Universität Göttingen.

Effen, I. (1995): Erfolgsfaktoren strategischer Gruppen - dargestellt am Beispiel des Bucheinzelhandels, Saarbrücken.

Fischer, J. (1989): Brauereiverkäufe: Eine empirische Untersuchung zu einem Spezialproblem der Unternehmensbewertung, München.

Fontaine, J. (2003): Logistik in der Getränkebranche, in: Henke, M./Schulte, A.T. (Hrsg.): Aktuelle Herausforderungen für das Management in der deutschen Brauwirtschaft. Wolfgang Lück zum 65. Geburtstag, Krefeld, S. 91-104.

Frese, E. (1987): Unternehmungsführung, Landsberg a. Lech.

Friedrichs, J. (1990): Methoden der empirischen Sozialforschung, 14. Auflage, Opladen.

Gabler (1997): Gablers Wirtschaftslexikon, 14. Auflage, Wiesbaden.

Gaitanides, M./Westphal, J. (1991): Strategische Gruppen und Unternehmenserfolg: Ergebnisse einer empirischen Studie, in: Zeitschrift für Planung, 2. Jg., S. 247265.

Gehrckens, H.M. (1999): Getränkekonzepte für heute und morgen - Positionierung ist entscheidend, in: Brauwelt, 139. Jg., Heft 28/29, S. 1319.

Glaum, M. et al. (2003): Wachstumsstrategien internationaler Unternehmungen: 10 Thesen, in: Zeitschrift für betriebswirtschaftliche Forschung, 29. Jg., S. 823-846.

Goehler, A.W. (1993): Der Erfolg großer Familienunternehmen im fortgeschrittenen Marktlebenszyklus - dargestellt am Beispiel der deutschen Brauwirtschaft, Dissertation, St. Gallen.

Göttgens, O. (1996): Erfolgsfaktoren in stagnierenden und schrumpfenden Märkten, Wiesbaden.

Hahn, P. (2002a): Kooperation und Wettbewerb in der Brauwirtschaft, in: Brauwelt, 142. Jg., Heft 9/10, S. 298-306.

Hahn, P. (2002b): Mittelständische Kooperationen - Strategiealternativen für die Brauwirtschaft, in: Brauwelt, 142. Jg., Heft 20/21, S. 705-708.

Hahn, P. (2004): Steuererhöhung statt Subventionsabbau, in: Brauwelt, 144. Jg., Heft 11, S. 270-271. 
Hatten, K.J./Schendel, D.E. (1977): Heterogenity Within an Industry: Firm Conduct in the U.S. Brewing Industry, in: Journal of Industrial Economics, 26. Jg., S. 97113.

Hatten, K.J./Schendel, D.E/Cooper, A.C. (1978): A Strategic Model of U.S. Brewing Industry: 1952-1971, in: Academy of Management Journal, 21. Jg., S. 592-610.

Hatten, K.J./Hatten, M.L. (1985): Some Empirical Insights for Strategic Marketers: The Case of Beer, in: Strategic Marketing and Management, S. 275-292.

Hatten, K.J./Hatten, M.L. (1987): Strategic Groups, Asymmetrical Mobility Barriers and Contestability, in: Strategic Management Journal, 8. Jg., S. 329-342.

Heimig, D. (2003): Gut für das Image, in: Lebensmittel Zeitung, Nr. 18 vom 2.05.2003, S. 54.

Henke, M. (2002): Strategische Kooperationen im Mittelstand: Potentiale des Coopetition-Konzeptes für kleine und mittlere Unternehmen, München.

Henze, A. (1994): Marktforschung - Grundlage für Marketing und Marktpolitik, Stuttgart.

Herrmann, A./Homburg, C. (1999): Marktforschung: Ziele, Vorgehensweisen und Methoden, in: Herrmann, A./Homburg, C. (Hrsg.), Marktforschung: Methoden, Anwendungen, Praxisbeispiele, Wiesbaden, S. 19-32.

Hermannsen, H. (2005): Aktueller Wochenend-Kommentar vom 11. Juni 2005 zur Situation der Mälzer, in: Agrarzeitung Ernährungsdienst, 11.06.2005, S. 3.

Hesse, J. (2002): Kooperative Markenführung, in: Brauwelt, 142. Jg., Heft 50, S. 19141916.

Heyse, K.U. (2002a): Wunsch nach Luxus steigt, in: Brauwelt, 142. Jg., Heft 12, S. 392.

Heyse, K.U. (2002b): Mehr Kooperation für die deutsche Brauwirtschaft, in: Brauwelt, 142. Jg., Heft 15, S. 480.

Heyse, K.U. (2003): Der deutsche Biermarkt: 1993 und 2002, in: Henke, M./Schulte, A.T. (Hrsg.): Aktuelle Herausforderungen für das Management in der deutschen Brauwirtschaft. Wolfgang Lück zum 65. Geburtstag, Krefeld, S. 21-35.

Hiedemann, K. (2002): Umkämpfte Nische, in: Food Service, Nr. 5 vom 14.05.2002, S. 40 .

Hofbauer, A. (2005): Auf zum Olymp: Export-Kooperation als Erfolgs-Strategie, in: Brauindustrie, 90. Jg., Heft 11, S. 3.

Hofer, C.W./Schendel, D. (1978): Strategy Formulation: Analytical Concepts, St. Paul. 
Hofnagel, D. (2005): Aktueller Wochenend-Kommentar vom 17. Dezember 2005 zum Braugerstenanbau, in: Agrarzeitung Ernährungsdienst, 17.12.2005, S. 3.

Hofnagel, J.R./Kortmann, F. (1999): Strategische Allianzen in der deutschen Brauwirtschaft unter besonderer Berücksichtigung der Logistik, Dortmund.

Holler, D./Kahlen, C. (2003): Aktive Routenplaner, in: Lebensmittel Zeitung Spezial, Nr. 2 vom 06.06.2003, S. 26.

Homburg, C. (1992): Wettbewerbsanalyse mit dem Konzept der strategischen Gruppen: Mit einem Beispiel aus dem Maschinenbau, in: Marktforschung \& Management, 5. Jg., S. 83-87.

Homburg, C./Sütterlin, S. (1992): Strategische Gruppen: Ein Survey, in: Zeitschrift für Betriebswirtschaft, 62. Jg., Wiesbaden, S. 635-662.

Hoppe, H.C./Lehmann-Grube, U. (2001): Second-Mover Advantages in Dynamic Quality Competition, in: Journal of Economics \& Management Strategy, 10. Jg., S. 419-433.

Houthoofd, N./Heene, A. (1997): Strategic Groups as Subsets of Strategic Scope Groups in the Belgian Brewing Industry, in: Strategic Management Journal, 18. Jg., S. 653- 666.

Huber, H.W. (2002): Erhaltung der Wettbewerbsfähigkeit in der mittelständischen Brauwirtschaft - Ergebnisse einer empirischen Untersuchung, in: Brauwelt, 142. Jg., Heft 8, S. 244-247.

Hüttner, M. (1999): Grundzüge der Marktforschung, 6. Auflage, München.

Hungenberg, H. (2001): Strategisches Management in Unternehmen: Ziele - Prozesse - Verfahren, 2. Auflage, Wiesbaden.

Hunt, M. (1972): Competition in the Major Home Appliance Industry, 1960 - 1970, Dissertation, Harvard University.

Information Resources GmbH (2005): Bier in Deutschland: Absatz im LEH und Getränkeabholmärkten nach Vertriebslinie und Gebindeart -Mehrweg - 1999 bis 2004, in: Verlagsgruppe Deutscher Fachverlag (Hrsg.), Branchendossier Bier 2005. Ausgewählte Fachartikel mit Markt- und Firmeninformationen zur Warengruppe Bier, Frankfurt a. M.

Institut für Wirtschaftsforschung (2005a): Branchen spezial Getränkefachgroßhandel, in: Bundesverband der Deutschen Volksbanken und Raiffeisenbanken (Hrsg.), Text und Redaktion: ifo Institut für Wirtschaftsforschung, Bericht Nr. 9, August 2005, Wiesbaden.

Institut für Wirtschaftsforschung (2005b): Pressemitteilung: ifo Konjunkturprognose 2006: Deutsche Wirtschaft im Aufschwung, 19.12.2006, München. 
Jacoby, A. (2005): Not macht erfinderisch, in: Lebensmittel Zeitung, Nr. 15 vom 15.04.2005, S. 52.

Kahlen, C. (2002): Grossisten unter Druck, in: Lebensmittel Zeitung, Nr. 30 vom 26.07.2003, S. 33.

Kallmeyer, U. (2002): Rede von Ulrich Kallmeyer, Vorstandvorsitzender der Radeberger Gruppe AG, Bilanzpressekonferenz der Radeberger Gruppe AG 2002 am 26.05.2002.

Karopka, H.-J. et al. (2004): Die Bierdose bekommt Konkurrenz, in: Lebensmittel Zeitung, Nr. 2 vom 09.01.2004, S. 42.

Kelch, K. (2003): Brauindustrie in Zahlen: Aktivitäten ausländischer Brauereien in der Bundesrepublik Deutschland, in: Brauindustrie, 88. Jg., Heft 11, S. 40-42.

Kelch, K. (2004a): Brauindustrie in Zahlen: Die Veränderung in den Brauereigruppen und großen Privatbrauereien über 2 Mio. hl im Jahr 2003, in: Brauindustrie, 89. Jg., Heft 2, S. 44-45.

Kelch, K. (2004b): Ausländische Brauereien in Deutschland, in: Brauwelt, 144. Jg., Heft 48, S. 1608-1609.

Kelch, K. (2005a): Die Entwicklung der Fassbieranteile von 2002 bis 2004, in: Brauwelt, 145. Jg., Heft 36, S. 1150-1154.

Kelch, K. (2005b): Selbst hergestellter Bierausstoß von 108 Brauereien, in: Brauwelt, 145. Jg., Heft 37, S. 1222-1223.

Kelch, K. (2006): Die 34 größten Biermarken mit ihrem Inlandsabsatz, in: Brauwelt, 146. Jg., Heft 7, S. 196-197.

Kirchhoff, S. et al. (2003): Fragebogen: Datenbasis, Konstruktion, und Auswertung, 3. Auflage, Opladen.

Klemm-Bax, S. (2000): Erfolgsfaktoren: Ein unscharfer Modellansatz zur Bestimmung des Unternehmenserfolgs auf der Grundlage empirischer Daten, Dissertation, Paderborn.

Knieps, G. (2001): Wettbewerbsökonomie: Regulierungstheorie, Industrieökonomie, Wettbewerbspolitik, Berlin.

Kohlbrück, O. (2002): Brauer zapfen neue Kanäle an, in: Horizont, Nr. 24 vom 13.06.2002, S. 17.

Kohlbrück, O. (2003): Beck`s startet goldene Zeiten, in: Horizont, Nr. 7 vom 13.02.2003, S. 6 .

Kolbrück, O. (2005): Bierbrauer im Goldrausch, in: Horizont, Nr. 10 vom 10.03.2005, S. 17. 
Krost, H. (2004a): Pfand verbannt Einweg, in: Lebensmittel Zeitung, Nr. 1 vom 02.01.2004, S. 3.

Krost, H. (2004b): „Plastikbier“ hat noch Potenzial, in: Lebensmittel Zeitung, Nr. 2 vom 09.01.2004, S. 2.

Krüger, W. (2002): Auswirkungen des Internet auf Wertketten und Geschäftsmodelle, in: Frese, E./Stöber, H. (Hrsg.): E-Organisation: Strategische und organisatorische Herausforderungen des Internet, Wiesbaden, S. 63-89.

Kuhl. V. (1990): Erfolgreiches Bier-Marketing nach dem Urteil des EUGH zum Reinheitsgebot, Frankfurt a. M.

Kuttenkeuler, S.C. (2001): Entwicklungsprobleme deutscher Brauereien am Ende des 20. Jahrhunderts, Stuttgart.

Latz-Weber, H. (2003a): Bierfrust am Markt, in: Lebensmittel Zeitung, Nr. 18 vom 02.05.2003, S. 50 .

Latz-Weber, H. (2003b): Vielfalt als Antwort auf das Pflichtpfand, in: Lebensmittel Zeitung, Nr. 44 vom 31.10.2003, S. 37.

Latz-Weber, H. (2003c): Junge Biere im Trend, in: Lebensmittel Zeitung, Nr. 18 vom 02.05.2003, S. 50 .

Latz-Weber, H. (2003d): Turbulente Zeiten - Biermarkt: Ausrichtungen und Tendenzen, in: Brauindustrie, 88. Jg., Heft 11, S. 68-71.

Latz-Weber, H. (2004a): Braubranche in bierernster Lage, in: Lebensmittel Zeitung, Nr. 44 vom 29.10.2004, S. 42.

Latz- Weber, H. (2004b): Überleben in Kooperationen, in: Lebensmittel Zeitung, Nr. 10 vom 5.03.2004, S. 59.

Leask, G./Parnell, J.A. (2005): Integrating Strategic Groups and the Resource Based Perspective: Understanding the Competitive Process, in: European Management Journal, 23. Jg., Nr. 4, S. 458-470.

Lechner, G. (2003): Die Faszination der Menge, in: Die Welt - Bierreport 2003, S. 6061.

Lehn, J. et al. (1996): Lorenzkurve und Gini-Koeffizient zur statistischen Beschreibung von Konzentration, Darmstadt.

Lenzhofer, W. (2003): Im unternehmerischen Fokus: Der Gewinn oder „Die Rückkehr zu mehr Profitabilität", in: Henke, M./Schulte, A.T. (Hrsg.): Aktuelle Herausforderungen für das Management in der deutschen Brauwirtschaft. Wolfgang Lück zum 65. Geburtstag, Krefeld, S. 1-19.

Leuthel, M. (2001): Wie die Konsumavantgarde die Gläser füllt, in: Lebensmittel Zeitung, Nr. 48 vom 29.11.2001, S. 19. 
Ludin, D. (2001): Globalisierung als regionale Chance: Erfolgreiche und nachhaltige Strategieentwicklung für mittelständische Brauereien, Köln.

Lück, W./Henke, M. (2003): Coopetition - Kooperationsstrategie für den Mittelstand, in: Frankfurter Allgemeine Zeitung, Nr. 148 vom 30.06.2003, S. 22.

Macharzina, K. (2003): Unternehmensführung: Das internationale Managementwissen - Konzepte - Methoden - Praxis, 4. Auflage, Wiesbaden.

Marx, T. (1998): Internationale Marketingstrategien in der deutschen Brauwirtschaft, Frankfurt a. M.

Mason, E. (1949): The Current State of the Monopoly Problem in the U.S., in: Harvard Law Review, 62. Jg., S. 1265-1285.

Mau, M. (2000): Supply Chain Management - Realisierung von Wertschöpfungspotentialen durch ECR-Kooperationen zwischen mittelständischer Industrie und Handel im Lebensmittelsektor, Frankfurt a. M.

McGee, J. (1985): Strategic Groups: A Bridge Between Industry Structure and Strategic Management?, in: Thomas, H./Gardner, G. (Hrsg.):Strategic Marketing and Management, S. 293-313.

McGee, J./Thomas, H. (1986): Strategic Groups: Theory, Research and Taxonomy, in: Strategic Management Journal, 6. Jg., S. 141-160.

McLeay, F./Martin, S./Zwart, T. (1996): Farm Business Marketing Behaviour and Strategic Groups in Agriculture, in: Agribusiness, 12. Jg., S. 339-351.

Meissner, H.G./Gerber, S. (1980): Die Auslandsinvestition als Entscheidungsproblem, in: Betriebswirtschaftliche Forschung und Praxis, 32. Jg., S. 217-228.

Mewes, P. (2005): Erfrischend und nicht süß, in: Der Hotelier, Nr. 4 vom 18.06.2005, S. 58.

Miller, D. (1993): The Architecture of Simplicity, in: Academy of Management Review, 18. Jg., S. 116-138.

Minderlein, M. (1989): Markteintrittsbarrieren und Unternehmensstrategie Industrieökonomische Ansätze und eine Fallstudie zum Personal-ComputerMarkt, Wiesbaden.

Nagel, B. / Brüggelambert, G. (1991): Markt und Konzentration in der Brauwirtschaft, 3. Auflage, Kassel.

Niederhut-Bollmann, C. (2005): Tabellenband zum Forschungsprojekt: Strategische Gruppen in der deutschen Brauwirtschaft, Universität Göttingen. 
Niederhut-Bollmann, C./Theuvsen, L. (2006): Das Internet als Marketing- und Vertriebsinstrument: Eine empirische Untersuchung in der deutschen Brauwirtschaft, in: Wenkel, K.-O./ Wagner, P./ Morgenstern, M./Luzi, K./Eiermann, P. (Hrsg.): Land- und Ernährungswirtschaft im Wandel Aufgaben und Herausforderungen für die Agrar- und Umweltinformatik, Referate der 26. GIL Jahrestagung vom 06.-08. März 2006 in Potsdam, Bonn, S. 197-200.

Omlor, D. (2003): Ost-Westlicher Bierhahn, in: Die Welt - Bierreport 2003, S. 36-37.

Otto, K. (2001): Gesunder Mix gegen Durststrecke im Biermarkt, in: Media \& Marketing, Nr. 4 vom 01.04.2001, S. 18-24.

o. V. (1999): Alkoholische Getränke - Grundlagen zur Werbeplanung, Hamburg.

o. V. (2000a): Gastronomie schafft Trends, in: Brauwelt, 140. Jg., Heft 42/43, S. 1717.

o. V. (2000b): Trinkgewohnheiten, in: Brauwelt, 140. Jg., Heft 12, S. 456.

o. V. (2002a): Getränkegattungen und Alkoholkonsum in der EU, in: Brauwelt, 142. Jg., Heft 36/37, S. 1231-1232.

o. V. (2002b): Der Werbekuchen schrumpft, in: Brauwelt, 142. Jg., Heft 25, S. 845.

o. V. (2002c): Biere in der Szene, in: Brauwelt, 142. Jg., Heft 42/43, S. 1455.

o. V. (2002d): Aktuelle Themen des GFGH, in: Brauwelt, 142. Jg., Heft 29, S. 1003 1005 .

o. V. (2002e): Talfahrt der Gastronomie ungebremst, in: Brauwelt, 142. Jg., Heft 51/52, S. 1954-1955.

o. V. (2002f): Aktuelle Themen aus der Gastronomie, in: Brauwelt, 142. Jg., Heft 12, S. 408-409.

o. V. (2002g): AfG - Markt 2002: Trends und Highlights, in: Brauwelt, 142. Jg., Heft 51/52, S. 1953.

o. V. (2002h): Getränkegattungen und Alkoholkonsum in der EU, in: Brauwelt, 142. Jg., Heft 36/37, S. 1231-1232.

o. V. (2002i): Hopfenmarkt - Saison 2001, in: Brauwelt, 142. Jg., Heft 17, S. 593.

o. V. (2003a): Die Damen gehen von der „Fahne“, in: Die Welt - Bierreport 2003, S. 38-39.

o. V. (2003b): Seit zwanzig Jahren Öko-Bier, in: Die Welt - Bierreport 2003, S. 48.

o. V. (2003c): Rückblick auf 30 Jahre Lebensmitteleinzelhandel, in: Brauwelt, 143. Jg., Heft 49, S. 1676. 
o. V. (2004a): Quo vadis Deutscher Biermarkt?, in: Brauwelt, 144. Jg., Heft 51/52, S. 1722.

o. V. (2004b): Deutsche Brauereien produzieren 2003 weniger Bier, in: Brauwelt, Heft 4/5, S. 93.

o. V. (2004c): Biersteuererhöhung um 12 Prozent ist mittelstandsfeindlich, in: Brauwelt, 144. Jg., Heft 3, S. 51-52.

o. V. (2005a): Ein Weg zur Konsolidierung des deutschen Biermarktes, in: Brauwelt, 145. Jg., Heft 22, S. 678-680.

o. V. (2005b): Brauereien setzen auf Klarglas, in: Brauwelt, 145. Jg., Heft 51/52, S. 1636.

o. V. (2005c): Kleingebinde wachsen auch im Biermarkt, in: Brauwelt, 145. Jg., Heft 23/24, S. 706-707.

o. V. (2005d): Glas und Metall vereint, in: Verpackungs-Rundschau, 24.01.2005, http://www.verpackungsrundschau.de/archiv/news/2005/01/news_d.html; Zugriffsdatum: 29.03.2006.

o. V. (2005e): Dosenpfand - flächendeckende Regelung bis 1. Mai 2006?, in: Brauwelt, 145. Jg., Heft 34/35, S. 1076.

o. V. (2005f): Pfand: gilt von Samstag an, in: Lebensmittel Zeitung, 24.05.2005, www.lz-net.de; Zugriffsdatum: 02.04.2006.

o. V. (2005g): Novellierung der Verpackungsverordnung beschlossen, in: Brauwelt, 145. Jg., Heft 10, S. 256.

o. V. (2005h): Mehrwertsteuererhöhung ist das falsche Signal, in: Brauwelt, 145. Jg., Heft 31/32, S. 919.

o. V. (2005i): EU-Kommission fährt Bollwerke gegen Alkohol auf, in: Brauwelt, 145. Jg., Heft 15, S. 462-463.

o. V. (2006a): Absatz von Bier und Biermischgetränken 2001 bis 2005, in: Brauindustrie, 91. Jg., Heft 3, S. 7.

o. V. (2006b): Bierabsatz 2005 leicht rückläufig, in: Lebensmittel Zeitung, Nr. 5 vom 03.02.2006, S. 18 .

o. V. (2006c): Brauereigruppen und Privatbrauereien - Ausstoßentwicklung, in: Brauwelt, 146. Jg., Heft 10, S. 258-260.

o. V. (2006d): Die deutsche Malzindustrie 2006, in: Brauwelt, 146. Jg., Heft 17, S. 209210. 
o. V. (2006e): Convenience beflügelt den Packmittelmarkt - Fach Pack: Mehrwert durch Innovation, http://press.nuernbergmesse.de/fachpack/25.pm.2506.html; Zugriffsdatum: 29.03.2006.

o. V. (2006f): Deutschland wird zum Einwegland, in: Brauwelt, 146. Jg., Heft 4/5, S. 87.

o. V. (2006g): Ablehnung der geplanten Biersteuererhöhung, in: Brauwelt, 146. Jg., Heft 7, S. 169-170.

Patton, G.R. (1976): A Simultaneous Equation of corporate Strategy: The Case of the U:S Brewing Industry, Dissertation, Purdue Universität.

Peitsmeier, H. (2004): 60 Biermarken sollten es schon sein, in: Frankfurter Allgemeine Sonntagszeitung, Nr. 51 vom 19.12.2004, S. 33.

Piepelow, V. (1997): Die europäischen Linienfluggesellschaften im Wettbewerb: eine Analyse mittels des Konzepts der strategischen Gruppen, Frankfurt a. M.

Pimper, O. (1998): Das Konzept der strategischen Gruppen und seine Anwendung auf die Bankbranche, Frankfurt a. M.

Plato (2004): World Beer Report 2004, Plato Logic Limited, London.

Plato (2005): Country Draught Beer Reports - West Europe, Plato Logic Limited, London.

Porter, M.E. (1979): The Structure Within Industries and Companies Performance, in: Review of Economics and Statistics, 61. Jg., S. 214-227.

Porter, M.E. (1980): Competitive Strategy: Techniques for Analyzing Industries and Competitors, New York - London.

Porter, M.E. (1981): The Contributions of Industrial Organization to Strategic Management, in: Academy of Management Review, 6. Jg., S. 609-620.

Porter, M. E. (1985): Competitive Advantage: Creating and Sustaining Superior Performance, New York - London.

Porter, M.E. (1986): Wettbewerbsvorteile: Spitzenleistungen erreichen und behaupten, Frankfurt a. M.

Porter, M.E. (1995): Wettbewerbsstrategie: Methoden zur Analyse von Branchen und Konkurrenten, Frankfurt a. M.

Porter, M.E. (2001): Strategy and the Internet, in: Harvard Business Review, 79 Jg., S. 63-78.

Prahalad, C.K./Hamel, G. (1990): The Core Competence of the Corporation, in: Harvard Business Review, 68. Jg., S. 79-91. 
Pschorr, J. (2003): Positionierung von Markenbieren in schwierigen Zeiten, in: Henke, M./Schulte, A.T. (Hrsg.): Aktuelle Herausforderungen für das Management in der deutschen Brauwirtschaft. Wolfgang Lück zum 65. Geburtstag, Krefeld, S. 77-90.

Rehse, H.-P. (2004): Der landwirtschaftliche Jahresabschluss II, aid infodienst: Verbraucherschutz, Ernährung, Landwirtschaft e. V. (Hrsg.), Bonn.

Rolinck, B. (2002): Branchenkultur: Theoretische Grundlagen und eine empirische Untersuchung in der deutschen Brauereibranche, Dissertation, Berlin.

Rosbach, B. (2005): Sortimente - Bier, in: Lebensmittel Zeitung Spezial, Nr. 3 vom 30.09.2005, S. 44.

Rosenoe, A. (2005): A Four-Dimensional Product Innovativeness Typology: Introducing Seven New Product Project Types for the Study of Innovation Management. Working Paper No. 01-2005, Copenhagen Business School, Institute of Informatics.

Schendel, D./Patton, R. (1978): A Simultaneous Equation of Corporate Strategy, in: Management Science, 24. Jg., S. 1611-1621.

Scherer, F.M./Ross, D. (1990): Industrial Market Structure and Economic Performance, Boston.

Schmidt-Auerbach, M. (2003): Nationale Wackelkandidaten, in: Lebensmittel Zeitung Spezial, Nr. 2 vom 06.06.2003, S. 44.

Schönrock, D. (2003): Individualkästen bringen Handel Freud und Leid, in: Lebensmittel Zeitung, Nr. 44 vom 31.10.2003, S. 47.

Schulte, A. T. (1998): Internationalisierung der deutschen Brauwirtschaft. Notwendigkeit, Potentiale und Bereitschaft zur internationalen Markterweiterung, Krefeld.

Statistisches Bundesamt (2003a): Pressebroschüre zur Bevölkerung Deutschlands bis 2050 - Ergebnisse der 10. koordinierten Bevölkerungsvorausberechnung, Statistisches Bundesamt (Hrsg.), 06. Juni 2005, Berlin.

Statistisches Bundesamt (2003b): Statistisches Jahrbuch 2003 für die Bundesrepublik Deutschland, Wiesbaden.

Statistisches Bundesamt (2005): Haushaltstypen, www.destatis.de; Zugriffsdatum: 30.03.2006.

Stauder, T. (1995): Qualitätsmanagement im Kundenservice: Logistik, Finanzierung und Beratung im deutschen Biermarkt, Wiesbaden.

The Brewers of Europe (2003): The Brewers of Europe Statistics, www.brewersofeurope.org; Zugriffsdatum: 20.02.2006. 
Theuvsen, L. (2001): Kernkompetenzorientierte Unternehmensführung: Grundzüge und Bewertung, in: Das Wirtschaftsstudium, 30. Jg., S. 1644-1650.

Theuvsen, L. (2002): Lebensmittelvertrieb über das Internet. Chancen und Strategien kleiner und mittelständischer Hersteller, in: Zeitschrift für Agrarinformatik, 10. Jg., S. 41-50.

Theuvsen, L. (2003a): Selling Food on the Internet: Chances and Strategies of Small and Medium-sized Manufacturers, in: Harnos, Z. et al. (Hrsg.): Information Technology for a Better Agri-food Sector, Environment and Rural Living, Debrecen, S. 206-211.

Theuvsen, L. (2003b): Kooperationen in der Landwirtschaft - Formen, Wirkung und aktuelle Bedeutung, Diskussionsbeitrag 0303 des Instituts für Agrarökonomie der Universität Göttingen.

Theuvsen, L. (2005): The Prospects of Electronic Commerce: The Case of the Food Industry, in: Baier, D./Wernecke, K.-D. (Hrsg.): Innovations in Classification, Data Science, and Information Systems, Heidelberg - Berlin, S. 406-415.

Verstl, I. (2001): Mit Bier im Börsenfieber, in: NGZ - Der Hotelier, Nr. 3 vom 05.03.2001, S. 58 .

Verstl, I. (2005): Die Sache mit den Zahlen, in: Brauwelt, 145. Jg., Heft 7, S. 173.

Verstl, I. (2006): Des einen Freud ist des anderen Leid, in: Brauwelt, 146. Jg., Heft 4/5, S. 85-86.

Vossen, M. (2001): Brauer wollen Zugriff, in: Lebensmittel Zeitung, Nr. 42 vom 19.10.2001, S. 18 .

Vossen, M. (2002): Brauer hoffen auf neue Preisschwellen, in: Lebensmittel Zeitung, Nr. 3 vom 18.01.2002, S. 14.

Vossen, M. (2003a): Beck`s punktet mit „Gold“, in: Lebensmittel Zeitung, Nr. 41 vom 10.10.2003, S. 17.

Vossen, M. (2003b): Alcopops greifen weiter Biermix an, in: Lebensmittel Zeitung, Nr. 42 vom 17.10.2003, S. 58.

Vossen, M. (2003c): Waterloo für Einweg-Bierbrauer, in: Lebensmittel Zeitung, Nr. 29 vom 18.07.2003, S. 14.

Vossen, M. (2004): GFGH: Die neuen Verteiler, in: Lebensmittel Zeitung, Nr. 14 vom 02.04.2005, S. 44.

Vossen, M. (2005): Biermultis bedrängen deutsche Brauer, in: Lebensmittel Zeitung, Nr. 37 vom 16.09.2005, S. 12.

Vossen, M. (2006): Einweg heizt Systemwettbewerb an, in: Lebensmittel Zeitung, 9.02.2006, www.lz-net.de; Zugriffsdatum: 03.04.2006. 
Wagner, P.-O. (1997): Erfolgsfaktorenforschung für Finanzdienstleister im Electronic Commerce, in: Beiträge zur Marketingwissenschaft, Nr. 12, Universität Göttingen.

Walgenbach, P. (2001): Institutionalistische Ansätze der Organisationstheorie, in: Alfred Kieser (Hrsg.): Organisationstheorien, 4. Auflage, Stuttgart u.a., S. 319353.

Weick, K.E. (1979): The Social Psychology of Organizing. 2. Auflage, Reading, MA.

Weick, K.E. (1985): Der Prozess des Organisierens, Frankfurt a. M.

Weick, K.E. (2001): Drop Your Tools, in: Bardmann, T.M./Groth, T. (Hrsg.): Zirkuläre Positionen 3: Organisation, Management und Beratung, Wiesbaden, S. 123-138.

Wiechell, R. (2001): Kooperationen als strategische Option in der Braubranche, in: Brauwelt, 141. Jg., Heft 42, S. 1823-1827.

Wiese; F. (1993): Der Strukturwandel im deutschen Biermarkt. Eine Analyse unter besonderer Berücksichtigung des Konsumentenverhaltens und der Absatzpolitik der Brauereien, Dissertation, Köln.

Wilke, K. (2002): Schwieriges Feld, in: Handelsjournal, o. J., Nr. 2, S. 34-35.

Zentralverband der deutschen Werbewirtschaft (2005): Die werbestärksten Branchen in Deutschland 2004, schriftliche Auskunft vom 09.03.2006.

Zoll (2006): Die Biersteuer, www.zoll.de; Zugriffsdatum: 05.04.2006. 


\section{Anhang}

ANLAGE 1: FoRSCHUNGSSTAND IN DER BRAUWIRTSCHAFT ZUM KONZEPT STRATEGISCHER GRUPPEN

ANLAGE 2: EINBINDUNG ALLE ABGELEITETEN VARIABLEN IN DAS THEORETISCHE REFERENZMODELL

ANLAge 3: Muster des ANSChreibens AN DIE BRAUEREIEN . 212

ANLAGE 4: MUSTER DES REFERENZSCHREIBENS DER REGIONALEN MITGLIEDSVERBÄNDE DES DEUTSCHEN BRAUERBUNDES .

ANLAGE 5: MUSTER DES VERWENDETEN FragEBogeNS 215

ANHANG 6: TABELLENBAND ZUM FORSCHUNGSPROJEKT 231 


\begin{tabular}{|c|c|c|c|c|c|}
\hline $\begin{array}{c}\text { Autor/Jahr } \\
\text { Titel der } \\
\text { Veröffentlichung }\end{array}$ & Datenquellen & Ziel & $\begin{array}{c}\text { Kriterien der } \\
\text { Gruppenabgrenzung }\end{array}$ & $\begin{array}{l}\text { Verfahren zur } \\
\text { Gruppenbildung }\end{array}$ & $\begin{array}{c}\text { Ergebnisse } \\
\text { Gruppe/ } \\
\text { Erfolgsanalyse }\end{array}$ \\
\hline $\begin{array}{l}\text { Hatten/ } \\
\text { Schendel (1977) } \\
\text { Heterogeneity Within } \\
\text { an Industry: Firm } \\
\text { Conduct in the U.S. } \\
\text { Brewing Industry }\end{array}$ & $\begin{array}{l}13 \text { Unternehmen } \\
\text { der Brauindustrie in } \\
\text { den USA, 1952-71 }\end{array}$ & $\begin{array}{l}\text { Abgrenzung von } \\
\text { Gruppen }\end{array}$ & $\begin{array}{l}\text { Regressionsanalyse marktbezogener } \\
\text { Aspekte } \\
8 \text { Variablen zu Produktion (Zahl, Alter, } \\
\text { Kapitalintensität der Produktanlagen), } \\
\text { Marketing (Anzahl der Marken, } \\
\text { Verhältnis Reichweite/Umsatz, Preis) } \\
\text { Struktur (Konzentrationsverhältnis } \\
\text { über acht Unternehmen, } \\
\text { Unternehmensgröße) }\end{array}$ & $\begin{array}{l}\text { Clusteranalyse, } \\
\text { Regressionsanalyse }\end{array}$ & $\begin{array}{l}6 \text { Gruppen; Rentabilitäts- } \\
\text { unterschiede resultieren v.a. aus } \\
\text { der Stärke der Vertriebs- } \\
\text { repräsentanz, } \\
\text { überregional tätige Brauereien } \\
\text { arbeiten rentabler als } \\
\text { Nischenanbieter }\end{array}$ \\
\hline $\begin{array}{l}\text { Hatten, Schendel, } \\
\text { Cooper (1978) } \\
\text { A Strategic Model } \\
\text { of the U.S. Brewing } \\
\text { Industry:1952-1971 }\end{array}$ & $\begin{array}{l}13 \text { Unternehmen } \\
\text { der Brauindustrie in } \\
\text { den USA, 1952-71 }\end{array}$ & $\begin{array}{l}\text { Abgrenzung von } \\
\text { Gruppen; } \\
\text { Vergleich von } \\
\text { Gruppen und } \\
\text { Gesamtbranche }\end{array}$ & $\begin{array}{l}\text { Regressionsanalyse marktbezogener } \\
\text { Aspekte } \\
16 \text { Variablen zu Produktion (Länge } \\
\text { des Produktionszyklus, durchschn. } \\
\text { Kapazität), Marketing (Ausgaben für } \\
\text { Marketing,Werbeintensität), Finanzen } \\
\text { (Verbindlichkeiten, Akquisition) } \\
\text { Branchenstruktur (Konzentrationsgrad) }\end{array}$ & $\begin{array}{l}\text { Clusteranalyse, } \\
\text { Korrelationsanalyse }\end{array}$ & $\begin{array}{l}6 \text { Gruppen können abgegrenzt } \\
\text { werden, diese stimmen trotz des } \\
\text { identischen Datensatzes mit } \\
\text { Hatten/Schendel (1977) nicht } \\
\text { überein, da eine größere Anzahl } \\
\text { von Variablen berücksichtigt } \\
\text { wurde }\end{array}$ \\
\hline $\begin{array}{l}\text { Schendel/ } \\
\text { Patton (1978) } \\
\text { A Simultaneous } \\
\text { Equation Model of } \\
\text { Corporate Strategy }\end{array}$ & $\begin{array}{l}12 \text { Unternehmen } \\
\text { der Brauindustrie in } \\
\text { den USA, 1952-71 }\end{array}$ & $\begin{array}{l}\text { Abgrenzung von } \\
\text { Gruppen; } \\
\text { Vergleich von } \\
\text { Gruppen und } \\
\text { Gesamtbranche }\end{array}$ & $\begin{array}{l}\text { a priori festgelegte Strukturmerkmale } \\
\text { Unternehmensgröße (absolute } \\
\text { Produktionsausbringung), } \\
\text { geographische Reichweite (regionaler/ } \\
\text { nationaler Markt) }\end{array}$ & Regressionsanalyse & $\begin{array}{l}\text { angenommene Abgrenzung von } \\
3 \text { Gruppen durch } \\
\text { Regressionsanalyse bestätigt, } \\
\text { große regionale und kleine } \\
\text { regionale Anbieter unterscheiden } \\
\text { sich sowohl untereinander als auch } \\
\text { gegenüber dem } \\
\text { Branchendurchschnitt } \\
\end{array}$ \\
\hline $\begin{array}{l}\text { Hatten/Hatten } 1985 \\
\text { Some Empirical } \\
\text { Insights for } \\
\text { Strategic Marketers: } \\
\text { The Case of Beer }\end{array}$ & $\begin{array}{l}16 \text { Unternehmen } \\
\text { der Brauindustrie in } \\
\text { den USA, 1952-80 }\end{array}$ & $\begin{array}{l}\text { Bestimmung des } \\
\text { Zusammenhangs } \\
\text { zwischen Markt- } \\
\text { anteil und } \\
\text { Rentabilität }\end{array}$ & $\begin{array}{l}\text { Regressionsanalyse marktbezogener } \\
\text { Kriterien } \\
8 \text { variablen der Marketing-Strategie: } \\
\text { Preis, Anzeigen, Anzahl der Marken, } \\
\text { nationaler relativer Marktanteil }\end{array}$ & $\begin{array}{l}\text { Clusteranalyse, } \\
\text { Korrelationsanalyse }\end{array}$ & $\begin{array}{l}3 \text { Gruppen, Profitabilitäts- } \\
\text { unterschiede resultieren aus } \\
\text { Stärke der Vertriebspräsens; } \\
\text { überregionale Anbieter verfügen } \\
\text { über eine größere Rentabilität als } \\
\text { Nischenabieter }\end{array}$ \\
\hline
\end{tabular}




\begin{tabular}{|c|c|c|c|c|c|}
\hline $\begin{array}{c}\text { Autor/Jahr } \\
\text { Titel der } \\
\text { Veröffentlichung } \\
\end{array}$ & Datenquellen & Ziel & $\begin{array}{c}\text { Kriterien der } \\
\text { Gruppenabgrenzung }\end{array}$ & $\begin{array}{c}\text { Verfahren zur } \\
\text { Gruppenbildung }\end{array}$ & $\begin{array}{c}\text { Ergebnisse } \\
\text { Gruppe/ } \\
\text { Erfolgsanalyse } \\
\end{array}$ \\
\hline $\begin{array}{l}\text { Brunken (1990) } \\
\text { Wettbewerbs- } \\
\text { strategien in der } \\
\text { mittelständischen } \\
\text { Brauwirtschaft }\end{array}$ & $\begin{array}{l}62 \text { mittelständische } \\
\text { deutsche } \\
\text { Brauereien }\end{array}$ & $\begin{array}{l}\text { Abgrenzung von } \\
\text { Gruppen; } \\
\text { Ableitung von } \\
\text { Aussagen zum } \\
\text { Wettbewerbs- } \\
\text { erfolg der } \\
\text { Gruppen; }\end{array}$ & $\begin{array}{l}\text { Gruppenabgrenzung anhand } \\
\text { von } 14 \text { a-priori festgelegten } \\
\text { Marketingfaktoren aus den Elementen: } \\
\text { Sortiment, Gebinde, Werbung, Preis, } \\
\text { Distribution, Diversifikationsgrad, } \\
\text { Handelsfunktion, Brauereifunktion }\end{array}$ & $\begin{array}{l}\text { Faktoranalyse, } \\
\text { Clusteranalyse }\end{array}$ & $\begin{array}{l}\text { Identifikation von } 3 \text { Gruppen: } \\
\text { Sortimentskonzentration, } \\
\text { Sortimentsdifferenzierung, } \\
\text { Gastronomiestrategie; } \\
\text { Gruppen unterscheiden sich } \\
\text { hinsichtlich ihres Wettbewerbs- } \\
\text { erfolgs }\end{array}$ \\
\hline $\begin{array}{l}\text { Goehler (1993) } \\
\text { Der Erfolg großer } \\
\text { Familienunternehmen } \\
\text { im fortgeschrittenen } \\
\text { Marktlebenszyklus- } \\
\text { dargestellt am } \\
\text { Beispiel der deutschen } \\
\text { Brauwirtschaft }\end{array}$ & $\begin{array}{l}24 \text { Unternehmen der } \\
\text { deutschen } \\
\text { Brauwirtschaft }\end{array}$ & $\begin{array}{l}\text { Abgrenzung von } \\
\text { Gruppen; } \\
\text { Identifikation von } \\
\text { Erfolgsfaktoren } \\
\text { großer } \\
\text { Familien- } \\
\text { unternehmen }\end{array}$ & $\begin{array}{l}\text { Gruppenabgrenzung anhand a-priori } \\
\text { festgelegter Mobilitätsbarrieren } \\
\text { Unternehmenscharakter (Kapital, } \\
\text { Management, Organisation) } \\
\text { Nachfragesegment (Produkt, Distribution, } \\
\text { Märkte) }\end{array}$ & $\begin{array}{l}\text { keine Anwendung } \\
\text { statistischer } \\
\text { Datenanalyse, } \\
\text { lediglich } \\
\text { Unternehmensvergleich }\end{array}$ & $\begin{array}{l}\text { Identifikation von } 3 \text { Gruppen: } \\
\text { große Familienbrauereien, } \\
\text { Konzernbrauereien, } \\
\text { Lokal- und Regionalbrauereien, } \\
\text { Gruppen unterscheiden sich } \\
\text { hinsichtlich ihres Wettbewerbs- } \\
\text { erfolgs, } \\
\text { Identifikation von } \\
\text { Erfolgsfaktoren }\end{array}$ \\
\hline $\begin{array}{l}\text { Day/Lewin/Li (1995) } \\
\text { Strategic Leaders or } \\
\text { strategic groups: A } \\
\text { longitudinal Data } \\
\text { Envelopment Analysis } \\
\text { of the U.S. brewing } \\
\text { industry }\end{array}$ & $\begin{array}{l}11 \text { Unternehmen der } \\
\text { Brauereiindustrie in } \\
\text { den USA, 1969-70 }\end{array}$ & $\begin{array}{l}\text { Abgrenzung von } \\
\text { Gruppen }\end{array}$ & $\begin{array}{l}\text { a priori Strukturmerkmale festgelegt } \\
\text { Produktionsmenge, operatives Ergebnis, } \\
\text { Produktionskosten, Kapital in Produktiven } \\
\text { Anlagevermögen, Werbeausgaben }\end{array}$ & $\begin{array}{l}\text { Data Envelopment } \\
\text { Analysis }\end{array}$ & $\begin{array}{l}\text { es ergeben sich keine klaren } \\
\text { Gruppenstrukturen, erkennbar } \\
\text { sind richtungsweisende } \\
\text { Unternehmen an denen sich } \\
\text { andere Unternehmen orientieren }\end{array}$ \\
\hline $\begin{array}{l}\text { Houthoofd/ } \\
\text { Heene (1997) } \\
\text { Strategic Groups as } \\
\text { Subsets of Strategic } \\
\text { Scope Groups in the } \\
\text { Belgian Brewing } \\
\text { Industry }\end{array}$ & $\begin{array}{l}36 \text { Unternehmen der } \\
\text { Brauindustrie in } \\
\text { Belgien 1985-1988 }\end{array}$ & $\begin{array}{l}\text { Abgrenzung von } \\
\text { Gruppen }\end{array}$ & $\begin{array}{l}\text { a priori Strukturmerkmale festgelegt } \\
9 \text { Variablen: Intensität des festen } \\
\text { Anlagevermögens, variable Kosten, } \\
\text { neue Marken, Werbeintensität, } \\
\text { Betriebskapitalintensität, Anteil eigener } \\
\text { Produkte am Umsatz, } \\
\text { Investitionsintensität }\end{array}$ & $\begin{array}{l}\text { Faktoranalyse, } \\
\text { Clusteranalyse }\end{array}$ & $\begin{array}{l}\text { Ermittlung von } 4 \text { Faktoren, auf } \\
\text { deren Basis sich } 5 \text { Gruppen } \\
\text { abgrenzen lassen; Unterschiede } \\
\text { vor allem bei Marketing und } \\
\text { Innovation; } \\
\text { keine deutlichen Rentabilitäts- } \\
\text { unterschiede zwischen Gruppen }\end{array}$ \\
\hline
\end{tabular}




\begin{tabular}{|c|c|c|c|c|c|}
\hline $\begin{array}{c}\text { Autor/Jahr } \\
\text { Titel der } \\
\text { Veröffentlichung }\end{array}$ & Datenquellen & Ziel & $\begin{array}{c}\text { Kriterien der } \\
\text { Gruppenabgrenzung }\end{array}$ & $\begin{array}{l}\text { Verfahren zur } \\
\text { Gruppenbildung }\end{array}$ & $\begin{array}{c}\text { Ergebnisse } \\
\text { Gruppe/ } \\
\text { Erfolgsanalyse }\end{array}$ \\
\hline $\begin{array}{l}\text { Marx (1998) } \\
\text { Internationale } \\
\text { Marketingstrategien } \\
\text { in der deutschen } \\
\text { Brauwirtschaft }\end{array}$ & $\begin{array}{l}50(\text { von } 70) \\
\text { international } \\
\text { operierenden } \\
\text { deutschen } \\
\text { Brauereien }\end{array}$ & $\begin{array}{l}\text { Abgrenzung } \\
\text { von Gruppen; } \\
\text { Ableitung von } \\
\text { Handlungs- } \\
\text { empfehlungen } \\
\text { für die } \\
\text { Gestaltung } \\
\text { internationaler } \\
\text { Marketing- } \\
\text { strategien }\end{array}$ & $\begin{array}{l}\text { Gruppenabgrenzung anhand } 25 \text { a-priori } \\
\text { festgelegter Strategievariablen, } \\
\text { Kostenführerschaft, } \\
\text { Qualitätsführerschaft, Produkt- } \\
\text { spezialitäten, regionale Konzentration, } \\
\text { Produktprogrammabdeckung, Gebinde- } \\
\text { form, Werbebotschaft, Verkaufs- } \\
\text { förderung, Distributionsstruktur, Preis, } \\
\text { Lizenzvergabe, Unternehmensakquisition } \\
\text { Vertriebskooperation...... }\end{array}$ & Clusteranalyse & $\begin{array}{l}\text { Identifizierung von } 4 \text { Gruppen } \\
\text { Differenzierte Kontrollstrategie, } \\
\text { preisorientierte } \\
\text { Expansionsstrategie, } \\
\text { nischenorientierte Gelegenheits- } \\
\text { exportstrategie, standardisierte } \\
\text { Fokussierungsstrategie; } \\
\text { Gruppen unterscheiden sich } \\
\text { hinsichtlich ihres Wettbewerbs- } \\
\text { erfolgs }\end{array}$ \\
\hline $\begin{array}{l}\text { Ludin (2001) } \\
\text { Globalisierung als } \\
\text { regionale Chance }\end{array}$ & $\begin{array}{l}44 \text { oberbayerische } \\
\text { Brauereien }\end{array}$ & $\begin{array}{l}\text { Abgrenzung } \\
\text { von } \\
\text { Gruppen }\end{array}$ & $\begin{array}{l}\text { Gruppenabgrenzung anhand a priori } \\
\text { festgelegter Merkmale: Umsatz durch } \\
\text { Bier, Umsatz in Oberbayern, Anzahl } \\
\text { der Mitarbeiter, jeweils für die Jahre } \\
\text { 1968, 1983, 1998, Durchführung des } \\
\text { Lohnsudverfahrens bei anderen } \\
\text { Brauereien bzw. für andere Brauereien, } \\
\text { getätigte Investitionen1984 bis 1998, } \\
\text { eingesetzte Absatzmittler } 1998\end{array}$ & Clusteranalyse & $\begin{array}{l}\text { Identifizierung von } 3 \text { Gruppen } \\
\text { lokale Großbrauereien mit } \\
\text { weltweitem Markt, globale kleine } \\
\text { und mittlere Brauereien, lokale } \\
\text { kleine und mittlere Brauereien }\end{array}$ \\
\hline
\end{tabular}

Quelle: In Anlehnung an Bartölke, 2000: S. 174ff.; Hatten/Schendel, 1977: S. 97ff.; Hatten/Schendel/Cooper, 1978: S. 592ff.; Schendel/Patton, 1978: S. 1611ff.; Hatten/Hatten, 1985: S. 275ff.; Brunken, 1990: S. 148ff.; Goehler, 1993: S. 192ff.; Day/Levin/Li, 1995: S. 619ff.; Houthoofd/Heene, 1997: S. 653ff.; Marx, 1998: S. 88ff.; Ludin, 2001: S. 289ff.. 


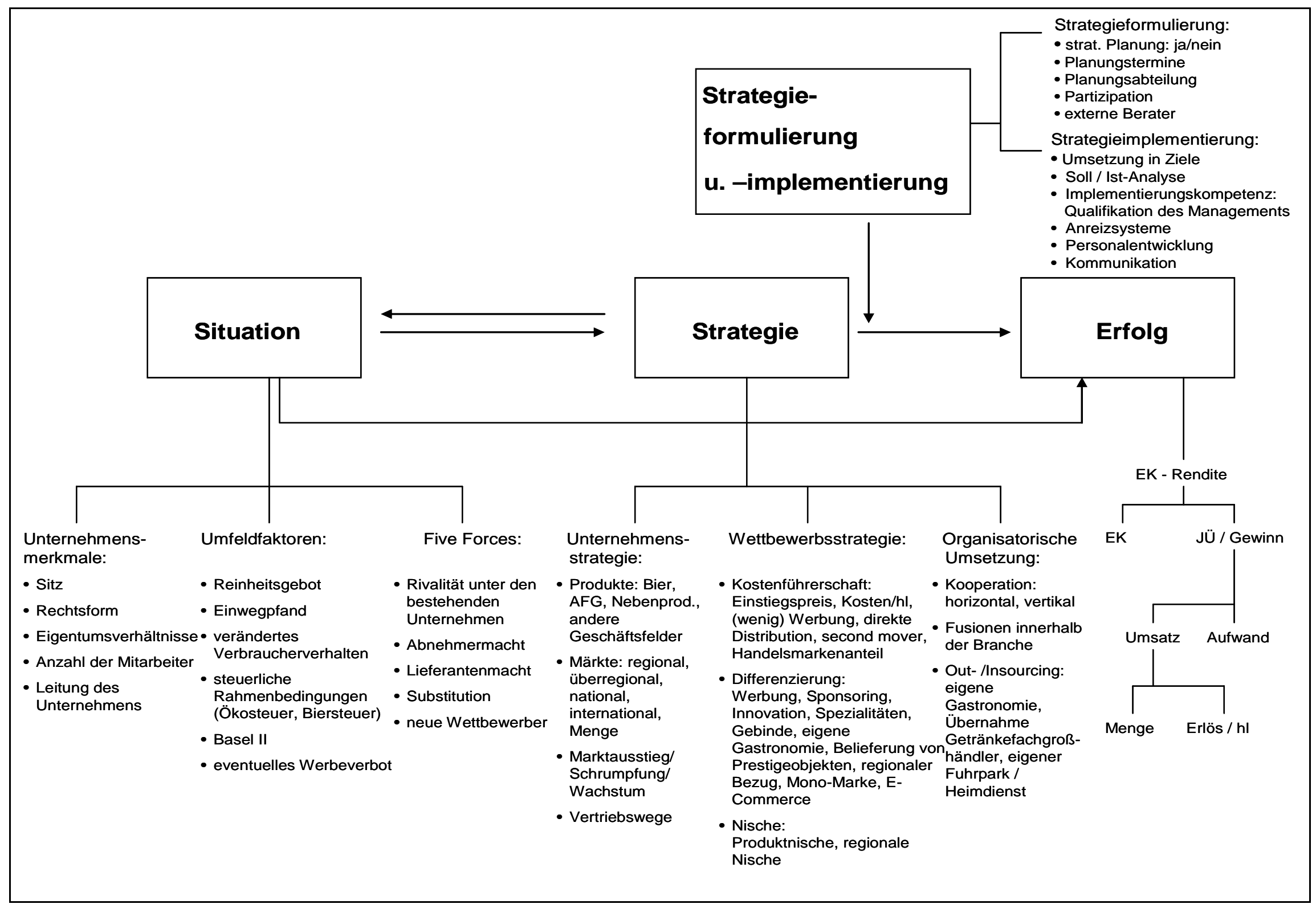




\section{GEORG-AUGUST-UNIVERSIIÄTCÖITINGEN Institut für Agrarökonomie}

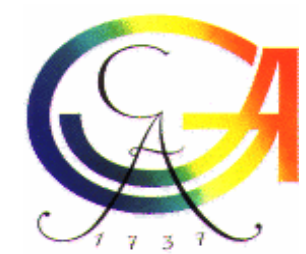

M. Sc. Christoph Niederhut-Bollmann- Institut für Agrarökonomie $\underline{\text { Platz der Göttinger Sieben } 5 \text { - D-37073 Göttingen }}$

«Brauerei»

«Straße»

$« \mathrm{PLZ} » « \mathrm{Ort} »$
Prof. Dr. Ludwig Theuvsen

M. Sc. Christoph Niederhut-Bollmann

Postanschrift:

Institut für Agrarökonomie

Lehrstuhl für BWL des Agribusiness

Platz der Göttinger Sieben 5

D-37073 Göttingen

Tel.: $\quad 0551 / 39-9573$

Fax: 0551/39-4621

E-Mail: c.bollmann@uni-goettingen.de Göttingen, den

\section{Große Strategie-Studie 2005 -Wo stehe ich? Wo stehen meine Mitbewerber?}

Sehr geehrte,

im Rahmen meiner Dissertation an der Georg-August-Universität Göttingen befasse ich mich mit dem Thema „Strategische Gruppen in der deutschen Brauwirtschaft“. Aus diesem Grund führe ich eine Befragung aller deutschen Brauereien durch.

Im Ergebnis entsteht ein differenziertes Bild der Branchenstruktur und Unternehmensstrategien. Dieses gibt Ihnen als Brauerei eine Hilfestellung, die eigene Unternehmensstrategie in einem schwierigen Marktumfeld zu bewerten und zu überdenken.

Für aussagefähige Ergebnisse sind Informationen aus der Praxis unerlässlich. Daher wäre ich Ihnen sehr dankbar, wenn Sie mich bei meinem wissenschaftlichen Vorhaben unterstützen und den beiliegenden Fragebogen für Ihre Brauerei (nicht Gruppe/Konzern) soweit wie möglich beantwortet zurückschicken würden. Nach Aussagen von Praktikern, die den Fragebogen getestet haben, benötigt man für die Beantwortung ca. 25 Minuten.

Wenn Sie an den Ergebnissen der Befragung interessiert sind, dann tragen Sie bitte auf der letzten Seite Ihre E-Mail-Adresse oder Postanschrift ein. Fügen Sie diese Angaben bitte in dem kleinen Briefumschlag dem Rückschreiben bei. Nach Eintreffen des Rückumschlags werden die Angaben in der Postabteilung vom Fragebogen getrennt, so dass eine Identifikation Ihres Unternehmens nicht möglich ist. Ich schicke Ihnen - sobald die Ergebnisse vorliegen - eine Auswertung zu, so dass für Sie die Möglichkeit besteht, Ihr Unternehmen im Vergleich zu Ihren Mitbewerbern in der deutschen Brauwirtschaft einzuordnen. 
Jede einzelne Antwort trägt zum Gelingen des Projektes bei. Bitte schicken Sie den Fragebogen auch dann zurück, wenn Sie unter Umständen nicht alle Fragen beantworten können oder wollen. Dafür liegt dem Schreiben ein bereits frankierter und adressierter Rückumschlag bei. Bei Rückfragen stehe ich Ihnen unter der oben angegebenen Telefonnummer jederzeit gerne zur Verfügung.

Vielen Dank im Voraus für Ihre Unterstützung.

Mit freundlichen Grüßen

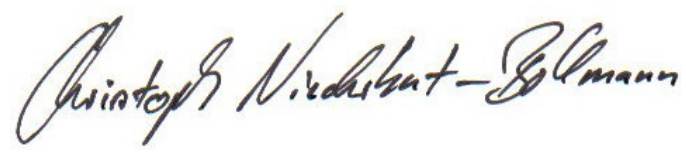

M.Sc. Christoph Niederhut-Bollmann

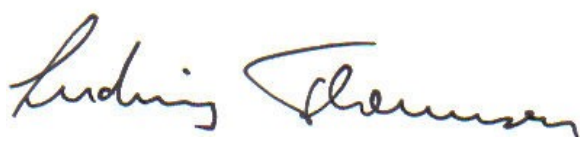

Prof. Dr. Ludwig Theuvsen (wissenschaftliche Leitung)

Anlagen:

- Anschreiben des Verbandes Rheinisch-Westfälischer Brauereien e. V.

- Fragebogen

- frankierter Rückumschlag sowie ein kleiner Umschlag für die E-MailAdresse bzw. Anschrift 


\section{Anlage 4: Muster des Referenzschreibens der regionalen Mitgliedsverbände des} Deutschen Brauerbundes

\section{Waperifther \\ Wrauerbund e.1B. 19.98 \\ 1.}

Ihr kompetenter Partner.

An die

bayerischen Brauereien

Thre Zeichen und thre Nachricht vorr

$$
\begin{aligned}
& \text { Unser Zeichen } \\
& \mathrm{Dr} \text {. Ebb/Br } \\
& \text { 01 Rundbrief bay. Brauereien Strategische Gruppen.doc }
\end{aligned}
$$

\section{Strategische Gruppen in der deutschen Brauwirtschaft}

Sehr geehrte Damen und Herren,

immer wieder ist die Brauwirtschaft Gegenstand wissenschaftlicher Untersuchungen. Neben technischen/technologischen Fragestellungen widmen sich Wissenschaftler dabei auch immer wieder ökonomischen Aspekten unserer Branche.

Die spezifische Struktur der deutschen, insbesondere der bayerischen Brauwirtschaft verbietet es dabei, die Ergebnisse wissenschaftlicher Untersuchungen aus anderen Ländern einfach auf unseren Markt zu übertragen. Um so interessanter ist es damit auch für uns, aus solchen Forschungsprojekten, die sich konkret dem deutschen Biermarkt widmen, mehr über uns als Branche und unseren Markt zu erfahren.

Sie erhalten heute einen Fragebogen, mit dem Herr Christoph Niederhut-Bollmann Sie um Unterstützung bei einem Forschungsvorhaben über die deutsche Brauwirtschaft bittet.

Ich wäre Ihnen sehr dankbar, wenn Sie eine Teilnahme an der Befragung wohlwollend prüfen und sich die Zeit für die Beantwortung seines Fragebogens nehmen würden.

Mit freundlichen Grüßen

BAYERISCHER BRAUERBUND E. V.

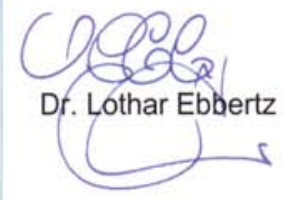

Bayerischer Brauertund e.V. Posttachanschnit: Posttach 340162 - 80098 München - Hausanschnit: Oskar-von-Milier-Fing 1 (Braverhaus) - 80333 München

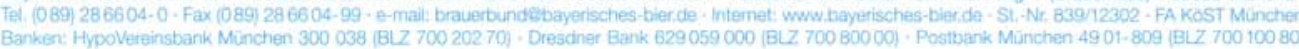


Anlage 5: Muster des verwendeten Fragebogens

\title{
Georg-August-Universität Göttingen
}

\section{Lehrstuhl für Betriebswirtschaftslehre des Agribusiness}

Prof. Dr. Ludwig Theuvsen

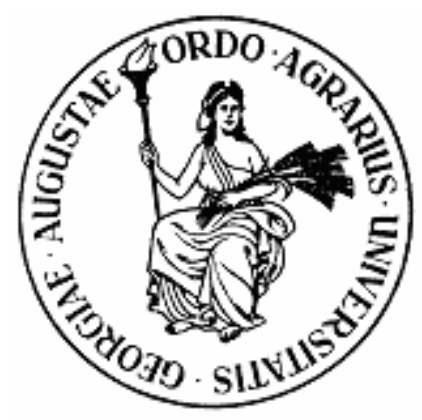

\section{Fragebogen zum Forschungsprojekt:}

\section{Strategische Gruppen in der deutschen Brauwirtschaft}

\author{
Ansprechpartner: M. Sc. Christoph Niederhut-Bollmann \\ Institut für Agrarökonomie \\ Lehrstuhl für BWL des Agribusiness \\ Platz der Göttinger Sieben 5 \\ 37073 Göttingen \\ Tel.: $\quad 0551 / 39-9573$ (Universität) \\ 0175/182 3330 (privat)
}

E-Mail: c.bollmann@uni-goettingen.de 
Aufbau des Fragebogens:

I Allgemeine Fragen

II Situation und Entwicklung Ihres Unternehmens

III Märkte und Produkte

IV Kooperationen

V Erfolg

VI Strategieformulierung und Implementierung

\section{Bearbeitungshinweise:}

- Der Fragebogen beinhaltet 44 Fragen, die fast ausschließlich durch Ankreuzen und Zahlennennungen beantwortet werden können.

- Bei allen Zahlennennungen genügen ca.-Angaben.

- Bei vielen Fragen wird Ihnen die Möglichkeit gegeben, auf einer 5-stufigen Skala anzugeben, inwieweit die jeweils genannten Antwortvorgaben auf Ihr Unternehmen zutreffen. Kreuzen Sie dort bitte jeweils nur ein Kästchen an.

- Bitte senden Sie den Fragebogen auch dann zurück, wenn Sie nicht alle Fragen beantworten möchten oder können. 


\section{Allgemeine Fragen}

\section{In welchem Bundesland befindet sich Ihr Unternehmen?}

\section{Welche Rechtsform hat Ihr Unternehmen?}

\begin{tabular}{|c|c|}
\hline Einzelunternehmen & $\square$ \\
\hline $\mathrm{GmbH}$ & $\square$ \\
\hline $\mathrm{AG}$ & $\square$ \\
\hline $\mathrm{KG}$ & $\square$ \\
\hline GmbH \& Co. KG & $\square$ \\
\hline $\begin{array}{l}\text { Sonstige, } \\
\text { und zwar }\end{array}$ & $\square$ \\
\hline
\end{tabular}

\subsection{Ist Ihr Unternehmen in einen Konzern eingebunden?}

\section{Ja Nein}

3. Wie viele Mitarbeiter waren in den letzten drei Jahren im Durchschnitt in Ihrem Unternehmen beschäftigt?

ca. Beschäftigte pro Jahr

\section{Durch wen wird Ihr Unternehmen geleitet?}

Inhaber oder Gesellschafter

Angestellter Geschäftsführer bzw. Vorstand

5. Wie groß ist das Kernabsatzgebiet Ihres Unternehmens? (Das Kernabsatzgebiet bezieht sich auf den Absatzradius um Ihre Brauerei, in welchem ca. $70 \%$ des gesamten Absatzes erzielt werden.)
Lokal (bis $50 \mathrm{~km})$
Regional (50 bis $150 \mathrm{~km})$
Überregional
National

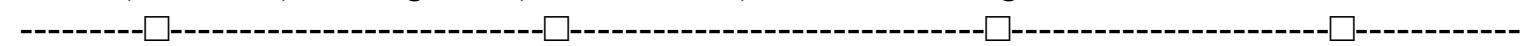

6. In welcher Abteilung sind Sie überwiegend tätig? (Mehrfachnennungen möglich)

\begin{tabular}{|l|c|}
\hline Geschäftsführung & $\square$ \\
\hline Marketing / Marktforschung & $\square$ \\
\hline Vertrieb & $\square$ \\
\hline Controlling & $\square$ \\
\hline Finanzwesen & $\square$ \\
\hline Unternehmenskommunikation & $\square$ \\
\hline Personal & $\square$ \\
\hline Forschung und Entwicklung & $\square$ \\
\hline Produktion / Abfüllung & $\square$ \\
\hline $\begin{array}{l}\text { Sonstige, } \\
\text { und zwar......................................................................... }\end{array}$ & $\square$ \\
\hline
\end{tabular}




\section{Situation und Entwicklung Ihres Unternehmens}

1. Wie beurteilen Sie den Wettbewerbsdruck in Ihrem Kernabsatzgebiet?

sehr niedrig niedrig hoch $\begin{gathered}\text { weder niedrig } \\ \text { noch hoch }\end{gathered} \quad$ sehr hoch

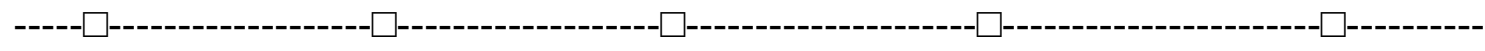

2. Wie beurteilen Sie Ihre Wettbewerbsstärke gegenüber den Hauptwettbewerbern in Ihrem Kernabsatzgebiet?
deutlich geringer
geringer
gleich
höher
deutlich höher
----- $\square---------------------\square-$
$\square------$
$------$
$\square----------------------\square-$
3. Sind in den letzten Jahren Wettbewerber aus Ihrem Kernabsatzgebiet aus der Produktion ausgeschieden oder von anderen Brauereien übernommen worden?

Ja

Nein

Wenn ja:

Wie viele sind ca. ausgeschieden?

Anzahl

Wie viele sind ca. übernommen worden?

4. In welchem Umfang betrachten Sie einen Eintritt von neuen Wettbewerbern in Ihr Kernabsatzgebiet als eine Bedrohung für Ihr Unternehmen?

\begin{tabular}{|c|c|c|c|c|}
\hline $\begin{array}{c}\text { in sehr geringem } \\
\text { Umfang }\end{array}$ & $\begin{array}{l}\text { in geringem } \\
\text { Umfang }\end{array}$ & $\begin{array}{l}\text { in weder geringem } \\
\text { noch hohem } \\
\text { Umfang }\end{array}$ & $\begin{array}{l}\text { in hohem } \\
\text { Umfang }\end{array}$ & $\begin{array}{l}\text { in sehr hohem } \\
\text { Umfang }\end{array}$ \\
\hline
\end{tabular}

5. Wie beurteilen Sie die Verhandlungsmacht der unten aufgeführten Absatzmittler gegenüber Ihrem Unternehmen?

sehr
niedrig $\quad$ niedrig $\begin{gathered}\text { weder niedrig } \\ \text { noch hoch }\end{gathered}$ hoch sehr hoch

unabhängige Getränke-

einzelhändler

Getränkeeinzelhandelsketten

Getränkefachgroßhandel

Lebensmitteleinzelhandel

Gastronomie

$\begin{array}{cr}\text { sehr } & \text { niedrig } \\ \text { niedrig } & \\ \square & \square \\ \square & \square \\ \square & \square \\ \square & \square \\ \square & \square\end{array}$

6. Wie beurteilen Sie die Verhandlungsmacht der wichtigsten Lieferanten gegenüber Ihrem Unternehmen?

sehr niedrig niedrig hoch $\quad \begin{gathered}\text { weder niedrig } \\ \text { noch hoch }\end{gathered} \quad$ sehr hoch

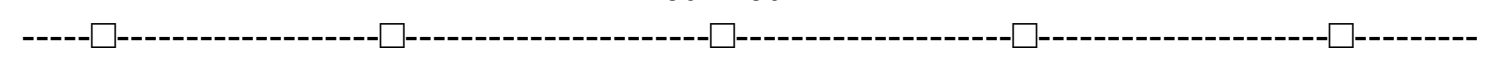


7. Wie stark bedrohen Ersatzprodukte (z.B. Mineralwasser, Wein, Alkopops) die Absatzchancen Ihres Unternehmens?

\begin{tabular}{|c|c|c|c|c|}
\hline $\begin{array}{l}\text { in sehr geringem } \\
\text { Umfang }\end{array}$ & $\begin{array}{l}\text { in geringem } \\
\text { Umfang }\end{array}$ & $\begin{array}{l}\text { in weder geringem } \\
\text { noch hohem } \\
\text { Umfang }\end{array}$ & $\begin{array}{l}\text { in hohem } \\
\text { Umfang }\end{array}$ & $\begin{array}{l}\text { in sehr hohem } \\
\text { Umfang }\end{array}$ \\
\hline
\end{tabular}

8. Die nachfolgenden Aussagen behandeln verschiedene Umfeldfaktoren, die Ihr Unternehmen betreffen können. Welches der im Folgenden genannten Statements, die so oder ähnlich von Managern anderer Unternehmen geäußert wurden, trifft auf Ihr Unternehmen zu?

\begin{tabular}{|l|c|c|c|c|c|}
\hline & $\begin{array}{c}\text { Stimme } \\
\text { voll- } \\
\text { ständig } \\
\text { zu }\end{array}$ & $\begin{array}{c}\text { Stimme } \\
\text { zu }\end{array}$ & $\begin{array}{c}\text { Weder } \\
\text { noch }\end{array}$ & $\begin{array}{c}\text { Lehne } \\
\text { ab }\end{array}$ & $\begin{array}{c}\text { Lehne } \\
\text { voll- } \\
\text { ständig } \\
\text { ab }\end{array}$ \\
\hline $\begin{array}{l}\text { Das Reinheitsgebot ist für die deutsche } \\
\text { Brauwirtschaft von herausragender Bedeutung. }\end{array}$ & $\square$ & $\square$ & $\square$ & $\square$ & $\square$ \\
\hline $\begin{array}{l}\text { Durch die Einführung des Einwegpfands konnten wir } \\
\text { unsere Wettbewerbssituation deutlich verbessern. }\end{array}$ & $\square$ & $\square$ & $\square$ & $\square$ & $\square$ \\
\hline $\begin{array}{l}\text { Das veränderte Verbraucherverhalten hat einen } \\
\text { starken Einfluss auf die Wettbewerbsintensität. }\end{array}$ & $\square$ & $\square$ & $\square$ & $\square$ & $\square$ \\
\hline $\begin{array}{l}\text { Die steuerlichen Rahmenbedingungen (z.B. Bier- } \\
\text { steuererhöhung, Ökosteuer) sehen wir als eine starke } \\
\text { Belastung für die zukünftige Entwicklung an. }\end{array}$ & $\square$ & $\square$ & $\square$ & $\square$ & $\square$ \\
\hline $\begin{array}{l}\text { Durch eine restriktivere Kreditvergabe der Banken } \\
\text { (Basel II) werden wir Schwierigkeiten bei einer } \\
\text { Kreditgewährung bekommen. }\end{array}$ & $\square$ & $\square$ & $\square$ & $\square$ & $\square$ \\
\hline $\begin{array}{l}\text { Ein Werbeverbot für Bier würde unsere } \\
\text { Wettbewerbssituation deutlich verschlechtern. }\end{array}$ & $\square$ & $\square$ & $\square$ & $\square$ & $\square$ \\
\hline
\end{tabular}

9. In welchem der im Folgenden aufgeführten Bereiche hat Ihr Unternehmen in den letzten 5 Jahren Zukäufe oder Verkäufe durchgeführt?

\section{Bereich}

Eine oder mehrere Brauereien

Markenrechte (Lizenzen) von anderen Brauereien

Andere Getränkeproduzenten (z.B. Brunnenbetrieb, Spirituosen)

Gastronomieobjekte

Aktivitäten ohne Bezug zum Kerngeschäft (z.B. Immobilien)

\section{Zukäufe Verkäufe}

$\begin{array}{ll}\square & \square \\ \square & \square \\ \square & \square \\ \square & \square \\ \square & \square\end{array}$

Weder Zukäufe noch Verkäufe

10. Haben Sie in der Vergangenheit eine Übernahme eines oder mehrerer Getränkefachgroßhändler vorgenommen oder planen Sie eine solche Übernahme?

Ja

In Planung

Nein 
11. Wie beurteilen Sie die Wettbewerbsposition Ihres Unternehmens im Vergleich zu Ihren stärksten Mitbewerbern hinsichtlich der folgenden Bereiche?

\begin{tabular}{|l|c|c|c|c|c|}
\hline $\begin{array}{l}\text { Im Vergleich zu unseren stärksten } \\
\text { Mitbewerbern ist/sind }\end{array}$ & $\begin{array}{c}\text { deutlich } \\
\text { niedriger }\end{array}$ & niedriger & gleich & $\begin{array}{c}\text { höher } \\
\text { deutlich } \\
\text { höher }\end{array}$ \\
\hline die Qualität der Produkte ..... & $\square$ & $\square$ & $\square$ & $\square$ & $\square$ \\
\hline die Kapazitätsauslastung ..... & $\square$ & $\square$ & $\square$ & $\square$ & $\square$ \\
\hline der Marktanteil ..... & $\square$ & $\square$ & $\square$ & $\square$ & $\square$ \\
\hline die Verkaufspreise ..... & $\square$ & $\square$ & $\square$ & $\square$ & $\square$ \\
\hline die Innovationskraft ..... & $\square$ & $\square$ & $\square$ & $\square$ & $\square$ \\
\hline das Markenimage ..... & $\square$ & $\square$ & $\square$ & $\square$ & $\square$ \\
\hline die Höhe der Werbeausgaben ..... & $\square$ & $\square$ & $\square$ & $\square$ & $\square$ \\
\hline die Investitionen z.B. in Anlagen ..... & $\square$ & $\square$ & $\square$ & $\square$ & $\square$ \\
\hline $\begin{array}{l}\text { der Umfang der Serviceleistungen (z.B. Beratung, } \\
\text { Konzepterstellung, Kundenkontakt) ..... }\end{array}$ & $\square$ & $\square$ & $\square$ & $\square$ & $\square$ \\
\hline
\end{tabular}

\section{Märkte und Produkte}

\section{Produktpolitik}

1.1 Wie verteilt sich der Gesamtgetränkeabsatz Ihres Unternehmens auf die folgenden Produkte?

(in \% des Gesamtgetränkeabsatzes, z.B.: Pils-Biere $=65 \%$, Biermischgetränke $=10 \%$,

$\mathrm{AfG}=25 \%$, Produkte, die nicht abgesetzt werden $=0$ )

\begin{tabular}{|l|l|}
\hline Produkte & insgesamt $\mathbf{1 0 0} \%$ \\
\hline Pils - Biere & \\
\hline Weizenbiere & \\
\hline Lager-Hell und Export-Hell & \\
\hline Dunkel/Export-Dunkel, Schwarzbier & \\
\hline Kölsch & \\
\hline Alt & \\
\hline Starkbiere (ober- und untergärig) & \\
\hline Biobier & \\
\hline Alkoholfreie oder Light-Biere & \\
\hline Biermischgetränke & \\
\hline Alkoholfreie Getränke & \\
\hline Sonstiges & $=\mathbf{1 0 0} \%$ \\
\hline Summe & \\
\hline
\end{tabular}


1.2 Wie verteilt sich der Gesamtgetränkeabsatz Ihres Unternehmens auf Getränke aus eigener Herstellung sowie Getränke aus Fremdbezug? (in \% des Gesamtgetränkeabsatzes)

\begin{tabular}{|l|c|}
\hline & insgesamt $\mathbf{1 0 0} \%$ \\
\hline Getränke aus eigener Herstellung & \\
\hline Getränke aus Fremdbezug & \\
\hline Summe & $=\mathbf{1 0 0} \%$ \\
\hline
\end{tabular}

1.3 Welchen Anteil am Gesamtausstoß nimmt Ihre Hauptbiermarke ein?

(in \% des Bierausstoßes)

ca.

$\%$

1.4 Zu welchem Preis werden normalerweise Ihre Biermarke mit dem höchsten Absatzanteil sowie das preiswerteste Bier Ihres Unternehmens im Handel angeboten? (Hinweis: Bitte geben Sie auch die jeweilige Kastenform ( 20 x 0,51, 24 x 0,331, sonstige Kastenform an.)

\begin{tabular}{|c|c|c|c|c|c|c|}
\hline \multirow[b]{3}{*}{ Preis in $€$} & \multicolumn{3}{|c|}{ Hauptbiermarke } & \multicolumn{3}{|c|}{ Preiswertestes Bier } \\
\hline & \multicolumn{3}{|c|}{ Kastenform } & \multicolumn{3}{|c|}{ Kastenform } \\
\hline & $20 \times 0,51$ & $24 \times 0,331$ & $\begin{array}{c}\text { Sonstige, } \\
\text { und } \\
\text { zwar... } \\
\text {............. }\end{array}$ & $20 \times 0,51$ & $24 \times 0,331$ & $\begin{array}{c}\begin{array}{c}\text { Sonstige, } \\
\text { und } \\
\text { zwar... } \\
\text {............ }\end{array}\end{array}$ \\
\hline 12 und mehr & $\square$ & $\square$ & $\square$ & $\square$ & $\square$ & $\square$ \\
\hline $11-11,99$ & $\square$ & $\square$ & $\square$ & $\square$ & $\square$ & $\square$ \\
\hline $10-10,99$ & $\square$ & $\square$ & $\square$ & $\square$ & $\square$ & $\square$ \\
\hline $9-9,99$ & $\square$ & $\square$ & $\square$ & $\square$ & $\square$ & $\square$ \\
\hline $8-8,99$ & $\square$ & $\square$ & $\square$ & $\square$ & $\square$ & $\square$ \\
\hline $7-7,99$ & $\square$ & $\square$ & $\square$ & $\square$ & $\square$ & $\square$ \\
\hline $6-6,99$ & $\square$ & $\square$ & $\square$ & $\square$ & $\square$ & $\square$ \\
\hline $5-5,99$ & $\square$ & $\square$ & $\square$ & $\square$ & $\square$ & $\square$ \\
\hline unter 5 & $\square$ & $\square$ & $\square$ & $\square$ & $\square$ & $\square$ \\
\hline
\end{tabular}

1.5 Welchen Anteil nehmen Marken bzw. Handelsmarken bei der Vermarktung Ihrer Produkte ein? Bitte machen Sie Ihre Angabe jeweils in \% (z.B. : Markenartikel = 70 \%, Handelsmarken = $30 \%)$.

\begin{tabular}{|l|r|}
\hline Markenartikel & $\%$ \\
\hline Handelsmarken & $\%$ \\
\hline Summe & $\mathbf{1 0 0} \%$ \\
\hline
\end{tabular}

1.6 Wie hoch ist der Anteil der folgenden Gebindearten am Gesamtbierausstoß Ihres

Unternehmens? (in \% des Gesamtbierausstoßes)

Glasflasche (Mehrweg)

PET (Mehrweg)

Fass

Einweg (z.B. Dosen, Einweg Flaschen, Party Dose)

Sonstiges

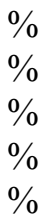




\subsection{Vertreibt Ihr Unternehmen neben Getränken und Nebenprodukten (Gläser, Bierdeckel, Textilien, Feuerzeuge usw.) auch noch andere Produkte oder Dienstleistungen? (z.B. Catering, Eventmanagement, Reisen, Komplementärprodukte wie Nahrungsmittel oder Spirituosen usw.)}

Ja

In Planung

Nein

1.7.1 Wenn ja oder in Planung, welche?

1.8 Die nachfolgenden Aussagen behandeln die Märkte und Produkte Ihres Unternehmens. Welches der im Folgenden genannten Statements, die so oder ähnlich von Managern anderer Unternehmen geäußert wurden, trifft auf Ihr Unternehmen zu?

\begin{tabular}{|c|c|c|c|c|c|}
\hline & $\begin{array}{l}\text { Stimme } \\
\text { voll- } \\
\text { ständig } \\
\quad \text { zu }\end{array}$ & $\begin{array}{c}\text { Stimme } \\
\text { zu }\end{array}$ & $\begin{array}{l}\text { Weder } \\
\text { noch }\end{array}$ & $\begin{array}{l}\text { Lehne } \\
\text { ab }\end{array}$ & $\begin{array}{l}\text { Lehne } \\
\text { voll- } \\
\text { ständig } \\
\text { ab }\end{array}$ \\
\hline $\begin{array}{l}\text { Nebenprodukte wie z.B. Gläser, Textilien, Feuerzeuge } \\
\text { usw. sind ein wichtiges Einnahmefeld unseres Unter- } \\
\text { nehmens. }\end{array}$ & $\square$ & $\square$ & $\square$ & $\square$ & $\square$ \\
\hline $\begin{array}{l}\text { Beim Vertrieb von Nebenprodukten stehen in unserem } \\
\text { Unternehmen Marketingaspekte im Vordergrund. }\end{array}$ & $\square$ & $\square$ & $\square$ & $\square$ & $\square$ \\
\hline $\begin{array}{l}\text { Um unseren Marktanteil auszubauen, ziehen wir einen } \\
\text { Zukauf anderer Brauereien in Betracht. }\end{array}$ & $\square$ & $\square$ & $\square$ & $\square$ & $\square$ \\
\hline $\begin{array}{l}\text { Der Internationalisierung messen wir in der gegen- } \\
\text { wärtigen Situation eine hohe Bedeutung zu. }\end{array}$ & $\square$ & $\square$ & $\square$ & $\square$ & $\square$ \\
\hline $\begin{array}{l}\text { Wir sind mit unserem jetzigen Marktanteil zufrieden } \\
\text { und ergreifen daher keine Maßnahmen zur Er- } \\
\text { weiterung. }\end{array}$ & $\square$ & $\square$ & $\square$ & $\square$ & $\square$ \\
\hline $\begin{array}{l}\text { Um unser Angebot zu erweitern, ziehen wir einen } \\
\text { Zukauf anderer Getränkehersteller (z.B. Brunnen- } \\
\text { betrieb, Erfrischungsgetränke, Spirituosen) in Betracht. }\end{array}$ & $\square$ & $\square$ & $\square$ & $\square$ & $\square$ \\
\hline $\begin{array}{l}\text { Um unseren Marktanteil auszubauen, ziehen wir einen } \\
\text { Zukauf von Markenrechten (Lizenzen) anderer } \\
\text { Brauereien in Betracht. }\end{array}$ & $\square$ & $\square$ & $\square$ & $\square$ & $\square$ \\
\hline $\begin{array}{l}\text { In der Zukunft wird die Bedeutung der Internationali- } \\
\text { sierung in unserem Unternehmen steigen. }\end{array}$ & $\square$ & $\square$ & $\square$ & $\square$ & $\square$ \\
\hline $\begin{array}{l}\text { Brauereibesichtigungen sind für uns eine wichtige } \\
\text { Einnahmequelle. }\end{array}$ & $\square$ & $\square$ & $\square$ & $\square$ & $\square$ \\
\hline $\begin{array}{l}\text { Mit Innovationen bemühen wir uns immer, die Ersten } \\
\text { am Markt zu sein. }\end{array}$ & $\square$ & $\square$ & $\square$ & $\square$ & $\square$ \\
\hline $\begin{array}{l}\text { Für die Zukunft gehen wir davon aus, dass das Internet } \\
\text { ein immer wichtigerer Absatzweg für unser Bier wird. }\end{array}$ & $\square$ & $\square$ & $\square$ & $\square$ & $\square$ \\
\hline $\begin{array}{l}\text { Wir werden auch in Zukunft einen eigenen Fuhrpark } \\
\text { betreiben. }\end{array}$ & $\square$ & $\square$ & $\square$ & $\square$ & $\square$ \\
\hline $\begin{array}{l}\text { In Zukunft könnten wir uns vorstellen, die Brautätig- } \\
\text { keit auszulagern, um uns voll auf den Vertrieb zu } \\
\text { konzentrieren. }\end{array}$ & $\square$ & $\square$ & $\square$ & $\square$ & $\square$ \\
\hline
\end{tabular}




\section{Märkte und Absatzwege}

2.1 Wie verteilt sich der gesamte Getränkeabsatz Ihres Unternehmens auf die folgenden Absatzwege? Bitte machen Sie Ihre Angabe wieder jeweils in \% (z.B. Getränkefachgroßhandel $=40 \%$, Lebensmitteleinzelhandel $=35 \%$ und Gastronomie $=25 \%$ )

\begin{tabular}{|l|c|}
\hline Lebensmitteleinzelhandel (ohne Discounter) & \\
\hline Discounter & \\
\hline Convenience-Stores (z.B. Tankstellen) & \\
\hline Getränkefachgroßhandel & \\
\hline Getränkeabholmärkte & \\
\hline Gastronomie und Großverbraucher (z.B. Verpflegungsbetriebe) & \\
\hline Eigener Heimdienst & \\
\hline Vertriebskooperationen mit anderen Brauereien & \\
\hline Export & \\
\hline E-Commerce & \\
\hline $\begin{array}{l}\text { Sonstige, } \\
\text { und zwar............................................................. }\end{array}$ & \\
\hline Summe & $\mathbf{1 0 0 \%}$ \\
\hline
\end{tabular}

2.2 Verfügt Ihr Unternehmen über brauereieigene Absatzstätten?

(Bitte geben Sie an, über welche und wie viele Absatzstätten Sie verfügen)

\section{Art der brauereieigenen Absatzstätte}

Gastronomieobjekte (im Eigentum bzw. Pacht der Brauerei)

Ja Nein Anzahl

Getränkefachgroßhandel

Getränkeabholmärkte

Sonstige,

und zwar

2.3 Wie viele Ihrer Gastronomiekunden sind durch Bierlieferverträge an Ihr Unternehmen gebunden? (in \% der gesamten Gastronomiekunden)

ca. $\%$

2.4 Wie schätzen Sie das Prestige der durchschnittlich von Ihnen belieferten Gastronomieobjekte im Vergleich zu dem Ihrer Hauptmitbewerber ein?

deutlich geringer geringer gleich höher deutlich höher

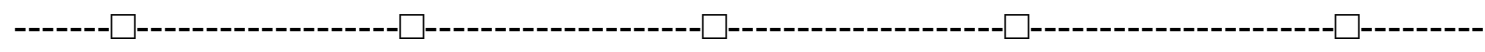


2.5 Ist Ihr Unternehmen international tätig oder beabsichtigen Sie in naher Zukunft international tätig zu werden?

Ja

In Planung

Nein

(Wenn ja oder in Planung, weiter mit Frage 2.5.1; wenn nein, weiter mit Frage 3.)

2.5.1 Wenn ja, seit wann sind Sie international tätig?

Jahre

2.5.2 Welche der unten aufgeführten Markterschließungsstrategien verwenden

Sie im Ausland? (Mehrfachnennungen möglich)

Export

Lizenzvergabe

Joint Venture

Übernahme ausländischer Brauereien

Andere Formen,

und zwar....

2.5.3 Wie hoch war im Jahr 2003 ca. Ihr Auslandsabsatz (Export, Lizenzvergabe, Joint Venture, Übernahme ausländische Brauereien u.a. Formen)? (in \% des Gesamtabsatzes)

ca. \% des Gesamtabsatzes

2.5.4 Wie hat sich Ihr Auslandsabsatz in den letzen drei Jahren ca. verändert?

Zunahme/Abnahme \%:

ca. $\%$

\section{Kosten}

3.1 Wie hoch sind etwa die durchschnittlichen Gesamtkosten Ihres Unternehmens pro Hektoliter Bierausstoß?

ca. $€ / \mathbf{h l}$

keine Angabe

3.2 Wie schätzen Sie die durchschnittlichen Gesamtkosten Ihres Unternehmens im Vergleich zum Branchendurchschnitt ein?

deutlich geringer geringer gleich höher deutlich höher

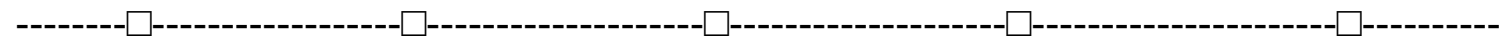




\section{Marketing und Marktführung}

4.1 Wie hoch waren ungefähr die jährlichen Marketingausgaben (inkl. Sponsoring, z.B. von Vereinen und Verkaufsförderung) Ihres Unternehmens im Durchschnitt der letzten drei Jahre? (in €/hl)

$\begin{array}{ll}2001 & € / \mathrm{hl} \\ 2002 & € / \mathrm{hl} \\ 2003 & € / \mathrm{hl}\end{array}$

4.2 Die nachfolgenden Aussagen behandeln die Markenführung Ihres Unternehmens. Welches der im Folgenden genannten Statements, die so oder ähnlich von Managern anderer Unternehmen geäußert wurden, trifft auf Ihr Unternehmen zu?

\begin{tabular}{|c|c|c|c|c|c|}
\hline & $\begin{array}{l}\text { Stimme } \\
\text { voll- } \\
\text { ständig } \\
\text { zu }\end{array}$ & $\begin{array}{c}\text { Stimme } \\
\mathbf{z u}\end{array}$ & $\begin{array}{c}\text { Weder } \\
\text { noch }\end{array}$ & $\begin{array}{l}\text { Lehne } \\
\text { ab }\end{array}$ & $\begin{array}{c}\text { Lehne } \\
\text { voll- } \\
\text { ständig } \\
\text { ab }\end{array}$ \\
\hline $\begin{array}{l}\text { Die Marke ist eine zentrale Größe im Management } \\
\text { unseres Unternehmens. }\end{array}$ & $\square$ & $\square$ & $\square$ & $\square$ & $\square$ \\
\hline $\begin{array}{l}\text { Auch in schwierigen Zeiten wird bei uns an der } \\
\text { Werbung nicht gespart. }\end{array}$ & $\square$ & $\square$ & $\square$ & $\square$ & $\square$ \\
\hline $\begin{array}{l}\text { Nur mit einer starken Marke können wir langfristig } \\
\text { erfolgreich sein. }\end{array}$ & $\square$ & $\square$ & $\square$ & $\square$ & $\square$ \\
\hline $\begin{array}{l}\text { Unsere Werbung führen wir hauptsächlich auf } \\
\text { nationaler Ebene durch (Fernsehen, Illustrierte usw.). }\end{array}$ & $\square$ & $\square$ & $\square$ & $\square$ & $\square$ \\
\hline $\begin{array}{l}\text { Wir stellen im Marketing häufig unsere Brautradition } \\
\text { heraus. }\end{array}$ & $\square$ & $\square$ & $\square$ & $\square$ & $\square$ \\
\hline $\begin{array}{l}\text { Das Sponsoring regionaler Vereine und Veran- } \\
\text { staltungen halten wir für ein wichtiges Marketing- } \\
\text { instrument. }\end{array}$ & $\square$ & $\square$ & $\square$ & $\square$ & $\square$ \\
\hline $\begin{array}{l}\text { Verkaufsförderung /Promotion setzen wir häufig bei } \\
\text { regionalen Veranstaltungen (z.B. Stadtfeste, Sport- } \\
\text { veranstaltungen) ein. }\end{array}$ & $\square$ & $\square$ & $\square$ & $\square$ & $\square$ \\
\hline $\begin{array}{l}\text { Bei Sponsoring setzen wir eher auf national beachtete } \\
\text { Veranstaltungen bzw. Vereine. }\end{array}$ & $\square$ & $\square$ & $\square$ & $\square$ & $\square$ \\
\hline $\begin{array}{l}\text { Unsere Werbung setzen wir eher regional bis über- } \\
\text { regional (z.B. regionale Tageszeitungen, Hörfunk, } \\
\text { Plakate) ein. }\end{array}$ & $\square$ & $\square$ & $\square$ & $\square$ & $\square$ \\
\hline $\begin{array}{l}\text { Wünsche und Erwartungen der Endverbraucher prägen } \\
\text { unsere Markenpolitik. }\end{array}$ & $\square$ & $\square$ & $\square$ & $\square$ & $\square$ \\
\hline Die Markenführung erfolgt stark zielgruppenorientiert. & $\square$ & $\square$ & $\square$ & $\square$ & $\square$ \\
\hline $\begin{array}{l}\text { In unserem Unternehmen gibt es durchsetzungsfähige } \\
\text { Brand-/ Produktmanager. }\end{array}$ & $\square$ & $\square$ & $\square$ & $\square$ & $\square$ \\
\hline $\begin{array}{l}\text { Brauereibesichtigungen halten wir für ein wichtiges } \\
\text { Marketinginstrument. }\end{array}$ & $\square$ & $\square$ & $\square$ & $\square$ & $\square$ \\
\hline $\begin{array}{l}\text { Unsere Homepage halten wir für ein wichtiges Marke- } \\
\text { tinginstrument. }\end{array}$ & $\square$ & $\square$ & $\square$ & $\square$ & $\square$ \\
\hline
\end{tabular}




\section{Innovation}

\subsection{In welchen der unten aufgeführten Bereiche haben Sie in den letzten Jahren Innovationen} durchgeführt oder planen diese?

\section{Art der Innovation}

\section{Produkt:}

Biermischgetränke

Milderes Bier

Light Bier

Alkoholfreies Bier

Neue Biersorten im Sortiment

\section{Gebinde:}

Flaschenform (z.B. Longneck-, Reliefflasche)

Bügelflasche

Flaschenfarbe (z.B. Weißglas)

PET-Flasche

Flaschenetiketten (z.B. Design)

Selbstkühlendes Fass

Kastengröße (z.B. 10 x 0,51)

Kastendesign

Neue Marke/n

Marketinginnovationen

Sonstiges,

und zwar.

\section{Innovation durchgeführt} oder in Planung

Ja

Nein

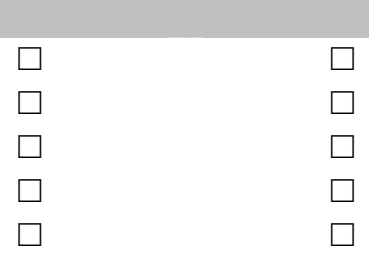

\section{Kooperationen}

1. Wie hoch schätzen Sie das Potenzial der im Folgenden aufgeführten Kooperationsbereiche mit anderen Brauereien für Ihr Unternehmen ein?

\begin{tabular}{|c|c|c|c|c|c|}
\hline $\begin{array}{l}\text { Das Kooperationspotenzial im Bereich } \\
\text {...................... ist }\end{array}$ & $\begin{array}{l}\text { sehr } \\
\text { niedrig }\end{array}$ & niedrig & $\begin{array}{c}\text { weder } \\
\text { niedrig } \\
\text { noch } \\
\text { hoch }\end{array}$ & hoch & $\begin{array}{l}\text { sehr } \\
\text { hoch }\end{array}$ \\
\hline ... Einkauf & $\square$ & $\square$ & $\square$ & $\square$ & $\square$ \\
\hline ... Brauen & $\square$ & $\square$ & $\square$ & $\square$ & $\square$ \\
\hline ... Abfüllen & $\square$ & $\square$ & $\square$ & $\square$ & $\square$ \\
\hline ... Sortiment (z.B. Produktaustausch) & $\square$ & $\square$ & $\square$ & $\square$ & $\square$ \\
\hline$\ldots$ Vertrieb & $\square$ & $\square$ & $\square$ & $\square$ & $\square$ \\
\hline ... Distribution (z.B. Fuhrpark) & $\square$ & $\square$ & $\square$ & $\square$ & $\square$ \\
\hline ... Marketing & $\square$ & $\square$ & $\square$ & $\square$ & $\square$ \\
\hline ... Produktentwicklung & $\square$ & $\square$ & $\square$ & $\square$ & $\square$ \\
\hline ... Internationalisierung & $\square$ & $\square$ & $\square$ & $\square$ & $\square$ \\
\hline
\end{tabular}


2. Kooperiert Ihr Unternehmen mit einer oder mehreren anderen Brauereien oder planen Sie eine solche Zusammenarbeit?

Ja

In Planung

Nein

(Wenn ja, oder in Planung weiter mit Frage 2.1; wenn nein, weiter mit Frage 3.)

2.1 Wenn ja bzw. in Planung: In welchen der unten aufgeführten Bereiche sind Sie an Kooperationen mit anderen Brauereien beteiligt oder planen eine solche?

\begin{tabular}{|l|c|c|}
\hline Kooperationsart mit anderer Brauerei & $\begin{array}{c}\text { bestehende } \\
\text { Kooperation }\end{array}$ & $\begin{array}{c}\text { Kooperation in } \\
\text { Planung }\end{array}$ \\
\hline Einkauf & $\square$ & $\square$ \\
\hline Brauen & $\square$ & $\square$ \\
\hline Abfüllen & $\square$ & $\square$ \\
\hline Sortiment & $\square$ & $\square$ \\
\hline Vertrieb & $\square$ & $\square$ \\
\hline Distribution & $\square$ & $\square$ \\
\hline Marketing & $\square$ & $\square$ \\
\hline Produktentwicklung & $\square$ & $\square$ \\
\hline Internationalisierung & $\square$ & $\square$ \\
\hline
\end{tabular}

3. Wie hoch schätzen Sie das Potenzial der im Folgenden aufgeführten Kooperationen mit Unternehmen im vor- oder nachgelagerten Bereich für Ihr Unternehmen ein?

\begin{tabular}{|l|c|c|c|c|c|}
\hline $\begin{array}{l}\text { Kooperation im vor- oder nachgelagerten } \\
\text { Bereich }\end{array}$ & $\begin{array}{c}\text { sehr } \\
\text { niedrig }\end{array}$ & niedrig & $\begin{array}{c}\text { weder } \\
\text { niedrig } \\
\text { noch hoch }\end{array}$ & hoch & $\begin{array}{c}\text { sehr } \\
\text { hoch }\end{array}$ \\
\hline Mälzerei & $\square$ & $\square$ & $\square$ & $\square$ & $\square$ \\
\hline Getränkefachgroßhandel & $\square$ & $\square$ & $\square$ & $\square$ & $\square$ \\
\hline $\begin{array}{l}\text { Andere Absatzmittler (z.B. System- } \\
\text { gastronomie, Handelsmarkenproduktion) }\end{array}$ & $\square$ & $\square$ & $\square$ & $\square$ & $\square$ \\
\hline $\begin{array}{l}\text { Sonstige, } \\
\text { und zwar........................................ }\end{array}$ & $\square$ & $\square$ & $\square$ & $\square$ & $\square$ \\
\hline
\end{tabular}

4. Ist Ihr Unternehmen an einer Kooperation mit einem oder mehreren Unternehmen im vor- oder nachgelagerten Bereich beteiligt oder planen Sie eine solche?

Ja

In Planung

Nein

(Wenn ja oder in Planung, weiter mit Frage 4.1; wenn nein, weiter mit V. Erfolg.)

4.1 Wenn ja bzw. in Planung: In welchem der unten aufgeführten Bereiche sind Sie an Kooperationen mit Unternehmen im vor- oder nachgelagerten Bereich beteiligt oder planen eine solche?

\begin{tabular}{|l|c|c|}
\hline Kooperation im vor- oder nachgelagerten Bereich & $\begin{array}{l}\text { bestehende } \\
\text { Kooperation }\end{array}$ & $\begin{array}{l}\text { Kooperation in } \\
\text { Planung }\end{array}$ \\
\hline Mälzerei & $\square$ & $\square$ \\
\hline Getränkefachgroßhandel & $\square$ & $\square$ \\
\hline $\begin{array}{l}\text { Andere Absatzmittler (z.B. Systemgastronomie, } \\
\text { Handelsmarkenproduktion) }\end{array}$ & $\square$ & $\square$ \\
\hline $\begin{array}{l}\text { Sonstige, } \\
\text { und zwar....................................................... }\end{array}$ & $\square$ & $\square$ \\
\hline
\end{tabular}




\section{Erfolg}

1. Bitte geben Sie an, wie hoch der Gesamtgetränkeausstoß Ihres

Unternehmens (nicht Gruppe/Konzern) im Jahr 2003 war.

Bis $5.000 \mathrm{hl}$

5.000 bis $10.000 \mathrm{hl}$

$10.000 \mathrm{bis} 50.000 \mathrm{hl}$

50.000 bis $100.000 \mathrm{hl}$

$100.000 \mathrm{bis} 250.000 \mathrm{hl}$

250.000 bis $500.000 \mathrm{hl}$

500.000 bis 1 Mio. hl

1 Mio.bis 2 Mio. $\mathrm{hl}$

Über 2 Mio. hl

davon Bier (in \%):

ca. $\%$

2. Bitte geben Sie die ungefähre prozentuale Veränderung der nachfolgenden Erfolgsgrößen in den letzten drei Jahren an. (gefragt ist nach der Gesamtänderung der letzten drei Jahre)

\begin{tabular}{lccccccc} 
& $\begin{array}{c}\text { über 10 \% } \\
\text { Rückgang }\end{array}$ & $\begin{array}{l}\mathbf{5 \%} \text { bis 10\% } \\
\text { Rückgang }\end{array}$ & $\begin{array}{c}\text { bis 5\% } \\
\text { Rückgang }\end{array}$ & $\begin{array}{c}\text { gleich } \\
\text { bleibend }\end{array}$ & $\begin{array}{c}\text { bis 5\% } \\
\text { Steigerung }\end{array}$ & $\begin{array}{c}\mathbf{5 \%} \text { bis 10\% } \\
\text { Steigerung }\end{array}$ & $\begin{array}{c}\text { über } \mathbf{1 0 \%} \\
\text { Steigerung }\end{array}$ \\
\hline $\begin{array}{l}\text { Gesamtge- } \\
\text { tränkeausstoß }\end{array}$ & $\square$ & $\square$ & $\square$ & $\square$ & $\square$ & $\square$ & $\square$ \\
Umsatz & $\square$ & $\square$ & $\square$ & $\square$ & $\square$ & $\square$ & $\square$ \\
Gewinn & $\square$ & $\square$ & $\square$ & $\square$ & $\square$ & $\square$ & $\square$ \\
$\begin{array}{l}\text { Return on } \\
\text { Investment }\end{array}$ & $\square$ & $\square$ & $\square$ & $\square$ & $\square$ & $\square$ & $\square$ \\
\end{tabular}

3. Welchen durchschnittlichen Return on Investment konnten Sie in den letzten Jahren erzielen?(in \%)

\section{$\%$}

keine Angabe

4. Nun noch einige kurze Fragen zum Erfolg Ihres Unternehmens im Vergleich zum Branchendurchschnitt. Wie sah es da in den letzten drei Jahren aus?

\begin{tabular}{|l|c|c|c|c|c|}
\hline & $\begin{array}{c}\text { deutlich } \\
\text { niedriger }\end{array}$ & niedriger & gleich & $\begin{array}{c}\text { höher } \\
\text { deutlich } \\
\text { höher }\end{array}$ \\
\hline $\begin{array}{l}\text { Unsere Produktivität (Umsatz minus } \\
\text { Fremdleistungen je Beschäftigtem) war ..... }\end{array}$ & $\square$ & $\square$ & $\square$ & $\square$ & $\square$ \\
\hline $\begin{array}{l}\text { Unsere durchschnittliche Rentabilität } \\
\text { (Betriebsergebnis/Gesamtkapital) war .... }\end{array}$ & $\square$ & $\square$ & $\square$ & $\square$ & $\square$ \\
\hline $\begin{array}{l}\text { Unsere Finanzkraft (z.B. freie Mittel für } \\
\text { neue Aktivitäten / Möglichkeit der } \\
\text { Aufnahmen zusätzlicher Mittel) war..... }\end{array}$ & $\square$ & $\square$ & $\square$ & $\square$ & $\square$ \\
\hline
\end{tabular}




\section{Strategieformulierung und Implementierung}

1. Zum Ende noch einige Aussagen zur Strategieformulierung und Implementierung. Welches der im Folgenden genannten Statements, die so oder ähnlich von Managern anderer Unternehmen geäußert wurden, trifft auf Ihr Unternehmen zu?

\begin{tabular}{|c|c|c|c|c|c|}
\hline & $\begin{array}{l}\text { Stimme } \\
\text { voll- } \\
\text { ständig } \\
\text { zu }\end{array}$ & $\begin{array}{l}\text { Stimme } \\
\mathbf{z u}\end{array}$ & $\begin{array}{l}\text { Weder } \\
\text { noch }\end{array}$ & $\begin{array}{l}\text { Lehne } \\
\text { ab }\end{array}$ & $\begin{array}{l}\text { Lehne } \\
\text { voll- } \\
\text { ständig } \\
\text { ab }\end{array}$ \\
\hline $\begin{array}{l}\text { Auch im Tagesgeschäft haben wir immer die lang- } \\
\text { fristige Strategie im Auge. }\end{array}$ & $\square$ & $\square$ & $\square$ & $\square$ & $\square$ \\
\hline $\begin{array}{l}\text { Die Verantwortung für die strategische Unternehmens- } \\
\text { führung ist bei uns klar geregelt (z.B. Inhaber, } \\
\text { Planungsabteilung). }\end{array}$ & $\square$ & $\square$ & $\square$ & $\square$ & $\square$ \\
\hline $\begin{array}{l}\text { Unsere Geschäftsentwicklung wird im Rahmen vorher } \\
\text { festgelegter Planungstermine regelmäßig überprüft. }\end{array}$ & $\square$ & $\square$ & $\square$ & $\square$ & $\square$ \\
\hline $\begin{array}{l}\text { Bei der strategischen Unternehmensplanung unter- } \\
\text { stützen uns regelmäßig externe Berater. }\end{array}$ & $\square$ & $\square$ & $\square$ & $\square$ & $\square$ \\
\hline $\begin{array}{l}\text { Unser Unternehmen ist in verschiedene Abteilungen } \\
\text { wie Marketing-, Vertriebs- sowie Planungsabteilung } \\
\text { gegliedert. }\end{array}$ & $\square$ & $\square$ & $\square$ & $\square$ & $\square$ \\
\hline $\begin{array}{l}\text { Es werden klare Ziele festgelegt, die bis zu einem } \\
\text { bestimmten Zeitpunkt zu erreichen sind. }\end{array}$ & $\square$ & $\square$ & $\square$ & $\square$ & $\square$ \\
\hline $\begin{array}{l}\text { Wir führen regelmäßig Soll-/Istanalysen zur Er- } \\
\text { reichung unserer Ziele und zur Anpassung an ver- } \\
\text { änderte Rahmenbedingungen durch. }\end{array}$ & $\square$ & $\square$ & $\square$ & $\square$ & $\square$ \\
\hline $\begin{array}{l}\text { Unser Management ist im Vergleich zum Branchen- } \\
\text { durchschnitt überdurchschnittlich innovativ und } \\
\text { erfolgreich. }\end{array}$ & $\square$ & $\square$ & $\square$ & $\square$ & $\square$ \\
\hline $\begin{array}{l}\text { Eine konsequente Weiterbildung unserer Mitarbeiter } \\
\text { durch externe und interne Stellen ist bei uns Standard. }\end{array}$ & $\square$ & $\square$ & $\square$ & $\square$ & $\square$ \\
\hline $\begin{array}{l}\text { Die Strategie und die Ziele unseres Unternehmens } \\
\text { werden regelmäßig an alle Führungskräfte und Mit- } \\
\text { arbeiter kommuniziert. }\end{array}$ & $\square$ & $\square$ & $\square$ & $\square$ & $\square$ \\
\hline \multicolumn{6}{|c|}{$\begin{array}{l}\text { Bitte beantworten Sie die abschließenden Fragen nur, wenn Ihr Unternehmen in einen } \\
\text { Konzern eingebunden ist. }\end{array}$} \\
\hline $\begin{array}{l}\text { Die strategischen Ziele unseres Unternehmens werden } \\
\text { gemeinsam mit der Konzernmutter festgelegt. }\end{array}$ & $\square$ & $\square$ & $\square$ & $\square$ & $\square$ \\
\hline $\begin{array}{l}\text { Wir sind in unserem Konzern für ein bestimmtes Preis- } \\
\text { bzw. Kundensegment zuständig. }\end{array}$ & $\square$ & $\square$ & $\square$ & $\square$ & $\square$ \\
\hline $\begin{array}{l}\text { Das Produktportfolio, das Marketing sowie Inno- } \\
\text { vationen werden in unserem Unternehmen konzern- } \\
\text { weit abgestimmt. }\end{array}$ & $\square$ & $\square$ & $\square$ & $\square$ & $\square$ \\
\hline $\begin{array}{l}\text { Wir haben in unserem Unternehmen nur einen be- } \\
\text { grenzten Entscheidungsspielraum, da die strategische } \\
\text { Unternehmensplanung größtenteils von der Konzern- } \\
\text { mutter vorgegeben wird. }\end{array}$ & $\square$ & $\square$ & $\square$ & $\square$ & $\square$ \\
\hline $\begin{array}{l}\text { Wir berichten der Konzernmutter regelmäßig über die } \\
\text { Geschäftsentwicklung unseres Unternehmens. }\end{array}$ & $\square$ & $\square$ & $\square$ & $\square$ & $\square$ \\
\hline
\end{tabular}


Die folgenden Angaben werden nach Eintreffen des Rückumschlags in der Postabteilung vom Fragebogen getrennt, so dass eine Identifikation Ihres Unternehmens nicht möglich ist. Sämtliche Angaben werden streng vertraulich behandelt.

Wenn Sie an den Ergebnissen der Befragung interessiert sind, dann tragen Sie bitte hier Ihre E-Mail-Adresse bzw. Ihre Anschrift ein. Fügen Sie diesen Bogen dann bitte in dem kleinen Briefumschlag dem Rückschreiben bei. Wir schicken Ihnen dann eine Auswertung zu, so dass für Sie die Möglichkeit besteht, Ihr Unternehmen im Vergleich $\mathrm{zu}$ Ihren Mitbewerbern in der deutschen Brauwirtschaft einzuordnen.

\section{E-Mail:}

oder

Anschrift:

Zum Schluss möchten wir Ihnen die Möglichkeit geben, ein kurzes Feedback zu dieser Befragung abzugeben. Was hat Sie gestört, was fanden Sie gut?

\section{Herzlichen Dank für Ihre Unterstützung!}


Anhang 6: Tabellenband zum Forschungsprojekt

\title{
Georg-August-Universität Göttingen
}

\section{Lehrstuhl für Betriebswirtschaftslehre des Agribusiness}

Prof. Dr. Ludwig Theuvsen

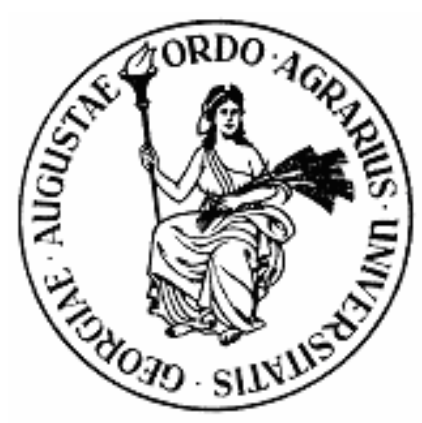

\section{Tabellenband zum Forschungsprojekt:}

\section{Strategische Gruppen in der deutschen Brauwirtschaft}

\author{
M. Sc. Christoph Niederhut-Bollmann \\ Institut für Agrarökonomie \\ Lehrstuhl für BWL des Agribusiness \\ Platz der Göttinger Sieben 5 \\ 37073 Göttingen \\ Tel.: 0551/39-9573 (Universität) \\ $0175 / 1823330$ (privat)
}

E-Mail: c.bollmann@uni-goettingen.de 
Rücklaufquote nach Ausstoßgrößenklassen der Brauereien:

\begin{tabular}{|c|c|c|c|}
\hline $\begin{array}{l}\text { Betriebsgrößenklasse } \\
\text { nach der Gesamt- } \\
\text { jahreserzeugung (hl) }\end{array}$ & $\begin{array}{c}\text { Betriebene } \\
\text { Braustätten im Jahr } \\
\text { 2004* }\end{array}$ & $\begin{array}{l}\text { Rücklauf an } \\
\text { ausgefüllten } \\
\text { Fragebögen }\end{array}$ & $\begin{array}{l}\text { Rücklaufquote } \\
\text { in } \%\end{array}$ \\
\hline bis 5.000 & 796 & 92 & 11,55 \\
\hline bis 10.000 & 85 & \multirow{3}{*}{138} & \multirow{3}{*}{39,2} \\
\hline bis 50.000 & 195 & & \\
\hline bis 100.000 & 72 & & \\
\hline bis 200.000 & 44 & \multirow{2}{*}{42} & \multirow{2}{*}{55,26} \\
\hline bis 500.000 & 32 & & \\
\hline bis 1 Mill. & 21 & \multirow[b]{2}{*}{9} & \multirow[b]{2}{*}{18} \\
\hline über 1 Mill. & 29 & & \\
\hline Gesamt & 1274 & 281 & 22 \\
\hline
\end{tabular}

*Deutscher Brauer-Bund 2005

\section{Allgemeine Fragen}

Frage I 1: In welchem Bundesland befindet sich Ihr Unternehmen? (Rücklaufquote nach Bundesländern)

\begin{tabular}{|l|c|c|c|c|}
\hline & $\begin{array}{c}\text { Betriebene } \\
\text { Braustätten } \\
2004^{*}\end{array}$ & $\begin{array}{c}\text { Ange- } \\
\text { schriebene } \\
\text { Brauereien }\end{array}$ & $\begin{array}{c}\text { Rücklauf an } \\
\text { Fragebögen }\end{array}$ & $\begin{array}{c}\text { Rücklauf von } \\
\text { beantworteten } \\
\text { Fragebögen in } \\
\%\end{array}$ \\
\hline Baden Württemberg & 178 & 161 & 43 & 26,7 \\
\hline Bayern & 629 & 689 & 160 & 23,2 \\
\hline Berlin/Brandenburg & 38 & 30 & 5 & 16,7 \\
\hline Hessen & 63 & 60 & 10 & 16,7 \\
\hline Mecklenburg Vorpommern & 18 & 13 & 0 & 0 \\
\hline Niedersachsen/Bremen & 49 & 41 & 9 & 21,9 \\
\hline Nordrhein-Westfalen & 118 & 118 & 20 & 16,9 \\
\hline Rheinland-Pfalz/Saarland & 52 & 42 & 6 & 14,3 \\
\hline Sachsen & 55 & 43 & 9 & 20,9 \\
\hline Sachsen-Anhalt & 18 & 16 & 4 & 25 \\
\hline $\begin{array}{l}\text { Schleswig } \\
\text { Holstein/Hamburg }\end{array}$ & 13 & 13 & 2 & 15,3 \\
\hline Thüringen & 43 & 34 & 11 & 32,3 \\
\hline keine Angabe & 1274 & 1260 & 281 & 22,3 \\
\hline Gesamt & & & 2 & \\
\hline
\end{tabular}

* Quelle: Deutscher Brauer-Bund e.V., 2005. 
Frage I 2: Rechtsformen der an der Untersuchung beteiligten Brauereien nach Betriebsgrößenklasse:
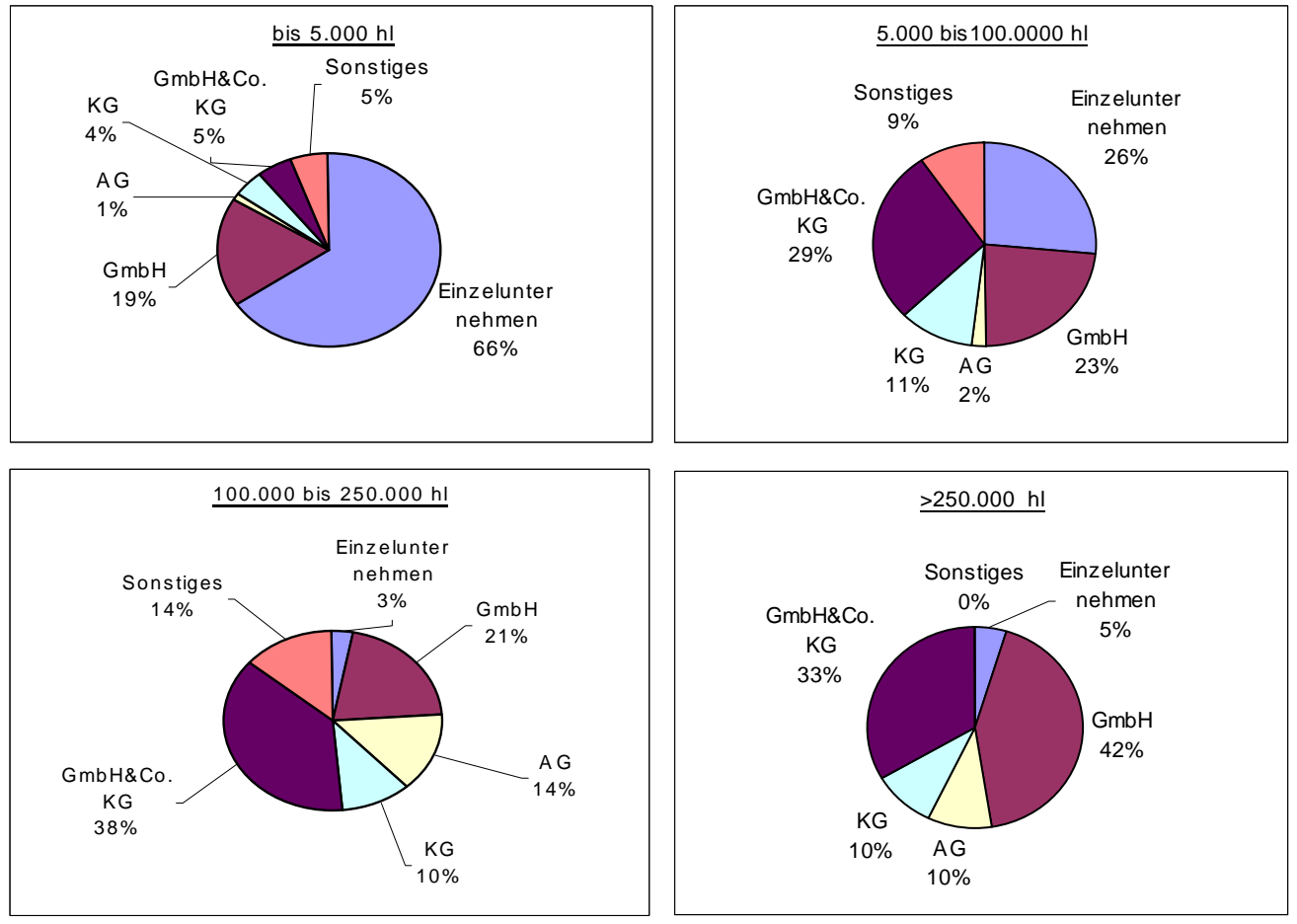

Quelle: Niederhut-Bollmann, C., Datensatz „Große Strategie-Studie 2005“, Göttingen 2005

\section{Frage I 2. 1: Ist Ihr Unternehmen in einen Konzern eingebunden?}

\begin{tabular}{|c|c|c|c|c|c|}
\hline & \multicolumn{4}{|c|}{ Gesamtgetränkeausstoß } & \multirow[b]{2}{*}{$\begin{array}{l}\text { Gesamt } \\
(\mathrm{n}=281)\end{array}$} \\
\hline & $\begin{array}{c}\text { Bis } 5.000 \mathrm{hl} \\
(\mathrm{n}=92)\end{array}$ & $\begin{array}{c}5.000-100.000 \\
\mathrm{hl} \\
(\mathrm{n}=138)\end{array}$ & $\begin{array}{c}100.000- \\
250.000 \mathrm{hl} \\
(\mathrm{n}=29)\end{array}$ & $\begin{array}{c}\text { Größer als } \\
250.000 \mathrm{hl} \\
(\mathrm{n}=22)\end{array}$ & \\
\hline $\mathrm{Ja}$ & $1 \quad(1,1 \%)$ & $3(2,2 \%)$ & $7 \quad(24,1 \%)$ & $9 \quad(40,9 \%)$ & $20 \quad(7,1 \%)$ \\
\hline Nein & $89 \quad(96,7 \%)$ & $134 \quad(97,1 \%)$ & $22 \quad(75,9 \%)$ & $13(59,1 \%)$ & $258 \quad(91,8 \%)$ \\
\hline $\begin{array}{l}\text { keine } \\
\text { Angabe }\end{array}$ & $2(2,2 \%)$ & $1 \quad(0,7 \%)$ & $0 \quad(0 \%)$ & $0 \quad(0 \%)$ & $3(1,1 \%)$ \\
\hline
\end{tabular}

Quelle: Niederhut-Bollmann, C., Datensatz „Große Strategie-Studie 2005“, Göttingen 2005. 


\section{Frage I 2. 2: Handelt es sich bei Ihrem Unternehmen um ein Familienunternehmen?}

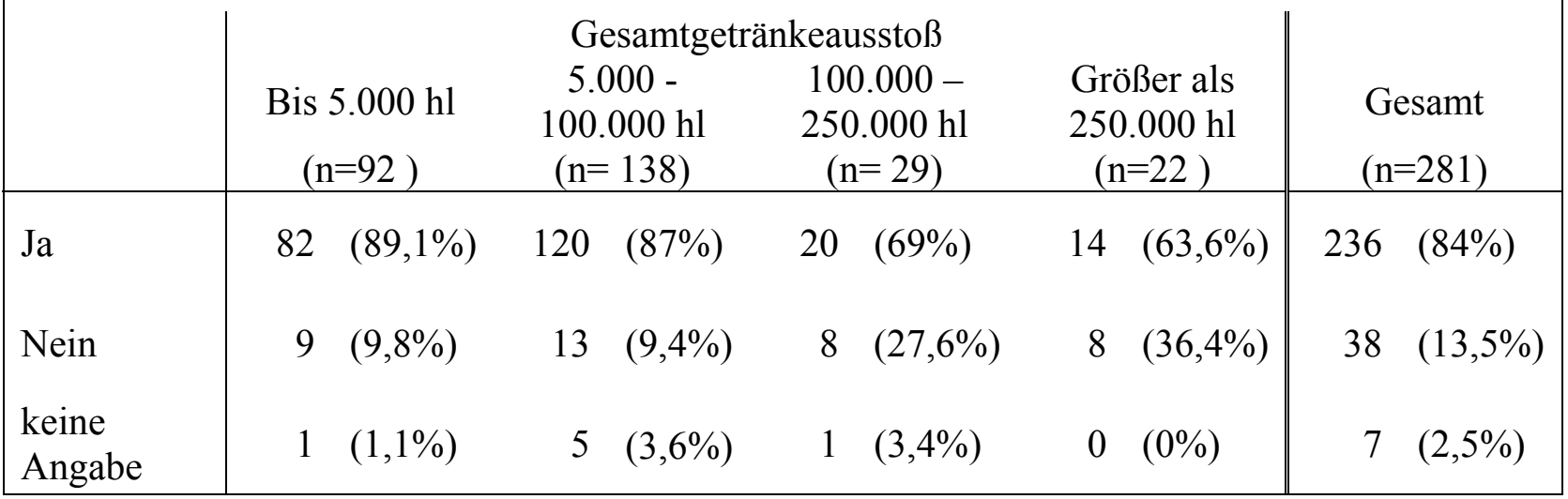

Quelle: Niederhut-Bollmann, C., Datensatz „Große Strategie-Studie 2005“, Göttingen 2005.

\section{Frage I 3: Wie viele Mitarbeiter waren in den letzten drei Jahren im Durchschnitt in Ihrem Unternehmen beschäftigt?}

\begin{tabular}{|c|c|c|c|c|c|c|c|c|c|}
\hline & \multicolumn{7}{|c|}{ Gesamtgetränkeausstoß } & \multirow{2}{*}{\multicolumn{2}{|c|}{$\begin{array}{l}\text { Gesamt } \\
(\mathrm{n}=281)\end{array}$}} \\
\hline & $\begin{array}{c}\text { Bis } 5.000 \mathrm{hl} \\
(\mathrm{n}=92)\end{array}$ & \multicolumn{2}{|c|}{$\begin{array}{c}5.000- \\
100.000 \mathrm{hl} \\
(\mathrm{n}=138)\end{array}$} & \multicolumn{2}{|c|}{$\begin{array}{c}100.000- \\
250.000 \mathrm{hl} \\
(\mathrm{n}=29)\end{array}$} & \multicolumn{2}{|c|}{$\begin{array}{c}\text { Größer als } \\
250.000 \mathrm{hl} \\
(\mathrm{n}=22)\end{array}$} & & \\
\hline $\begin{array}{l}\text { Keine } \\
\text { Mitarbeiter }\end{array}$ & $4 \quad 4,3 \%$ & & & & & & & & $1,4 \%$ \\
\hline $\begin{array}{l}1-10 \\
\text { Mitarbeiter }\end{array}$ & $66 \quad 71,7 \%$ & 36 & $26,1 \%$ & & & & & 102 & $36,3 \%$ \\
\hline $\begin{array}{l}11-30 \\
\text { Mitarbeiter }\end{array}$ & $16 \quad 17,4 \%$ & 68 & $49,3 \%$ & 1 & $3,4 \%$ & & & 85 & $30,2 \%$ \\
\hline $\begin{array}{l}31-60 \\
\text { Mitarbeiter }\end{array}$ & $1 \quad 1,1 \%$ & 28 & $20,3 \%$ & 6 & $20,7 \%$ & & & 35 & $12,5 \%$ \\
\hline $\begin{array}{l}61-90 \\
\text { Mitarbeiter }\end{array}$ & & 4 & $2,9 \%$ & 12 & $41,4 \%$ & 2 & $9,1 \%$ & 18 & $6,4 \%$ \\
\hline $\begin{array}{l}91-120 \\
\text { Mitarbeiter }\end{array}$ & & 1 & $0,7 \%$ & 8 & $27,6 \%$ & 7 & $31,8 \%$ & 16 & $5,7 \%$ \\
\hline $\begin{array}{l}\text { 121-150 } \\
\text { Mitarbeiter }\end{array}$ & & & & 2 & $6,9 \%$ & 2 & $9,1 \%$ & 4 & $1,4 \%$ \\
\hline $\begin{array}{l}\text { 150-180 } \\
\text { Mitarbeiter }\end{array}$ & & & & & & 3 & $13,6 \%$ & 3 & $1,1 \%$ \\
\hline $\begin{array}{l}\text { Mehr als } 180 \\
\text { Mitarbeiter }\end{array}$ & & & & & & 8 & $36,4 \%$ & 8 & $2,8 \%$ \\
\hline $\begin{array}{l}\text { Keine } \\
\text { Angabe }\end{array}$ & $5 \quad 5,4 \%$ & 1 & $0,7 \%$ & & & & & 6 & $2,1 \%$ \\
\hline
\end{tabular}

Quelle: Niederhut-Bollmann C., Datensatz „Große Strategie-Studie 2005“, Göttingen 2005 


\section{Frage I 4: Durch wen wird Ihr Unternehmen geleitet?}

\begin{tabular}{|c|c|c|c|c|c|}
\hline & \multicolumn{4}{|c|}{ Gesamtgetränkeausstoß } & \multirow[b]{2}{*}{$\begin{array}{l}\text { Gesamt } \\
(\mathrm{n}=281)\end{array}$} \\
\hline & $\begin{array}{c}\text { Bis } 5.000 \mathrm{hl} \\
\quad(\mathrm{n}=92)\end{array}$ & $\begin{array}{c}5.000- \\
100.000 \mathrm{hl} \\
(\mathrm{n}=138)\end{array}$ & $\begin{array}{c}100.000- \\
250.000 \mathrm{hl} \\
(\mathrm{n}=29)\end{array}$ & $\begin{array}{l}\text { Größer als } \\
250.000 \mathrm{hl} \\
(\mathrm{n}=22)\end{array}$ & \\
\hline $\begin{array}{l}\text { Inhaber oder } \\
\text { Gesellschafter }\end{array}$ & $83 \quad(90 \%)$ & $111 \quad(80 \%)$ & $15 \quad(52 \%)$ & $8 \quad(36 \%)$ & $217 \quad(77 \%)$ \\
\hline $\begin{array}{l}\text { Angestellter } \\
\text { Geschäftsführer bzw. } \\
\text { Vorstand }\end{array}$ & $9 \quad(10 \%)$ & $22(16 \%)$ & $14 \quad(48 \%)$ & $9 \quad(41 \%)$ & $54 \quad(19 \%)$ \\
\hline $\begin{array}{l}\text { Inhaber/Gesellschafter } \\
\text { und angestellter } \\
\text { Geschäftsführer bzw. } \\
\text { Vorstand }\end{array}$ & $0 \quad(0 \%)$ & $5(4 \%)$ & $0 \quad(0 \%)$ & $5 \quad(23 \%)$ & $10 \quad(4 \%)$ \\
\hline
\end{tabular}

Quelle: Niederhut-Bollmann, C., Datensatz „Große Strategie-Studie 2005“, Göttingen 2005

\section{Frage I 5: Wie groß ist das Kernabsatzgebiet Ihres Unternehmens?}

\begin{tabular}{|c|c|c|c|c|c|}
\hline & \multicolumn{4}{|c|}{ Gesamtgetränkeausstoß } & \multirow[b]{2}{*}{$\begin{array}{l}\text { Gesamt } \\
(\mathrm{n}=281)\end{array}$} \\
\hline & $\begin{array}{c}\text { Bis } 5.000 \mathrm{hl} \\
(\mathrm{n}=92)\end{array}$ & $\begin{array}{c}5.000- \\
100.000 \mathrm{hl} \\
(\mathrm{n}=138)\end{array}$ & $\begin{array}{c}100.000- \\
250.000 \mathrm{hl} \\
(\mathrm{n}=29)\end{array}$ & $\begin{array}{c}\text { Größer als } \\
250.000 \mathrm{hl} \\
(\mathrm{n}=22)\end{array}$ & \\
\hline $\begin{array}{l}\text { Lokal (bis } 50 \\
\mathrm{~km} \text { ) }\end{array}$ & $85 \quad(92,4 \%)$ & $106(76,8 \%)$ & $9 \quad(31 \%)$ & $1 \quad(4,5 \%)$ & $201 \quad(71,5 \%)$ \\
\hline $\begin{array}{l}\text { Regional (50 } \\
\text { bis } 150 \mathrm{~km})\end{array}$ & $7 \quad(7,6 \%)$ & $30 \quad(21,7 \%)$ & $19 \quad(65,5 \%)$ & $15 \quad(68,2 \%)$ & $71 \quad(25,3 \%)$ \\
\hline Überregional & $0 \quad(0 \%)$ & $1 \quad(0,7 \%)$ & $0 \quad(0 \%)$ & $1 \quad(4,5 \%)$ & $2 \quad(0,7 \%)$ \\
\hline National & $0 \quad(0 \%)$ & $1 \quad(0,7 \%)$ & $1 \quad(3,4 \%)$ & $5 \quad(22,7 \%)$ & $7 \quad(2,5 \%)$ \\
\hline
\end{tabular}

Quelle: Niederhut-Bollmann, C., Datensatz „Große Strategie-Studie 2005“, Göttingen 2005 


\section{Situation und Entwicklung Ihres Unternehmens}

\begin{tabular}{|c|c|c|c|c|c|}
\hline \multirow[b]{3}{*}{$\begin{array}{l}\text { sehr } \\
\text { niedrig }\end{array}$} & \multirow[b]{2}{*}{$\begin{array}{c}\text { Bis } 5.000 \mathrm{hl} \\
(\mathrm{n}=92)\end{array}$} & \multicolumn{2}{|c|}{ Gesamtgetränkeausstoß } & \multirow[b]{2}{*}{$\begin{array}{c}\text { Größer als } \\
250.000 \mathrm{hl} \\
(\mathrm{n}=22)\end{array}$} & \multirow[b]{2}{*}{$\begin{array}{l}\text { Gesamt } \\
(\mathrm{n}=281)\end{array}$} \\
\hline & & $\begin{array}{c}5.000- \\
100.000 \mathrm{hl} \\
(\mathrm{n}=138)\end{array}$ & $\begin{array}{c}100.000- \\
250.000 \mathrm{hl} \\
(\mathrm{n}=29)\end{array}$ & & \\
\hline & $3 \quad(3,3 \%)$ & $1 \quad(0,7 \%)$ & & & $4 \quad(1,4 \%)$ \\
\hline niedrig & $9 \quad(9,8 \%)$ & $2 \quad(1,4 \%)$ & & & $11 \quad(3,9 \%)$ \\
\hline $\begin{array}{l}\text { weder } \\
\text { niedrig } \\
\text { noch hoch }\end{array}$ & $19 \quad(20,7 \%)$ & $14 \quad(10,1 \%)$ & & & $33(11,7 \%)$ \\
\hline hoch & $39 \quad(42,4 \%)$ & $69 \quad(50 \%)$ & $18 \quad(62,1 \%)$ & $13 \quad(59,1 \%)$ & $139 \quad(49,5 \%)$ \\
\hline sehr hoch & $22 \quad(23,9 \%)$ & $51 \quad(37 \%)$ & $11 \quad(37,9 \%)$ & $9 \quad(40,9 \%)$ & $93 \quad(33,1 \%)$ \\
\hline $\begin{array}{l}\text { keine } \\
\text { Angabe }\end{array}$ & & $1 \quad(0,7 \%)$ & & & $1 \quad(0,4 \%)$ \\
\hline
\end{tabular}

Quelle: Niederhut-Bollmann, C., Datensatz „Große Strategie-Studie 2005“, Göttingen 2005.

Frage II 2: Wie beurteilen Sie Ihre Wettbewerbsstärke gegenüber den Hauptwettbewerbern in Ihrem Kernabsatzgebiet?

\begin{tabular}{|c|c|c|c|c|c|}
\hline & & Gesamtget & keausstoß & & \\
\hline & $\begin{array}{l}\text { Bis } 5.000 \mathrm{hl} \\
\quad(\mathrm{n}=92)\end{array}$ & $\begin{array}{c}5.000- \\
100.000 \mathrm{hl} \\
(\mathrm{n}=138)\end{array}$ & $\begin{array}{c}100.000- \\
250.000 \mathrm{hl} \\
(\mathrm{n}=29)\end{array}$ & $\begin{array}{c}\text { Größer als } \\
250.000 \mathrm{hl} \\
(\mathrm{n}=22)\end{array}$ & $\begin{array}{l}\text { Gesamt } \\
(\mathrm{n}=281)\end{array}$ \\
\hline $\begin{array}{l}\text { deutlich } \\
\text { geringer }\end{array}$ & $11 \quad(12 \%)$ & $6 \quad(4,3 \%)$ & & & $17 \quad(6 \%)$ \\
\hline geringer & $27 \quad(29,3 \%)$ & $24 \quad(17,4 \%)$ & $3 \quad(10,3 \%)$ & $1 \quad(4,5 \%)$ & $55 \quad(19,6 \%)$ \\
\hline gleich & $28 \quad(30,4 \%)$ & $64 \quad(46,4 \%)$ & $14(48,3 \%)$ & $13(59,1 \%)$ & $119(42,3 \%)$ \\
\hline höher & $24 \quad(26,1 \%)$ & $37 \quad(26,8 \%)$ & $12 \quad(41,4 \%)$ & $8 \quad(36,4 \%)$ & $81 \quad(28,8 \%)$ \\
\hline $\begin{array}{l}\text { deutlich } \\
\text { höher }\end{array}$ & $2 \quad(2,2 \%)$ & $5 \quad(3,6 \%)$ & & & $7 \quad(2,5 \%)$ \\
\hline $\begin{array}{l}\text { keine } \\
\text { Angabe }\end{array}$ & & $2 \quad(1,4 \%)$ & & & $2 \quad(0,7 \%)$ \\
\hline
\end{tabular}

Quelle: Niederhut-Bollmann, C., Datensatz „Große Strategie-Studie 2005“, Göttingen 2005. 


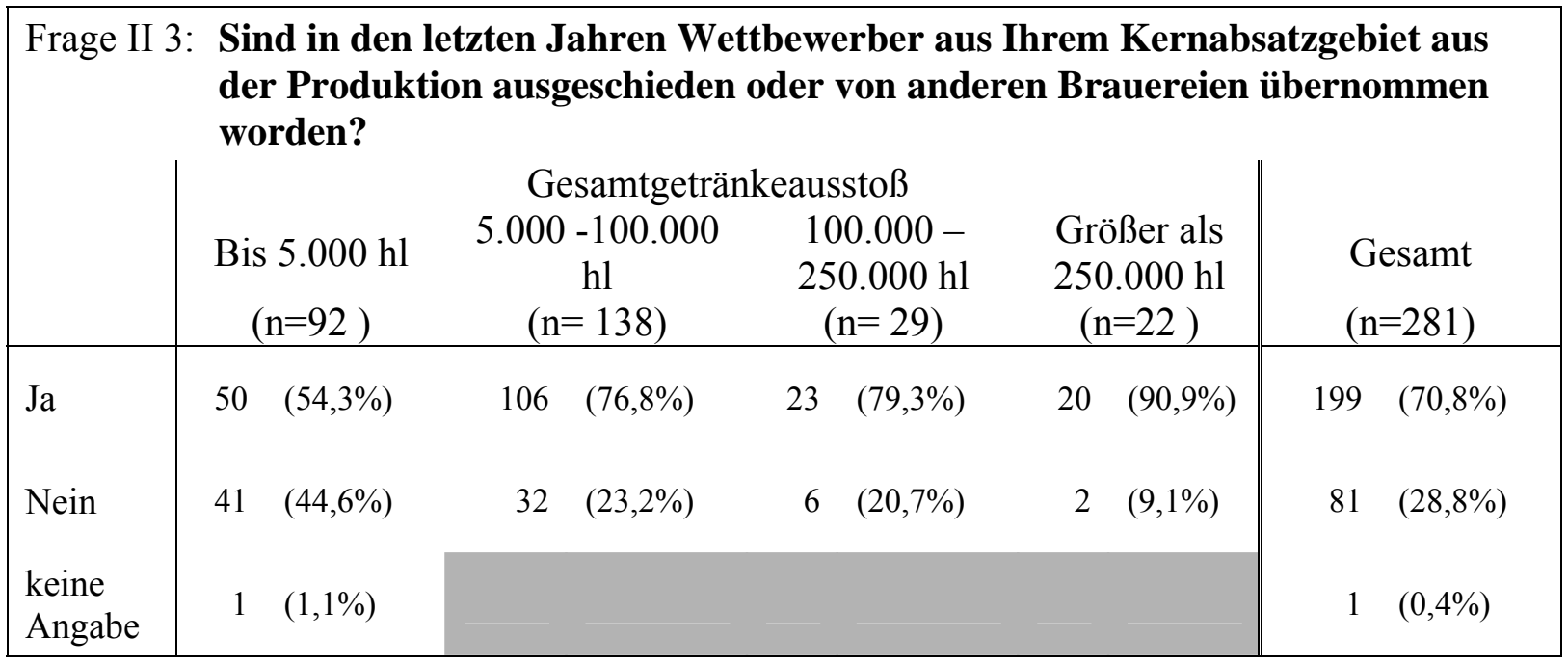

Quelle: Niederhut-Bollmann, C., Datensatz „Große Strategie-Studie 2005“, Göttingen 2005. Frage II 4: In welchem Umfang betrachten Sie einen Eintritt von neuen Wettbewerbern
in Ihr Kernabsatzgebiet als eine Bedrohung für Ihr Unternehmen?

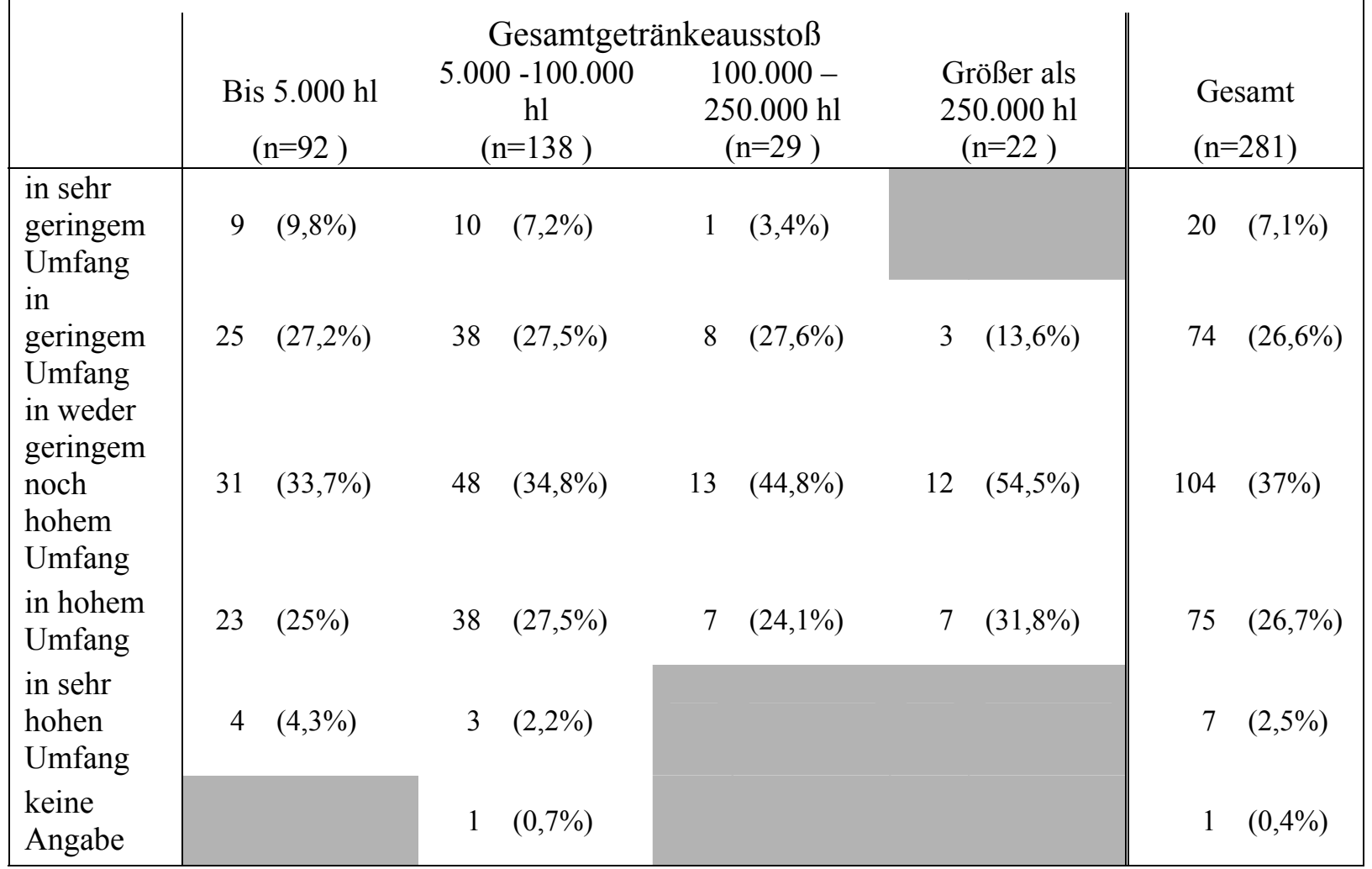

Quelle: Niederhut-Bollmann, C., Datensatz „Große Strategie-Studie 2005“, Göttingen 2005. 


\section{Frage II 5.1: Wie beurteilen Sie die Verhandlungsmacht der unabhängigen} Getränkeeinzelhändler gegenüber Ihrem Unternehmen?

\begin{tabular}{|c|c|c|c|c|c|}
\hline & $\begin{array}{c}\text { Bis } 5.000 \mathrm{hl} \\
\quad(\mathrm{n}=92)\end{array}$ & $\begin{array}{c}\text { Gesamtgetı } \\
5.000- \\
100.000 \mathrm{hl} \\
(\mathrm{n}=138)\end{array}$ & $\begin{array}{l}\text { keausstoß } \\
100.000- \\
250.000 \mathrm{hl} \\
(\mathrm{n}=29)\end{array}$ & $\begin{array}{c}\text { Größer als } \\
250.000 \mathrm{hl} \\
(\mathrm{n}=22)\end{array}$ & $\begin{array}{l}\text { Gesamt } \\
(\mathrm{n}=281)\end{array}$ \\
\hline $\begin{array}{l}\text { sehr } \\
\text { niedrig }\end{array}$ & $16 \quad(17,4 \%)$ & $10 \quad(7,2 \%)$ & $3 \quad(10,3 \%)$ & $3 \quad(13,6 \%)$ & $32 \quad(11,4 \%)$ \\
\hline niedrig & $16 \quad(17,4 \%)$ & $33 \quad(23,9 \%)$ & $9 \quad(31 \%)$ & $6 \quad(27,3 \%)$ & $64 \quad(22,8 \%)$ \\
\hline $\begin{array}{l}\text { weder } \\
\text { niedrig } \\
\text { noch hoch }\end{array}$ & $25 \quad(27,2 \%)$ & $61 \quad(44,2 \%)$ & $12(41,4 \%)$ & $10 \quad(45,5 \%)$ & $108 \quad(38,4 \%)$ \\
\hline hoch & $15 \quad(16,3 \%)$ & $29 \quad(21 \%)$ & $5 \quad(17,2 \%)$ & $2 \quad(9,1 \%)$ & $51 \quad(18,1 \%)$ \\
\hline sehr hoch & $6 \quad(6,5 \%)$ & $2 \quad(1,4 \%)$ & & & $8 \quad(2,8 \%)$ \\
\hline $\begin{array}{l}\text { keine } \\
\text { Angabe }\end{array}$ & $14 \quad(15,2 \%)$ & $3 \quad(2,2 \%)$ & & $1 \quad(4,5 \%)$ & $18 \quad(6,4 \%)$ \\
\hline
\end{tabular}

Quelle: Niederhut-Bollmann, C., Datensatz „Große Strategie-Studie 2005“, Göttingen 2005.

\begin{tabular}{|c|c|c|c|c|c|}
\hline \multirow[t]{2}{*}{ Frage II 5.2} & \multicolumn{5}{|c|}{$\begin{array}{l}\text { Wie beurteilen Sie die Verhandlungsmacht von Getränkeeinzelhandels- } \\
\text { ketten gegenüber Ihrem Unternehmen? }\end{array}$} \\
\hline & $\begin{array}{c}\text { Bis } 5.000 \mathrm{hl} \\
\quad(\mathrm{n}=92)\end{array}$ & $\begin{array}{c}\text { Gesamtgetr } \\
5.000- \\
100.000 \mathrm{hl} \\
(\mathrm{n}=138)\end{array}$ & $\begin{array}{l}\text { keausstoß } \\
100.000- \\
250.000 \mathrm{hl} \\
(\mathrm{n}=29)\end{array}$ & $\begin{array}{c}\text { Größer als } \\
250.000 \mathrm{hl} \\
(\mathrm{n}=22)\end{array}$ & $\begin{array}{l}\text { Gesamt } \\
(\mathrm{n}=281)\end{array}$ \\
\hline $\begin{array}{l}\text { sehr } \\
\text { niedrig }\end{array}$ & $22 \quad(23,9 \%)$ & $6 \quad(4,3 \%)$ & & & $28 \quad(10 \%)$ \\
\hline niedrig & $10 \quad(10,9 \%)$ & $20 \quad(14,5 \%)$ & $2 \quad(6,9 \%)$ & $2 \quad(9,1 \%)$ & $34 \quad(12,1 \%)$ \\
\hline $\begin{array}{l}\text { weder } \\
\text { niedrig } \\
\text { noch hoch }\end{array}$ & $16(17,4 \%)$ & $37 \quad(26,8 \%)$ & $8 \quad(27,6 \%)$ & $6 \quad(27,3 \%)$ & $67 \quad(23,8 \%)$ \\
\hline hoch & $13(14,1 \%)$ & $47 \quad(34,1 \%)$ & $17 \quad(58,6 \%)$ & $14(63,6 \%)$ & $91 \quad(32,4 \%)$ \\
\hline sehr hoch & $15 \quad(16,3 \%)$ & $21 \quad(15,2 \%)$ & $2 \quad(6,9 \%)$ & & $38 \quad(13,5 \%)$ \\
\hline $\begin{array}{l}\text { keine } \\
\text { Angabe }\end{array}$ & $16 \quad(17,4 \%)$ & $7 \quad(5,1 \%)$ & & & $23 \quad(8,2 \%)$ \\
\hline
\end{tabular}

Quelle: Niederhut-Bollmann, C., Datensatz „Große Strategie-Studie 2005“, Göttingen 2005. 


\begin{tabular}{|c|c|c|c|c|c|}
\hline \multirow[t]{2}{*}{ Frage II 5.3} & \multicolumn{5}{|c|}{$\begin{array}{l}\text { Wie beurteilen Sie die Verhandlungsmacht des Getränkefachgroßhandels } \\
\text { gegenüber Ihrem Unternehmen? }\end{array}$} \\
\hline & $\begin{array}{c}\text { Bis } 5.000 \mathrm{hl} \\
\quad(\mathrm{n}=92)\end{array}$ & $\begin{array}{l}\text { Gesamtgetı } \\
5.000- \\
100.000 \mathrm{hl} \\
(\mathrm{n}=138)\end{array}$ & $\begin{array}{l}\text { keaussto } \beta \\
100.000- \\
250.000 \mathrm{hl} \\
(\mathrm{n}=29)\end{array}$ & $\begin{array}{c}\text { Größer als } \\
250.000 \mathrm{hl} \\
(\mathrm{n}=22)\end{array}$ & $\begin{array}{l}\text { Gesamt } \\
(\mathrm{n}=281)\end{array}$ \\
\hline $\begin{array}{l}\text { sehr } \\
\text { niedrig }\end{array}$ & $20 \quad(21,7 \%)$ & $5 \quad(3,6 \%)$ & & & $25 \quad(8,9 \%)$ \\
\hline niedrig & $11(12 \%)$ & $12 \quad(8,7 \%)$ & & $4 \quad(18,2 \%)$ & $27 \quad(9,6 \%)$ \\
\hline $\begin{array}{l}\text { weder } \\
\text { niedrig } \\
\text { noch hoch }\end{array}$ & $18 \quad(19,6 \%)$ & $42 \quad(30,4 \%)$ & $9 \quad(31 \%)$ & $5 \quad(22,7 \%)$ & $74 \quad(26,3 \%)$ \\
\hline hoch & $14 \quad(15,2 \%)$ & $58 \quad(42 \%)$ & $18 \quad(62,1 \%)$ & $9 \quad(40,9 \%)$ & $99 \quad(35,2 \%)$ \\
\hline sehr hoch & $14 \quad(15,2 \%)$ & $16(11,6 \%)$ & $2 \quad(6,9 \%)$ & $4 \quad(18,2 \%)$ & $36 \quad(12,8 \%)$ \\
\hline $\begin{array}{l}\text { keine } \\
\text { Angabe }\end{array}$ & $15 \quad(16,3 \%)$ & $5 \quad(3,6 \%)$ & & & $20 \quad(7,1 \%)$ \\
\hline
\end{tabular}

Quelle: Niederhut-Bollmann, C., Datensatz „Große Strategie-Studie 2005“, Göttingen 2005.

\begin{tabular}{|c|c|c|c|c|c|}
\hline \multirow[t]{2}{*}{ Frage II 5.4} & \multicolumn{5}{|c|}{$\begin{array}{l}\text { Wie beurteilen Sie die Verhandlungsmacht des Lebensmitteleinzelhandels } \\
\text { gegenüber Ihrem Unternehmen? }\end{array}$} \\
\hline & $\begin{array}{l}\text { Bis } 5.000 \mathrm{hl} \\
\quad(\mathrm{n}=92)\end{array}$ & $\begin{array}{l}\text { Gesamtgetr } \\
5.000- \\
100.000 \mathrm{hl} \\
(\mathrm{n}=138)\end{array}$ & $\begin{array}{l}\text { keaussto } \\
100.000- \\
250.000 \mathrm{hl} \\
(\mathrm{n}=29)\end{array}$ & $\begin{array}{c}\text { Größer als } \\
250.000 \mathrm{hl} \\
(\mathrm{n}=22)\end{array}$ & $\begin{array}{l}\text { Gesamt } \\
(\mathrm{n}=281)\end{array}$ \\
\hline $\begin{array}{l}\text { sehr } \\
\text { niedrig }\end{array}$ & $26 \quad(28,3 \%)$ & $9 \quad(6,5 \%)$ & & $2 \quad(9,1 \%)$ & $37 \quad(13,2 \%)$ \\
\hline niedrig & $13 \quad(14,1 \%)$ & $24 \quad(17,4 \%)$ & $4 \quad(13,8 \%)$ & & $41 \quad(14,6 \%)$ \\
\hline $\begin{array}{l}\text { weder } \\
\text { niedrig } \\
\text { noch hoch }\end{array}$ & $18 \quad(19,6 \%)$ & $47 \quad(34,1 \%)$ & $12(41,4 \%)$ & $4 \quad(18,2 \%)$ & $81 \quad(28,8 \%)$ \\
\hline hoch & $12 \quad(13,0 \%)$ & $37 \quad(26,8 \%)$ & $6 \quad(20,7 \%)$ & $9 \quad(40,9 \%)$ & $64 \quad(22,8 \%)$ \\
\hline sehr hoch & $8 \quad(8,7 \%)$ & $16 \quad(11,6 \%)$ & $7 \quad(24,1 \%)$ & $7 \quad(31,8 \%)$ & $38 \quad(13,5 \%)$ \\
\hline $\begin{array}{l}\text { keine } \\
\text { Angabe }\end{array}$ & $15 \quad(16,3 \%)$ & $5 \quad(3,6 \%)$ & & & $20 \quad(7,1 \%)$ \\
\hline
\end{tabular}

Quelle: Niederhut-Bollmann, C., Datensatz „Große Strategie-Studie 2005“, Göttingen 2005. 


\begin{tabular}{|c|c|c|c|c|c|}
\hline \multirow[t]{2}{*}{ Frage II 5.5} & \multicolumn{5}{|c|}{$\begin{array}{l}\text { Wie beurteilen Sie die Verhandlungsmacht der Gastronomie gegenüber } \\
\text { Ihrem Unternehmen? }\end{array}$} \\
\hline & $\begin{array}{c}\text { Bis } 5.000 \mathrm{hl} \\
\quad(\mathrm{n}=92)\end{array}$ & $\begin{array}{c}\text { Gesamtget } \\
5.000- \\
100.000 \mathrm{hl} \\
(\mathrm{n}=138)\end{array}$ & $\begin{array}{l}\text { keausstoß } \\
100.000- \\
250.000 \mathrm{hl} \\
(\mathrm{n}=29)\end{array}$ & $\begin{array}{c}\text { Größer als } \\
250.000 \mathrm{hl} \\
(\mathrm{n}=22)\end{array}$ & $\begin{array}{l}\text { Gesamt } \\
(\mathrm{n}=281)\end{array}$ \\
\hline $\begin{array}{l}\text { sehr } \\
\text { niedrig }\end{array}$ & $9 \quad(9,8 \%)$ & $5 \quad(3,6 \%)$ & $2 \quad(6,9 \%)$ & $1 \quad(4,5 \%)$ & $17 \quad(6 \%)$ \\
\hline niedrig & $22 \quad(23,9 \%)$ & $19(13,8 \%)$ & $4 \quad(13,8 \%)$ & $7 \quad(31,8 \%)$ & $52 \quad(18,5 \%)$ \\
\hline $\begin{array}{l}\text { weder } \\
\text { niedrig } \\
\text { noch hoch }\end{array}$ & $28 \quad(30,4 \%)$ & $66 \quad(47,8 \%)$ & $16 \quad(55,2 \%)$ & $11 \quad(50 \%)$ & $121 \quad(43,1 \%)$ \\
\hline hoch & $18 \quad(19,6 \%)$ & $35 \quad(25,4 \%)$ & $6 \quad(20,7 \%)$ & $2 \quad(9,1 \%)$ & $61 \quad(21,7 \%)$ \\
\hline sehr hoch & $5 \quad(5,4 \%)$ & $10 \quad(7,2 \%)$ & $1 \quad(3,4 \%)$ & & $16 \quad(5,7 \%)$ \\
\hline $\begin{array}{l}\text { keine } \\
\text { Angabe }\end{array}$ & $10 \quad(10,9 \%)$ & $3 \quad(2,2 \%)$ & & $1 \quad(4,5 \%)$ & $14 \quad(5 \%)$ \\
\hline
\end{tabular}

Quelle: Niederhut-Bollmann, C., Datensatz „Große Strategie-Studie 2005“, Göttingen 2005.

\section{Frage II 6: Wie beurteilen Sie die Verhandlungsmacht der wichtigsten Lieferanten gegenüber Ihrem Unternehmen?}

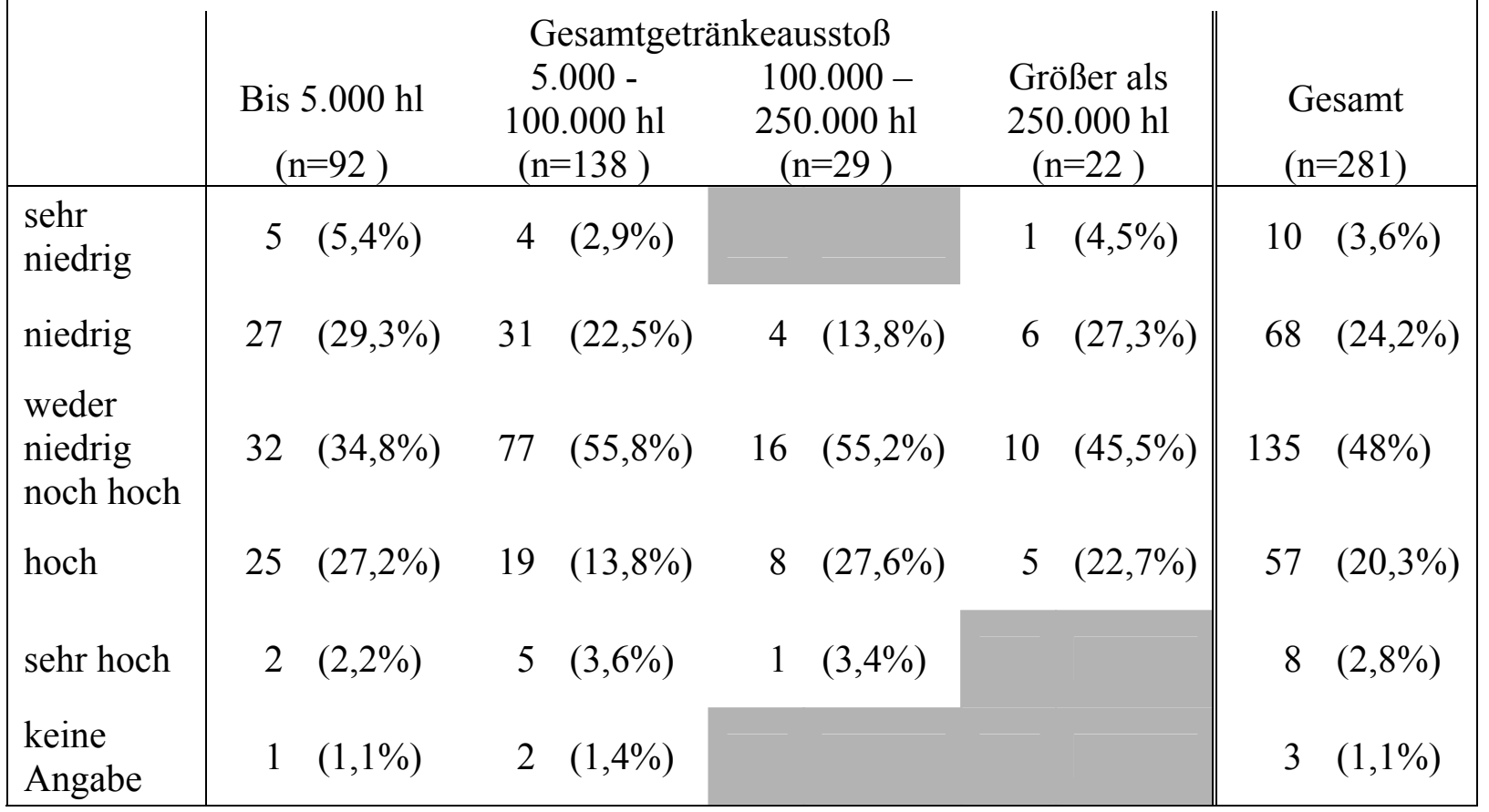

Quelle: Niederhut-Bollmann, C., Datensatz „Große Strategie-Studie 2005“, Göttingen 2005. 


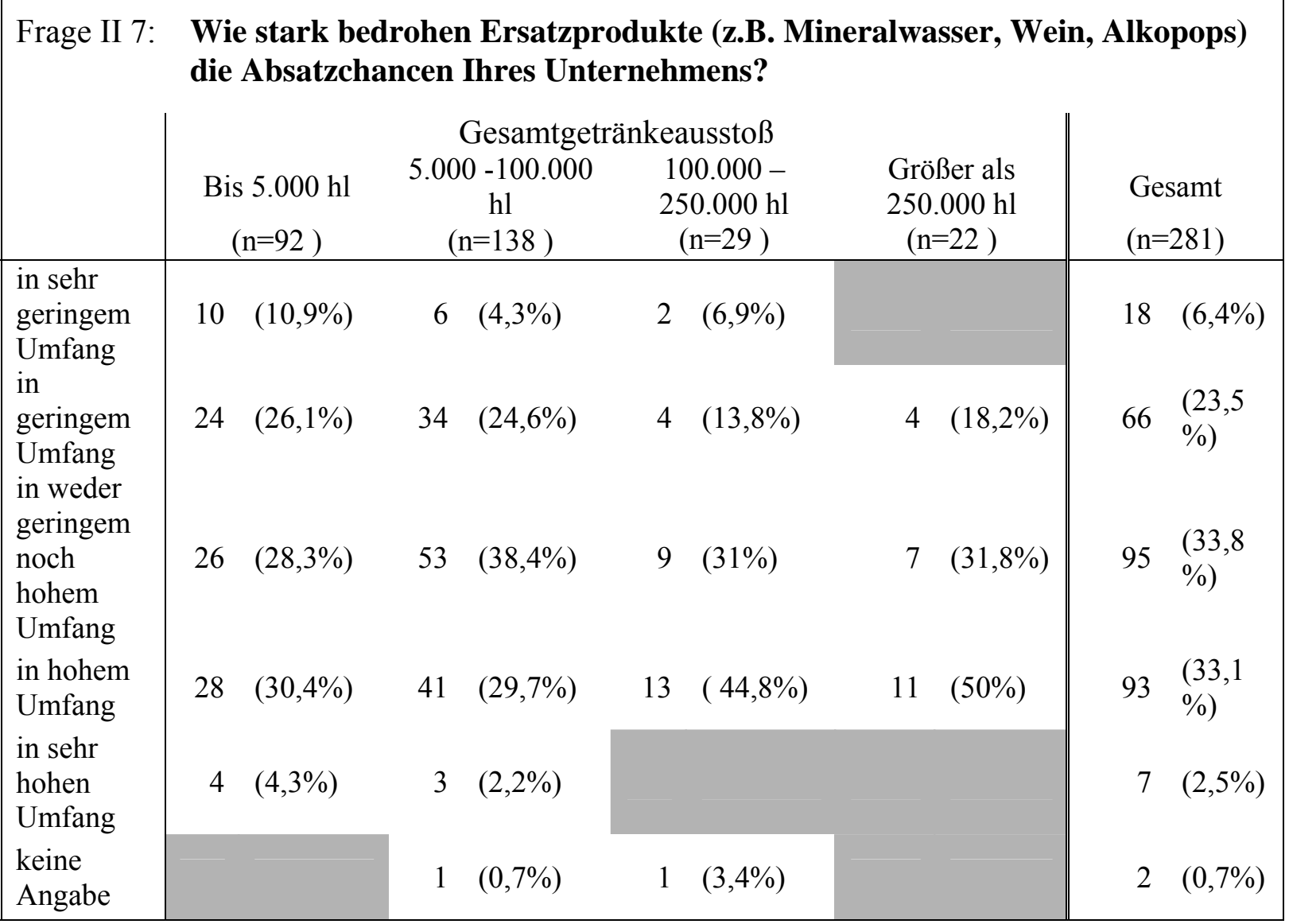

Quelle: Niederhut-Bollmann, C., Datensatz „Große Strategie-Studie 2005“, Göttingen 2005.

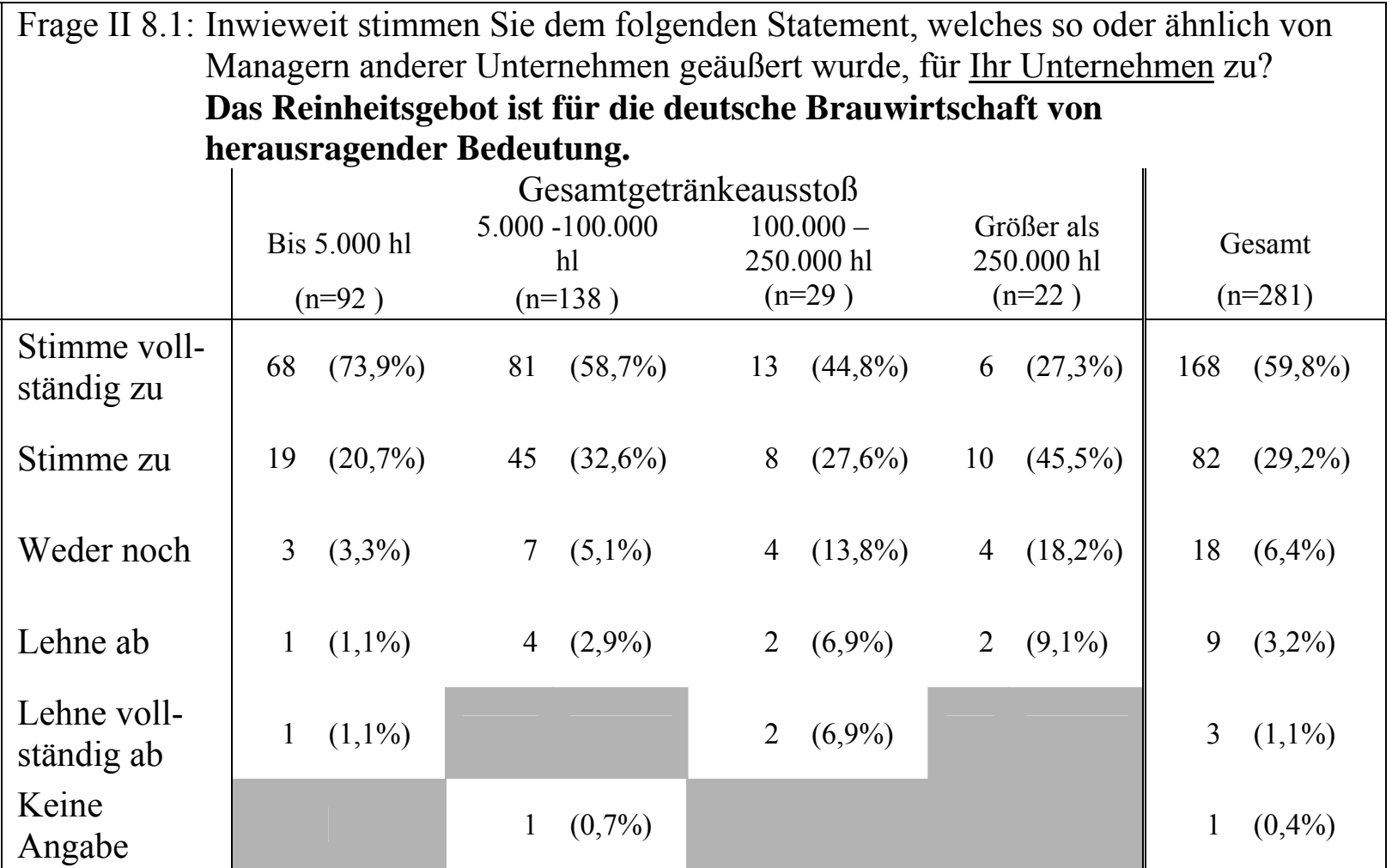

Quelle: Niederhut-Bollmann, C., Datensatz „Große Strategie-Studie 2005“, Göttingen 2005. 


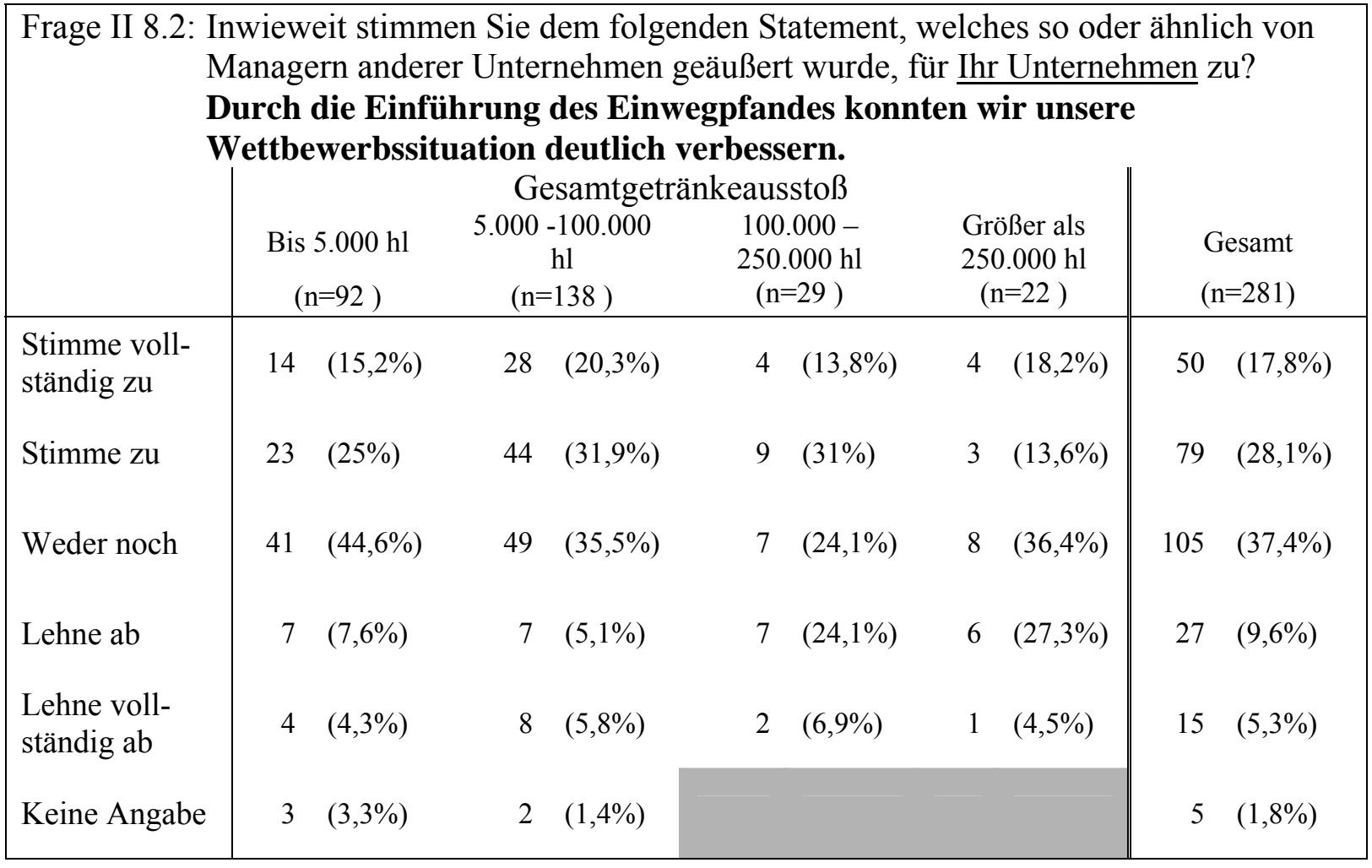

Quelle: Niederhut-Bollmann, C., Datensatz „Große Strategie-Studie 2005“, Göttingen 2005.

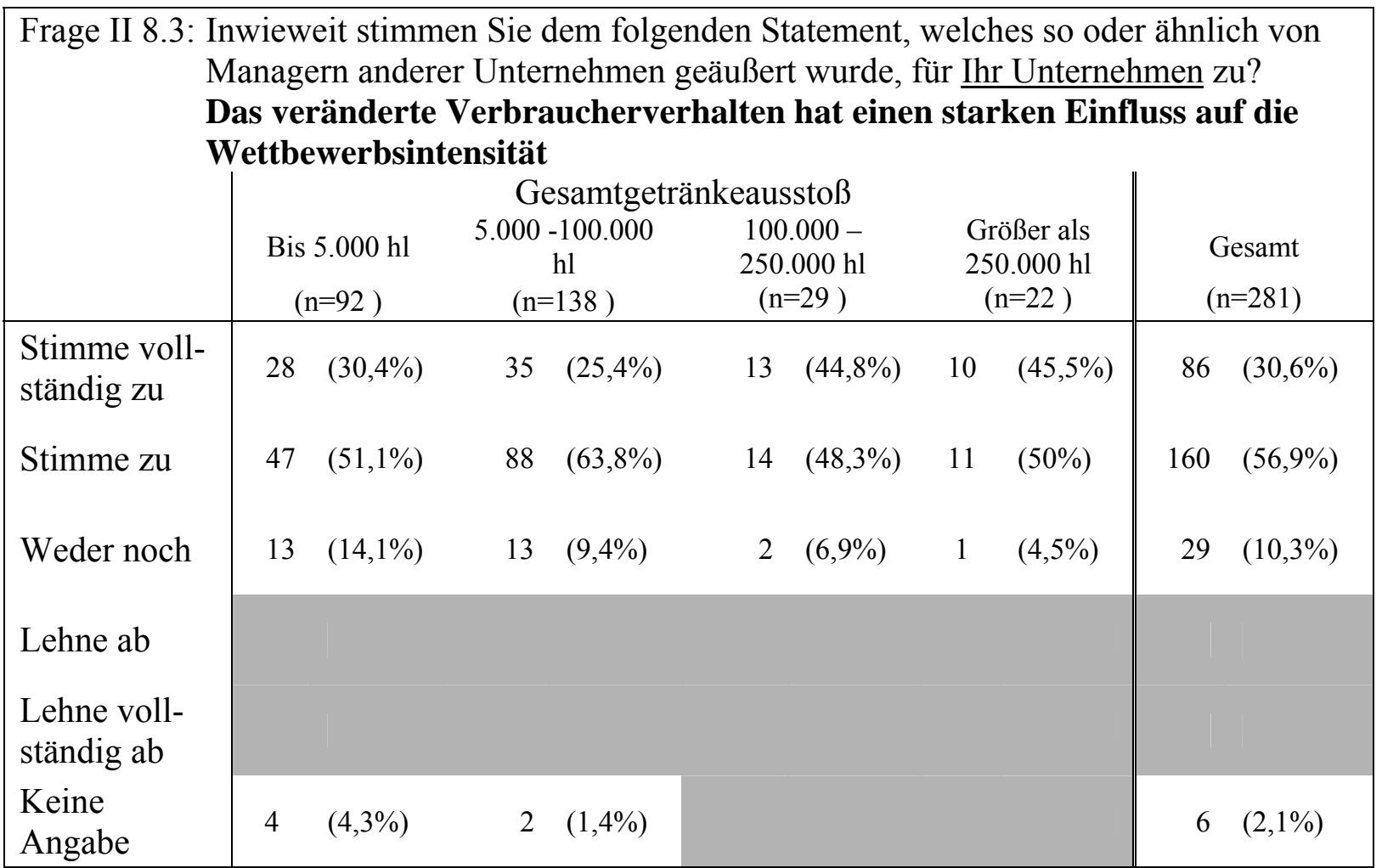

Quelle: Niederhut-Bollmann, C., Datensatz „Große Strategie-Studie 2005“, Göttingen 2005. 


\begin{tabular}{|c|c|c|c|c|c|c|}
\hline & \multicolumn{6}{|c|}{$\begin{array}{l}\text { Wieweit stimmen Sie dem folgenden Statement, welches so oder ähnlich von } \\
\text { Ianagern anderer Unternehmen geäußert wurde, für Ihr Unternehmen zu? } \\
\text { ie steuerlichen Rahmenbedingungen (z.B. Biersteuererhöhung, Ökosteuer) } \\
\text { hen wir als eine starke Belastung für die zukünftige Entwicklung an. }\end{array}$} \\
\hline & $\begin{array}{l}\text { Bis } 5.000 \mathrm{hl} \\
\quad(\mathrm{n}=92)\end{array}$ & $\begin{array}{c}5.000-100.000 \\
\mathrm{hl} \\
(\mathrm{n}=138)\end{array}$ & $\begin{array}{l}100.000- \\
250.000 \mathrm{hl} \\
(\mathrm{n}=29)\end{array}$ & $\begin{array}{l}\text { Größer als } \\
250.000 \mathrm{hl} \\
(\mathrm{n}=22)\end{array}$ & \multicolumn{2}{|c|}{$\begin{array}{l}\text { Gesamt } \\
(\mathrm{n}=281)\end{array}$} \\
\hline $\begin{array}{l}\text { Stimme voll- } \\
\text { ständig zu }\end{array}$ & $39 \quad(42,4 \%)$ & $79 \quad(57,2 \%)$ & $14 \quad(48,3 \%)$ & $7 \quad(31,8 \%)$ & 139 & $(49,5 \%)$ \\
\hline Stimme zu & $38 \quad(41,3 \%)$ & $48 \quad(34,8 \%)$ & $12 \quad(41,4 \%)$ & $10 \quad(45,5 \%)$ & 108 & $(38,4 \%)$ \\
\hline Weder noch & $(10,9 \%)$ & $5 \quad(3,6 \%)$ & $(6,9 \%)$ & $5 \quad(22,7 \%)$ & 22 & $(7,8 \%)$ \\
\hline Lehne ab & $(4,3 \%)$ & $5 \quad(3,6 \%)$ & $1 \quad(3,4 \%)$ & & 10 & $(3,6 \%)$ \\
\hline $\begin{array}{l}\text { Lehne voll- } \\
\text { ständig ab }\end{array}$ & & & & & & \\
\hline $\begin{array}{l}\text { Keine } \\
\text { Angabe }\end{array}$ & $1 \quad(1,1 \%)$ & $1 \quad(0,7 \%)$ & & & 2 & $(0,7 \%)$ \\
\hline
\end{tabular}

Quelle: Niederhut-Bollmann, C., Datensatz „Große Strategie-Studie 2005“, Göttingen 2005.

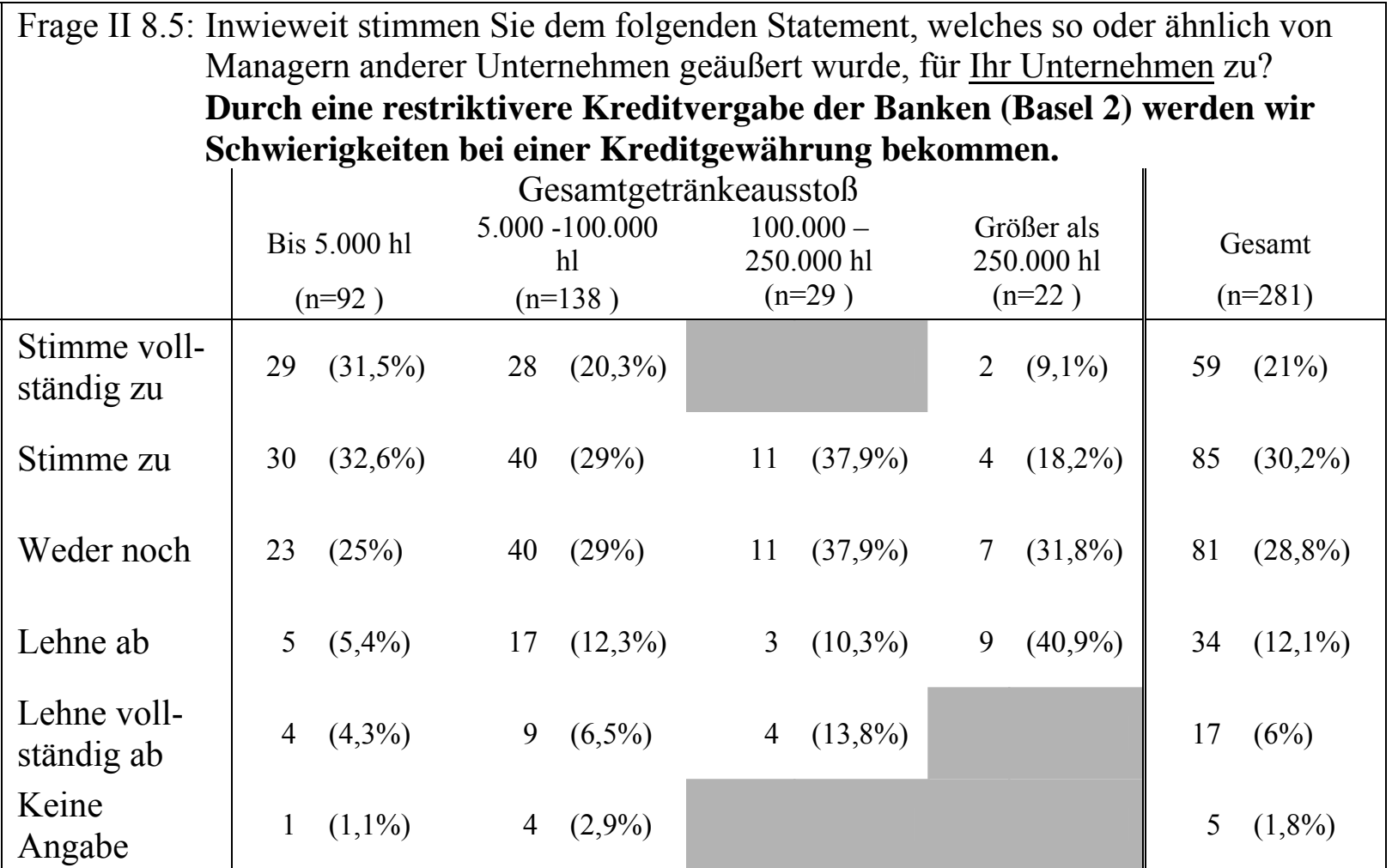

Quelle: Niederhut-Bollmann, C., Datensatz „Große Strategie-Studie 2005“, Göttingen 2005. 


\begin{tabular}{|c|c|c|c|c|c|c|c|c|c|}
\hline \multirow[t]{3}{*}{ 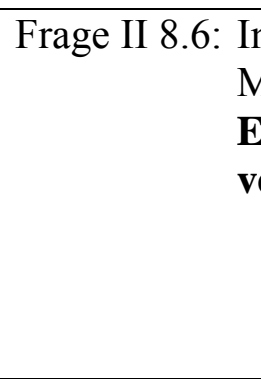 } & \multicolumn{9}{|c|}{$\begin{array}{l}\text { wieweit stimmen Sie dem folgenden Statement, welches so oder ähnlich von } \\
\text { anagern anderer Unternehmen geäußert wurde, für Ihr Unternehmen zu? } \\
\text { in Werbeverbot für Bier würde unsere Wettbewerbssituation deutlich } \\
\text { arschlechtern. }\end{array}$} \\
\hline & \multirow[b]{2}{*}{$\begin{array}{l}\text { Bis } 5.000 \mathrm{hl} \\
\quad(\mathrm{n}=92)\end{array}$} & \multicolumn{4}{|c|}{ Gesamtgetränkeausstoß } & \multirow{2}{*}{\multicolumn{2}{|c|}{$\begin{array}{l}\text { Größer als } \\
250.000 \mathrm{hl} \\
(\mathrm{n}=22)\end{array}$}} & \multirow{2}{*}{\multicolumn{2}{|c|}{$\begin{array}{l}\text { Gesamt } \\
(\mathrm{n}=281)\end{array}$}} \\
\hline & & $\begin{array}{r}5.000 \\
(\mathrm{n}\end{array}$ & $\begin{array}{l}100.000 \\
1 \\
138)\end{array}$ & & $\begin{array}{l}000- \\
000 \mathrm{hl} \\
29)\end{array}$ & & & & \\
\hline $\begin{array}{l}\text { Stimme voll- } \\
\text { ständig zu }\end{array}$ & $37 \quad(40,2 \%)$ & 24 & $(17,4 \%)$ & 7 & $(24,1 \%)$ & & $(22,7 \%)$ & 73 & $(26 \%)$ \\
\hline Stimme zu & $21 \quad(22,8 \%)$ & 32 & $(23,2 \%)$ & 8 & $(27,6 \%)$ & 5 & $(22,7 \%)$ & 66 & $(23,5 \%)$ \\
\hline Weder noch & $(22,8 \%)$ & 49 & $(35,5 \%)$ & 11 & $(37,9 \%)$ & 8 & $(36,4 \%)$ & 89 & $(31,7 \%)$ \\
\hline Lehne ab & $(9,8 \%)$ & 22 & $(15,9 \%)$ & 1 & $(3,4 \%)$ & & $(18,2 \%)$ & 36 & $(12,8 \%)$ \\
\hline $\begin{array}{l}\text { Lehne voll- } \\
\text { ständig ab }\end{array}$ & $(4,3 \%)$ & 10 & $(7,2 \%)$ & 1 & $(3,4 \%)$ & & & 15 & $(5,3 \%)$ \\
\hline $\begin{array}{l}\text { Keine } \\
\text { Angabe }\end{array}$ & & & $(0,7 \%)$ & 1 & $(3,4 \%)$ & & & 2 & $(0,7 \%)$ \\
\hline
\end{tabular}

Quelle: Niederhut-Bollmann, C., Datensatz „Große Strategie-Studie 2005“, Göttingen 2005.

\section{Frage II 9.1: Hat Ihr Unternehmen in den letzten Jahren 5 Jahren eine oder mehrere andere Brauereien verkauft oder zugekauft?}

\begin{tabular}{|c|c|c|c|c|c|}
\hline & & Gesamtget & keausstoß & & \\
\hline & $\begin{array}{c}\text { Bis } 5.000 \mathrm{hl} \\
\quad(\mathrm{n}=92)\end{array}$ & $\begin{array}{c}5.000- \\
100.000 \mathrm{hl} \\
(\mathrm{n}=138)\end{array}$ & $\begin{array}{c}100.000- \\
250.000 \mathrm{hl} \\
(\mathrm{n}=29)\end{array}$ & $\begin{array}{c}\text { Größer als } \\
250.000 \mathrm{hl} \\
(\mathrm{n}=22) \\
\end{array}$ & $\begin{array}{l}\text { Gesamt } \\
(n=281)\end{array}$ \\
\hline Zukäufe & $3 \quad(3,3 \%)$ & $7 \quad(5,1 \%)$ & $5 \quad(17,2 \%)$ & $9 \quad(40,9 \%)$ & $24 \quad(8,5 \%)$ \\
\hline Verkäufe & & & & $1 \quad(4,5 \%)$ & $1 \quad(0,4 \%)$ \\
\hline $\begin{array}{l}\text { Weder } \\
\text { Zukäufe } \\
\text { noch } \\
\text { Verkäufe }\end{array}$ & $84 \quad(91,3 \%)$ & $126 \quad(91,3 \%)$ & $23 \quad(79,3 \%)$ & $12(54,5 \%)$ & $245 \quad(87,2 \%)$ \\
\hline $\begin{array}{l}\text { Zukäufe } \\
\text { und } \\
\text { Verkäufe }\end{array}$ & & $1 \quad(0,7 \%)$ & & & $1 \quad(0,4 \%)$ \\
\hline $\begin{array}{l}\text { keine } \\
\text { Angabe }\end{array}$ & $5 \quad(5,4 \%)$ & $4 \quad(2,9 \%)$ & $1 \quad(3,4 \%)$ & & $10 \quad(3,6 \%)$ \\
\hline
\end{tabular}

Quelle: Niederhut-Bollmann, C., Datensatz „Große Strategie-Studie 2005“, Göttingen 2005. 


\begin{tabular}{|c|c|c|c|c|c|}
\hline \multicolumn{6}{|c|}{$\begin{array}{l}\text { Frage II 9.2: Hat Ihr Unternehmen in den letzten Jahren } 5 \text { Jahren Markenrechte } \\
\text { (Lizenzen) von anderen Brauereien zugekauft oder an andere verkauft? }\end{array}$} \\
\hline & $\begin{array}{c}\text { Bis } 5.000 \mathrm{hl} \\
(\mathrm{n}=92)\end{array}$ & $\begin{array}{c}\text { Gesamtget } \\
5.000- \\
100.000 \mathrm{hl} \\
(\mathrm{n}=138) \\
\end{array}$ & $\begin{array}{l}\text { keaussto } \beta \\
100.000- \\
250.000 \mathrm{hl} \\
(\mathrm{n}=29)\end{array}$ & $\begin{array}{c}\text { Größer als } \\
250.000 \mathrm{hl} \\
(\mathrm{n}=22)\end{array}$ & $\begin{array}{l}\text { Gesamt } \\
(\mathrm{n}=281)\end{array}$ \\
\hline Zukäufe & $2 \quad(2,2 \%)$ & $8 \quad(5,8 \%)$ & $5 \quad(17,2 \%)$ & $4 \quad(18,2 \%)$ & $19 \quad(6,8 \%)$ \\
\hline Verkäufe & $1 \quad(1,1 \%)$ & & $1 \quad(3,4 \%)$ & $1 \quad(4,5 \%)$ & $3 \quad(1,1 \%)$ \\
\hline $\begin{array}{l}\text { Weder } \\
\text { Zukäufe } \\
\text { noch } \\
\text { Verkäufe }\end{array}$ & $85 \quad(92,4 \%)$ & $125(90,6 \%)$ & $22 \quad(75,9 \%)$ & $17 \quad(77,3 \%)$ & $249(88,6 \%)$ \\
\hline $\begin{array}{l}\text { keine } \\
\text { Angabe }\end{array}$ & $4 \quad(4,3 \%)$ & $5 \quad(3,6 \%)$ & $1 \quad(3,4 \%)$ & & $10 \quad(3,6 \%)$ \\
\hline
\end{tabular}

Quelle: Niederhut-Bollmann, C., Datensatz „Große Strategie-Studie 2005“, Göttingen 2005.

\begin{tabular}{|c|c|c|c|c|c|}
\hline \multicolumn{6}{|c|}{$\begin{array}{l}\text { Frage II 9.3: Hat Ihr Unternehmen in den letzten Jahren } 5 \text { Jahren andere } \\
\text { Getränkeproduzenten (z.B. Brunnenbetriebe, Spirituosen) zugekauft oder } \\
\text { verkauft? }\end{array}$} \\
\hline & & Gesamtget & keausstoß & & \multirow[b]{2}{*}{$\begin{array}{l}\text { Gesamt } \\
(\mathrm{n}=281)\end{array}$} \\
\hline & $\begin{array}{c}\text { Bis } 5.000 \mathrm{hl} \\
(\mathrm{n}=92)\end{array}$ & $\begin{array}{l}5.000- \\
100.000 \mathrm{hl} \\
(\mathrm{n}=138)\end{array}$ & $\begin{array}{l}100.000- \\
250.000 \mathrm{hl} \\
(\mathrm{n}=29)\end{array}$ & $\begin{array}{l}\text { Größer als } \\
250.000 \mathrm{hl} \\
(\mathrm{n}=22)\end{array}$ & \\
\hline Zukäufe & $1 \quad(1,1 \%)$ & $1 \quad(0,7 \%)$ & $1 \quad(3,4 \%)$ & $1 \quad(4,5 \%)$ & $4 \quad(1,4 \%)$ \\
\hline Verkäufe & & & & $1 \quad(4,5 \%)$ & $1 \quad(0,4 \%)$ \\
\hline \multirow{3}{*}{$\begin{array}{l}\text { Weder } \\
\text { Zukäufe } \\
\text { noch } \\
\text { Verkäufe } \\
\text { Zukäufe } \\
\text { und } \\
\text { Verkäufe } \\
\text { keine } \\
\text { Angabe }\end{array}$} & $86 \quad(93,5 \%)$ & $131 \quad(94,9 \%)$ & $26 \quad(89,7 \%)$ & $20 \quad(90,9 \%)$ & $263 \quad(93,6 \%)$ \\
\hline & & $1 \quad(0,7 \%)$ & & & $1 \quad(0,4 \%)$ \\
\hline & $5 \quad(5,4 \%)$ & $5 \quad(3,6 \%)$ & $2 \quad(6,9 \%)$ & & $12 \quad(4,3 \%)$ \\
\hline
\end{tabular}

Quelle: Niederhut-Bollmann, C., Datensatz „Große Strategie-Studie 2005“, Göttingen 2005. 
Frage II 9.4: Hat Ihr Unternehmen in den letzten Jahren 5 Jahren Gastronomieobjekte zugekauft oder verkauft?

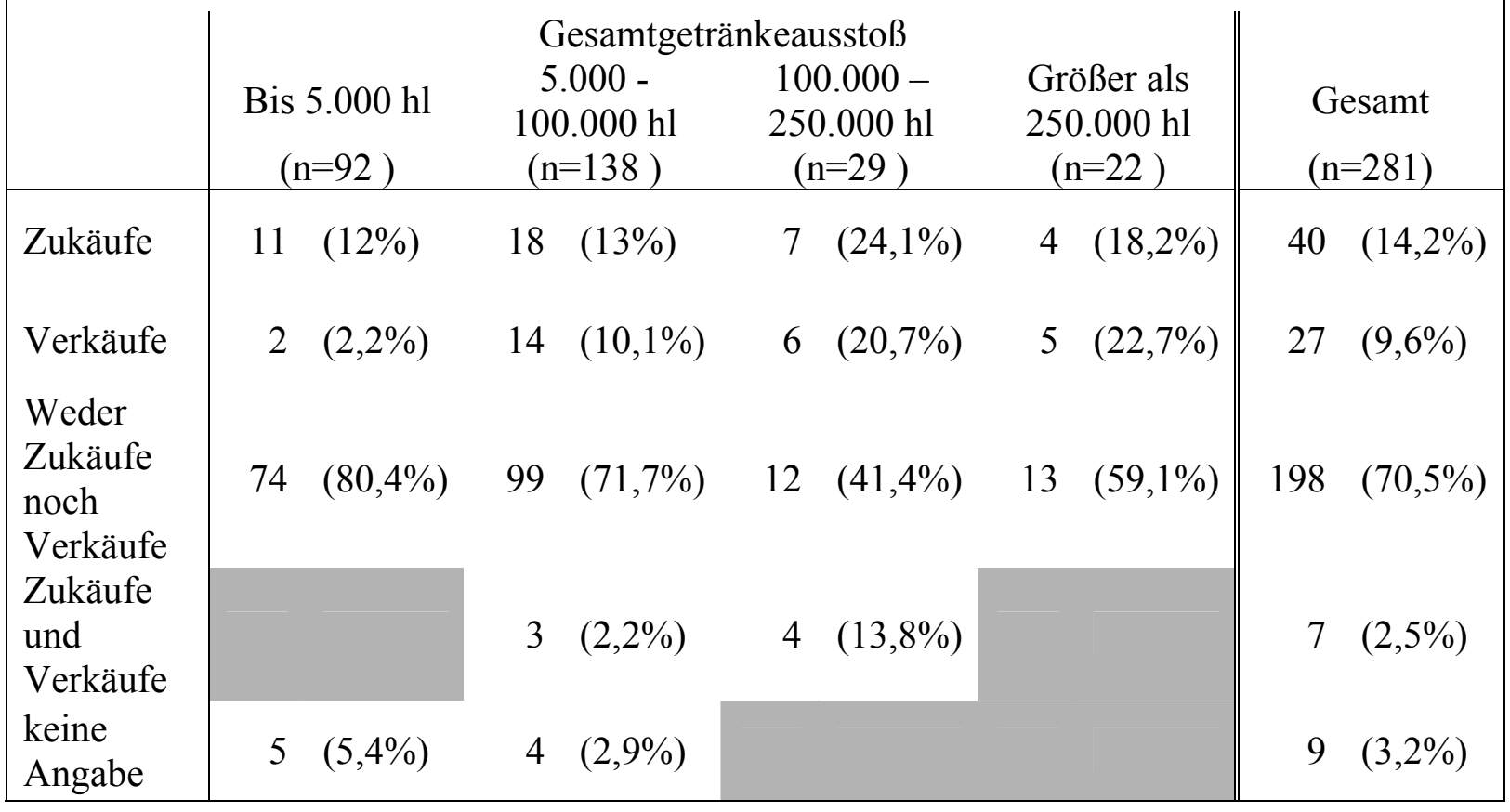

Quelle: Niederhut-Bollmann, C., Datensatz „Große Strategie-Studie 2005“, Göttingen 2005.

Frage II 9.5: Hat Ihr Unternehmen in den letzten 5 Jahren bei Aktivitäten ohne Bezug zum Kerngeschäft (z.B. Immobilien) Zukaufe oder Verkäufe durchgeführt?

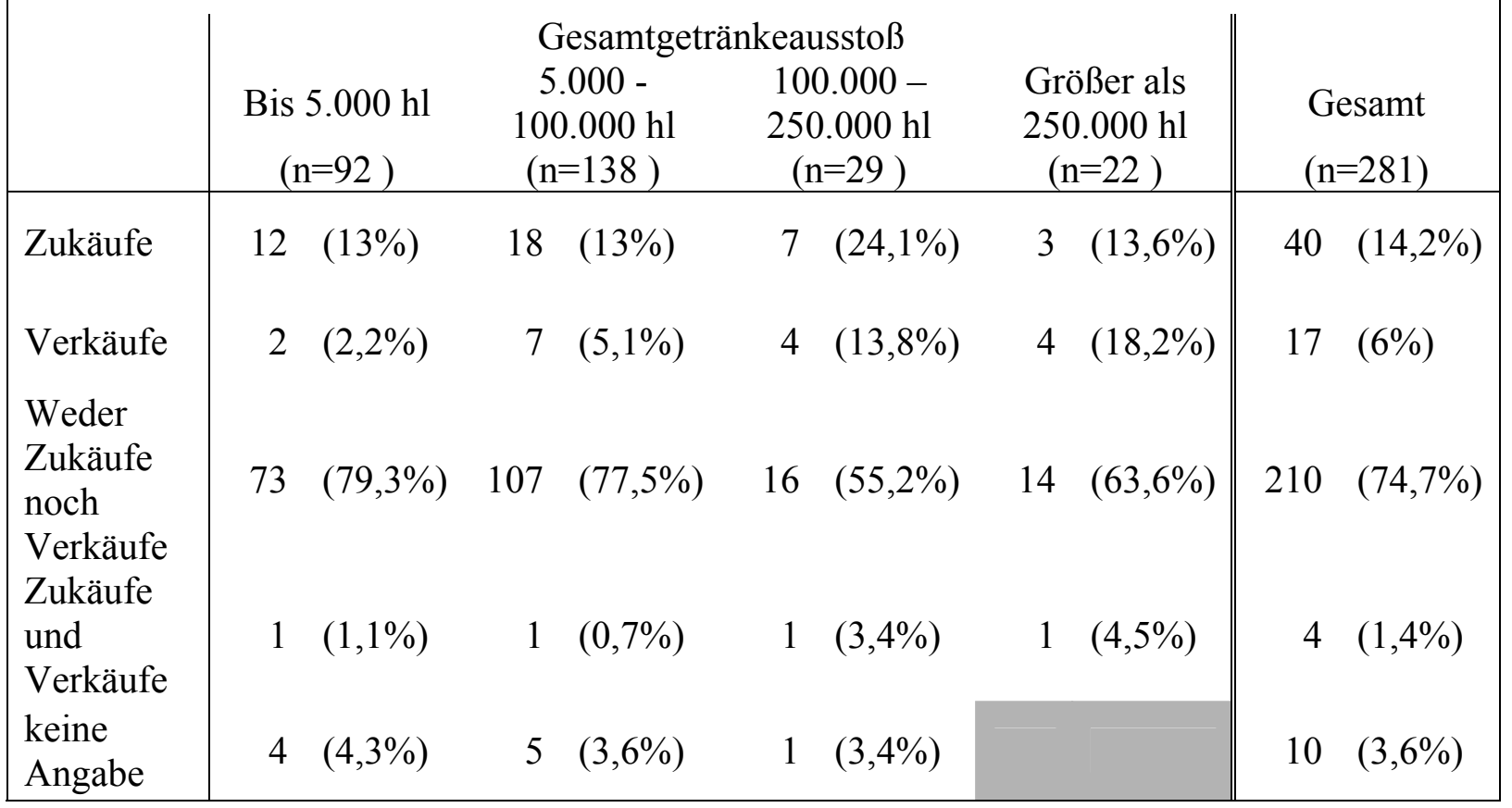

Quelle: Niederhut-Bollmann, C., Datensatz „Große Strategie-Studie 2005“, Göttingen 2005. 


\begin{tabular}{|c|c|c|c|c|c|}
\hline \multirow[t]{2}{*}{ Frag } & \multicolumn{5}{|c|}{$\begin{array}{l}\text { Haben Sie in der Vergangenheit eine Übernahme eines oder mehrerer } \\
\text { Getränkefachgroßhändler vorgenommen oder planen Sie eine solche } \\
\text { Übernahme? }\end{array}$} \\
\hline & $\begin{array}{l}\text { Bis } 5.000 \mathrm{hl} \\
\quad(\mathrm{n}=92)\end{array}$ & $\begin{array}{l}\text { Gesamtgetr } \\
5.000- \\
100.000 \mathrm{hl} \\
(\mathrm{n}=138)\end{array}$ & $\begin{array}{l}\text { keausstoß } \\
100.000- \\
250.000 \mathrm{hl} \\
(\mathrm{n}=29)\end{array}$ & $\begin{array}{l}\text { Größer als } \\
250.000 \mathrm{hl} \\
(\mathrm{n}=22)\end{array}$ & $\begin{array}{l}\text { Gesamt } \\
(\mathrm{n}=281)\end{array}$ \\
\hline $\mathrm{Ja}$ & $1 \quad(1,1 \%)$ & $3 \quad(2,2 \%)$ & $3 \quad(10,3 \%)$ & $1 \quad(4,5 \%)$ & $8 \quad(2,8 \%)$ \\
\hline $\begin{array}{l}\text { In } \\
\text { Planung }\end{array}$ & $2 \quad(2,2 \%)$ & $4 \quad(2,9 \%)$ & $2 \quad(6,9 \%)$ & $4 \quad(18,2 \%)$ & $12 \quad(4,3 \%)$ \\
\hline $\begin{array}{l}\text { Ja und } \\
\text { weitere in } \\
\text { Planung }\end{array}$ & $1 \quad(1,1 \%)$ & & $2(6,9 \%)$ & $1 \quad(4,5 \%)$ & $4 \quad(1,4 \%)$ \\
\hline Nein & $86 \quad(93,5 \%)$ & $129 \quad(93,5 \%)$ & $22 \quad(75,9 \%)$ & $16 \quad(72,7 \%)$ & $253 \quad(90 \%)$ \\
\hline $\begin{array}{l}\text { keine } \\
\text { Angabe }\end{array}$ & $2 \quad(2,2 \%)$ & $2 \quad(1,4 \%)$ & & & $4 \quad(1,4 \%)$ \\
\hline
\end{tabular}

Quelle: Niederhut-Bollmann, C., Datensatz „Große Strategie-Studie 2005“, Göttingen 2005.

\begin{tabular}{|c|c|c|c|c|c|}
\hline \multicolumn{6}{|c|}{$\begin{array}{l}\text { Frage II 11.1: Wie beurteilen Sie die Wettbewerbsposition Ihres Unternehmens im } \\
\text { Vergleich zu Ihren stärksten Mitbewerbern hinsichtlich der Qualität } \\
\text { der Produkte? }\end{array}$} \\
\hline & \multicolumn{4}{|c|}{ Gesamtgetränkeausstoß } & \multirow[b]{2}{*}{$\begin{array}{l}\text { Gesamt } \\
(\mathrm{n}=281)\end{array}$} \\
\hline & $\begin{array}{l}\text { Bis } 5.000 \mathrm{hl} \\
\quad(\mathrm{n}=92)\end{array}$ & $\begin{array}{c}5.000- \\
100.000 \mathrm{hl} \\
(\mathrm{n}=138)\end{array}$ & $\begin{array}{c}100.000- \\
250.000 \mathrm{hl} \\
(\mathrm{n}=29)\end{array}$ & $\begin{array}{c}\text { Größer als } \\
250.000 \mathrm{hl} \\
(\mathrm{n}=22)\end{array}$ & \\
\hline $\begin{array}{l}\text { deutlich } \\
\text { niedriger }\end{array}$ & $4 \quad(4,3 \%)$ & & & & $4 \quad(1,4 \%)$ \\
\hline niedriger & $10 \quad(10,9 \%)$ & $3(2,2 \%)$ & $1 \quad(3,4 \%)$ & $1 \quad(4,5 \%)$ & $15 \quad(5,3 \%)$ \\
\hline gleich & $28 \quad(30,4 \%)$ & $56 \quad(40,6 \%)$ & $7 \quad(24,1 \%)$ & $9 \quad(40,9 \%)$ & $100 \quad(35,6 \%)$ \\
\hline höher & $30 \quad(32,6 \%)$ & $65(47,1 \%)$ & $15 \quad(51,7 \%)$ & $10 \quad(45,5 \%)$ & $120 \quad(42,7 \%)$ \\
\hline $\begin{array}{l}\text { deutlich } \\
\text { höher }\end{array}$ & $16(17,4 \%)$ & $12(8,7 \%)$ & $6 \quad(20,7 \%)$ & $2(9,1 \%)$ & $36 \quad(12,8 \%)$ \\
\hline $\begin{array}{l}\text { keine } \\
\text { Angabe }\end{array}$ & $4 \quad(4,3 \%)$ & $2(1,4 \%)$ & & & $6 \quad(2,1 \%)$ \\
\hline
\end{tabular}

Quelle: Niederhut-Bollmann, C., Datensatz „Große Strategie-Studie 2005“, Göttingen 2005. 


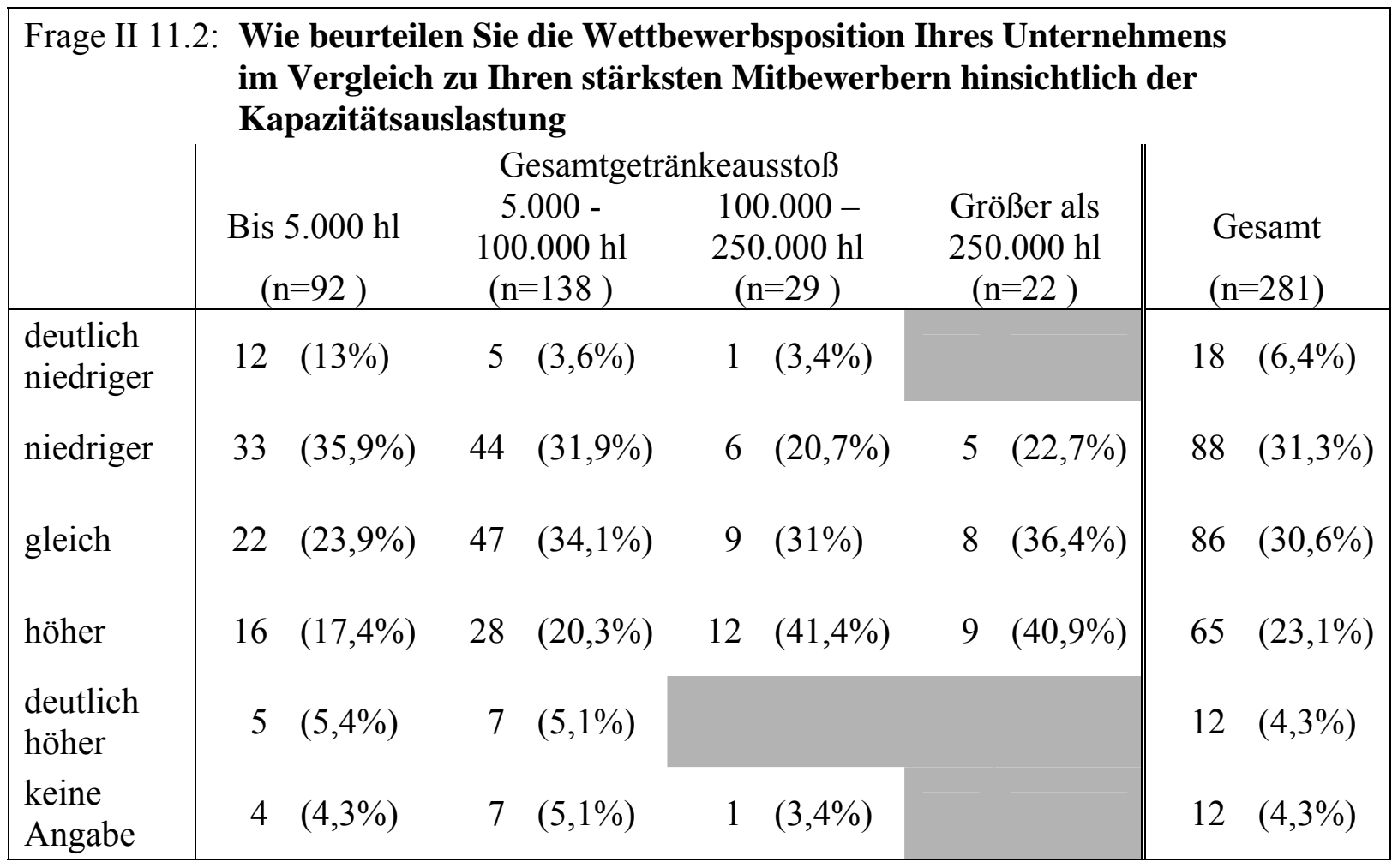

Quelle: Niederhut-Bollmann, C., Datensatz „Große Strategie-Studie 2005“, Göttingen 2005.

Frage II 11.3: Wie beurteilen Sie die Wettbewerbsposition Ihres Unternehmens im
Vergleich zu Ihren stärksten Mitbewerbern hinsichtlich des Marktanteils?

Quelle: Niederhut-Bollmann, C., Datensatz „Große Strategie-Studie 2005“, Göttingen 2005. 


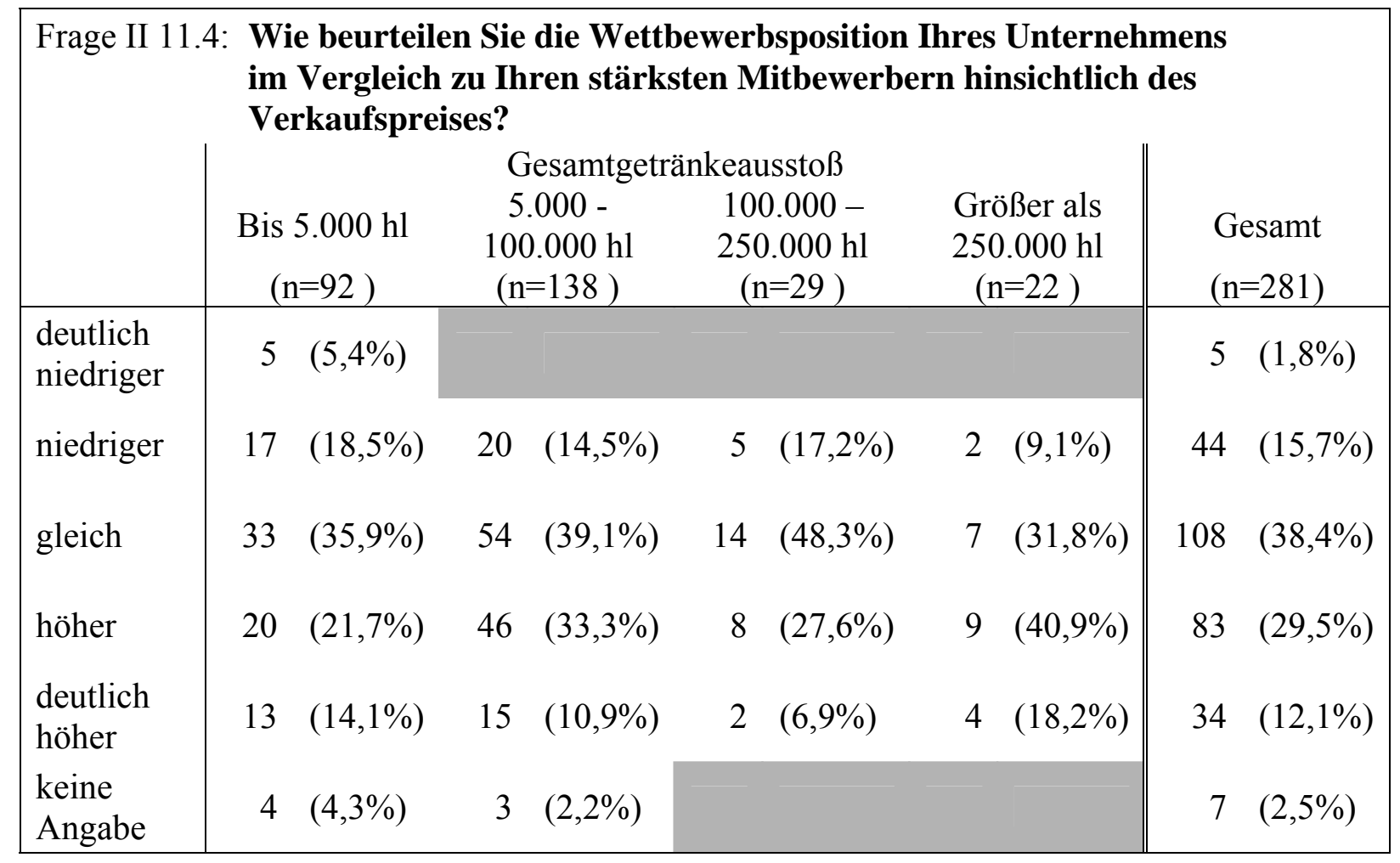

Quelle: Niederhut-Bollmann, C., Datensatz „Große Strategie-Studie 2005“, Göttingen 2005.

\begin{tabular}{|c|c|c|c|c|c|}
\hline \multicolumn{6}{|c|}{$\begin{array}{l}\text { Frage II 11.5: Wie beurteilen Sie die Wettbewerbsposition Ihres Unternehmens } \\
\text { im Vergleich zu Ihren stärksten Mitbewerbern hinsichtlich der } \\
\text { Innovationskraft? }\end{array}$} \\
\hline & & Gesamtget & keausstoß & & \multirow[b]{2}{*}{$\begin{array}{l}\text { Gesamt } \\
(\mathrm{n}=281)\end{array}$} \\
\hline & $\begin{array}{l}\text { Bis } 5.000 \mathrm{hl} \\
\quad(\mathrm{n}=92)\end{array}$ & $\begin{array}{c}5.000- \\
100.000 \mathrm{hl} \\
(\mathrm{n}=138)\end{array}$ & $\begin{array}{c}100.000- \\
250.000 \mathrm{hl} \\
(\mathrm{n}=29)\end{array}$ & $\begin{array}{c}\text { Größer als } \\
250.000 \mathrm{hl} \\
(\mathrm{n}=22)\end{array}$ & \\
\hline $\begin{array}{l}\text { deutlich } \\
\text { niedriger }\end{array}$ & $7 \quad(7,6 \%)$ & $4 \quad(2,9 \%)$ & & & $11 \quad(3,9 \%)$ \\
\hline niedriger & $20 \quad(21,7 \%)$ & $29 \quad(21 \%)$ & $5 \quad(17,2 \%)$ & $5 \quad(22,7 \%)$ & $59 \quad(21 \%)$ \\
\hline gleich & $23 \quad(25 \%)$ & $44 \quad(31,9 \%)$ & $9 \quad(31 \%)$ & $7 \quad(31,8 \%)$ & $83 \quad(29,5 \%)$ \\
\hline höher & $26 \quad(28,3 \%)$ & $47 \quad(34,1 \%)$ & $12(41,4 \%)$ & $10 \quad(45,5 \%)$ & $95 \quad(33,8 \%)$ \\
\hline $\begin{array}{l}\text { deutlich } \\
\text { höher }\end{array}$ & $11(12 \%)$ & $8 \quad(5,8 \%)$ & $3 \quad(10,3 \%)$ & & $22 \quad(7,8 \%)$ \\
\hline $\begin{array}{l}\text { keine } \\
\text { Angabe }\end{array}$ & $5 \quad(5,4 \%)$ & $6 \quad(4,3 \%)$ & & & $11(3,9 \%)$ \\
\hline
\end{tabular}

Quelle: Niederhut-Bollmann, C., Datensatz „Große Strategie-Studie 2005“, Göttingen 2005. 


\begin{tabular}{|c|c|c|c|c|c|}
\hline \multicolumn{6}{|c|}{$\begin{array}{l}\text { Frage II 11.6: Wie beurteilen Sie die Wettbewerbsposition Ihres Unternehmens } \\
\text { im Vergleich zu Ihren stärksten Mitbewerbern hinsichtlich des } \\
\text { Markenimages? }\end{array}$} \\
\hline & & Gesamtget & keausstoß & & \multirow[b]{2}{*}{$\begin{array}{l}\text { Gesamt } \\
(\mathrm{n}=281)\end{array}$} \\
\hline & $\begin{array}{l}\text { Bis } 5.000 \mathrm{hl} \\
\quad(\mathrm{n}=92)\end{array}$ & $\begin{array}{l}5.000- \\
100.000 \mathrm{hl} \\
(\mathrm{n}=138)\end{array}$ & $\begin{array}{l}100.000- \\
250.000 \mathrm{hl} \\
(\mathrm{n}=29)\end{array}$ & $\begin{array}{l}\text { Größer als } \\
250.000 \mathrm{hl} \\
(\mathrm{n}=22)\end{array}$ & \\
\hline $\begin{array}{l}\text { deutlich } \\
\text { niedriger }\end{array}$ & $10 \quad(10,9 \%)$ & $5 \quad(3,6 \%)$ & $1 \quad(3,4 \%)$ & & $16 \quad(5,7 \%)$ \\
\hline niedriger & $23 \quad(25 \%)$ & $34 \quad(24,6 \%)$ & $5 \quad(17,2 \%)$ & $1 \quad(4,5 \%)$ & $63 \quad(22,4 \%)$ \\
\hline gleich & $22 \quad(23,9 \%)$ & $41 \quad(29,7 \%)$ & $4 \quad(13,8 \%)$ & $10 \quad(45,5 \%)$ & $77 \quad(27,4 \%)$ \\
\hline höher & $22 \quad(23,9 \%)$ & $43 \quad(31,2 \%)$ & $13(44,8 \%)$ & $10 \quad(45,5 \%)$ & $88 \quad(31,3 \%)$ \\
\hline $\begin{array}{l}\text { deutlich } \\
\text { höher }\end{array}$ & $9 \quad(9,8 \%)$ & $12 \quad(8,7 \%)$ & $5 \quad(17,2 \%)$ & $1 \quad(4,5 \%)$ & $27 \quad(9,6 \%)$ \\
\hline $\begin{array}{l}\text { keine } \\
\text { Angabe }\end{array}$ & $6 \quad(6,5 \%)$ & $3 \quad(2,2 \%)$ & $1 \quad(3,4 \%)$ & & $10 \quad(3,6 \%)$ \\
\hline
\end{tabular}

Quelle: Niederhut-Bollmann, C., Datensatz „Große Strategie-Studie 2005“, Göttingen 2005.

\begin{tabular}{|c|c|c|c|c|c|}
\hline \multicolumn{6}{|c|}{$\begin{array}{l}\text { Frage II 11.7: Wie beurteilen Sie die Wettbewerbsposition Ihres Unternehmens im } \\
\text { Vergleich zu Ihren stärksten Mitbewerbern hinsichtlich der Höhe der } \\
\text { Werbeausgaben? }\end{array}$} \\
\hline & \multicolumn{4}{|c|}{ Gesamtgetränkeausstoß } & \multirow[b]{2}{*}{$\begin{array}{l}\text { Gesamt } \\
(n=281)\end{array}$} \\
\hline & $\begin{array}{c}\text { Bis } 5.000 \mathrm{hl} \\
\quad(\mathrm{n}=92)\end{array}$ & $\begin{array}{l}5.000- \\
100.000 \mathrm{hl} \\
(\mathrm{n}=138)\end{array}$ & $\begin{array}{c}100.000- \\
250.000 \mathrm{hl} \\
(\mathrm{n}=29)\end{array}$ & $\begin{array}{l}\text { Größer als } \\
250.000 \mathrm{hl} \\
(\mathrm{n}=22)\end{array}$ & \\
\hline $\begin{array}{l}\text { deutlich } \\
\text { niedriger }\end{array}$ & $40 \quad(43,5 \%)$ & $30 \quad(21,7 \%)$ & $10(34,5 \%)$ & $5 \quad(22,7 \%)$ & $85 \quad(30,2 \%)$ \\
\hline niedriger & $24 \quad(26,1 \%)$ & $67 \quad(48,6 \%)$ & $7 \quad(24,1 \%)$ & $6 \quad(27,3 \%)$ & $104(37 \%)$ \\
\hline gleich & $8 \quad(8,7 \%)$ & $21 \quad(15,2 \%)$ & $5 \quad(17,2 \%)$ & $7 \quad(31,8 \%)$ & $41 \quad(14,6 \%)$ \\
\hline höher & $10 \quad(10,9 \%)$ & $12 \quad(8,7 \%)$ & $5 \quad(17,2 \%)$ & $3(13,6 \%)$ & $30 \quad(10,7 \%)$ \\
\hline $\begin{array}{l}\text { deutlich } \\
\text { höher }\end{array}$ & $5 \quad(5,4 \%)$ & $4 \quad(2,9 \%)$ & & $1(4,5 \%)$ & $10 \quad(3,6 \%)$ \\
\hline $\begin{array}{l}\text { keine } \\
\text { Angabe }\end{array}$ & $5 \quad(5,4 \%)$ & $4 \quad(2,9 \%)$ & $2(6,9 \%)$ & & $11 \quad(3,9 \%)$ \\
\hline
\end{tabular}

Quelle: Niederhut-Bollmann, C., Datensatz „Große Strategie-Studie 2005“, Göttingen 2005. 


\begin{tabular}{|c|c|c|c|c|c|}
\hline \multicolumn{6}{|c|}{$\begin{array}{l}\text { Frage II 11.8: Wie beurteilen Sie die Wettbewerbsposition Ihres Unternehmens im } \\
\text { Vergleich zu Ihren stärksten Mitbewerbern hinsichtlich der Investitionen } \\
\text { z.B. in Anlagen? }\end{array}$} \\
\hline & \multicolumn{3}{|c|}{ Gesamtgetränkeausstoß } & \multirow[b]{2}{*}{$\begin{array}{l}\text { Größer als } \\
250.000 \mathrm{hl} \\
(\mathrm{n}=22)\end{array}$} & \multirow[b]{2}{*}{$\begin{array}{l}\text { Gesamt } \\
(\mathrm{n}=281)\end{array}$} \\
\hline & $\begin{array}{c}\text { Bis } 5.000 \mathrm{hl} \\
(\mathrm{n}=92)\end{array}$ & $\begin{array}{l}5.000- \\
100.000 \mathrm{hl} \\
(\mathrm{n}=138)\end{array}$ & $\begin{array}{l}100.000- \\
250.000 \mathrm{hl} \\
(\mathrm{n}=29)\end{array}$ & & \\
\hline $\begin{array}{l}\text { deutlich } \\
\text { niedriger }\end{array}$ & $22 \quad(23,9 \%)$ & $14(10,1 \%)$ & & & $36 \quad(12,8 \%)$ \\
\hline niedriger & $30 \quad(32,6 \%)$ & $37 \quad(26,8 \%)$ & $7 \quad(24,1 \%)$ & $5 \quad(22,7 \%)$ & $(28,1 \%)$ \\
\hline gleich & $19 \quad(20,7 \%)$ & $43(31,2 \%)$ & $(34,5 \%)$ & $8 \quad(36,4 \%)$ & $80 \quad(28,5 \%)$ \\
\hline höher & $15 \quad(16,3 \%)$ & $35 \quad(25,4 \%)$ & $7 \quad(24,1 \%)$ & $6 \quad(27,3 \%)$ & $63(22,4 \%)$ \\
\hline $\begin{array}{l}\text { deutlich } \\
\text { höher }\end{array}$ & $2(2,2 \%)$ & $5 \quad(3,6 \%)$ & $4 \quad(13,8 \%)$ & $3 \quad(13,6 \%)$ & $14 \quad(5,0 \%)$ \\
\hline $\begin{array}{l}\text { keine } \\
\text { Angabe }\end{array}$ & $4 \quad(4,3 \%)$ & $4 \quad(2,9 \%)$ & $1 \quad(3,4 \%)$ & & $9 \quad(3,2 \%)$ \\
\hline
\end{tabular}

Quelle: Niederhut-Bollmann, C., Datensatz „Große Strategie-Studie 2005“, Göttingen 2005.

\begin{tabular}{|c|c|c|c|c|c|}
\hline \multicolumn{6}{|c|}{$\begin{aligned} & \text { Frage II 11.9: } \text { Wie beurteilen Sie die Wettbewerbsposition Ihres Unternehmens im } \\
& \text { Vergleich zu Ihren stärksten Mitbewerbern hinsichtlich des Umfangs der } \\
& \text { Serviceleistungen (z.B. Beratung, Konzepterstellung, Kundenkontakt)? }\end{aligned}$} \\
\hline & $\begin{array}{l}\text { Bis } 5.000 \mathrm{hl} \\
\quad(\mathrm{n}=92)\end{array}$ & $\begin{array}{l}5.000- \\
100.000 \mathrm{hl} \\
(\mathrm{n}=138)\end{array}$ & $\begin{array}{c}100.000- \\
250.000 \mathrm{hl} \\
(\mathrm{n}=29)\end{array}$ & $\begin{array}{l}\text { Größer als } \\
250.000 \mathrm{hl} \\
(\mathrm{n}=22)\end{array}$ & $\begin{array}{l}\text { Gesamt } \\
(n=281)\end{array}$ \\
\hline $\begin{array}{l}\text { deutlich } \\
\text { niedriger }\end{array}$ & $12(13 \%)$ & $3 \quad(2,2 \%)$ & & $1 \quad(4,5 \%)$ & $16 \quad(5,7 \%)$ \\
\hline niedriger & $18 \quad(19,6 \%)$ & $20 \quad(14,5 \%)$ & $6 \quad(20,7 \%)$ & $2 \quad(9,1 \%)$ & $46 \quad(16,4 \%)$ \\
\hline gleich & $21 \quad(22,8 \%)$ & $41 \quad(29,7 \%)$ & $5 \quad(17,2 \%)$ & $7 \quad(31,8 \%)$ & $74 \quad(26,3 \%)$ \\
\hline höher & $28 \quad(30,4 \%)$ & $60 \quad(43,5 \%)$ & $12 \quad(41,4 \%)$ & $10 \quad(45,5 \%)$ & $110(39,1 \%)$ \\
\hline $\begin{array}{l}\text { deutlich } \\
\text { höher }\end{array}$ & $7 \quad(7,6 \%)$ & $12 \quad(8,7 \%)$ & $6 \quad(20,7 \%)$ & $2 \quad(9,1 \%)$ & $27 \quad(9,6 \%)$ \\
\hline $\begin{array}{l}\text { keine } \\
\text { Angabe }\end{array}$ & $6 \quad(6,5 \%)$ & $2(1,4 \%)$ & & & $8 \quad(2,8 \%)$ \\
\hline
\end{tabular}

Quelle: Niederhut-Bollmann, C., Datensatz „Große Strategie-Studie 2005“, Göttingen 2005. 


\section{Märkte und Produkte}

\section{Produktpolitik}

\begin{tabular}{|c|c|c|c|c|c|c|c|c|c|c|}
\hline \multicolumn{2}{|c|}{ Frage III 1.1.1: } & \multicolumn{9}{|c|}{$\begin{array}{l}\text { Wie hoch ist der Anteil des Pils-Bieres am Gesamtgetränkeabsatz } \\
\text { Ihres Unternehmens? }\end{array}$} \\
\hline & \multicolumn{2}{|c|}{$\begin{array}{c}\text { Bis } 5.000 \mathrm{hl} \\
(\mathrm{n}=92)\end{array}$} & $\begin{array}{r}5.00 \\
\quad(1 \\
\end{array}$ & $\begin{array}{l}\text { Gesamtget } \\
-100.000 \\
\mathrm{hl} \\
=138)\end{array}$ & $\begin{array}{r}10 \\
25 \\
\end{array}$ & $\begin{array}{l}\text { stoß } \\
.000- \\
.000 \mathrm{hl} \\
=29)\end{array}$ & \multicolumn{2}{|c|}{$\begin{array}{c}\text { Größer als } \\
250.000 \mathrm{hl} \\
(\mathrm{n}=22)\end{array}$} & \multicolumn{2}{|c|}{$\begin{array}{l}\text { Gesamt } \\
(\mathrm{n}=281)\end{array}$} \\
\hline $\begin{array}{l}\text { nicht im } \\
\text { Sortiment }\end{array}$ & 26 & $(28,3 \%)$ & 8 & $(5,8 \%)$ & & $(3,4 \%)$ & & $(18,2 \%)$ & 39 & $(13,9 \%)$ \\
\hline bis $20 \%$ & 19 & $(20,7 \%)$ & 71 & $(51,4 \%)$ & 11 & $(37,9 \%)$ & & $(27,3 \%)$ & 107 & $(38,1 \%)$ \\
\hline$>20-40 \%$ & 26 & $(28,3 \%)$ & 24 & $(17,4 \%)$ & & $(13,8 \%)$ & 1 & $(4,5 \%)$ & 55 & $(19,6 \%)$ \\
\hline$>40-60 \%$ & 13 & $(14,1 \%)$ & 25 & $(18,1 \%)$ & & $(13,8 \%)$ & 2 & $(9,1 \%)$ & 44 & $(15,7 \%)$ \\
\hline$>60-80 \%$ & 5 & $(5,4 \%)$ & 8 & $(5,8 \%)$ & 5 & $(17,2 \%)$ & 2 & $(9,1 \%)$ & 20 & $(7,1 \%)$ \\
\hline$>80-99 \%$ & 1 & $(1,1 \%)$ & 1 & $(0,7 \%)$ & 4 & $(13,8 \%)$ & 6 & $(27,3 \%)$ & 12 & $(4,3 \%)$ \\
\hline nur Pils & 2 & $(2,2 \%)$ & & & & & & & 2 & $(0,7 \%)$ \\
\hline $\begin{array}{l}\text { keine } \\
\text { Angabe }\end{array}$ & & & 1 & $(0,7 \%)$ & & & & $(4,5 \%)$ & 2 & $(0,7 \%)$ \\
\hline
\end{tabular}

Quelle: Niederhut-Bollmann, C., Datensatz „Große Strategie-Studie 2005“, Göttingen 2005.

\section{Frage III 1.1.2: Wie hoch ist der Anteil des Weizenbieres am Gesamtgetränkeabsatz} Ihres Unternehmens?

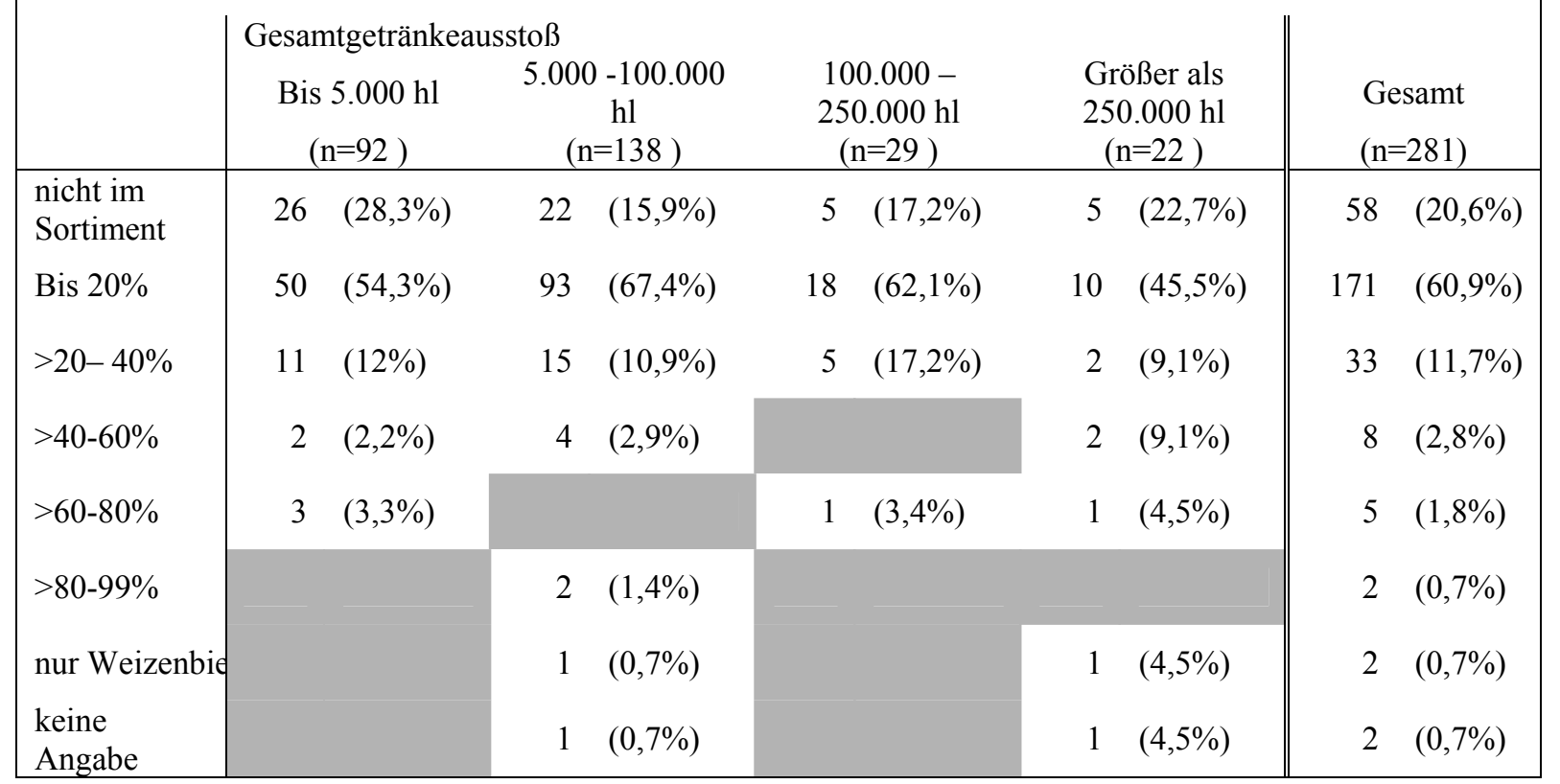

Quelle: Niederhut-Bollmann, C., Datensatz „Große Strategie-Studie 2005“, Göttingen 2005. 


\begin{tabular}{|c|c|c|c|c|c|c|c|c|c|c|}
\hline \multirow[t]{3}{*}{ Frage III 1.1.} & \multicolumn{10}{|c|}{$\begin{array}{l}\text { Wie hoch ist der Anteil der Lager-Hell- und Export-Hell-Biere am } \\
\text { Gesamtgetränkeabsatz Ihres Unternehmens? }\end{array}$} \\
\hline & \multicolumn{8}{|c|}{ Gesamtgetränkeausstoß } & \multirow{2}{*}{\multicolumn{2}{|c|}{$\begin{array}{l}\text { Gesamt } \\
(\mathrm{n}=281)\end{array}$}} \\
\hline & Bis & $\begin{array}{l}5.000 \mathrm{hl} \\
\mathrm{n}=92)\end{array}$ & & $\begin{array}{l}-100.000 \\
\mathrm{hl} \\
=138)\end{array}$ & & $\begin{array}{l}0.000- \\
.000 \mathrm{hl} \\
\mathrm{l}=29)\end{array}$ & & $\begin{array}{l}\text { ¡er als } \\
.000 \mathrm{hl} \\
=22)\end{array}$ & & \\
\hline $\begin{array}{l}\text { nicht im } \\
\text { Sortiment }\end{array}$ & 45 & $(48,9 \%)$ & & $(13 \%)$ & & $(13,8 \%)$ & & $(40,9 \%)$ & 76 & $(27 \%)$ \\
\hline Bis $20 \%$ & 16 & $(17,4 \%)$ & 54 & $(39,1 \%)$ & 12 & $(41,4 \%)$ & 7 & $(31,8 \%)$ & 89 & $(31,7 \%)$ \\
\hline$>20-40 \%$ & 19 & $(20,7 \%)$ & 39 & $(28,3 \%)$ & 8 & $(27,6 \%)$ & 4 & $(18,2 \%)$ & 70 & $(24,9 \%)$ \\
\hline$>40-60 \%$ & 8 & $(8,7 \%)$ & 18 & $(13 \%)$ & 4 & $(13,8 \%)$ & 1 & $(4,5 \%)$ & 31 & $(11 \%)$ \\
\hline$>60-80 \%$ & 2 & $(2,2 \%)$ & 6 & $(4,3 \%)$ & & $(3,4 \%)$ & & & & $(3,2 \%)$ \\
\hline$>80-99 \%$ & 2 & $(2,2 \%)$ & 2 & $(1,4 \%)$ & & & & & & $(1,4 \%)$ \\
\hline $\begin{array}{l}\text { nur Lager-He } \\
\text { und Expor } \\
\text { Hell }\end{array}$ & & & & & & & & & & \\
\hline $\begin{array}{l}\text { keine } \\
\text { Angabe }\end{array}$ & & & & $(0,7 \%)$ & & & & $(4,5 \%)$ & & $(0,7 \%)$ \\
\hline
\end{tabular}

Quelle: Niederhut-Bollmann, C., Datensatz „Große Strategie-Studie 2005“, Göttingen 2005.

\section{Frage III 1.1.4: Wie hoch ist der Anteil der Dunkel/Export-Dunkel und Schwarzbiere am Gesamtgetränkeabsatz Ihres Unternehmens?}

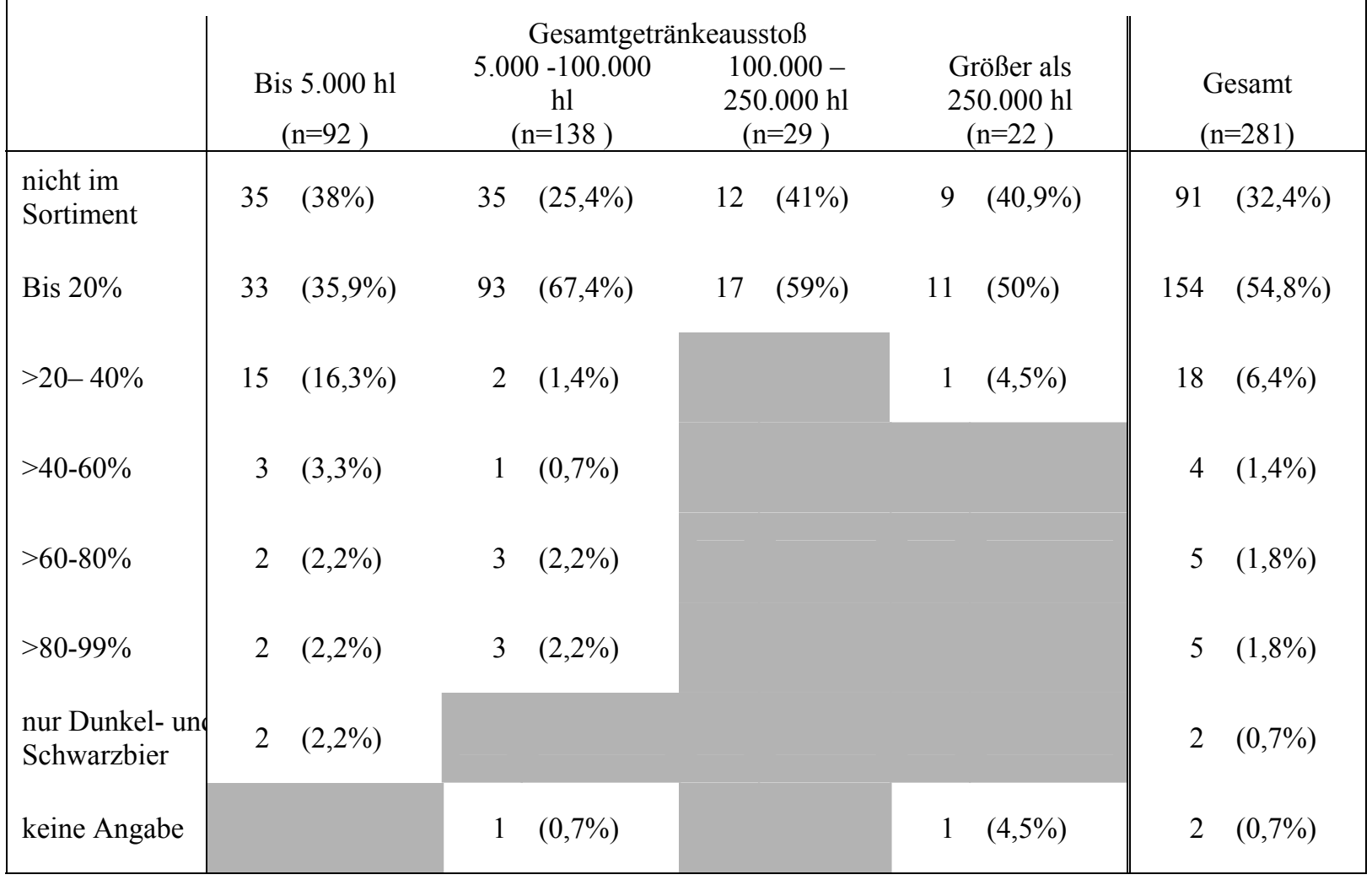

Quelle: Niederhut-Bollmann, C., Datensatz „Große Strategie-Studie 2005“, Göttingen 2005. 


\begin{tabular}{|c|c|c|c|c|c|c|c|}
\hline \multicolumn{2}{|c|}{ Frage III 1.1.5: } & \multicolumn{6}{|c|}{$\begin{array}{l}\text { Wie hoch ist der Anteil von Kölsch am Gesamtgetränkeabsatz Ihres } \\
\text { Unternehmens? }\end{array}$} \\
\hline & \multicolumn{4}{|c|}{ Gesamtgetränkeausstoß } & \multirow[b]{2}{*}{$\begin{array}{c}\text { Größer als } \\
250.000 \mathrm{hl} \\
(\mathrm{n}=22)\end{array}$} & \multirow{2}{*}{\multicolumn{2}{|c|}{$\begin{array}{l}\text { Gesamt } \\
(n=281)\end{array}$}} \\
\hline & & $\begin{array}{l}5.000 \mathrm{hl} \\
\mathrm{n}=92)\end{array}$ & $\begin{array}{c}5.000-100.000 \\
\mathrm{hl} \\
(\mathrm{n}=138)\end{array}$ & $\begin{array}{c}100.000- \\
250.000 \mathrm{hl} \\
(\mathrm{n}=29)\end{array}$ & & & \\
\hline $\begin{array}{l}\text { nicht im } \\
\text { Sortiment }\end{array}$ & & $(97,8 \%)$ & $135 \quad(97,8 \%)$ & $29 \quad(100 \%)$ & $17 \quad(77,3 \%)$ & 271 & $(96,4 \%)$ \\
\hline bis $20 \%$ & 1 & $(1,1 \%)$ & $1 \quad(0,7 \%)$ & & $2 \quad(9,1 \%)$ & & $(1,4 \%)$ \\
\hline$>20-40 \%$ & 1 & $(1,1 \%)$ & & & & & $(0,4 \%)$ \\
\hline$>40-60 \%$ & & & $1 \quad(0,7 \%)$ & & & & $(0,4 \%)$ \\
\hline$>60-80 \%$ & & & & & & & \\
\hline$>80-99 \%$ & & & & & $1 \quad(4,5 \%)$ & & $(0,4 \%)$ \\
\hline nur Kölsch & & & & & $1 \quad(4,5 \%)$ & & $(0,4 \%)$ \\
\hline $\begin{array}{l}\text { keine } \\
\text { Angabe }\end{array}$ & & & $1 \quad(0,7 \%)$ & & $1 \quad(4,5 \%)$ & & $(0,7 \%)$ \\
\hline
\end{tabular}

Quelle: Niederhut-Bollmann, C., Datensatz „Große Strategie-Studie 2005“, Göttingen 2005.

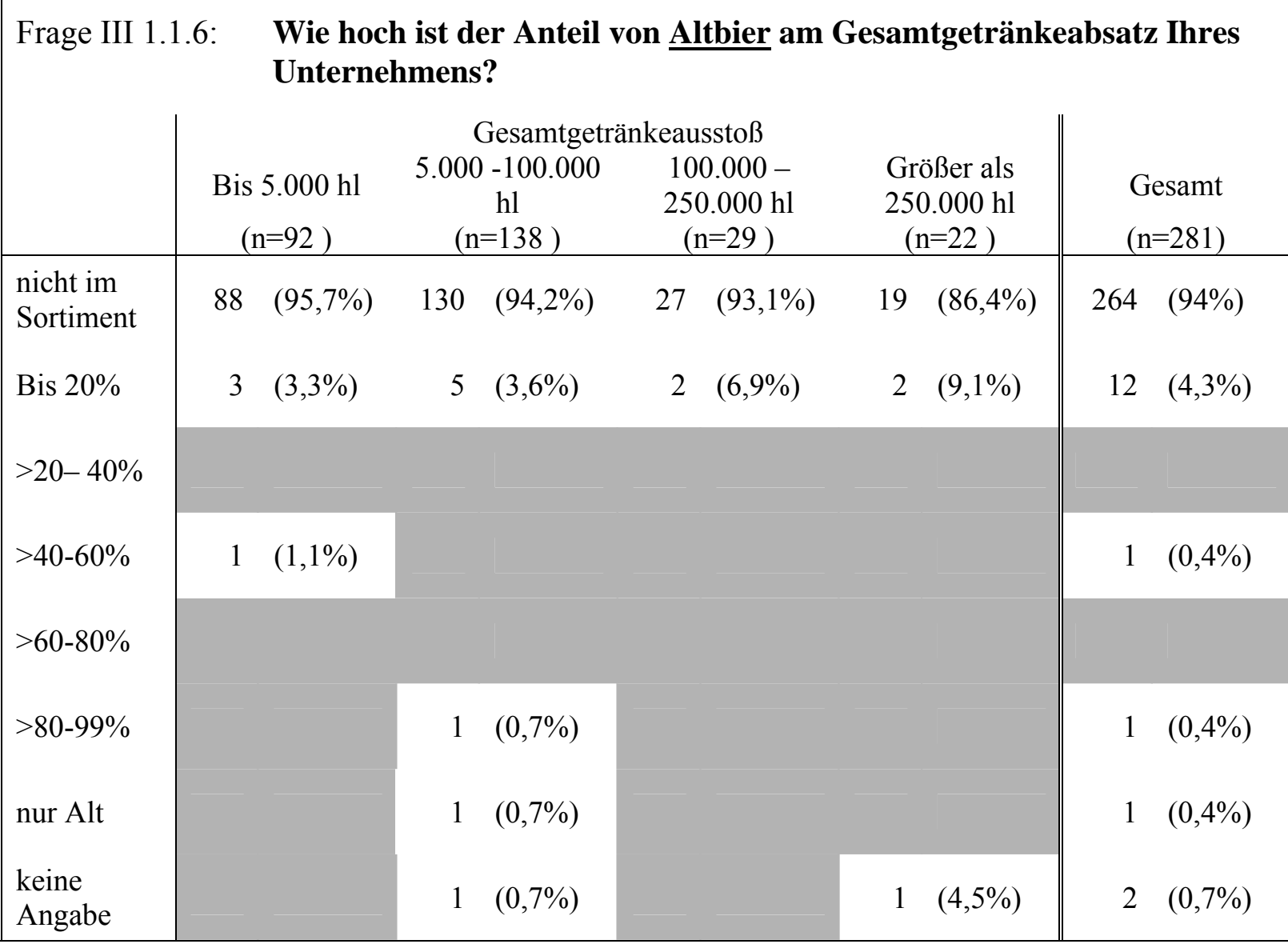

Quelle: Niederhut-Bollmann, C., Datensatz „Große Strategie-Studie 2005“, Göttingen 2005. 


\section{Frage III 1.1.7: Wie hoch ist der Anteil von Starkbieren am Gesamtgetränkeabsatz} Ihres Unternehmens?

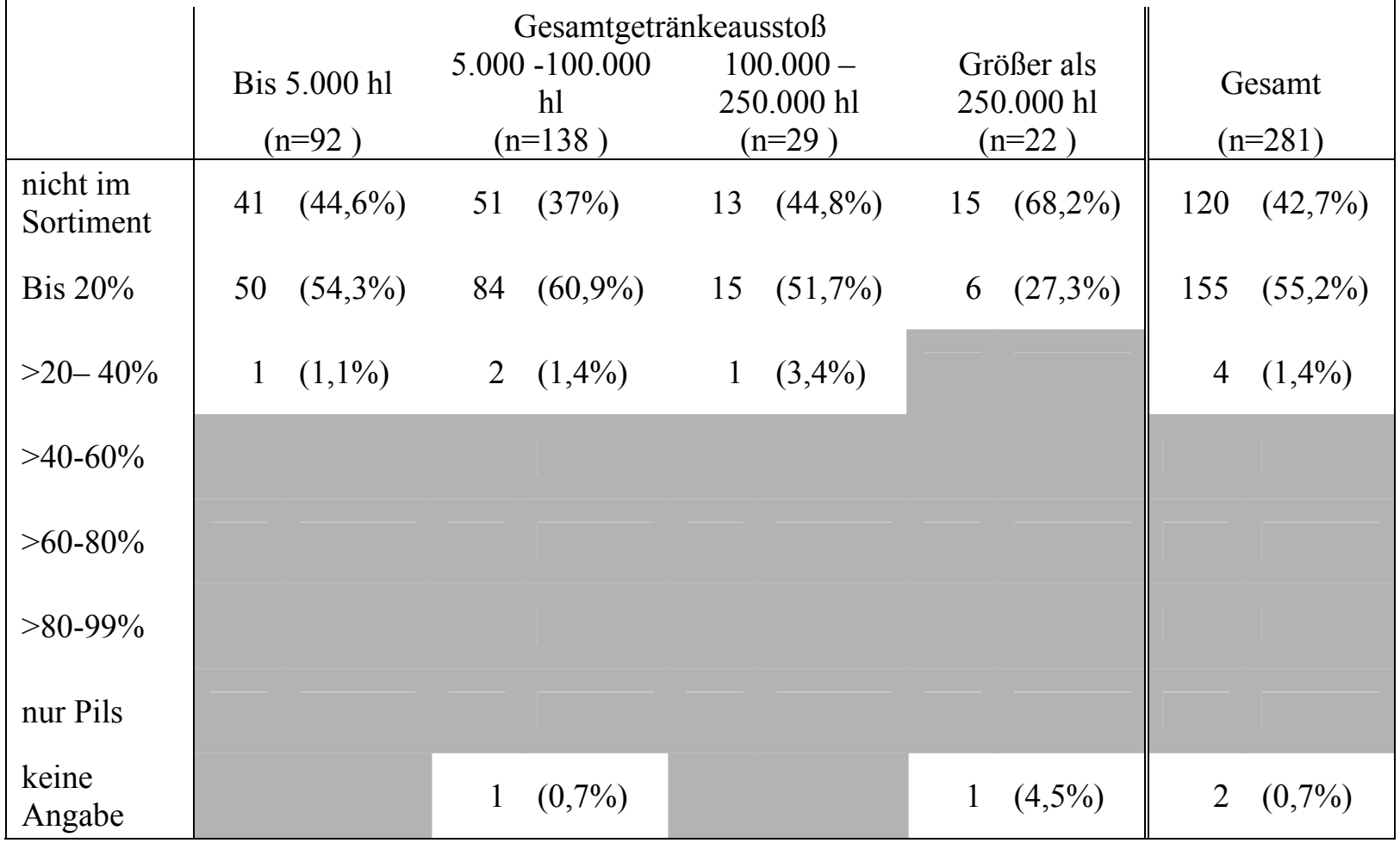

Quelle: Niederhut-Bollmann, C., Datensatz „Große Strategie-Studie 2005“, Göttingen 2005.

\section{Frage III 1.1.8: Wie hoch ist der Anteil von Biobier am Gesamtgetränkeabsatz Ihres Unternehmens?}

\begin{tabular}{|c|c|c|c|c|c|}
\hline & \multicolumn{4}{|c|}{ Gesamtgetränkeausstoß } & \multirow[b]{2}{*}{$\begin{array}{l}\text { Gesamt } \\
(n=281)\end{array}$} \\
\hline & $\begin{array}{c}\text { Bis } 5.000 \mathrm{hl} \\
\quad(\mathrm{n}=92)\end{array}$ & $\begin{array}{c}5.000-100.000 \\
\mathrm{hl} \\
(\mathrm{n}=138)\end{array}$ & $\begin{array}{c}100.000- \\
250.000 \mathrm{hl} \\
(\mathrm{n}=29)\end{array}$ & $\begin{array}{c}\text { Größer als } \\
250.000 \mathrm{hl} \\
(\mathrm{n}=22)\end{array}$ & \\
\hline $\begin{array}{l}\text { nicht im } \\
\text { Sortiment }\end{array}$ & $87 \quad(94,6 \%)$ & $128 \quad(92,8 \%)$ & $28 \quad(96,6 \%)$ & $21 \quad(95,5 \%)$ & $264 \quad(94 \%)$ \\
\hline Bis $20 \%$ & $4 \quad(4,3 \%)$ & $8 \quad(5,8 \%)$ & $1 \quad(3,4 \%)$ & & $13(4,6 \%)$ \\
\hline$>20-40 \%$ & & $1 \quad(0,7 \%)$ & & & $1 \quad(0,4 \%)$ \\
\hline$>40-60 \%$ & & & & & \\
\hline$>60-80 \%$ & & & & & \\
\hline$>80-99 \%$ & & & & & \\
\hline nur Biobier & $1 \quad(1,1 \%)$ & & & & $1 \quad(0,4 \%)$ \\
\hline $\begin{array}{l}\text { keine } \\
\text { Angabe }\end{array}$ & & $1 \quad(0,7 \%)$ & & $1 \quad(4,5 \%)$ & $2(0,7 \%)$ \\
\hline
\end{tabular}

Quelle: Niederhut-Bollmann, C., Datensatz „Große Strategie-Studie 2005“, Göttingen 2005. 


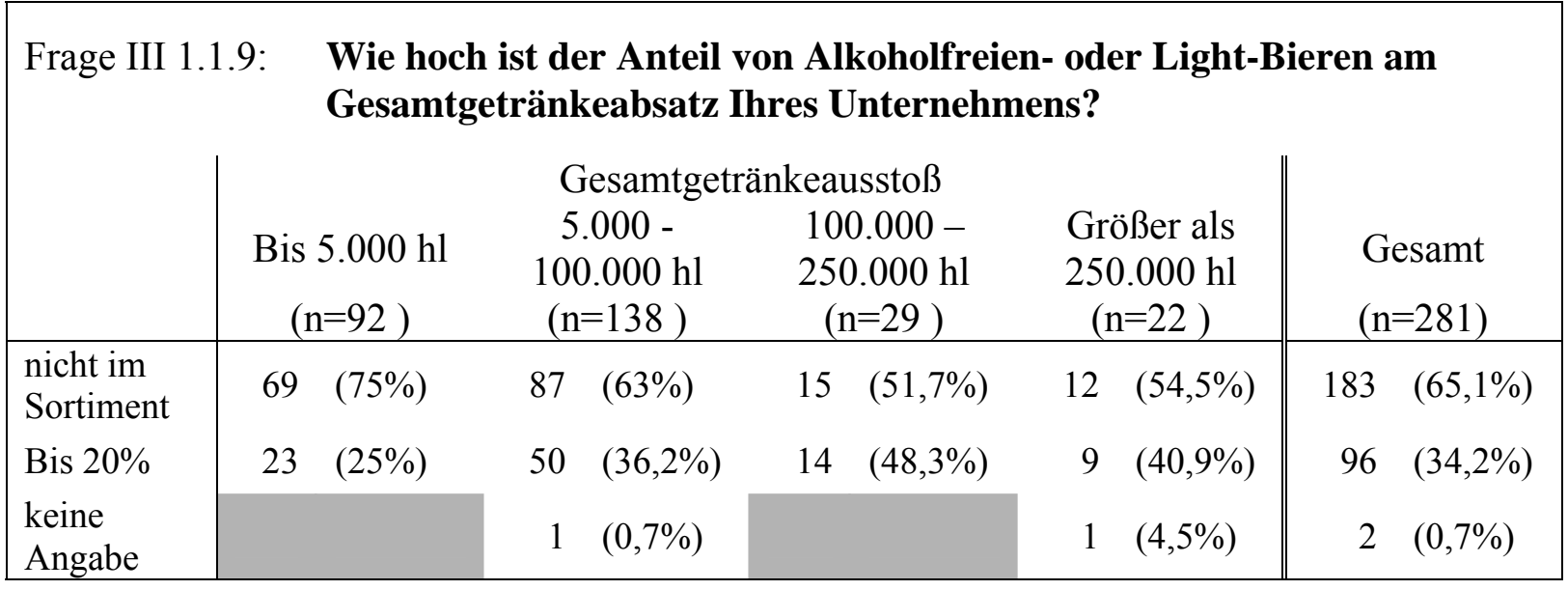

Quelle: Niederhut-Bollmann, C., Datensatz „Große Strategie-Studie 2005“, Göttingen 2005.

\begin{tabular}{|c|c|c|c|c|c|c|}
\hline \multicolumn{6}{|c|}{ Frage III 1.1.10: } & \multirow[b]{3}{*}{$\begin{array}{l}\text { Gesamt } \\
(\mathrm{n}=281)\end{array}$} \\
\hline & \multirow{2}{*}{\multicolumn{2}{|c|}{$\begin{array}{l}\text { Bis } 5.000 \mathrm{hl} \\
\quad(\mathrm{n}=92)\end{array}$}} & \multicolumn{2}{|c|}{ Gesamtgetränkeausstoß } & \multirow[b]{2}{*}{$\begin{array}{c}\text { Größer als } \\
250.000 \mathrm{hl} \\
(\mathrm{n}=22)\end{array}$} & \\
\hline & & & $\begin{array}{c}5.000- \\
100.000 \mathrm{hl} \\
(\mathrm{n}=138)\end{array}$ & $\begin{array}{c}100.000- \\
250.000 \mathrm{hl} \\
(\mathrm{n}=29)\end{array}$ & & \\
\hline $\begin{array}{l}\text { nicht im } \\
\text { Sortiment }\end{array}$ & 69 & $(75 \%)$ & $55 \quad(39,9 \%)$ & $8 \quad(27,6 \%)$ & $10 \quad(45,5 \%)$ & $142 \quad(50,5 \%)$ \\
\hline Bis $20 \%$ & 22 & $(23,9 \%)$ & $82 \quad(59,4 \%)$ & $21 \quad(72,4 \%)$ & $11 \quad(50 \%)$ & $136 \quad(48,4 \%)$ \\
\hline$>20-40 \%$ & 1 & $(1,1 \%)$ & & & & $1 \quad(0,4 \%)$ \\
\hline $\begin{array}{l}\text { keine } \\
\text { Angabe }\end{array}$ & & & $1 \quad(0,7 \%)$ & & $1 \quad(4,5 \%)$ & $2 \quad(0,7 \%)$ \\
\hline
\end{tabular}

Quelle: Niederhut-Bollmann, C., Datensatz „Große Strategie-Studie 2005“, Göttingen 2005.

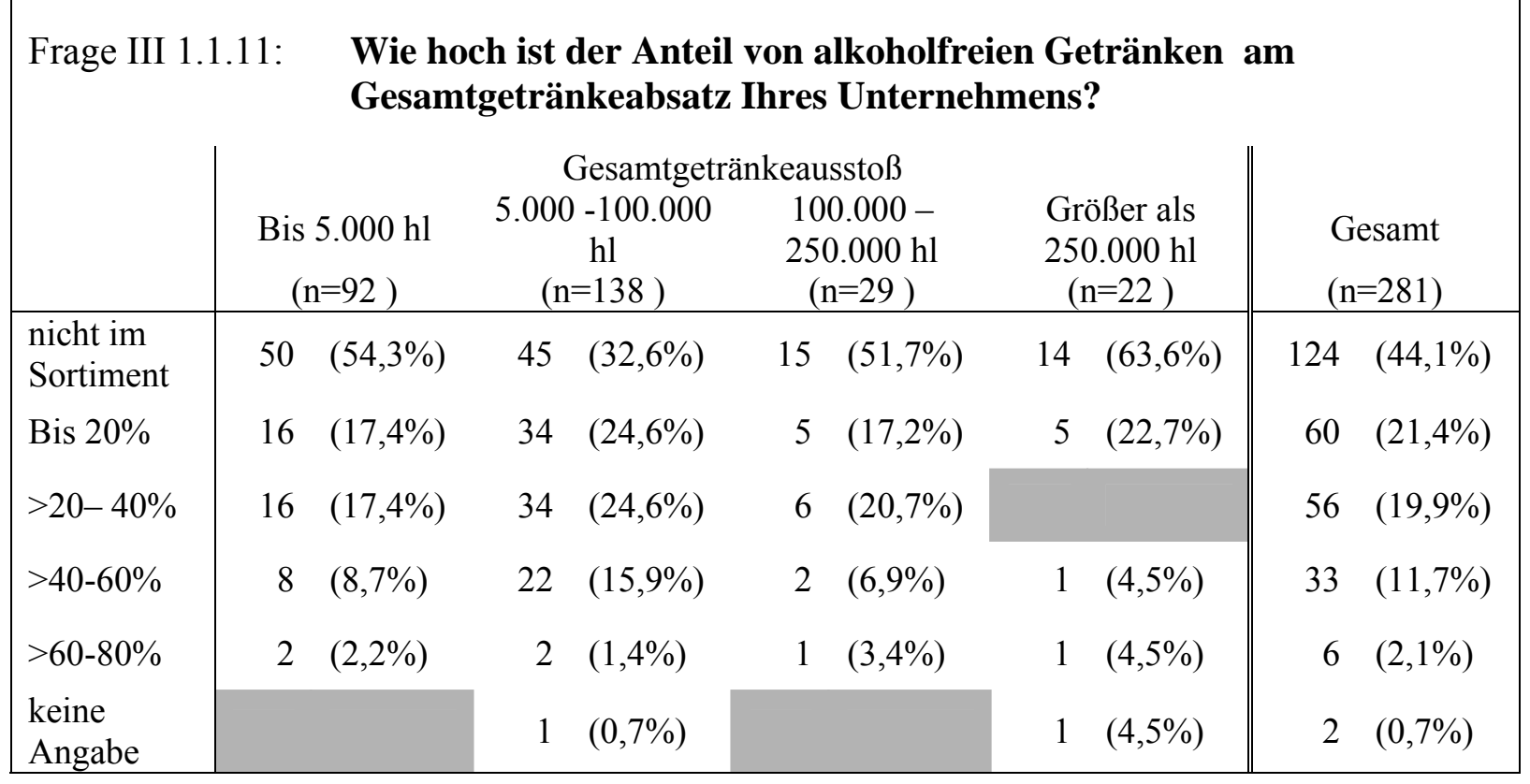

Quelle: Niederhut-Bollmann, C., Datensatz „Große Strategie-Studie 2005“, Göttingen 2005. 


\section{Frage III 1.1.12: Wie hoch ist der Anteil von sonstigen Getränken am Gesamtgetränkeabsatz Ihres Unternehmens?}

\begin{tabular}{|c|c|c|c|c|c|}
\hline & & Gesamtgetı & keausstoß & & \\
\hline & $\begin{array}{l}\text { Bis } 5.000 \mathrm{hl} \\
\quad(\mathrm{n}=92)\end{array}$ & $\begin{array}{c}5.000- \\
100.000 \mathrm{hl} \\
(\mathrm{n}=138)\end{array}$ & $\begin{array}{c}100.000- \\
250.000 \mathrm{hl} \\
(\mathrm{n}=29)\end{array}$ & $\begin{array}{c}\text { Größer als } \\
250.000 \mathrm{hl} \\
(\mathrm{n}=22)\end{array}$ & $\begin{array}{l}\text { Gesamt } \\
(\mathrm{n}=281)\end{array}$ \\
\hline $\begin{array}{l}\text { nicht im } \\
\text { Sortiment }\end{array}$ & $71 \quad(77,2 \%)$ & $120 \quad(87 \%)$ & $25 \quad(86,2 \%)$ & $17 \quad(77,3 \%)$ & $233 \quad(82,9 \%)$ \\
\hline Bis $20 \%$ & $17 \quad(18,5 \%)$ & $16(11,6 \%)$ & $4 \quad(13,8 \%)$ & $4 \quad(18,2 \%)$ & $41 \quad(14,6 \%)$ \\
\hline$>20-40 \%$ & $1 \quad(1,1 \%)$ & $1 \quad(0,7 \%)$ & & & $2 \quad(0,7 \%)$ \\
\hline$>40-60 \%$ & & & & & \\
\hline$>60-80 \%$ & $1 \quad(1,1 \%)$ & & & & $1 \quad(0,4 \%)$ \\
\hline$>80-99 \%$ & $1 \quad(1,1 \%)$ & & & & $1 \quad(0,4 \%)$ \\
\hline $\begin{array}{l}\text { nur sonstige } \\
\text { Getränke }\end{array}$ & $1 \quad(1,1 \%)$ & & & & $1 \quad(0,4 \%)$ \\
\hline $\begin{array}{l}\text { keine } \\
\text { Angabe }\end{array}$ & & $1 \quad(0,7 \%)$ & & $1 \quad(4,5 \%)$ & $2 \quad(0,7 \%)$ \\
\hline
\end{tabular}

Quelle: Niederhut-Bollmann, C., Datensatz „Große Strategie-Studie 2005“, Göttingen 2005.

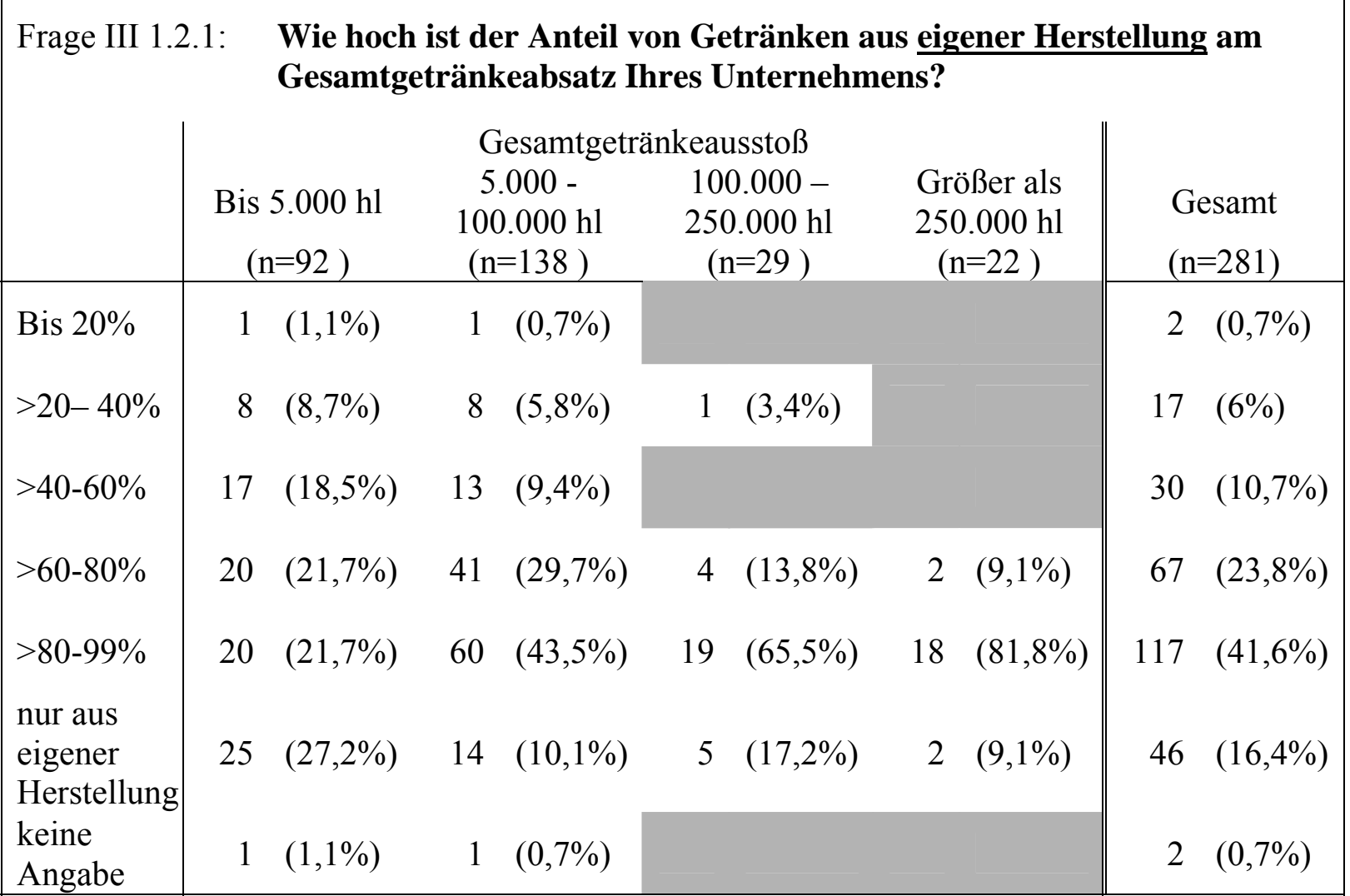

Quelle: Niederhut-Bollmann, C., Datensatz „Große Strategie-Studie 2005“, Göttingen 2005. 


\begin{tabular}{|c|c|c|c|c|c|c|c|}
\hline \multirow[t]{3}{*}{ Frage III 1.2.2 } & \multicolumn{7}{|c|}{$\begin{array}{l}\text { Wie hoch ist der Anteil von Getränken aus Fremdbezug am } \\
\text { Gesamtgetränkeabsatz Ihres Unternehmens? }\end{array}$} \\
\hline & \multirow[b]{2}{*}{$\begin{array}{l}\text { Bis } 5.000 \mathrm{hl} \\
(\mathrm{n}=92)\end{array}$} & \multicolumn{3}{|c|}{ Gesamtgetränkeausstoß } & \multirow[b]{2}{*}{$\begin{array}{c}\text { Größer als } \\
250.000 \mathrm{hl} \\
(\mathrm{n}=22)\end{array}$} & \multirow{2}{*}{\multicolumn{2}{|c|}{$\begin{array}{l}\text { Gesamt } \\
(\mathrm{n}=281)\end{array}$}} \\
\hline & & & $\begin{array}{l}.000- \\
.000 \mathrm{hl} \\
=138)\end{array}$ & $\begin{array}{c}100.000- \\
250.000 \mathrm{hl} \\
(\mathrm{n}=29)\end{array}$ & & & \\
\hline $\begin{array}{l}\text { Kein } \\
\text { Fremdbezug }\end{array}$ & $25 \quad(27,2 \%)$ & & $(10,1 \%)$ & $5 \quad(17,2 \%)$ & $2 \quad(9,1 \%)$ & 46 & $(16,4 \%)$ \\
\hline bis $20 \%$ & $27 \quad(29,3 \%)$ & 77 & $(55,8 \%)$ & $21 \quad(72,4 \%)$ & $18 \quad(81,8 \%)$ & 143 & $(50,9 \%)$ \\
\hline$>20-40 \%$ & $22 \quad(23,9 \%)$ & 29 & $(21 \%)$ & $2 \quad(6,9 \%)$ & $2 \quad(9,1 \%)$ & 55 & $(19,6 \%)$ \\
\hline$>40-60 \%$ & $12 \quad(13 \%)$ & 13 & $(9,4 \%)$ & & & 25 & $(8,9 \%)$ \\
\hline$>60-80 \%$ & $5 \quad(5,4 \%)$ & 3 & $(2,2 \%)$ & $1 \quad(3,4 \%)$ & & 9 & $(3,2 \%)$ \\
\hline$>80-99 \%$ & & & $(0,7 \%)$ & & & 1 & $(0,4 \%)$ \\
\hline $\begin{array}{l}\text { keine } \\
\text { Angabe }\end{array}$ & $1 \quad(1,1 \%)$ & & $(0,7 \%)$ & & & 2 & $(0,7 \%)$ \\
\hline
\end{tabular}

Quelle: Niederhut-Bollmann, C., Datensatz „Große Strategie-Studie 2005“, Göttingen 2005.

Frage III 1.3: Welchen Anteil am Gesamtausstoß nimmt Ihre Hauptbiermarke ein?

\begin{tabular}{|c|c|c|c|c|c|}
\hline & \multicolumn{4}{|c|}{ Gesamtgetränkeausstoß } & \multirow[b]{2}{*}{$\begin{array}{l}\text { Gesamt } \\
(n=281)\end{array}$} \\
\hline & $\begin{array}{c}\text { Bis } 5.000 \mathrm{hl} \\
\quad(\mathrm{n}=92)\end{array}$ & $\begin{array}{c}5.000- \\
100.000 \mathrm{hl} \\
(\mathrm{n}=138)\end{array}$ & $\begin{array}{c}100.000- \\
250.000 \mathrm{hl} \\
(\mathrm{n}=29)\end{array}$ & $\begin{array}{c}\text { Größer als } \\
250.000 \mathrm{hl} \\
(\mathrm{n}=22) \\
\end{array}$ & \\
\hline Bis $20 \%$ & $2(2,2 \%)$ & $8 \quad(5,8 \%)$ & $5 \quad(17,2 \%)$ & $1 \quad(4,5 \%)$ & $16 \quad(5,7 \%)$ \\
\hline$>20-40 \%$ & $23 \quad(25 \%)$ & $33 \quad(23,9 \%)$ & $5 \quad(17,2 \%)$ & $4 \quad(18,2 \%)$ & $65 \quad(23,1 \%)$ \\
\hline$>40-60 \%$ & $21 \quad(22,8 \%)$ & $56 \quad(40,6 \%)$ & $6 \quad(20,7 \%)$ & $6 \quad(27,3 \%)$ & $89 \quad(31,7 \%)$ \\
\hline$>60-80 \%$ & $15 \quad(16,3 \%)$ & $29 \quad(21 \%)$ & $9 \quad(31 \%)$ & $4 \quad(18,2 \%)$ & $57 \quad(20,3 \%)$ \\
\hline$>80-99 \%$ & $13(14,1 \%)$ & $7 \quad(5,1 \%)$ & $3(10,3 \%)$ & $4 \quad(18,2 \%)$ & $27 \quad(9,6 \%)$ \\
\hline $\begin{array}{l}\text { Nur eine } \\
\text { Marke }\end{array}$ & $15 \quad(16,3 \%)$ & $3(2,2 \%)$ & $1 \quad(3,4 \%)$ & $2(9,1 \%)$ & $21 \quad(7,5 \%)$ \\
\hline $\begin{array}{l}\text { keine } \\
\text { Angabe }\end{array}$ & $3(3,3 \%)$ & $2(1,4 \%)$ & & $1 \quad(4,5 \%)$ & $6 \quad(2,1 \%)$ \\
\hline
\end{tabular}

Quelle: Niederhut-Bollmann, C., Datensatz „Große Strategie-Studie 2005“, Göttingen 2005. 


\begin{tabular}{|c|c|c|c|c|c|c|c|}
\hline \multicolumn{2}{|c|}{ Frage III 1.4.1: } & \multicolumn{6}{|c|}{$\begin{array}{l}\text { Zu welchem Preis wird Ihre Hauptbiermarke in der Kastenform } 20 \mathrm{x} \\
\underline{0,5} \text { I normalerweise im Handel angeboten? }\end{array}$} \\
\hline Preis in $€$ & & $\begin{array}{l}\text { s } 5.000 \mathrm{hl} \\
(\mathrm{n}=92)\end{array}$ & & $\begin{array}{l}\text { esamtgetr } \\
000- \\
.000 \mathrm{hl} \\
=138)\end{array}$ & $\begin{array}{c}\text { keaussto } \beta \\
100.000- \\
250.000 \mathrm{hl} \\
(\mathrm{n}=29)\end{array}$ & $\begin{array}{c}\text { Größer als } \\
250.000 \mathrm{hl} \\
(\mathrm{n}=22)\end{array}$ & $\begin{array}{l}\text { Gesamt } \\
(\mathrm{n}=281)\end{array}$ \\
\hline $\begin{array}{l}12 \text { und } \\
\text { mehr }\end{array}$ & 16 & $(17,4 \%)$ & 35 & $(25,4 \%)$ & $8 \quad(27,6 \%)$ & $7 \quad(31,8 \%)$ & $66 \quad(23,5 \%)$ \\
\hline $11-11,99$ & 11 & $(12 \%)$ & 46 & $(33,3 \%)$ & $10 \quad(34,5 \%)$ & $7 \quad(31,8 \%)$ & $74 \quad(26,3 \%)$ \\
\hline $10-10,99$ & 18 & $(19,6 \%)$ & 33 & $(23,9 \%)$ & $6 \quad(20,7 \%)$ & $3 \quad(13,6 \%)$ & $60 \quad(21,4 \%)$ \\
\hline $9-9,99$ & 8 & $(8,7 \%)$ & 13 & $(9,4 \%)$ & $3 \quad(10,3 \%)$ & $1 \quad(4,5 \%)$ & $25 \quad(8,9 \%)$ \\
\hline $8-8,99$ & 1 & $(1,1 \%)$ & & $(1,4 \%)$ & $1 \quad(3,4 \%)$ & & $4 \quad(1,4 \%)$ \\
\hline $7-7,99$ & 1 & $(1,1 \%)$ & & $(0,7 \%)$ & & & $2 \quad(0,7 \%)$ \\
\hline $\begin{array}{l}\text { keine } \\
\text { Angabe }\end{array}$ & 37 & $(40,2 \%)$ & & $(5,9 \%)$ & $1 \quad(3,4 \%)$ & $4 \quad(18,2 \%)$ & $50 \quad(17,8 \%)$ \\
\hline
\end{tabular}

Quelle: Niederhut-Bollmann, C., Datensatz „Große Strategie-Studie 2005“, Göttingen 2005.

\begin{tabular}{|c|c|c|c|c|c|c|c|c|}
\hline \multicolumn{2}{|c|}{ Frage III 1.4.2: } & \multicolumn{7}{|c|}{$\begin{array}{l}\text { Zu welchem Preis wird Ihre Hauptbiermarke in der Kastenform } 24 \text { x } \\
\text { 0,33 I normalerweise im Handel angeboten? }\end{array}$} \\
\hline Preis in $€$ & & $5.000 \mathrm{hl}$ & & $\begin{array}{l}\text { Gesamtgetr } \\
5.000- \\
0.000 \mathrm{hl} \\
\mathrm{n}=138)\end{array}$ & $\begin{array}{c}\text { keausstoß } \\
100.000- \\
250.000 \mathrm{hl} \\
(\mathrm{n}=29)\end{array}$ & $\begin{array}{c}\text { Größer als } \\
250.000 \mathrm{hl} \\
(\mathrm{n}=22)\end{array}$ & & $\begin{array}{l}\text { esamt } \\
=281)\end{array}$ \\
\hline $\begin{array}{l}12 \text { und } \\
\text { mehr }\end{array}$ & 3 & $(3,3 \%)$ & 18 & $(13 \%)$ & $4 \quad(13,8 \%)$ & $4 \quad(18,2 \%)$ & 29 & $(10,3 \%)$ \\
\hline $11-11,99$ & 2 & $(2,2 \%)$ & 10 & $(7,2 \%)$ & $2 \quad(6,9 \%)$ & $5 \quad(22,7 \%)$ & 19 & $(6,8 \%)$ \\
\hline $10-10,99$ & 4 & $(4,3 \%)$ & 6 & $(4,3 \%)$ & $4 \quad(13,8 \%)$ & $1 \quad(4,5 \%)$ & 15 & $(5,3 \%)$ \\
\hline $9-9,99$ & & $(1,1 \%)$ & & & $2 \quad(6,9 \%)$ & $1 \quad(4,5 \%)$ & & $(1,4 \%)$ \\
\hline $8-8,99$ & & $(2,2 \%)$ & & & $2 \quad(6,9 \%)$ & $1 \quad(4,5 \%)$ & & $(1,8 \%)$ \\
\hline $7-7,99$ & & & & $(1,4 \%)$ & $1 \quad(3,4 \%)$ & & & $(1,1 \%)$ \\
\hline $\begin{array}{l}\text { keine } \\
\text { Angabe }\end{array}$ & & $(87 \%)$ & 102 & $(73,9 \%)$ & $14 \quad(48,3 \%)$ & $10 \quad(45,5 \%)$ & 206 & $(73,3 \%)$ \\
\hline
\end{tabular}

Quelle: Niederhut-Bollmann, C., Datensatz „,Große Strategie-Studie 2005“, Göttingen 2005. 


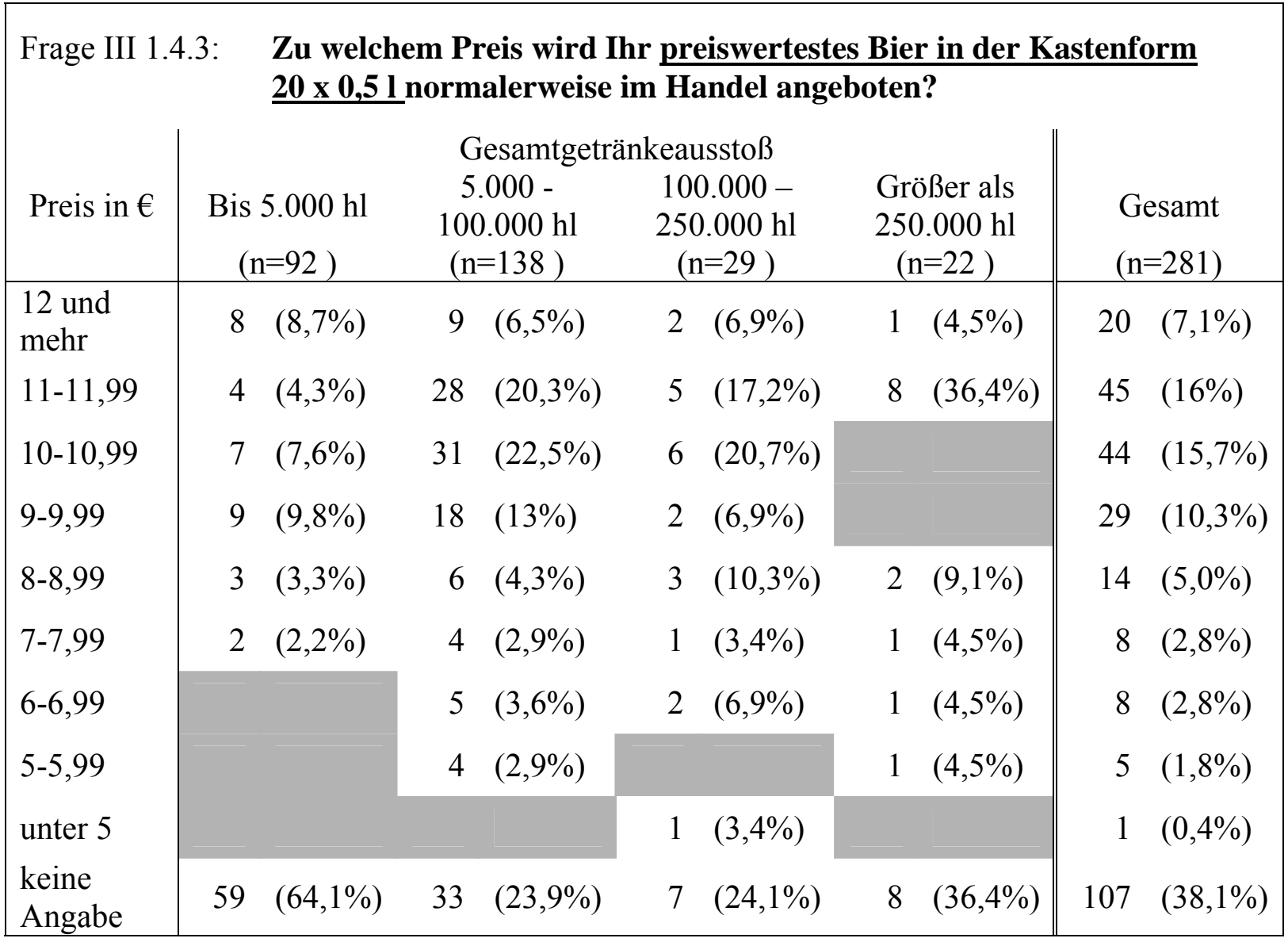

Quelle: : Niederhut-Bollmann, C., Datensatz „Große Strategie-Studie 2005“, Göttingen 2005.

\begin{tabular}{|c|c|c|c|c|c|c|c|}
\hline Frage III 1. & & $\begin{array}{l}\text { Zu welcl } \\
24 \times 0,33 \\
\end{array}$ & $\begin{array}{l}\text { m Preis wird } \\
\text { normalerwei }\end{array}$ & $\begin{array}{l}\text { Ir preiswertest } \\
\text { im Handel an }\end{array}$ & $\begin{array}{l}\text { Bier in der } \mathrm{K} \\
\text { boten? }\end{array}$ & ctonf & form \\
\hline Preis in $€$ & & $\begin{array}{l}5.000 \mathrm{hl} \\
\mathrm{n}=92)\end{array}$ & $\begin{array}{c}\text { Gesamtgetr } \\
5.000- \\
100.000 \mathrm{hl} \\
(\mathrm{n}=138)\end{array}$ & $\begin{array}{l}\text { nkeausstoß } \\
100.000- \\
250.000 \mathrm{hl} \\
(\mathrm{n}=29)\end{array}$ & $\begin{array}{c}\text { Größer als } \\
250.000 \mathrm{hl} \\
(\mathrm{n}=22)\end{array}$ & & $\begin{array}{l}\text { Gesamt } \\
n=281)\end{array}$ \\
\hline $\begin{array}{l}12 \text { und } \\
\text { mehr }\end{array}$ & 1 & $(1,1 \%)$ & $7 \quad(5,1 \%)$ & $1 \quad(3,4 \%)$ & & & $(3,2 \%)$ \\
\hline $11-11,99$ & 2 & $(2,2 \%)$ & $7 \quad(5,1 \%)$ & $1 \quad(3,4 \%)$ & $4 \quad(18,2 \%)$ & & $(5 \%)$ \\
\hline $10-10,99$ & 2 & $(2,2 \%)$ & $5 \quad(3,6 \%)$ & $2 \quad(6,9 \%)$ & & & $(3,2 \%)$ \\
\hline $9-9,99$ & 2 & $(2,2 \%)$ & & $1 \quad(3,4 \%)$ & & & $(1,1 \%)$ \\
\hline $8-8,99$ & 1 & $(1,1 \%)$ & $1 \quad(0,7 \%)$ & & & & $(0,7 \%)$ \\
\hline 7-7,99 & 1 & $(1,1 \%)$ & & $1 \quad(3,4 \%)$ & & & $(0,7 \%)$ \\
\hline $\begin{array}{l}\text { keine } \\
\text { Angabe }\end{array}$ & 83 & $(90,2 \%)$ & $118 \quad(85,5 \%)$ & $23 \quad(79,3 \%)$ & $18 \quad(81,8 \%)$ & 242 & $(86,1 \%)$ \\
\hline
\end{tabular}

Quelle: : Niederhut-Bollmann, C., Datensatz „Große Strategie-Studie 2005“, Göttingen 2005. 


\begin{tabular}{|c|c|c|c|c|c|c|c|c|c|c|}
\hline \multirow[t]{2}{*}{ Frage III 1} & \multicolumn{10}{|c|}{$\begin{array}{l}\text { Welchen Anteil nehmen Markenartikel bei der Vermarktung Ihrer } \\
\text { Produkte ein? }\end{array}$} \\
\hline & \multicolumn{2}{|c|}{$\begin{array}{l}\text { Bis } 5.000 \mathrm{hl} \\
\quad(\mathrm{n}=92)\end{array}$} & & $\begin{array}{l}\text { Gesamtg } \\
5.000- \\
0.000 \mathrm{hl} \\
\mathrm{n}=138)\end{array}$ & $\begin{array}{r}\text { kes } \\
1 \\
2\end{array}$ & $\begin{array}{l}\text { usstoß } \\
0.000- \\
0.000 \mathrm{hl} \\
\mathrm{n}=29)\end{array}$ & \multicolumn{2}{|c|}{$\begin{array}{c}\text { Größer als } \\
250.000 \mathrm{hl} \\
(\mathrm{n}=22)\end{array}$} & \multicolumn{2}{|c|}{$\begin{array}{l}\text { Gesamt } \\
(\mathrm{n}=281)\end{array}$} \\
\hline Bis $20 \%$ & 1 & $(1,1 \%)$ & & & & & & & & $(0,4 \%)$ \\
\hline$>20-40 \%$ & 1 & $(1,1 \%)$ & 3 & $(2,2 \%)$ & & & & $(9,1 \%)$ & 6 & $(2,1 \%)$ \\
\hline$>40-60 \%$ & 7 & $(7,6 \%)$ & 9 & $(6,5 \%)$ & & & & $(4,5 \%)$ & 17 & $(6 \%)$ \\
\hline$>60-80 \%$ & 7 & $(7,6 \%)$ & 10 & $(7,2 \%)$ & 3 & $(10,3 \%)$ & 1 & $(4,5 \%)$ & 21 & $(7,5 \%)$ \\
\hline$>80-99 \%$ & 11 & $(12 \%)$ & 23 & $(16,7 \%)$ & 2 & $(6,9 \%)$ & 4 & $(18,2 \%)$ & 40 & $(14,2 \%)$ \\
\hline $\begin{array}{l}\text { Nur } \\
\text { Marken }\end{array}$ & 22 & $(23,9 \%)$ & 67 & $(48,6 \%)$ & 22 & $(75,9 \%)$ & 13 & $(59,1 \%)$ & 124 & $(44,1 \%)$ \\
\hline $\begin{array}{l}\text { keine } \\
\text { Angabe }\end{array}$ & 43 & $(46,7 \%)$ & 26 & $(18,8 \%)$ & 2 & $(6,9 \%)$ & 1 & $(4,5 \%)$ & 72 & $(25,6 \%)$ \\
\hline
\end{tabular}

Quelle: : Niederhut-Bollmann, C., Datensatz „Große Strategie-Studie 2005“, Göttingen 2005.

\begin{tabular}{|c|c|c|c|c|c|c|c|c|}
\hline \multirow[t]{2}{*}{ Frage III 1} & \multicolumn{8}{|c|}{$\begin{array}{l}\text { Welchen Anteil nehmen Handelsmarken bei der Vermarktung } \\
\text { Ihrer Produkte ein? }\end{array}$} \\
\hline & \multicolumn{2}{|c|}{$\begin{array}{l}\text { Bis } 5.000 \mathrm{hl} \\
\quad(\mathrm{n}=92)\end{array}$} & & $\begin{array}{l}\text { Jesamtge } \\
.000- \\
.000 \mathrm{hl} \\
=138)\end{array}$ & $\begin{array}{c}\text { keaussto } \beta \\
100.000- \\
250.000 \mathrm{hl} \\
(\mathrm{n}=29)\end{array}$ & $\begin{array}{c}\text { Größer als } \\
250.000 \mathrm{hl} \\
(\mathrm{n}=22)\end{array}$ & \multicolumn{2}{|c|}{$\begin{array}{l}\text { Gesamt } \\
(\mathrm{n}=281)\end{array}$} \\
\hline $\begin{array}{l}\text { Handels- } \\
\text { marken }\end{array}$ & 22 & $(23,9 \%)$ & 67 & $(48,6 \%)$ & $22 \quad(75,9 \%)$ & $13 \quad(59,1 \%)$ & 124 & $(44,1 \%)$ \\
\hline bis $20 \%$ & 15 & $(16,3 \%)$ & 28 & $(20,3 \%)$ & $2 \quad(6,9 \%)$ & $5 \quad(22,7 \%)$ & 50 & $(17,8 \%)$ \\
\hline$>20-40 \%$ & 4 & $(4,3 \%)$ & 6 & $(4,3 \%)$ & $3 \quad(10,3 \%)$ & $1 \quad(4,5 \%)$ & 14 & $(5 \%)$ \\
\hline$>40-60 \%$ & 6 & $(6,5 \%)$ & 10 & $(7,2 \%)$ & & $1 \quad(4,5 \%)$ & 17 & $(6 \%)$ \\
\hline$>60-80 \%$ & 1 & $(1,1 \%)$ & 1 & $(0,7 \%)$ & & $1 \quad(4,5 \%)$ & 3 & $(1,1 \%)$ \\
\hline$>80-99 \%$ & 1 & $(1,1 \%)$ & & & & & 1 & $(0,4 \%)$ \\
\hline $\begin{array}{l}\text { keine } \\
\text { Angabe }\end{array}$ & 43 & $(46,7 \%)$ & 26 & $(18,8 \%)$ & $2 \quad(6,9 \%)$ & $1 \quad(4,5 \%)$ & 72 & $(25,6 \%)$ \\
\hline
\end{tabular}

Quelle: : Niederhut-Bollmann, C., Datensatz „Große Strategie-Studie 2005“, Göttingen 2005. 


\begin{tabular}{|c|c|c|c|c|c|}
\hline \multirow[t]{3}{*}{ Frage III 1.6.1 } & \multicolumn{5}{|c|}{$\begin{array}{l}\text { Wie hoch ist der Anteil der Gebindeart Glasflasche (Mehrweg) am } \\
\text { Gesamtbierausstoß Ihres Unternehmens? }\end{array}$} \\
\hline & \multirow[b]{2}{*}{$\begin{array}{c}\text { Bis } 5.000 \mathrm{hl} \\
(\mathrm{n}=92)\end{array}$} & \multicolumn{2}{|c|}{ Gesamtgetränkeausstoß } & \multirow[b]{2}{*}{$\begin{array}{c}\text { Größer als } \\
250.000 \mathrm{hl} \\
(\mathrm{n}=22)\end{array}$} & \multirow[b]{2}{*}{$\begin{array}{l}\text { Gesamt } \\
(\mathrm{n}=281)\end{array}$} \\
\hline & & $\begin{array}{c}5.000- \\
100.000 \mathrm{hl} \\
(\mathrm{n}=138)\end{array}$ & $\begin{array}{c}100.000- \\
250.000 \mathrm{hl} \\
(\mathrm{n}=29)\end{array}$ & & \\
\hline $\begin{array}{l}\text { nicht im } \\
\text { Sortiment }\end{array}$ & $12(13 \%)$ & $1 \quad(0,7 \%)$ & & & $13(4,6 \%)$ \\
\hline Bis $20 \%$ & $16 \quad(17,4 \%)$ & $2(1,4 \%)$ & & & $18 \quad(6,4 \%)$ \\
\hline$>20-40 \%$ & $9 \quad(9,8 \%)$ & $7 \quad(5,1 \%)$ & & $1 \quad(4,5 \%)$ & $17(6 \%)$ \\
\hline$>40-60 \%$ & $19 \quad(20,7 \%)$ & $19 \quad(13,8 \%)$ & $6 \quad(20,7 \%)$ & $2 \quad(9,1 \%)$ & $46 \quad(16,4 \%)$ \\
\hline$>60-80 \%$ & $22 \quad(23,9 \%)$ & $70 \quad(50,7 \%)$ & $12 \quad(41,4 \%)$ & $11 \quad(50 \%)$ & $115(40,9 \%)$ \\
\hline$>80-99 \%$ & $5 \quad(5,4 \%)$ & $34 \quad(24,6 \%)$ & $11(37,9 \%)$ & $8 \quad(36,4 \%)$ & $58 \quad(20,6 \%)$ \\
\hline $\begin{array}{l}\text { nur Glas- } \\
\text { flasche }\end{array}$ & $6 \quad(6,5 \%)$ & $3 \quad(2,2 \%)$ & & & $9 \quad(3,2 \%)$ \\
\hline $\begin{array}{l}\text { keine } \\
\text { Angabe }\end{array}$ & $3 \quad(3,3 \%)$ & $2 \quad(1,4 \%)$ & & & $5 \quad(1,8 \%)$ \\
\hline Mittelwert* & $54,61 \%$ & $72,59 \%$ & $75,48 \%$ & $76,09 \%$ & $67,94 \%$ \\
\hline
\end{tabular}

* In die Berechnung des Mittelwertes sind nur die Unternehmen einbezogen, welche eine Angabe gemacht haben und die Gebindeart Glasflasche (Mehrweg) im Sortiment führen.

Quelle: Niederhut-Bollmann, C., Datensatz „Große Strategie-Studie 2005“, Göttingen 2005.

\section{Frage III 1.6.2: Wie hoch ist der Anteil der Gebindeart PET (Mehrweg) am Gesamtbierausstoß Ihres Unternehmens?}

\begin{tabular}{|c|c|c|c|c|c|c|}
\hline & \multicolumn{4}{|c|}{ Gesamtgetränkeausstoß } & \multirow{2}{*}{\multicolumn{2}{|c|}{$\begin{array}{l}\text { Gesamt } \\
(\mathrm{n}=281)\end{array}$}} \\
\hline & $\begin{array}{c}\text { Bis } 5.000 \mathrm{hl} \\
(\mathrm{n}=92)\end{array}$ & $\begin{array}{c}5.000- \\
100.000 \mathrm{hl} \\
(\mathrm{n}=138)\end{array}$ & $\begin{array}{c}100.000- \\
250.000 \mathrm{hl} \\
(\mathrm{n}=29)\end{array}$ & $\begin{array}{c}\text { Größer als } \\
250.000 \mathrm{hl} \\
(\mathrm{n}=22)\end{array}$ & & \\
\hline $\begin{array}{l}\text { nicht im } \\
\text { Sortiment }\end{array}$ & $85 \quad(92,4 \%)$ & $130 \quad(94,2 \%)$ & $(100 \%)$ & $19 \quad(86,4 \%)$ & 263 & $(93,6 \%)$ \\
\hline Bis $20 \%$ & $3 \quad(3,3 \%)$ & $6 \quad(4,3 \%)$ & & $3 \quad(13,6 \%)$ & 12 & $(4,3 \%)$ \\
\hline$>20-40 \%$ & $1 \quad(1,1 \%)$ & & & & & $(0,4 \%)$ \\
\hline $\begin{array}{l}\text { keine } \\
\text { Angabe }\end{array}$ & $3 \quad(3,3 \%)$ & $2(1,4 \%)$ & & & & $(1,8 \%)$ \\
\hline Mittelwert & $12,75 \%$ & $10,66 \%$ & $0 \%$ & $1,66 \%$ & & $9,23 \%$ \\
\hline
\end{tabular}

* In die Berechnung des Mittelwertes sind nur die Unternehmen einbezogen, welche eine Angabe gemacht haben und die Gebindeart PET im Sortiment führen.

Quelle: Niederhut-Bollmann, C., Datensatz „Große Strategie-Studie 2005“, Göttingen 2005. 


\begin{tabular}{|c|c|c|c|c|c|}
\hline \multirow[t]{2}{*}{ Frage III 1.6.3 } & \multicolumn{5}{|c|}{$\begin{array}{l}\text { Wie hoch ist der Anteil der Gebindeart Fass am Gesamtbierausstoß } \\
\text { Ihres Unternehmens? }\end{array}$} \\
\hline & $\begin{array}{l}\text { Bis } 5.000 \mathrm{hl} \\
\quad(\mathrm{n}=92)\end{array}$ & $\begin{array}{c}\text { Gesamtgetrà } \\
5.000- \\
100.000 \mathrm{hl} \\
(\mathrm{n}=138)\end{array}$ & $\begin{array}{l}\text { keaussto } \\
100.000- \\
250.000 \mathrm{hl} \\
(\mathrm{n}=29)\end{array}$ & $\begin{array}{c}\text { Größer als } \\
250.000 \mathrm{hl} \\
(\mathrm{n}=22)\end{array}$ & $\begin{array}{l}\text { Gesamt } \\
(\mathrm{n}=281)\end{array}$ \\
\hline $\begin{array}{l}\text { nicht im } \\
\text { Sortiment }\end{array}$ & $10 \quad(10,9 \%)$ & $4 \quad(2,9 \%)$ & & & $14 \quad(5 \%)$ \\
\hline Bis $20 \%$ & $17 \quad(18,5 \%)$ & $54 \quad(39,1 \%)$ & $15 \quad(51,7 \%)$ & $13 \quad(59,1 \%)$ & $99 \quad(35,2 \%)$ \\
\hline$>20-40 \%$ & $30 \quad(32,6 \%)$ & $62 \quad(44,9 \%)$ & $13(44,8 \%)$ & $7 \quad(31,8 \%)$ & $112(39,9 \%)$ \\
\hline$>40-60 \%$ & $10 \quad(10,9 \%)$ & $12 \quad(8,7 \%)$ & $1 \quad(3,4 \%)$ & $2 \quad(9,1 \%)$ & $25 \quad(8,9 \%)$ \\
\hline$>60-80 \%$ & $8 \quad(8,7 \%)$ & $3 \quad(2,2 \%)$ & & & $11 \quad(3,9 \%)$ \\
\hline$>80-99 \%$ & $8 \quad(8,7 \%)$ & & & & $8 \quad(2,8 \%)$ \\
\hline nur Fass & $6 \quad(6,5 \%)$ & $1 \quad(0,7 \%)$ & & & $7 \quad(2,5 \%)$ \\
\hline $\begin{array}{l}\text { keine } \\
\text { Angabe }\end{array}$ & $3 \quad(3,3 \%)$ & $2 \quad(1,4 \%)$ & & & $5 \quad(1,8 \%)$ \\
\hline Mittelwert* & $47,03 \%$ & $27,84 \%$ & $22,96 \%$ & $22,18 \%$ & $32,61 \%$ \\
\hline
\end{tabular}

* In die Berechnung des Mittelwertes sind nur die Unternehmen einbezogen, welche eine Angabe gemacht haben und die Gebindeart Fass im Sortiment führen.

Quelle: Niederhut-Bollmann, C., Datensatz „Große Strategie-Studie 2005“, Göttingen 2005.

\begin{tabular}{|c|c|c|c|c|c|}
\hline \multirow[t]{2}{*}{ Frage III 1.6.} & \multicolumn{5}{|c|}{$\begin{array}{l}\text { Wie hoch ist der Anteil der Gebindeart Einweg am Gesamtbierausstoß } \\
\text { Ihres Unternehmens? }\end{array}$} \\
\hline & $\begin{array}{l}\text { Bis } 5.000 \mathrm{hl} \\
(\mathrm{n}=92)\end{array}$ & $\begin{array}{c}\text { Gesamtgetr } \\
5.000- \\
100.000 \mathrm{hl} \\
(\mathrm{n}=138) \\
\end{array}$ & $\begin{array}{c}\text { keausstoß } \\
100.000- \\
250.000 \mathrm{hl} \\
(\mathrm{n}=29)\end{array}$ & $\begin{array}{c}\text { Größer als } \\
250.000 \mathrm{hl} \\
(\mathrm{n}=22)\end{array}$ & $\begin{array}{l}\text { Gesamt } \\
(\mathrm{n}=281)\end{array}$ \\
\hline $\begin{array}{l}\text { nicht im } \\
\text { Sortiment }\end{array}$ & $83 \quad(90,2 \%)$ & $124 \quad(89,9 \%)$ & $22 \quad(75,9 \%)$ & $12(54,5 \%)$ & $241 \quad(85,8 \%)$ \\
\hline Bis $20 \%$ & $6 \quad(6,5 \%)$ & $12 \quad(8,7 \%)$ & $6 \quad(20,7 \%)$ & $10 \quad(45,5 \%)$ & $34 \quad(12,1 \%)$ \\
\hline$>20-40 \%$ & & & $1 \quad(3,4 \%)$ & & $1 \quad(0,4 \%)$ \\
\hline $\begin{array}{l}\text { keine } \\
\text { Angabe }\end{array}$ & $3 \quad(3,3 \%)$ & $2 \quad(1,4 \%)$ & & & $5 \quad(1,8 \%)$ \\
\hline Mittelwert* & $5,66 \%$ & $3,75 \%$ & $5,85 \%$ & $3,08 \%$ & $4,3 \%$ \\
\hline
\end{tabular}

* In die Berechnung des Mittelwertes sind nur die Unternehmen einbezogen, welche eine Angabe gemacht haben und die Gebindeart Einweg im Sortiment führen.

Quelle: Niederhut-Bollmann, C., Datensatz „Große Strategie-Studie 2005“, Göttingen 2005. 


\begin{tabular}{|c|c|c|c|c|c|}
\hline \multirow[t]{2}{*}{ Frage III 1.6.5 } & \multicolumn{4}{|c|}{$\begin{array}{l}\text { Wie hoch ist der Anteil der Gebindeart Sonstiges am } \\
\text { Gesamtbierausstoß Ihres Unternehmens? }\end{array}$} & \multirow[b]{2}{*}{$\begin{array}{l}\text { Gesamt } \\
(\mathrm{n}=281)\end{array}$} \\
\hline & $\begin{array}{l}\text { Bis } 5.000 \mathrm{hl} \\
\quad(\mathrm{n}=92)\end{array}$ & $\begin{array}{c}\text { Gesamtget } \\
5.000- \\
100.000 \mathrm{hl} \\
(\mathrm{n}=138) \\
\end{array}$ & $\begin{array}{c}\text { keausstoß } \\
100.000- \\
250.000 \mathrm{hl} \\
(\mathrm{n}=29)\end{array}$ & $\begin{array}{c}\text { Größer als } \\
250.000 \mathrm{hl} \\
(\mathrm{n}=22)\end{array}$ & \\
\hline $\begin{array}{l}\text { nicht im } \\
\text { Sortiment }\end{array}$ & $77 \quad(83,7 \%)$ & $134 \quad(97,1 \%)$ & $28 \quad(96,6 \%)$ & $21 \quad(95,5 \%)$ & $260 \quad(92,5 \%)$ \\
\hline Bis $20 \%$ & $3 \quad(3,3 \%)$ & $2 \quad(1,4 \%)$ & $1 \quad(4,5 \%)$ & $1 \quad(4,5 \%)$ & $7 \quad(2,5 \%)$ \\
\hline$>20-40 \%$ & $1 \quad(1,1 \%)$ & & & & $1 \quad(0,4 \%)$ \\
\hline$>40-60 \%$ & & & & & \\
\hline$>60-80 \%$ & $2 \quad(2,2 \%)$ & & & & $2 \quad(0,7 \%)$ \\
\hline$>80-99 \%$ & $5 \quad(5,4 \%)$ & & & & $5 \quad(1,8 \%)$ \\
\hline $\begin{array}{l}\text { nur sonstige } \\
\text { Gebinde }\end{array}$ & $1 \quad(1,1 \%)$ & & & & $1 \quad(0,4 \%)$ \\
\hline $\begin{array}{l}\text { keine } \\
\text { Angabe }\end{array}$ & $3 \quad(3,3 \%)$ & $2 \quad(1,4 \%)$ & & & $5 \quad(1,8 \%)$ \\
\hline Mittelwert* & $66,08 \%$ & $8,0 \%$ & $5,0 \%$ & $1,7 \%$ & $50,98 \%$ \\
\hline
\end{tabular}

* In die Berechnung des Mittelwertes sind nur die Unternehmen einbezogen, welche eine Angabe gemacht haben und die Gebindeart Sonstiges im Sortiment führen.

Quelle: Niederhut-Bollmann, C., Datensatz „Große Strategie-Studie 2005“, Göttingen 2005.

\begin{tabular}{|c|c|c|c|c|c|}
\hline \multirow[t]{2}{*}{ Frage III 1.} & \multicolumn{5}{|c|}{$\begin{array}{l}\text { Vertreibt Ihr Unternehmen neben Getränken und Nebenprodukten } \\
\text { (Gläser, Bierdeckel, Textilien, Feuerzeuge usw.) auch noch andere } \\
\text { Produkte oder Dienstleistungen?(z.B. Catering, Eventmanagement, } \\
\text { Reisen, Komplementärprodukte wie Nahrungsmittel oder Spirituosen usw.) }\end{array}$} \\
\hline & $\begin{array}{c}\text { Bis } 5.000 \mathrm{hl} \\
(\mathrm{n}=92)\end{array}$ & $\begin{array}{l}5.000- \\
100.000 \mathrm{hl} \\
(\mathrm{n}=138)\end{array}$ & $\begin{array}{c}100.000- \\
250.000 \mathrm{hl} \\
(\mathrm{n}=29)\end{array}$ & $\begin{array}{l}\text { Größer als } \\
250.000 \mathrm{hl} \\
(\mathrm{n}=22)\end{array}$ & $\begin{array}{l}\text { Gesamt } \\
(\mathrm{n}=281)\end{array}$ \\
\hline $\mathrm{Ja}$ & $41 \quad(44,6 \%)$ & $34 \quad(24,6 \%)$ & $9 \quad(31 \%)$ & $3 \quad(13,6 \%)$ & $87 \quad(31 \%)$ \\
\hline $\begin{array}{l}\text { In } \\
\text { Planung }\end{array}$ & $1 \quad(1,1 \%)$ & $2 \quad(1,4 \%)$ & $1 \quad(3,4 \%)$ & & $4 \quad(1,4 \%)$ \\
\hline Nein & $49 \quad(53,3 \%)$ & $102 \quad(73,9 \%)$ & $19 \quad(65,5 \%)$ & $19 \quad(86,4 \%)$ & $189(67,3 \%)$ \\
\hline $\begin{array}{l}\text { keine } \\
\text { Angabe }\end{array}$ & $1 \quad(1,1 \%)$ & & & & $1 \quad(0,4 \%)$ \\
\hline
\end{tabular}

Quelle: Niederhut-Bollmann, C., Datensatz „Große Strategie-Studie 2005“, Göttingen 2005. 


\begin{tabular}{|c|c|c|c|c|c|c|c|c|c|c|}
\hline \multirow[t]{2}{*}{ Frage III 1.8.1: } & \multicolumn{10}{|c|}{$\begin{array}{l}\text { Inwieweit stimmen Sie dem folgenden Statement, welches so oder ähnlich } \\
\text { von Managern anderer Unternehmen geäußert wurde, für Ihr } \\
\text { Unternehmen zu? } \\
\text { Nebenprodukte wie z.B. Gläser, Textilien, Feuerzeuge usw. sind ein } \\
\text { wichtiges Einnahmefeld unseres Unternehmens. } \\
\quad \text { Gesamtgetränkeausstoß }\end{array}$} \\
\hline & & $\begin{array}{l}5.000 \mathrm{hl} \\
=92)\end{array}$ & $\begin{array}{r}5.000 \\
\quad(\mathrm{n}\end{array}$ & $\begin{array}{l}100.000 \\
\text { hl } \\
138)\end{array}$ & & $\begin{array}{l}000- \\
000 \mathrm{hl} \\
29)\end{array}$ & & $\begin{array}{l}\text { Ber als } \\
.000 \mathrm{hl} \\
=22)\end{array}$ & & iesamt \\
\hline $\begin{array}{l}\text { Stimme voll- } \\
\text { ständig zu }\end{array}$ & & $(5,4 \%)$ & 2 & $(1,4 \%)$ & & & & & & $(2,5 \%)$ \\
\hline Stimme zu & 15 & $(16,3 \%)$ & 8 & $(5,8 \%)$ & & $(17,2 \%)$ & & $(4,5 \%)$ & 29 & $(10,3 \%)$ \\
\hline Weder noch & 33 & $(35,9 \%)$ & 47 & $(34,1 \%)$ & 7 & $(24,1 \%)$ & & $(40,9 \%)$ & 96 & $(34,2 \%)$ \\
\hline Lehne ab & & $(22,8 \%)$ & 56 & $(40,6 \%)$ & 12 & $(41,4 \%)$ & & $(31,8 \%)$ & 96 & $(34,2 \%)$ \\
\hline $\begin{array}{l}\text { Lehne voll- } \\
\text { ständig ab }\end{array}$ & & $(16,3 \%)$ & 25 & $(18,1 \%)$ & 5 & $(17,2 \%)$ & & $(22,7 \%)$ & 50 & $(17,8 \%)$ \\
\hline $\begin{array}{l}\text { Keine } \\
\text { Angabe }\end{array}$ & & $(3,3 \%)$ & & & & & & & & $(1,1 \%)$ \\
\hline
\end{tabular}

Quelle: Niederhut-Bollmann, C., Datensatz „,Große Strategie-Studie 2005“, Göttingen 2005.

\begin{tabular}{|c|c|c|c|c|c|c|c|c|c|c|}
\hline \multirow[t]{2}{*}{ Frage III 1.8.2 } & \multicolumn{10}{|c|}{$\begin{array}{l}\text { Inwieweit stimmen Sie dem folgenden Statement, welches so oder ähnlich } \\
\text { von Managern anderer Unternehmen geäußert wurde, für Ihr } \\
\text { Unternehmen zu? } \\
\text { Beim Vertrieb von Nebenprodukten stehen in unserem Unternehmen } \\
\text { Marketingaspekte im Vordergrund. }\end{array}$} \\
\hline & & $\begin{array}{l}5.000 \mathrm{hl} \\
=92)\end{array}$ & $\begin{array}{r}5.000 \\
\quad(\mathrm{n} \\
\end{array}$ & $\begin{array}{l}100.000 \\
\text { hl } \\
138)\end{array}$ & & $\begin{array}{l}000- \\
000 \mathrm{hl} \\
29)\end{array}$ & & $\begin{array}{l}\text { Ber als } \\
.000 \mathrm{hl} \\
=22)\end{array}$ & & $\begin{array}{l}\text { esamt } \\
=281 \text { ) }\end{array}$ \\
\hline $\begin{array}{l}\text { Stimme voll- } \\
\text { ständig zu }\end{array}$ & & $(6,5 \%)$ & 11 & $(8 \%)$ & 6 & $(20,7 \%)$ & & $(13,6 \%)$ & 26 & $(9,3 \%)$ \\
\hline Stimme zu & 34 & $(37 \%)$ & 59 & $(42,8 \%)$ & 15 & $(51,7 \%)$ & 12 & $(54,5 \%)$ & 120 & $(42,7 \%)$ \\
\hline Weder noch & 28 & $(30,4 \%)$ & 29 & $(21 \%)$ & 5 & $(17,2 \%)$ & & $(18,2 \%)$ & 66 & $(23,5 \%)$ \\
\hline Lehne ab & 14 & $(15,2 \%)$ & 25 & $(18,1 \%)$ & 2 & $(6,9 \%)$ & & $(9,1 \%)$ & 43 & $(15,3 \%)$ \\
\hline $\begin{array}{l}\text { Lehne voll- } \\
\text { ständig ab }\end{array}$ & 5 & $(5,4 \%)$ & 12 & $(8,7 \%)$ & & $(3,4 \%)$ & & $(4,5 \%)$ & 19 & $(6,8 \%)$ \\
\hline $\begin{array}{l}\text { Keine } \\
\text { Angabe }\end{array}$ & & $(5,4 \%)$ & 2 & $(1,4 \%)$ & & & & & 7 & $(2,5 \%)$ \\
\hline
\end{tabular}

Quelle: Niederhut-Bollmann, C., Datensatz „Große Strategie-Studie 2005“, Göttingen 2005. 


\begin{tabular}{|c|c|c|c|c|c|c|c|c|c|c|}
\hline \multirow[t]{2}{*}{ Frage III 1.8 .3} & \multicolumn{10}{|c|}{$\begin{array}{l}\text { Inwieweit stimmen Sie dem folgenden Statement, welches so oder ähnlich } \\
\text { von Managern anderer Unternehmen geäußert wurde, für Ihr } \\
\text { Unternehmen zu? } \\
\text { Um unseren Marktanteil auszubauen, ziehen wir einen Zukauf } \\
\text { anderer Brauereien in Betracht. }\end{array}$} \\
\hline & & $\begin{array}{l}5.000 \mathrm{hl} \\
=92)\end{array}$ & $\begin{array}{r}5.000 \\
\quad(\mathrm{n}=\end{array}$ & $\begin{array}{l}100.000 \\
\text { hl } \\
138)\end{array}$ & & $\begin{array}{l}000- \\
000 \mathrm{hl} \\
29)\end{array}$ & & $\begin{array}{l}\text { Ber als } \\
000 \mathrm{hl} \\
=22)\end{array}$ & & $\begin{array}{l}\text { esamt } \\
=281 \text { ) }\end{array}$ \\
\hline $\begin{array}{l}\text { Stimme voll- } \\
\text { ständig zu }\end{array}$ & & & 4 & $(2,9 \%)$ & 2 & $(6,9 \%)$ & & $(4,5 \%)$ & 7 & $(2,5 \%)$ \\
\hline Stimme zu & 1 & $(1,1 \%)$ & 9 & $(6,5 \%)$ & 7 & $(24,1 \%)$ & & $(31,8 \%)$ & 24 & $(8,5 \%)$ \\
\hline Weder noch & 16 & $(17,4 \%)$ & 18 & $(13 \%)$ & 3 & $(10,3 \%)$ & & $(27,3 \%)$ & 43 & $(15,3 \%)$ \\
\hline Lehne ab & & $(19,6 \%)$ & 43 & $(31,3 \%)$ & 5 & $(17,2 \%)$ & & $(27,3 \%)$ & 72 & $(25,6 \%)$ \\
\hline $\begin{array}{l}\text { Lehne voll- } \\
\text { ständig ab }\end{array}$ & & $(56,5 \%)$ & 62 & $(44,9 \%)$ & 12 & $(41,4 \%)$ & & $(9,1 \%)$ & 128 & $(45,6 \%)$ \\
\hline $\begin{array}{l}\text { Keine } \\
\text { Angabe }\end{array}$ & & $(5,4 \%)$ & 2 & $(1,4 \%)$ & & & & & 7 & $(2,5 \%)$ \\
\hline
\end{tabular}

Quelle: Niederhut-Bollmann, C., Datensatz „Große Strategie-Studie 2005“, Göttingen 2005.

\begin{tabular}{|c|c|c|c|c|c|c|c|c|c|c|}
\hline \multirow[t]{2}{*}{ Frage III 1.8.4: } & \multicolumn{10}{|c|}{$\begin{array}{l}\text { Inwieweit stimmen Sie dem folgenden Statement, welches so oder ähnlich } \\
\text { von Managern anderer Unternehmen geäußert wurde, für } \underline{\mathrm{Ihr}} \\
\text { Unternehmen zu? } \\
\text { Der Internationalisierung messen wir in der gegenwärtigen Situation } \\
\text { eine hohe Bedeutung zu. }\end{array}$} \\
\hline & & $\begin{array}{l}5.000 \mathrm{hl} \\
=92)\end{array}$ & $\begin{array}{r}5.000 \\
\quad(\mathrm{n}\end{array}$ & $\begin{array}{l}100.000 \\
\mathrm{hl} \\
138)\end{array}$ & & $\begin{array}{l}000- \\
00 \mathrm{hl} \\
29)\end{array}$ & & $\begin{array}{l}\text { Ber als } \\
000 \mathrm{hl} \\
=22)\end{array}$ & & $\begin{array}{l}\text { esamt } \\
=281)\end{array}$ \\
\hline $\begin{array}{l}\text { Stimme voll- } \\
\text { ständig zu }\end{array}$ & & $(5,4 \%)$ & 8 & $(5,8 \%)$ & 1 & $(3,4 \%)$ & & $(4,5 \%)$ & 15 & $(5,3 \%)$ \\
\hline Stimme zu & 13 & $(14,1 \%)$ & 36 & $(26,1 \%)$ & 9 & $(31 \%)$ & 11 & $(50 \%)$ & 69 & $(24,6 \%)$ \\
\hline Weder noch & 24 & $(26,1 \%)$ & 35 & $(25,4 \%)$ & 13 & $(44,8 \%)$ & & $(22,7 \%)$ & 77 & $(27,4 \%)$ \\
\hline Lehne ab & 21 & $(22,8 \%)$ & 36 & $(26,1 \%)$ & 2 & $(6,9 \%)$ & & $(18,2 \%)$ & 63 & $(22,4 \%)$ \\
\hline $\begin{array}{l}\text { Lehne voll- } \\
\text { Ständig ab }\end{array}$ & 24 & $(26,1 \%)$ & 23 & $(16,7 \%)$ & 4 & $(13,8 \%)$ & & $(4,5 \%)$ & 52 & $(18,5 \%)$ \\
\hline $\begin{array}{l}\text { Keine } \\
\text { Angabe }\end{array}$ & & $(5,4 \%)$ & & & & & & & & $(1,8 \%)$ \\
\hline
\end{tabular}

Quelle: Niederhut-Bollmann, C., Datensatz „Große Strategie-Studie 2005“, Göttingen 2005. 


\begin{tabular}{|c|c|c|c|c|c|c|c|c|c|c|}
\hline \multirow[t]{2}{*}{ Frage III 1.8.5: } & \multicolumn{10}{|c|}{$\begin{array}{l}\text { Inwieweit stimmen Sie dem folgenden Statement, welches so oder } \\
\text { ähnlich von Managern anderer Unternehmen geäußert wurde, für Ihr } \\
\text { Unternehmen zu? } \\
\text { Wir sind mit unserem jetzigen Marktanteil zufrieden und ergreifen } \\
\text { daher keine Maßnahmen zur Erweiterung. }\end{array}$} \\
\hline & & $\begin{array}{l}5.000 \mathrm{hl} \\
=92 \text { ) }\end{array}$ & $\begin{array}{r}5.000 \\
\quad(\mathrm{n}\end{array}$ & $\begin{array}{l}100.000 \\
\mathrm{hl} \\
138)\end{array}$ & & $\begin{array}{l}00- \\
00 \mathrm{hl} \\
29)\end{array}$ & & $\begin{array}{l}\text { ßer als } \\
.000 \mathrm{hl} \\
=22)\end{array}$ & & $\begin{array}{l}\text { iesamt } \\
=281 \text { ) }\end{array}$ \\
\hline $\begin{array}{l}\text { Stimme voll- } \\
\text { ständig zu }\end{array}$ & & $(4,3 \%)$ & 5 & $(3,6 \%)$ & 2 & $(6,9 \%)$ & & & 11 & $(3,9 \%)$ \\
\hline Stimme zu & 18 & $(19,6 \%)$ & 24 & $(17,4 \%)$ & 3 & $(10,3 \%)$ & & $(4,5 \%)$ & 46 & $(16,4 \%)$ \\
\hline Weder noch & 20 & $(21,7 \%)$ & 28 & $(20,3 \%)$ & 3 & $(10,3 \%)$ & & $(18,2 \%)$ & 55 & $(19,6 \%)$ \\
\hline Lehne ab & 26 & $(28,3 \%)$ & 66 & $(47,8 \%)$ & 13 & $(44,8 \%)$ & 11 & $(50 \%)$ & 116 & $(41,3 \%)$ \\
\hline $\begin{array}{l}\text { Lehne voll- } \\
\text { Ständig ab }\end{array}$ & 18 & $(19,6 \%)$ & 14 & $(10,1 \%)$ & 8 & $(27,6 \%)$ & 6 & $(27,3 \%)$ & 46 & $(16,4 \%)$ \\
\hline $\begin{array}{l}\text { Keine } \\
\text { Angabe }\end{array}$ & & $(6,5 \%)$ & 1 & $(0,7 \%)$ & & & & & 7 & $(2,5 \%)$ \\
\hline
\end{tabular}

Quelle: Niederhut-Bollmann, C., Datensatz „Große Strategie-Studie 2005“, Göttingen 2005.

\begin{tabular}{|c|c|c|c|c|c|c|c|c|c|}
\hline \multirow[t]{2}{*}{ Frage III 1.8.6: } & \multicolumn{9}{|c|}{$\begin{array}{l}\text { Inwieweit stimmen Sie dem folgenden Statement, welches so oder ähnlich } \\
\text { von Managern anderer Unternehmen geäußert wurde, für } \underline{\mathrm{Ihr}} \\
\text { Unternehmen zu? } \\
\text { Um unser Angebot zu erweitern, ziehen wir einen Zukauf anderer } \\
\text { Getränkehersteller (z.B. Brunnenbetriebe, Erfrischungsgetränke, } \\
\text { Spirituosen) in Betracht. }\end{array}$} \\
\hline & & $\begin{array}{l}5.000 \mathrm{hl} \\
=92)\end{array}$ & $\begin{array}{r}5.000 \\
(\mathrm{n} \\
\end{array}$ & $\begin{array}{l}100.000 \\
\mathrm{hl} \\
138)\end{array}$ & & $\begin{array}{l}000- \\
000 \mathrm{hl} \\
=29)\end{array}$ & $\begin{array}{c}\text { Größer als } \\
250.000 \mathrm{hl} \\
(\mathrm{n}=22)\end{array}$ & & $\begin{array}{l}\text { esamt } \\
=281)\end{array}$ \\
\hline $\begin{array}{l}\text { Stimme voll- } \\
\text { ständig zu }\end{array}$ & & $(2,2 \%)$ & 1 & $(0,7 \%)$ & & $(3,4 \%)$ & & & $(1,4 \%)$ \\
\hline Stimme zu & 3 & $(3,3 \%)$ & 6 & $(4,3 \%)$ & 1 & $(3,4 \%)$ & $2 \quad(9,1 \%)$ & 12 & $(4,3 \%)$ \\
\hline Weder noch & 18 & $(19,6 \%)$ & 19 & $(13,8 \%)$ & 4 & $(13,8 \%)$ & $5 \quad(22,7 \%)$ & 46 & $(16,4 \%)$ \\
\hline Lehne ab & 20 & $(21,7 \%)$ & 53 & $(38,4 \%)$ & 8 & $(27,6 \%)$ & $11 \quad(50 \%)$ & 92 & $(32,7 \%)$ \\
\hline $\begin{array}{l}\text { Lehne voll- } \\
\text { ständig ab }\end{array}$ & & $(47,8 \%)$ & 58 & $(42 \%)$ & 14 & $(48,3 \%)$ & $4 \quad(18,2 \%)$ & 120 & $(42,7 \%)$ \\
\hline $\begin{array}{l}\text { Keine } \\
\text { Angabe }\end{array}$ & & $(5,4 \%)$ & 1 & $(0,7 \%)$ & & $(3,4 \%)$ & & & $(2,5 \%)$ \\
\hline
\end{tabular}

Quelle: Niederhut-Bollmann, C., Datensatz „Große Strategie-Studie 2005“, Göttingen 2005. 


\begin{tabular}{|c|c|c|c|c|c|c|c|c|c|c|}
\hline \multirow[t]{2}{*}{ Frage III 1.8.7 } & \multicolumn{10}{|c|}{$\begin{array}{l}\text { Inwieweit stimmen Sie dem folgenden Statement, welches so oder ähnlich } \\
\text { von Managern anderer Unternehmen geäußert wurde, für Ihr } \\
\text { Unternehmen zu? } \\
\text { Um unseren Marktanteil auszubauen, ziehen wir einen Zukauf von } \\
\text { Markenrechten (Lizenzen) anderer Brauereien in Betracht. }\end{array}$} \\
\hline & & $\begin{array}{l}5.000 \mathrm{hl} \\
=92)\end{array}$ & $\begin{array}{r}5.000 \\
\quad(\mathrm{n}=\end{array}$ & $\begin{array}{l}100.000 \\
\text { hl } \\
138)\end{array}$ & & $\begin{array}{l}000- \\
00 \mathrm{hl} \\
29)\end{array}$ & & $\begin{array}{l}\text { Ber als } \\
000 \mathrm{hl} \\
=22)\end{array}$ & & $\begin{array}{l}\text { esamt } \\
=281 \text { ) }\end{array}$ \\
\hline $\begin{array}{l}\text { Stimme voll- } \\
\text { ständig zu }\end{array}$ & & $(1,1 \%)$ & & & & & & $(4,5 \%)$ & & $(0,7 \%)$ \\
\hline Stimme zu & 4 & $(4,3 \%)$ & 10 & $(7,2 \%)$ & 3 & $(10,3 \%)$ & & $(18,2 \%)$ & 21 & $(7,5 \%)$ \\
\hline Weder noch & 14 & $(15,2 \%)$ & 18 & $(13 \%)$ & 8 & $(27,6 \%)$ & & $(18,2 \%)$ & 44 & $(15,7 \%)$ \\
\hline Lehne ab & 22 & $(23,9 \%)$ & 54 & $(39,1 \%)$ & 6 & $(20,7 \%)$ & 10 & $(45,5 \%)$ & 92 & $(32,7 \%)$ \\
\hline $\begin{array}{l}\text { Lehne voll- } \\
\text { ständig ab }\end{array}$ & 47 & $(51,1 \%)$ & 55 & $(39,9 \%)$ & 12 & $(41,4 \%)$ & & $(13,6 \%)$ & 117 & $(41,6 \%)$ \\
\hline $\begin{array}{l}\text { Keine } \\
\text { Angabe }\end{array}$ & & $(4,3 \%)$ & 1 & $(0,7 \%)$ & & & & & & $(1,8 \%)$ \\
\hline
\end{tabular}

Quelle: Niederhut-Bollmann, C., Datensatz „,Große Strategie-Studie 2005“, Göttingen 2005.

\begin{tabular}{|c|c|c|c|c|c|c|c|c|c|c|}
\hline \multirow[t]{2}{*}{ Frage III 1.8.8: } & \multicolumn{10}{|c|}{$\begin{array}{l}\text { Inwieweit stimmen Sie dem folgenden Statement, welches so oder ähnlich } \\
\text { von Managern anderer Unternehmen geäußert wurde, für Ihr } \\
\text { Unternehmen zu? } \\
\text { In der Zukunft wird die Bedeutung der Internationalisierung in } \\
\text { unserem Unternehmen steigen. }\end{array}$} \\
\hline & & $\begin{array}{l}5.000 \mathrm{hl} \\
=92)\end{array}$ & $\begin{array}{r}5.000 \\
\quad(\mathrm{n} \\
\end{array}$ & $\begin{array}{l}100.000 \\
\mathrm{hl} \\
138)\end{array}$ & & $\begin{array}{l}000- \\
00 \mathrm{hl} \\
29)\end{array}$ & & $\begin{array}{l}\text { Ber als } \\
.000 \mathrm{hl} \\
=22)\end{array}$ & & $\begin{array}{l}\text { esamt } \\
=281)\end{array}$ \\
\hline $\begin{array}{l}\text { Stimme voll- } \\
\text { ständig zu }\end{array}$ & 2 & $(2,2 \%)$ & 4 & $(2,9 \%)$ & 1 & $(3,4 \%)$ & & $(4,5 \%)$ & 8 & $(2,8 \%)$ \\
\hline Stimme zu & 9 & $(9,8 \%)$ & 16 & $(11,6 \%)$ & 10 & $(34,5 \%)$ & & $(31,8 \%)$ & 42 & $(14,9 \%)$ \\
\hline Weder noch & 24 & $(26,1 \%)$ & 38 & $(27,5 \%)$ & 6 & $(20,7 \%)$ & & $(9,1 \%)$ & 70 & $(24,9 \%)$ \\
\hline Lehne ab & 19 & $(20,7 \%)$ & 41 & $(29,7 \%)$ & 5 & $(17,2 \%)$ & 8 & $(36,4 \%)$ & 73 & $(26 \%)$ \\
\hline $\begin{array}{l}\text { Lehne voll- } \\
\text { ständig ab }\end{array}$ & 32 & $(34,8 \%)$ & 37 & $(26,8 \%)$ & 7 & $(24,1 \%)$ & & $(18,2 \%)$ & 80 & $(28,5 \%)$ \\
\hline $\begin{array}{l}\text { Keine } \\
\text { Angabe }\end{array}$ & & $(6,5 \%)$ & 2 & $(1,4 \%)$ & & & & & 8 & $(2,8 \%)$ \\
\hline
\end{tabular}

Quelle: Niederhut-Bollmann, C., Datensatz „Große Strategie-Studie 2005“, Göttingen 2005. 


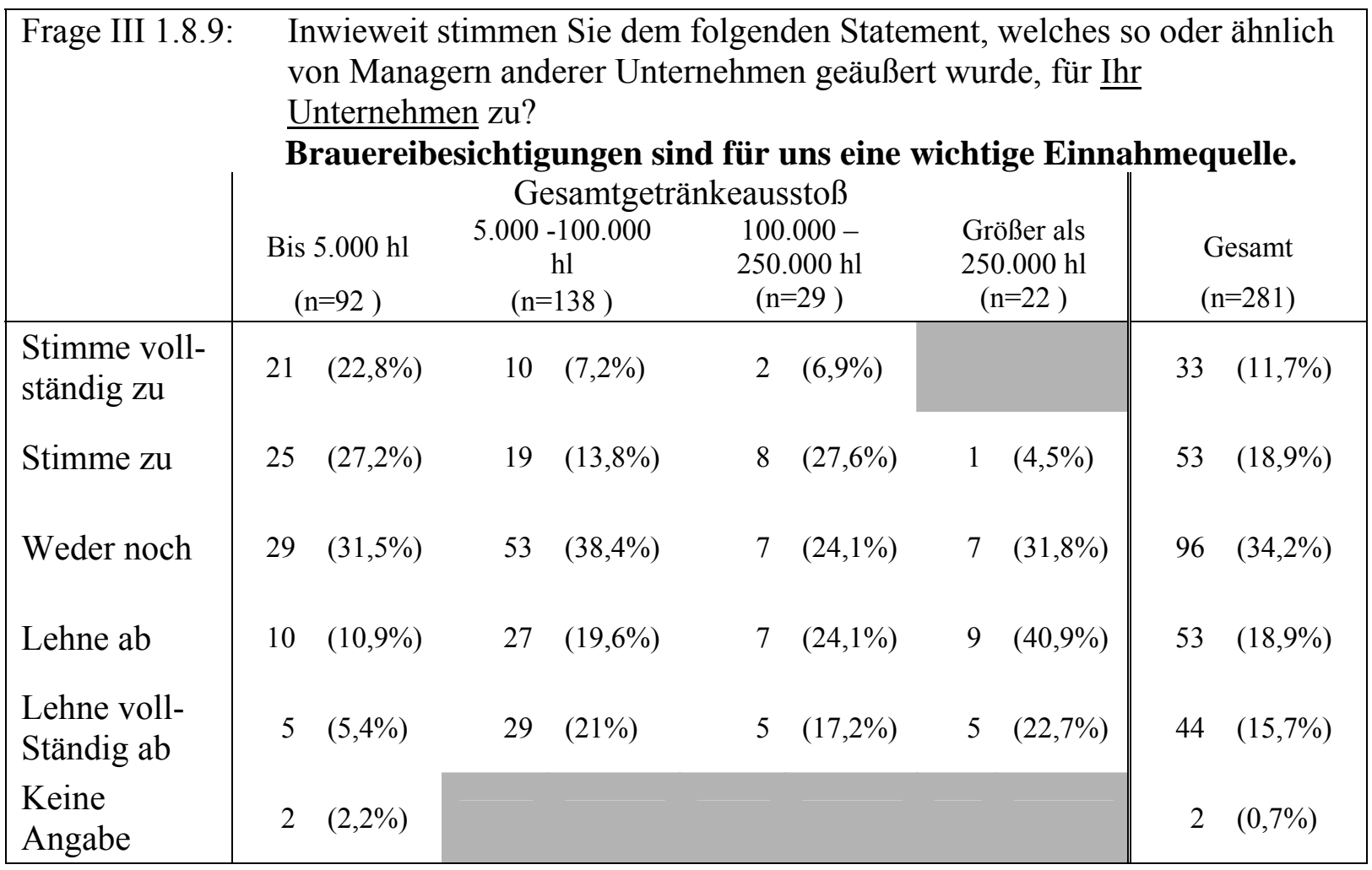

Quelle: Niederhut-Bollmann, C., Datensatz „Große Strategie-Studie 2005“, Göttingen 2005.

\begin{tabular}{|c|c|c|c|c|c|c|c|c|c|c|}
\hline \multirow[t]{3}{*}{ Frage III 1.8.1 } & \multicolumn{10}{|c|}{$\begin{array}{l}\text { Inwieweit stimmen Sie dem folgenden Statement, welches so oder } \\
\text { ähnlich von Managern anderer Unternehmen geäußert wurde, für } \underline{\operatorname{Ihr}} \\
\text { Unternehmen zu? } \\
\text { Mit Innovationen bemühen wir uns immer, die ersten am Markt zu } \\
\text { sein. }\end{array}$} \\
\hline & \multirow{2}{*}{\multicolumn{2}{|c|}{$\begin{array}{c}\text { Bis } 5.000 \mathrm{hl} \\
\quad(\mathrm{n}=92)\end{array}$}} & \multicolumn{4}{|c|}{ Gesamtgetränkeausstoß } & \multirow{2}{*}{\multicolumn{2}{|c|}{$\begin{array}{c}\text { Größer als } \\
250.000 \mathrm{hl} \\
(\mathrm{n}=22)\end{array}$}} & \multirow{2}{*}{\multicolumn{2}{|c|}{$\begin{array}{l}\text { Gesamt } \\
(\mathrm{n}=281)\end{array}$}} \\
\hline & & & $\begin{array}{r}5.000 \\
\quad(\mathrm{n}=\end{array}$ & $\begin{array}{l}100.000 \\
\mathrm{hl} \\
138)\end{array}$ & & $\begin{array}{l}000- \\
00 \mathrm{hl} \\
29)\end{array}$ & & & & \\
\hline $\begin{array}{l}\text { Stimme voll- } \\
\text { ständig zu }\end{array}$ & & $(14,1 \%)$ & 10 & $(7,2 \%)$ & 2 & $(6,9 \%)$ & & $(4,5 \%)$ & 26 & $(9,3 \%)$ \\
\hline Stimme zu & 2 & $(26,1 \%)$ & 45 & $(32,6 \%)$ & 16 & $(55,2 \%)$ & 14 & $(63,6 \%)$ & 99 & $(35,2 \%)$ \\
\hline Weder noch & 28 & $(30,4 \%)$ & 58 & $(42 \%)$ & 9 & $(31 \%)$ & & $(27,3 \%)$ & 101 & $(35,9 \%)$ \\
\hline Lehne ab & & $(15,2 \%)$ & 17 & $(12,3 \%)$ & & $(3,4 \%)$ & & $(4,5 \%)$ & 33 & $(11,7 \%)$ \\
\hline $\begin{array}{l}\text { Lehne voll- } \\
\text { ständig ab }\end{array}$ & & $(9,8 \%)$ & 7 & $(5,1 \%)$ & & $(3,4 \%)$ & & & 17 & $(6 \%)$ \\
\hline $\begin{array}{l}\text { Keine } \\
\text { Angabe }\end{array}$ & & $(4,3 \%)$ & 1 & $(0,7 \%)$ & & & & & 5 & $(1,8 \%)$ \\
\hline
\end{tabular}

Quelle: Niederhut-Bollmann, C., Datensatz „Große Strategie-Studie 2005“, Göttingen 2005. 


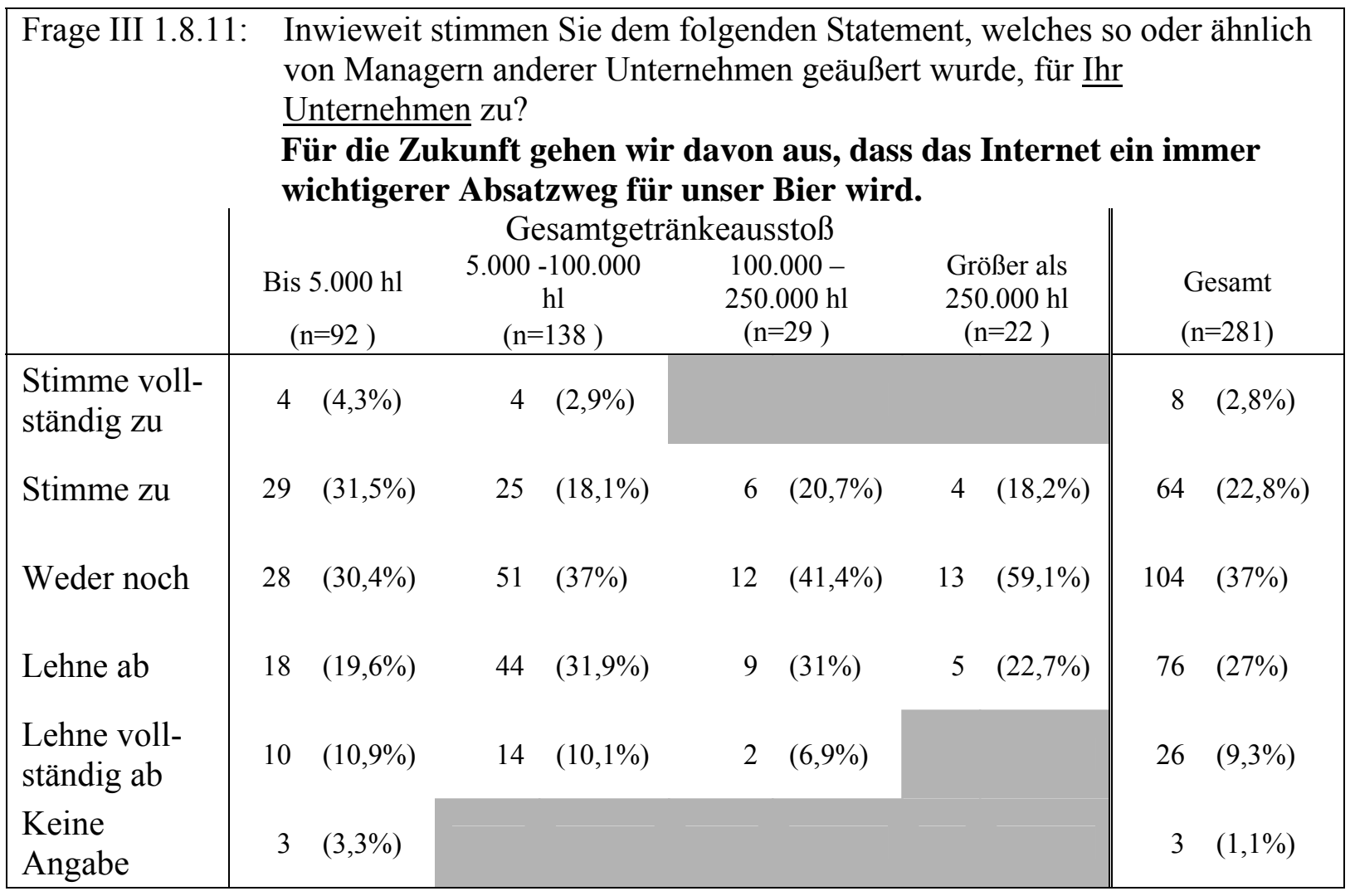

Quelle: Niederhut-Bollmann, C., Datensatz „,Große Strategie-Studie 2005“, Göttingen 2005.

\begin{tabular}{|c|c|c|c|c|c|c|c|c|c|c|}
\hline \multirow[t]{2}{*}{ Frage III 1.8.12: } & \multicolumn{10}{|c|}{$\begin{array}{l}\text { Inwieweit stimmen Sie dem folgenden Statement, welches so oder ähnlich } \\
\text { von Managern anderer Unternehmen geäußert wurde, für } \underline{\mathrm{Ihr}} \\
\underline{\text { Unternehmen zu? }}\end{array}$} \\
\hline & & $\begin{array}{l}5.000 \mathrm{hl} \\
=92)\end{array}$ & $\begin{array}{r}5.000 \\
\quad(\mathrm{n} \\
\end{array}$ & $\begin{array}{l}100.000 \\
\mathrm{hl} \\
138)\end{array}$ & & $\begin{array}{l}000- \\
00 \mathrm{hl} \\
29)\end{array}$ & & $\begin{array}{l}\text { Ber als } \\
.000 \mathrm{hl} \\
=22)\end{array}$ & & $\begin{array}{l}\text { esamt } \\
=281 \text { ) }\end{array}$ \\
\hline $\begin{array}{l}\text { Stimme voll- } \\
\text { ständig zu }\end{array}$ & 18 & $(19,6 \%)$ & 52 & $(37,7 \%)$ & 7 & $(24,1 \%)$ & & $(13,6 \%)$ & 80 & $(28,5 \%)$ \\
\hline Stimme zu & 39 & $(42,4 \%)$ & 71 & $(51,4 \%)$ & 11 & $(37,9 \%)$ & 7 & $(31,8 \%)$ & 128 & $(45,6 \%)$ \\
\hline Weder noch & 13 & $(14,1 \%)$ & 3 & $(2,2 \%)$ & 5 & $(17,2 \%)$ & 3 & $(13,6 \%)$ & 24 & $(8,5 \%)$ \\
\hline Lehne ab & & $(12 \%)$ & 6 & $(4,3 \%)$ & 3 & $(10,3 \%)$ & 3 & $(13,6 \%)$ & 23 & $(8,2 \%)$ \\
\hline $\begin{array}{l}\text { Lehne voll- } \\
\text { ständig ab }\end{array}$ & 7 & $(7,6 \%)$ & 5 & $(3,6 \%)$ & 3 & $(10,3 \%)$ & 6 & $(27,3 \%)$ & 21 & $(7,5 \%)$ \\
\hline $\begin{array}{l}\text { Keine } \\
\text { Angabe }\end{array}$ & & $(4,3 \%)$ & 1 & $(0,7 \%)$ & & & & & 5 & $(1,8 \%)$ \\
\hline
\end{tabular}

Quelle: Niederhut-Bollmann, C., Datensatz „Große Strategie-Studie 2005“, Göttingen 2005. 


\begin{tabular}{|c|c|c|c|c|c|c|c|c|c|c|}
\hline \multirow[t]{2}{*}{ Frage III 1.8.13 } & \multicolumn{10}{|c|}{$\begin{array}{l}\text { Inwieweit stimmen Sie dem folgenden Statement, welches so oder ähnlich } \\
\text { von Managern anderer Unternehmen geäußert wurde, für Ihr } \\
\text { Unternehmen zu? } \\
\text { In Zukunft könnten wir uns vorstellen, die Brautätigkeit auszulagern, } \\
\text { um uns voll auf den Vertrieb zu konzentrieren. }\end{array}$} \\
\hline & & $\begin{array}{l}5.000 \mathrm{hl} \\
\mathrm{n}=92)\end{array}$ & $\begin{array}{r}5.000 \\
(\mathrm{n}\end{array}$ & $\begin{array}{l}100.000 \\
\mathrm{hl} \\
138)\end{array}$ & & $\begin{array}{l}000- \\
000 \mathrm{hl} \\
=29)\end{array}$ & & $\begin{array}{l}\text { Ber als } \\
.000 \mathrm{hl} \\
=22)\end{array}$ & \multicolumn{2}{|c|}{$\begin{array}{l}\text { Gesamt } \\
(\mathrm{n}=281)\end{array}$} \\
\hline $\begin{array}{l}\text { Stimme voll- } \\
\text { ständig zu }\end{array}$ & & $(3,3 \%)$ & 3 & $(2,2 \%)$ & & & & & & $(2,1 \%)$ \\
\hline Stimme zu & 7 & $(7,6 \%)$ & 7 & $(5,1 \%)$ & 3 & $(10,3 \%)$ & & $(4,5 \%)$ & 18 & $(6,4 \%)$ \\
\hline Weder noch & 14 & $(15,2 \%)$ & 15 & $(10,9 \%)$ & 1 & $(3,4 \%)$ & 1 & $(4,5 \%)$ & 31 & $(11 \%)$ \\
\hline Lehne $a b$ & 21 & $(22,8 \%)$ & 45 & $(32,6 \%)$ & 9 & $(31 \%)$ & 7 & $(31,8 \%)$ & 82 & $(29,2 \%)$ \\
\hline $\begin{array}{l}\text { Lehne voll- } \\
\text { Ständig ab }\end{array}$ & & $(46,7 \%)$ & 67 & $(48,6 \%)$ & 16 & $(55,2 \%)$ & 13 & $(59,1 \%)$ & 139 & $(49,5 \%)$ \\
\hline $\begin{array}{l}\text { Keine } \\
\text { Angabe }\end{array}$ & & $(4,3 \%)$ & 1 & $(0,7 \%)$ & & & & & 5 & $(1,8 \%)$ \\
\hline
\end{tabular}

Quelle: Niederhut-Bollmann, C., Datensatz „Große Strategie-Studie 2005“, Göttingen 2005.

\section{Märkte und Absatzwege}

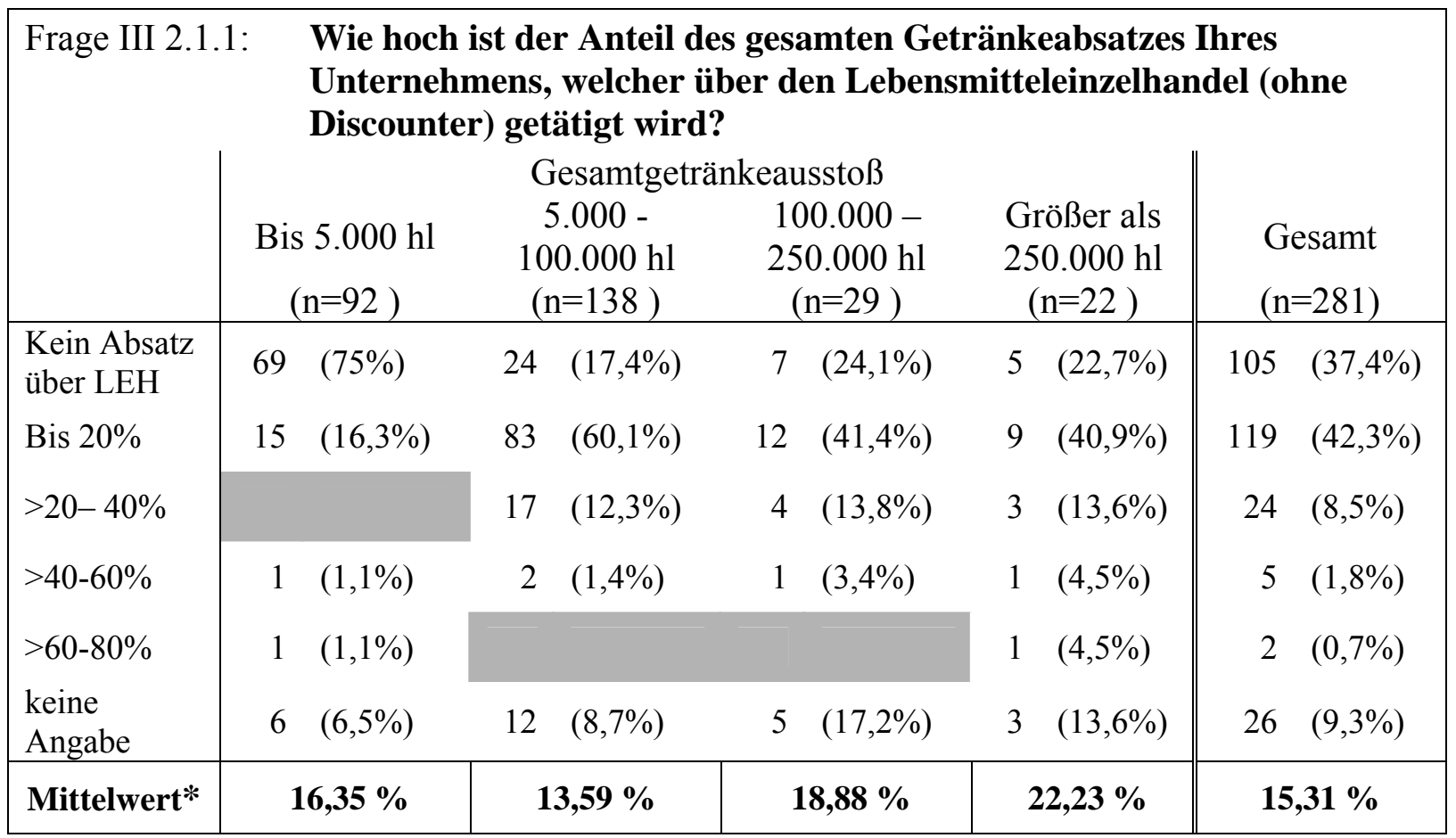

* In die Berechnung des Mittelwertes sind nur die Unternehmen einbezogen, welche eine Angabe gemacht haben und Getränkeabsatz über den LEH tätigen.

Quelle: Niederhut-Bollmann, C., Datensatz „Große Strategie-Studie 2005“, Göttingen 2005. 


\begin{tabular}{|c|c|c|c|c|c|}
\hline \multirow[t]{3}{*}{ Frage III 2.1.} & \multicolumn{5}{|c|}{$\begin{array}{l}\text { Wie hoch ist der Anteil des gesamten Getränkeabsatzes Ihres } \\
\text { Unternehmens, welcher über die Discounter getätigt wird? }\end{array}$} \\
\hline & \multirow[b]{2}{*}{$\begin{array}{l}\text { Bis } 5.000 \mathrm{hl} \\
\quad(\mathrm{n}=92)\end{array}$} & \multicolumn{2}{|c|}{ Gesamtgetränkeausstoß } & \multirow[b]{2}{*}{$\begin{array}{c}\text { Größer als } \\
250.000 \mathrm{hl} \\
(\mathrm{n}=22)\end{array}$} & \multirow[b]{2}{*}{$\begin{array}{l}\text { Gesamt } \\
(\mathrm{n}=281)\end{array}$} \\
\hline & & $\begin{array}{c}5.000- \\
100.000 \mathrm{hl} \\
(\mathrm{n}=138)\end{array}$ & $\begin{array}{c}100.000- \\
250.000 \mathrm{hl} \\
(\mathrm{n}=29)\end{array}$ & & \\
\hline $\begin{array}{l}\text { Kein Absatz } \\
\text { über } \\
\text { Discounter }\end{array}$ & $84 \quad(91,3 \%)$ & $104 \quad(75,4 \%)$ & $21 \quad(72,4 \%)$ & $13 \quad(59,1 \%)$ & $222 \quad(79 \%)$ \\
\hline Bis $20 \%$ & $2 \quad(2,2 \%)$ & $21 \quad(15,2 \%)$ & $3 \quad(10,3 \%)$ & $6 \quad(27,3 \%)$ & $32 \quad(11,4 \%)$ \\
\hline$>20-40 \%$ & & $1 \quad(0,7 \%)$ & & & $1 \quad(0,4 \%)$ \\
\hline keine Angabe & $6 \quad(6,5 \%)$ & $12 \quad(8,7 \%)$ & $5 \quad(17,2 \%)$ & $3 \quad(13,6 \%)$ & $26 \quad(9,3 \%)$ \\
\hline Mittelwert* & $12,5 \%$ & 8,18 \% & $2,67 \%$ & 7,17 \% & 7,76 \% \\
\hline
\end{tabular}

* In die Berechnung des Mittelwertes sind nur die Unternehmen einbezogen, welche eine Angabe gemacht haben und Getränkeabsatz über den Discount tätigen

Quelle: Niederhut-Bollmann, C., Datensatz „Große Strategie-Studie 2005“, Göttingen 2005.

\begin{tabular}{|c|c|c|c|c|c|}
\hline \multirow[t]{2}{*}{ Frage III 2.1.3 } & \multicolumn{5}{|c|}{$\begin{array}{l}\text { Wie hoch ist der Anteil des gesamten Getränkeabsatzes Ihres } \\
\text { Unternehmens, welcher über Convenience-Stores (z.B. Tankstellen) } \\
\text { getätigt wird? }\end{array}$} \\
\hline & $\begin{array}{c}\text { Bis } 5.000 \mathrm{hl} \\
\quad(\mathrm{n}=92)\end{array}$ & $\begin{array}{l}\text { Gesamtge } \\
5.000- \\
100.000 \mathrm{hl} \\
(\mathrm{n}=138)\end{array}$ & $\begin{array}{l}100.000- \\
250.000 \mathrm{hl} \\
(\mathrm{n}=29)\end{array}$ & $\begin{array}{l}\text { Größer als } \\
250.000 \mathrm{hl} \\
(\mathrm{n}=22)\end{array}$ & $\begin{array}{l}\text { Gesamt } \\
(n=281)\end{array}$ \\
\hline $\begin{array}{l}\text { Kein Absatz } \\
\text { über C.-S. }\end{array}$ & $78 \quad(84,8 \%)$ & $75 \quad(54,3 \%)$ & $12 \quad(41,4 \%)$ & $12 \quad(54,5 \%)$ & $177 \quad(63 \%)$ \\
\hline Bis $20 \%$ & $8 \quad(8,7 \%)$ & $51 \quad(37 \%)$ & $12 \quad(41,4 \%)$ & $7 \quad(31,8 \%)$ & $78 \quad(27,8 \%)$ \\
\hline keine Angabe & $6 \quad(6,5 \%)$ & $12 \quad(8,7 \%)$ & $(17,2 \%)$ & $3 \quad(13,6 \%)$ & $26 \quad(9,3 \%)$ \\
\hline Mittelwert* & $5,14 \%$ & $4,06 \%$ & $4,17 \%$ & $3,29 \%$ & $4,12 \%$ \\
\hline
\end{tabular}

* In die Berechnung des Mittelwertes sind nur die Unternehmen einbezogen, welche eine Angabe gemacht haben und Getränkeabsatz über Convenience-Stores tätigen

Quelle: Niederhut-Bollmann, C., Datensatz „Große Strategie-Studie 2005“, Göttingen 2005. 


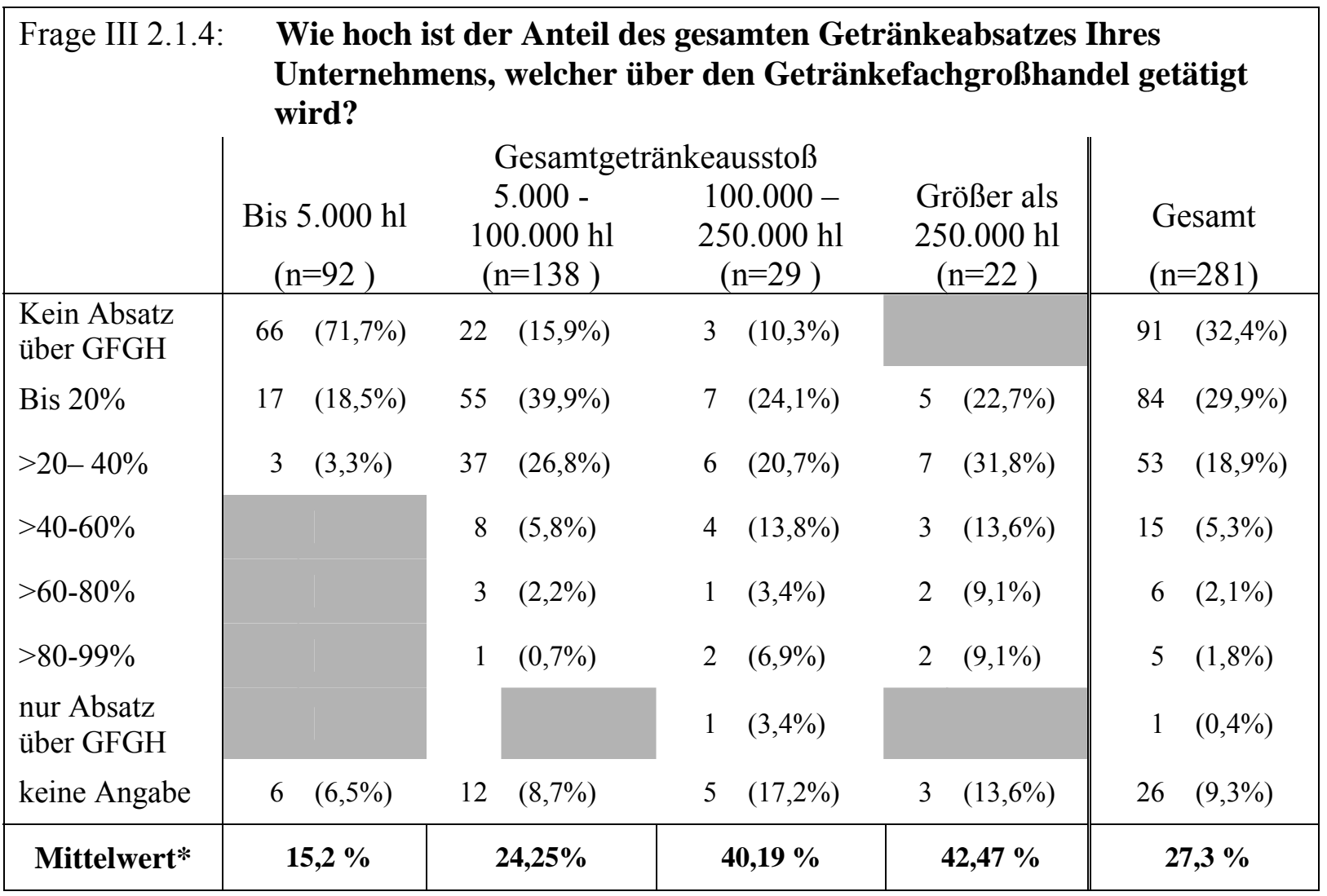

* In die Berechnung des Mittelwertes sind nur die Unternehmen einbezogen, welche eine Angabe gemacht haben und Getränkeabsatz über den Convenience-Stores tätigen

Quelle: Niederhut-Bollmann, C., Datensatz „Große Strategie-Studie 2005“, Göttingen 2005.

\begin{tabular}{|c|c|c|c|c|c|}
\hline \multirow[t]{2}{*}{ Frage III 2.1.5 } & \multicolumn{5}{|c|}{$\begin{array}{l}\text { Wie hoch ist der Anteil des gesamten Getränkeabsatzes Ihres } \\
\text { Unternehmens, welcher über Getränkeabholmarkte abgesetzt wird? }\end{array}$} \\
\hline & $\begin{array}{l}\text { Bis } 5.000 \mathrm{hl} \\
\quad(\mathrm{n}=92)\end{array}$ & $\begin{array}{c}\text { Gesamtge } \\
5.000- \\
100.000 \mathrm{hl} \\
(\mathrm{n}=138)\end{array}$ & $\begin{array}{c}\text { keausstoß } \\
100.000- \\
250.000 \mathrm{hl} \\
(\mathrm{n}=29)\end{array}$ & $\begin{array}{c}\text { Größer als } \\
250.000 \mathrm{hl} \\
(\mathrm{n}=22)\end{array}$ & $\begin{array}{l}\text { Gesamt } \\
(\mathrm{n}=281)\end{array}$ \\
\hline $\begin{array}{l}\text { Kein Absatz } \\
\text { über GA }\end{array}$ & $43 \quad(46,7 \%)$ & $10 \quad(7,2 \%)$ & $\begin{array}{ll}6 \quad(20,7 \%) \\
\end{array}$ & $5 \quad(22,7 \%)$ & $64 \quad(22,8 \%)$ \\
\hline Bis $20 \%$ & $31 \quad(33,7 \%)$ & $72 \quad(52,2 \%)$ & $(34,5 \%)$ & $12 \quad(54,4 \%)$ & $125 \quad(44,5 \%)$ \\
\hline$>20-40 \%$ & $7 \quad(7,6 \%)$ & $39 \quad(28,3 \%)$ & $7 \quad(24,1 \%)$ & $1 \quad(4,5 \%)$ & $54 \quad(19,2 \%)$ \\
\hline$>40-60 \%$ & $4 \quad(4,3 \%)$ & $3 \quad(2,2 \%)$ & & $1 \quad(4,5 \%)$ & $8 \quad(2,8 \%)$ \\
\hline$>60-80 \%$ & $1 \quad(1,1 \%)$ & $2 \quad(1,4 \%)$ & $1 \quad(3,4 \%)$ & & $4 \quad(1,4 \%)$ \\
\hline keine Angabe & $6 \quad(6,5 \%)$ & $12 \quad(8,7 \%)$ & $5 \quad(17,2 \%)$ & $3 \quad(13,6 \%)$ & $26 \quad(9,3 \%)$ \\
\hline Mittelwert* & $20,65 \%$ & $20,79 \%$ & $22,89 \%$ & $14,21 \%$ & $20,48 \%$ \\
\hline
\end{tabular}

* In die Berechnung des Mittelwertes sind nur die Unternehmen einbezogen, welche eine Angabe gemacht haben und Getränkeabsatz über Getränkeabholmärkte tätigen

Quelle: Niederhut-Bollmann, C., Datensatz „Große Strategie-Studie 2005“, Göttingen 2005. 


\section{Frage III 2.1.6: Wie hoch ist der Anteil des gesamten Getränkeabsatzes Ihres Unternehmens, welcher über Gastronomie und Großverbraucher (z.B. Verpflegungsbetriebe) abgesetzt wird?}

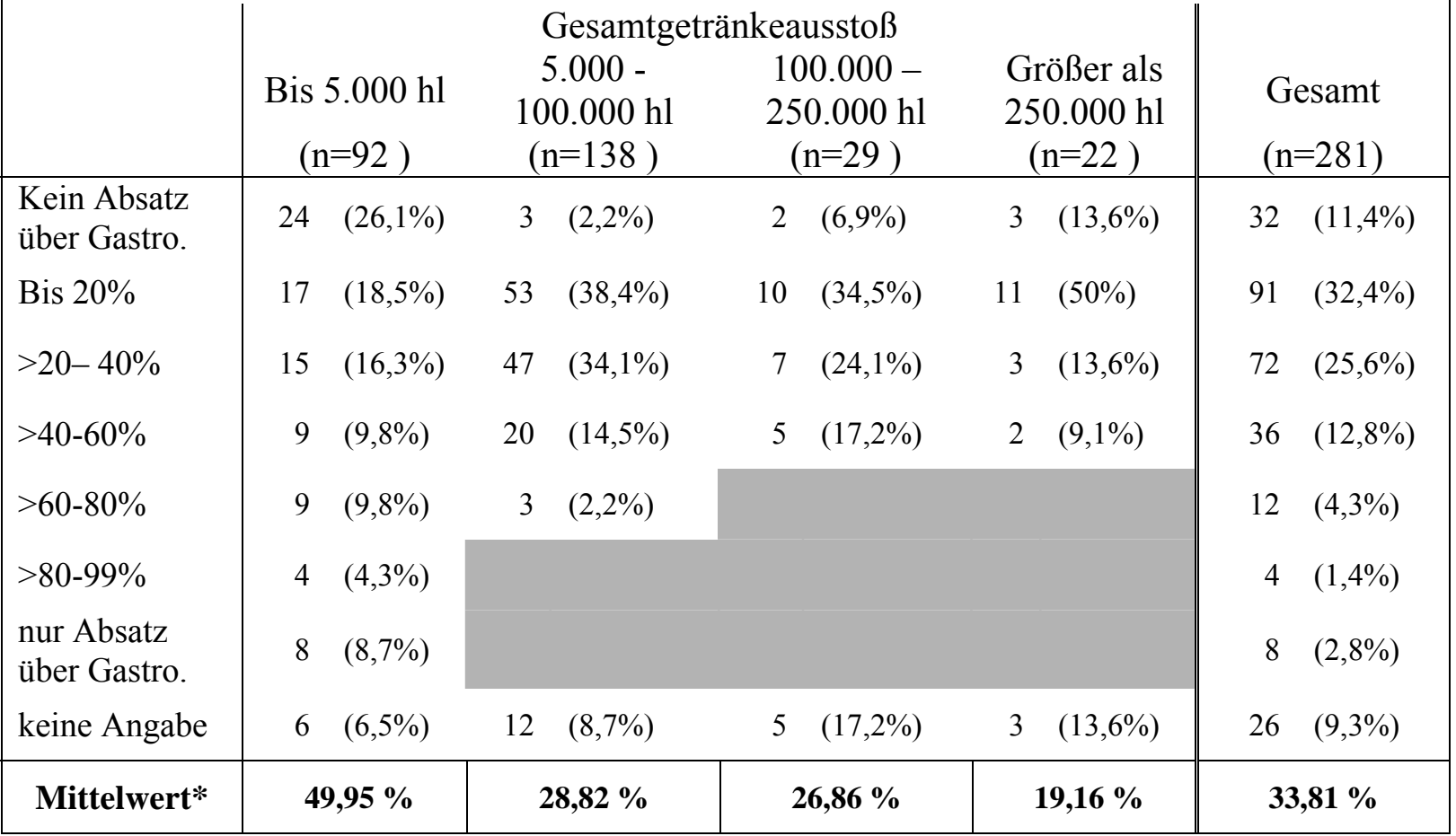

* In die Berechnung des Mittelwertes sind nur die Unternehmen einbezogen, welche eine Angabe gemacht haben und Getränkeabsatz über Gastronomie und Großverbraucher tätigen.

Quelle: Niederhut-Bollmann, C., Datensatz „Große Strategie-Studie 2005“, Göttingen 2005.

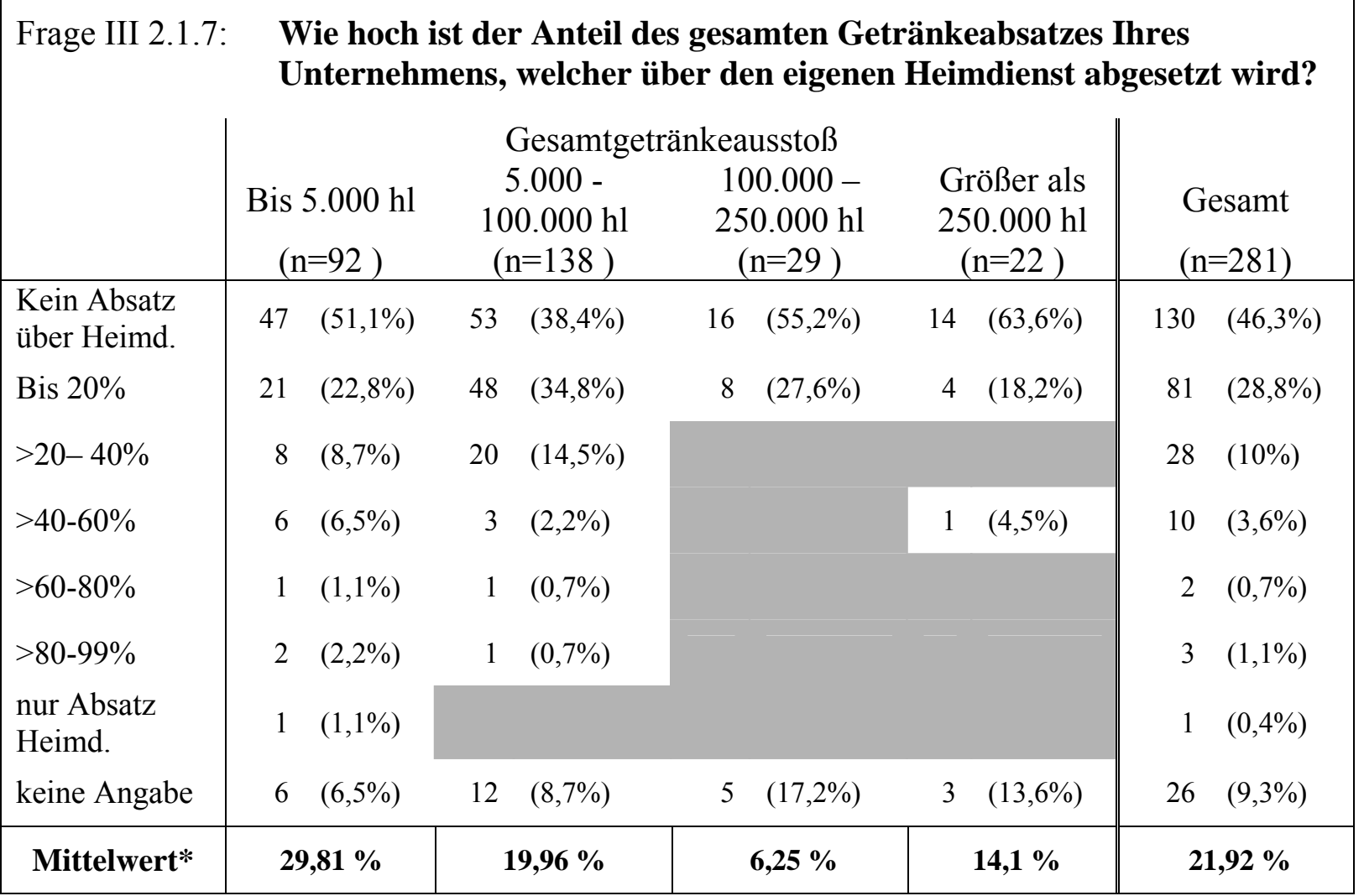

* In die Berechnung des Mittelwertes sind nur die Unternehmen einbezogen, welche eine Angabe gemacht haben und Getränkeabsatz über eigenen Heimdienst tätigen

Quelle: Niederhut-Bollmann, C., Datensatz „Große Strategie-Studie 2005“, Göttingen 2005 


\begin{tabular}{|c|c|c|c|c|c|}
\hline \multirow[t]{3}{*}{ Frage III 2.1.8 } & \multicolumn{5}{|c|}{$\begin{array}{l}\text { Wie hoch ist der Anteil des gesamten Getränkeabsatzes Ihres } \\
\text { Unternehmens, welcher über Vertriebskooperationen mit anderen } \\
\text { Brauereien abgesetzt wird? }\end{array}$} \\
\hline & \multirow[b]{2}{*}{$\begin{array}{c}\text { Bis } 5.000 \mathrm{hl} \\
(\mathrm{n}=92)\end{array}$} & \multicolumn{2}{|c|}{ Gesamtgetränkeausstoß } & \multirow[b]{2}{*}{$\begin{array}{c}\text { Größer als } \\
250.000 \mathrm{hl} \\
(\mathrm{n}=22)\end{array}$} & \multirow[b]{2}{*}{$\begin{array}{l}\text { Gesamt } \\
(\mathrm{n}=281)\end{array}$} \\
\hline & & $\begin{array}{l}5.000- \\
100.000 \mathrm{hl} \\
(\mathrm{n}=138)\end{array}$ & $\begin{array}{l}100.000- \\
250.000 \mathrm{hl} \\
(\mathrm{n}=29)\end{array}$ & & \\
\hline $\begin{array}{l}\text { Kein Absatz } \\
\text { über VK }\end{array}$ & $78 \quad(84,8 \%)$ & $93 \quad(67,4 \%)$ & $18 \quad(62,1 \%)$ & $13 \quad(59,1 \%)$ & $202 \quad(71,9 \%)$ \\
\hline Bis $20 \%$ & $7 \quad(7,6 \%)$ & $33 \quad(23,9 \%)$ & $5 \quad(17,2 \%)$ & $5 \quad(22,7 \%)$ & $50 \quad(17,8 \%)$ \\
\hline$>20-40 \%$ & & & $1 \quad(3,4 \%)$ & & $1 \quad(0,4 \%)$ \\
\hline$>40-60 \%$ & & & & $1 \quad(4,5 \%)$ & $1 \quad(0,4 \%)$ \\
\hline $\begin{array}{l}\text { nur Absatz } \\
\text { über VK }\end{array}$ & $1 \quad(1,1 \%)$ & & & & $1 \quad(0,4 \%)$ \\
\hline keine Angabe & $6 \quad(6,5 \%)$ & $12 \quad(8,7 \%)$ & $5 \quad(17,2 \%)$ & $3 \quad(13,6 \%)$ & $26 \quad(9,3 \%)$ \\
\hline Mittelwert & $17 \%$ & $7,08 \%$ & $9,5 \%$ & $15,25 \%$ & $9,77 \%$ \\
\hline
\end{tabular}

* In die Berechnung des Mittelwertes sind nur die Unternehmen einbezogen, welche eine Angabe gemacht haben und Getränkeabsatz über Vertriebskooperationen mit anderen Brauereien tätigen Quelle: Niederhut-Bollmann, C., Datensatz „Große Strategie-Studie 2005“, Göttingen 2005.

\begin{tabular}{|c|c|c|c|c|c|}
\hline \multirow[t]{2}{*}{ Frage III 2.1.9: } & \multicolumn{5}{|c|}{$\begin{array}{l}\text { Wie hoch ist der Anteil des gesamten Getränkeabsatzes Ihres } \\
\text { Unternehmens, welcher über den Export abgesetzt wird? }\end{array}$} \\
\hline & $\begin{array}{l}\text { Bis } 5.000 \mathrm{hl} \\
(\mathrm{n}=92)\end{array}$ & $\begin{array}{c}\text { Gesamtge } \\
5.000- \\
100.000 \mathrm{hl} \\
(\mathrm{n}=138)\end{array}$ & $\begin{array}{c}\text { keausstoß } \\
100.000- \\
250.000 \mathrm{hl} \\
(\mathrm{n}=29)\end{array}$ & $\begin{array}{c}\text { Größer als } \\
250.000 \mathrm{hl} \\
(\mathrm{n}=22)\end{array}$ & $\begin{array}{l}\text { Gesamt } \\
(\mathrm{n}=281)\end{array}$ \\
\hline $\begin{array}{l}\text { Kein Absatz } \\
\text { über Export }\end{array}$ & $85 \quad(92,4 \%)$ & $102 \quad(73,9 \%)$ & $16 \quad(55,2 \%)$ & $9 \quad(40,9 \%)$ & $212 \quad(75,4 \%)$ \\
\hline Bis $20 \%$ & & $24 \quad(17,4 \%)$ & $8 \quad(27,6 \%)$ & $10 \quad(45,5 \%)$ & $42 \quad(14,9 \%)$ \\
\hline keine Angabe & $7 \quad(7,6 \%)$ & $12 \quad(8,7 \%)$ & $5 \quad(17,2 \%)$ & $3 \quad(13,6 \%)$ & $27 \quad(9,6 \%)$ \\
\hline Mittelwert* & $0 \%$ & $6,1 \%$ & $3,75 \%$ & $4,2 \%$ & $5,2 \%$ \\
\hline
\end{tabular}

* In die Berechnung des Mittelwertes sind nur die Unternehmen einbezogen, welche eine Angabe gemacht haben und Getränkeabsatz über den Export tätigen

Quelle: Niederhut-Bollmann, C., Datensatz „Große Strategie-Studie 2005“, Göttingen 2005. 


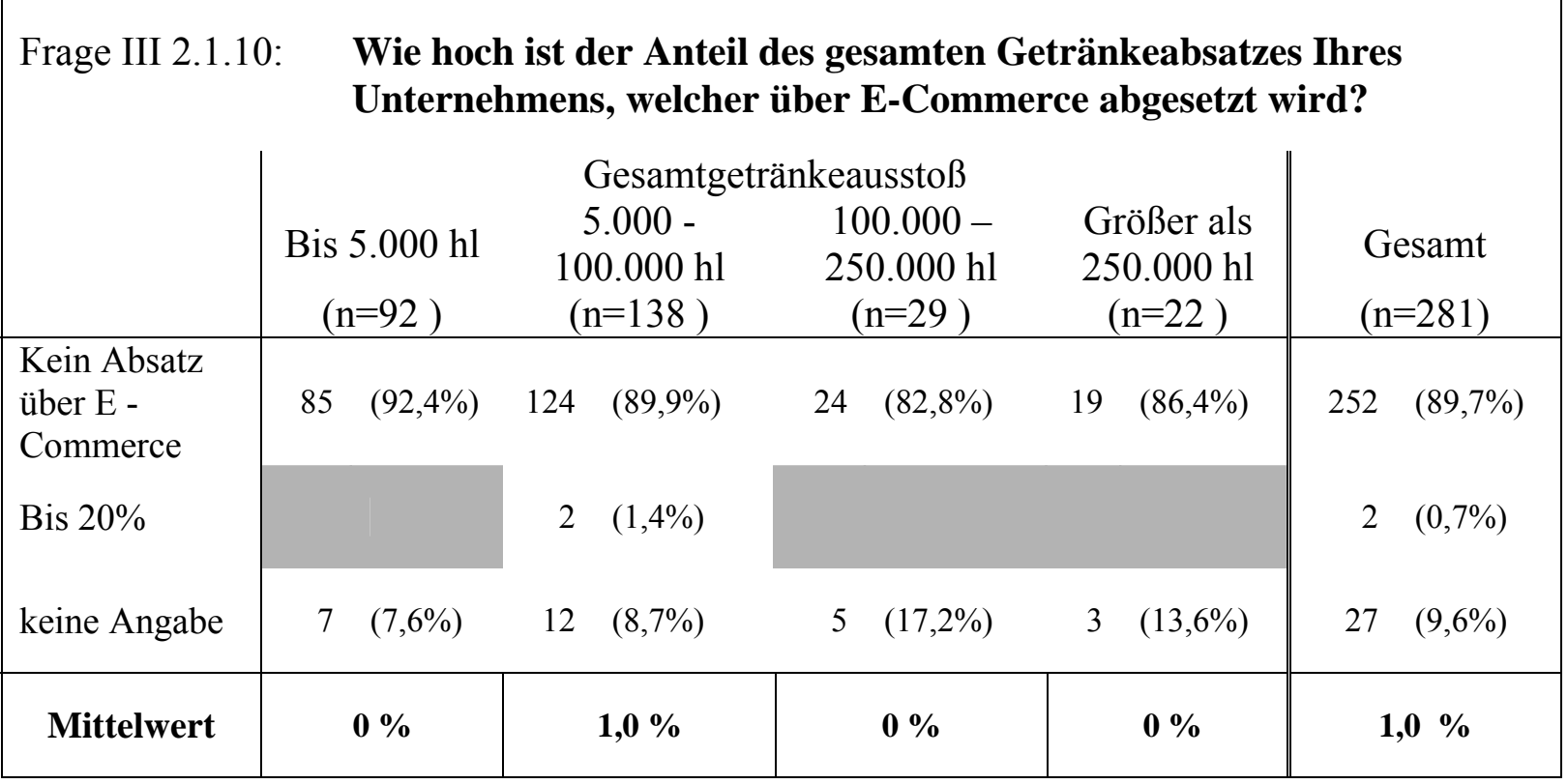

* In die Berechnung des Mittelwertes sind nur die Unternehmen einbezogen, welche eine Angabe gemacht haben und Getränkeabsatz über E-Commerce tätigen

Quelle: Niederhut-Bollmann, C., Datensatz „Große Strategie-Studie 2005“, Göttingen 2005.

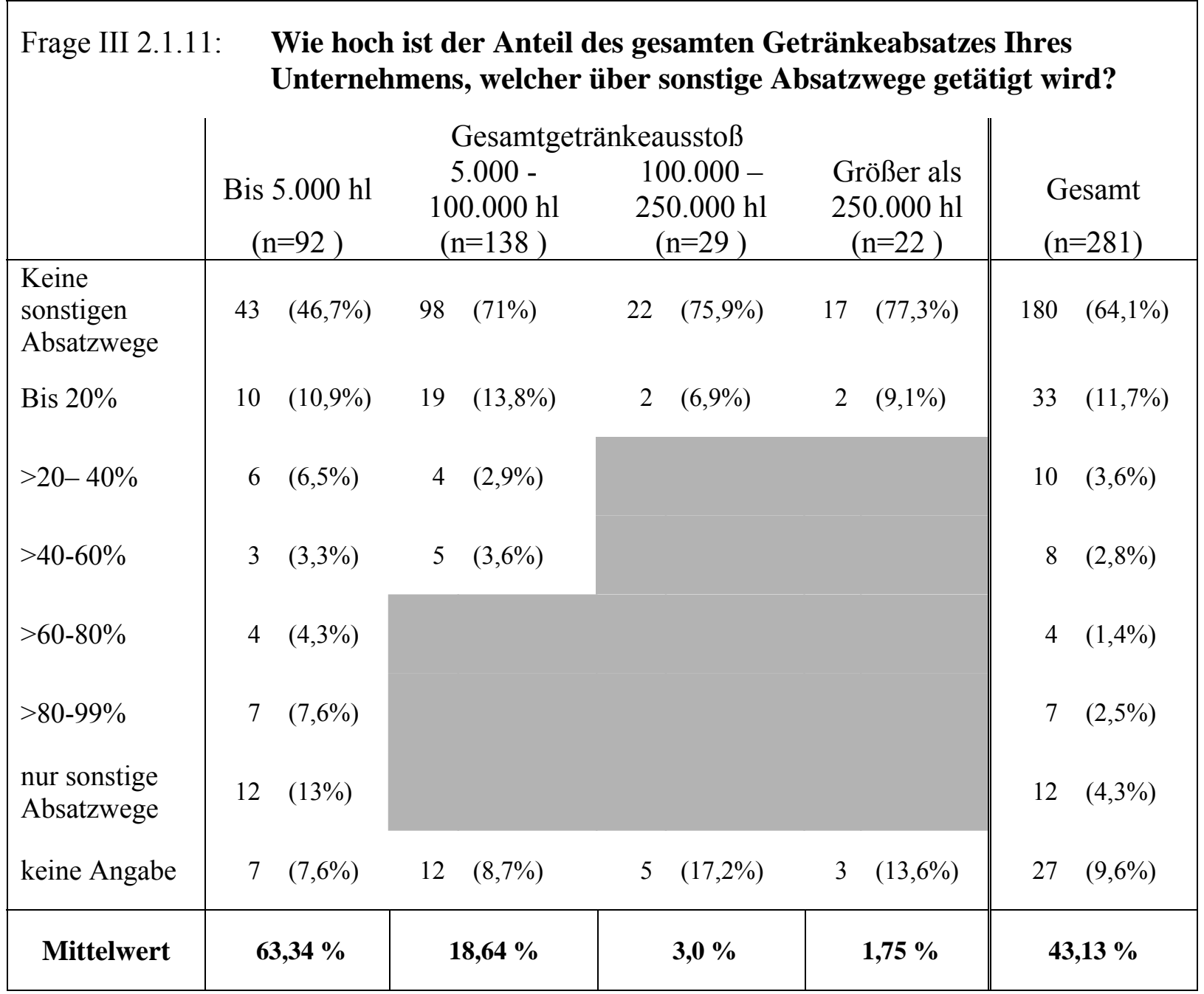

* In die Berechnung des Mittelwertes sind nur die Unternehmen einbezogen, welche eine Angabe gemacht haben und Getränkeabsatz über sonstige Absatzwege tätigen

Quelle: Niederhut-Bollmann, C., Datensatz „Große Strategie-Studie 2005“, Göttingen 2005. 


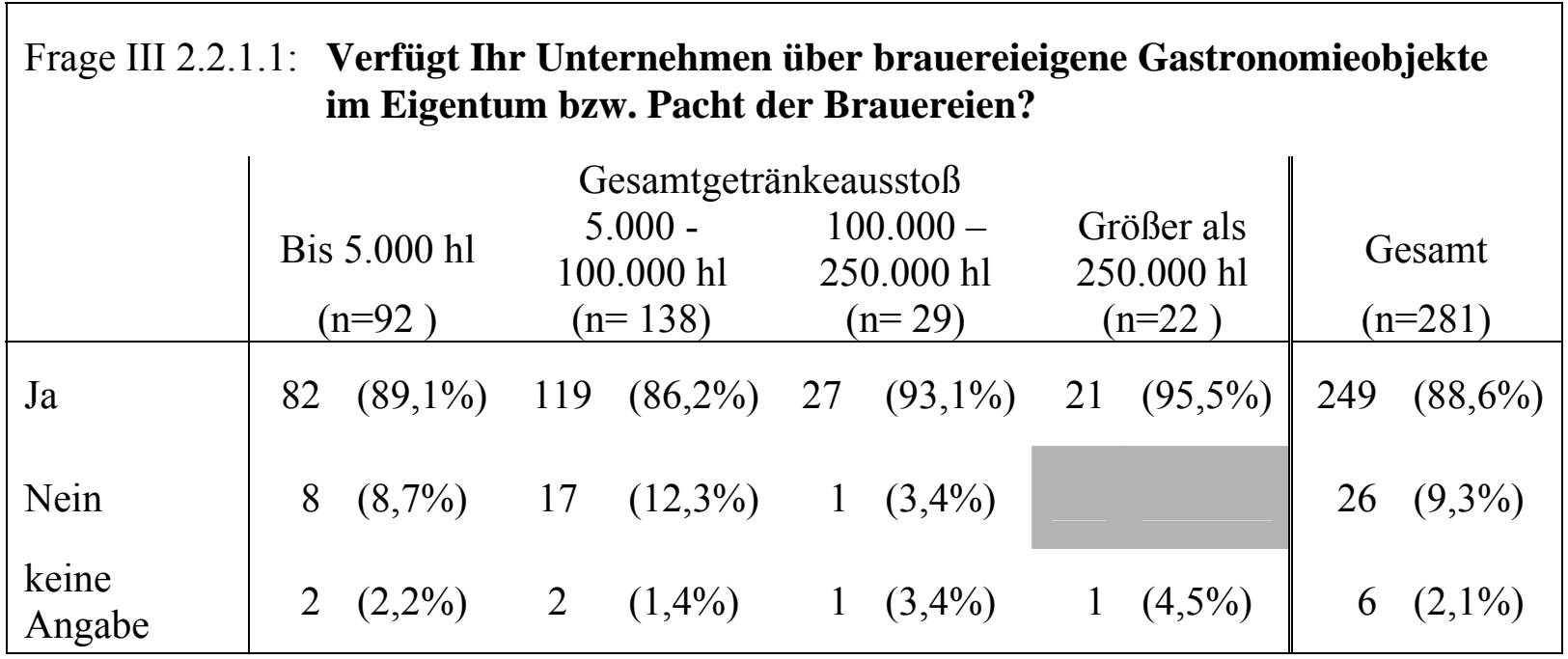

Quelle: Niederhut-Bollmann, C., Datensatz „Große Strategie-Studie 2005“, Göttingen 2005.

\begin{tabular}{|c|c|c|c|c|c|}
\hline \multicolumn{6}{|c|}{ Frage III 2.2.1.2: } \\
\hline \multirow[b]{3}{*}{ Kein Objekt } & \multirow[b]{2}{*}{$\begin{array}{c}\text { Bis } 5.000 \mathrm{hl} \\
(\mathrm{n}=92)\end{array}$} & \multicolumn{2}{|c|}{ Gesamtgetränkeausstoß } & \multirow[b]{2}{*}{$\begin{array}{c}\text { Größer als } \\
250.000 \mathrm{hl} \\
(\mathrm{n}=22)\end{array}$} & \multirow[b]{2}{*}{$\begin{array}{l}\text { Gesamt } \\
(n=281)\end{array}$} \\
\hline & & $\begin{array}{c}5.000- \\
100.000 \mathrm{hl} \\
(\mathrm{n}=138)\end{array}$ & $\begin{array}{c}100.000- \\
250.000 \mathrm{hl} \\
(\mathrm{n}=29)\end{array}$ & & \\
\hline & $7 \quad(7,6 \%)$ & $17 \quad(12,3 \%)$ & $1 \quad(3,4 \%)$ & & $25 \quad(8,9 \%)$ \\
\hline Bis 5 & $61 \quad(66,3 \%)$ & $62 \quad(44,9 \%)$ & $3 \quad(10,4 \%)$ & $4 \quad(18,2 \%)$ & $130 \quad(46,3 \%)$ \\
\hline$>5-10$ & $1 \quad(1,1 \%)$ & $18 \quad(13,1 \%)$ & $5 \quad(17,2 \%)$ & & $24 \quad(8,5 \%)$ \\
\hline$>10-20$ & $1 \quad(1,1 \%)$ & $13(9,4 \%)$ & $2 \quad(6,9 \%)$ & $2 \quad(9,1 \%)$ & $18 \quad(6,4 \%)$ \\
\hline$>20-40$ & & $5 \quad(3,6 \%)$ & $3 \quad(10,4 \%)$ & $3(13,6 \%)$ & $11(3,9 \%)$ \\
\hline Mehr als 40 & & & $5 \quad(17 \%)$ & $2(9 \%)$ & $7 \quad(2,7 \%)$ \\
\hline $\begin{array}{l}\text { keine } \\
\text { Angabe }\end{array}$ & $22 \quad(23,9 \%)$ & $23 \quad(16,7 \%)$ & $10 \quad(34,5 \%)$ & $11(50 \%)$ & $66 \quad(23,5 \%)$ \\
\hline $\begin{array}{c}\text { Mittlere } \\
\text { Anzahl von } \\
\text { Objekten* }\end{array}$ & 1,87 & 6,51 & 38 & 27,54 & 9,17 \\
\hline
\end{tabular}

* In die Berechnung der mittleren Anzahl von Gastronomieobjekten, die sich im Eigentum bzw. Pacht der Brauerei befinden, sind nur die Unternehmen einbezogen, welche eine Angabe gemacht haben und über eigene Gastronomieobjekte verfügen

Quelle: Niederhut-Bollmann, C., Datensatz „Große Strategie-Studie 2005“, Göttingen 2005. 


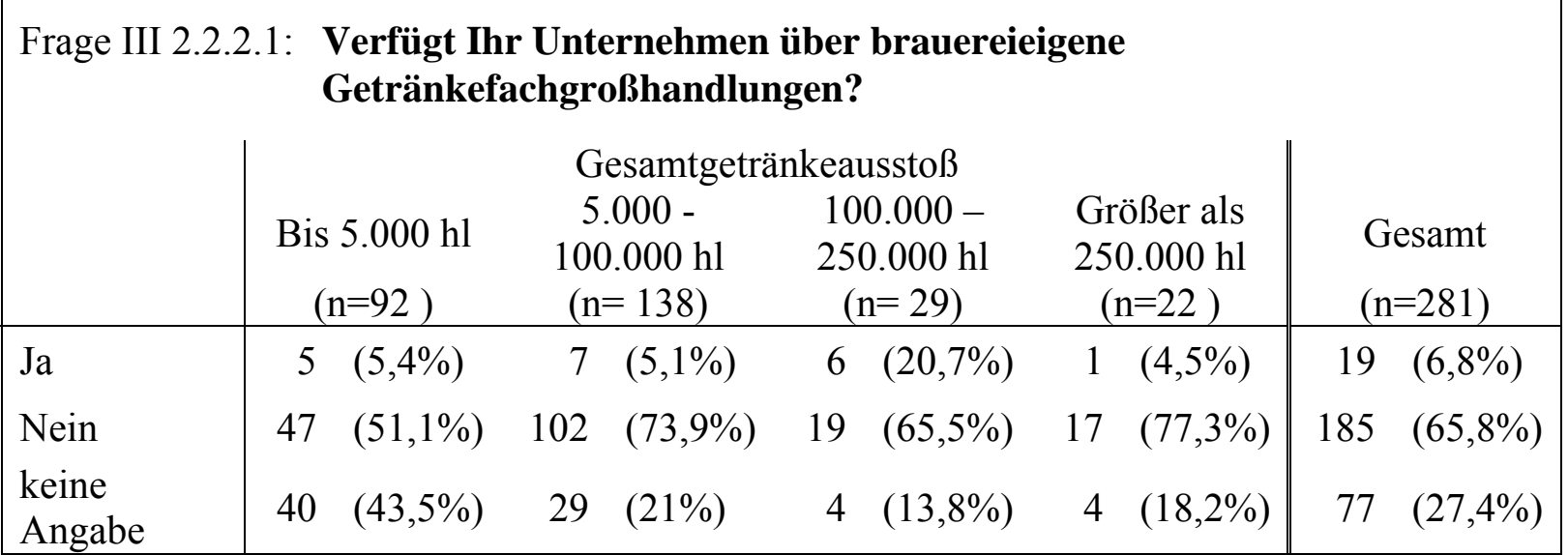

Quelle: Niederhut-Bollmann, C., Datensatz „Große Strategie-Studie 2005“, Göttingen 2005.

\section{Frage III 2.2.2.2.: Über wie viele brauereieigene Getränkefachgroßhandlungen verfügt Ihr Unternehmen?}

\begin{tabular}{|c|c|c|c|c|c|}
\hline & $\begin{array}{c}\text { Bis } 5.000 \mathrm{hl} \\
(\mathrm{n}=92)\end{array}$ & $\begin{array}{c}\text { Gesamtgetr } \\
5.000- \\
100.000 \mathrm{hl} \\
(\mathrm{n}=138)\end{array}$ & $\begin{array}{l}\text { keaussto } \beta \\
100.000- \\
250.000 \mathrm{hl} \\
(\mathrm{n}=29)\end{array}$ & $\begin{array}{c}\text { Größer als } \\
250.000 \mathrm{hl} \\
(\mathrm{n}=22)\end{array}$ & $\begin{array}{l}\text { Gesamt } \\
(\mathrm{n}=281)\end{array}$ \\
\hline Kein Objekt & $44 \quad(47,8 \%)$ & $(73,9 \%)$ & $17 \quad(58,6 \%)$ & $17 \quad(77,3 \%)$ & $180 \quad(64,1 \%)$ \\
\hline 1 Objekt & $2 \quad(2,2 \%)$ & $4 \quad(2,9 \%)$ & $3 \quad(10,3 \%)$ & $1 \quad(4,5 \%)$ & $10 \quad(3,6 \%)$ \\
\hline $\begin{array}{l}2 \text { und mehr } \\
\text { Objekte }\end{array}$ & $2 \quad(2,2 \%)$ & $1 \quad(0,7 \%)$ & $2 \quad(6,9 \%)$ & & $5 \quad(1,9 \%)$ \\
\hline $\begin{array}{l}\text { keine } \\
\text { Angabe }\end{array}$ & $44 \quad(47,8 \%)$ & $31 \quad(22,5 \%)$ & $7 \quad(24,1 \%)$ & $4 \quad(18,2 \%)$ & $86 \quad(30,6 \%)$ \\
\hline $\begin{array}{c}\text { Mittlere } \\
\text { Anzahl von } \\
\text { Objekten* }\end{array}$ & 3,25 & 4,8 & 1,4 & 1 & 3 \\
\hline
\end{tabular}

* In die Berechnung der mittleren Anzahl von Getränkefachgroßhandlungen, die sich im Eigentum bzw. Pacht der Brauerei befinden, sind nur die Unternehmen einbezogen, welche eine Angabe gemacht haben und über eigene Getränkefachgroßhandlungen verfügen

Quelle: Niederhut-Bollmann, C., Datensatz „Große Strategie-Studie 2005“, Göttingen 2005.

Frage III 2.2.3.1: Verfügt Ihr Unternehmen über brauereieigene
Getränkeabholmärkte?

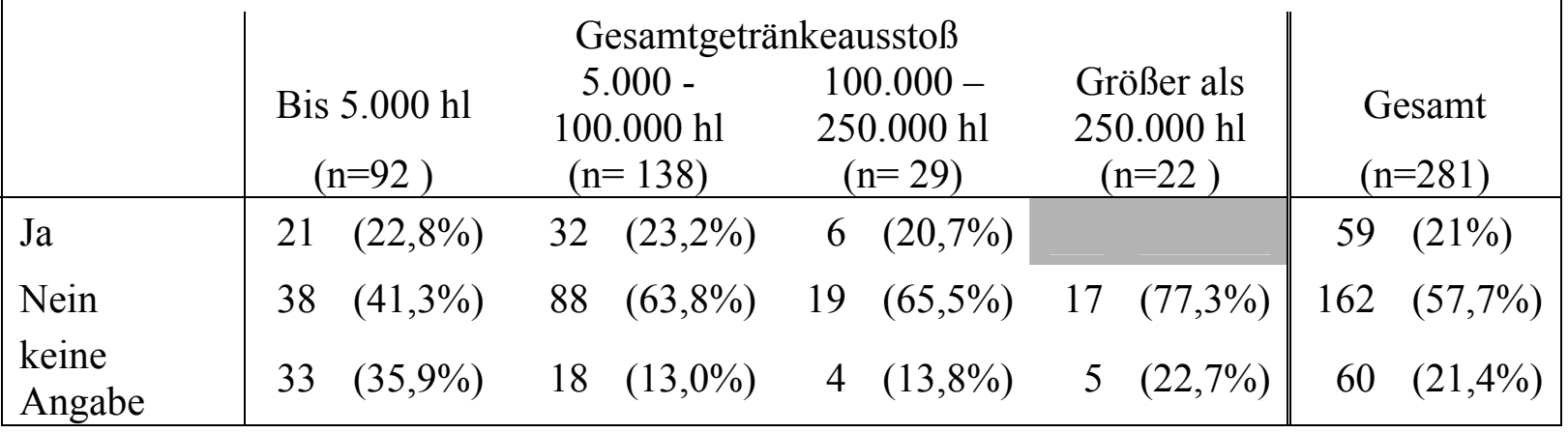

Quelle: Niederhut-Bollmann, C., Datensatz „Große Strategie-Studie 2005“, Göttingen 2005 


\begin{tabular}{|c|c|c|c|c|c|c|c|}
\hline \multirow[t]{2}{*}{ Frage III 2.2.3 } & \multicolumn{7}{|c|}{$\begin{array}{l}\text { Über wie viele brauereieigene Getränkeabholmärkte verfügt Ihr } \\
\text { Unternehmen? }\end{array}$} \\
\hline & \multicolumn{2}{|c|}{$\begin{array}{l}\text { Bis } 5.000 \mathrm{hl} \\
\quad(\mathrm{n}=92)\end{array}$} & & $\begin{array}{l}\text { esamtgetr } \\
.000- \\
.000 \mathrm{hl} \\
=138)\end{array}$ & $\begin{array}{l}\text { akeaussto } \beta \\
100.000- \\
250.000 \mathrm{hl} \\
(\mathrm{n}=29)\end{array}$ & $\begin{array}{c}\text { Größer als } \\
250.000 \mathrm{hl} \\
(\mathrm{n}=22)\end{array}$ & $\begin{array}{l}\text { Gesamt } \\
(\mathrm{n}=281)\end{array}$ \\
\hline Kein Objekt & 35 & $(38 \%)$ & 86 & $(62,3 \%)$ & $17 \quad(58,6 \%)$ & $17 \quad(77,3 \%)$ & $155 \quad(55,2 \%)$ \\
\hline 1 Objekt & 14 & $(15,2 \%)$ & 19 & $(13,8 \%)$ & $2 \quad(6,9 \%)$ & & $35 \quad(12,5 \%)$ \\
\hline 2-5 Objekte & 1 & $(1,1 \%)$ & 6 & $(4,3 \%)$ & $3 \quad(10,2 \%)$ & & $10 \quad(3,6 \%)$ \\
\hline 6-10 Objekte & 1 & $(1,1 \%)$ & 1 & $(0,7 \%)$ & $1 \quad(3,4 \%)$ & & $3 \quad(1,2 \%)$ \\
\hline Mehr als 10 & 1 & $(1,1 \%)$ & 1 & $(0,7 \%)$ & & & $2 \quad(0,7 \%)$ \\
\hline $\begin{array}{l}\text { keine } \\
\text { Angabe }\end{array}$ & 40 & $(43,5 \%)$ & 25 & $(18,1 \%)$ & $6 \quad(20,7 \%)$ & $5 \quad(22,7 \%)$ & $76 \quad(27 \%)$ \\
\hline $\begin{array}{c}\text { Mittlere } \\
\text { Anzahl von } \\
\text { Objekten* }\end{array}$ & & 2,35 & & 2,11 & 3,67 & $\mathbf{0}$ & 2,38 \\
\hline
\end{tabular}

* In die Berechnung der mittleren Anzahl der Getränkeabholmärkte, die sich im Eigentum bzw. Pacht der Brauerei befinden, sind nur die Unternehmen einbezogen, welche eine Angabe gemacht haben und über eigene Getränkeabholmärkte verfügen

Quelle: Niederhut-Bollmann, C., Datensatz „Große Strategie-Studie 2005“, Göttingen 2005.

Frage III 2.2.4.1: Verfügt Ihr Unternehmen über sonstige brauereieigene Absatzstätten?

\begin{tabular}{|c|c|c|c|c|c|}
\hline & \multicolumn{4}{|c|}{ Gesamtgetränkeausstoß } & \multirow[b]{2}{*}{$\begin{array}{l}\text { Gesamt } \\
(\mathrm{n}=281)\end{array}$} \\
\hline & $\begin{array}{c}\text { Bis } 5.000 \mathrm{hl} \\
(\mathrm{n}=92)\end{array}$ & $\begin{array}{c}5.000- \\
100.000 \mathrm{hl} \\
(\mathrm{n}=138)\end{array}$ & $\begin{array}{c}100.000- \\
250.000 \mathrm{hl} \\
(\mathrm{n}=29)\end{array}$ & $\begin{array}{c}\text { Größer als } \\
250.000 \mathrm{hl} \\
(\mathrm{n}=22)\end{array}$ & \\
\hline $\mathrm{Ja}$ & $3 \quad(3,3 \%)$ & $11 \quad(8 \%)$ & $1 \quad(3,4 \%)$ & $1 \quad(4,5 \%)$ & $16 \quad(5,7 \%)$ \\
\hline Nein & $24 \quad(26,1 \%)$ & $41 \quad(29,7 \%)$ & $(24,1 \%)$ & $2 \quad(9,1 \%)$ & $74 \quad(26,3 \%)$ \\
\hline $\begin{array}{l}\text { keine } \\
\text { Angabe }\end{array}$ & $65 \quad(70,7 \%)$ & $86 \quad(62,3 \%)$ & $(72,4 \%)$ & $19 \quad(86,4 \%)$ & $191 \quad(68 \%)$ \\
\hline
\end{tabular}

Quelle: Niederhut-Bollmann, C., Datensatz „Große Strategie-Studie 2005“, Göttingen 2005. 


\begin{tabular}{|c|c|c|c|c|c|c|c|c|}
\hline \multirow[t]{2}{*}{ Frage III 2.2.4 } & \multicolumn{8}{|c|}{$\begin{array}{l}\text { Über wie viele sonstige brauereieigene Absatzstätten verfügt Ihr } \\
\text { Unternehmen? }\end{array}$} \\
\hline & \multicolumn{2}{|c|}{$\begin{array}{l}\text { Bis } 5.000 \mathrm{hl} \\
\quad(\mathrm{n}=92)\end{array}$} & & $\begin{array}{l}.000- \\
.000 \mathrm{hl} \\
=138)\end{array}$ & $\begin{array}{r}\text { kea } \\
10 \\
25 \\
(\end{array}$ & $\begin{array}{l}\text { ussto } \beta \\
0.000- \\
0.000 \mathrm{hl} \\
\mathrm{n}=29)\end{array}$ & $\begin{array}{c}\text { Größer als } \\
250.000 \mathrm{hl} \\
(\mathrm{n}=22)\end{array}$ & $\begin{array}{l}\text { Gesamt } \\
(\mathrm{n}=281)\end{array}$ \\
\hline Kein Objekt & 20 & $(21,7 \%)$ & 41 & $(29,7 \%)$ & 7 & $(24,1 \%)$ & $2 \quad(9,1 \%)$ & $70 \quad(24,9 \%)$ \\
\hline 1 Objekt & 1 & $(1,1 \%)$ & 5 & $(3,6 \%)$ & & & & $6 \quad(2,1 \%)$ \\
\hline 2-5 Objekte & & & & $(0,7 \%)$ & & & & $1 \quad(0,4 \%)$ \\
\hline 6-10 Objekte & & $(1,1 \%)$ & & $(0,7 \%)$ & & & & $2 \quad(0,7 \%)$ \\
\hline Mehr als 10 & & & & $(0,7 \%)$ & & & $1 \quad(4,5 \%)$ & $2 \quad(0,8 \%)$ \\
\hline $\begin{array}{l}\text { keine } \\
\text { Angabe }\end{array}$ & 70 & $(76,1 \%)$ & 89 & $(64,5 \%)$ & 22 & $(75,9 \%)$ & $19(86,4 \%)$ & $200 \quad(71,2 \%)$ \\
\hline $\begin{array}{c}\text { Mittlere } \\
\text { Anzahl von } \\
\text { Objekten* }\end{array}$ & & 5 & & 4,875 & & $\mathbf{0}$ & 100 & 13,54 \\
\hline
\end{tabular}

* In die Berechnung der mittleren Anzahl der sonstigen Absatzstätten, die sich im Eigentum bzw. Pacht der Brauerei befinden, sind nur die Unternehmen einbezogen, welche eine Angabe gemacht haben und über sonstige eigene Absatzstätten verfügen

Quelle: Niederhut-Bollmann, C., Datensatz „Große Strategie-Studie 2005“, Göttingen 2005.

\begin{tabular}{|c|c|c|c|c|c|}
\hline \multirow[t]{3}{*}{ Frage III 2.3: } & \multicolumn{5}{|c|}{$\begin{array}{l}\text { Wie viele Ihrer Gastronomiekunden sind durch Bierlieferverträge an } \\
\text { Ihr Unternehmen gebunden ((in \% der gesamten Gastronomiekunden)? }\end{array}$} \\
\hline & \multirow[b]{2}{*}{$\begin{array}{c}\text { Bis } 5.000 \mathrm{hl} \\
(\mathrm{n}=92)\end{array}$} & \multicolumn{2}{|c|}{ Gesamtgetränkeausstoß } & \multirow[b]{2}{*}{$\begin{array}{c}\text { Größer als } \\
250.000 \mathrm{hl} \\
(\mathrm{n}=22)\end{array}$} & \multirow[b]{2}{*}{$\begin{array}{l}\text { Gesamt } \\
(\mathrm{n}=281)\end{array}$} \\
\hline & & $\begin{array}{c}5.000- \\
100.000 \mathrm{hl} \\
(\mathrm{n}=138)\end{array}$ & $\begin{array}{c}100.000- \\
250.000 \mathrm{hl} \\
(\mathrm{n}=29)\end{array}$ & & \\
\hline $\begin{array}{l}\text { Keine Verträge } \\
\text { mit Gastr. }\end{array}$ & $37 \quad(40,2 \%)$ & $(7,2 \%)$ & $2 \quad(6,9 \%)$ & & $49 \quad(17,4 \%)$ \\
\hline Bis $20 \%$ & $15 \quad(16,3 \%)$ & $(35,5 \%)$ & $(20,7 \%)$ & $1 \quad(4,5 \%)$ & $71 \quad(25,3 \%)$ \\
\hline$>20-40 \%$ & $4 \quad(4,3 \%)$ & $(27,5 \%)$ & $7 \quad(24,1 \%)$ & $4 \quad(18,2 \%)$ & $53 \quad(18,4 \%)$ \\
\hline$>40-60 \%$ & $4 \quad(4,3 \%)$ & $(11,6 \%)$ & $6 \quad(20,7 \%)$ & $3 \quad(13,6 \%)$ & $(10,3 \%)$ \\
\hline$>60-80 \%$ & $7 \quad(7,6 \%)$ & $13 \quad(9,4 \%)$ & $6 \quad(20,7 \%)$ & $6 \quad(27,3 \%)$ & $32 \quad(11,4 \%)$ \\
\hline$>80-99 \%$ & $1 \quad(1,1 \%)$ & & & $3 \quad(13,6 \%)$ & $4 \quad(1,4 \%)$ \\
\hline $100 \%$ gebunden & $4 \quad(4,3 \%)$ & $(2,2 \%)$ & & $1 \quad(4,5 \%)$ & $8 \quad(2,8 \%)$ \\
\hline keine Angabe & $20 \quad(21,7 \%)$ & $(6,5 \%)$ & $2 \quad(6,9 \%)$ & $4 \quad(18,2 \%)$ & $35 \quad(12,5 \%)$ \\
\hline $\begin{array}{c}\text { Mittelwert* } \\
\text { Lieferverträge }\end{array}$ & $42,63 \%$ & $33,38 \%$ & $45,2 \%$ & $63,56 \%$ & $39,28 \%$ \\
\hline
\end{tabular}

* In die Berechnung des Mittelwertes der durch Bierlieferverträge gebunden Gastronomiekunden, sind nur die Unternehmen einbezogen, welche eine Angabe gemacht haben und über Bierlieferverträge verfügen

Quelle: Niederhut-Bollmann, C., Datensatz „,Große Strategie-Studie 2005“, Göttingen 2005. 


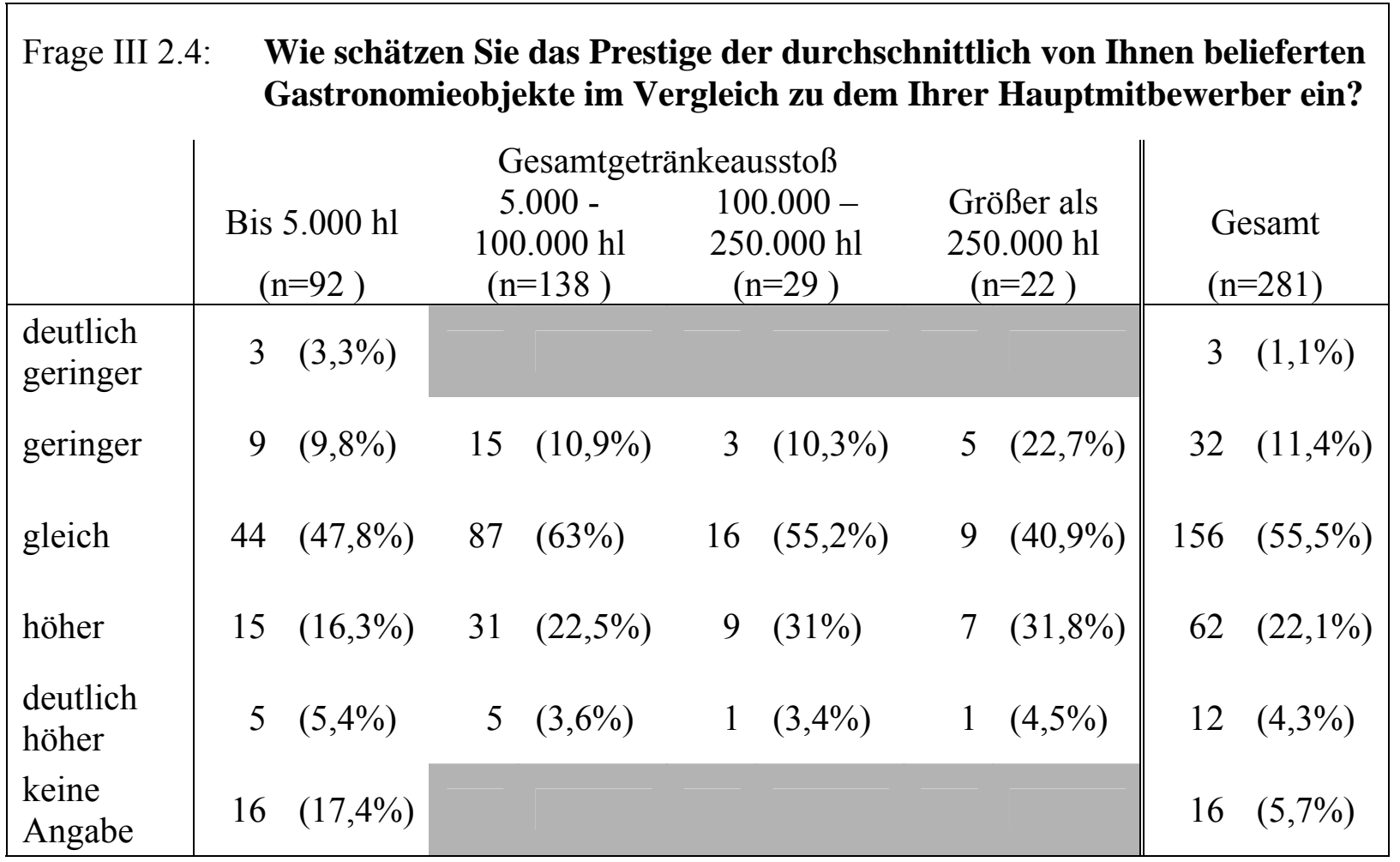

Quelle: Niederhut-Bollmann, C., Datensatz „Große Strategie-Studie 2005“, Göttingen 2005.

\section{Frage III 2.5: Ist Ihr Unternehmen international tätig oder beabsichtigen Sie in naher Zukunft international tätig zu werden?}

\begin{tabular}{|c|c|c|c|c|c|}
\hline & \multicolumn{4}{|c|}{ Gesamtgetränkeausstoß } & \multirow[b]{2}{*}{$\begin{array}{l}\text { Gesamt } \\
(\mathrm{n}=281)\end{array}$} \\
\hline & $\begin{array}{c}\text { Bis } 5.000 \mathrm{hl} \\
\quad(\mathrm{n}=92)\end{array}$ & $\begin{array}{c}5.000- \\
100.000 \mathrm{hl} \\
(\mathrm{n}=138)\end{array}$ & $\begin{array}{c}100.000- \\
250.000 \mathrm{hl} \\
(\mathrm{n}=29)\end{array}$ & $\begin{array}{c}\text { Größer als } \\
250.000 \mathrm{hl} \\
(\mathrm{n}=22)\end{array}$ & \\
\hline $\mathrm{Ja}$ & & $26 \quad(18,8 \%)$ & $12(41,4 \%)$ & $15(68,2 \%)$ & $53(18,9 \%)$ \\
\hline $\begin{array}{l}\text { In } \\
\text { Planung }\end{array}$ & $4 \quad(4,3 \%)$ & $4 \quad(2,9 \%)$ & $1 \quad(3,4 \%)$ & & $9 \quad(3,2 \%)$ \\
\hline Nein & $88 \quad(95,7 \%)$ & $108 \quad(78,3 \%)$ & $16 \quad(55,2 \%)$ & $7 \quad(31,8 \%)$ & $219 \quad(77,9 \%)$ \\
\hline
\end{tabular}

Quelle: Niederhut-Bollmann, C., Datensatz „Große Strategie-Studie 2005“, Göttingen 2005. 


\section{Frage III 2.5.1: Seit wann ist Ihr Unternehmen international tätig?}

\begin{tabular}{|c|c|c|c|c|c|}
\hline & \multicolumn{4}{|c|}{ Gesamtgetränkeausstoß } & \multirow[b]{2}{*}{$\begin{array}{l}\text { Gesamt } \\
(n=53)\end{array}$} \\
\hline & $\begin{array}{c}\text { Bis } 5.000 \\
\text { hl } \\
(n=0)\end{array}$ & $\begin{array}{c}5.000- \\
100.000 \mathrm{hl} \\
(\mathrm{n}=26)\end{array}$ & $\begin{array}{c}100.000- \\
250.000 \mathrm{hl} \\
(\mathrm{n}=12)\end{array}$ & $\begin{array}{c}\text { Größer als } \\
250.000 \mathrm{hl} \\
(\mathrm{n}=15)\end{array}$ & \\
\hline Bis 5 Jahre & & $11 \quad(42,4 \%)$ & $2(16,7 \%)$ & $2(13,3 \%)$ & $15 \quad(28,3 \%)$ \\
\hline$>5-10$ Jahre & & $3 \quad(11,5 \%)$ & & $3 \quad(20 \%)$ & $6 \quad(11,3 \%)$ \\
\hline $\begin{array}{l}>10-20 \\
\text { Jahre }\end{array}$ & & $9 \quad(34,6 \%)$ & $5 \quad(41,7 \%)$ & $3(20 \%)$ & $17 \quad(32,1 \%)$ \\
\hline$>20$ Jahre & & $2(7,7 \%)$ & $1 \quad(8,3 \%)$ & $3(20 \%)$ & $(11,3 \%)$ \\
\hline $\begin{array}{l}\text { keine } \\
\text { Angabe }\end{array}$ & & $1 \quad(3,8 \%)$ & $4 \quad(33,3 \%)$ & $4 \quad(26,7 \%)$ & $9 \quad(17 \%)$ \\
\hline $\begin{array}{l}\text { Mittelwert* } \\
\text { in Jahren }\end{array}$ & & 10,12 & 15,88 & 23,18 & 14,43 \\
\hline
\end{tabular}

* Bei der Berechnung des Mittelwertes (internationale Tätigkeit der Unternehmen in Jahren) wurden nur die Unternehmen berücksichtigt, die eine Angabe gemacht haben und international tätig sind.

Quelle: Niederhut-Bollmann, C., Datensatz „Große Strategie-Studie 2005“, Göttingen 2005.

\section{Frage III 2.5.2: Welche der unten aufgeführten Markterschließungsstrategien verwenden Sie im Ausland?}

\begin{tabular}{|c|c|c|c|c|c|}
\hline $\begin{array}{l}\text { Markterschließungs- } \\
\text { strategie im Ausland }\end{array}$ & & $\begin{array}{c}\text { Gesan } \\
5.000-100.000 \\
\mathrm{hl} \\
(\mathrm{n}=26)\end{array}$ & $\begin{array}{c}\text { tränkeausstoß } \\
100.000- \\
250.000 \mathrm{hl} \\
(\mathrm{n}=12)\end{array}$ & $\begin{array}{c}\text { Größer als } \\
250.000 \mathrm{hl} \\
(\mathrm{n}=15) \\
\end{array}$ & $\begin{array}{l}\text { Gesamt } \\
(\mathrm{n}=53)\end{array}$ \\
\hline \multirow{2}{*}{ Export } & $\mathrm{Ja}$ & $25 \quad(96,2 \%)$ & $12 \quad(100 \%)$ & $14 \quad(93,3 \%)$ & $51 \quad(96,2 \%)$ \\
\hline & Nein & $1 \quad(3,8 \%)$ & & $1 \quad(6,7 \%)$ & $2 \quad(3,8 \%)$ \\
\hline \multirow{2}{*}{ Lizenzvergabe } & $\mathrm{Ja}$ & $1 \quad(3,8 \%)$ & $1 \quad(8,3 \%)$ & $2 \quad(13,3 \%)$ & $4 \quad(7,5 \%)$ \\
\hline & Nein & $25 \quad(96,2 \%)$ & $11 \quad(91,7 \%)$ & $13 \quad(86,7 \%)$ & $49 \quad(92,5 \%)$ \\
\hline \multirow{2}{*}{ Joint Venture } & $\mathrm{Ja}$ & & & $1 \quad(6,7 \%)$ & $1 \quad(1,9 \%)$ \\
\hline & Nein & $26 \quad(100 \%)$ & $12 \quad(100 \%)$ & $14 \quad(93,7 \%)$ & $52 \quad(98,1 \%)$ \\
\hline \multirow{2}{*}{$\begin{array}{c}\text { Übernahme } \\
\text { ausländischer } \\
\text { Brauereien }\end{array}$} & $\mathrm{Ja}$ & & & & \\
\hline & Nein & $26 \quad(100 \%)$ & $12(100 \%)$ & $15 \quad(100 \%)$ & $53 \quad(100 \%)$ \\
\hline \multirow{2}{*}{ Andere Formen } & $\mathrm{Ja}$ & $1 \quad(3,8 \%)$ & & $1 \quad(6,7 \%)$ & $2 \quad(3,8 \%)$ \\
\hline & Nein & $25 \quad(96,2 \%)$ & $12 \quad(100 \%)$ & $14 \quad(93,3 \%)$ & $51 \quad(96,2 \%)$ \\
\hline
\end{tabular}

Quelle: Niederhut-Bollmann, C., Datensatz „Große Strategie-Studie 2005“, Göttingen 2005. 


\begin{tabular}{|c|c|c|c|c|c|c|}
\hline Frage III 2.5.3: & $\begin{array}{l}\text { Wie hoc } \\
\text { Lizenzv } \\
\text { Gesamt }\end{array}$ & $\begin{array}{l}\text { war im Jahr } \\
\text { sabe, Joint V } \\
\text { satzes) }\end{array}$ & $\begin{array}{l}3 \text { ca. Ihr Au } \\
\text { ures und anc }\end{array}$ & $\begin{array}{l}\text { dabsatz (Ex } \\
\text { Formen)? }\end{array}$ & $\begin{array}{l}\mathrm{rt}, \\
\% \mathrm{~d}\end{array}$ & \\
\hline & & Gesamt & änkeausstoß & & & \\
\hline & $\begin{array}{c}\text { Bis } \\
5.000 \mathrm{hl} \\
(\mathrm{n}=0)\end{array}$ & $\begin{array}{c}5.000- \\
100.000 \mathrm{hl} \\
(\mathrm{n}=26)\end{array}$ & $\begin{array}{c}100.000- \\
250.000 \mathrm{hl} \\
(\mathrm{n}=12)\end{array}$ & $\begin{array}{c}\text { Größer als } \\
250.000 \mathrm{hl} \\
(\mathrm{n}=15)\end{array}$ & & $\begin{array}{l}\text { Jesamt } \\
n=53)\end{array}$ \\
\hline Bis 2,5\% & & $8 \quad(30,8 \%)$ & $5 \quad(41,7 \%)$ & $5 \quad(33,3 \%)$ & 18 & $(34 \%)$ \\
\hline$>2,5-5 \%$ & & $4 \quad(15,4 \%)$ & $5 \quad(41,7 \%)$ & $3 \quad(20 \%)$ & 12 & $(22,7 \%)$ \\
\hline$>5-10 \%$ & & $8 \quad(30,8 \%)$ & $2 \quad(16,7 \%)$ & $4 \quad(26,7 \%)$ & 14 & $(26,7 \%)$ \\
\hline$>10-20 \%$ & & $2 \quad(7,7 \%)$ & & $1 \quad(6,7 \%)$ & 3 & $(5,7 \%)$ \\
\hline$>20 \%$ & & $1 \quad(3,8 \%)$ & & $1 \quad(6,7 \%)$ & 2 & $(3,8 \%)$ \\
\hline keine Angabe & & $3 \quad(11,5 \%)$ & & $1 \quad(6,7 \%)$ & 4 & $(7,5 \%)$ \\
\hline $\begin{array}{c}\text { Mittelwert* } \\
\text { Auslandabsatz }\end{array}$ & & 7,36 \% & $4,04 \%$ & $6,51 \%$ & & ,31\% \\
\hline
\end{tabular}

* In die Berechnung des Mittelwertes des Auslandsabsatzes, sind nur die Unternehmen einbezogen, welche eine Angabe gemacht haben und Absatz im Ausland tätigen

Quelle: Niederhut-Bollmann, C., Datensatz „Große Strategie-Studie 2005“, Göttingen 2005.

Frage III 2.5.4: Wie hat sich der Auslandsabsatz in den letzten drei Jahren ca. verändert? Zunahme/Abnahme \%:

\begin{tabular}{|c|c|c|c|c|c|c|}
\hline & $\begin{array}{c}\text { Bis } 5.000 \mathrm{hl} \\
(\mathrm{n}=0)\end{array}$ & $\begin{array}{c}\text { Gesamtgetr } \\
5.000- \\
100.000 \mathrm{hl} \\
(\mathrm{n}=26)\end{array}$ & & $\begin{array}{l}\text { usstoß } \\
0.000- \\
.000 \mathrm{hl} \\
.=12)\end{array}$ & $\begin{array}{l}\text { Größer als } \\
250.000 \mathrm{hl} \\
(\mathrm{n}=15)\end{array}$ & $\begin{array}{l}\text { Gesamt } \\
(\mathrm{n}=53)\end{array}$ \\
\hline Bis $-10 \%$ & & $2 \quad(7,6 \%)$ & & & & $2 \quad(3,8 \%)$ \\
\hline 0 bis $+5 \%$ & & $5 \quad(19,2 \%)$ & 3 & $(25 \%)$ & $3 \quad(20 \%)$ & $11(20,8 \%)$ \\
\hline$>5$ bis $10 \%$ & & $2 \quad(7,7 \%)$ & 2 & $(16,7 \%)$ & & $4 \quad(7,6 \%)$ \\
\hline$>10$ bis $20 \%$ & & & 2 & $(16,7 \%)$ & $2 \quad(13,3 \%)$ & $4 \quad(7,6 \%)$ \\
\hline$>20$ bis $30 \%$ & & $2 \quad(7,7 \%)$ & 1 & $(8,3 \%)$ & $1 \quad(6,7 \%)$ & $4 \quad(7,6 \%)$ \\
\hline$>30 \%$ & & $4 \quad(15,4 \%)$ & 3 & $(25 \%)$ & $1 \quad(6,7 \%)$ & $8 \quad(15,1 \%)$ \\
\hline keine Angabe & & $11 \quad(42,3 \%)$ & 1 & $(8,3 \%)$ & $8 \quad(53,3 \%)$ & $20 \quad(37,7 \%)$ \\
\hline $\begin{array}{c}\text { Mittelwert* } \\
\text { Veränderung } \\
\text { Auslandsabsatz } \\
\end{array}$ & & $+25,93 \%$ & & $2,36 \%$ & $+17,15 \%$ & $+22,88 \%$ \\
\hline
\end{tabular}

* In die Berechnung des Mittelwertes der Veränderung des Auslandsabsatzes, sind nur die Unternehmen einbezogen, welche eine Angabe gemacht haben und Absatz im Ausland tätigen

Quelle: Niederhut-Bollmann, C., Datensatz „Große Strategie-Studie 2005“, Göttingen 2005. 


\section{Kosten}

\begin{tabular}{|c|c|c|c|c|c|}
\hline Frage III 3.1 & $\begin{array}{l}\text { Wie hoch si } \\
\text { Unternehm }\end{array}$ & $\begin{array}{l}\text { d etwa die dur } \\
\text { is pro Hektoli }\end{array}$ & $\begin{array}{l}\text { hschnittlichen } \\
\text { r Bierausstoß }\end{array}$ & esamtkosten & Ires \\
\hline Kosten in $€$ & $\begin{array}{c}\text { Bis } 5.000 \mathrm{hl} \\
\quad(\mathrm{n}=92)\end{array}$ & $\begin{array}{c}\text { Gesamtgetr } \\
5.000- \\
100.000 \mathrm{hl} \\
(\mathrm{n}=138)\end{array}$ & $\begin{array}{l}\text { keausstoß } \\
100.000- \\
250.000 \mathrm{hl} \\
(\mathrm{n}=29)\end{array}$ & $\begin{array}{c}\text { Größer als } \\
250.000 \mathrm{hl} \\
(\mathrm{n}=22)\end{array}$ & $\begin{array}{l}\text { Gesamt } \\
(\mathrm{n}=281)\end{array}$ \\
\hline Unter 30 & $1 \quad(1,1 \%)$ & & & & $1 \quad(0,4 \%)$ \\
\hline$>30-40$ & $8 \quad(8,8 \%)$ & $15 \quad(10,8 \%)$ & & & $23 \quad(8,3 \%)$ \\
\hline$>40-50$ & $6 \quad(6,6 \%)$ & $4 \quad(2,8 \%)$ & & $2 \quad(9 \%)$ & $12 \quad(4,3 \%)$ \\
\hline$>50-60$ & $6 \quad(6,6 \%)$ & $3 \quad(2,1 \%)$ & $1 \quad(3,4 \%)$ & $1 \quad(4,5 \%)$ & $11 \quad(3,9 \%)$ \\
\hline$>60-70$ & $7 \quad(7,7 \%)$ & $7 \quad(5,1 \%)$ & $2 \quad(6,9 \%)$ & & $16 \quad(5,8 \%)$ \\
\hline$>70-80$ & $5 \quad(5,5 \%)$ & $6 \quad(4,3 \%)$ & $1 \quad(3,4 \%)$ & & $12 \quad(4,3 \%)$ \\
\hline$>80-90$ & $1 \quad(1,1 \%)$ & $1 \quad(0,7 \%)$ & & & $2 \quad(0,7 \%)$ \\
\hline$>90-100$ & $2 \quad(2,2 \%)$ & $2 \quad(1,4 \%)$ & & & $4 \quad(1,5 \%)$ \\
\hline Über 100 & $5 \quad(5,5 \%)$ & $1 \quad(0,7 \%)$ & & & $6 \quad(2,2 \%)$ \\
\hline $\begin{array}{l}\text { keine } \\
\text { Angabe }\end{array}$ & $51 \quad(55,4 \%)$ & $99 \quad(71,7 \%)$ & $25 \quad(86,2 \%)$ & $19 \quad(86,4 \%)$ & $194 \quad(68,9 \%)$ \\
\hline $\begin{array}{l}\text { Mittelwert* } \\
\text { Kosten pro } \\
\text { hl }\end{array}$ & $67,26 €$ & $58,19 €$ & $66,25 €$ & $53,33 €$ & $62,81 €$ \\
\hline
\end{tabular}

* In die Berechnung des Mittelwertes der durchschnittlichen Kosten pro Hektoliter, sind nur die Unternehmen einbezogen, welche eine Angabe gemacht haben.

Quelle: Niederhut-Bollmann, C., Datensatz „Große Strategie-Studie 2005“, Göttingen 2005.

\begin{tabular}{|c|c|c|c|c|c|c|c|c|c|}
\hline \multirow[t]{3}{*}{ Frage III 3} & \multicolumn{9}{|c|}{$\begin{array}{l}\text { Wie schätzen Sie die durchschnittlichen Gesamtkosten Ihres } \\
\text { Unternehmens im Vergleich zum Branchendurchschnitt ein? }\end{array}$} \\
\hline & \multirow{2}{*}{\multicolumn{2}{|c|}{$\begin{array}{l}\text { Bis } 5.000 \mathrm{hl} \\
\quad(\mathrm{n}=92)\end{array}$}} & \multicolumn{4}{|c|}{ Gesamtgetränkeausstoß } & \multirow[b]{2}{*}{$\begin{array}{c}\text { Größer als } \\
250.000 \mathrm{hl} \\
(\mathrm{n}=22)\end{array}$} & \multirow{2}{*}{\multicolumn{2}{|c|}{$\begin{array}{l}\text { Gesamt } \\
(\mathrm{n}=281)\end{array}$}} \\
\hline & & & & $\begin{array}{l}.000- \\
.000 \mathrm{hl} \\
=138)\end{array}$ & & $\begin{array}{l}0.000- \\
.000 \mathrm{hl} \\
=29)\end{array}$ & & & \\
\hline $\begin{array}{l}\text { deutlich } \\
\text { geringer }\end{array}$ & & $(1,1 \%)$ & 4 & $(2,9 \%)$ & & & $1 \quad(4,5 \%)$ & 6 & $(2,1 \%)$ \\
\hline geringer & 1 & $(10,9 \%)$ & 13 & $(9,4 \%)$ & 10 & $(34,5 \%)$ & $8 \quad(36,4 \%)$ & 41 & $(14,6 \%)$ \\
\hline gleich & 1 & $(18,5 \%)$ & 36 & $(26,1 \%)$ & 4 & $(13,8 \%)$ & $4 \quad(18,2 \%)$ & 61 & $(21,7 \%)$ \\
\hline höher & 3 & $(42,4 \%)$ & 66 & $(47,8 \%)$ & 13 & $(44,8 \%)$ & $6 \quad(27,3 \%)$ & 124 & $(44,1 \%)$ \\
\hline $\begin{array}{l}\text { deutlich } \\
\text { höher }\end{array}$ & & $(22,8 \%)$ & 18 & $(13 \%)$ & & & $1 \quad(4,5 \%)$ & 40 & $(14,2 \%)$ \\
\hline $\begin{array}{l}\text { keine } \\
\text { Angabe }\end{array}$ & & $(4,3 \%)$ & & $(0,7 \%)$ & & $(6,9 \%)$ & $2(9,1 \%)$ & & $(3,2 \%)$ \\
\hline
\end{tabular}

Quelle: Niederhut-Bollmann, C., Datensatz „Große Strategie-Studie 2005“, Göttingen 2005. 


\section{Marketing und Marktführung}

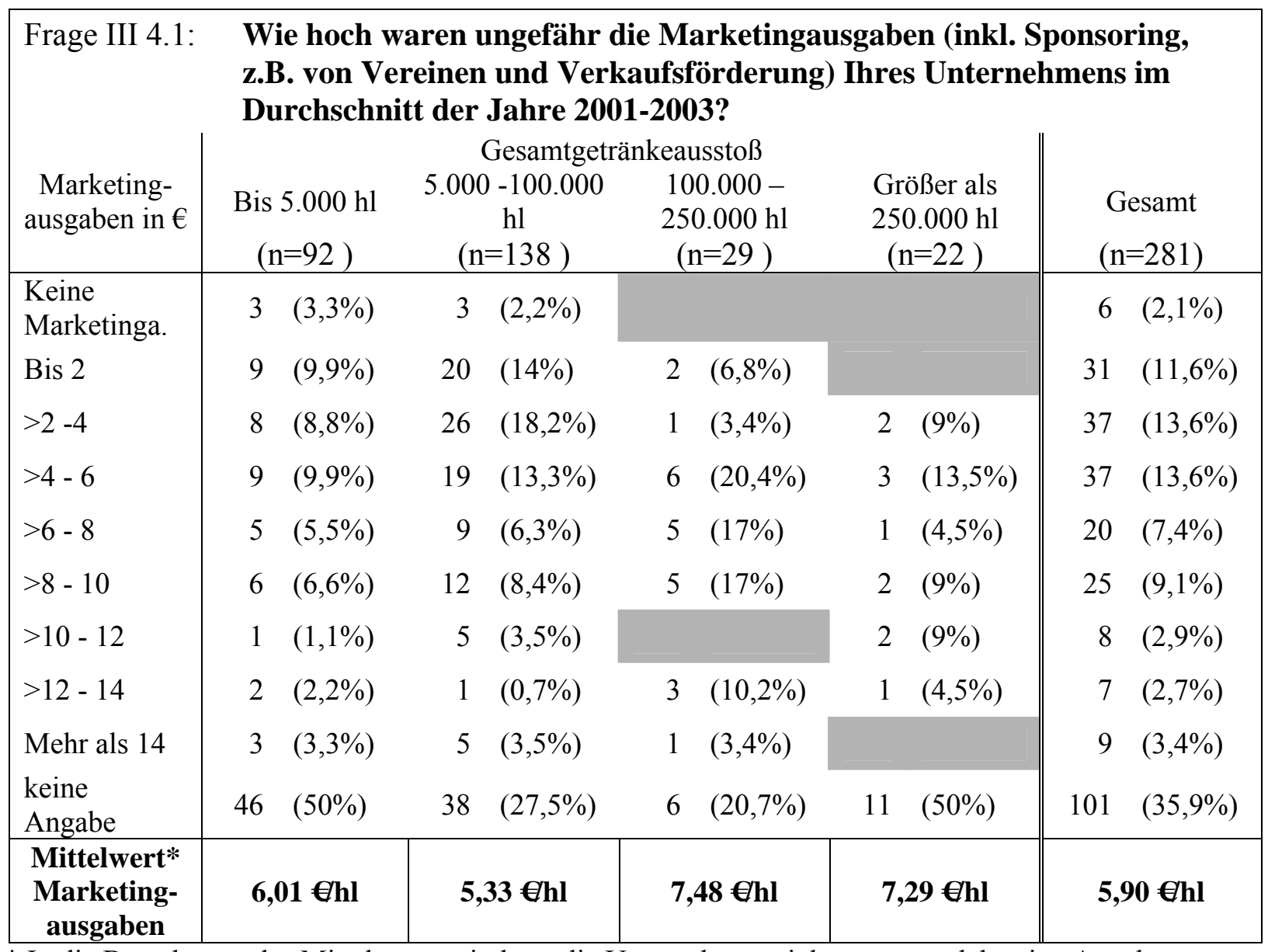

* In die Berechnung des Mittelwertes sind nur die Unternehmen einbezogen, welche eine Angabe gemacht haben und Marketingausgaben getätigt haben.

Quelle: Niederhut-Bollmann, C., Datensatz „Große Strategie-Studie 2005“, Göttingen 2005.

\begin{tabular}{|c|c|c|c|c|c|}
\hline \multirow[t]{3}{*}{ Frage III 4.1.1: } & \multicolumn{5}{|c|}{$\begin{array}{l}\text { Darstellung der jährlichen Marketingausgaben im Durchschnitt der } \\
\text { letzten drei Jahre nach Gesamtgetränkeausstoß? }\end{array}$} \\
\hline & & Gesamtg & keausstoß & & \\
\hline & $\begin{array}{c}\text { Bis } 5.000 \mathrm{hl} \\
(\mathrm{n}=46)\end{array}$ & $\begin{array}{c}5.000- \\
100.000 \mathrm{hl} \\
(\mathrm{n}=100)\end{array}$ & $\begin{array}{c}100.000- \\
250.000 \mathrm{hl} \\
(\mathrm{n}=23)\end{array}$ & $\begin{array}{l}\text { Größer als } \\
250.000 \mathrm{hl} \\
(\mathrm{n}=11)\end{array}$ & $\begin{array}{l}\text { Gesamt } \\
(\mathrm{n}=180)\end{array}$ \\
\hline $\begin{array}{l}\text { Durchschnittliche } \\
\text { Marketingausgaben } \\
\text { 2001* }\end{array}$ & $5,26 € / h l$ & $5,20 € / h l$ & $7,44 € / h l$ & 7,07 €/hl & $5,62 € / h l$ \\
\hline $\begin{array}{l}\text { Durchschnittliche } \\
\text { Marketingausgaben } \\
\text { 2002* }\end{array}$ & $5,86 € / h l$ & $5,35 € / h l$ & 7,34 €/hl & $7,54 € / h l$ & $5,87 € / h l$ \\
\hline $\begin{array}{l}\text { Durchschnittliche } \\
\text { Marketingausgaben } \\
\text { 2003* }\end{array}$ & 6,92€/hl & $5,44 € / \mathrm{hl}$ & $7,66 € / h l$ & 7,27 €/hl & $6,22 € / h l$ \\
\hline $\begin{array}{l}\text { Durchschnittliche } \\
\text { Marketingausgaben } \\
\text { 2001-2003* }\end{array}$ & 6,01 €/hl & $5,33 € / h l$ & $7,48 € / h l$ & $7,29 € / \mathrm{hl}$ & $5,90 € / \mathrm{hl}$ \\
\hline
\end{tabular}

* In die Berechnung der durchschnittlichen Marketingausgaben sind nur die Unternehmen einbezogen, welche Angaben zu Ihren Marketingausgaben getätigt haben.

Quelle: Niederhut-Bollmann, C., Datensatz „Große Strategie-Studie 2005“, Göttingen 2005. 


\begin{tabular}{|c|c|c|c|c|c|c|}
\hline \multirow[t]{3}{*}{ Frage III 4.2.1: } & \multicolumn{6}{|c|}{$\begin{array}{l}\text { Inwieweit stimmen Sie dem folgenden Statement, welches so oder ähnlich } \\
\text { von Managern anderer Unternehmen geäußert wurde, für Ihr } \\
\text { Unternehmen zu? } \\
\text { Die Marke ist eine zentrale Größe im Management unseres } \\
\text { Unternehmens. }\end{array}$} \\
\hline & \multicolumn{4}{|c|}{ Gesamtgetränkeausstoß } & \multirow{2}{*}{\multicolumn{2}{|c|}{$\begin{array}{l}\text { Gesamt } \\
(\mathrm{n}=281)\end{array}$}} \\
\hline & $\begin{array}{l}\text { Bis } 5.000 \mathrm{hl} \\
\quad(\mathrm{n}=92)\end{array}$ & $\begin{array}{c}5.000-100.000 \\
\mathrm{hl} \\
(\mathrm{n}=138)\end{array}$ & $\begin{array}{c}100.000- \\
250.000 \mathrm{hl} \\
(\mathrm{n}=29)\end{array}$ & $\begin{array}{c}\text { Größer als } \\
250.000 \mathrm{hl} \\
(\mathrm{n}=22)\end{array}$ & & \\
\hline $\begin{array}{l}\text { Stimme voll- } \\
\text { ständig zu }\end{array}$ & $28 \quad(30,4 \%)$ & $42 \quad(30,4 \%)$ & $16 \quad(55,2 \%)$ & $9 \quad(40,9 \%)$ & 95 & $(33,8 \%)$ \\
\hline Stimme zu & $40 \quad(43,5 \%)$ & $77 \quad(55,8 \%)$ & $12(41,4 \%)$ & $13(59,1 \%)$ & 142 & $(50,5 \%)$ \\
\hline Weder noch & $15 \quad(16,3 \%)$ & $12 \quad(8,7 \%)$ & $1 \quad(3,4 \%)$ & & 28 & $(10 \%)$ \\
\hline Lehne ab & $2(2,2 \%)$ & $1 \quad(0,7 \%)$ & & & & $(1,1 \%)$ \\
\hline $\begin{array}{l}\text { Lehne voll- } \\
\text { Ständig ab }\end{array}$ & & $1 \quad(0,7 \%)$ & & & & $(0,4 \%)$ \\
\hline $\begin{array}{l}\text { Keine } \\
\text { Angabe }\end{array}$ & $7 \quad(7,6 \%)$ & $5 \quad(3,6 \%)$ & & & 12 & $(4,3 \%)$ \\
\hline
\end{tabular}

Quelle: Niederhut-Bollmann, C., Datensatz „Große Strategie-Studie 2005“, Göttingen 2005.

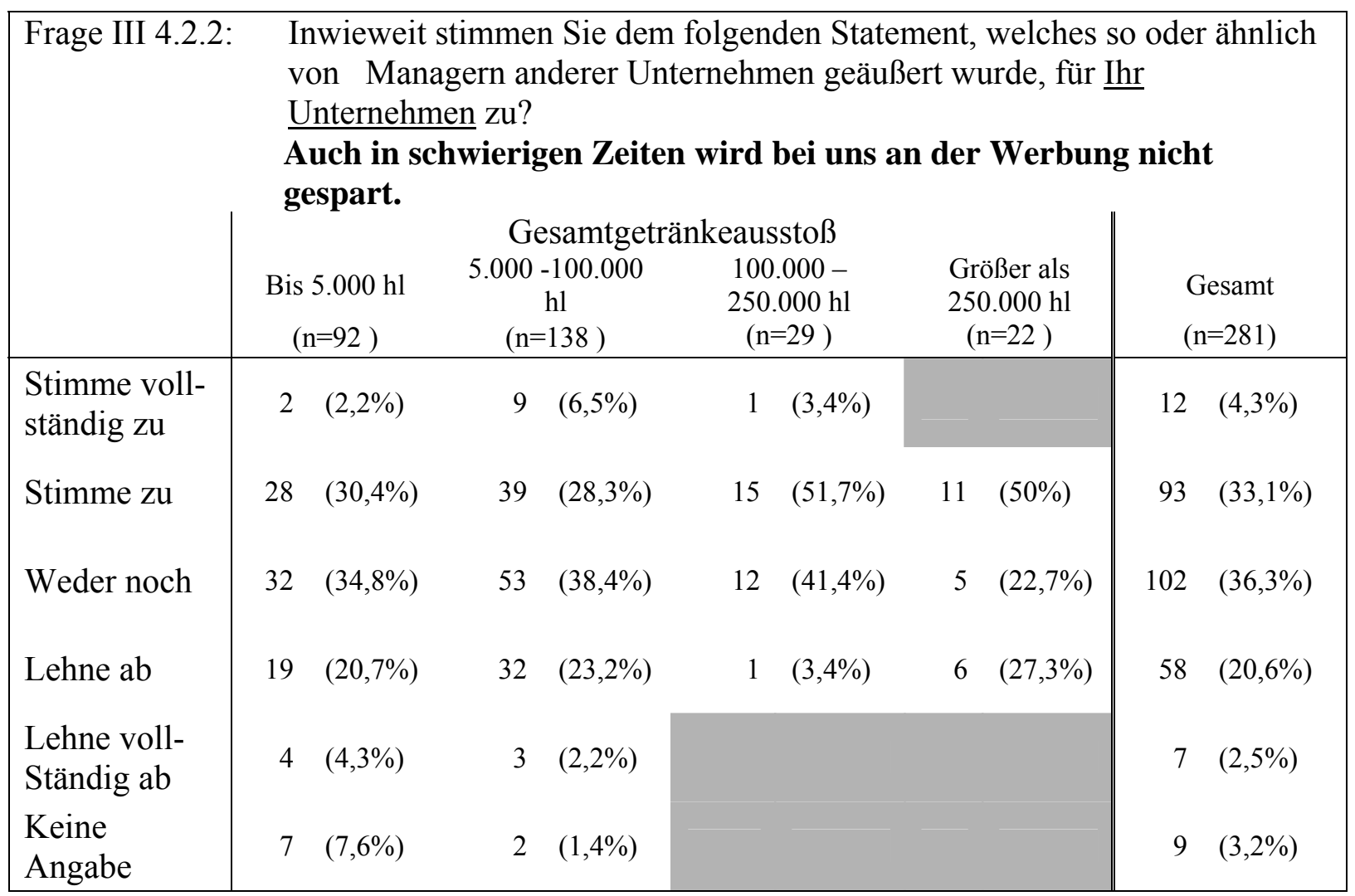

Quelle: Niederhut-Bollmann, C., Datensatz „Große Strategie-Studie 2005“, Göttingen 2005. 


\begin{tabular}{|c|c|c|c|c|c|c|c|}
\hline \multirow[t]{2}{*}{ Frage III 4.2.3 } & \multicolumn{7}{|c|}{$\begin{array}{l}\text { Inwieweit stimmen Sie dem folgenden Statement, welches so oder ähnlich } \\
\text { von Managern anderer Unternehmen geäußert wurde, für Ihr } \\
\text { Unternehmen zu? } \\
\text { Nur mit einer starken Marke können wir langfristig erfolgreich sein. }\end{array}$} \\
\hline & $\begin{array}{l}\text { Bis } 5.000 \mathrm{hl} \\
\quad(\mathrm{n}=92)\end{array}$ & $\begin{array}{r}5.000 \\
\quad(\mathrm{n}=\end{array}$ & $\begin{array}{l}100.000 \\
\mathrm{l} \\
138)\end{array}$ & $\begin{array}{c}100.000- \\
250.000 \mathrm{hl} \\
(\mathrm{n}=29)\end{array}$ & $\begin{array}{c}\text { Größer als } \\
250.000 \mathrm{hl} \\
(\mathrm{n}=22)\end{array}$ & & $\begin{array}{l}\text { esamt } \\
=281)\end{array}$ \\
\hline $\begin{array}{l}\text { Stimme voll- } \\
\text { ständig zu }\end{array}$ & $28 \quad(30,4 \%)$ & 39 & $(28,3 \%)$ & $18 \quad(62,1 \%)$ & $11 \quad(50 \%)$ & & $(34,2 \%)$ \\
\hline Stimme zu & $40 \quad(43,5 \%)$ & 80 & $(58 \%)$ & $11 \quad(37,9 \%)$ & $10 \quad(45,5 \%)$ & 141 & $(50,2 \%)$ \\
\hline Weder noch & $(13 \%)$ & 13 & $(9,4 \%)$ & & $1 \quad(4,5 \%)$ & 26 & $(9,3 \%)$ \\
\hline Lehne ab & $(4,3 \%)$ & & $(0,7 \%)$ & & & & $(1,8 \%)$ \\
\hline $\begin{array}{l}\text { Lehne voll- } \\
\text { Ständig ab }\end{array}$ & & & $(0,7 \%)$ & & & & $(0,4 \%)$ \\
\hline $\begin{array}{l}\text { Keine } \\
\text { Angabe }\end{array}$ & $(8,7 \%)$ & 4 & $(2,9 \%)$ & & & 12 & $(4,3 \%)$ \\
\hline
\end{tabular}

Quelle: Niederhut-Bollmann, C., Datensatz „Große Strategie-Studie 2005“, Göttingen 2005.

\begin{tabular}{|c|c|c|c|c|c|c|c|c|c|c|}
\hline \multirow[t]{2}{*}{ Frage III 4.2.4: } & \multicolumn{10}{|c|}{$\begin{array}{l}\text { Inwieweit stimmen Sie dem folgenden Statement, welches so oder ähnlich } \\
\text { von Managern anderer Unternehmen geäußert wurde, für } \underline{\mathrm{Ihr}} \\
\text { Unternehmen zu? } \\
\text { Unsere Werbung führen wir hauptsächlich auf nationaler Ebene } \\
\text { durch (Fernsehen, Illustrierte usw.). }\end{array}$} \\
\hline & & $\begin{array}{l}5.000 \mathrm{hl} \\
=92)\end{array}$ & $\begin{array}{r}5.000 \\
\quad(\mathrm{n}= \\
\end{array}$ & $\begin{array}{l}100.000 \\
\mathrm{hl} \\
138)\end{array}$ & & $\begin{array}{l}000- \\
000 \mathrm{hl} \\
29)\end{array}$ & & $\begin{array}{l}\text { Ber als } \\
.000 \mathrm{hl} \\
=22)\end{array}$ & & $\begin{array}{l}\text { esamt } \\
=281 \text { ) }\end{array}$ \\
\hline $\begin{array}{l}\text { Stimme voll- } \\
\text { ständig zu }\end{array}$ & & $(4,3 \%)$ & 5 & $(3,6 \%)$ & & $(10,3 \%)$ & & & 12 & $(4,3 \%)$ \\
\hline Stimme zu & 10 & $(10,9 \%)$ & 15 & $(10,9 \%)$ & 1 & $(3,4 \%)$ & & $(9,1 \%)$ & 28 & $(10 \%)$ \\
\hline Weder noch & & $(28,3 \%)$ & 27 & $(19,6 \%)$ & 2 & $(6,9 \%)$ & & $(22,7 \%)$ & 60 & $(21,4 \%)$ \\
\hline Lehne ab & 9 & $(9,8 \%)$ & 26 & $(18,8 \%)$ & 3 & $(10,3 \%)$ & 10 & $(45,5 \%)$ & 48 & $(17,1 \%)$ \\
\hline $\begin{array}{l}\text { Lehne voll- } \\
\text { Ständig ab }\end{array}$ & & $(35,9 \%)$ & 63 & $(45,7 \%)$ & 20 & $(69 \%)$ & & $(22,7 \%)$ & 121 & $(43,1 \%)$ \\
\hline $\begin{array}{l}\text { Keine } \\
\text { Angabe }\end{array}$ & & $(10,9 \%)$ & 2 & $(1,4 \%)$ & & & & & 12 & $(4,3 \%)$ \\
\hline
\end{tabular}

Quelle: Niederhut-Bollmann, C., Datensatz „Große Strategie-Studie 2005“, Göttingen 2005. 


\begin{tabular}{|c|c|c|c|c|c|c|c|c|c|c|}
\hline \multirow[t]{2}{*}{ Frage III 4.2.5: } & \multicolumn{10}{|c|}{$\begin{array}{l}\text { Inwieweit stimmen Sie dem folgenden Statement, welches so oder ähnlich } \\
\text { von Managern anderer Unternehmen geäußert wurde, für Ihr } \\
\text { Unternehmen zu? } \\
\text { Wir stellen im Marketing häufig unsere Brautradition heraus. }\end{array}$} \\
\hline & & $\begin{array}{l}5.000 \mathrm{hl} \\
=92)\end{array}$ & $\begin{array}{r}5.000 \\
\quad(\mathrm{n}\end{array}$ & $\begin{array}{l}100.000 \\
\mathrm{hl} \\
138)\end{array}$ & & $\begin{array}{l}000- \\
000 \mathrm{hl} \\
=29)\end{array}$ & & $\begin{array}{l}\text { Ber als } \\
.000 \mathrm{hl} \\
=22)\end{array}$ & & $\begin{array}{l}\text { esamt } \\
=281)\end{array}$ \\
\hline $\begin{array}{l}\text { Stimme voll- } \\
\text { ständig zu }\end{array}$ & & $(25 \%)$ & 18 & $(13 \%)$ & 5 & $(17,2 \%)$ & & $(4,5 \%)$ & 47 & $(16,7 \%)$ \\
\hline Stimme zu & 33 & $(35,9 \%)$ & 81 & $(58,7 \%)$ & 14 & $(48,3 \%)$ & 12 & $(54,5 \%)$ & 140 & $(49,8 \%)$ \\
\hline Weder noch & 23 & $(25 \%)$ & 30 & $(21,7 \%)$ & 6 & $(20,7 \%)$ & 5 & $(22,7 \%)$ & 64 & $(22,8 \%)$ \\
\hline Lehne ab & & $(4,3 \%)$ & 4 & $(2,9 \%)$ & 3 & $(10,3 \%)$ & & $(18,2 \%)$ & 15 & $(5,3 \%)$ \\
\hline $\begin{array}{l}\text { Lehne voll- } \\
\text { Ständig ab }\end{array}$ & & $(1,1 \%)$ & 1 & $(0,7 \%)$ & & $(3,4 \%)$ & & & 3 & $(1,1 \%)$ \\
\hline $\begin{array}{l}\text { Keine } \\
\text { Angabe }\end{array}$ & & $(8,7 \%)$ & 4 & $(2,9 \%)$ & & & & & 12 & $(4,3 \%)$ \\
\hline
\end{tabular}

Quelle: Niederhut-Bollmann, C., Datensatz „Große Strategie-Studie 2005“, Göttingen 2005.

\begin{tabular}{|c|c|c|c|c|c|c|c|c|c|}
\hline \multirow[t]{2}{*}{ Frage III 4.2.6: } & \multicolumn{9}{|c|}{$\begin{array}{l}\text { Inwieweit stimmen Sie dem folgenden Statement, welches so oder ähnlich } \\
\text { von Managern anderer Unternehmen geäußert wurde, für } \underline{\mathrm{Ihr}} \\
\text { Unternehmen zu? } \\
\text { Das Sponsoring regionaler Vereine und Veranstaltungen halten wir } \\
\text { für ein wichtiges Marketinginstrument. }\end{array}$} \\
\hline & & $\begin{array}{l}5.000 \mathrm{hl} \\
=92)\end{array}$ & $\begin{array}{r}5.000 \\
\quad(\mathrm{n} \\
\end{array}$ & $\begin{array}{l}100.000 \\
\mathrm{hl} \\
138)\end{array}$ & & $\begin{array}{l}000- \\
00 \mathrm{hl} \\
29)\end{array}$ & $\begin{array}{c}\text { Größer als } \\
250.000 \mathrm{hl} \\
(\mathrm{n}=22)\end{array}$ & & $\begin{array}{l}\text { esamt } \\
=281 \text { ) }\end{array}$ \\
\hline $\begin{array}{l}\text { Stimme voll- } \\
\text { ständig zu }\end{array}$ & & $(6,5 \%)$ & 27 & $(19,6 \%)$ & 14 & $(48,3 \%)$ & $5 \quad(22,7 \%)$ & 52 & $(18,5 \%)$ \\
\hline Stimme zu & 46 & $(50 \%)$ & 77 & $(55,8 \%)$ & 10 & $(34,5 \%)$ & $15 \quad(68,2 \%)$ & 148 & $(52,7 \%)$ \\
\hline Weder noch & 20 & $(21,7 \%)$ & 24 & $(17,4 \%)$ & & $(13,8 \%)$ & $2 \quad(9,1 \%)$ & 50 & $(17,8 \%)$ \\
\hline Lehne ab & 7 & $(7,6 \%)$ & 5 & $(3,6 \%)$ & & $(3,4 \%)$ & & 13 & $(4,6 \%)$ \\
\hline $\begin{array}{l}\text { Lehne voll- } \\
\text { Ständig ab }\end{array}$ & & $(6,5 \%)$ & 2 & $(1,4 \%)$ & & & & 8 & $(2,8 \%)$ \\
\hline $\begin{array}{l}\text { Keine } \\
\text { Angabe }\end{array}$ & & $(7,6 \%)$ & 3 & $(2,2 \%)$ & & & & 10 & $(3,6 \%)$ \\
\hline
\end{tabular}

Quelle: Niederhut-Bollmann, C., Datensatz „Große Strategie-Studie 2005“, Göttingen 2005. 


\begin{tabular}{|c|c|c|c|c|c|c|c|c|c|c|}
\hline \multirow[t]{2}{*}{ Frage III 4.2.7: } & \multicolumn{10}{|c|}{$\begin{array}{l}\text { Inwieweit stimmen Sie dem folgenden Statement, welches so oder ähnlich } \\
\text { von Managern anderer Unternehmen geäußert wurde, für Ihr } \\
\text { Unternehmen zu? } \\
\text { Verkaufsförderung/Promotion setzen wir häufig bei regionalen } \\
\text { Veranstaltungen (z.B. Stadtfesten, Sportveranstaltungen) ein. } \\
\quad \text { Gesamtgetränkeausstoß }\end{array}$} \\
\hline & & $\begin{array}{l}5.000 \mathrm{hl} \\
=92)\end{array}$ & $\begin{array}{r}5.000 \\
\quad(\mathrm{n}=\end{array}$ & $\begin{array}{l}100.000 \\
\mathrm{hl} \\
138)\end{array}$ & & $\begin{array}{l}000- \\
000 \mathrm{hl} \\
29)\end{array}$ & & $\begin{array}{l}\text { Ber als } \\
000 \mathrm{hl} \\
=22)\end{array}$ & & $\begin{array}{l}\text { esamt } \\
=281)\end{array}$ \\
\hline $\begin{array}{l}\text { Stimme voll- } \\
\text { ständig zu }\end{array}$ & & $(8,7 \%)$ & 17 & $(12,3 \%)$ & 10 & $(34,5 \%)$ & & $(9,1 \%)$ & 37 & $(13,2 \%)$ \\
\hline Stimme zu & 33 & $(35,9 \%)$ & 74 & $(53,6 \%)$ & 12 & $(41,4 \%)$ & 15 & $(68,2 \%)$ & 134 & $(47,7 \%)$ \\
\hline Weder noch & 30 & $(32,6 \%)$ & 26 & $(18,8 \%)$ & 5 & $(17,2 \%)$ & & $(13,6 \%)$ & 64 & $(22,8 \%)$ \\
\hline Lehne ab & & $(5,4 \%)$ & 12 & $(8,7 \%)$ & & $(6,9 \%)$ & & $(9,1 \%)$ & 21 & $(7,5 \%)$ \\
\hline $\begin{array}{l}\text { Lehne voll- } \\
\text { Ständig ab }\end{array}$ & & $(8,7 \%)$ & 5 & $(3,6 \%)$ & & & & & 13 & $(4,6 \%)$ \\
\hline $\begin{array}{l}\text { Keine } \\
\text { Angabe }\end{array}$ & & $(8,7 \%)$ & 4 & $(2,9 \%)$ & & & & & 12 & $(4,3 \%)$ \\
\hline
\end{tabular}

Quelle: Niederhut-Bollmann, C., Datensatz „Große Strategie-Studie 2005“, Göttingen 2005.

\begin{tabular}{|c|c|c|c|c|c|c|c|c|c|c|}
\hline \multirow[t]{2}{*}{ Frage III 4.2.8: } & \multicolumn{10}{|c|}{$\begin{array}{l}\text { Inwieweit stimmen Sie dem folgenden Statement, welches so oder ähnlich } \\
\text { von Managern anderer Unternehmen geäußert wurde, für } \underline{\mathrm{Ihr}} \\
\text { Unternehmen zu? } \\
\text { Bei Sponsoring setzen wir eher auf national beachtete Veranstaltungen } \\
\text { bzw. Vereine. }\end{array}$} \\
\hline & & $\begin{array}{l}5.000 \mathrm{hl} \\
=92)\end{array}$ & $\begin{array}{r}\mathrm{G} \\
5.000 \\
(\mathrm{n}=\end{array}$ & $\begin{array}{l}\text { samtget } \\
100.000 \\
\text { hl } \\
138)\end{array}$ & $\begin{array}{r}\text { eaus } \\
100 \\
250 \\
(\mathrm{n}\end{array}$ & $\begin{array}{l}\text { toß } \\
000- \\
000 \mathrm{hl} \\
29)\end{array}$ & \multicolumn{2}{|c|}{$\begin{array}{c}\text { Größer als } \\
250.000 \mathrm{hl} \\
(\mathrm{n}=22)\end{array}$} & \multicolumn{2}{|c|}{$\begin{array}{l}\text { Gesamt } \\
(\mathrm{n}=281)\end{array}$} \\
\hline $\begin{array}{l}\text { Stimme voll- } \\
\text { ständig zu }\end{array}$ & & $(2,2 \%)$ & 4 & $(2,9 \%)$ & & $(3,4 \%)$ & & $(4,5 \%)$ & 8 & $(2,8 \%)$ \\
\hline Stimme zu & 17 & $(18,5 \%)$ & 16 & $(11,6 \%)$ & 2 & $(6,9 \%)$ & & $(4,5 \%)$ & 36 & $(12,8 \%)$ \\
\hline Weder noch & 29 & $(31,5 \%)$ & 27 & $(19,6 \%)$ & 5 & $(17,2 \%)$ & & $(13,6 \%)$ & 64 & $(22,8 \%)$ \\
\hline Lehne $a b$ & 11 & $(12 \%)$ & 27 & $(19,6 \%)$ & 5 & $(17,2 \%)$ & 11 & $(50 \%)$ & 54 & $(19,2 \%)$ \\
\hline $\begin{array}{l}\text { Lehne voll- } \\
\text { Ständig ab }\end{array}$ & & $(26,1 \%)$ & 57 & $(41,3 \%)$ & 16 & $(55,2 \%)$ & & $(27,3 \%)$ & 103 & $(36,7 \%)$ \\
\hline $\begin{array}{l}\text { Keine } \\
\text { Angabe }\end{array}$ & & $(9,8 \%)$ & 7 & $(5,1 \%)$ & & & & & 16 & $(5,7 \%)$ \\
\hline
\end{tabular}

Quelle: Niederhut-Bollmann, C., Datensatz „Große Strategie-Studie 2005“, Göttingen 2005. 


\begin{tabular}{|c|c|c|c|c|c|c|c|c|c|c|}
\hline \multirow[t]{2}{*}{ Frage III 4.2.9 } & \multicolumn{10}{|c|}{$\begin{array}{l}\text { Inwieweit stimmen Sie dem folgenden Statement, welches so oder ähnlich } \\
\text { von Managern anderer Unternehmen geäußert wurde, für Ihr } \\
\text { Unternehmen zu? } \\
\text { Unsere Werbung setzen wir eher regional bis überregional (z.B. } \\
\text { regionale Tageszeitungen, Hörfunk, Plakate) ein. } \\
\quad \text { Gesamtgetränkeausstoß }\end{array}$} \\
\hline & & $\begin{array}{l}5.000 \mathrm{hl} \\
\mathrm{n}=92)\end{array}$ & $\begin{array}{r}5.000 \\
\quad(\mathrm{n}\end{array}$ & $\begin{array}{l}100.000 \\
\mathrm{hl} \\
138)\end{array}$ & & $\begin{array}{l}000- \\
000 \mathrm{hl} \\
=29)\end{array}$ & & $\begin{array}{l}\text { Ber als } \\
.000 \mathrm{hl} \\
=22)\end{array}$ & & $\begin{array}{l}\text { iesamt } \\
=281 \text { ) }\end{array}$ \\
\hline $\begin{array}{l}\text { Stimme voll- } \\
\text { ständig zu }\end{array}$ & & $(10,9 \%)$ & 28 & $(20,3 \%)$ & 14 & $(48,3 \%)$ & & $(22,7 \%)$ & & $(20,3 \%)$ \\
\hline Stimme zu & 38 & $(41,3 \%)$ & 72 & $(52,2 \%)$ & 10 & $(34,5 \%)$ & 11 & $(50 \%)$ & 131 & $(46,6 \%)$ \\
\hline Weder noch & 2 & $(23,9 \%)$ & 13 & $(9,4 \%)$ & & $(6,9 \%)$ & & & 37 & $(13,2 \%)$ \\
\hline Lehne ab & & $(8,7 \%)$ & 16 & $(11,6 \%)$ & 2 & $(6,9 \%)$ & & $(22,7 \%)$ & 31 & $(11 \%)$ \\
\hline $\begin{array}{l}\text { Lehne voll- } \\
\text { Ständig ab }\end{array}$ & & $(4,3 \%)$ & 5 & $(3,6 \%)$ & & $(3,4 \%)$ & & $(4,5 \%)$ & 11 & $(3,9 \%)$ \\
\hline $\begin{array}{l}\text { Keine } \\
\text { Angabe }\end{array}$ & & $(10,9 \%)$ & 4 & $(2,9 \%)$ & & & & & 14 & $(5 \%)$ \\
\hline
\end{tabular}

Quelle: Niederhut-Bollmann, C., Datensatz „Große Strategie-Studie 2005“, Göttingen 2005.

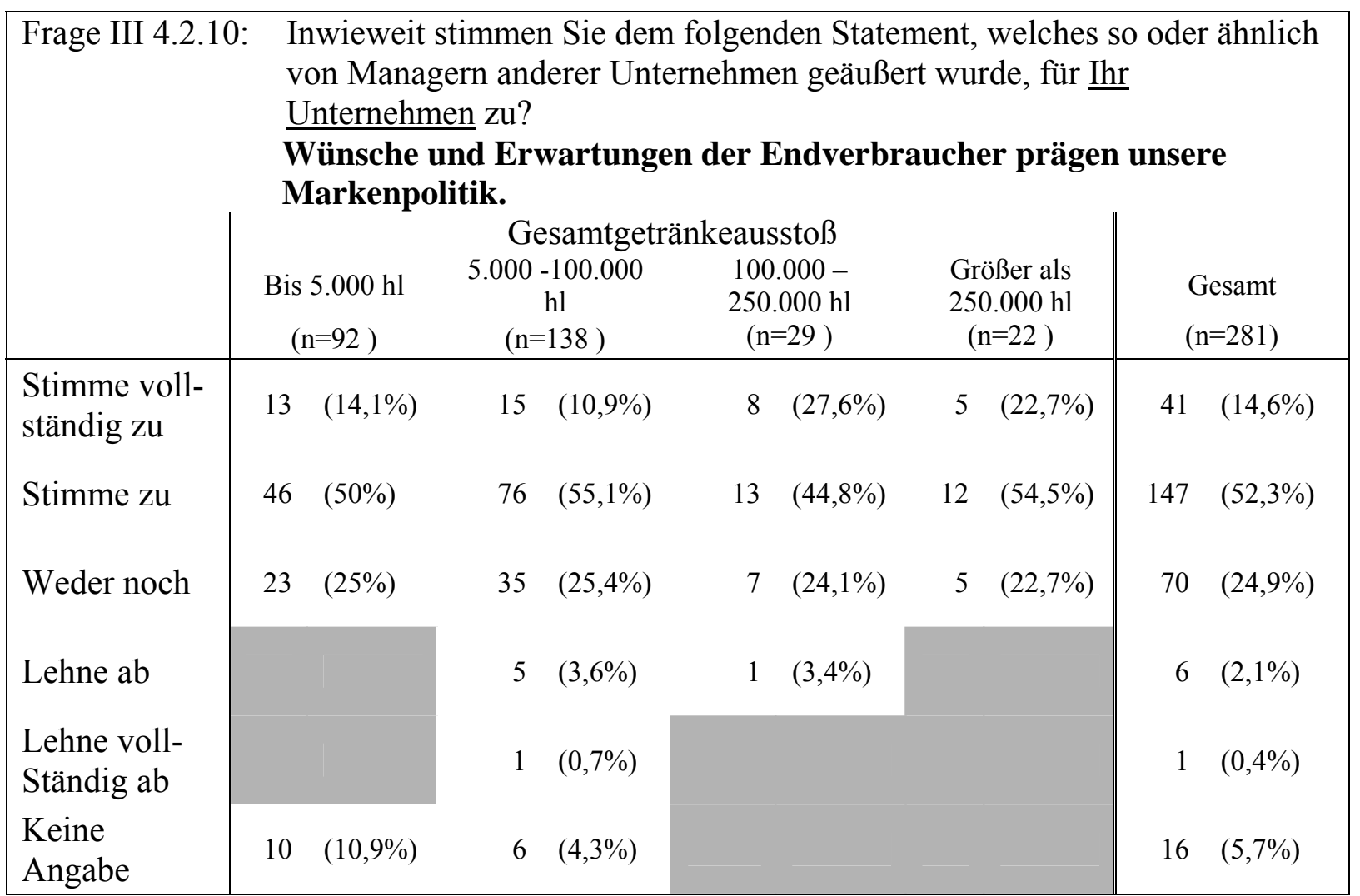

Quelle: Niederhut-Bollmann, C., Datensatz „Große Strategie-Studie 2005“, Göttingen 2005. 


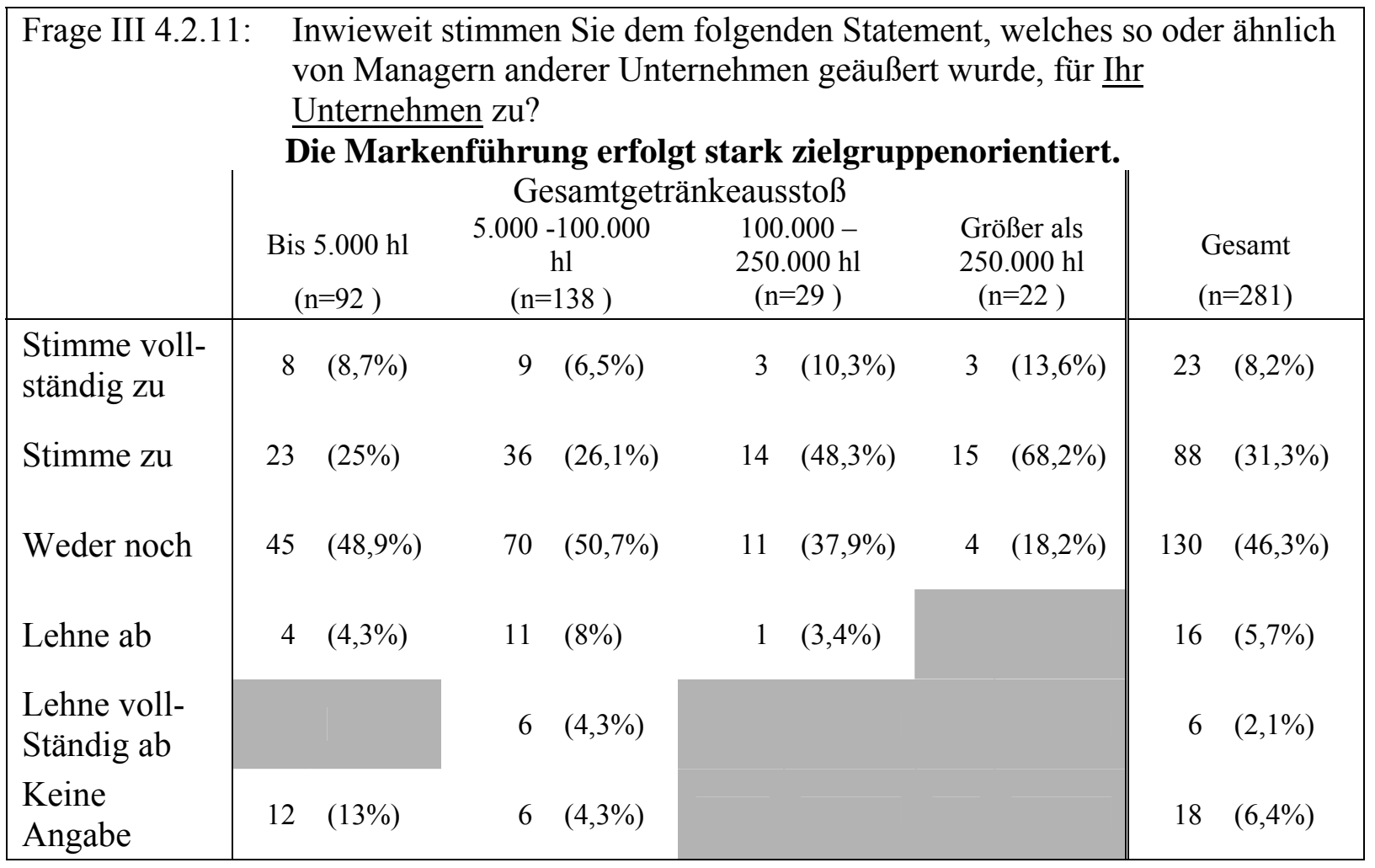

Quelle: Niederhut-Bollmann, C., Datensatz „Große Strategie-Studie 2005“, Göttingen 2005.

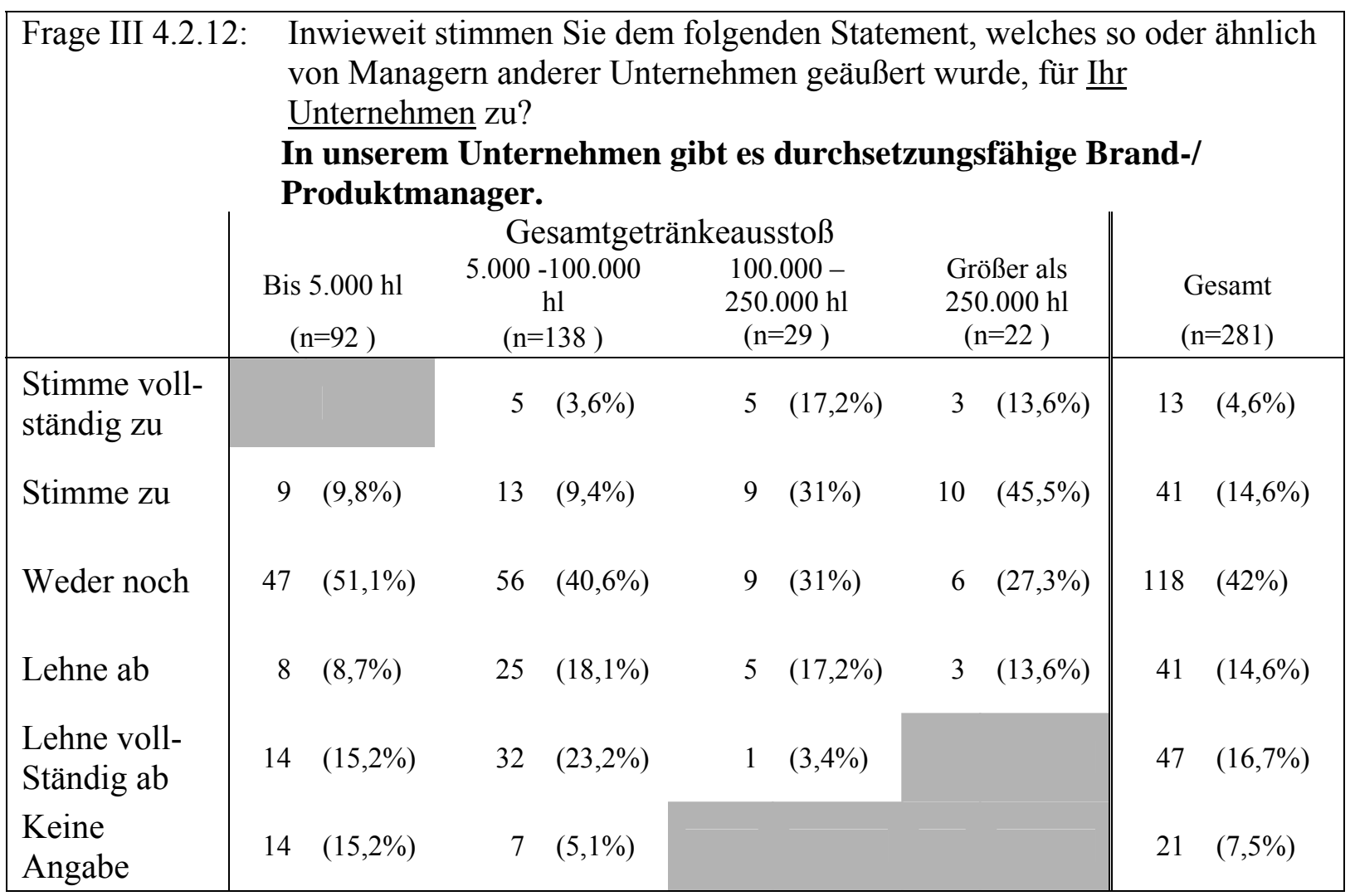

Quelle: Niederhut-Bollmann, C., Datensatz „Große Strategie-Studie 2005“, Göttingen 2005. 


\begin{tabular}{|c|c|c|c|c|c|c|c|}
\hline \multirow[t]{2}{*}{ Frage III 4.2 .13} & \multicolumn{5}{|c|}{$\begin{array}{l}\text { Inwieweit stimmen Sie dem folgenden Statement, welches } \\
\text { von Managern anderer Unternehmen geäußert wurde, für Ih } \\
\text { Unternehmen zu? } \\
\text { Brauereibesichtigungen halten wir für ein wichtiges } \\
\text { Marketinginstrument. } \\
\quad \text { Gesamtgetränkeausstoß }\end{array}$} & \multirow{2}{*}{\multicolumn{2}{|c|}{$\begin{array}{l}\text { Gesamt } \\
(\mathrm{n}=281)\end{array}$}} \\
\hline & $\begin{array}{c}\text { Bis } 5.000 \mathrm{hl} \\
(\mathrm{n}=92)\end{array}$ & \multicolumn{2}{|c|}{$\begin{array}{c}5.000-100.000 \\
\mathrm{hl} \\
(\mathrm{n}=138)\end{array}$} & $\begin{array}{c}100.000- \\
250.000 \mathrm{hl} \\
(\mathrm{n}=29)\end{array}$ & $\begin{array}{c}\text { Größer als } \\
250.000 \mathrm{hl} \\
(\mathrm{n}=22)\end{array}$ & & \\
\hline $\begin{array}{l}\text { Stimme voll- } \\
\text { ständig zu }\end{array}$ & $39 \quad(42,4 \%)$ & 44 & $(31,9 \%)$ & $15 \quad(51,7 \%)$ & $1 \quad(4,5 \%)$ & 99 & $(35,2 \%)$ \\
\hline Stimme zu & $30 \quad(32,6 \%)$ & 68 & $(49,3 \%)$ & $11 \quad(37,9 \%)$ & $18 \quad(81,8 \%)$ & 127 & $(45,2 \%)$ \\
\hline Weder noch & $(19,6 \%)$ & 18 & $(13 \%)$ & $3 \quad(10,3 \%)$ & $2 \quad(9,1 \%)$ & 41 & $(14,6 \%)$ \\
\hline Lehne ab & $(1,1 \%)$ & 3 & $(2,2 \%)$ & & & 4 & $(1,4 \%)$ \\
\hline $\begin{array}{l}\text { Lehne voll- } \\
\text { Ständig ab }\end{array}$ & & & $(1,4 \%)$ & & $1 \quad(4,5 \%)$ & 3 & $(1,1 \%)$ \\
\hline $\begin{array}{l}\text { Keine } \\
\text { Angabe }\end{array}$ & $4 \quad(4,3 \%)$ & 3 & $(2,2 \%)$ & & & 7 & $(2,5 \%)$ \\
\hline
\end{tabular}

Quelle: Niederhut-Bollmann, C., Datensatz „Große Strategie-Studie 2005“, Göttingen 2005.

\begin{tabular}{|c|c|c|c|c|c|c|c|c|c|c|}
\hline \multirow[t]{2}{*}{ Frage III 4.2.1 } & \multicolumn{10}{|c|}{$\begin{array}{l}\text { Inwieweit stimmen Sie dem folgenden Statement, welches so oder ähnlich } \\
\text { von Managern anderer Unternehmen geäußert wurde, für Ihr } \\
\text { Unternehmen zu? } \\
\text { Unsere Homepage halten wir für ein wichtiges Marketinginstrument. }\end{array}$} \\
\hline & & $\begin{array}{l}5.000 \mathrm{hl} \\
\mathrm{n}=92)\end{array}$ & $\begin{array}{r}5.000 \\
\quad(\mathrm{n}\end{array}$ & $\begin{array}{l}100.000 \\
\text { hl } \\
138)\end{array}$ & & $\begin{array}{l}000- \\
00 \mathrm{hl} \\
29)\end{array}$ & & $\begin{array}{l}\text { Ber als } \\
.000 \mathrm{hl} \\
=22)\end{array}$ & & $\begin{array}{l}\text { esamt } \\
=281)\end{array}$ \\
\hline $\begin{array}{l}\text { Stimme voll- } \\
\text { ständig zu }\end{array}$ & & $(20,7 \%)$ & 10 & $(7,2 \%)$ & & $(24,1 \%)$ & & & & $(12,8 \%)$ \\
\hline Stimme zu & 3 & $(41,3 \%)$ & 76 & $(55,1 \%)$ & 14 & $(48,3 \%)$ & 18 & $(81,8 \%)$ & 146 & $(52 \%)$ \\
\hline Weder noch & 2 & $(23,9 \%)$ & 35 & $(25,4 \%)$ & & $(27,6 \%)$ & & $(18,2 \%)$ & 69 & $(24,6 \%)$ \\
\hline Lehne ab & & $(4,3 \%)$ & 8 & $(5,8 \%)$ & & & & & 12 & $(4,3 \%)$ \\
\hline $\begin{array}{l}\text { Lehne voll- } \\
\text { Ständig ab }\end{array}$ & & $(2,2 \%)$ & 5 & $(3,6 \%)$ & & & & & 7 & $(2,5 \%)$ \\
\hline $\begin{array}{l}\text { Keine } \\
\text { Angabe }\end{array}$ & & $(7,6 \%)$ & 4 & $(2,9 \%)$ & & & & & 11 & $(3,9 \%)$ \\
\hline
\end{tabular}

Quelle: Niederhut-Bollmann, C., Datensatz „,Große Strategie-Studie 2005“, Göttingen 2005. 


\section{Innovation}

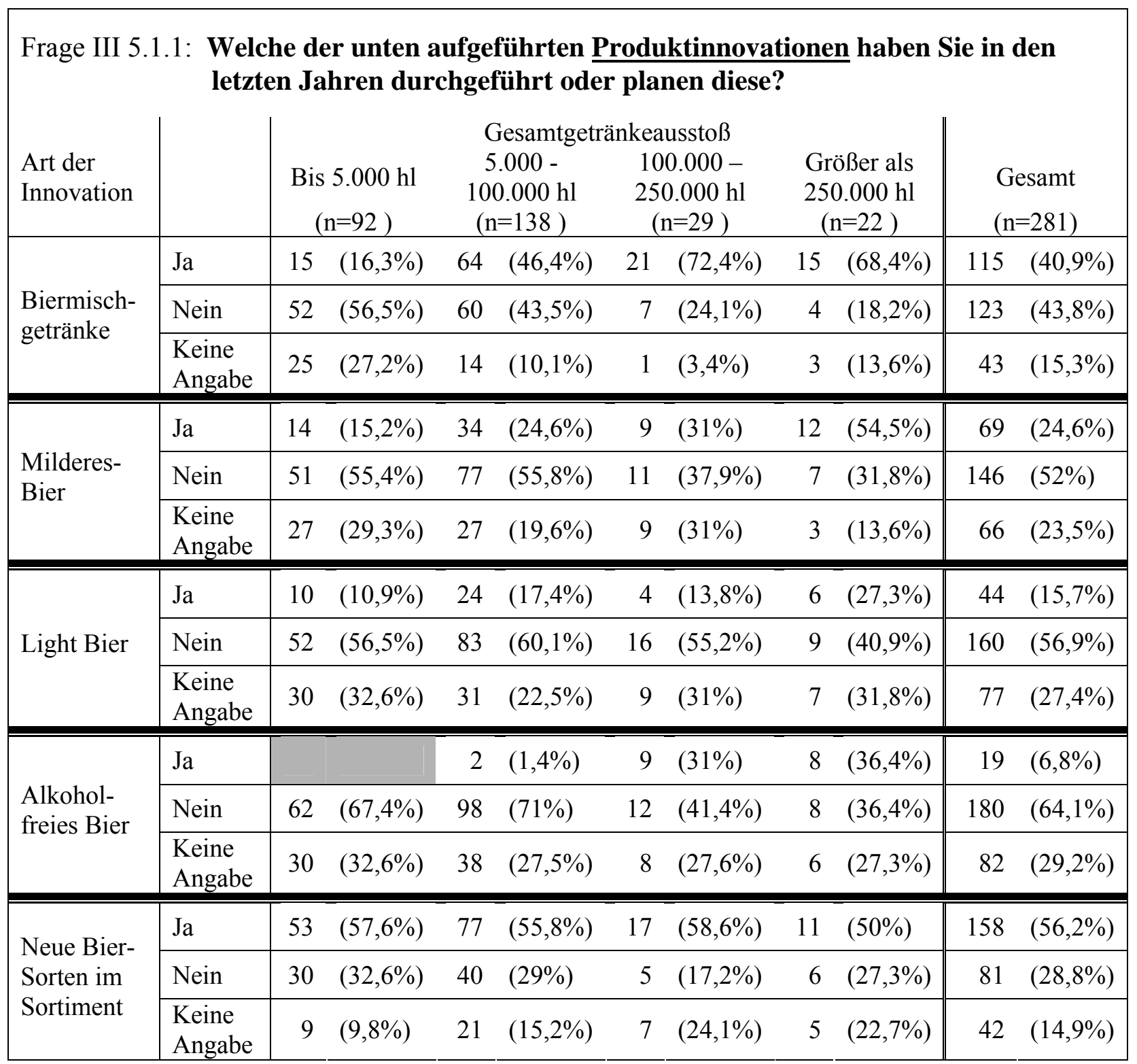

Quelle: Niederhut-Bollmann, C., Datensatz „Große Strategie-Studie 2005“, Göttingen 2005. 
Frage III 5.1.2: Welche der unten aufgeführten Gebindeinnovationen haben Sie in den letzten Jahren durchgeführt oder planen diese?

\begin{tabular}{|c|c|c|c|c|c|c|}
\hline $\begin{array}{l}\text { Art der } \\
\text { Innovation }\end{array}$ & & $\begin{array}{c}\text { Bis } 5.000 \\
\text { hl } \\
(n=92)\end{array}$ & $\begin{array}{c}\text { Gesamtgetr } \\
5.000- \\
100.000 \mathrm{hl} \\
(\mathrm{n}=138)\end{array}$ & $\begin{array}{l}\text { nkeaussto } \beta \\
100.000- \\
250.000 \mathrm{hl} \\
(\mathrm{n}=29)\end{array}$ & $\begin{array}{c}\text { Größer als } \\
250.000 \mathrm{hl} \\
(\mathrm{n}=22)\end{array}$ & $\begin{array}{l}\text { Gesamt } \\
(n=281)\end{array}$ \\
\hline \multirow{3}{*}{$\begin{array}{l}\text { Flaschenform } \\
\text { (z.B. } \\
\text { Longneck-, } \\
\text { Reliefflasche) }\end{array}$} & $\mathrm{Ja}$ & $21 \quad(22,8 \%)$ & $60 \quad(43,5 \%)$ & $20 \quad(69 \%)$ & $10 \quad(45,5 \%)$ & $111 \quad(39,5 \%)$ \\
\hline & Nein & $41 \quad(44,6 \%)$ & $56 \quad(40,6 \%)$ & $6 \quad(20,7 \%)$ & $7 \quad(31,8 \%)$ & $110 \quad(39,1 \%)$ \\
\hline & $\begin{array}{l}\text { Keine } \\
\text { Angabe }\end{array}$ & $30 \quad(32,6 \%)$ & $22 \quad(15,9 \%)$ & $3 \quad(10,3 \%)$ & $5 \quad(22,7 \%)$ & $60 \quad(21,4 \%)$ \\
\hline \multirow{3}{*}{ Bügelflasche } & $\mathrm{Ja}$ & $35 \quad(38 \%)$ & $34 \quad(24,6 \%)$ & $9 \quad(31 \%)$ & $8 \quad(36,4 \%)$ & $86 \quad(30,6 \%)$ \\
\hline & Nein & $34 \quad(37 \%)$ & $73 \quad(52,9 \%)$ & $12 \quad(41,4 \%)$ & $9 \quad(40,9 \%)$ & $128 \quad(45,6 \%)$ \\
\hline & $\begin{array}{l}\text { Keine } \\
\text { Angabe }\end{array}$ & $23 \quad(25 \%)$ & $31 \quad(22,5 \%)$ & $(27,6 \%)$ & $5 \quad(22,7 \%)$ & $67 \quad(23,8 \%)$ \\
\hline \multirow{3}{*}{$\begin{array}{l}\text { Flaschenfarbe } \\
\text { (z.B. } \\
\text { Weißglas) }\end{array}$} & $\mathrm{Ja}$ & $3 \quad(3,3 \%)$ & $15 \quad(10,9 \%)$ & $4 \quad(13,8 \%)$ & $10 \quad(45,5 \%)$ & $32 \quad(11,4 \%)$ \\
\hline & Nein & $52 \quad(56,5 \%)$ & $84 \quad(60,9 \%)$ & $16 \quad(55,2 \%)$ & $7 \quad(31,8 \%)$ & $159 \quad(56,6 \%)$ \\
\hline & $\begin{array}{l}\text { Keine } \\
\text { Angabe }\end{array}$ & $37 \quad(40,2 \%)$ & $39 \quad(28,3 \%)$ & $9 \quad(31 \%)$ & $5 \quad(22,7 \%)$ & $90 \quad(32 \%)$ \\
\hline \multirow{3}{*}{ PET-Flasche } & $\mathrm{Ja}$ & $1 \quad(1,1 \%)$ & $1 \quad(0,7 \%)$ & $1 \quad(3,4 \%)$ & $7 \quad(31,8 \%)$ & $10 \quad(3,6 \%)$ \\
\hline & Nein & $55 \quad(59,8 \%)$ & $95 \quad(68,8 \%)$ & $17 \quad(58,6 \%)$ & $8 \quad(36,4 \%)$ & $175 \quad(62,3 \%)$ \\
\hline & $\begin{array}{l}\text { Keine } \\
\text { Angabe }\end{array}$ & $36 \quad(39,1 \%)$ & $42 \quad(30,4 \%)$ & $11 \quad(37,9 \%)$ & $7 \quad(31,8 \%)$ & $96 \quad(34,2 \%)$ \\
\hline \multirow{3}{*}{$\begin{array}{l}\text { Flaschen- } \\
\text { Etiketten } \\
\text { (z.B. Design) }\end{array}$} & $\mathrm{Ja}$ & $40 \quad(43,5 \%)$ & $91 \quad(65,9 \%)$ & $19 \quad(65,5 \%)$ & $15 \quad(68,2 \%)$ & $165 \quad(58,7 \%)$ \\
\hline & Nein & $30 \quad(32,6 \%)$ & $27 \quad(19,6 \%)$ & $4 \quad(13,8 \%)$ & $5 \quad(22,7 \%)$ & $66 \quad(23,5 \%)$ \\
\hline & $\begin{array}{l}\text { Keine } \\
\text { Angabe }\end{array}$ & $22 \quad(23,9 \%)$ & $20 \quad(14,5 \%)$ & $6 \quad(20,7 \%)$ & $2 \quad(9,1 \%)$ & $50 \quad(17,8 \%)$ \\
\hline \multirow{3}{*}{$\begin{array}{l}\text { Selbstküh- } \\
\text { lendes Fass }\end{array}$} & $\mathrm{Ja}$ & $3 \quad(3,3 \%)$ & $1 \quad(0,7 \%)$ & & $1 \quad(4,5 \%)$ & $5 \quad(1,8 \%)$ \\
\hline & Nein & $53 \quad(57,6 \%)$ & $96 \quad(69,6 \%)$ & $19 \quad(65,5 \%)$ & $14 \quad(63,6 \%)$ & $182 \quad(64,8 \%)$ \\
\hline & $\begin{array}{l}\text { Keine } \\
\text { Angabe }\end{array}$ & $36 \quad(39,1 \%)$ & $41 \quad(29,7 \%)$ & $10 \quad(34,5 \%)$ & $7 \quad(31,8 \%)$ & $94 \quad(33,5 \%)$ \\
\hline
\end{tabular}

Quelle: Niederhut-Bollmann, C., Datensatz „Große Strategie-Studie 2005“, Göttingen 2005. 
Frage III 5.1.3: In welchen der unten aufgeführten Bereiche haben Sie in den letzten Jahren Innovationen durchgeführt oder planen diese?

\begin{tabular}{|c|c|c|c|c|c|c|}
\hline $\begin{array}{l}\text { Art der } \\
\text { Innovation }\end{array}$ & & $\begin{array}{c}\text { Bis } 5.000 \\
\mathrm{hl} \\
(\mathrm{n}=92)\end{array}$ & $\begin{array}{c}\text { Gesamtgetı } \\
5.000- \\
100.000 \mathrm{hl} \\
(\mathrm{n}=138)\end{array}$ & $\begin{array}{c}\text { nkeausstoß } \\
100.000- \\
250.000 \mathrm{hl} \\
(\mathrm{n}=29)\end{array}$ & $\begin{array}{c}\text { Größer als } \\
250.000 \mathrm{hl} \\
(\mathrm{n}=22)\end{array}$ & $\begin{array}{l}\text { Gesamt } \\
(\mathrm{n}=281)\end{array}$ \\
\hline \multirow{3}{*}{$\begin{array}{l}\text { Kastengröße } \\
(\text { z.B. } 10 \mathrm{x} \\
0,51)\end{array}$} & $\mathrm{Ja}$ & $12 \quad(13 \%)$ & $13 \quad(9,4 \%)$ & $8 \quad(27,6 \%)$ & $8 \quad(36,4 \%)$ & $41 \quad(14,6 \%)$ \\
\hline & Nein & $48 \quad(52,2 \%)$ & $84 \quad(60,9 \%)$ & $11 \quad(37,9 \%)$ & $11 \quad(50 \%)$ & $154 \quad(54,8 \%)$ \\
\hline & $\begin{array}{l}\text { Keine } \\
\text { Angabe }\end{array}$ & $32 \quad(34,8 \%)$ & $41 \quad(29,7 \%)$ & $10 \quad(34,5 \%)$ & $3 \quad(13,6 \%)$ & $86 \quad(30,6 \%)$ \\
\hline \multirow{3}{*}{ Kastendesign } & $\mathrm{Ja}$ & $10 \quad(10,9 \%)$ & $37 \quad(26,8 \%)$ & $11 \quad(37,9 \%)$ & $10 \quad(45,5 \%)$ & $68 \quad(24,2 \%)$ \\
\hline & Nein & $47 \quad(51,1 \%)$ & $64 \quad(46,4 \%)$ & $8 \quad(27,6 \%)$ & $8 \quad(36,4 \%)$ & $127 \quad(45,2 \%)$ \\
\hline & $\begin{array}{l}\text { Keine } \\
\text { Angabe }\end{array}$ & $35 \quad(38 \%)$ & $37 \quad(26,8 \%)$ & $10 \quad(34,5 \%)$ & $4 \quad(18,2 \%)$ & $86 \quad(30,6 \%)$ \\
\hline \multirow{3}{*}{$\begin{array}{l}\text { Neue } \\
\text { Marke/n }\end{array}$} & $\mathrm{Ja}$ & $20 \quad(21,7 \%)$ & $36 \quad(26,1 \%)$ & $7 \quad(24,1 \%)$ & $7 \quad(31,8 \%)$ & $70 \quad(24,9 \%)$ \\
\hline & Nein & $41 \quad(44,6 \%)$ & $59 \quad(42,8 \%)$ & $9 \quad(31 \%)$ & $10 \quad(45,5 \%)$ & $119 \quad(42,3 \%)$ \\
\hline & $\begin{array}{l}\text { Keine } \\
\text { Angabe }\end{array}$ & $31 \quad(33,7 \%)$ & $43 \quad(31,2 \%)$ & $13 \quad(44,8 \%)$ & $5 \quad(22,7 \%)$ & $92 \quad(32,7 \%)$ \\
\hline \multirow{3}{*}{$\begin{array}{l}\text { Marketing- } \\
\text { innovationen }\end{array}$} & $\mathrm{Ja}$ & $13 \quad(14,1 \%)$ & $37 \quad(26,8 \%)$ & $9 \quad(31 \%)$ & $6 \quad(27,3 \%)$ & $65 \quad(23,1 \%)$ \\
\hline & Nein & $40 \quad(43,5 \%)$ & $51 \quad(37 \%)$ & $5 \quad(17,2 \%)$ & $5 \quad(22,7 \%)$ & $101 \quad(35,9 \%)$ \\
\hline & $\begin{array}{l}\text { Keine } \\
\text { Angabe }\end{array}$ & $39 \quad(42,4 \%)$ & $50 \quad(36,2 \%)$ & $15 \quad(51,7 \%)$ & $11 \quad(50 \%)$ & $115 \quad(40,9 \%)$ \\
\hline \multirow{3}{*}{$\begin{array}{l}\text { Sonstige } \\
\text { Innovationen }\end{array}$} & $\mathrm{Ja}$ & $(3,3 \%)$ & $2 \quad(1,4 \%)$ & $2 \quad(6,9 \%)$ & $1 \quad(4,5 \%)$ & $8 \quad(2,8 \%)$ \\
\hline & Nein & $16 \quad(17,4 \%)$ & $19 \quad(13,8 \%)$ & $6 \quad(20,7 \%)$ & $2 \quad(9 \%)$ & $43 \quad(15,3 \%)$ \\
\hline & $\begin{array}{l}\text { Keine } \\
\text { Angabe }\end{array}$ & $73 \quad(79,3 \%)$ & $117 \quad(84,8 \%)$ & $21 \quad(72,4 \%)$ & $19 \quad(86,4 \%)$ & $230 \quad(81,9 \%)$ \\
\hline
\end{tabular}

Quelle: Niederhut-Bollmann, C., Datensatz „Große Strategie-Studie 2005“, Göttingen 2005. 


\section{Kooperationen}

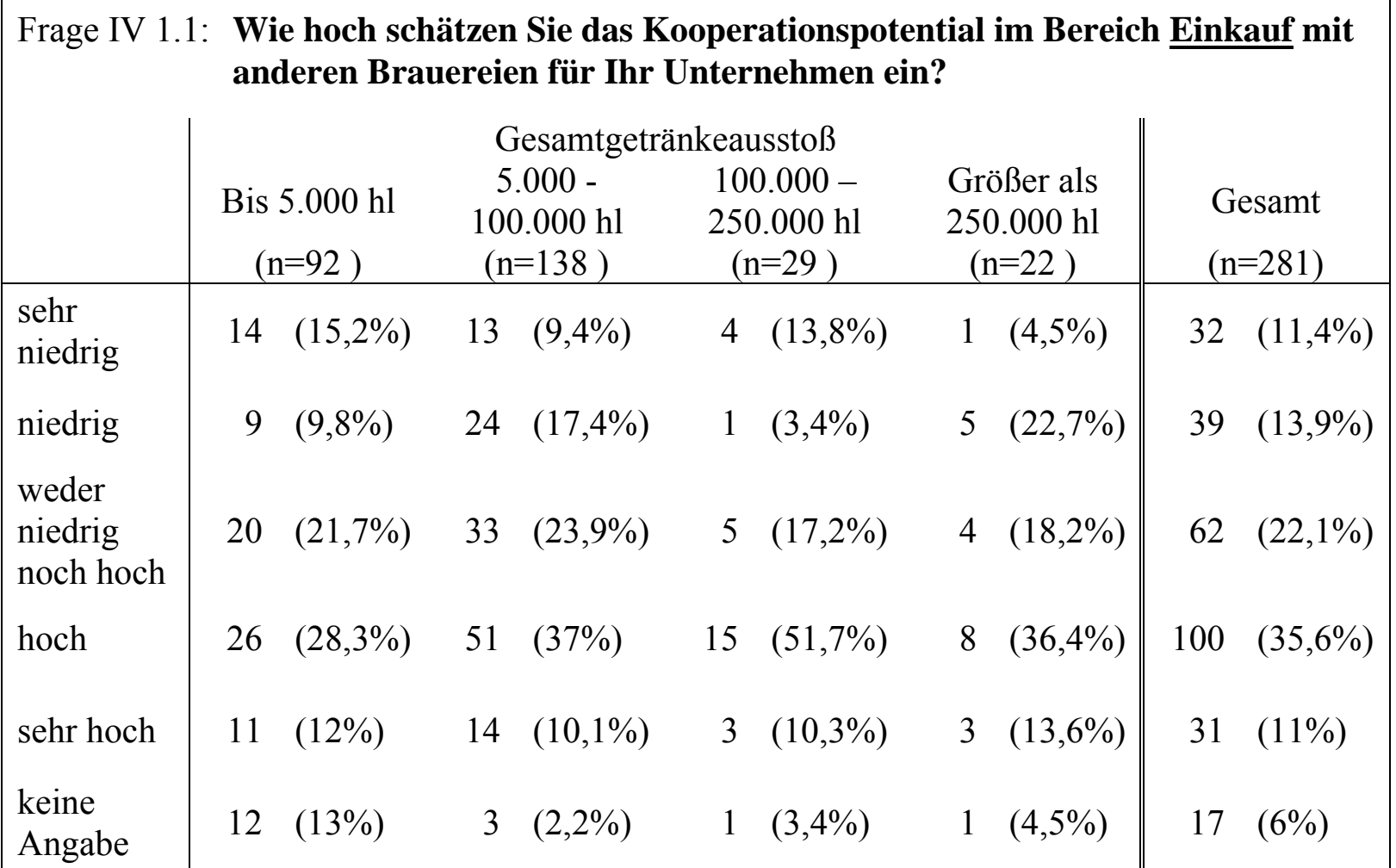

Quelle: Niederhut-Bollmann, C., Datensatz „Große Strategie-Studie 2005“, Göttingen 2005.

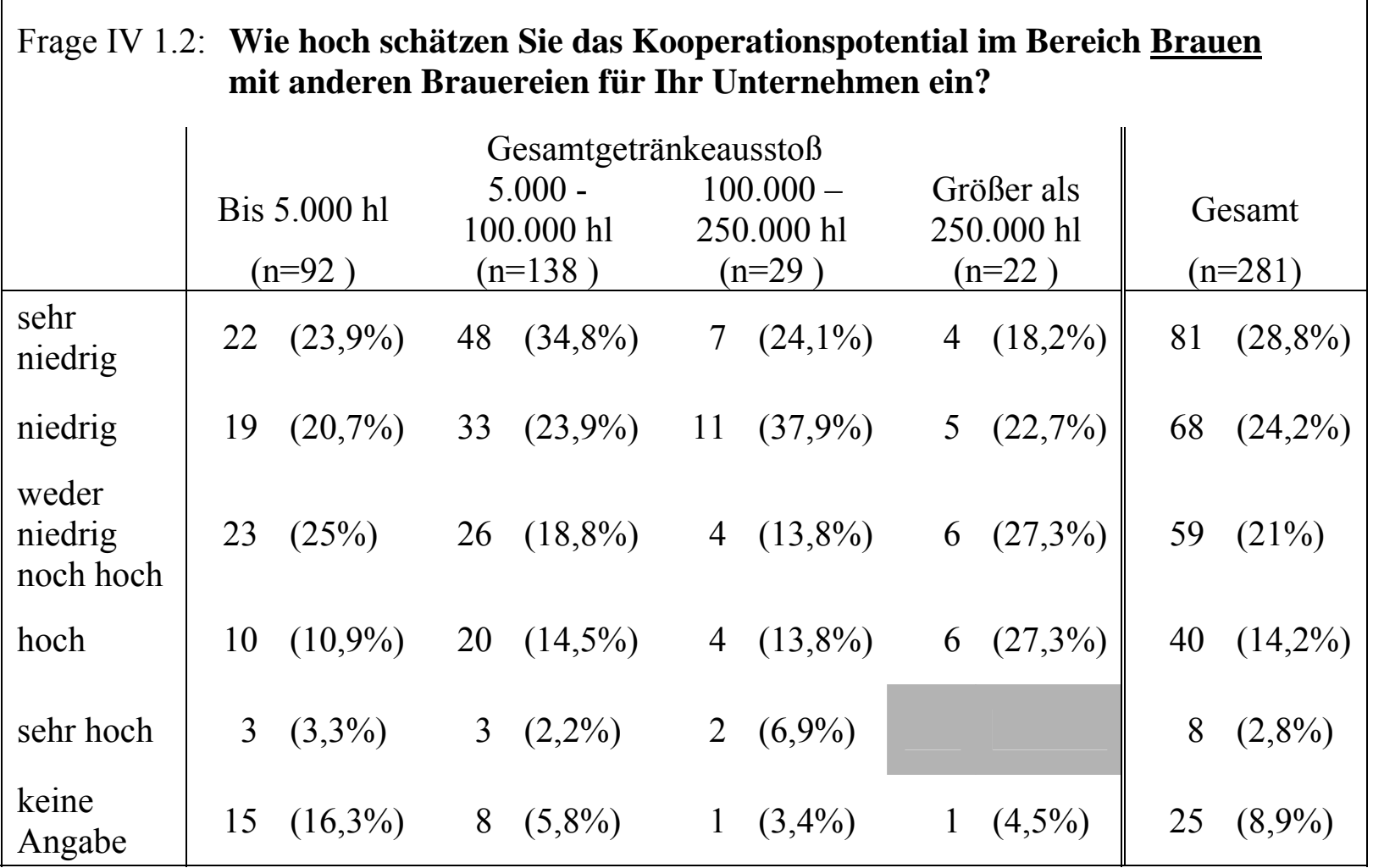

Quelle: Niederhut-Bollmann, C., Datensatz „Große Strategie-Studie 2005“, Göttingen 2005. 


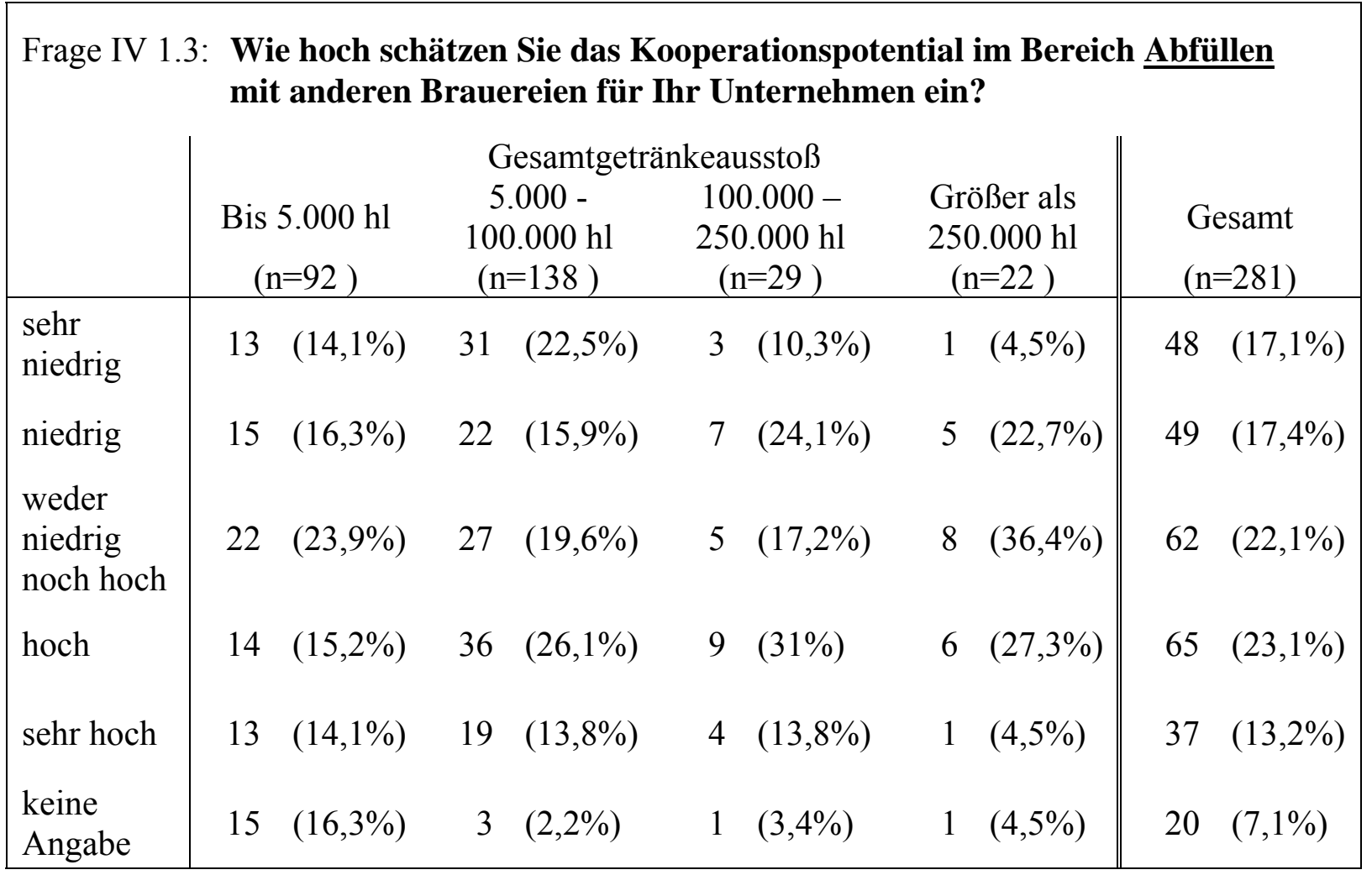

Quelle: Niederhut-Bollmann, C., Datensatz „Große Strategie-Studie 2005“, Göttingen 2005.

\begin{tabular}{|c|c|c|c|c|c|}
\hline \multirow[t]{3}{*}{ Frage IV 1.4} & \multicolumn{5}{|c|}{$\begin{array}{l}\text { Wie hoch schätzen Sie das Kooperationspotential im Bereich Sortiment } \\
\text { (z.B. Produktaustausch) mit anderen Brauereien für Ihr Unternehmen } \\
\text { ein? }\end{array}$} \\
\hline & \multirow[b]{2}{*}{$\begin{array}{l}\text { Bis } 5.000 \mathrm{hl} \\
\quad(\mathrm{n}=92)\end{array}$} & \multicolumn{2}{|c|}{ Gesamtgetränkeausstoß } & \multirow[b]{2}{*}{$\begin{array}{l}\text { Größer als } \\
250.000 \mathrm{hl} \\
(\mathrm{n}=22)\end{array}$} & \multirow[b]{2}{*}{$\begin{array}{l}\text { Gesamt } \\
(\mathrm{n}=281)\end{array}$} \\
\hline & & $\begin{array}{l}5.000- \\
100.000 \mathrm{hl} \\
(\mathrm{n}=138)\end{array}$ & $\begin{array}{l}100.000- \\
250.000 \mathrm{hl} \\
(\mathrm{n}=29)\end{array}$ & & \\
\hline $\begin{array}{l}\text { sehr } \\
\text { niedrig }\end{array}$ & $15 \quad(16,3 \%)$ & $22(15,9 \%)$ & $6 \quad(20,7 \%)$ & & $43 \quad(15,3 \%)$ \\
\hline niedrig & $15 \quad(16,3 \%)$ & $25 \quad(18,1 \%)$ & $6 \quad(20,7 \%)$ & $6 \quad(27,3 \%)$ & $52 \quad(18,5 \%)$ \\
\hline $\begin{array}{l}\text { weder } \\
\text { niedrig } \\
\text { noch hoch }\end{array}$ & $29 \quad(31,5 \%)$ & $47 \quad(34,1 \%)$ & $7 \quad(24,1 \%)$ & $8 \quad(36,4 \%)$ & $91 \quad(32,4 \%)$ \\
\hline hoch & $15 \quad(16,3 \%)$ & $37 \quad(26,8 \%)$ & $8 \quad(27,6 \%)$ & $7 \quad(31,8 \%)$ & $67 \quad(23,8 \%)$ \\
\hline sehr hoch & $4 \quad(4,3 \%)$ & $3(2,2 \%)$ & $1 \quad(3,4 \%)$ & & $8 \quad(2,8 \%)$ \\
\hline $\begin{array}{l}\text { keine } \\
\text { Angabe }\end{array}$ & $14 \quad(15,2 \%)$ & $4 \quad(2,9 \%)$ & $1 \quad(3,4 \%)$ & $1 \quad(4,5 \%)$ & $20 \quad(7,1 \%)$ \\
\hline
\end{tabular}

Quelle: Niederhut-Bollmann, C., Datensatz „Große Strategie-Studie 2005“, Göttingen 2005. 


\begin{tabular}{|c|c|c|c|c|c|}
\hline \multirow[t]{2}{*}{ Frage IV 1.5} & \multicolumn{5}{|c|}{$\begin{array}{l}\text { Wie hoch schätzen Sie das Kooperationspotential im Bereich Vertrieb } \\
\text { mit anderen Brauereien für Ihr Unternehmen ein? }\end{array}$} \\
\hline & $\begin{array}{l}\text { Bis } 5.000 \mathrm{hl} \\
\quad(\mathrm{n}=92)\end{array}$ & $\begin{array}{c}\text { Gesamtgetr } \\
5.000- \\
100.000 \mathrm{hl} \\
(\mathrm{n}=138)\end{array}$ & $\begin{array}{c}\text { keausstoß } \\
100.000- \\
250.000 \mathrm{hl} \\
(\mathrm{n}=29)\end{array}$ & $\begin{array}{c}\text { Größer als } \\
250.000 \mathrm{hl} \\
(\mathrm{n}=22)\end{array}$ & $\begin{array}{l}\text { Gesamt } \\
(\mathrm{n}=281)\end{array}$ \\
\hline $\begin{array}{l}\text { sehr } \\
\text { niedrig }\end{array}$ & $18 \quad(19,6 \%)$ & $42 \quad(30,4 \%)$ & $9 \quad(31 \%)$ & $3 \quad(13,6 \%)$ & $72 \quad(25,6 \%)$ \\
\hline niedrig & $18 \quad(19,6 \%)$ & $36 \quad(26,1 \%)$ & $6 \quad(20,7 \%)$ & $2 \quad(9,1 \%)$ & $62 \quad(22,1 \%)$ \\
\hline $\begin{array}{l}\text { weder } \\
\text { niedrig } \\
\text { noch hoch }\end{array}$ & $25 \quad(27,2 \%)$ & $37 \quad(26,8 \%)$ & $10 \quad(34,5 \%)$ & $6 \quad(27,3 \%)$ & $78 \quad(27,8 \%)$ \\
\hline hoch & $11 \quad(12 \%)$ & $17 \quad(12,3 \%)$ & $3 \quad(10,3 \%)$ & $7 \quad(31,8 \%)$ & $38 \quad(13,5 \%)$ \\
\hline sehr hoch & $4 \quad(4,3 \%)$ & & & $2 \quad(9,1 \%)$ & $6 \quad(2,1 \%)$ \\
\hline $\begin{array}{l}\text { keine } \\
\text { Angabe }\end{array}$ & $16 \quad(17,4 \%)$ & $6 \quad(4,3 \%)$ & $1 \quad(3,4 \%)$ & $2 \quad(9,1 \%)$ & $25 \quad(8,9 \%)$ \\
\hline
\end{tabular}

Quelle: Niederhut-Bollmann, C., Datensatz „Große Strategie-Studie 2005“, Göttingen 2005.

Frage IV 1.6: Wie hoch schätzen Sie das Kooperationspotential im Bereich Distribution (z.B. Fuhrpark) mit anderen Brauereien für Ihr Unternehmen ein?

\begin{tabular}{|c|c|c|c|c|c|c|}
\hline & \multicolumn{4}{|c|}{ Gesamtgetränkeausstoß } & \multirow{2}{*}{\multicolumn{2}{|c|}{$\begin{array}{l}\text { Gesamt } \\
(\mathrm{n}=281)\end{array}$}} \\
\hline & $\begin{array}{c}\text { Bis } 5.000 \mathrm{hl} \\
\quad(\mathrm{n}=92)\end{array}$ & $\begin{array}{c}5.000- \\
100.000 \mathrm{hl} \\
(\mathrm{n}=138)\end{array}$ & $\begin{array}{c}100.000- \\
250.000 \mathrm{hl} \\
(\mathrm{n}=29)\end{array}$ & $\begin{array}{c}\text { Größer als } \\
250.000 \mathrm{hl} \\
(\mathrm{n}=22)\end{array}$ & & \\
\hline $\begin{array}{l}\text { sehr } \\
\text { niedrig }\end{array}$ & $22 \quad(23,9 \%)$ & $42 \quad(30,4 \%)$ & $11 \quad(37,9 \%)$ & $4 \quad(18,2 \%)$ & 79 & $(28,1 \%)$ \\
\hline niedrig & $15 \quad(16,3 \%)$ & $36 \quad(26,1 \%)$ & $4 \quad(13,8 \%)$ & $6 \quad(27,3 \%)$ & 61 & $(21,7 \%)$ \\
\hline $\begin{array}{l}\text { weder } \\
\text { niedrig } \\
\text { noch hoch }\end{array}$ & $24 \quad(26,1 \%)$ & $(25,4 \%)$ & $(17,2 \%)$ & $8 \quad(36,4 \%)$ & 72 & $(25,6 \%)$ \\
\hline hoch & $12(13 \%)$ & $16 \quad(11,6 \%)$ & $7 \quad(24,1 \%)$ & $2 \quad(9,1 \%)$ & 37 & $(13,2 \%)$ \\
\hline sehr hoch & $3 \quad(3,3 \%)$ & $3(2,2 \%)$ & $1 \quad(3,4 \%)$ & & 7 & $(2,5 \%)$ \\
\hline $\begin{array}{l}\text { keine } \\
\text { Angabe }\end{array}$ & $16 \quad(17,4 \%)$ & $6 \quad(4,3 \%)$ & $1 \quad(3,4 \%)$ & $2(9,1 \%)$ & 25 & $(8,9 \%)$ \\
\hline
\end{tabular}

Quelle: Niederhut-Bollmann, C., Datensatz „Große Strategie-Studie 2005“, Göttingen 2005. 


\begin{tabular}{|c|c|c|c|c|c|}
\hline \multirow[t]{2}{*}{ Frage IV 1.7: } & \multicolumn{5}{|c|}{$\begin{array}{l}\text { Wie hoch schätzen Sie das Kooperationspotential im Bereich Marketing } \\
\text { mit anderen Brauereien für Ihr Unternehmen ein? }\end{array}$} \\
\hline & $\begin{array}{l}\text { Bis } 5.000 \mathrm{hl} \\
(\mathrm{n}=92)\end{array}$ & $\begin{array}{c}\text { Gesamtgetr } \\
5.000- \\
100.000 \mathrm{hl} \\
(\mathrm{n}=138)\end{array}$ & $\begin{array}{l}\text { keausstoß } \\
100.000- \\
250.000 \mathrm{hl} \\
(\mathrm{n}=29)\end{array}$ & $\begin{array}{c}\text { Größer als } \\
250.000 \mathrm{hl} \\
(\mathrm{n}=22)\end{array}$ & $\begin{array}{l}\text { Gesamt } \\
(\mathrm{n}=281)\end{array}$ \\
\hline $\begin{array}{l}\text { sehr } \\
\text { niedrig }\end{array}$ & $21 \quad(22,8 \%)$ & $55 \quad(39,9 \%)$ & $14 \quad(48,3 \%)$ & $10 \quad(45,5 \%)$ & $100 \quad(35,6 \%)$ \\
\hline niedrig & $19 \quad(20,7 \%)$ & $40 \quad(29 \%)$ & $9 \quad(31 \%)$ & $3 \quad(13,6 \%)$ & $71 \quad(25,3 \%)$ \\
\hline $\begin{array}{l}\text { weder } \\
\text { niedrig } \\
\text { noch hoch }\end{array}$ & $23 \quad(25 \%)$ & $30 \quad(21,7 \%)$ & $4 \quad(13,8 \%)$ & $6 \quad(27,3 \%)$ & $63 \quad(22,4 \%)$ \\
\hline hoch & $10 \quad(10,9 \%)$ & $7 \quad(5,1 \%)$ & $1 \quad(3,4 \%)$ & $2 \quad(9,1 \%)$ & $20 \quad(7,1 \%)$ \\
\hline sehr hoch & $2 \quad(2,2 \%)$ & & & & $2 \quad(0,7 \%)$ \\
\hline $\begin{array}{l}\text { keine } \\
\text { Angabe }\end{array}$ & $17 \quad(18,5 \%)$ & $6 \quad(4,3 \%)$ & $1 \quad(3,4 \%)$ & $1 \quad(4,5 \%)$ & $25 \quad(8,9 \%)$ \\
\hline
\end{tabular}

Quelle: Niederhut-Bollmann, C., Datensatz „Große Strategie-Studie 2005“, Göttingen 2005.

Frage IV 1.8: Wie hoch schätzen Sie das Kooperationspotential im Bereich Produktentwicklung mit anderen Brauereien für Ihr Unternehmen ein?

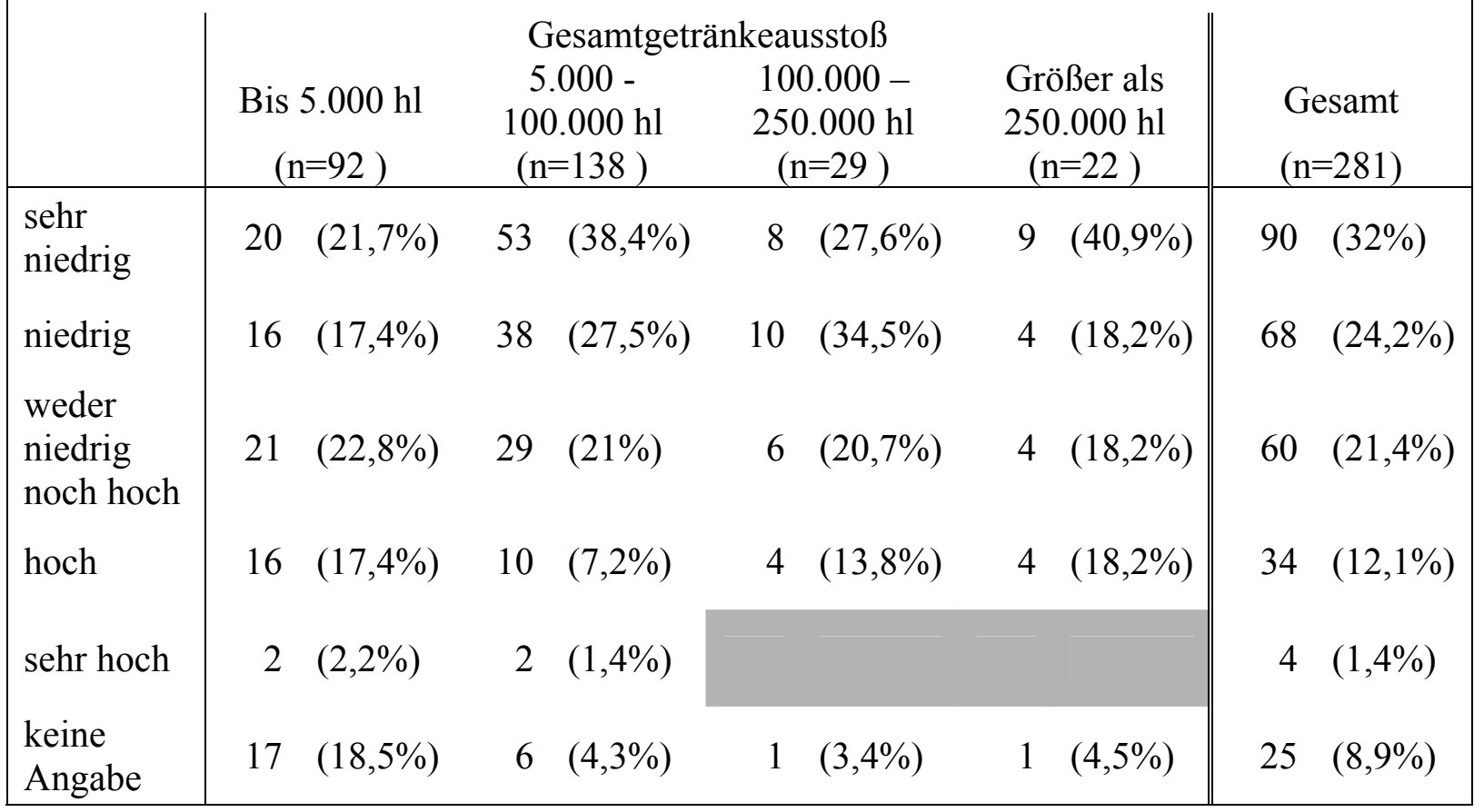

Quelle: Niederhut-Bollmann, C., Datensatz „Große Strategie-Studie 2005“, Göttingen 2005. 


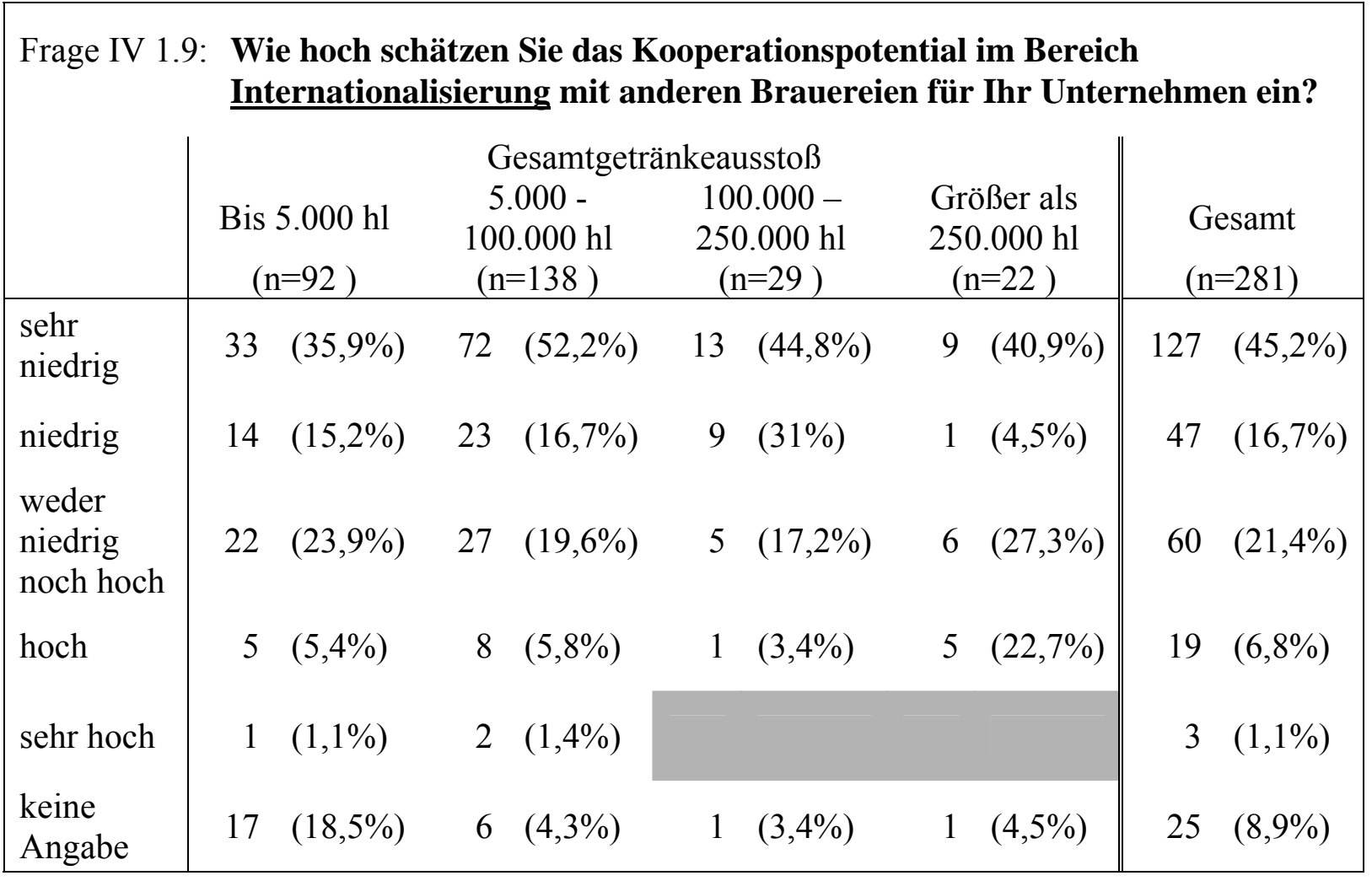

Quelle: Niederhut-Bollmann, C., Datensatz „Große Strategie-Studie 2005“, Göttingen 2005.

Frage IV 2: Kooperiert Ihr Unternehmen mit einer oder mehreren anderen Brauereien oder planen Sie eine solche Zusammenarbeit?

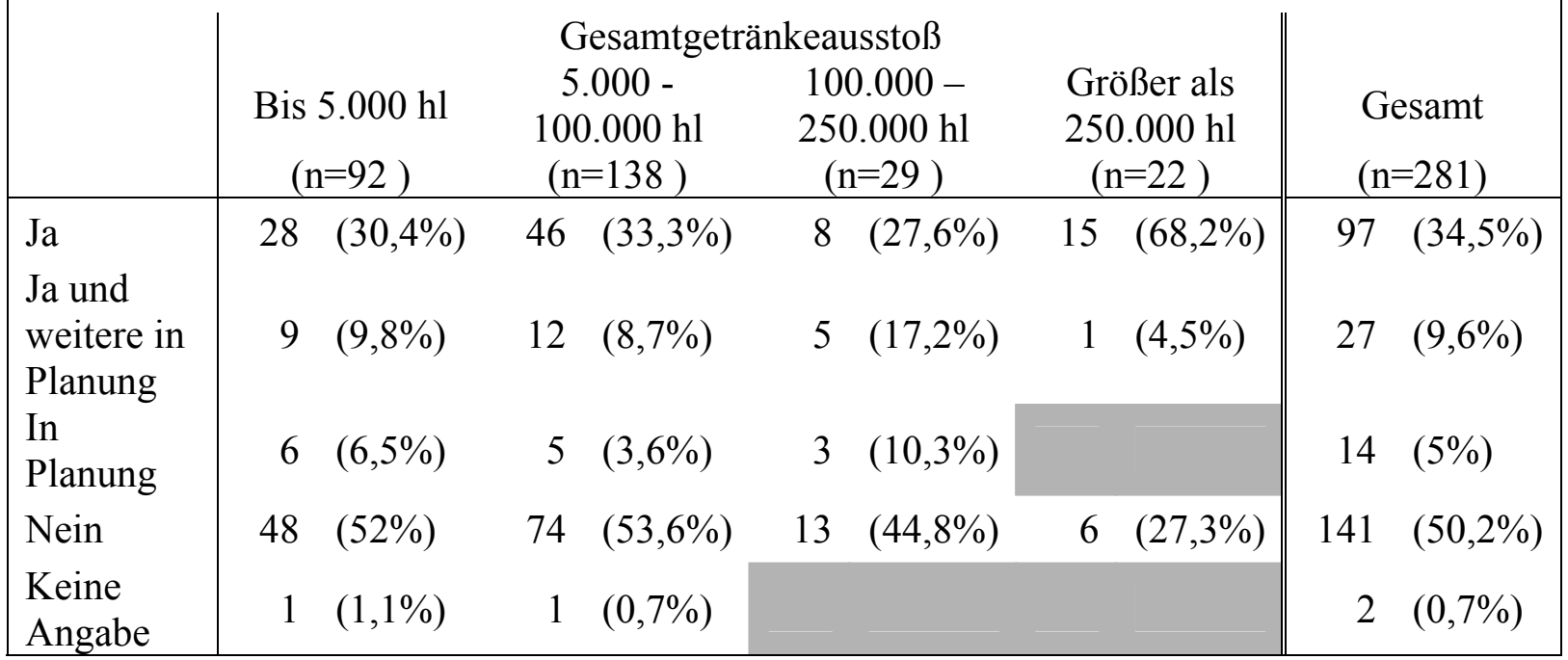

Quelle: Niederhut-Bollmann, C., Datensatz „Große Strategie-Studie 2005“, Göttingen 2005. 


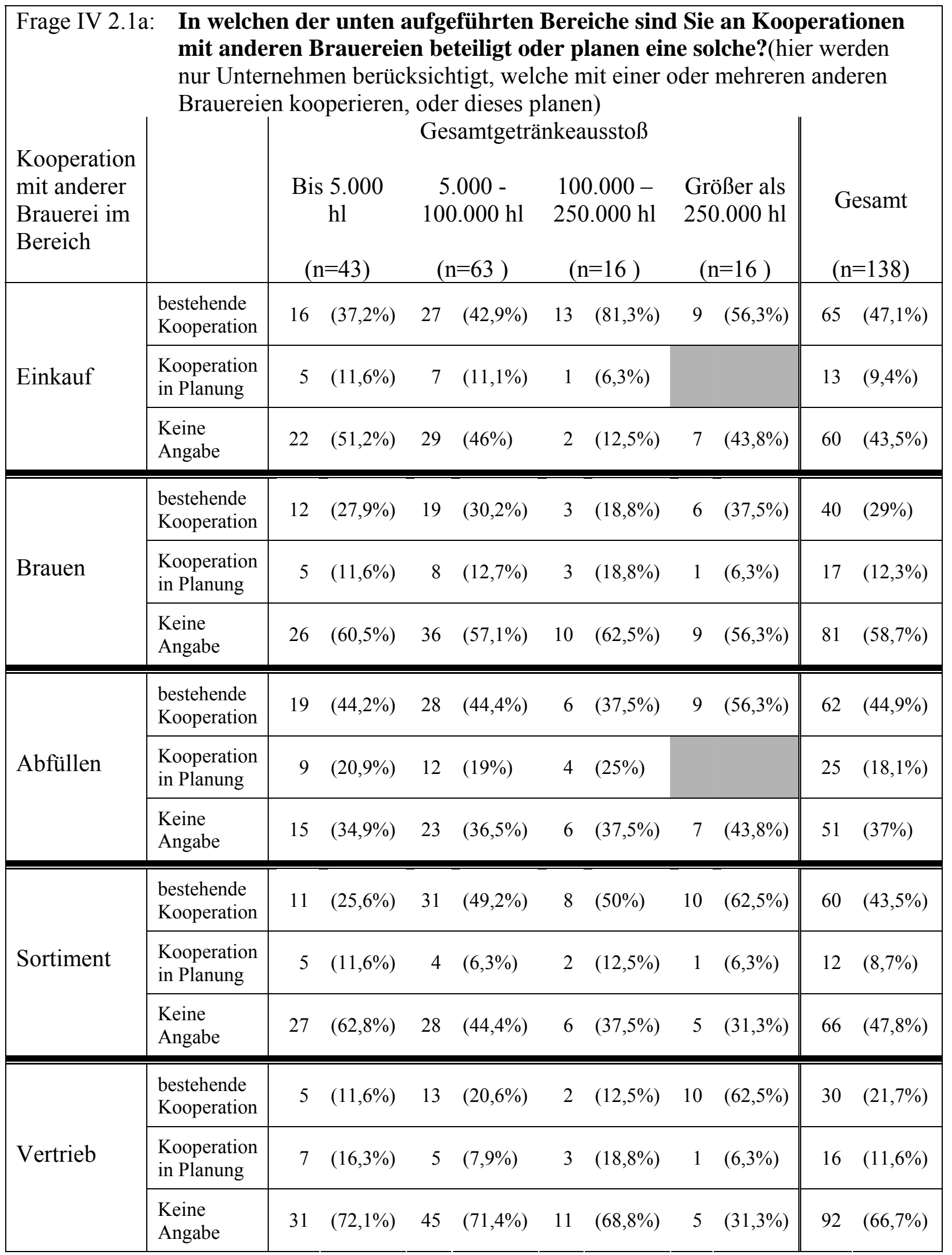

Quelle: Niederhut-Bollmann, C., Datensatz „Große Strategie-Studie 2005“, Göttingen 2005. 


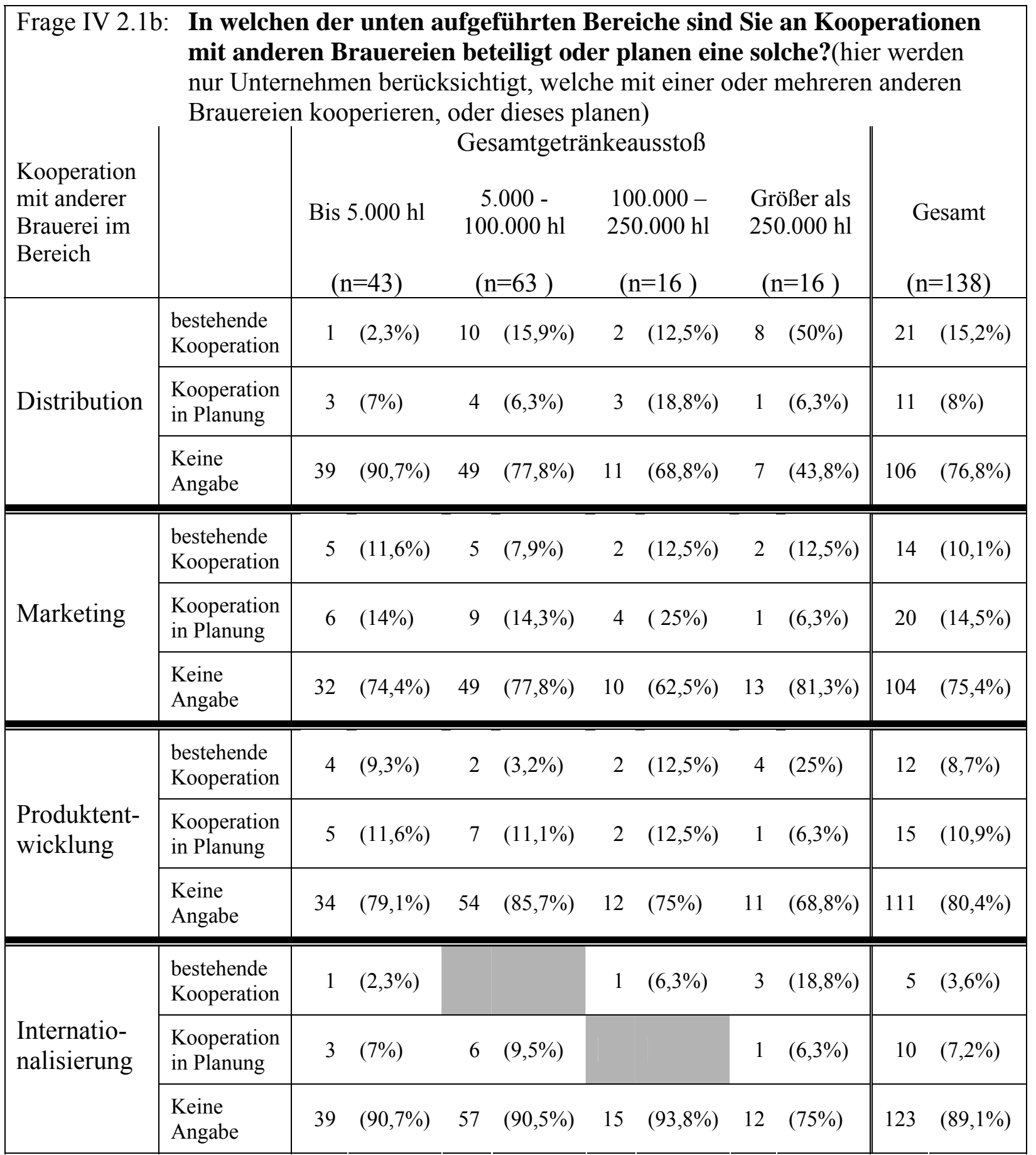

Quelle: Niederhut-Bollmann, C., Datensatz „Große Strategie-Studie 2005“, Göttingen 2005. 
Frage IV 3.1: Wie hoch schätzen Sie das Kooperationspotenzial mit Mälzereien im vorgelagerten Bereich für Ihr Unternehmen ein?

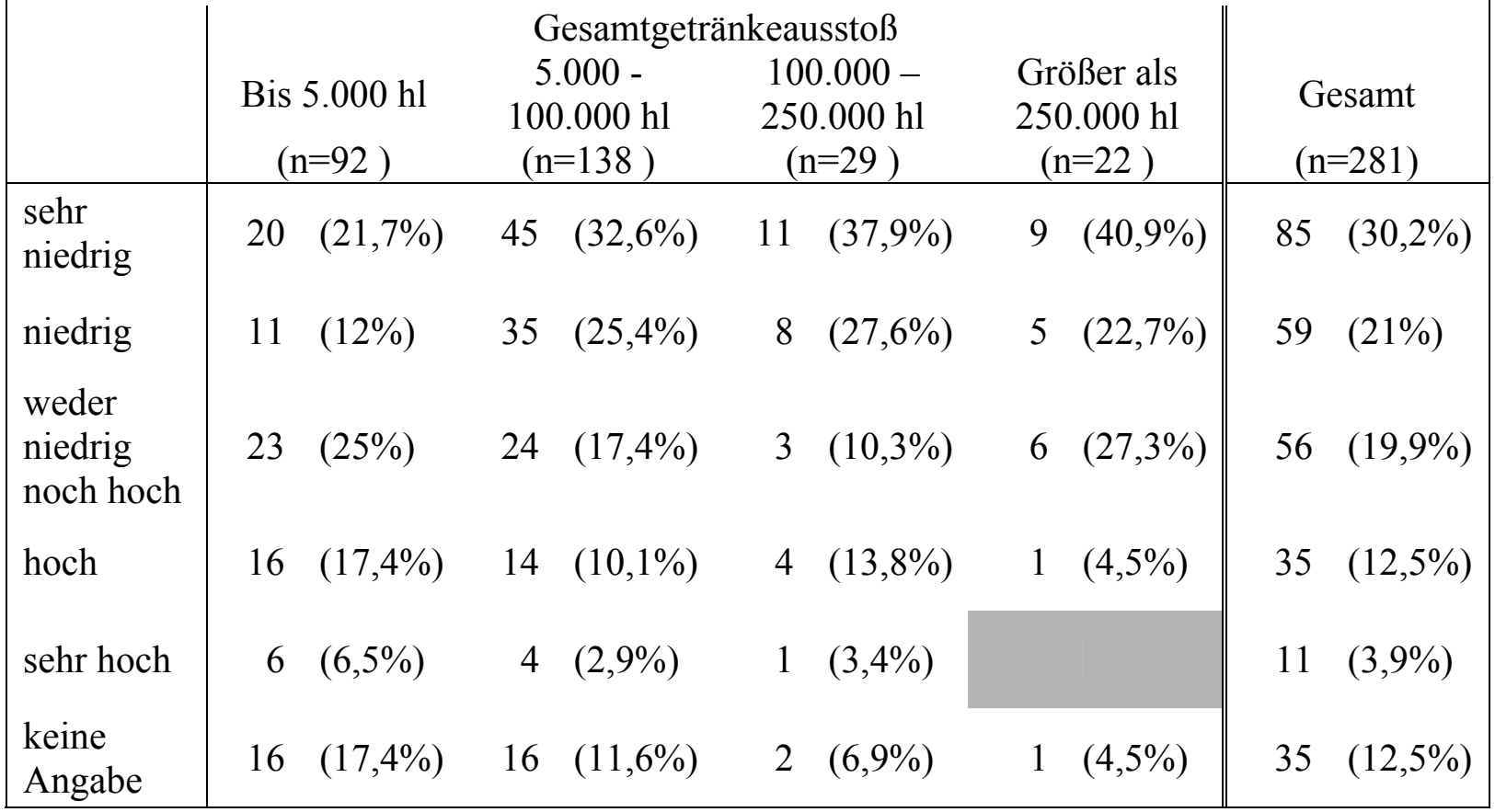

Quelle: Niederhut-Bollmann, C., Datensatz „Große Strategie-Studie 2005“, Göttingen 2005.

\begin{tabular}{|c|c|c|c|c|c|}
\hline \multirow[t]{2}{*}{ Frage IV 3.} & \multicolumn{5}{|c|}{$\begin{array}{l}\text { Wie hoch schätzen Sie das Kooperationspotenzial mit dem Getränke- } \\
\text { fachgroßhandel im nachgelagerten Bereich für Ihr Unternehmen ein? }\end{array}$} \\
\hline & $\begin{array}{l}\text { Bis } 5.000 \mathrm{hl} \\
\quad(\mathrm{n}=92)\end{array}$ & $\begin{array}{c}\text { Gesamtgetr } \\
5.000- \\
100.000 \mathrm{hl} \\
(\mathrm{n}=138)\end{array}$ & $\begin{array}{c}\text { keaussto } \beta \\
100.000- \\
250.000 \mathrm{hl} \\
(\mathrm{n}=29)\end{array}$ & $\begin{array}{c}\text { Größer als } \\
250.000 \mathrm{hl} \\
(\mathrm{n}=22)\end{array}$ & $\begin{array}{l}\text { Gesamt } \\
(\mathrm{n}=281)\end{array}$ \\
\hline $\begin{array}{l}\text { sehr } \\
\text { niedrig }\end{array}$ & $17 \quad(18,5 \%)$ & $19(13,8 \%)$ & $4 \quad(13,8 \%)$ & $1 \quad(4,5 \%)$ & $41 \quad(14,6 \%)$ \\
\hline niedrig & $13 \quad(14,1 \%)$ & $19 \quad(13,8 \%)$ & $5 \quad(17,2 \%)$ & & $37 \quad(13,2 \%)$ \\
\hline $\begin{array}{l}\text { weder } \\
\text { niedrig } \\
\text { noch hoch }\end{array}$ & $26 \quad(28,3 \%)$ & $46 \quad(33,3 \%)$ & $2 \quad(6,9 \%)$ & $4 \quad(18,2 \%)$ & $78 \quad(27,8 \%)$ \\
\hline hoch & $12(13 \%)$ & $32(23,2 \%)$ & $12(41,4 \%)$ & $14 \quad(63,6 \%)$ & $70 \quad(24,9 \%)$ \\
\hline sehr hoch & $5 \quad(5,4 \%)$ & $3 \quad(2,2 \%)$ & $4 \quad(13,8 \%)$ & $2 \quad(9,1 \%)$ & $14 \quad(5 \%)$ \\
\hline $\begin{array}{l}\text { keine } \\
\text { Angabe }\end{array}$ & $19 \quad(20,7 \%)$ & $19(13,8 \%)$ & $2 \quad(6,9 \%)$ & $1 \quad(4,5 \%)$ & $41 \quad(14,6 \%)$ \\
\hline
\end{tabular}

Quelle: Niederhut-Bollmann, C., Datensatz „Große Strategie-Studie 2005“, Göttingen 2005. 


\begin{tabular}{|c|c|c|c|c|c|}
\hline Frage & $\begin{array}{l}\text { Wie hoch sch } \\
\text { Absatzmittle } \\
\text { im nachgelas }\end{array}$ & $\begin{array}{l}\text { zen Sie das } 1 \\
\text { (z.B. System } \\
\text { ten Bereich }\end{array}$ & $\begin{array}{l}\text { perationsp } \\
\text { tronomie, } \\
\text { Ihr Untern }\end{array}$ & $\begin{array}{l}\text { zial mit an } \\
\text { delsmarken } \\
\text { en ein? }\end{array}$ & luktion) \\
\hline & & Gesamtgetr & keausstoß & & \\
\hline & $\begin{array}{c}\text { Bis } 5.000 \mathrm{hl} \\
(\mathrm{n}=92)\end{array}$ & $\begin{array}{c}5.000- \\
100.000 \mathrm{hl} \\
(\mathrm{n}=138)\end{array}$ & $\begin{array}{c}100.000- \\
250.000 \mathrm{hl} \\
(\mathrm{n}=29)\end{array}$ & $\begin{array}{c}\text { Größer als } \\
250.000 \mathrm{hl} \\
(\mathrm{n}=22)\end{array}$ & $\begin{array}{l}\text { Gesamt } \\
(\mathrm{n}=281)\end{array}$ \\
\hline $\begin{array}{l}\text { sehr } \\
\text { niedrig }\end{array}$ & $18 \quad(19,6 \%)$ & $21 \quad(15,2 \%)$ & $5 \quad(17,2 \%)$ & $2 \quad(9,1 \%)$ & $46 \quad(16,4 \%)$ \\
\hline niedrig & $12(13 \%)$ & $34 \quad(24,6 \%)$ & $5 \quad(17,2 \%)$ & $2 \quad(9,1 \%)$ & $53 \quad(18,9 \%)$ \\
\hline $\begin{array}{l}\text { weder } \\
\text { niedrig } \\
\text { noch hoch }\end{array}$ & $31 \quad(33,7 \%)$ & $38 \quad(27,5 \%)$ & $9 \quad(31 \%)$ & $10 \quad(45,5 \%)$ & $88 \quad(31,3 \%)$ \\
\hline hoch & $12(13 \%)$ & $26 \quad(18,8 \%)$ & $5 \quad(17,2 \%)$ & $7 \quad(31,8 \%)$ & $50 \quad(17,8 \%)$ \\
\hline sehr hoch & $1 \quad(1,1 \%)$ & & $2 \quad(6,9 \%)$ & & $3 \quad(1,1 \%)$ \\
\hline $\begin{array}{l}\text { keine } \\
\text { Angabe }\end{array}$ & $18 \quad(19,6 \%)$ & $19(13,8 \%)$ & $3 \quad(10,3 \%)$ & $1 \quad(4,5 \%)$ & $41 \quad(14,6 \%)$ \\
\hline
\end{tabular}

Quelle: Niederhut-Bollmann, C., Datensatz „Große Strategie-Studie 2005“, Göttingen 2005.

\begin{tabular}{|c|c|c|c|c|c|c|}
\hline \multirow[t]{3}{*}{ Frage IV 3.} & \multicolumn{6}{|c|}{$\begin{array}{l}\text { Wie hoch schätzen Sie das Potenzial von sonstigen Kooperationen im } \\
\text { vor- oder nachgelagerten für Ihr Unternehmen ein? }\end{array}$} \\
\hline & \multirow[b]{2}{*}{$\begin{array}{l}\text { Bis } 5.000 \mathrm{hl} \\
(\mathrm{n}=92)\end{array}$} & \multicolumn{2}{|c|}{ Gesamtgetränkeausstoß } & \multirow[b]{2}{*}{$\begin{array}{c}\text { Größer als } \\
250.000 \mathrm{hl} \\
(\mathrm{n}=22)\end{array}$} & \multirow{2}{*}{\multicolumn{2}{|c|}{$\begin{array}{l}\text { Gesamt } \\
(\mathrm{n}=281)\end{array}$}} \\
\hline & & $\begin{array}{c}5.000- \\
100.000 \mathrm{hl} \\
(\mathrm{n}=138)\end{array}$ & $\begin{array}{c}100.000- \\
250.000 \mathrm{hl} \\
(\mathrm{n}=29)\end{array}$ & & & \\
\hline $\begin{array}{l}\text { sehr } \\
\text { niedrig }\end{array}$ & $2(2,2 \%)$ & $6 \quad(4,3 \%)$ & $1 \quad(3,4 \%)$ & & & $(3,2 \%)$ \\
\hline niedrig & $5 \quad(5,4 \%)$ & $3 \quad(2,2 \%)$ & $1 \quad(3,4 \%)$ & & & $(3,2 \%)$ \\
\hline $\begin{array}{l}\text { weder } \\
\text { niedrig } \\
\text { noch hoch }\end{array}$ & $9 \quad(9,8 \%)$ & $6 \quad(4,3 \%)$ & & $2(9,1 \%)$ & 17 & $(6 \%)$ \\
\hline hoch & & $1 \quad(0,7 \%)$ & & & & $(0,4 \%)$ \\
\hline sehr hoch & $1 \quad(1,1 \%)$ & & & & & $(0,4 \%)$ \\
\hline $\begin{array}{l}\text { keine } \\
\text { Angabe }\end{array}$ & $75 \quad(81,5 \%)$ & $122 \quad(88,4 \%)$ & $27 \quad(93,1 \%)$ & $20 \quad(90,9 \%)$ & 244 & $(86,8 \%)$ \\
\hline
\end{tabular}

Quelle: Niederhut-Bollmann, C., Datensatz „Große Strategie-Studie 2005“, Göttingen 2005. 


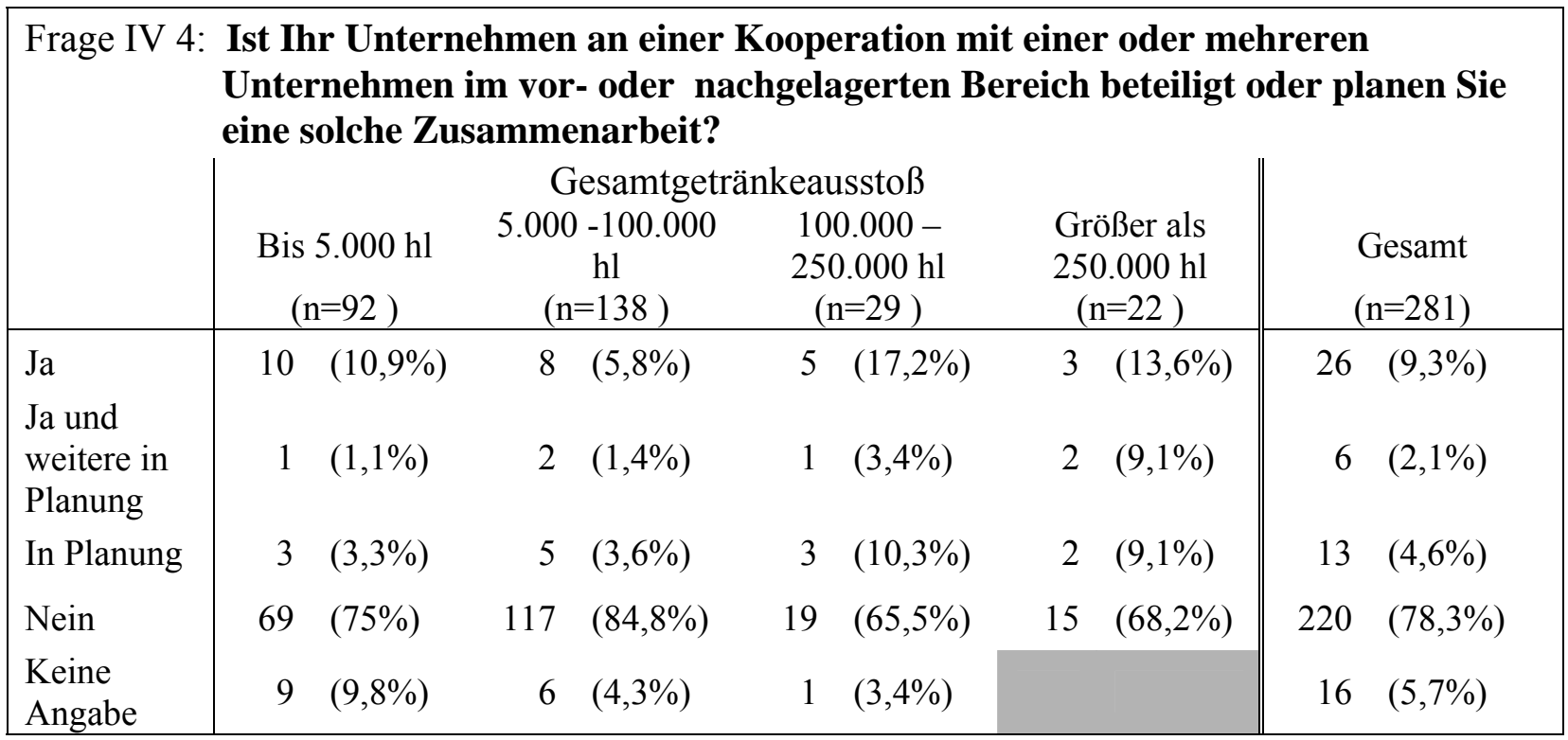

Quelle: Niederhut-Bollmann, C., atensatz „Große Strategie-Studie 2005 “, Göttingen 2005.

\begin{tabular}{|c|c|c|c|c|c|c|}
\hline $\begin{aligned} \text { Frage IV 4.1: } & \text { In w } \\
& \text { Unte } \\
& \text { eine } \\
& \text { oder } \\
& \text { koop }\end{aligned}$ & $\begin{array}{l}\text { chen der } \\
\text { nehmen in } \\
\text { olche?(hie } \\
\text { hehreren ar } \\
\text { rieren, ode }\end{array}$ & $\begin{array}{l}\text { nten aufgefi } \\
\text { vor- oder n } \\
\text { werden nur } \\
\text { leren Untern } \\
\text { dieses plane }\end{array}$ & $\begin{array}{l}\text { hrten Bereic } \\
\text { achgelagerte } \\
\text { Jnternehmen } \\
\text { ehmen im vor } \\
\text { a) }\end{array}$ & $\begin{array}{l}\text { he sind Sie } \\
\text { n Bereich b } \\
\text { berücksicht } \\
\text { - oder nach }\end{array}$ & $\begin{array}{l}\text { n Kooper } \\
\text { teiligt ode } \\
\text { t, welche } \\
\text { elagerten }\end{array}$ & $\begin{array}{l}\text { ionen mit } \\
\text { planen } \\
\text { t einem } \\
\text { eich }\end{array}$ \\
\hline & & & Gesamtgeträ1 & nkeausstoß & & \\
\hline $\begin{array}{l}\text { Kooperation im } \\
\text { vor- oder } \\
\text { Nachgelagerten } \\
\text { Bereich mit... }\end{array}$ & & $\begin{array}{c}\text { Bis } 5.000 \\
\text { hl } \\
(n=14)\end{array}$ & $\begin{array}{c}5.000- \\
100.000 \mathrm{hl} \\
(\mathrm{n}=15)\end{array}$ & $\begin{array}{c}100.000- \\
250.000 \\
\mathrm{hl} \\
(\mathrm{n}=9)\end{array}$ & $\begin{array}{c}\text { Größer } \\
\text { als } \\
250.000 \\
\text { hl } \\
(n=7)\end{array}$ & $\begin{array}{l}\text { Gesamt } \\
(n=45)\end{array}$ \\
\hline & $\begin{array}{l}\text { bestehende } \\
\text { Kooperation }\end{array}$ & $5 \quad(35,7 \%)$ & $2 \quad(13,3 \%)$ & $2(22,2 \%)$ & & $9 \quad(20 \%)$ \\
\hline Mälzerei & $\begin{array}{l}\text { Kooperation } \\
\text { in Planung }\end{array}$ & $2 \quad(14,3 \%)$ & $2 \quad(13,3 \%)$ & & $1 \quad(14,3 \%)$ & $5 \quad(11,1 \%)$ \\
\hline & $\begin{array}{l}\text { Keine } \\
\text { Angabe }\end{array}$ & $7 \quad(50 \%)$ & $11 \quad(73,3 \%)$ & $7 \quad(77,8 \%)$ & $6 \quad(85,7 \%)$ & $31 \quad(68,9 \%)$ \\
\hline & $\begin{array}{l}\text { bestehende } \\
\text { Kooperation }\end{array}$ & $5 \quad(35,7 \%)$ & $4 \quad(26,7 \%)$ & $3 \quad(33,3 \%)$ & $3 \quad(42,9 \%)$ & $15 \quad(37,4 \%)$ \\
\hline $\begin{array}{l}\text { Getränkefach- } \\
\text { großhandel }\end{array}$ & $\begin{array}{l}\text { Kooperation } \\
\text { in Planung }\end{array}$ & & $5 \quad(33,3 \%)$ & $3 \quad(33,3 \%)$ & $3 \quad(42,9 \%)$ & $11 \quad(24,4 \%)$ \\
\hline & $\begin{array}{l}\text { Keine } \\
\text { Angabe }\end{array}$ & $9 \quad(64,3 \%)$ & $6 \quad(40 \%)$ & $3 \quad(33,3 \%)$ & $1 \quad(14,3 \%)$ & $19 \quad(42,2 \%)$ \\
\hline $\begin{array}{l}\text { Andere Absatz- } \\
\text { mittler (z.B. }\end{array}$ & $\begin{array}{l}\text { bestehende } \\
\text { Kooperation }\end{array}$ & $3 \quad(21,4 \%)$ & $2 \quad(13,3 \%)$ & $1 \quad(11,1 \%)$ & $2 \quad(28,6 \%)$ & $8 \quad(17,8 \%)$ \\
\hline $\begin{array}{l}\text { Systemgastronomie, } \\
\text { Handelsmarken- }\end{array}$ & $\begin{array}{l}\text { Kooperation } \\
\text { in Planung }\end{array}$ & $2 \quad(14,3 \%)$ & $3 \quad(20 \%)$ & $1 \quad(11,1 \%)$ & $1 \quad(14,3 \%)$ & $7 \quad(15,6 \%)$ \\
\hline produktion) & $\begin{array}{l}\text { Keine } \\
\text { Angabe }\end{array}$ & $9 \quad(64,3 \%)$ & $10 \quad(66,7 \%)$ & $7 \quad(77,8 \%)$ & $4 \quad(57,1 \%)$ & $30 \quad(66,7 \%)$ \\
\hline Sonstige & $\begin{array}{l}\text { bestehende } \\
\text { Kooperation }\end{array}$ & $1 \quad(7,1 \%)$ & $2 \quad(13,3 \%)$ & & $1 \quad(14,3 \%)$ & $4 \quad(8,9 \%)$ \\
\hline $\begin{array}{l}\text { Kooperationen im } \\
\text { vor- oder nachge- }\end{array}$ & $\begin{array}{l}\text { Kooperation } \\
\text { in Planung }\end{array}$ & & & & $1 \quad(14,3 \%)$ & $1 \quad(2,2 \%)$ \\
\hline lagerten Bereich & $\begin{array}{l}\text { Keine } \\
\text { Angabe }\end{array}$ & $13 \quad(92,9 \%)$ & $13 \quad(86,7 \%)$ & $9 \quad(100 \%)$ & $5 \quad(71,4 \%)$ & $40 \quad(88,9 \%)$ \\
\hline
\end{tabular}

Quelle: Niederhut-Bollmann, C., Datensatz „Große Strategie-Studie 2005“, Göttingen 2005. 


\section{Erfolg}

\section{Frage V 1a: Bitte geben sie an, wie hoch der Gesamtgetränkeausstoß Ihres Unternehmens (nicht Gruppe Konzern)im Jahr 2003 war.}

\begin{tabular}{|c|c|c|c|}
\hline $\begin{array}{l}\text { Betriebsgrößenklasse } \\
\text { nach der Gesamt- } \\
\text { jahreserzeugung (hl) }\end{array}$ & $\begin{array}{c}\text { Betriebene } \\
\text { Braustätten im Jahr } \\
\text { 2004* }\end{array}$ & $\begin{array}{l}\text { Rücklauf an } \\
\text { ausgefüllten } \\
\text { Fragebögen }\end{array}$ & Rücklaufquote in $\%$ \\
\hline bis 5.000 & 796 & 92 & 11,55 \\
\hline bis 10.000 & 85 & \multirow{3}{*}{138} & \multirow{3}{*}{39,2} \\
\hline bis 50.000 & 195 & & \\
\hline bis 100.000 & 72 & & \\
\hline bis 200.000 & 44 & \multirow{2}{*}{42} & \multirow{2}{*}{55,26} \\
\hline bis 500.000 & 32 & & \\
\hline bis 1 Mill. & 21 & \multirow{2}{*}{9} & \multirow{2}{*}{18} \\
\hline über 1 Mill. & 29 & & \\
\hline Gesamt & 1274 & 281 & 22 \\
\hline
\end{tabular}

*Deutscher Brauer-Bund 2005

Frage V 1b: Wie hoch ist der Anteil des Bieres (in \%) am Gesamtgetränkeausstoß Ihres Unternehmens?(Bezugszeitraum 2003)

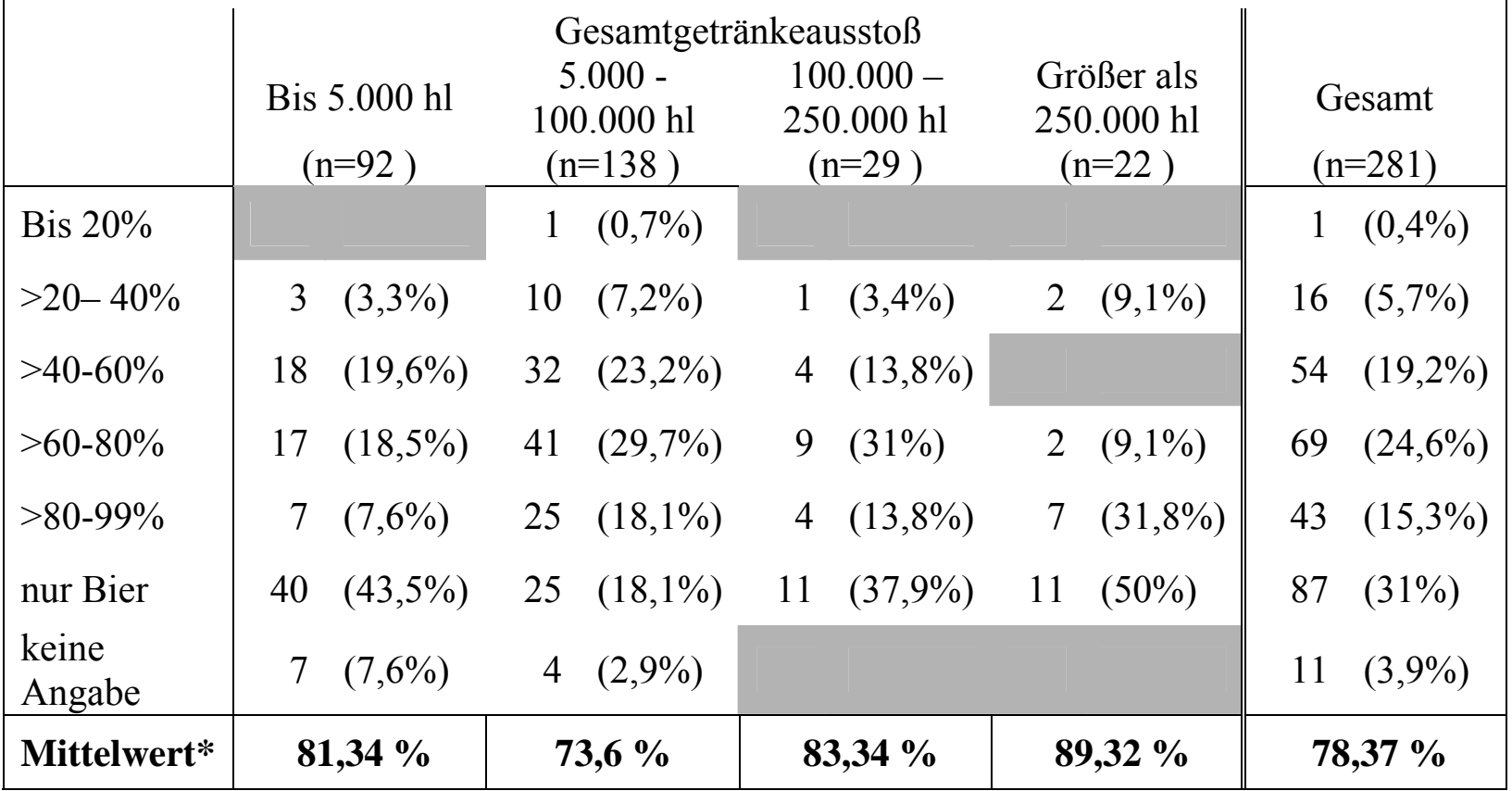

* In die Berechnung des Mittelwertes sind nur die Unternehmen einbezogen, welche eine Angabe gemacht haben.

Quelle: Niederhut-Bollmann, C., Datensatz „Große Strategie-Studie 2005“, Göttingen 2005. 


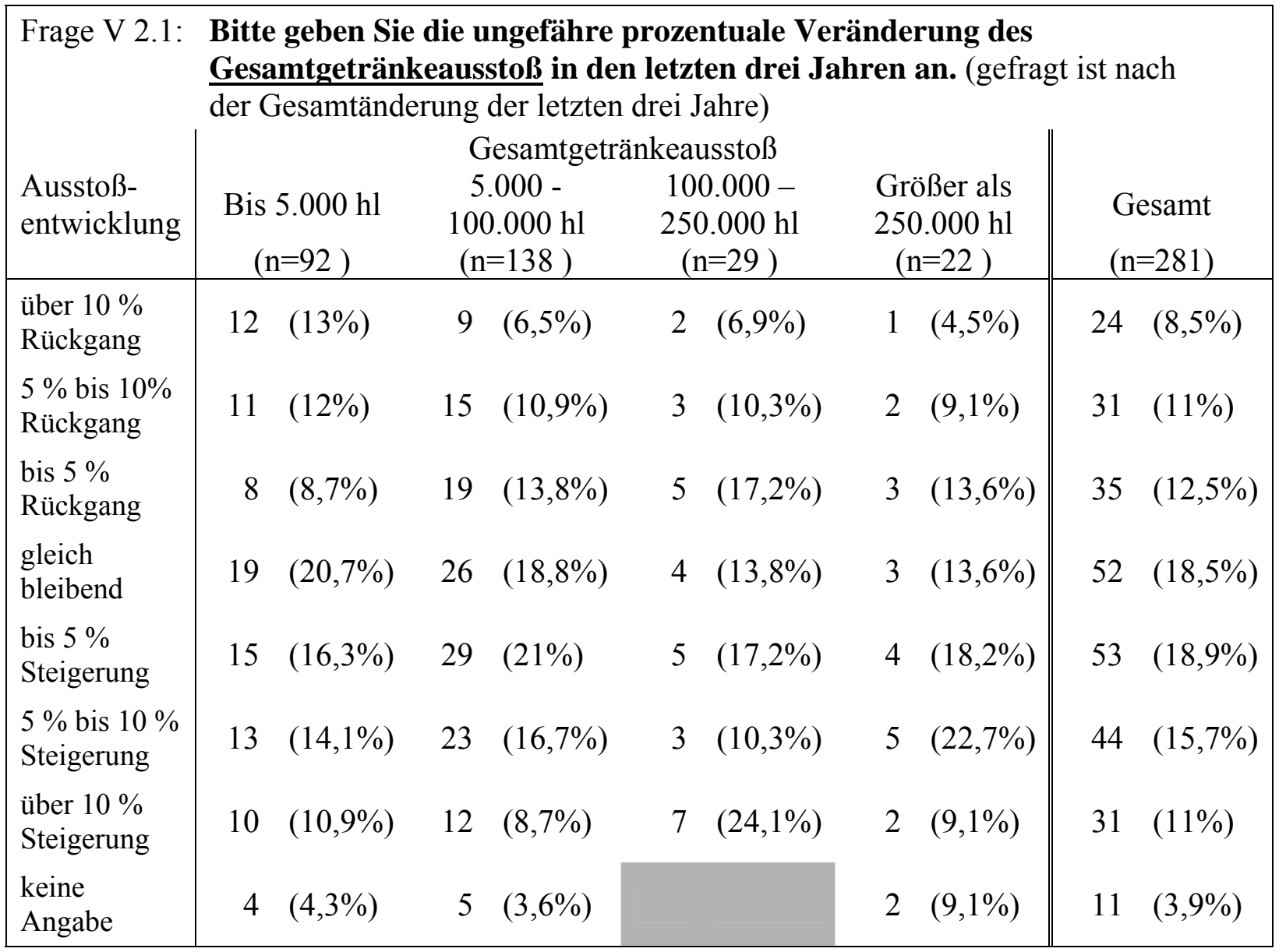

Quelle: Niederhut-Bollmann, C., Datensatz „Große Strategie-Studie 2005“, Göttingen 2005.

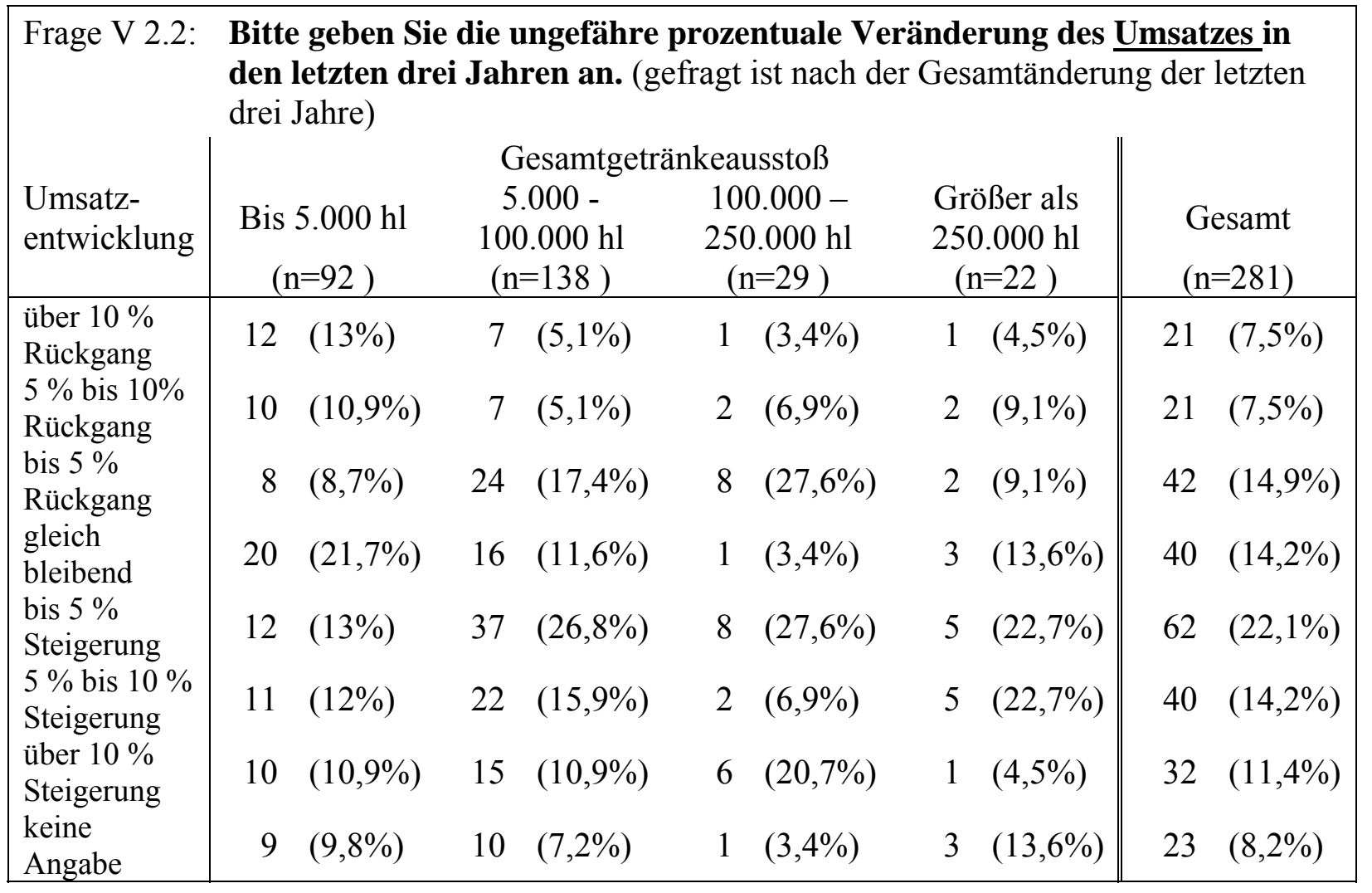

Quelle: Niederhut-Bollmann, C., Datensatz „Große Strategie-Studie 2005“, Göttingen 2005. 


\begin{tabular}{|c|c|c|c|c|c|}
\hline Frage V 2.3: & $\begin{array}{l}\text { Bitte geben Si } \\
\text { den letzten dr } \\
\text { drei Jahre) }\end{array}$ & $\begin{array}{l}\text { lie ungefähre } \\
\text { Jahren an. (g }\end{array}$ & $\begin{array}{l}\text { ozentuale } \mathbf{V} \\
\text { agt ist nach d }\end{array}$ & $\begin{array}{l}\text { nderung des } \\
\text { Gesamtänderu }\end{array}$ & winnes in \\
\hline $\begin{array}{l}\text { Gewinn- } \\
\text { entwicklung }\end{array}$ & $\begin{array}{l}\text { Bis } 5.000 \mathrm{hl} \\
\quad(\mathrm{n}=92)\end{array}$ & $\begin{array}{c}\text { Gesamtgetr } \\
5.000- \\
100.000 \mathrm{hl} \\
(\mathrm{n}=138)\end{array}$ & $\begin{array}{l}\text { keausstoß } \\
100.000- \\
250.000 \mathrm{hl} \\
(\mathrm{n}=29)\end{array}$ & $\begin{array}{c}\text { Größer als } \\
250.000 \mathrm{hl} \\
(\mathrm{n}=22)\end{array}$ & $\begin{array}{l}\text { Gesamt } \\
(\mathrm{n}=281)\end{array}$ \\
\hline $\begin{array}{l}\text { über } 10 \% \\
\text { Rückgang }\end{array}$ & $8 \quad(8,7 \%)$ & $4 \quad(2,9 \%)$ & $1 \quad(3,4 \%)$ & $1 \quad(4,5 \%)$ & $14 \quad(5 \%)$ \\
\hline $\begin{array}{l}5 \% \text { bis } 10 \% \\
\text { Rückgang }\end{array}$ & $8 \quad(8,7 \%)$ & $5 \quad(3,6 \%)$ & $3 \quad(10,3 \%)$ & & $16 \quad(5,7 \%)$ \\
\hline $\begin{array}{l}\text { bis } 5 \% \\
\text { Rückgang }\end{array}$ & $12(13 \%)$ & $18 \quad(13 \%)$ & & & $30 \quad(10,7 \%)$ \\
\hline $\begin{array}{l}\text { gleich } \\
\text { bleibend }\end{array}$ & $25 \quad(27,2 \%)$ & $42 \quad(30,4 \%)$ & $9 \quad(31 \%)$ & $6 \quad(27,3 \%)$ & $82 \quad(29,2 \%)$ \\
\hline $\begin{array}{l}\text { bis } 5 \% \\
\text { Steigerung }\end{array}$ & $15 \quad(16,3 \%)$ & $23 \quad(16,7 \%)$ & $5 \quad(17,2 \%)$ & $3 \quad(13,6 \%)$ & $46 \quad(16,4 \%)$ \\
\hline $\begin{array}{l}5 \% \text { bis } 10 \% \\
\text { Steigerung }\end{array}$ & $8 \quad(8,7 \%)$ & $15 \quad(10,9 \%)$ & $3 \quad(10,3 \%)$ & $7 \quad(31,8 \%)$ & $33 \quad(11,7 \%)$ \\
\hline $\begin{array}{l}\text { über } 10 \% \\
\text { Steigerung }\end{array}$ & $5 \quad(5,4 \%)$ & $16(11,6 \%)$ & $7 \quad(24,1 \%)$ & $2 \quad(9,1 \%)$ & $30 \quad(10,7 \%)$ \\
\hline $\begin{array}{l}\text { keine } \\
\text { Angabe }\end{array}$ & $11 \quad(12 \%)$ & $15 \quad(10,9 \%)$ & $1 \quad(3,4 \%)$ & $3 \quad(13,6 \%)$ & $30 \quad(10,7 \%)$ \\
\hline
\end{tabular}

Quelle: Niederhut-Bollmann, C., Datensatz „Große Strategie-Studie 2005“, Göttingen 2005.

\begin{tabular}{|c|c|c|c|c|c|}
\hline Frage V 2.4: & $\begin{array}{l}\text { Bitte geben Si } \\
\text { Investment in } \\
\text { Gesamtänderur }\end{array}$ & $\begin{array}{l}\text { die ungefähre } \\
\text { en letzten dre } \\
\text { der letzten dr }\end{array}$ & $\begin{array}{l}\text { rozentuale Ve } \\
\text { ahren an. (ge } \\
\text { Jahre) }\end{array}$ & $\begin{array}{l}\text { nderung des } \\
\text { gt ist nach der }\end{array}$ & turn on \\
\hline $\begin{array}{l}\text { Entwicklung } \\
\text { des ROI }\end{array}$ & $\begin{array}{l}\text { Bis } 5.000 \mathrm{hl} \\
\quad(\mathrm{n}=92)\end{array}$ & $\begin{array}{c}\text { Gesamtgetı } \\
5.000- \\
100.000 \mathrm{hl} \\
(\mathrm{n}=138)\end{array}$ & $\begin{array}{l}\text { keausstoß } \\
100.000- \\
250.000 \mathrm{hl} \\
(\mathrm{n}=29)\end{array}$ & $\begin{array}{c}\text { Größer als } \\
250.000 \mathrm{hl} \\
(\mathrm{n}=22)\end{array}$ & $\begin{array}{l}\text { Gesamt } \\
(\mathrm{n}=281)\end{array}$ \\
\hline $\begin{array}{l}\text { über } 10 \% \\
\text { Rückgang }\end{array}$ & $4 \quad(4,3 \%)$ & $4 \quad(2,9 \%)$ & $2 \quad(6,9 \%)$ & $1 \quad(4,5 \%)$ & $11 \quad(3,9 \%)$ \\
\hline $\begin{array}{l}5 \% \text { bis } 10 \% \\
\text { Rückgang }\end{array}$ & $7 \quad(7,6 \%)$ & $9 \quad(6,5 \%)$ & $2 \quad(6,9 \%)$ & & $18 \quad(6,4 \%)$ \\
\hline $\begin{array}{l}\text { bis } 5 \% \\
\text { Rückgang }\end{array}$ & $6 \quad(6,5 \%)$ & $8 \quad(5,8 \%)$ & $1 \quad(3,4 \%)$ & & $15 \quad(5,3 \%)$ \\
\hline $\begin{array}{l}\text { gleich } \\
\text { bleibend }\end{array}$ & $27 \quad(29,3 \%)$ & $44 \quad(31,9 \%)$ & $8 \quad(27,6 \%)$ & $6 \quad(27,3 \%)$ & $85 \quad(30,2 \%)$ \\
\hline $\begin{array}{l}\text { bis } 5 \% \\
\text { Steigerung }\end{array}$ & $8 \quad(8,7 \%)$ & $12 \quad(8,7 \%)$ & $3 \quad(10,3 \%)$ & $2 \quad(9,1 \%)$ & $25 \quad(8,9 \%)$ \\
\hline $\begin{array}{l}5 \% \text { bis } 10 \% \\
\text { Steigerung }\end{array}$ & $3 \quad(3,3 \%)$ & $14 \quad(10,1 \%)$ & $2 \quad(6,9 \%)$ & $3 \quad(13,6 \%)$ & $22 \quad(7,8 \%)$ \\
\hline $\begin{array}{l}\text { über } 10 \% \\
\text { Steigerung }\end{array}$ & $2 \quad(2,2 \%)$ & $9 \quad(6,5 \%)$ & $4 \quad(13,8 \%)$ & $4 \quad(18,2 \%)$ & $19 \quad(6,8 \%)$ \\
\hline keine Angabe & $35 \quad(38 \%)$ & $38 \quad(27,5 \%)$ & $7 \quad(24,1 \%)$ & $6 \quad(27,3 \%)$ & $86 \quad(30,6 \%)$ \\
\hline
\end{tabular}

Quelle: Niederhut-Bollmann, C., Datensatz „Große Strategie-Studie 2005“, Göttingen 2005. 


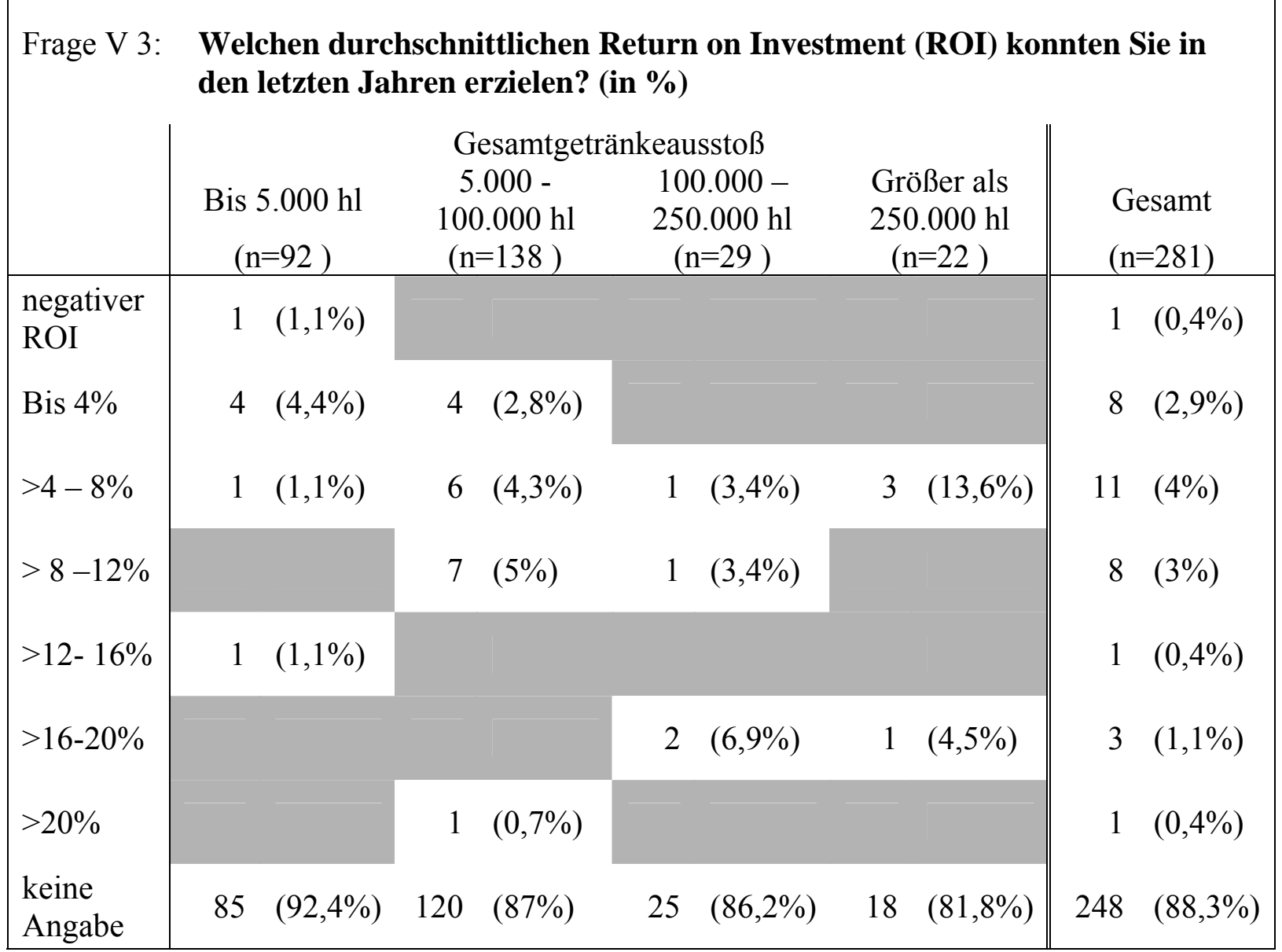

Quelle: Niederhut-Bollmann, C., Datensatz „Große Strategie-Studie 2005“, Göttingen 2005.

\begin{tabular}{|c|c|c|c|c|c|c|c|c|c|c|}
\hline & \multicolumn{10}{|c|}{$\begin{array}{l}\text { Nun noch einige Fragen zum Erfolg Ihres Unternehmens im Vergleich zum } \\
\text { Branchendurchschnitt. Wie sah es da in den letzten Jahren aus? Unsere } \\
\text { Produktivität (Umsatz minus Fremdleistungen je Beschäftigtem) war...... }\end{array}$} \\
\hline & \multirow{2}{*}{\multicolumn{2}{|c|}{$\begin{array}{l}\text { Bis } 5.000 \mathrm{hl} \\
\quad(\mathrm{n}=92)\end{array}$}} & \multicolumn{4}{|c|}{ Gesamtgetränkeausstoß } & \multirow{2}{*}{\multicolumn{2}{|c|}{$\begin{array}{l}\text { Größer als } \\
250.000 \mathrm{hl} \\
(\mathrm{n}=22)\end{array}$}} & \multirow{2}{*}{\multicolumn{2}{|c|}{$\begin{array}{l}\text { Gesamt } \\
(\mathrm{n}=281)\end{array}$}} \\
\hline & & & & $\begin{array}{l}000- \\
.000 \mathrm{hl} \\
=138\end{array}$ & & $\begin{array}{l}.000- \\
.000 \mathrm{hl} \\
=29)\end{array}$ & & & & \\
\hline $\begin{array}{l}\text { deutlich } \\
\text { niedriger }\end{array}$ & & $(6,5 \%)$ & 7 & $(5,1 \%)$ & & & & & 13 & $(4,6 \%)$ \\
\hline niedriger & & $(23,9 \%)$ & 34 & $(24,6 \%)$ & 8 & $(27,6 \%)$ & & $(9,1 \%)$ & 66 & $(23,5 \%)$ \\
\hline gleich & & $(40,2 \%)$ & 49 & $(35,5 \%)$ & 9 & $(31 \%)$ & & $(22,7 \%)$ & 100 & $(35,6 \%)$ \\
\hline höher & & $(20,7 \%)$ & 27 & $(19,6 \%)$ & 9 & $(31 \%)$ & 10 & $(45,5 \%)$ & 65 & $(23,1 \%)$ \\
\hline $\begin{array}{l}\text { deutlich } \\
\text { höher }\end{array}$ & & $(1,1 \%)$ & 8 & $(5,8 \%)$ & 1 & $(3,4 \%)$ & & $(9,1 \%)$ & 12 & $(4,3 \%)$ \\
\hline $\begin{array}{l}\text { keine } \\
\text { Angabe }\end{array}$ & & $(7,6 \%)$ & 13 & $(9,4 \%)$ & & $(6,9 \%)$ & & $(13,6 \%)$ & 25 & $(8,9 \%)$ \\
\hline
\end{tabular}

Quelle: Niederhut-Bollmann, C., Datensatz „,Große Strategie-Studie 2005“, Göttingen 2005. 


\begin{tabular}{|c|c|c|c|c|c|}
\hline \multirow[t]{2}{*}{ Frage V 4.2} & \multicolumn{5}{|c|}{$\begin{array}{l}\text { Nun noch einige Fragen zum Erfolg Ihres Unternehmens im Vergleich zum } \\
\text { Branchendurchschnitt. Wie sah es da in den letzten Jahren aus? Unsere } \\
\text { durchschnittliche Rentabilität (Betriebsergebnis/ Gesamtkapital) war }\end{array}$} \\
\hline & $\begin{array}{l}\text { Bis } 5.000 \mathrm{hl} \\
\quad(\mathrm{n}=92)\end{array}$ & $\begin{array}{l}\text { Gesamtget } \\
5.000- \\
100.000 \mathrm{hl} \\
(\mathrm{n}=138)\end{array}$ & $\begin{array}{l}\text { keausstoß } \\
100.000- \\
250.000 \mathrm{hl} \\
(\mathrm{n}=29)\end{array}$ & $\begin{array}{l}\text { Größer als } \\
250.000 \mathrm{hl} \\
(\mathrm{n}=22)\end{array}$ & $\begin{array}{l}\text { Gesamt } \\
(\mathrm{n}=281)\end{array}$ \\
\hline $\begin{array}{l}\text { deutlich } \\
\text { niedriger }\end{array}$ & $7 \quad(7,6 \%)$ & $1 \quad(0,7 \%)$ & & & $8 \quad(2,8 \%)$ \\
\hline niedriger & $29 \quad(31,5 \%)$ & $35 \quad(25,4 \%)$ & $7 \quad(24,1 \%)$ & $3 \quad(13,6 \%)$ & $74 \quad(26,3 \%)$ \\
\hline gleich & $(31,5 \%)$ & $43 \quad(31,2 \%)$ & $4 \quad(13,8 \%)$ & $3 \quad(13,6 \%)$ & $79 \quad(28,1 \%)$ \\
\hline höher & $17 \quad(18,5 \%)$ & $36 \quad(26,1 \%)$ & $10 \quad(34,5 \%)$ & $8 \quad(36,4 \%)$ & $71 \quad(25,3 \%)$ \\
\hline $\begin{array}{l}\text { deutlich } \\
\text { höher }\end{array}$ & $1 \quad(1,1 \%)$ & $12(8,7 \%)$ & $6 \quad(20,7 \%)$ & $5 \quad(22,7 \%)$ & $24 \quad(8,5 \%)$ \\
\hline $\begin{array}{l}\text { keine } \\
\text { Angabe }\end{array}$ & $9 \quad(9,8 \%)$ & $11 \quad(8 \%)$ & $2 \quad(6,9 \%)$ & $3 \quad(13,6 \%)$ & $25 \quad(8,9 \%)$ \\
\hline
\end{tabular}

Quelle: Niederhut-Bollmann, C., Datensatz „Große Strategie-Studie 2005“, Göttingen 2005.

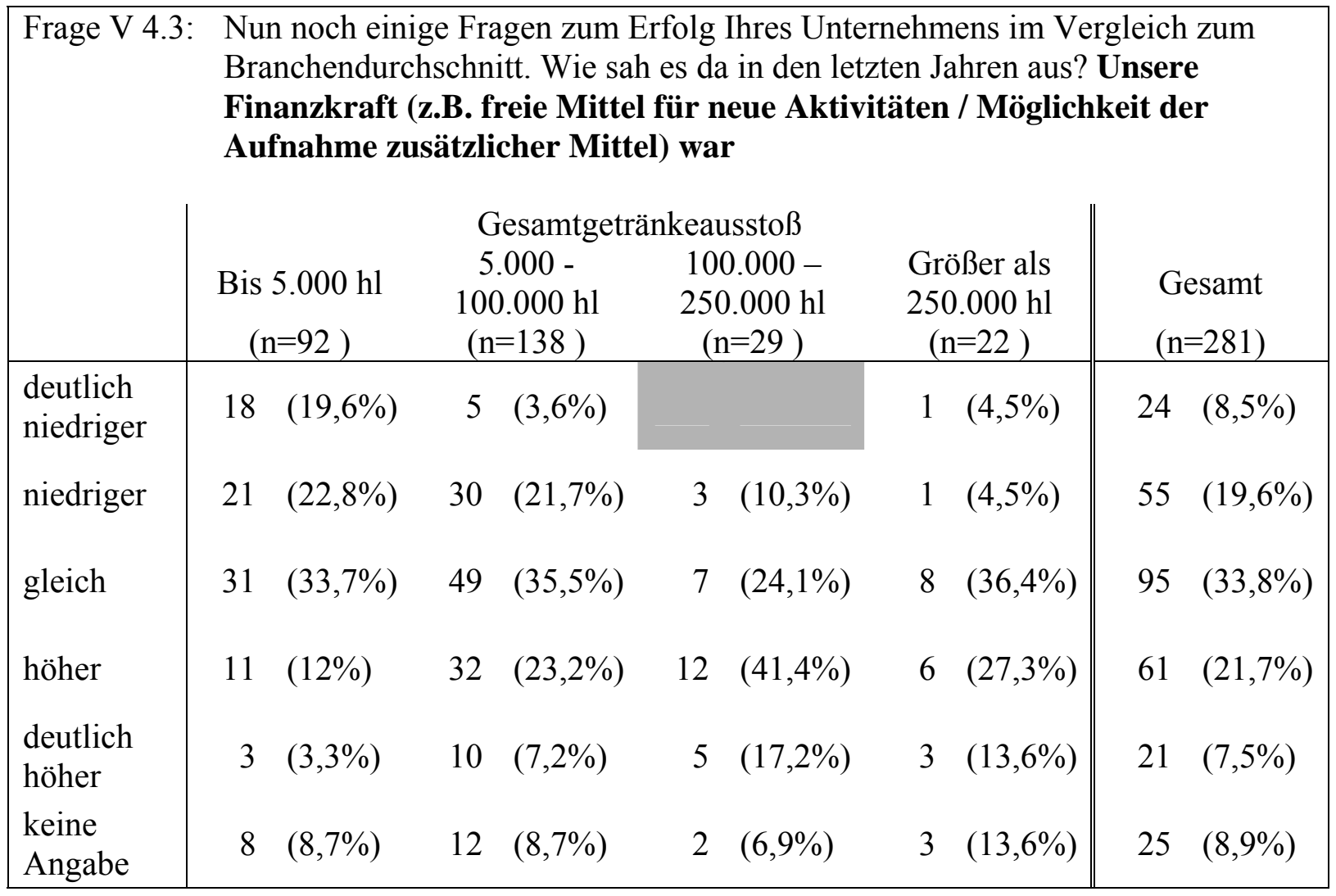

Quelle: Niederhut-Bollmann, C., Datensatz „Große Strategie-Studie 2005“, Göttingen 2005. 


\section{Strategieformulierung und Implementierung}

\begin{tabular}{|c|c|c|c|c|c|}
\hline & \multicolumn{5}{|c|}{$\begin{array}{l}\text { Zum Ende noch einige Aussagen zur Strategieformulierung und Implemen- } \\
\text { tierung. Inwieweit stimmen Sie dem folgenden Statement, welches so } \\
\text { oder ähnlich von Managern anderer Unternehmen geäußert wurde, für Ihr } \\
\text { Unternehmen zu? } \\
\text { Auch im Tagesgeschäft haben wir immer die langfristige Strategie im Auge. }\end{array}$} \\
\hline & $\begin{array}{c}\text { Bis } 5.000 \mathrm{hl} \\
(\mathrm{n}=92)\end{array}$ & $\begin{array}{c}5.000-100.000 \\
\mathrm{hl} \\
(\mathrm{n}=138)\end{array}$ & $\begin{array}{c}100.000- \\
250.000 \mathrm{hl} \\
(\mathrm{n}=29)\end{array}$ & $\begin{array}{c}\text { Größer als } \\
250.000 \mathrm{hl} \\
(\mathrm{n}=22)\end{array}$ & $\begin{array}{l}\text { Gesamt } \\
(\mathrm{n}=281)\end{array}$ \\
\hline $\begin{array}{l}\text { Stimme voll- } \\
\text { ständig zu }\end{array}$ & $17 \quad(18,5 \%)$ & $(13 \%)$ & $(31 \%)$ & $9 \quad(40,9 \%)$ & $53 \quad(18,9 \%)$ \\
\hline Stimme zu & $49 \quad(53,3 \%)$ & $(61,6 \%)$ & $(65,5 \%)$ & $11 \quad(50 \%)$ & $164 \quad(58,4 \%)$ \\
\hline Weder noch & $(16,3 \%)$ & $(13 \%)$ & $(3,4 \%)$ & $1 \quad(4,5 \%)$ & $35 \quad(12,5 \%)$ \\
\hline Lehne ab & $(4,3 \%)$ & $7 \quad(5,1 \%)$ & & $1 \quad(4,5 \%)$ & $12 \quad(4,3 \%)$ \\
\hline $\begin{array}{l}\text { Lehne voll- } \\
\text { Ständig ab }\end{array}$ & & & & & \\
\hline $\begin{array}{l}\text { Keine } \\
\text { Angabe }\end{array}$ & $7 \quad(7,6 \%)$ & $10 \quad(7,2 \%)$ & & & $17 \quad(6 \%)$ \\
\hline
\end{tabular}

Quelle: Niederhut-Bollmann, C., Datensatz „Große Strategie-Studie 2005“, Göttingen 2005.

Frage VI 1.2: Zum Ende noch einige Aussagen zur Strategieformulierung und Implementierung. Inwieweit stimmen Sie dem folgenden Statement, welches so oder ähnlich von Managern anderer Unternehmen geäußert wurde, für Ihr Unternehmen zu?

Die Verantwortung für die strategische Unternehmensführung ist bei uns klar geregelt (z.B. Inhaber, Planungsabteilung).

\begin{tabular}{|c|c|c|c|c|c|}
\hline & \multicolumn{4}{|c|}{ Gesamtgetränkeausstoß } & \multirow[b]{2}{*}{$\begin{array}{l}\text { Gesamt } \\
(\mathrm{n}=281)\end{array}$} \\
\hline & $\begin{array}{l}\text { Bis } 5.000 \mathrm{hl} \\
\quad(\mathrm{n}=92)\end{array}$ & $\begin{array}{c}5.000-100.000 \\
\mathrm{hl} \\
(\mathrm{n}=138)\end{array}$ & $\begin{array}{c}100.000- \\
250.000 \mathrm{hl} \\
(\mathrm{n}=29)\end{array}$ & $\begin{array}{c}\text { Größer als } \\
250.000 \mathrm{hl} \\
(\mathrm{n}=22)\end{array}$ & \\
\hline $\begin{array}{l}\text { Stimme voll- } \\
\text { ständig zu }\end{array}$ & $27 \quad(29,3 \%)$ & $47 \quad(34,1 \%)$ & $12(41,4 \%)$ & $9 \quad(40,9 \%)$ & $95 \quad(33,8 \%)$ \\
\hline Stimme zu & $43 \quad(46,7 \%)$ & $69 \quad(50 \%)$ & $17 \quad(58,6 \%)$ & $11 \quad(50 \%)$ & $140 \quad(49,8 \%)$ \\
\hline Weder noch & $13 \quad(14,1 \%)$ & $13(9,4 \%)$ & & $1 \quad(4,5 \%)$ & $27 \quad(9,6 \%)$ \\
\hline Lehne ab & $2 \quad(2,2 \%)$ & $2 \quad(1,4 \%)$ & & $1 \quad(4,5 \%)$ & $5 \quad(1,8 \%)$ \\
\hline $\begin{array}{l}\text { Lehne voll- } \\
\text { Ständig ab }\end{array}$ & & & & & \\
\hline $\begin{array}{l}\text { Keine } \\
\text { Angabe }\end{array}$ & $7 \quad(7,6 \%)$ & $7 \quad(5,1 \%)$ & & & $14 \quad(5 \%)$ \\
\hline
\end{tabular}

Quelle: Niederhut-Bollmann, C., Datensatz „Große Strategie-Studie 2005“, Göttingen 2005. 


\begin{tabular}{|c|c|c|c|c|c|c|c|c|c|c|}
\hline \multirow[t]{2}{*}{ rage VI 1.3: } & \multicolumn{10}{|c|}{$\begin{array}{l}\text { Zum Ende noch einige Aussagen zur Strategieformulierung und Implemen- } \\
\text { tierung. Inwieweit stimmen Sie dem folgenden Statement, welches so oder } \\
\text { ähnlich von Managern anderer Unternehmen geäußert wurde, für Ihr } \\
\underline{\text { Unternehmen zu? }}\end{array}$} \\
\hline & & $\begin{array}{l}5.000 \mathrm{hl} \\
=92)\end{array}$ & $\begin{array}{r}5.000 \\
(\mathrm{n}\end{array}$ & $\begin{array}{l}-100.000 \\
\text { hl } \\
=138)\end{array}$ & & $\begin{array}{l}000- \\
00 \mathrm{hl} \\
29)\end{array}$ & & $\begin{array}{l}\text { ßer als } \\
.000 \mathrm{hl} \\
=22)\end{array}$ & & $\begin{array}{l}\text { esamt } \\
=281 \text { ) }\end{array}$ \\
\hline $\begin{array}{l}\text { Stimme voll- } \\
\text { ständig zu }\end{array}$ & 3 & $(3,3 \%)$ & 11 & $(8 \%)$ & 6 & $(20,7 \%)$ & & $(45,5 \%)$ & 30 & $(10,7 \%)$ \\
\hline Stimme zu & 32 & $(34,8 \%)$ & 56 & $(40,6 \%)$ & 17 & $(58,6 \%)$ & 10 & $(45,5 \%)$ & 115 & $(40,9 \%)$ \\
\hline Weder noch & 38 & $(41,3 \%)$ & 48 & $(34,8 \%)$ & 5 & $(17,2 \%)$ & 1 & $(4,5 \%)$ & 92 & $(32,7 \%)$ \\
\hline Lehne ab & 8 & $(8,7 \%)$ & 12 & $(8,7 \%)$ & 1 & $(3,4 \%)$ & 1 & $(4,5 \%)$ & 22 & $(7,8 \%)$ \\
\hline $\begin{array}{l}\text { Lehne voll- } \\
\text { Ständig ab }\end{array}$ & 3 & $(3,3 \%)$ & 2 & $(1,4 \%)$ & & & & & 5 & $(1,8 \%)$ \\
\hline $\begin{array}{l}\text { Keine } \\
\text { Angabe }\end{array}$ & & $(8,7 \%)$ & 9 & $(6,5 \%)$ & & & & & 17 & $(6 \%)$ \\
\hline
\end{tabular}

Quelle: Niederhut-Bollmann, C., Datensatz „Große Strategie-Studie 2005“, Göttingen 2005.

\begin{tabular}{|c|c|c|c|c|c|c|c|c|c|}
\hline & \multicolumn{9}{|c|}{$\begin{array}{l}\text { Zum Ende noch einige Aussagen zur Strategieformulierung und Implemen- } \\
\text { tierung. Inwieweit stimmen Sie dem folgenden Statement, welches so oder } \\
\text { ähnlich von Managern anderer Unternehmen geäußert wurde, für Ihr } \\
\text { Unternehmen zu? } \\
\text { Bei der strategischen Unternehmensplanung unterstützen uns regelmäßig } \\
\text { externe Berater. }\end{array}$} \\
\hline & \multirow[b]{2}{*}{$\begin{array}{l}\text { Bis } 5.000 \mathrm{hl} \\
\quad(\mathrm{n}=92)\end{array}$} & \multicolumn{4}{|c|}{ Gesamtgetränkeausstoß } & \multirow{2}{*}{\multicolumn{2}{|c|}{$\begin{array}{c}\text { Größer als } \\
250.000 \mathrm{hl} \\
(\mathrm{n}=22)\end{array}$}} & \multirow{2}{*}{\multicolumn{2}{|c|}{$\begin{array}{l}\text { Gesamt } \\
(\mathrm{n}=281)\end{array}$}} \\
\hline & & $\begin{array}{r}5.000 \\
(\mathrm{n}\end{array}$ & $\begin{array}{l}100.000 \\
\mathrm{hl} \\
138)\end{array}$ & & $\begin{array}{l}000- \\
000 \mathrm{hl} \\
29)\end{array}$ & & & & \\
\hline $\begin{array}{l}\text { Stimme voll- } \\
\text { ständig zu }\end{array}$ & & 6 & $(4,3 \%)$ & 4 & $(13,8 \%)$ & & $(9,1 \%)$ & 12 & $(4,3 \%)$ \\
\hline Stimme zu & $(12 \%)$ & 36 & $(26,1 \%)$ & 8 & $(27,6 \%)$ & & $(27,3 \%)$ & 61 & $(21,7 \%)$ \\
\hline Weder noch & $(39,1 \%)$ & 37 & $(26,8 \%)$ & 8 & $(27,6 \%)$ & & $(22,7 \%)$ & 86 & $(30,6 \%)$ \\
\hline Lehne ab & $(27,2 \%)$ & 31 & $(22,5 \%)$ & 5 & $(17,2 \%)$ & 7 & $(31,8 \%)$ & 68 & $(24,2 \%)$ \\
\hline $\begin{array}{l}\text { Lehne voll- } \\
\text { Ständig ab }\end{array}$ & $13 \quad(14,1 \%)$ & 20 & $(14,5 \%)$ & & $(13,8 \%)$ & & $(9,1 \%)$ & 3 & $(13,9 \%)$ \\
\hline $\begin{array}{l}\text { Keine } \\
\text { Angabe }\end{array}$ & $(7,6 \%)$ & 8 & $(5,8 \%)$ & & & & & 15 & $(5,3 \%)$ \\
\hline
\end{tabular}

Quelle: Niederhut-Bollmann, C., Datensatz „Große Strategie-Studie 2005“, Göttingen 2005. 


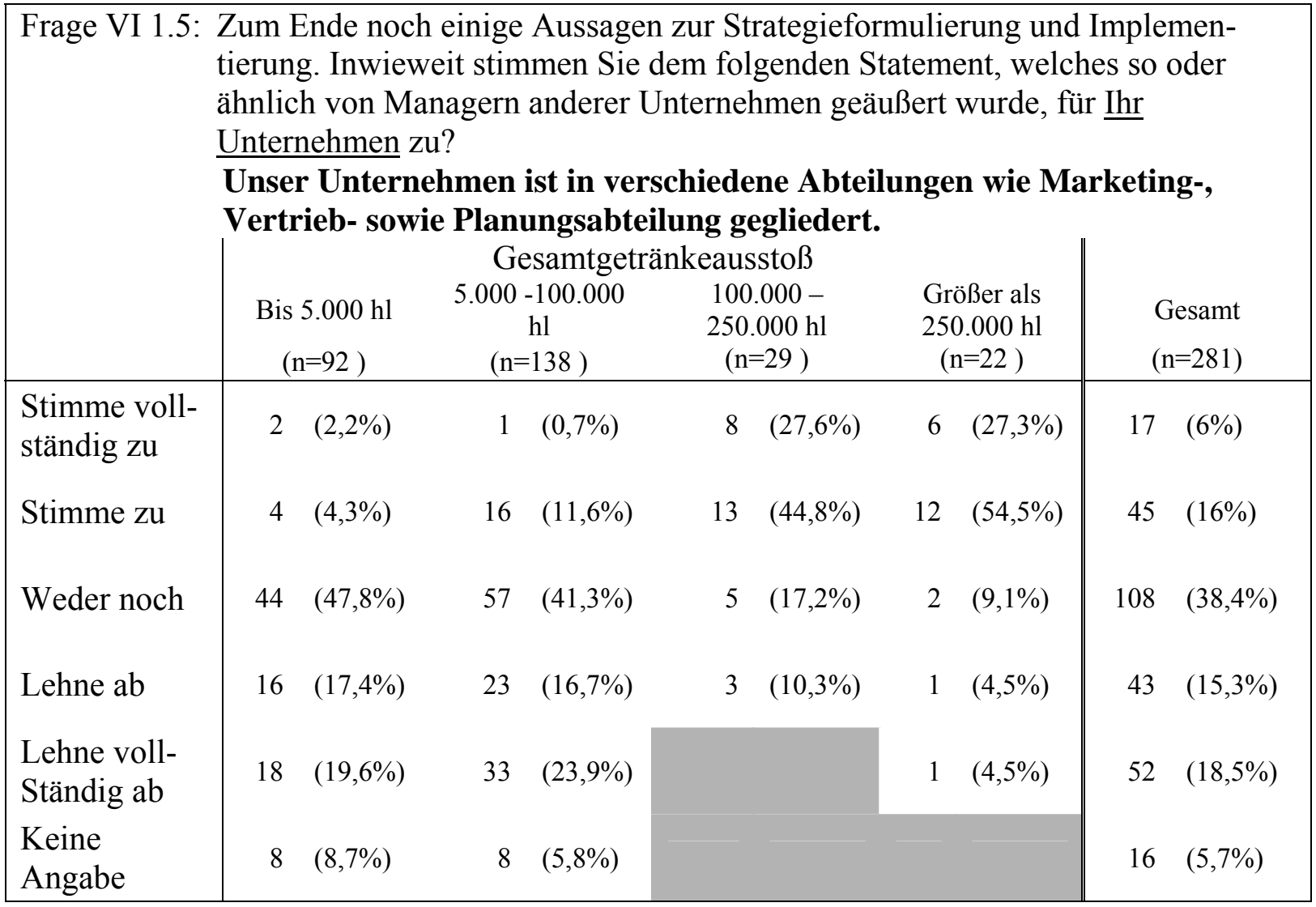

Quelle: Niederhut-Bollmann, C., Datensatz „,Große Strategie-Studie 2005“, Göttingen 2005.

\begin{tabular}{|c|c|c|c|c|c|c|c|c|c|}
\hline & \multicolumn{9}{|c|}{$\begin{array}{l}\text { Zum Ende noch einige Aussagen zur Strategieformulierung und Implemen- } \\
\text { tierung. Inwieweit stimmen Sie dem folgenden Statement, welches so oder } \\
\text { ähnlich von Managern anderer Unternehmen geäußert wurde, für Ihr } \\
\text { Unternehmen zu? } \\
\text { Es werden klare Ziele festgelegt, die bis zu einem bestimmten Zeitpunkt } \\
\text { zu erreichen sind. }\end{array}$} \\
\hline & \multirow[b]{2}{*}{$\begin{array}{l}\text { Bis } 5.000 \mathrm{hl} \\
\quad(\mathrm{n}=92)\end{array}$} & \multicolumn{4}{|c|}{ ad. Gesamtgetränkeausstoß } & \multirow{2}{*}{\multicolumn{2}{|c|}{$\begin{array}{l}\text { Größer als } \\
250.000 \mathrm{hl} \\
(\mathrm{n}=22)\end{array}$}} & \multirow{2}{*}{\multicolumn{2}{|c|}{$\begin{array}{l}\text { Gesamt } \\
(n=281)\end{array}$}} \\
\hline & & $\begin{array}{r}5.000 \\
\quad(\mathrm{n}=\end{array}$ & $\begin{array}{l}100.000 \\
\mathrm{hl} \\
138)\end{array}$ & & $\begin{array}{l}000- \\
000 \mathrm{hl} \\
29)\end{array}$ & & & & \\
\hline $\begin{array}{l}\text { Stimme voll- } \\
\text { ständig zu }\end{array}$ & $6 \quad(6,5 \%)$ & 10 & $(7,2 \%)$ & 5 & $(17,2 \%)$ & & $(27,3 \%)$ & 27 & $(9,6 \%)$ \\
\hline Stimme zu & $(32,6 \%)$ & 53 & $(38,4 \%)$ & 18 & $(62,1 \%)$ & 13 & $(59,1 \%)$ & 114 & $(40,6 \%)$ \\
\hline Weder noch & $(33,7 \%)$ & 45 & $(32,6 \%)$ & & $(13,8 \%)$ & & $(4,5 \%)$ & 81 & $(28,8 \%)$ \\
\hline Lehne ab & $(12 \%)$ & 15 & $(10,9 \%)$ & 2 & $(6,9 \%)$ & & $(9,1 \%)$ & 30 & $(10,7 \%)$ \\
\hline $\begin{array}{l}\text { Lehne voll- } \\
\text { Ständig ab }\end{array}$ & $5 \quad(5,4 \%)$ & 6 & $(4,3 \%)$ & & & & & 11 & $(3,9 \%)$ \\
\hline $\begin{array}{l}\text { Keine } \\
\text { Angabe }\end{array}$ & $(9,8 \%)$ & 9 & $(6,5 \%)$ & & & & & 18 & $(6,4 \%)$ \\
\hline
\end{tabular}

Quelle: Niederhut-Bollmann, C., Datensatz „Große Strategie-Studie 2005“, Göttingen 2005. 


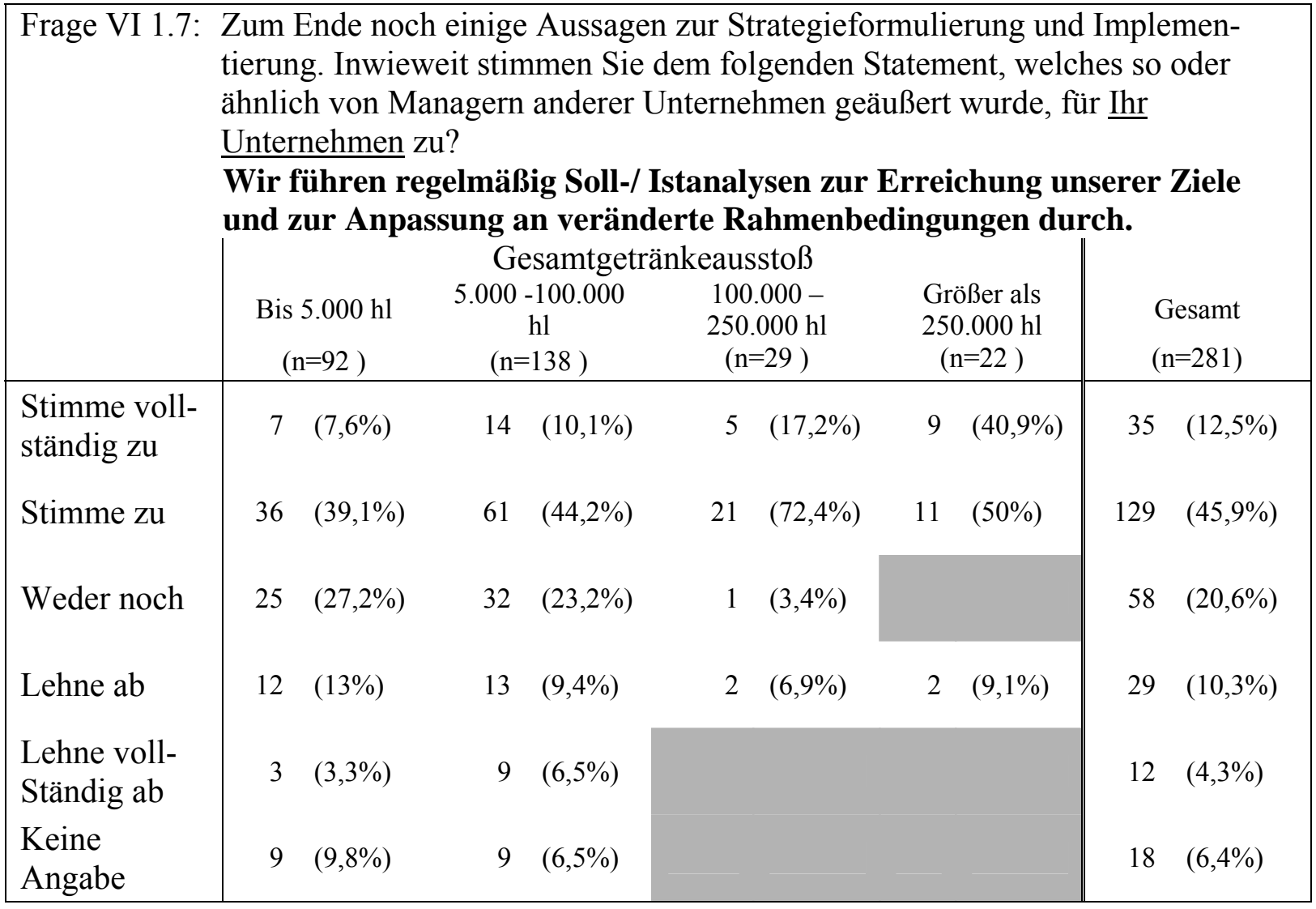

Quelle: Niederhut-Bollmann, C., Datensatz „Große Strategie-Studie 2005“, Göttingen 2005.

\begin{tabular}{|c|c|c|c|c|c|c|c|c|}
\hline & \multicolumn{8}{|c|}{$\begin{array}{l}\text { Zum Ende noch einige Aussagen zur Strategieformulierung und Implemen- } \\
\text { tierung. Inwieweit stimmen Sie dem folgenden Statement, welches so oder } \\
\text { ähnlich von Managern anderer Unternehmen geäußert wurde, für Ihr } \\
\text { Unternehmen zu? } \\
\text { Unser Management ist im Vergleich zum Branchendurchschnitt } \\
\text { überdurchschnittlich innovativ und erfolgreich. } \\
\quad \text { Gesamtgetränkeausstoß }\end{array}$} \\
\hline & & $\begin{array}{l}5.000 \mathrm{hl} \\
\mathrm{n}=92)\end{array}$ & $\begin{array}{r}5.000 \\
\quad(\mathrm{n}\end{array}$ & $\begin{array}{l}-100.000 \\
\text { hl } \\
=138)\end{array}$ & $\begin{array}{c}100.000- \\
250.000 \mathrm{hl} \\
(\mathrm{n}=29)\end{array}$ & $\begin{array}{c}\text { Größer als } \\
250.000 \mathrm{hl} \\
(\mathrm{n}=22)\end{array}$ & & $\begin{array}{l}\text { Sesamt } \\
\mathrm{n}=281 \text { ) }\end{array}$ \\
\hline $\begin{array}{l}\text { Stimme voll- } \\
\text { ständig zu }\end{array}$ & & $(3,3 \%)$ & 6 & $(4,3 \%)$ & $2 \quad(6,9 \%)$ & $6 \quad(27,3 \%)$ & & $(6 \%)$ \\
\hline Stimme zu & 23 & $(25 \%)$ & 42 & $(30,4 \%)$ & $18 \quad(62,1 \%)$ & $8 \quad(36,4 \%)$ & 91 & $(32,4 \%)$ \\
\hline Weder noch & & $(47,8 \%)$ & 70 & $(50,7 \%)$ & $(27,6 \%)$ & $5 \quad(22,7 \%)$ & 127 & $(45,2 \%)$ \\
\hline Lehne ab & & $(9,8 \%)$ & 10 & $(7,2 \%)$ & & $1 \quad(4,5 \%)$ & 20 & $(7,1 \%)$ \\
\hline $\begin{array}{l}\text { Lehne voll- } \\
\text { Ständig ab }\end{array}$ & & $(3,3 \%)$ & 2 & $(1,4 \%)$ & & & & $(1,8 \%)$ \\
\hline $\begin{array}{l}\text { Keine } \\
\text { Angabe }\end{array}$ & & $(10,9 \%)$ & 8 & $(5,8 \%)$ & $1 \quad(3,4 \%)$ & $2 \quad(9,1 \%)$ & 21 & $(7,5 \%)$ \\
\hline
\end{tabular}

Quelle: Niederhut-Bollmann, C., Datensatz „Große Strategie-Studie 2005“, Göttingen 2005. 


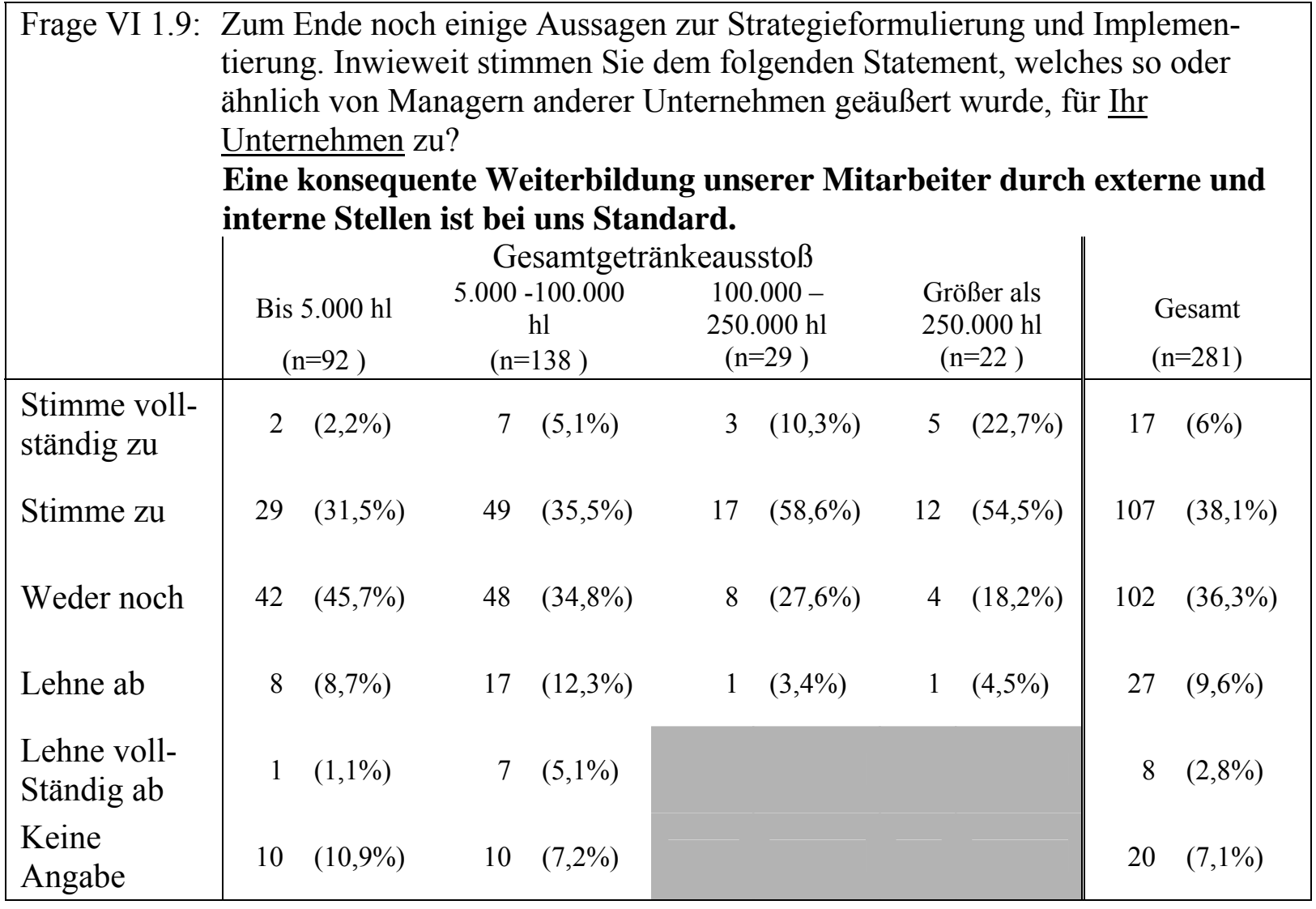

Quelle: Niederhut-Bollmann, C., Datensatz „,Große Strategie-Studie 2005“, Göttingen 2005.

\begin{tabular}{|c|c|c|c|c|c|c|}
\hline \multirow[t]{2}{*}{ Frage } & \multicolumn{6}{|c|}{$\begin{array}{l}\text { Zum Ende noch einige Aussagen zur Strategieformulierung und Implemen- } \\
\text { tierung. Inwieweit stimmen Sie dem folgenden Statement, welches so oder } \\
\text { ähnlich von Managern anderer Unternehmen geäußert wurde, für Ihr } \\
\text { Unternehmen zu? } \\
\text { Die Strategie und die Ziele unseres Unternehmens werden regelmäßig } \\
\text { an alle Führungskräfte und Mitarbeiter kommuniziert. } \\
\quad \text { Gesamtgetränkeausstoß }\end{array}$} \\
\hline & $\begin{array}{l}\text { Bis } 5.000 \mathrm{hl} \\
\quad(\mathrm{n}=92)\end{array}$ & $\begin{array}{c}5.000-100.000 \\
\mathrm{hl} \\
(\mathrm{n}=138)\end{array}$ & $\begin{array}{c}100.000- \\
250.000 \mathrm{hl} \\
(\mathrm{n}=29)\end{array}$ & $\begin{array}{c}\text { Größer als } \\
250.000 \mathrm{hl} \\
(\mathrm{n}=22)\end{array}$ & & $\begin{array}{l}\text { iesamt } \\
=281 \text { ) }\end{array}$ \\
\hline $\begin{array}{l}\text { Stimme voll- } \\
\text { ständig zu }\end{array}$ & $7 \quad(7,6 \%)$ & $11 \quad(8 \%)$ & $6 \quad(20,7 \%)$ & $8 \quad(36,4 \%)$ & 32 & $(11,4 \%)$ \\
\hline Stimme zu & $(33,7 \%)$ & $68 \quad(49,3 \%)$ & $19 \quad(65,5 \%)$ & $13 \quad(59,1 \%)$ & 131 & $(46,6 \%)$ \\
\hline Weder noch & $(43,5 \%)$ & $34 \quad(24,6 \%)$ & $4 \quad(13,8 \%)$ & & 78 & $(27,8 \%)$ \\
\hline Lehne ab & $(3,3 \%)$ & $10 \quad(7,2 \%)$ & & $1 \quad(4,5 \%)$ & 14 & $(5 \%)$ \\
\hline $\begin{array}{l}\text { Lehne voll- } \\
\text { Ständig ab }\end{array}$ & & $4 \quad(2,9 \%)$ & & & & $(1,4 \%)$ \\
\hline $\begin{array}{l}\text { Keine } \\
\text { Angabe }\end{array}$ & $11 \quad(12 \%)$ & $11 \quad(8 \%)$ & & & 22 & $(7,8 \%)$ \\
\hline
\end{tabular}

Quelle: Niederhut-Bollmann, C., Datensatz „Große Strategie-Studie 2005“, Göttingen 2005. 


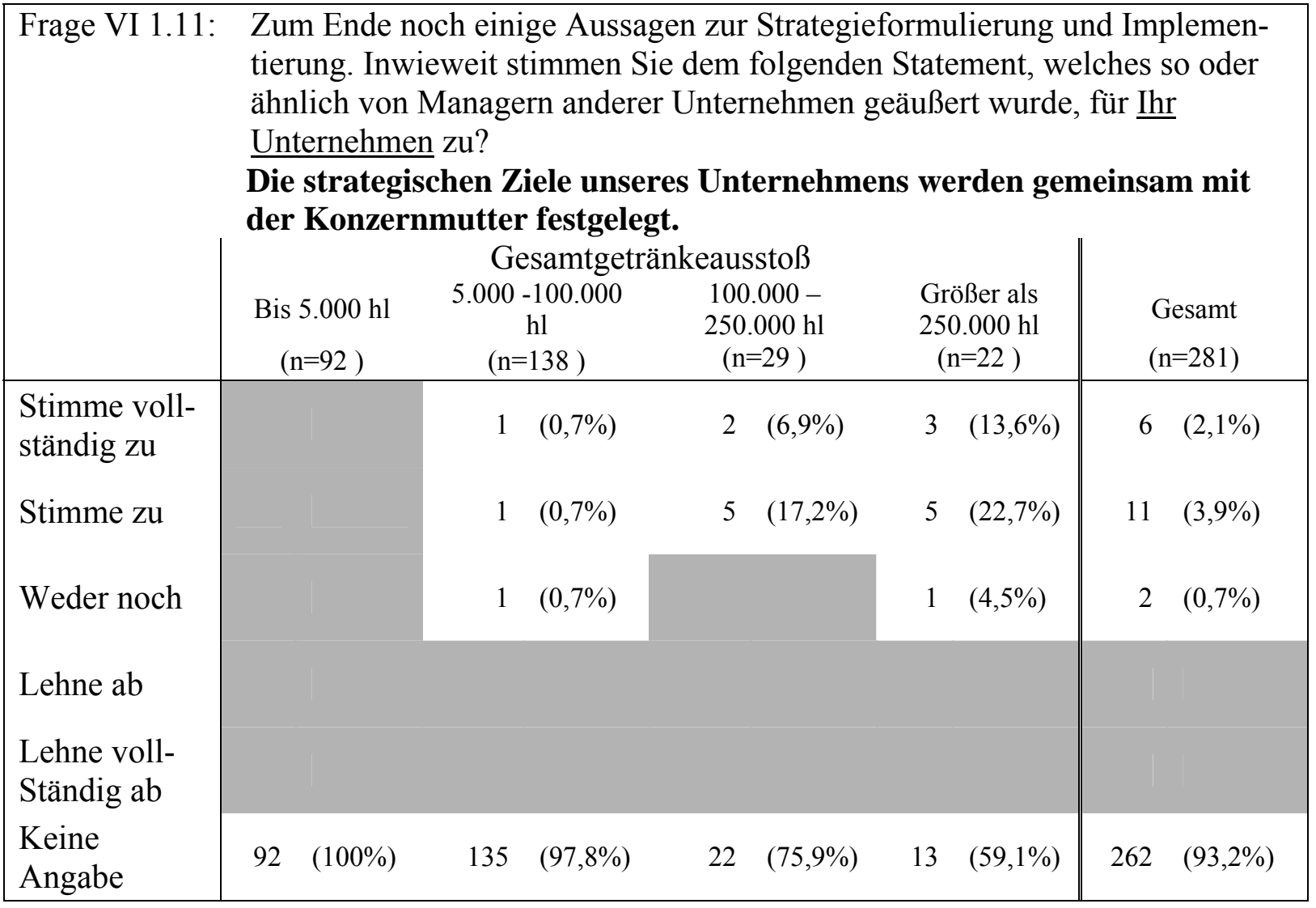

Quelle: Niederhut-Bollmann, C., Datensatz „Große Strategie-Studie 2005“, Göttingen 2005.

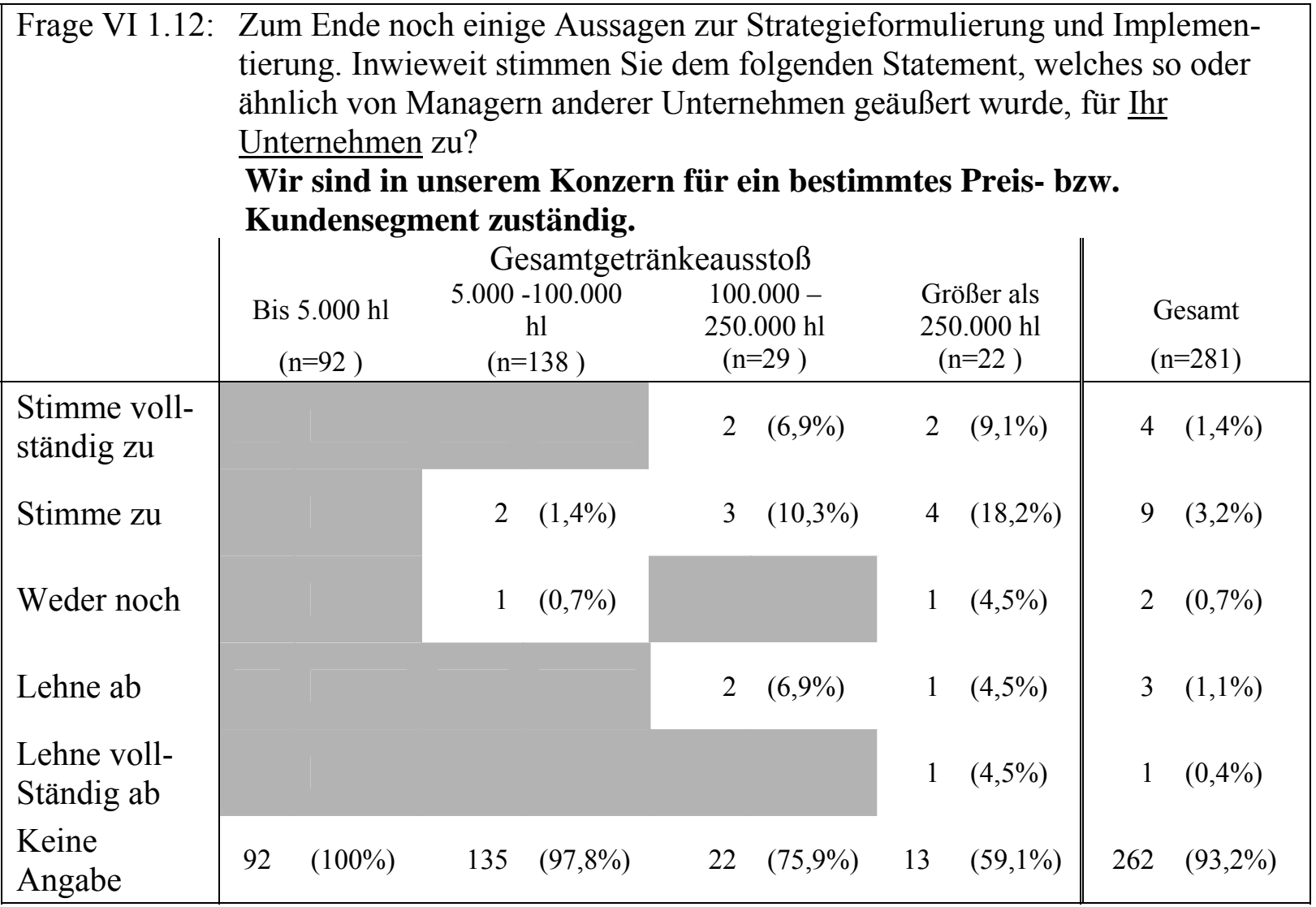

Quelle: Niederhut-Bollmann, C., Datensatz „Große Strategie-Studie 2005“, Göttingen 2005. 
Frage VI 1.13: Zum Ende noch einige Aussagen zur Strategieformulierung und Implementierung. Inwieweit stimmen Sie dem folgenden Statement, welches so oder ähnlich von Managern anderer Unternehmen geäußert wurde, für Ihr Unternehmen zu?

Das Produktportfolio, das Marketing sowie Innovationen werden in unserem Unternehmen Konzernweit abgestimmt.

\begin{tabular}{|c|c|c|c|c|c|c|}
\hline & \multicolumn{4}{|c|}{ Gesamtgetränkeausstoß } & \multirow{2}{*}{\multicolumn{2}{|c|}{$\begin{array}{l}\text { Gesamt } \\
(\mathrm{n}=281)\end{array}$}} \\
\hline & $\begin{array}{l}\text { Bis } 5.000 \mathrm{hl} \\
\quad(\mathrm{n}=92)\end{array}$ & $\begin{array}{c}5.000-100.000 \\
\mathrm{hl} \\
(\mathrm{n}=138)\end{array}$ & $\begin{array}{c}100.000- \\
250.000 \mathrm{hl} \\
(\mathrm{n}=29)\end{array}$ & $\begin{array}{c}\text { Größer als } \\
250.000 \mathrm{hl} \\
(\mathrm{n}=22)\end{array}$ & & \\
\hline $\begin{array}{l}\text { Stimme voll- } \\
\text { ständig zu }\end{array}$ & & & $1 \quad(3,4 \%)$ & $1 \quad(4,5 \%)$ & & $(0,7 \%)$ \\
\hline Stimme zu & & $2 \quad(1,4 \%)$ & $2 \quad(6,9 \%)$ & $5 \quad(22,7 \%)$ & 9 & $(3,2 \%)$ \\
\hline Weder noch & & $1 \quad(0,7 \%)$ & $(6,9 \%)$ & $(13,6 \%)$ & 6 & $(2,1 \%)$ \\
\hline Lehne ab & & & $2 \quad(6,9 \%)$ & & & $(0,7 \%)$ \\
\hline $\begin{array}{l}\text { Lehne voll- } \\
\text { Ständig ab }\end{array}$ & & & & & & \\
\hline $\begin{array}{l}\text { Keine } \\
\text { Angabe }\end{array}$ & $92(100 \%)$ & $135(97,8 \%)$ & $22 \quad(75,9 \%)$ & $13(59,1 \%)$ & 262 & $(93,2 \%)$ \\
\hline
\end{tabular}

Quelle: Niederhut-Bollmann, C., Datensatz „Große Strategie-Studie 2005“, Göttingen 2005.

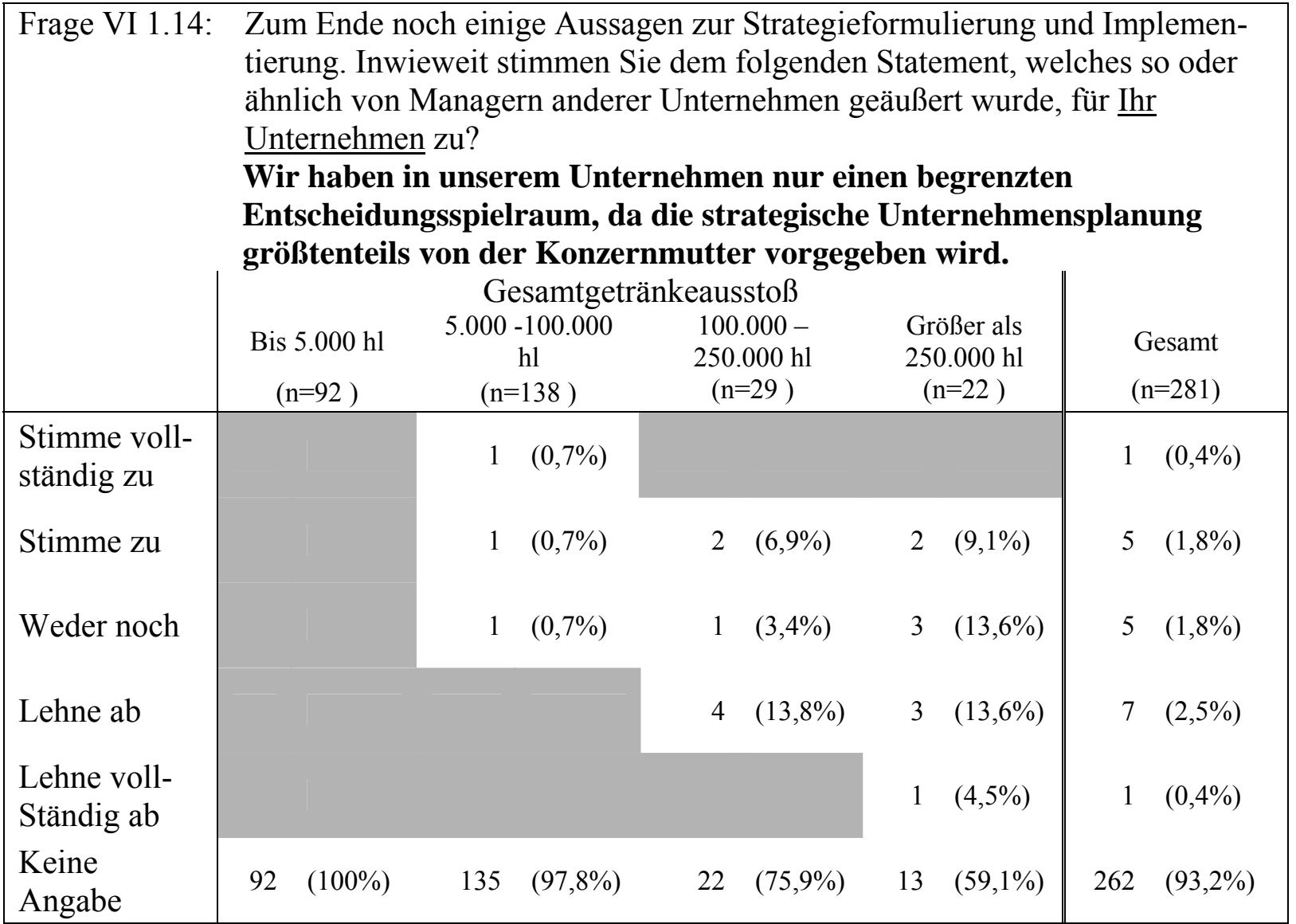

Quelle: Niederhut-Bollmann, C., Datensatz „Große Strategie-Studie 2005“, Göttingen 2005. 


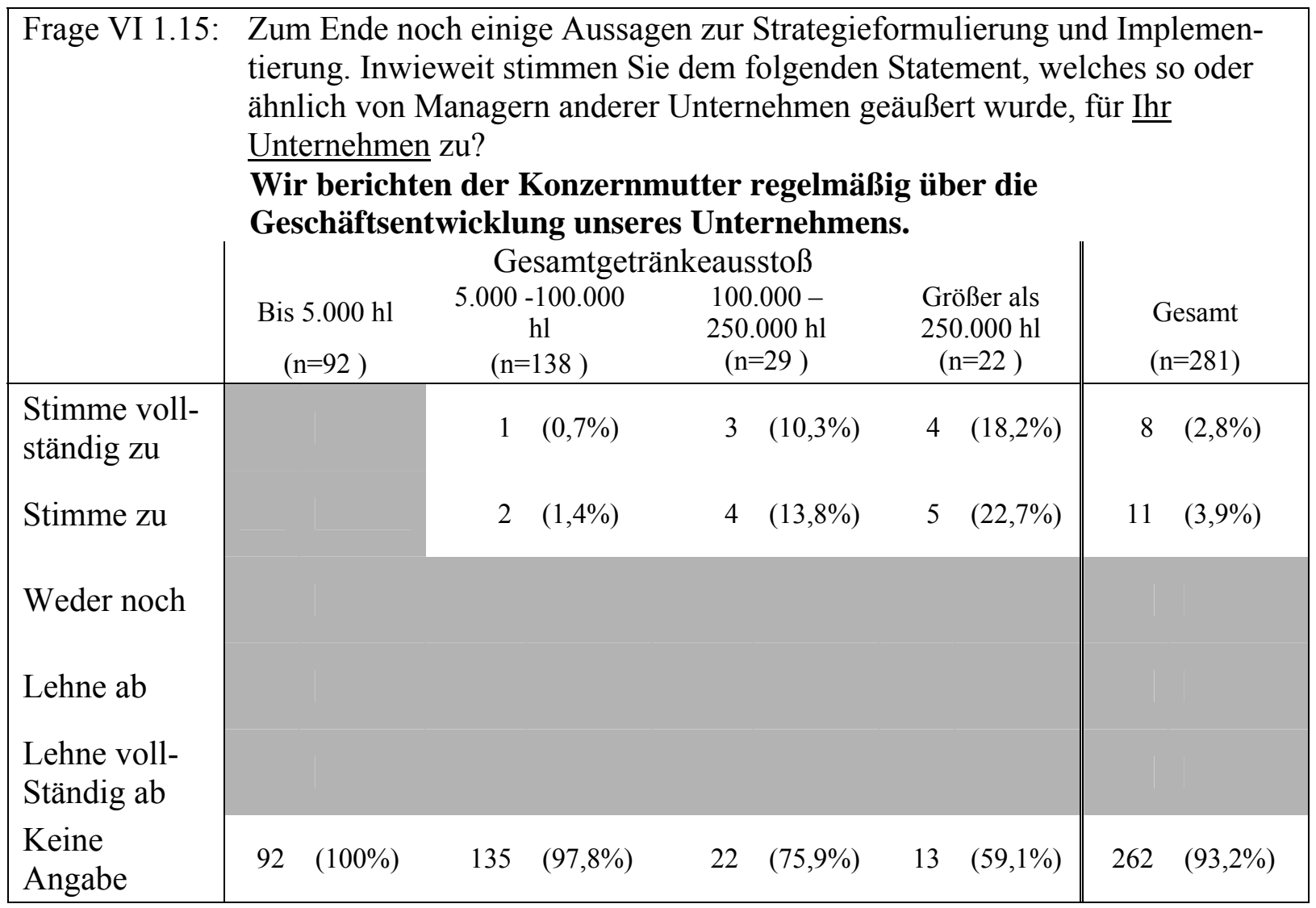

Quelle: Niederhut-Bollmann, C., Datensatz „Große Strategie-Studie 2005“, Göttingen 2005. 


\section{LEBENSLAUF}

PERSÖNLICHE DATEN

AUSBILDUNGSDATEN

1982-1986

1986-1988

1988-1995

August 1995-Juli 1997

\section{STUDIUM}

Oktober 1997 -

Oktober 2002

15.10 .2002

seit Januar 2003
Christoph Niederhut-Bollmann

geb.: 23. Juni 1975 in Springe

Eltern: Dieter Niederhut-Bollmann, Landwirt

Ursula Niederhut-Bollmann, geb. Lampe, Hausfrau

Grundschule Adensen

Orientierungsstufe Nordstemmen

Gymnasium Michelsenschule Hildesheim

Abschluss: Allgemeine Hochschulreife

Ausbildung zum Landwirt

Studium der Agrarwissenschaften an der

Georg-August-Universität zu Göttingen

Studienvertiefung nach dem Vordiplom: Agrarökonomie

Masterprüfung in der Fachrichtung Wirtschafts- und

Sozialwissenschaften des Landbaus

Wissenschaftlicher Mitarbeiter am Lehrstuhl von

Prof. Dr. L. Theuvsen

Institut für Agrarökonomie

Georg-August-Universität-Göttingen

\section{STUDIENBEGLEIDENDE TÄTIGKEITEN}

WS 2001/2002

\section{WEIERBILDUNG}

Mai 1998

Oktober/

November 2002

November 2002

FREMDSPRACHEN

\section{COMPUTERKENNTNISSE}

Microsoft Word, Excel, PowerPoint, SPSS

Englischsprachkurs in Oxford (England) (England)

Englisch in Wort und Schrift, Latein

Rhetorikseminar der Konrad-Adenauer-Stiftung in Wendgräben

Praktikum bei Bidwells Property Consultants in Northampton

begleitender Tutor der Lehrveranstaltung "Einführung in die landwirtschaftliche Betriebslehre und Umweltökonomie" 